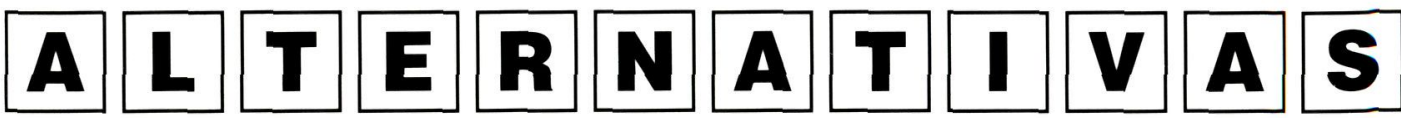

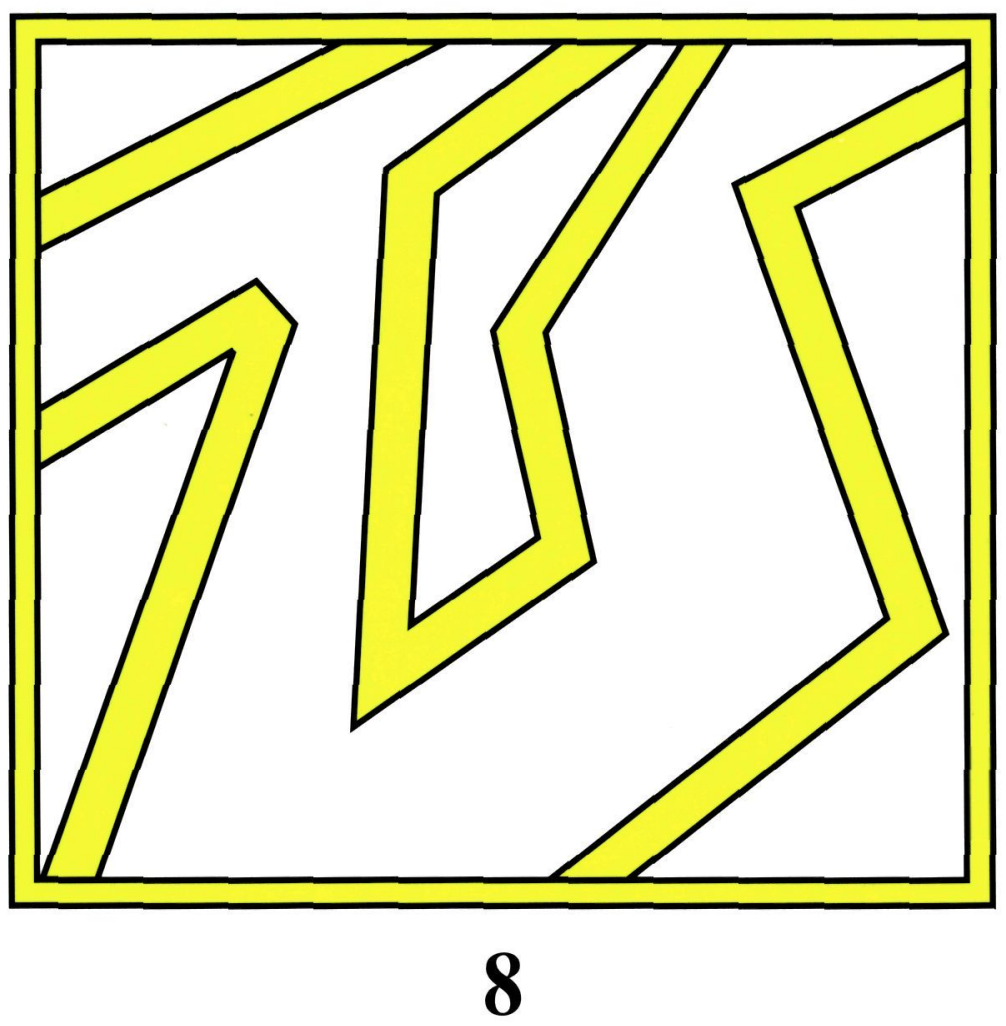

CUADERNOS DE TRABAJO SOCIAL 




\title{
ALTERNATIVAS
}

\author{
CUADERNOS \\ DE \\ TRABAJO SOCIAL
}


ALTERNATIVAS. CUADERNOS DE TRABAJO SOCIAL. N. ${ }^{\circ}$. Octubre 2000.

\section{CONSEJO EDITORIAL:}

Directora de la revista: Hortensia Redero Bellido

Directora técnica: M. ${ }^{\mathrm{a}}$ Asunción Martínez Román

Vocales: Yolanda Domenech López

Carmen López Sánchez

$M^{a}$ Teresa Mira-Perceval Pastor

Begoña San Miguel Hoyo

Esther Villegas Castrillo

EDICIÓN Y ADMINISTRACIÓN:

Escuela Universitaria de Trabajo Social. Universidad de Alicante.

03690 San Vicente del Raspeig. Alicante. España.

Telf.: $965903770 \cdot$ Fax: 965903572

e-mail (Escuela): eu.trabajosocial@ua.es

Depósito Legal: M. 37.152-1992.

I.S.S.N.: $\quad 1133-0473$.

Impresión:

ROMGRAFIC, S.L.

Martínez de Velasco, 17. 03013 Alicante (España)

Telf./Fax: $965201392 \cdot$ e-mail: romgrafic@navegalia.com

\section{Encuadernación:}

LIMENCOP, S.L. (Centro Especial de Empleo)

Zarandieta, 7. Tel. 9652571 12. 03010 Alicante (España)

Precio del ejemplar: 2.500 ptas.

Reservados todos los derechos

Suscripciones y venta:

Librería Compás-Universidad, S.L.

Centro de Servicios Universitarios. Universidad de Alicante.

03690 San Vicente del Raspeig - Alicante (España)

Apdo. de correos n. ${ }^{\circ} 6095 \cdot 03080$ Alicante (España)

Telf.: 965909390 - Fax: 965909391

e-mail: compasuniversid@teleline.es

www.libreriacompas.com

PRÓXIMA SECCIÓN MONOGRÁFICA:

Cuando crece la esperanza de vida

Plazo para la presentación de artículos: 1 de septiembre de 2001. 


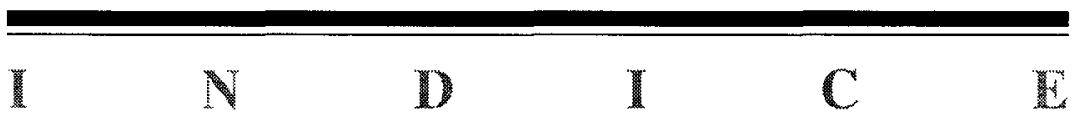



M. Asunción Martínez Román. Directora técnica del Consejo Editorial de la Revista «Altemativas. Cuadernos de Trabajo Social».

Editorial

\section{Servicios Sociales para menores en Europa.}

Bernd Seidenstücker. Prf. Dr. Hab. Escuela Técnica Superior de Darmstdat y Universidad Técnica de Berlín (Instituto de Pedagogía Social). Barbara Mutke, Diplomada en Pedagogía. Colaboradora científica Universidad Técnica de Berlín (Instituto de Pedagogía Social).

Servicios Sociales para menores en Alemania.

Hortensia Redero Bellido. Departamento de Trabajo Social y Servicios Sociales Universidad de Alicante.

Servicios Sociales para menores en Francia.

M. a Asunción Martínez Román. Departamento de Trabajo Social y Servicios Sociales. Universidad de Alicante.

Cambios reciente en los Servicios Sociales para menores en Inglaterra.

Miguel Angel Mateo Pérez. Departamento de Sociología II, Psicología, Comunicación y Didáctica. Universidad de Alicante.

"Pobreza infantil en veinticinco países industrializados". Datos y evidencias desde el Luxembourg Income Study. 


\section{Tribuna libre}

Johan Galtung. Senior Advisor, UNRISD, in preparation for the World Summit for Social Development, Copenhagen, march 11-12, 1995. Professor of Peace Studies; Universitaet Witten/Herdecke, University of Hawai'i. European Peace University, Universidad de Alicante, TRASCEND Member, International Scientific Board, Swiss Academy for Development.

On the social costs of modernization. Social disintegration. Atomielanomie and social development.

Jorge Hurtado. Departamento de Sociología II, Psicología, Comunicación y Didáctica. Universidad de Alicante.

La infancia en un mundo desbocado.

Clarisa Ramos Feijóo. Departamento de Trabajo Social y Servicios Sociales. Universidad de Alicante.

Enfoque comunitario, modernidad y postmodernidad. El Trabajo Social con la Comunidad en tiempos de la globalización.

José Francisco Campos Vidal. Departamento de Filosofía. Sección Trabajo Social y Servicios Sociales. Universidad de las Islas Baleares.

Los factores terapéuticos: ¿Qué es lo que produce cambios en los grupos?

Raúl Soriano. Trabajador Social. Marisa Dorado. Médica. Médicos del Mundo. Valencia.

VIH/SIDA y reducción de daños entre usuarios de drogas inyectables.

Alfredo Hidalgo Lavié. Escuela Universitaria de Trabajo Social de Jerez. Universidad de Cádiz.

Pros y contras de la política de cooperación española. La Ley de Cooperación Internacional para el Desarrollo a examen. 


\section{Documentación}

Ley Orgánica 5/2000, de 12 de enero, reguladora de la responsabilidad penal de los menores. BOE $n^{\circ} 287$ 2000. Sección 1.

Ley Orgánica 7/2000, de 22 de diciembre, de modificación de la Ley Orgánica 10/1995, de 23 de noviembre, del Código Penal de los Menores, en relación con los delitos de terrorismo. BOE $n^{o}$ 307-2000. Sec. I. .......

IV. Libros

$\mathrm{M}^{\mathrm{a}}$ José Escartín Caparrós. Departamento de Trabajo Social y Servicios Sociales. Universidad de Alicante.

Título: La violencia doméstica. Una nueva visión de un viejo problema. Editorial Paidós, Colección Trabajo Social, 9. Barcelona, 2000. Autora: A. Mullender. Traducción: M.Jimenez.

Hortensia Redero Bellido. Departamento de Trabajo Social y Servicios Sociales. Universidad de Alicante.

Título: Nuevas perspectivas de los Servicios Sociales. Universidad Nacional de Educación a Distancia, Madrid, 2000. Coordinadores: José Antonio Díaz Martínez y $M^{a}$ José Salvador Pedraza.

Begoña San Miguel del Hoyo. Departamento de Sociología II, Psicología, Comunicación y Didáctica. Universidad de Alicante.

Título: Política Social. Editorial Ariel. Barcelona, 2000. Autora: $M^{a}$ Teresa Montagut.

\section{Noticias}

Seminario de la Federación Internacional de Trabajadores Sociales Asia Pacífico. "Millenium Challenges and Action for Social Work Education and Practice". 
Singapur, del 31 de julio al 3 de agosto de 2001 .

Seminario Europeo de la Federación Internacional de Trabajadores Sociales. "Managing Conflicts in Social WorkDealing with Contradictions". Viena y Bratislava, del 27 al 30 de agosto de 2001.

Congreso Mundial de la Federación Internacional de Trabajadores Sociales "Building Effective Strategies in Social Work Practice in a New Era". Zimbawe, del 28 de julio al 2 de agosto de 2001.

Programa de Doctorado. Curso 2000-2001. "Análisis del Estado de Bienestar: estrategias de intervención social". Departamento de Trabajo Social. Universidad Pública de Navarra.

Números publicados

Número 1 (1992)

323

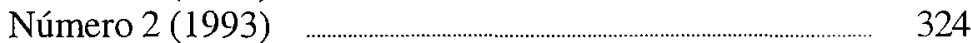

Número 3 (1995) _.......................................................... 326

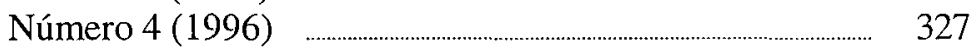

Número 5 (1997) _................................................................... 329

Número 6 (1998) _............................................................... 330

Número 7 (1999) ............................................................................... 331

Pautas generales para la presentación de artículos 


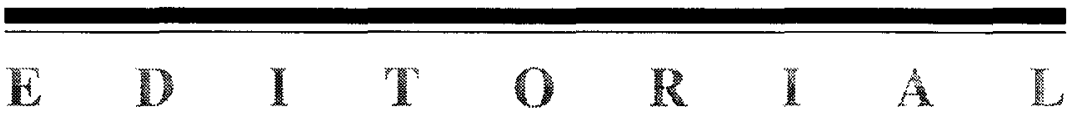





\section{M. ${ }^{a}$ ASUNCIÓN MARTÍNEZ ROMÁN.}

Directora técnica del Consejo Editorial de la Revista «Alternativas. Cuadernos de Trabajo Social».

El número 8 de la Revista "Alternativas. Cuadernos de Trabajo Social" es una primera aproximación al conocimiento de las diferentes modalidades de atención social a los menores en Europa. Las políticas de atención a los menores han coincidido en reconocer que se trata de sujetos altamente vulnerables por razón de edad y la historia reciente nos muestra diferentes modos de concretar la función que ha de corresponder al Estado para garantizar el bienestar de esos sujetos frágiles sin lesionar los derechos de los padres. Así, a lo largo del siglo XX podemos observar diferentes modalidades de actuación pública: 1) fuerte intervención pública separando al menor de su familia de origen; 2) reconocimiento de la importancia de la familia biológica en el desarrollo armónico del menor, con reconocimiento de los derechos de los padres incluyendo la recepción de apoyo público; 3 ) reconocimiento de los derechos del menor que pasa a ser el sujeto central.

Las tendencias más actuales destacan este papel central del menor como sujeto de derechos y el reconocimiento de que la familia biológica es la principal responsable de su cuidado, si bien la sociedad ha de arbitrar modos de control y de sustitución de la familia cuando ésta pone en peligro o no puede garantizar el bienestar del menor. Por lo tanto, al hablar de bienestar del menor hay que tener en cuenta tanto a la propia familia como institución social, su conceptualización, los cambios socioculturales, sus diversas modalidades, etc., como, también, las políticas dirigidas al menor y a la familia, lo que directamente o indirectamente tiene estrecha relación con el bienestar de las madres y en las que se reflejan las diferentes ideologías.

Con el fin de contribuir al conocimiento de los modos de promover el bienestar de los menores en Europa, este número de Alternativas presenta un panorama global de los Servicios Sociales de atención a los menores en tres países: Alemania, Francia e Inglaterra. Se ha tratado de describir y analizar las modalidades de intervención pública y los 
roles asignados a la familia; la normativa vigente para garantizar el bienestar del menor protegiéndole de aquellas situaciones que puedan obstaculizar su desarrollo integral; la descentralización/centralización; las nuevas fronteras entre los servicios públicos y privados (entidades lucrativas y no lucrativas) y los roles asignados a los profesionales que prestan sus servicios en ellos, en particular, en el caso de los Trabajadores Sociales.

Un primer artículo, "Servicios Sociales para menores en Alemania", es el trabajo de B. Seidenstücker y B. Mutke, quienes destacan el principio de subsidiariedad de la intervención pública en Alemania, con un significativo rol asignado a la asistencia social privada representada por seis grandes Federaciones de Organizaciones privadas no lucrativas, agrupadas en una Confederación, que reciben financiación pública por sus servicios. Tras describir los servicios sociales para menores y adolescentes, plantean un interrogante sobre la idoneidad del modelo ante la nueva realidad social marcada por recursos económicos escasos y nuevas necesidades derivadas del desempleo, destacando que no es adecuado considerar los problemas únicamente como problemas personales, obviando la dimensión social. En "Servicios Sociales en Francia", H. Redero describe un modelo que trata de proteger al menor con actuaciones preventivas para que pueda permanecer en su propio medio familiar y social, mediante una política familiar que promueve la natalidad y el cuidado de los menores. Se describe la normativa vigente y las características de los Servicios Sociales cuya administración, gestión y prestación está descentralizada como competencia de los Departamentos, estando a cargo de los Municipios la atención primaria. Las entidades sociales privadas sin ánimo de lucro también colaboran en la oferta de servicios para menores con apoyo financiero público. El tercero de este bloque de trabajos, los "Servicios Sociales en Inglaterra", analiza las consecuencias de las políticas sociales de los 80 y presenta sintéticamente la evolución reciente de los Servicios Sociales y, entre ellos, los correspondientes a la atención de los menores y sus familias. Se describe la normativa vigente y se señalan los principales temas objeto de debate centrados en los límites, insuficiencias y carencias en cuestiones como la descentralización, privatización, prevención, seguimiento y evaluación de los menores en protección, participación de las familias y los menores, problemas organizativos de los Departamentos de Servicios Sociales o los roles asignados a los Trabajadores Sociales. En definitiva, se trata de unos Servicios Sociales sometidos a cambios significativos que hay que enmarcar en un proceso de cambio político global.

Para finalizar esta sección monográfica, M. A. Mateo en su artículo "Pobreza infantil en veinticinco países industrializados. Datos y 
evidencias desde el Luxemboug Income Study", analiza la pobreza infantil en los países industrializados a partir del Luxembourg Income Study. En la discusión de los resultados se destaca la existencia de diferencias significativas entre las variables que explican la pobreza infantil en hogares monoparentales encabezados por una mujer y el resto de hogares defendiendo que, si se quiere asegurar que las políticas sociales puedan prevenir y reducir la pobreza de los menores que viven a cargo de sus madres, es necesario incorporar la perspectiva de género al estudio de los procesos de empobrecimiento.

En la sección Tribuna Libre, se puede encontrar el documento "On the Social Costs of Modernization: Social Desintegration, Atomie/ Anomie and Social Development" que J. Galtung, científico social e investigador para la paz, presentó como experto de Naciones Unidas en las reuniones preparatorias de la Cumbre Mundial sobre Desarrollo Social (Copenhague, 11-12 marzo 1995). Es una versión muy lúcida de los problemas que han atravesado los distintos tipos de sociedad, desde la primitiva a la contemporánea, haciendo ver cómo los cambios en la estructura social y la cultura han llevado a la situación actual de falta de normas compartidas y desestructuración social y sus consiguientes efectos: violencia, criminalidad y desorganización social. Por su parte, el artículo de J. Hurtado, "La infancia en un mundo desbocado", revisa las investigaciones recientes sobre el estado de la infancia, describiendo la clase de mundo que espera a los menores, con muchas probabilidades de encontrar importantes obstáculos que impidan su desarrollo humano y nuevas situaciones de vulnerabilidad. El autor da la voz de alarma al considerar que se ha dado un retroceso en las conquistas sociales y de los derechos de los niños.

En el ámbito de la práctica del Trabajo Social, se presentan tres trabajos que aluden al trabajo con la comunidad y con grupos, así como a la intervención que gira en torno a la "reducción de daños". En el primero de ellos, "Enfoque comunitario, modernidad y postmodernidad. El Trabajo Social con la Comunidad en tiempos de globalización", C. Ramos analiza la interacción entre Trabajo Social con la comunidad y el fenómeno de la globalización, reflexionando acerca de la aparente contradicción existente entre la comunidad tradicional y el objetivo del Trabajo Social Comunitario. Su propuesta es la búsqueda de alternativas de conciliación de las figuras de comunidad, como referente del Trabajo Social Comunitario, y la de sociedad, referente en su análisis del Trabajo Social, como una exigencia de la compleja realidad social actual. F. Campos, en su artículo "Los factores terapéuticos: ¿qué es lo que produce cambios en los grupos?", desde la perspectiva de los grupos centrados sobre el cliente, se pregunta cómo puede ayudar el Trabajo Social de Grupo y reflexiona sobre 
las condiciones necesarias para que se produzcan mejoras en el funcionamiento social. Por último, R. Soriano y M. Dorado abordan el tema "VIH/SIDA y reducción de daños entre usuarios de drogas inyectables", exponiendo los beneficios de las políticas que actúan sobre los daños y las intervenciones de reducción de daños, avalados por la experiencia de su ejercicio profesional en "Médicos del MundoValencia".

Para finalizar esta Tribuna, un último artículo referido a la Cooperación internacional, ámbito que puede considerarse un "nuevo yacimiento de empleo" para los Trabajadores Sociales y otras profesiones del ámbito psicosocial. A. Hidalgo en su artículo "Pros y contras de la política de cooperación española. La Ley de Cooperación Internacional para el Desarrollo a examen", plantea una serie de reflexiones sobre la política española de cooperación y, en particular, sobre la vigente Ley 23/1998 de 7 de julio.

En la sección Documentación se pueden encontrar los textos de la Ley Orgánica 5/2000, de 12 de enero, reguladora de la responsabilidad penal de los menores y de la Ley Orgánica 7/2000, de 22 de diciembre, de modificación de la Ley Orgánica 10/1995, de 23 de noviembre, del Código Penal de los Menores, en relación con los delitos de terrorismo. $\mathrm{Y}$, finalmente, las secciones Libros y Noticias.

Agradecemos todas las valiosas colaboraciones recibidas y esperamos contar con interesantes colaboraciones para nuestro próximo número que tendrá como tema "Cuando crece la esperanza de vida". 
1. SERVIVIOSSOCHALES

PARA MENORES

TNEUROPA 



\section{SERVICIOS SOCIALES PARA MENORES EN ALEMANIA}

\section{BERND SEIDENSTÜCKER}

Profesor Dr. Hab. Escuela Ténica Superior de Darmstdat y Universidad Técnica de Berlín (Instituto de Pedagogía Social).

\section{BARBARA MUTKE}

Diplomada en Pedagogía. Colaboradora científica de la Universidad Técnica de Berlín (Instituto de Pedagogía Social).

\section{INTRODUCCIÓN}

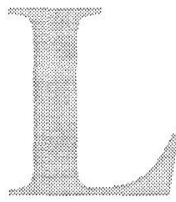

os servicios sociales para niños y adolescentes son el resultado del principio del Estado Social imperante en la República Federal de Alemania y corresponden a los objetivos constitucionales fundamentales del Estado en los que se insiste muy particularmente. El principio del Estado Social legitima al legislador para crear nuevos modos de abordar los problemas sociales y diseñar las prestaciones apropiadas. Los trabajos sociales (servicios) no deben ser tan sólo una parte pasiva del sistema social en su conjunto, sino que deben contribuir de manera activa en la realización de la idea del Estado Social en el marco de la realidad económica, social y cultural reinante.

Sin embargo, también en los Estados Sociales desarrollados, la realidad social enfrenta múltiples problemas. Pero, así mismo, existen un sinnúmero de actividades sociales en instituciones, privadas, no gubernamentales, municipales y estatales.

El principio del Estado Social está fundamentado en una serie de valores y principios sociales, en el ámbito constitucional:

- La obligación del poder estatal de respetar y proteger la dignidad humana, de la cual resulta, entre otras, la obligación práctica de garantizar a los ciudadanos necesitados un mínimo nivel material de existencia.

- La igualdad de todas las personas ante la ley.

- La igualdad entre hombres y mujeres.

- La prohibición de cualquier discriminación por motivos de etnia, raza, idioma, origen, religión o creencias religiosas o políticas.

- La obligación de no desfavorecer a nadie por sus minusvalías. 
- La obligación del Estado de prestar una protección particular a la familia, al matrimonio, a la maternidad y a los niños nacidos fuera del matrimonio.

\section{ORDENAMIENTO POLÍTICO-SOCIAL}

\subsection{Principio del Estado Social}

El fundamento del Estado Social está marcado por su principio de apertura y liberalidad. De esta forma, las distintas fuerzas sociales tienen la posibilidad de realizar sus ideales de justicia social mediante la participación constitucional y la formación de la voluntad política.

En las áreas centrales de la política social, es decir, de la seguridad social, de las prestaciones sociales y de la protección social, el "Bund" tiene la última palabra mediante su poder legislativo en la Cámara de los Diputados y en el Senado alemanes. En el ámbito del poder ejecutivo, los grupos temáticos mencionados aquí, son representados básicamente por: el Ministerio Federal de Trabajo y Asuntos Sociales, el Ministerio Federal de Salud y, más particularmente, el Ministerio de Familia, de la Tercera Edad, de la Mujer y de la Juventud.

El principio del Estado Social significa también que se presta ayuda a la persona particular siempre y cuando la protección social general no sea suficiente para cubrir sus necesidades básicas propias. En cualquier caso, no se trata en primer lugar ni exclusivamente de una ayuda material, sino de ayudas personales más amplias comprendidas en el trabajo social; a veces también se requieren intervenciones de emergencia y de apoyo humano en situaciones existenciales límites.

El principio del Estado Social no es una exigencia dirigida exclusivamente al Estado, sino que se realiza también en la relación solidaria y social entre los ciudadanos, en forma de autoayuda individual y colectiva y de apoyo vecinal en situaciones de emergencia.

El punto de cristalización de la política social en Alemania es el principio de subsidiariedad. Esto significa que, en principio, es la comunidad de base la que debe intervenir y que sólo se debe recurrir a los medios estatales cuando es inevitable. Si el individuo no se basta por sí solo, deben intervenir, en primer lugar: la familia, luego, el vecindario, el grupo de autoayuda, "la libre protección social" del municipio y, en última instancia, las instituciones estatales.

La subsidiariedad en la actuación estatal, y especialmente la municipal, resulta ser un tema central, ante todo en la relación entre la "libre 
protección social" y la "pública". Los organismos de la "libre protección social" reclaman, para su trabajo social, una prioridad condicionada que se refleja también en las normas básicas del derecho social, más aún cuando hay organismos no estatales que trabajan muchas veces sobre situaciones sociales de emergencia de forma innovadora. Sin embargo, la situación prioritaria de los organismos no estatales en la prestación de servicios sociales ha sido relegada por el legislador a lo largo de los últimos años, con la intención de enfrentar entre sí a los prestadores de servicios mediante una competición más dura.

\subsection{Relación entre la "asistencia social pública" y la "privada"}

La Constitución utiliza la definición de "asistencia social pública" y, por lo tanto, implica la existencia de la "asistencia social privada". Al mismo tiempo, delimita la asistencia social como área propia de la protección social ante el área de la seguridad social y la asistencia estatal. La "asistencia" es un principio básico para un amplio sistema de ayudas sociales que el Estado Social presta a los individuos, sin ninguna contraprestación, si éstos padecen una situación de emergencia que no pueden solucionar con sus propios recursos. Las áreas particulares que, en la realidad del trabajo social, no se pueden separar nítidamente unas de otras son, en principio, las siguientes:

\begin{tabular}{|l|l|l|}
\hline \multicolumn{3}{|c|}{ Asistencia Social } \\
\hline $\begin{array}{l}\text { Asistencia infantil y } \\
\text { juvenil }\end{array}$ & Ayudas Sociales & Asistencia Sanitaria \\
\hline Protección juvenil & $\begin{array}{l}\text { Ayuda para manutención } \\
\text { (incluida "ayuda para el } \\
\text { trabajo"), ayuda en situa- } \\
\text { ciones existenciales parti- } \\
\text { culares (especiales) }\end{array}$ & \\
\hline
\end{tabular}

Al nivel más bajo, la "asistencia pública" es asunto de las administraciones municipales (distritos rurales y ciudades). A los niveles más altos, la competencia para las tareas de asistencia recae, en parte, en los organismos comunales superiores y, en parte, en los Estados Federados (Bundesländer). A nivel del Estado Federal, esta competencia para la Asistencia Infantil y Juvenil le corresponde al Ministerio Federal para la Familia, la Tercera Edad, la Mujer y la Juventud. La competencia sobre las prestaciones sociales corresponde al Ministerio Federal de Trabajo y Asuntos Sociales. Los "organismos públicos" mencionados tienen la obligación legal de colaborar con los organismos de "asistencia social libre" y con los organismos y organizaciones no lucrativos y no gubernamentales, ante todo en el campo de la ayuda a los niños y a los adolescentes y en lo social. No deberían crear sus propios organis- 
mos si los organismos de la ("asistencia social privada") "asistencia social libre" ya dispusieran de instalaciones propias o si ya las tuviesen planificadas (subsidiariedad institucional). Sin embargo, la responsabilidad global con respecto a la planificación de servicios e instalaciones sociales corresponde por ley a los "organismos oficiales". La llamada ("asistencia social privada") "asistencia social libre" comprende la totalidad de las ayudas sociales e iniciativas de autoayuda que se dan sobre una base no lucrativa y solidaria y de forma organizada. Las organizaciones de "asistencia social libre" están federadas en seis confederaciones que conforman, a su vez, la Bundesarbeitsgemeinschaft der freien Wohlfahrtspflege (Confederación de la Asistencia Social Privada):

- Asistencia Social de los Trabajadores.

- Obras diacónica de la Iglesia Evangélica de Alemania.

- Unión de Cáritas Alemana.

- Unión de Asistencia Social Paritaria de Alemania.

- Cruz Roja Alemana.

- Comité Central de Bienestar de los Judíos en Alemania.

Para todas las asociaciones de la "asistencia social privada" rige el hecho de que hayan asimilado de manera amplia algunas tareas estatales en el ámbito social a la vez que tareas propias. Esto es admisible porque, según la Ley Constitucional, la obligación del Estado Social no favorece ningún monopolio social para el Estado. Todas las asociaciones de asistencia social son organismos que prestan un gran número de servicios indispensables, que disponen de instalaciones, asilos, internados y que organizan actividades culturales que sirven también para niños.

A cambio de su trabajo, las asociaciones de asistencia social reciben subvenciones por parte de los organismos oficiales, así como compensaciones por sus prestaciones. Sin embargo, también utilizan medios propios considerables que provienen, sobre todo, de donaciones en dinero y otros bienes. El trabajo no remunerado desempeña un papel muy importante en los servicios y organismos de la "asistencia social privada". Más particularmente, la Unión de Asistencia Social Paritaria de Alemania promueve iniciativas de autoayuda y las organizaciones correspondientes.

\subsection{Principios básicos y objetivos de los servicios sociales para niños y para adolescentes.}

La ayuda para niños y adolescentes está marcada por un gran número de diferentes valores y orientaciones, que se reflejan en un sinfín 
de diversos contenidos, métodos y formas de trabajo. Es preciso añadir que las prestaciones, según la Ley de Ayuda Infantil y Juvenil, se dirigen explícitamente a los organismos de la Asistencia Juvenil Pública (municipal). Sin embargo, la Asistencia Juvenil Pública debe colaborar con la Ayuda Juvenil privada en pro del bien de los jóvenes y de sus familias, y debe hacerlo de forma intensiva y solidaria. De hecho, numerosas prestaciones de la Ayuda Infantil y Juvenil se realizan por medio de los organismos de la Ayuda Infantil privada en base a los objetivos legales establecidos. Siempre que los organismos de la Ayuda Juvenil privada dispongan de instalaciones y servicios adecuados, la Ayuda Juvenil pública debería abstenerse, según las disposiciones legales en vigor, de establecer medios propios.

Los gastos de las medidas aplicadas por la Ayuda Juvenil privada son financiados por los organismos de la Ayuda Juvenil pública. Por lo tanto, se presta una ayuda educativa necesaria independientemente del hecho de que los padres de los niños y adolescentes puedan cubrir o no los gastos incurridos, basándose en sus recursos propios. Sin embargo, se les puede requerir cierta participación en los gastos. La Ayuda Infantil y Juvenil tiene, paralelamente a la familia y a la escuela, la función de socializar a las personas jóvenes -niños, adolescentes y jóvenes adul$\operatorname{tos}^{1}-$.

Con relación a la Ayuda Infantil y Juvenil, la Ayuda Familiar está determinada por:

- La Ley Constitución de la República Federal de Alemania.

- El Derecho de los Niños, como parte del Derecho Familiar.

- El Derecho de Ayuda Infantil y Juvenil (K.J.H.G.), como parte del Código Social.

Según esto, aunque la Ayuda Infantil y Juvenil pública se sitúen en segundo lugar con relación a la Educación Familiar, cada persona joven, sin embargo, tiene derecho a la promoción de su desarrollo y a una educación que desarrolle su personalidad de forma responsable y socialmente adaptada. Esto significa que:

- La educación comenzada en la familia debe ser apoyada y complementada por la Ayuda Infantil y Juvenil y

- que los niños y adolescentes sean protegidos por su bien, frente a peligros que atentan contra su bienestar.

En caso de que la familia, los padres u otras personas con derechos 
de tutoría no cumplan con el derecho del niño o del adolescente a ser educado adecuadamente, debe intervenir el organismo público de Ayuda Infantil y Juvenil, frecuentemente en colaboración con un organismo privado.

Según el artículo 27 de la K.J.H.G. (ley de ayuda para la niñez y la juventud) el derecho a una ayuda para la educación está condicionado a que "no se halle garantizada una formación orientada al bien del niño o del joven". Con este enfoque, la atención se dirige de los "problemas de comportamiento" y trastornos o disfunciones de los niños hacia el entorno social (familia, escuela, vecindario, etc.) y los factores que en estos medios son los causantes de los problemas. Esto favorece enfoques en el Trabajo Social y la Pedagogía Social orientados al medio ambiente y las condiciones cotidianas de vida. La orientación principal, político-social, que se expresa en la ley de Asistencia Infantil y Juvenil, se puede resumir con la fórmula: configuración de la ayuda para la educación como servicio social pedagógico.

Las ofertas de ayuda para niños y jóvenes se basan en un concepto distinto a los conceptos tradicionales anteriores que asociaban la ayuda para la educación a la intervención de un "poder estatal autoritario". La ayuda a la educación, en vez de ser un instrumento de intervención, pretende ser una oferta cualificada al servicio de familias y niños / jóvenes que se hallan en una situación existencial difícil. Dicha oferta se diseña para cada caso individual y se configura concretamente en colaboración con las familias y niños/jóvenes y en estrecha colaboración con los expertos de la Oficina Estatal Juvenil y con los de los organismos competentes (por ejemplo, hogares para menores) y servicios especiales (por ejemplo, Oficinas de Asesoría y orientación para la Formación).

La obligación social pedagógica de participación de los afectados se halla reflejada en las disposiciones legales determinadas en la Ley de Asistencia Infantil y Juvenil (planificación de ayuda, derecho a la decisión de los interesados, en relación a la forma y a la aplicación de la ayuda). Si la ayuda para la educación se debe desarrollar como un servicio, esto se debe reflejar en los contactos concretos entre los expertos de la Oficina Estatal Juvenil y las familias, es decir, los niños y los jóvenes (acortamiento de distancias). Además, la Oficina Estatal Juvenil debe redoblar sus esfuerzos en el trabajo de imagen pública, para reducir la imagen negativa tradicional de la Oficina Estatal Juvenil que todavía persiste. El presentar la asistencia juvenil como una tarea preventiva puede ser una contribución importante a esta meta.

Una pregunta importante es si todas las actividades desarrolladas por la asistencia juvenil pueden asumir el carácter de "servicios". En el 
interés de la protección civil de los niños, a veces se requiere, en casos individuales (también prescritos por ley), la intervención del Tribunal de la Familia, solicitada por la Oficina Estatal Juvenil, con el fin de actuar, si resultara necesario, en contra de la voluntad de las personas con derechos de tutoría (padres o, dado el caso, uno de ellos) o inclusive tener que demandarlos por actuaciones penales contra los niños (acerca de esto ver el apartado siguiente).

\section{BASES JURÍDICAS}

La ley que en Alemania rige el área de asistencia infantil y juvenil es la ya mencionada Ley de Asistencia Infantil y Juvenil (K.J.H.G), que entró en vigor el 1 de enero de 1991, tras largos esfuerzos encaminados a reformar la Jugenwohlfartsgesetz (Legislación de Bienestar para la Juventud) (J.W.G). La función central de la asistencia juvenil, según el K.J.H.G., es la promoción y la protección de los menores. "Cada persona joven tiene derecho a una promoción de su desarrollo y educación para adquirir una personalidad auto-responsable y para ser capaz de integrarse en la sociedad" (Art. 1, par. l K.J.H.G.). Para la realización de esta norma directiva, la Asistencia Infantil y Juvenil debe promover, entre otras cosas, el desarrollo individual y social de las personas jóvenes, apoyar y asesorar a los padres y demás personas con derechos de tutoría, así como proteger a niños y jóvenes de peligros para su bienestar (ver art.1, par. 3 de la K.J.H.G.). Esta ley se dirige a todas las personas jóvenes menores de 27 años. Las tareas de la asistencia juvenil no se circunscriben a personas jóvenes de nacionalidad alemana, sino que abarcan a todos los que tienen su residencia efectiva en Alemania.

\subsection{Derechos de los padres}

El art. 6. par. 2, frase 1 de la Constitución determina la responsabilidad de los padres frente a sus hijos, "El cuidado y la educación de los niños constituyen el derecho natural de los padres y el máximo deber que les corresponde como tal." Esta frase ha sido integrada textualmente en la Ley de Asistencia Juvenil. Los padres tienen la responsabilidad de determinar los contenidos y los valores de la educación de sus hijos. Para facilitar a los padres el cumplimiento de sus tareas, el legislador pone a la familia bajo la protección especial del orden estatal. Para ello, parte del hecho de que, normalmente, el niño encuentra en la familia las mejores condiciones para su socialización. El derecho educativo de los padres, sin embargo, no es unilateral sino que se halla 
sujeto a obligaciones. El derecho educativo y la obligación de los padres están indisolublemente entrelazados. Sin embargo, la obligación no debe interpretarse como una limitación del derecho, sino como una parte esencial del derecho de los padres que se puede definir como "la responsabilidad de los padres". Los padres deben ejercer su derecho educativo en el interés del niño para promover su bienestar al máximo.

\subsection{Obligación del Estado}

Sin embargo, si los padres ejercen su derecho educativo en contra de los intereses del niño, o si rehúsan ejercer su responsabilidad educativa, el Estado tiene la obligación de garantizar el cuidado y la educación del niño. Una intervención en la esfera educativa de los padres sólo puede darse si el bienestar físico, mental o psicológico del niño corre peligro por:

- el ejercicio abusivo de la autoridad paterna,

- descuido del niño,

- fracaso, sin culpa de los padres, o

- conducta de un tercero.

Y si los padres

- no están dispuestos o

- no están capacitados para hacer frente al peligro.

Aquí no importa si los padres se encuentran, a pesar de sus mejores intenciones, incapaces de enfrentarse a una determinada situación, si son indiferentes frente a un peligro, si les falta la conciencia suficiente o si el peligro está causado activamente por ellos mismos. En todos estos casos, el Tribunal puede resolver medidas necesarias para asegurar que el peligro no dañe al menor. En estos casos, el Estado tiene el derecho de supervisar a los padres en el cumplimiento de sus derechos educativos y de cuidados y, en casos particulares, a interferir en estos derechos por decisiones tomadas en los Tribunales normales. Sin embargo, el Estado sólo puede interferir en el derecho de los padres si el cuidado y la educación por parte de los padres no se corresponde con el bien del niño. Por lo tanto, el Estado no tiene la tarea de garantizar la mejor educación para el niño, sino de protegerle contra daños concretos. Esto significa que, mientras los padres se mantienen dentro del marco de sus planes educativos, por debajo del nivel de poner en peligro el bien del niño, las instituciones estatales sólo pueden ofrecerles apoyo, pero no pueden intervenir. Los métodos educativos que se encuentran en este marco deben ser aceptados por los niños afectados y por el Estado, aún cuando los conocimientos de ciencias humanas dan motivo para criticarlas justificadamente. 


\subsection{Tareas de la Asistencia Juvenil}

La obligación social de la asistencia juvenil se encuentra en el área de tensión indisoluble y debe

- apoyar, por una parte, a los padres para que ellos mismos puedan cumplir mejor sus derechos y obligaciones educativas, a favor del bien del niño, y por otra parte,

- proteger a niños y jóvenes de posibles peligros para su bienestar $\mathrm{y}$, dado el caso, imponer esta protección, aún en contra de la voluntad de los padres.

Este área de tensiones esencialmente indisociable constituye una característica fundamental de la actuación social pedagógica. Cada una de las prestaciones y tareas de la Asistencia Juvenil tiene su normativa en la K.J.H.G., como fundamento de principios. Las actividades solicitadas y ordenadas para la realización de derechos de personas jóvenes y de sus padres se hallan representadas como sistema jerárquico:

- Al nivel más alto, se presenta la obligación de contribuir al mantenimiento o la creación de condiciones existenciales positivas para las personas jóvenes y sus familias, así como de un entorno favorable tanto para los niños como para sus familias. Aquí se impone la idea de que la asistencia juvenil se transforma en representante de los menores y de sus familias en defensa de los intereses de éstos también en otros campos políticos (por ejemplo, en el mercado del trabajo, en el desarrollo urbanístico, etc.).

- Debe ofrecerse asesoramiento, apoyo y sostén a las familias con niños. Así, se apoya a los padres en sus tareas educativas y se les permite compaginar la vida familiar y las obligaciones económicas. Tales ofertas a las familias incluyen, en particular, los servicios de parvularios, de trabajo juvenil, de formación familiar o de asesoramiento familiar.

- Para familias que se encuentran en situaciones concretas de crisis y tensión, es menester ofrecer servicios especiales para que puedan superar las crisis (es decir, asesoramiento en casos de divorcios y separaciones, cuidados y manutención de los niños en situaciones de emergencia o ayudas a la educación) y, en el caso particular de que no se halle garantizada una educación adecuada para el bienestar del niño, de desarrollar y ofrecer las ayudas "adecuadas y necesarias".

- Si, a pesar de las ofertas de servicios de la Asistencia Juvenil, el bienestar del niño se encuentra en peligro, los expertos deben examinar si es preciso recurrir al Tribunal. En casos de situaciones límite o de peligro inminente, la Asistencia Juvenil puede intervenir para defender y asegurar los derechos del niño. 


\subsection{Prestaciones de la Asistencia Juvenil}

La tarea central de la Asistencia Juvenil consiste en promover el desarrollo de personas jóvenes y limitar o disminuir el riesgo de desventajas, en asesorar a los padres en sus tareas educativas, en proteger a los menores frente a peligros para su bienestar y en procurar crear o mantener condiciones existenciales positivas para personas jóvenes y para sus familias, así como promover un entorno favorable a los niños y a sus familias. Aquí, el núcleo de la ley toma forma de contenido pedagógico social mediante el cual los colaboradores de la Asistencia Juvenil deben crear prestaciones. La Ley de Asistencia Infantil y Juvenil ofrece un catálogo muy amplio de prestaciones promotoras y preventivas:

1. Programas y actividades ofrecidos o realizados para jóvenes, trabajo social con jóvenes y actividades educativas de protección a la niñez y la juventud.

2. Programas para apoyar la educación en la familia.

3. Programas especiales de apoyo y promoción de los niños en instituciones que prestan atención todo el día o ayudas diarias de acuerdo a la necesidad.

4. Ayuda para la formación y prestaciones complementarias.

5. Ayuda para niños y jóvenes con problemas psíquicos y prestaciones complementarias.

6. Ayuda para adultos jóvenes y apoyo y asesoría posterior a las medidas de ayuda.

Por una lado, se trata de prestaciones cuya iniciativa debería corresponder a las personas jóvenes o a sus tutores. Por lo tanto, se concede al ciudadano un derecho individual a reclamar ciertas prestaciones. Por otro lado, dichas prestaciones son una obligación de los organismos públicos que deben proponer ofertas adecuadas, servicios, instalaciones y actuaciones, sobre las cuales los ciudadanos pueden ejercer una pretensión de participación. A continuación trataremos más detalladamente las ayudas para la educación, ya que les corresponde un gran protagonismo en el contexto de los servicios sociales.

En las ayudas para la educación mencionadas en el apartado 4 se detallan ayudas pedagógicas que han sido aprobadas desde hace mucho tiempo en la práctica de la Asistencia Juvenil. Aquí se resumen, además de las formas clásicas, como el alojamiento externo en una institución o una familia cuidadora, las ayudas sólo parcialmente estacionarias. El conjunto se define de la manera siguiente:

- Art. 28 Asesoramiento para la educación. 
- Art. 29 Trabajo social de grupo.

- Art. 30 Asistencia educativa, ayuda y atención.

- Art. 31 Asistencia familiar social y pedagógica.

- Art. 32 Educación en un grupo diurno.

- Art. 33 Educación en una institución.

- Art. 34 Educación en una institución u otra forma de habitación atendida.

- Art. 35 Atención individual, social y pedagógica intensiva.

Se trata aquí de un listado de ejemplos de posibles ayudas. Se pueden incluir ayudas que no vienen mencionadas en esta lista. Esto ofrece a los colaboradores de la Asistencia Juvenil la posibilidad de ser lo suficientemente flexible para adecuar las ayudas a las necesidades específicas de los interesados y garantizar la base de una actuación cualificada y adecuada.

El derecho a la ayuda en la educación no corresponde a los menores, sino a los tutores de un niño o joven, cuando:

1. no está garantizada una educación adecuada al bienestar del niño o el joven y

2. cuando la ayuda para su desarrollo es necesaria y adecuada.

La situación jurídica se diferencia según la peligrosidad a la que se enfrenta el niño y su falta de garantía. En ambos casos, existe un derecho a ayudas en la educación. Se da el caso de un peligro al bienestar del niño cuando el menor se encuentra en una situación individual de socialización que le puede producir daños para su futuro y éstos son previsibles, al tiempo que el no alterar dicha situación representaría un peligro para el bienestar del niño. Si los padres se negaran a solicitar ayuda, esta situación podría llegar a un punto en que se deberían tomar medidas de tipo judicial. Por otro lado, el bienestar del niño tampoco está garantizado si la situación de socialización del menor se representa comparativamente como una situación de desventaja. En ambos casos, existe un derecho a ayuda a la educación. Una condición previa adicional para conseguir el derecho a ayuda es que la familia no esté en condiciones de superar por sí sola la situación de emergencia.

Además, la ayuda a la educación debe ser adecuada y precisa: aquí se debe estudiar tan detalladamente como sea posible la situación de socialización del menor. Cuanto más detallada, se podrá proporcionar una ayuda más precisa y más adecuada. La condición previa para ello reside en la evaluación cualificada del trabajador social, la tematización en el equipo y la imprescindible participación de los interesados en la elección de la forma de la ayuda. 
Las pretensiones a ayudas estacionarias, parcialmente estacionarias y móviles se hallan en relación de igualdad. La elección final se debe hacer exclusivamente según un punto de vista pedagógico. La elección de la forma de ayuda debe orientarse en función de la intensidad pedagógica de los modos de ayuda respectivos a la familia y debe corresponder al principio de la adecuación.

Se hace transparente el concepto sobre el que se basa el K.J.H.G.: se trata, en primer lugar, de una actuación preventiva de la Asistencia Juvenil para asegurar buenas condiciones de desarrollo del menor y para evitar intervenciones judiciales en el derecho de los padres. Con ello, se pretende mantener la familia como lugar de socialización del menor. Las ayudas exteriores deben apoyar a la familia para estabilizarla. Sin embargo, cuando las medidas móviles no se muestran efectivas, se deben imponer temporal o permanentemente nuevos hogares (familias de adopción, asilos o cualquier otra forma de vivencia atendida).

La ejecución de ayudas para la educación requiere la solicitud o, al menos, el consentimiento de los tutores. Estos no pueden ser obligados a aceptar ayudas mientras no se haya iniciado un procedimiento judicial. Por lo tanto, es muy importante ganarse a los interesados para una colaboración activa en el proceso de la ayuda.

Dado que los procesos de decisión acerca de la adecuación de las ayudas a la educación se hallan muy frecuentemente conectados a grandes dificultades a vencer por los expertos pedagógicos, el legislador se ha obligado a ejercer un control y una cobertura:

- Mediante la obligación del "trabajo en equipo de varios expertos" en el proceso de decisión acerca de la forma de ayuda aplicada en cada caso individual. La condición de organización de esta forma de colaboración se da en el trabajo en grupo de dichos expertos, que se halla protegido y es estructuralmente obligatorio.

- Por la posición fuertemente enfatizada por la ley de los padres y niños con derecho a la prestación, cuyos derechos son explícitamente resaltados en el proceso de colaboración y participación en el proceso de toma de decisiones acerca de la adecuación de la ayuda.

- Las prestaciones deseadas y ofrecidas no deberían ser fijadas a priori sino establecidas a lo largo de un proceso de negociación que toma en cuenta los intereses de los participantes. La necesidad de una supervisión continua de la decisión acordada es imprescindible, así como su revisión si fuera necesaria. 


\subsection{Ayudas de apoyo a las familias y otras ayudas complementa- rias}

\section{Asesoramiento en materia de Educación}

Para la superación de crisis familiares y de problemas en el desarrollo y educación de niños y jóvenes, las ofertas de asesoramiento pueden prestar ayudas. Partiendo de diferentes situaciones -niños con problemas escolares y con síntomas de conducta no adaptada, jóvenes con problemas sexuales y de pareja, problemas de empleo, problemas de fracaso escolar, drogodependencia juvenil, dificultades en el matrimonio o en la familia o problemas de estrés por parte de educadores solteros- se da un sinfín de requerimientos de asesoramiento. La tarea de asesoramiento debería ser de apoyo a los que buscan consejo para solucionar problemas de su vida cotidiana, sin que se les imponga una determinada solución.

En los desarrollos técnicos más recientes se analizan las múltiples situaciones problemáticas y el conjunto del sistema familiar y de forma pluridisciplinaria (con psicólogos de diferentes escuelas, pedagogos sociales, logopedas, juristas, etc.) a lo largo de este proceso de asesoramiento. Para superar una determinada limitación a una clientela "clásica" de clase media, resultan también eficaces ciertas posibilidades de acceso de niveles más bajos en "centros familiares". Allí se ofrecen, además de cursillos, posibilidades concretas para niños, jóvenes, madres y padres para el ocio y, por ejemplo, también posibilidades de intercambio para ropa de niños, talleres de reparación de bicicletas, comidas de mediodía y similares. También se pueden organizar encuentros informales en cafeterías o cantinas de los centros de asistencia.

\section{Trabajo social en grupo}

El trabajo social en grupo (también llamado cursillos de ejercicios y experiencias) constituye una oferta desarrollada desde la práctica de la Asistencia Juvenil para el aprendizaje social en grupos basado en la libre voluntad de acceso, e incluye también, además de adolescentes, niños mayores ( 12 a 14 años). El trabajo social en grupo consiste en un cursillo de atención pedagógica constante a niños y jóvenes que pasan por una crisis en su desarrollo. Lo que se pretende es "entrenar", basándose en actividades desarrolladas en grupo e incluyendo el entorno social, ciertas posibilidades de desarrollo y fortalecer la competencia social. Por norma general, los niños o jóvenes participan en estos cursos durante un período de 6 a 12 meses, a razón de 4 horas semanales. $\mathrm{El}$ número de participantes puede ir de 3 a 10 personas por grupo. El trabajo del grupo se puede complementar mediante excursiones y se- 
minarios de fin de semana. La configuración práctica del programa del curso se basa en un enfoque pedagógico de grupo como reuniones orientadas a la conversación, y con hincapié en la acción y la experiencia. Además de las formas de oferta relacionadas con cursos, también existen experiencias positivas con grupos fijos, es decir, grupos en los que se puede ingresar en cualquier momento y que se pueden dejar voluntariamente.

\section{Asistencia en la educación}

$\mathrm{La}$ asistencia en la educación se entiende como oferta social pedagógica de ayuda. Ésta está pensada particularmente para apoyar al niño o al adolescente y se distingue de otros métodos de apoyo social pedagógicos más enfocados hacia la familia y sus problemas. El abanico de edades de los niños y jóvenes atendidos en el marco de la asistencia en la educación es relativamente amplio. Se sitúa entre los 9 y los 16 años. La asistencia en la educación tiene por meta una relación de atención personal entre una persona adulta de confianza y un determinado niño o joven. La asistencia en la educación se materializa mediante un colaborador profesional de la Asistencia Juvenil (trabajador social/pedagogo social) o mediante empleados remunerados y puede durar desde algunos meses hasta tres años. Se aplican diferentes métodos de trabajo social o de pedagogía social (trabajo individual o en grupo). El núcleo del trabajo casi siempre consiste en conversaciones periódicas de asesoramiento con los niños/jóvenes y sus padres. Las formas de trabajo en grupo (por ejemplo, actividades de ocio en grupo) son también apreciadas.

\section{Ayuda familiar socio-pedagógica}

Una forma adicional de ayuda es la Ayuda Familiar Socio-Pedagógica. Ésta debe dar apoyo a las familias en sus tareas de educación, mediante una atención y un acompañamiento intensivo, para solucionar problemas cotidianos en contacto con autoridades e instituciones e impulsar la autoayuda. Normalmente, esta ayuda está enfocada a largo plazo y requiere la colaboración de las familias. En la Asistencia familiar socio-pedagógica móvil dirigida al conjunto de la familia existe la esperanza de que la familia vuelva a recuperar la capacidad de solucionar sus propios problemas y pueda afrontar la vida cotidiana gracias a esta atención y acompañamiento. En todos los casos, la colaboración de las familias es una condición necesaria para lograr esta meta.

\section{Grupos diurnos}

Como forma de apoyo, parcialmente estacionaria, se han estableci- 
do, a lo largo de los últimos años, la educación en un grupo diurno. Esta educación pretende apoyar el desarrollo del niño o del adolescente a través del aprendizaje social en el grupo, del seguimiento escolar y del trabajo de los padres para garantizar, con ello, la permanencia del niño o del adolescente en su familia de origen. Los grupos diurnos también pueden configurarse de acuerdo a objetivos específicos, así, por ejemplo, pueden ser de tipo pedagógico curativo o de terapia social. En este sentido, los grupos diurnos se diferencian, entre otros aspectos, por su dirección socio-pedagógica y/o socio-terapeútica y así mismo por los grupos de edad atendidos, la duración de la atención y la calificación de los profesionales que los atienden. Por norma, los grupos son mixtos en cuanto a edades y sexos, tienen entre 8 y 12 plazas y aceptan sobre todo a niños de entre 8 y 14 años. Además, existen algunos grupos para niños preescolares y adolescentes, normalmente con un número de plazas más reducido. La finalidad del trabajo de los grupos diurnos es la integración del desarrollo emocional y la estabilización del niño. La promoción y el acompañamiento de la integración escolar y la mejora y la estabilización de las relaciones entre padres y niños. La meta a largo plazo, sin embargo, es, también en este caso, sustituir a través de los éxitos de la promoción y del trabajo paralelo de los padres la atención en un grupo diurno por ofertas de asesoramiento y de atención menos intensivas, ante todo en el entorno de la familia de estos niños. La educación en los grupos diurnos debe contribuir a evitar que el niño sea alejado de su familia. La atención a niños y jóvenes en el seno de grupos diurnos puede sustituir el alojamiento fuera de la familia propia, siempre que existan posibilidades de activar recursos materiales y personales dentro de la familia con la participación de los padres. Si existen ciertas relaciones básicas dentro de la familia, el grupo diurno presenta la ventaja de causar una intervención menor sobre el ámbito privado de la familia.

Esquema de las formas de ayuda a las familias y sistemas complementarios:

\begin{tabular}{|c|c|c|}
\hline Orientación metódica & Ofertas & Finalidad principal delaayuda \\
\hline $\begin{array}{l}\text { Ayudas oricntadas a las fa- } \\
\text { milias/asistencia familiar } \\
\text { socio-pedagógica }\end{array}$ & $\begin{array}{l}\text { Asesoramiento pedagógi- } \\
\text { co }\end{array}$ & $\begin{array}{l}\text { Fortalecimicnto o recupcra- } \\
\text { ción de la capacidad educati- } \\
\text { va de la familia }\end{array}$ \\
\hline Ayuda a grupos & $\begin{array}{l}\text { Grupo diurno/trabajo so- } \\
\text { cial en grupo }\end{array}$ & \\
\hline $\begin{array}{l}\text { Ayudas orientadas a casos } \\
\text { individuales }\end{array}$ & Asistencia educativa & $\begin{array}{l}\text { Apoyo a niños mayores para } \\
\text { solucionar problemas (inde- } \\
\text { pendización) }\end{array}$ \\
\hline
\end{tabular}




\subsection{Alojamiento fuera de la familia de origen}

El alojamiento en familias de acogida y centros de acogida para menores eran -y son todavía-, junto a la adopción, las posibilidades más significativas de los servicios sociales para garantizar las condiciones de vida y el desarrollo de niños y jóvenes a partir de situaciones familiares deficientes, frustrantes o que comprometen el bienestar del niño.

Como consecuencia de la crítica a los centros de acogida para menores que se dio a finales de los años 60 , se llevó a cabo un gran esfuerzo con la intención de convertir los centros de acogida para menores en lugares dignos para niños y jóvenes (supresión del carácter de asilo). Dicha crítica, junto con el desarrollo explosivo de los costes, sobre todo en los últimos años, ha llevado a una revalorización de las familias de acogida como alternativa a la educación en centros de acogida para menores. No obstante, la proporción de los alojamientos en hogares de acogida fuera de la propia familia todavía representa un nivel de $50 \%$ y es predominante.

A pesar de las diferencias practicadas en el ámbito de los niños acogidos, en lo que se refiere a las diferentes formas de acogida (acogidas temporales breves, transitorias, duraderas y de las especializaciones en cuanto al contenido como centros de acogida pedagógico-curativos o terapéuticos), no existen suficientes personas dispuestas a acoger a niños en su propia familia, de acuerdo con las medidas requeridas. En el futuro se espera un fuerte impulso para mejorar la ayuda económica a los padres tutelares, que reciben una asistencia especializada permanente, así como una formación provechosa. De ese modo, se podrían nivelar las líneas divisorias entre profesionales en centros de acogida y en familias de acogida.

Desde hace años se ha llevado a cabo un desarrollo especializado positivo en al ámbito de los centros de acogida:

- Diferenciación entre las instituciones de educación en centros de acogida, en el sentido de una inclusión de ofertas ambulantes y parcialmente estacionarias.

- Construcción y aumento de hogares de acogida de tamaño pequeño, en lugares residenciales, con el fin de garantizar un ambiente familiar.

- Aumento y mejora de la atención ofrecida a los niños y jóvenes en la fase posterior a la salida de los centros de acogida

- Desarrollo de alternativas diferentes a las casas de acogida o centros para menores de carácter "cerrado". 
- Descentralización de las instituciones encargadas de la educación en centros de acogida, desarrollo de comunidades juveniles de vivienda, de domicilio...

La descentralización, diversificación y flexibilidad se han convertido en la actualidad en conceptos clave de una educación cambiante en centros de acogida. A través de unidades más pequeñas de formas de vivir (grupo colectivo de vivienda), debería contrarrestarse el anonimato de una vida cotidiana dirigida (por la Administración central) y adecuarse a la individualidad del niño o del joven asistido. La diversificación desestima el relegamiento y el traslado y la estigmatización resultantes. La flexibilidad supone, por fin, la ruptura de las fronteras entre un alojamiento más ambulante, parcialmente estacionario y estacionario, la posibilidad de transiciones fluidas, sobre todo, en formas estructuradas individualmente de transición de educación en centros de acogida en forma de domicilios «individuales atendidos» $u$ otras formas de acompañamiento y atención posterior.

Con relación a los desarrollos problemáticos, particularmente, de adolescentes, se han alcanzado formas de «atención individual sociopedagógica intensiva». Dichas formas deberían contribuir a que los adolescentes se puedan integrar gracias a un apoyo intensivo y a que encuentren un modo de vida responsable propio. La forma de ayuda está enfocada igualmente a largo plazo y la atención, forma de ayuda y asesoría debe tener en cuenta las necesidades individuales de los jóvenes.

La dificultad radica en que dicha forma especial de atención individual puede ir, de vez en cuando, acompañada del peligro de estigmatización para aquellos adolescentes en los que han fracasado otras formas de esfuerzos de educación hasta la fecha. Esta forma especial de atención se encuentra orientada principalmente a la situación de vida individual del joven y promueve, de vez en cuando, la presencia, o disponibilidad, de los pedagogos las veinticuatro horas del día. Su actividad abarca además de ayudas intensivas en lo que concierne a problemas personales y situaciones críticas, ayudas en la adquisición de una posibilidad de vivienda adecuada. Asimismo, abarca la ayuda de acceso a una formación escolar o profesional apropiada o de acceso a un trabajo así como la administración de remuneración y financiación formativa y laboral y otras ayudas financieras y ayudas de estructuración del tiempo de ocio.

La atención individual socio-pedagógica intensiva exige, por regla general, una motivación y capacidad de trabajo del profesional sociopedagógico especializado determinadas, sobre todo debido a que se debe mantener con los adolescentes estrechas relaciones personales en si- 
tuaciones y fases de desarrollo muy complicadas y abrumadoras. Además, el presente trabajo reclama una mayor medida en la reflexión, espontaneidad y disponibilidad de riesgo. Esta atención individual significa que el profesional sociopedagógico especializado para una o más atenciones es competente. Esta oferta de asistencia posee una función sustitutiva y en parte complementaria (como ayuda final) frente a las tradicionales formas de alojamiento en centros de acogida. Éstas no sólo se refieren a evitar un continuo alojamiento en centros de acogida para adolescentes de mayor edad sino también a la sustitución del alojamiento en centros de acogida a través de una atención individual intensiva.

\section{Cuadro de alojamiento fuera de la familia de origen}

\begin{tabular}{|l|l|l|}
\hline $\begin{array}{l}\text { Ayudas orientadas a la } \\
\text { familia }\end{array}$ & $\begin{array}{l}\text { Ayudas orientadas a } \\
\text { grupos }\end{array}$ & $\begin{array}{l}\text { Ayudas orientadas a casos } \\
\text { particulares }\end{array}$ \\
\hline $\begin{array}{l}\text { Familias de acogida a } \\
\text { tiempo completo }\end{array}$ & $\begin{array}{l}\text { Educación en centros } \\
\text { de acogida y formas adi- } \\
\text { cionales atendidas de } \\
\text { convivencia }\end{array}$ & $\begin{array}{l}\text { Atención individual socio- } \\
\text { pedagógica intensiva }\end{array}$ \\
\hline Familias de acogida & $\begin{array}{l}\text { Grupos estándar en centros } \\
\text { de acogida (8-10 niños) }\end{array}$ & $\begin{array}{l}\text { Formas flexibles de atención } \\
\text { individual }\end{array}$ \\
\hline $\begin{array}{l}\text { Familias de acogida profe- } \\
\text { sionales }\end{array}$ & $\begin{array}{l}\text { Casas subvencionadas para } \\
\text { niños }\end{array}$ & Atención flexible \\
\hline $\begin{array}{l}\text { Atención por parte de pa- } \\
\text { rientes }\end{array}$ & Grupo de viviendas & Vivienda individual atendida \\
\hline $\begin{array}{l}\text { Centros de educación (Edu- } \\
\text { cación profesional en una } \\
\text { situación de internamien- } \\
\text { to en familia) }\end{array}$ & & $\begin{array}{l}\text { Proyectos pedagógicos de } \\
\text { experiencias }\end{array}$ \\
\hline
\end{tabular}

\subsection{Datos y Valoración.}

A finales de 1998, se emplearon en Alemania 181.636 servicios sociales para niños, adolescentes y jóvenes de hasta 21 años en forma de ayudas ambulantes o estacionarias para la educación, puesto que se necesitaban apoyos especiales para su propio desarrollo. De un valor de media de 18.508.915 de este grupo de edad que vive en Alemania, existían servicios sociales activos en la fecha fijada para cerca de 980 de los 100.000 jóvenes que viven en Alemania. 148.636 recibieron una ayuda para la educación fuera de la familia de origen (aproximadamente 800 de 100.000), otros 33.000 una ayuda ambulante (aproximadamente 180 de 100.000$)^{2}$. Además, a lo largo de 1998, se asesoró a 
242.846 familias, a fin de respaldar a los padres en lo que concierne a la educación de los hijos.

Ayudas de educación para jóvenes, a 31-12-1998

Ayudas a la educación fuera de la casa de los padres

\begin{tabular}{|l|r|}
\hline Ayudas a la educación & N." de jóvenes \\
\hline Educación en un grupo diurno & 17.129 \\
\hline Alojamiento a tiempo completo en otra familia & 52.696 \\
\hline Educación en un centro de acogida y otras formas de vivienda atendida & 76.490 \\
\hline Atención individual sociopedagógica intensiva & 2.321 \\
\hline Total de ayudas fuera de la casa de los padres & $\mathbf{1 4 8 . 6 3 6}$ \\
\hline
\end{tabular}

Ayudas ambulantes para la educación

\begin{tabular}{|l|r|}
\hline Ayudas a la educación & N." de jóvenes \\
\hline Ayudas sociopedagógicas para la familia & 15.268 \\
\hline Apoyo a través de la asistencia educativa & 9.782 \\
\hline Apoyo a través de un asistente & 3.586 \\
\hline Trabajo de grupo social & 4.364 \\
\hline Total de ayudas ambulantes & $\mathbf{3 3 . 0 0 0}$ \\
\hline Asesoramiento institucional & 242.846 \\
\hline
\end{tabular}

En los últimos años, se han intensificado las ayudas ambulantes de forma considerable, lo que en el periodo que va de 1991 a 1998 condujo a casi una duplicación ( $83 \%$ ) del número total de los casos. No obstante, este hecho no significó -como se suponía al principio-que el número de ayudas estacionarias fuera retrógrado. Al contrario, dichas ayudas han aumentado de la misma manera y al mismo tiempo de forma patente $(18 \%)^{3}$.

Estos incrementos se mantienen en relación con las cargas ascendentes para redes familiares. Esto se debe, por un lado, al empeoramiento de las condiciones socioeconómicas globales (ingresos insignificantes, desempleo, recepción de ayudas sociales, mayor endeudamiento, condiciones problemáticas de vivienda, situaciones sociales críticas o de pobreza). Por otro lado, se debe también a acelerados procesos de individualización y de pluralización. Tiene lugar un cambio de formas de vida familiares que, asimismo, se convierten en factores que tienden a desestabilizar las condiciones infantiles de crecimiento. Otras situaciones problemáticas familiares que se basan en la realización de las prestaciones de ayuda juvenil se deben al esfuerzo excesivo de los padres o 
de uno de los padres en lo que se refiere a la educación, a relaciones conyugales problemáticas de los padres o de uno de los padres, a violencia familiar y a problemas de adicción.

Se pueden nombrar las categorías: abandono, malos tratos físicos, malos tratos psicológicos, abuso sexual, conflictos de autonomía, conflictos de adultos, como situaciones de amenaza diferentes que hacen necesarias ofertas de apoyo para niños y adolescentes. Sin embargo, las situaciones de peligro para niños y jóvenes no se pueden adjudicar simplemente a determinadas categorías sino que se presentan muy a menudo de forma combinada. Las situaciones problemáticas que de ello se deducen para los niños y adolescentes se manifiestan principalmente en los atrasos de aprendizaje y rendimiento, ausencia de centros escolares o de formación, comportamiento agresivo, así como en atrasos en el desarrollo y atenciones psíquicas y en dolencias y lesiones físicas.

Con respecto a una diferenciación de los problemas de las chicas y los chicos por razones de género y la forma como responden a ellos, se encontró que hay una diferencia en cuanto a la forma como están expuestos o responden a situaciones de violencia. Las chicas están más expuestas a situaciones de violencia y abuso sexual y los chicos reaccionan con mayor frecuencia con actitudes violentas y agresivas frente a situaciones de tensión.

Una mayor parte de los niños o bien de los adolescentes para los que se hacen necesarias prestaciones de ayudas proceden de familias incompletas. La mayor parte vive en casas de madres educadoras solas. Esto puede interpretarse como un frecuente esfuerzo excesivo del padre o de la madre en referencia a aquellas madres con la condición de educadora individual, que entonces se convierte, sobre todo, en algo problemático, si no se mantienen disponibles otros sistemas de apoyo tanto del Estado como sociofamiliares.

\subsection{Empleados de los servicios sociales para niños o adolescentes}

En las áreas específicas para niños y adolescentes se ha dado trabajo en Alemania a aproximadamente unos 100.000 especialistas. Los especialistas están formados en diferentes niveles: Berufsfachschulen [Escuelas de formación profesional] (puericultores), Fachschulen [escuelas técnicas] y Fachakademien [academias técnicas] (educadores), Fachhoschulen [escuelas técnicas superiores] (diplomatura universitaria en trabajo social y pedagogía social), así como universidades (Diplomatura en Pedagogía).

Dentro de estos niveles también podemos encontrar distintos tipos 
de formación específicos y complementarios, orientados a las distintas especialidades de los servicios sociales para niños o adolescentes. A este respecto encontramos: psicopedagogos, logopedas, pedagogos terapeutas, supervisores, terapeutas sociales, pedagogos de tiempo libre.

Cuadro de la formación de especialistas en pedagogía social:

\begin{tabular}{|l|l|l|}
\hline Centros de formación & Especialidades & Ámbitos de trabajo \\
\hline Universidad & $\begin{array}{l}\text { - Dipl. Pedagogía } \\
\text { - Dipl. Psicología } \\
\text { - Dipl. Sociología } \\
\text { - Otros estudios sociales }\end{array}$ & $\begin{array}{l}\text { Dirección, organización, pla- } \\
\text { nificación, pedagogía, todas } \\
\text { las áreas de trabajo. }\end{array}$ \\
\hline $\begin{array}{l}\text { Fachhochschulen } \\
\text { (Escuelas técnicas superio- } \\
\text { res) }\end{array}$ & $\begin{array}{l}\text { - Dipl. Pedagogía Social } \\
\text { - Dipl. Trabajo Social }\end{array}$ & $\begin{array}{l}\text { Dirección, pedagogía, organi- } \\
\text { zación, planificación, admi- } \\
\text { nistración, todas las áreas de } \\
\text { trabajo. }\end{array}$ \\
\hline $\begin{array}{l}\text { Facthschulen (Escuelas téc- } \\
\text { nicas) }\end{array}$ & $\begin{array}{l}\text { - Educador } \\
\text { - Pedagogo terapeuta }\end{array}$ & $\begin{array}{l}\text { Dirección de jardines de in- } \\
\text { fancia, pedagogía en servicios } \\
\text { para grupos (principalmente } \\
\text { en jardines de infancia) }\end{array}$ \\
\hline $\begin{array}{l}\text { Berufsfachschule/Beruf- } \\
\text { sausbildung (Escuelas de } \\
\text { formación profesional }\end{array}$ & $\begin{array}{l}\text { - Puericultor } \\
\text { péutico }\end{array}$ & $\begin{array}{l}\text { Ayuda a la educación } \\
\text { gruposogía en servicios para }\end{array}$ \\
\hline
\end{tabular}

\section{IV.PROSPECTIVA}

\subsection{Flexibilización de las ayudas a la educación}

El mantenimiento del equilibrio entre el ya descrito perfil especializado en las formas de ofertas individuales y la necesaria interdependencia de las ayudas, así como la posibilidad de la flexibilidad en un caso particular en la aplicación de las ofertas de ayuda, requiere una cooperación técnica continua entre las distintas instituciones y la Oficina de Protección al Menor.

Como los más recientes avances técnicos, se han desarrollado (ya mencionado en el punto 3.2) así los llamados centros de niños y de ayuda familiar y también "Centros de Ayuda Juvenil", es decir, ayudas de educación integrales, en los que se ofrecen «de forma centralizada» conceptos estructurales de organización, para evitar los traslados innecesarios de una institución a otra de los niños o adolescentes que reciben asistencia.

El objetivo es romper la especialización y separación de algunas formas de ayuda para una posterior reunificación de las mismas. Para 
ello se debe establecer la posibilidad para que se presten todas las ayudas ambulantes y parcialmente estacionarias para niños, adolescentes y familias a un lugar y de forma flexible, «amortiguar» las transiciones entre las formas de ayuda, evitar los cambios de organismos y las interrupciones.

La renuncia a una estandarización de las clases de ayuda específicas tiene la ventaja de que la actuación sociopedagógica puede ser llevada a cabo de manera individual y puede ser modificada en el proceso de ayuda conforme a hechos coyunturales, ya que no se lleva a cabo desde el principio la fijación de una determinada forma de oferta. Esto quiere decir que las formas de ayuda orientadas a la educación requieren un marco inequívoco (para que no sean manejadas a la voluntad de un particular o de un modo arbitrario). Para elaborar este marco se hace necesaria una determinación precisa de los objetivos de las ayudas y una planificación escrita de las mismas, los objetivos, los objetivos parciales, las funciones, las tramitaciones por escrito, las responsabilidades, el tiempo disponible y las retroacciones claramente denominadas por escrito y que da a los interesados y afectados la posibilidad de examinar la actividad del personal especializado en las instituciones en el contexto de la fijación de objetivos.

Con todo este desarrollo técnico favorable existe, sin embargo, en los últimos tiempos en relación con los niños y adolescentes con extremas dificultades de formación que no evidencian ningún trastorno psíquico importante, masivas críticas por parte de la opinión pública -hasta en el terreno político- en referencia a las propuestas de menor calado, como ésta, por ejemplo, que representa los cuidados sociopedagógicos específicos e intensivos (véase punto 3.2.). Estos conceptos -no completamente infundados- se ponen en duda debido a su falta de éxito y también supuestamente debido a sus costes excesivamente altos, especialmente, los así llamados viajes de experiencia pedagógica. En lugar de ello, se reclama una «actuación más dura» recurriendo a posiciones autoritarias que se suponían ya superadas. Estas exigencias también comprenden (de nuevo) la implantación de internados (custodia) para niños y adolescentes mayores. En algunas regiones alemanas esto ya es una realidad.

\subsection{Enfoques teóricos}

En los últimos años la respuesta que se dio al incremento de las situaciones de conflictos y problemas se basó en aumentar la formación y el número cada vez mayor de expertos. Sin embargo, esto iba acompañado de la psicologización y de una individualización de la situación de los problemas así como de la terapeutización en las estrategias 
de resolución, que, por lo demás, eliminaba casi totalmente la dimensión social. No sólo porque la psicologización/terapeutización ha provocado un encarecimiento excesivo de las ofertas de ayuda, sino también porque los resultados en esos amplios ámbitos no convencen lo suficiente, es ahora perceptible un tímido redescubrimiento del aspecto pedagógico. También, por supuesto, porque la normativa, por así decirlo, sufre una nueva y amplia valoración política.

Actualmente, los cada vez más escasos recursos financieros de los municipios y el hecho de que cada vez más personas son rechazadas del proceso activo laboral suscita cuestiones como hasta qué punto los servicios sociales para niños pueden volver a quedar ligados a las tradiciones de los años 70 en la República Federal Alemana.

Bajo el lema de la participación con la comunidad se crearon en Alemania las llamadas "Agencias del Voluntariado", por las que los ciudadanos/as también se ponen en disposición de desempeñar tareas sociales, aunque con otras motivaciones y esperanzas que hace 20 ó 30 años. A este respecto surge la pregunta: hasta qué punto los servicios sociales para niños y adolescentes así como otras áreas del trabajo social recogen estos desafíos de los procesos de cambio sociales ${ }^{4} \mathrm{o}$ anteponen de forma simplificada intereses cooperativos. Hasta qué punto serán capaces los servicios sociales de armonizar los recursos humanos existentes "competencia laica" con las experiencias humanas para integrar el aspecto profesional de forma productiva con la competencia cotidiana.

\section{BIBLIOGRAFÍA}

BÜRGER, U.: Entwicklungen der ambulanten hilfen zur Erziehung und Veränderungen in der Inanspruchnahme stationärer Erziehungshilfen in den 90 er Jahren. Landesjugendamt, Stuttgart 2000, unveröff. Manuskript.

GIARINI, O.; LIEDTKE, M.: Wie wir arbeiten werden. Der neue Bericht an den Club of Rome. Hoffmann und Campe 1998.

JORDAN, E.; SENGLING, D.: Jugendhilfe. Weinheim/München 2000.

KREFT, D.; MIELENZ, I.: Wörterbuch soziale Arbeit: Aufgabenfelder, Praxisfelder, Begriffe und Methoden sozialer Arbeit und Sozialpädagogik. Weinheim/Basel 1996.

MÜNDER, J.U.A.: Frankfurter Lehr- und Praxiskommentar zum SGB VIII. Münster 1998.

STATISCHES BUNDESAMT: Jugendhilfe, Fachserie 13, Reihe 6.1.1. Wiesbaden 2000.

+ Giarini/Lied ke. 



\title{
SERVICIOS SOCIALES PARA MENORES EN FRANCIA
}

\author{
HORTENSIA REDERO BELLIDO
}

Departamento de Trabajo Social y Servicios Sociales. Universidad de Alicante.

\section{INTRODUCCIÓN}

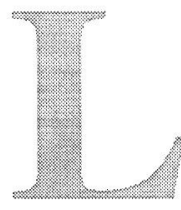

os Servicios sociales dirigidos a los menores y de apoyo a las familias tienen una amplia tradición en Francia. Ya en 1919 Henri Sellier presenta, en su programa electoral para la alcaldía de Suresnes, una propuesta para organizar Servicios de visitadores de la primera infancia, con una orientación médico social, a desarrollar por los municipios ${ }^{1}$.

A lo largo del tiempo han ido modificándose las modalidades de actuación, lo mismo que ha ocurrido en otros países. Así se ha pasado, en determinadas actuaciones, de desarrollar acciones para proteger al menor de su familia a desarrollar un planteamiento preventivo, dando prioridad a mantener al menor en su medio ambiente familiar y a potenciar el mismo, con el fin de proporcionar al menor un entorno adecua$\mathrm{do}^{2}$.

Esta orientación hacia una política familiar se refleja en la existencia de un amplio sistema de preescolar para los niños así como en la atención de día ${ }^{3}$. Esta política permite aumentar la natalidad, facilitar el acceso de los padres al mercado laboral y conseguir el desarrollo de los menores.

La actuación dirigida a los menores está ampliamente supervisada por los poderes públicos con el fin de vigilar su buen desarrollo. Esta atención se desarrolla a través de la ayuda social y la ación social, siendo la primera un derecho subjetivo para el ciudadano y una obligación para el Estado, regulada a través del Código de la Acción Social y

Arnault, A.M.; Bouquet, B. (1991): "Regard socio-historique sur la polyvalence de secteur", Vie Sociale, $\mathrm{n}^{\circ} 9-10$, pág. 5.

2 Borgetto, M.; Lafore, R. (1996): Droit de l'aide et de l'action sociales. Montchrestien. París. Págs. 144-145.

3 Ely, P.; Saunders, R. (1993); en Munday, B. (Ed.): European Social Services. European Institute Social Services, University of Kent. Canterbury. Reino Unido. 
la Familia, que sustituye al Código de la Familia y de la Ayuda Social ${ }^{4}$; la acción social se puede desarrollar por iniciativa de las distintas administraciones o por entidades privadas, tiene un carácter más discrecional, ya que puede desarrollar acciones facultativas y algunas otras que están parcialmente determinadas por algún tipo de reglamentación.

\section{DISTRIBUCIÓN DE COMPETENCIAS}

Desde los años 80, Francia es un Estado descentralizado, que implica una distribución de competencias entre el Estado a nivel central y las diferentes colectividades territoriales. En todos los niveles, excepto en los municipios, se encuentra una administración dual. La que representa a la administración central, designada por el gobiemo y la que es elegida por la población en su demarcación territorial. Territorialmente el país se divide en Regiones, relativamente nuevas, Departamentos y Municipios.

Las competencias en materia de protección de los menores se centran fundamentalmente en dos Ministerios: el Ministerio de Empleo y de la Solidaridad y el Ministerio de Justicia, que se ocupa de la protección jurídica de la juventud e interviene en la acción social y la ayuda social con la finalidad de proteger a los menores en situación de riesgo.

Dentro del Ministerio del Empleo y la Solidaridad, en relación con los menores, es importante la Dirección de Acción Social y, dentro de ésta, las Subdirecciones de animación territorial y del trabajo social y la Subdirección de las personas discapacitadas, así mismo es relevante la Dirección Interministerial de la Familia y el/la Ministro/a delegado/a de la familia y la infancia.

De este Ministerio, en materia de Servicios Sociales en sentido amplio, dependen las grandes instituciones, como son la Seguridad Social, los regímenes complementarios, la Mutualidad y la Ayuda social, así como la acción de protección de grupos e individuos: la familia, infancia, discapacitados, $3^{a}$ edad y personas en dificultad ${ }^{5}$. Dentro del sistema de Seguridad Social, la Caja Nacional de la Familia asume determinadas prestaciones dirigidas a las familias para atender a las necesidades de los menores.

Existen otros Ministerios con competencias en materias relacionadas con los niños y jóvenes: el de Educación (asume competencias en

4 Code de l'action sociale et des familles. Journal Officiel de la République Française, $n^{\circ}$ 297. Du 23 décembre 2000. 
materia de salud escolar, becas de enseñanza...), y el de la Juventud y los Deportes que desarrolla actividades socio-educativas y actividades socio-culturales.

El Ministerio regula los tres principales fondos de Seguridad Social y los Servicios Sociales, a través de legislación, políticas, planificación, establece las prestaciones mínimas de carácter universal y el nivel de tasas que los usuarios deben pagar por determinados servicios.

Las Regiones son el siguiente ámbito territorial cuyo representante del poder central es el Prefecto Regional. Tiene su propio personal formado por técnicos y funcionarios que conforman la Dirección Regional de Asuntos Sanitarios y Sociales (DRASS). La administración de los Servicios de Salud depende de este nivel, cuyo papel fundamental es de asesoramiento técnico, apoyo financiero y administrativo, control y evaluación y coordinación de los servicios sociales del siguiente escalón del gobierno, los Departamentos.

Los Departamentos, a través del personal de la Dirección Departamental de Asuntos Sanitarios y Sociales (DDASS), gestiona los servicios de salud y controla los establecimientos sanitarios y sociales. En general, el Prefecto es el responsable de que se ejecuten planes regionales de los servicios sanitarios y sociales, de autorizar la provisión local de esos servicios o de su contratación, de la coordinación financiera y de la inspección. Los servicios fundamentales que dependen de esta Dirección Departamental son los siguientes ${ }^{6}$ :

- Hospitales de corta, media y larga estancia.

- Camas medicalizadas en residencias de ancianos.

- Servicios domiciliarios de enfermería.

- Servicios psiquiátricos.

- Servicios de salud escolar.

- Subsidios por maternidad: expide los certificados de beneficiarios.

- Centros de atención precoz médico-social para niños discapacitados.

- Establecimientos residenciales para menores con grandes discapacidades.

- Talleres de trabajo (CATS) y centros de rehabilitación ocupacional para discapacitados adultos.

5 Borgetto, M.; Lafore, R. (1996): Droit de l'aide et de l'action sociales. París, Montchrestien, pág 72.

6 Ely, P.; Saunders, R. (1993): Ob. cit. págs. 124 y ss. 
- Centros de recepción especial para discapacitados severos.

- Supervisión y financiación del bienestar de los menores que son responsabilidad del estado.

- Proporcionar subsidios a individuos incluidos en proyectos del "Ingreso Mínimo de Inserción" (RMI).

En general dependen de este nivel los centros que desarrollan cuidados dirigidos a la salud.

\subsection{Administración territorial descentralizada}

El nivel más amplio corresponde a las Regiones. El Presidente electo del Consejo Regional puede tener, también, su propio personal de servicios sociales diseñando políticas, planificando y coordinando financieramente los servicios sociales de los Departamentos. En líneas generales las Regiones tienen escasas competencias directas.

Con la descentralización que se produce en el 82, la administración, gestión y prestación de los Servicios Sociales están encomendadas, en su mayoría, a los Departamentos; en concreto, es responsabilidad del Presidente electo del Consejo Departamental. Pueden prestar los servicios directamente o contratarlos con las entidades privadas sin ánimo de lucro.

El 22 de julio de 1983 se votó una ley que delegaba la responsabilidad administrativa de los servicios de protección a los niños a los Departamentos. El gobierno central conserva su poder legislativo y regulador. El Consejo de Departamento se encarga de la organización de los servicios de protección a los niños, la gestión de personal, la creación y financiación de las instituciones y del cobro de los servicios pres$\operatorname{tados}^{7}$. Todos los Departamentos han desarrollado servicios especializados dirigidos a los menores: Protección Maternal e Infantil, (PMI) y Ayuda Social a la Infancia (ASE).

El presidente del Consejo General es responsable de la provisión, financiación y gestión de subsidios legales y discrecionales de la Ayuda Social, y de los siguientes servicios sociales, los cuales, si no son proporcionados directamente, pueden ser contratados con entidades sin ánimo de lucro:

- Ayuda en el hogar y otros tipos de atención domiciliaria, aparte de los de enfermería, provisión, financiación y gestión de subsidios oficiales. 
- Atención residencial para ancianos y discapacitados menos severos.

- El personal de los Centros Comunitarios de Acción Social, CCAS.

- Servicios de atención de campo, de día y residenciales, para menores (Protección Maternal e Infantil -PMI- Ayuda Social a la Infancia - ASE- y los centros de entidades no lucrativas que pueden estar concertados).

- La creación de los proyectos de RMI.

Así, la prestación de servicios se desarrolla fundamentalmente por el Departamento, aunque la atención primaria se da en los municipios a través de los Centros Comunitarios de Acción Social, CCAS, cuyos trabajadores son contratados por el Departamento. Estos tienen capacidad para adaptar los servicios de acuerdo con las circunstancias demográficas, económicas y políticas. Pueden unirse varios Municipios para desarrollar programas y actividades conjuntamente. Los Municipios tienen un papel muy diverso; disponen de competencias obligatorias y facultativas, higiene publica, servicios de ayuda sanitaria a domicilio, centros de protección maternal e infantil, etc.

Existe por otro lado una amplia tradición en las actuaciones por parte de entidades sin ánimo de lucro, establecidas por la Ley de 1 de julio de 1901, y que desarrollan una amplia labor en el ámbito de los servicios dirigidos a menores y jóvenes. A partir de iniciativas de estas entidades se han desarrollado nuevas modalidades de actuación. No obstante, "algunas de ellas tienden a ganar credibilidad invirtiendo en servicios muy visibles, tales como grandes instituciones, antes que en servicios de atención primaria que proporcionan servicios individualizados"s. Pueden intervenir tanto en establecimientos como en medio abierto. Sus recursos económicos proceden de diversos ámbitos, entre ellos de la Administración Pública. Tienen que estar acreditadas por los poderes públicos y son objeto de controles regulares.

\section{SERVICIOS SOCIALES PARA MENORES}

La atención dirigida a los menores se puede desarrollar a través de los servicios generales y de servicios específicos para ellos.

\subsection{Servicios de atención primaria polivalente}

En líneas generales los Centros Comunitarios de Acción Social 
(CCAS) son la puerta de entrada a los Servicios Sociales, en la actualidad con tendencia a desarrollar un trabajo de tipo colectivo para dar respuesta a las necesidades de la población. Ofrecen servicios básicos, de carácter polivalente, que proporcionan información, servicios de asesoramiento, tramitación de prestaciones económicas, etc. Tienen encomendada una acción general de prevención y desarrollo social en el Municipio en estrecha colaboración con otras entidades públicas y privadas. «Son los encargados de la coordinación de la acción social en el municipio y, bien llevan directamente el trabajo con familias que tienen menores o ancianos, o son informados de ello. Pueden desarrollar servicios de cuidados de día para menores» ${ }^{9}$.

El Servicio de Acción Social de los Departamentos contrata trabajadores sociales de dichos Centros (CCAS), los cuales actúan en colaboración con el servicio de Protección Maternal e Infantil (PMI), para proporcionar asesoramiento social e inspección de menores en situación de riesgo, asesoramiento en abortos, y participación en trabajos de información individual o general. Tienen la responsabilidad de hacer el seguimiento de los niños PMI y de los que están atendidos por el ASE (que veremos a continuación), así como de las familias de acogimiento familiar que le son encomendadas.

Las principales misiones y actividades de los Servicios Sociales de atención primaria (Service Social Polyvalente de Secteur) relacionadas con los menores son las siguientes ${ }^{10}$ :

- Acogimiento-orientación.

- Seguimiento social de todas las familias en dificultad, problemas de alojamiento, económicos y financieros, administrativos y jurídicos, de salud, familiares, infancia.

- Alojamiento: acceso al alojamiento, hospedaje de urgencias, mantenimiento en el alojamiento.

- Económicos y financieros: salarios bajos, endeudamiento, desempleo...

- Administrativos y jurídicos: acceso a los derechos, restablecimiento de derechos.

- Salud: acceso a los cuidados, hospitalización, alcoholismo, toxicomanías...

- Familiares: problemas de comunicación, violencia, ruptura, aislamiento, guardia de niños...

9 Ely, P.; Saunders, R. (1993); en Munday, B. (Editor). Ob. cit. pag. 126.

10 Arnauld, A.M. ; Bouquet, B. (1991): "Regard socio-historique sur la polyvalence de secteur". Vie Sociale, nº 9-10. Pág. 15. 
- Infancia: fracaso escolar, absentismo, fuga, delincuencia.

- Seguimiento social de niños PMI (Protección Maternal e Infantil).

- Infancia en peligro, maltrato.

- Mandato ASE: seguimiento de los niños ASE (Ayuda Social a la Infancia) y de las familiar de acogimiento del sector (en algunos Departamentos).

- Aplicación de las nuevas políticas después de 1988:

- El maltrato: Ley de 10-7-1989.

- El sobre-endeudamiento de los particulares y de las familias: Ley de 31-12- 1989.

- Derecho al alojamiento y al seguimiento social: Ley de 31-51990.

\subsection{Servicios específicos de protección social para menores}

Las leyes más importantes en el tema de protección a la infancia son la del 30-6-75; ley sobre la infancia de 6-6-84; la que reforma algunos aspectos de ésta relativas a la ayuda social de 6-2-86; la de 10 de julio de 1989 sobre la prevención de los malos tratos a los menores, la ley de 5 de julio del 96 sobre la adopción y el Código de la Acción Social y la Familia, aprobado en diciembre de $2000^{11}$, que sustituye al código de la Familia y la Ayuda Social que se creó por decreto $\mathrm{n}^{\circ}$ 56-149 de 24 de enero de 1956. Dicho Código pretende recoger todo el conjunto de prestaciones de la ayuda social.

El planteamiento actual en la protección de los menores es que es imprescindible considerar su origen, sus vínculos familiares y su medio cultural, por lo que la actuación debe contemplar estos aspectos. En esta misma línea, se trata de que los niños permanezcan con sus padres, y si no es posible, al menos mantener los lazos entre los menores y sus familias; para ello, se pretende promocionar al máximo el medio familiar, con una voluntad primordialmente educativa. Se trata de implicar al máximo a los padres en la atención de los hijos para que puedan ejercer sus derechos y responsabilidades parentales, animándoles a participar en las decisiones a tomar acerca de sus hijos. Con este fin se crean centros a pequeña escala y se descentralizan los servicios ${ }^{12}$. En

$"$ Ordonnance $n^{\circ} 2000-1249 d u 21$ décembre 2000 relative à la partie Legislative du Code de l'action sociales et des familes. Journal Officiel de la République Française, 23 décembre 2000. Ésta sustituye a determinadas normativas anteriores y quedan integradas en ella.

12 Corbillon, M. (1995): "Francia", en Colton, M.J. y Hellinckx, W. (1995): La atención a la infancia en la Unión Europea. Guia por paises sobre acogimiento familiar y atención residencial. Madrid, Ministerio de Asuntos Sociales, pág.77. 
líneas generales se plantea una gradación de las medidas que van desde la atención en el medio familiar al internamiento en Centros en última instancia. Por otra parte, las circunstancias de los menores asistidos deben ser reevaluadas con regularidad y revisadas al menos una vez al año. Estas bases están contempladas en la Ley sobre los niños de 6 de junio de 1984.

Los principales servicios para familias y menores son responsabilidad del Presidente del Consejo General de los Departamentos, tal como se ha dicho anteriormente. Estos servicios tienen tres componentes principales: el Servicio de Protección Maternal e Infantil, PMI que va dirigido a las madres y los niños de corta edad, con una orientación fundamentalmente de salud. El Servicio de Ayuda Social a la Infancia, ASE. Esto se completa con el Servicio Judicial, Juez de Menores, que dependen del Ministerio de Justicia.

Con fecha 7 de marzo del 2000 se crea la figura del Defensor de los Niños, como autoridad independiente, para defender y promover los derechos del menor.

\subsubsection{El Servicio de Protección Maternal e Infantil (PMI)}

Este servicio fue establecido en 1945 con el objetivo de reducir la mortalidad materna e infantil. Es un servicio no personalizado bajo responsabilidad del Departamento. Desarrolla acciones médico-sociales dirigidas al conjunto de la población, para atender la maternidad y los primeros años de vida de los niños, así como acciones especiales sobre grupos de población desfavorecidos o de ciertos menores.

Potencia las acciones de carácter preventivo, especialmente durante el embarazo, planificación familiar, controles medico-sociales prenatales y post-natales y educación a los futuros padres.

Dirigido directamente a los niños, realiza actuaciones, también de tipo preventivo, durante los seis primeros años de vida del niño, en su propio medio, para lo cual se desarrollan intervenciones en el propio domicilio de puericultura y trabajadores del servicio Social del Departamento.

Por otra parte también presta asesoramiento, orientación profesional y control de los centros o servicios de acogidas de los niños pequeños, como casas nido, guarderías, jardines de infancia, medio escolar, etc.

Son importantes las actuaciones para detectar e intervenir precozmente en el caso de niños con discapacidad. En esta línea actúan los equipos de observación abierta y los Centros de Observación, que tie- 
nen carácter temporal, así como los centros de atención médico-social precoz, que están bajo supervisión e impulso de este servicio.

Con los grupos más vulnerables desarrolla acciones más puntuales para facilitar el mejor uso de los servicios sanitarios y sociales, con acciones preventivas médico sociales con familias de riesgo. Igualmente juega un papel importante para prevenir los malos tratos, a pesar de que esta función, actualmente, es responsabilidad del Servicio de Ayuda Social a la Infancia ${ }^{13}$.

Otro tipo de actividades indirectas son: recopilación de estadísticas en relación a la salud maternal e infantil y expedición de certificados oficiales de embarazo, salud y demás; actividades de educación y promoción de la salud; participación en el adiestramiento de comadronas, visitadores de salud (puericultoras) y enfermeras; vinculación o coordinación entre médicos de familia, hospitales, servicios psiquiátricos infantiles y juveniles, servicios de salud escolar y otros profesionales relevantes ${ }^{14}$.

Este Servicio de Protección Maternal e Infantil está bajo supervisión médica y depende de los servicios sanitarios.

\subsubsection{Servicio de Ayuda Social a la Infancia (ASE)}

Este servicio se plantea para afrontar los riesgos de tipo social que pueden afectar al desarrollo del menor, ya sea por su comportamiento $o$ por dificultades en el medio familiar. En líneas generales, los colectivos de población destinataria de este servicio son los siguientes: los menores sin lazos familiares ("Pupilos del Estado"), los menores víctimas de un medio familiar con carencias y los jóvenes delincuentes. También pueden ser atendidos los jóvenes mayores (18-21 año) que piden protección porque no tienen un medio familiar adecuado. Para ello se plantea una institución de carácter administrativo, el Servicio de Ayuda Social a la Infancia, y otra instancia de tipo jurídico, el Juez de Menores, apoyado por los servicios de Protección Jurídica de la Juventud que dependen del Ministerio de Justicia ${ }^{15}$.

Las líneas de actuación fundamentales se orientan a un trabajo de tipo preventivo, con medidas socio-educativas y de apoyo y promoción de las familias, con el objetivo de mantener al menor con su familia

13 Borgetto, M.; Lafore, R. (1996): Droit de l'aide et de l'action sociale, París, Montchrestien, págs. 145 y ss.

14 Ely, P; Saunders, R. (1993): ob. cit. pág 127.

is Borgetto, M.; Lafore, R. (1996): Droit de l'aide et de l'action sociale, París, Montchrestien, págs. 153 y ss. 
siempre que sea posible $o$, al menos, no romper los lazos familiares; si la situación es grave y no puede mantenerse en el medio familiar, se deberá hacer cargo del menor, bien a través de los distintos tipos de acogimiento de este servicio o a través de la protección judicial. Las actuaciones se fundamentan en el Código Civil y en el Código de la Acción Social y de la Familia. El propio Código Civil, en su artículo 375, establece que "si la salud, la seguridad o la moralidad de un menor no emancipado está en peligro, o si las condiciones de su educación están gravemente comprometidas, las medidas de asistencia educativa pueden ser ordenadas por la justicia a petición del padre y la madre conjuntamente, o de uno de ellos, del guardián o tutor, del menor mismo o del Ministerio Público. El Juez puede actuar de oficio a título excepcional".

El Servicio de Ayuda Social a la Infancia es el responsable de la prevención del maltrato y de la protección de los menores; actúa en colaboración con los otros servicios, PMI, Acción Social y los Servicios del Estado, especialmente los de justicia, educación y salud. Sus servicios están a disposición de todas las familias y de todos los menores y jóvenes adultos, hasta la edad de 21 años, que tengan circunstancias que afecten a su estabilidad.

El planteamiento de la actuación es doble: por una parte con acciones sobre el menor y el núcleo familiar para que las familias asuman sus responsabilidades educativas y de este modo prevenir las posibles situaciones de riesgo. Así viene establecido en el Código de la Acción Social y de la Familia en su artículo L 221-1-1 $1^{\circ}$ : "Aportar apoyo material, educativo y psicológico a los menores, su familia, a los menores emancipados y a los mayores de edad menores de 21 años enfrentados a dificultades sociales susceptibles de comprometer gravemente su equilibrio". Para esta actuación se proporcionan tanto medidas de apoyo en el hogar (por ejemplo, la ayuda a domicilio, recogida en el mismo Código), como ayudas económicas.

Las ayudas de apoyo en el hogar que se establecen son las siguientes:

- $\operatorname{Art}^{\circ}$. L 222-2: la ayuda a domicilio es atribuida sobre su demanda, o con su acuerdo, a la madre, al padre, o en su defecto a la persona que asume la carga efectiva del menor, cuando la salud de aquél, su seguridad, su mantenimiento o su educación lo exige y, para las prestaciones en especie, cuando el demandante no disponga de recursos suficientes.

- Es otorgada a las mujeres embarazadas enfrentadas a dificultades médicas o sociales y financieras mientras su salud o la del menor lo exige. 
- Puede contribuir a prevenir una interrupción voluntaria del embarazo.

- Puede ser concedida a los menores emancipados y a los mayores de edad menores de 21 años, enfrentados a dificultades sociales.

- Art $^{\circ}$ L 222-3: la ayuda a domicilio comporta, conjunta o separadamente:

- Intervención de un/una técnico/a de intervención social y familiar o de una ayuda al hogar.

- La intervención de un servicio de acción educativa.

- El pago de ayudas económicas efectuadas ya sea bajo la forma de ayudas excepcionales, asignación mensual, a título definitivo o bajo la condición de reintegro, eventualmente expedida en especie.

- Art $^{\circ}$ L 222-4: El socorro y la asignación mensual de ayuda a domicilio no se pueden ceder y son inembargables. Algunas veces, a petición del beneficiario, pueden ser otorgadas a toda persona temporalmente encargada del menor.

Cuando es nombrado un tutor de las prestaciones sociales, recibe de pleno derecho las asignaciones mensuales de ayuda a domicilio.

Por otra parte, con actuaciones preventivas, de naturaleza colectiva, en el medio más amplio donde se desenvuelven los menores y adolescentes, no solamente en el medio familiar. Estas acciones se desarrollan en los barrios, vecindario, extrarradio, con grupos de menores y adolescentes, y están dirigidas a conseguir la reinserción familiar y social. Es un trabajo de tipo comunitario orientado a que los propios interesados participen activamente, tanto para identificar sus necesidades como para desarrollar y demandar servicios. Se llevan a cabo distintos tipos de actuaciones, algunas de ellas de prevención especializadas, acciones de animación, organización de clubs, etc. desarrollados por equipos de prevención socio-educativos. Esta actuación puede ser llevada acabo tanto por el Servicio de ayuda Social a la Infancia como por los Servicios Sociales de los Centros Comunitarios de Acción Social o por entidades sin ánimo de lucro. Generalmente todas ellas trabajan en colaboración.

- Art $^{\circ}$ L 221-2-3: Organizar en los lugares donde se manifiestan los riesgos de inadaptación social, las acciones colectivas con vistas a prevenir la marginalización y a facilitar la inserción o la promoción social de los jóvenes y de las familias. 
Otra de las misiones del Servicio es la prevención del abandono del menor. En esto se plantean dos posibilidades: o bien el menor, por dificultades temporales, no puede permanecer con la familia y, a petición de ésta, es acogido temporalmente; o bien cuando hay riesgo de maltrato, privación de los cuidados que necesita, o corre un grave riesgo de caer en delincuencia; en estos casos se recurre al Juez de Menores que es quien tiene la competencia para tomar otro tipo de decisión, como puede ser quitar la tutela a los padres u otro tipo de medidas necesarias. Igualmente pueden ser acogidas las madres con hijos pequeños que tienen dificultades y los jóvenes más mayores o emancipados (18-21 años).

- Art $^{\circ}$ 222-5: Serán tomadas a cargo por el servicio de Ayuda Social a la Infancia sobre la decisión del Presidente del Consejo General:

- Los menores que no pueden provisionalmente ser mantenidos en su lugar de vida habitual.

- Los pupilos del Estado remitidos al servicio en las condiciones previstas en Ios artículos L 224-4, L 224-5, L 224-6 y L 224-8 ${ }^{16}$.

- Los menores confiados al servicio en aplicación del artículo 375 3 del Código Civil, de los artículos 375-5, 377, 377-1, 380, 433 del mismo código o del $4^{\circ}$ del artículo 10 y del $4^{\circ}$ del artículo 15 de la ordenanza $\mathrm{n}^{\circ} 45-174$ de febrero de 1945 relativa a la infancia delincuente.

- Las mujeres embarazadas y las madres aisladas con sus hijos de menos de 3 años que tengan necesidades de un apoyo material y psicológico.

- Pueden ser igualmente tomados a cargo a tí́tulo temporal por el servicio encargado de la ayuda social a la infancia, los menores emancipados y los mayores de edad menores de 21 años que tengan dificultades de inserción social, faltos de recursos o de apoyo familiar suficiente.

Para desarrollar esta función el Departamento debe organizar territorialmente los medios para hacerse cargo y alojar a estos menores. Estos medios comportan, especialmente, posibilidades de acogimiento de urgencias, así como estructuras de acogimiento para las mujeres embarazadas y las madres con sus hijos, como son los Hogares maternales, Centros de alojamiento y de reinserción social, y Residencias Sociales para acoger a mujeres y madres con hijos víctimas de los malos tratos. Estos servicios pueden ser del propio Departamento, 
de otras circunscripciones territoriales o bien pueden estar concertados con entidades privadas, cuyos establecimientos tienen que estar habilitados por los organismos públicos.

Para la prevención de los malos tratos y la atención a los niños maltratados existe un servicio telefónico de urgencias gratuito, que responde en todo momento a las peticiones de información o consejo sobre situaciones de malos tratos o sospecha de ellos. El nuevo código de la Acción Social y de la familia establece actuaciones de información y sensibilización a la población; recoger información acerca de los niños maltratados. En el caso de sospecha de malos tratos y falta de cooperación por parte de los padres, se puede remitir a la autoridad judicial ( $\operatorname{art}^{\circ}$ 226-4), y el Juez de Menores y el Presidente del Consejo General departamental deberán establecer una protección conjunta del menor.

Entre las intervenciones para el acogimiento que desarrolla el servicio están las Familias de acogida, que sustituyen a la familia de origen; en este caso los padres tienen que dar el consentimiento. Si hay dificultades u obstáculos importantes por parte de los padres biológicos, se puede considerar como una razón para que el menor ingrese en un centro de acogida temporal. También pueden ser acogidos en Hogares de colocación familiar especializada con Asistentes maternales remuneradas, que acogen en su domicilio a menores, como máximo pueden acoger a tres menores; tiene que estar reconocida por los órganos administrativos competentes del Departamento. El Servicio de Ayuda Social a la Infancia es el responsable de seleccionar y asesorar a los padres de acogida.

El servicio proporciona una gama muy amplia de centros y residencias de menores, de titularidad pública o de entidades privadas sin ánimo de lucro, como son las siguientes:

- Hogares para niños: pueden acoger a los menores temporalmente o de forma continuada o bien preparar a los niños para acogimiento familiar. Debe haber al menos uno en cada Departamento.

- Centros asistenciales de día.

- Hogares maternales.

- Centros judiciales de protección de la juventud, dependientes de la Protección Judicial de los Menores.

- Internados.

- Hostales para trabajadores que acogen a jóvenes mayores, entre 18 y 21 años.

- Instituciones para menores con discapacidad.

- Aldeas para niños y familias de acogida. 
La financiación de estos centros depende de la «categoría» de menores: los denominados Pupilos del Estado, que carecen de contacto con los padres; los jóvenes mayores que son remitidos por los jueces; o aquellos que no son responsabilidad de ningún Departamento, niños extranjeros, se financian por el Estado, ya que son de responsabilidad nacional; para el resto de los menores, los padres deben colaborar de acuerdo con los medios que tienen y el resto lo aporta el Departamento.

El Servicio tiene que controlar a las personas físicas o morales a las que ha confiado los menores con vistas a asegurar las condiciones materiales y morales de su colocación, tal como establece el Código de la Acción Social y de la Familia.

Los niños en situación de abandono, Pupilos del Estado, pueden ser entregados en adopción que puede ser simple y plena; ésta última implica para los adoptados las mismas obligaciones, con respecto a los padres adoptantes, que los hijos biológicos, prestar alimentos y socorrerlos en caso necesario.

"La responsabilidad de la supervisión de los menores en su propio domicilio puede, por tanto, ser ejercida por un trabajador del PMI, el CCAS, el ASE, el sector asociativo, o la Justicia (ver más adelante), o por una combinación de algunos de ellos, dependiendo de los acuerdos a nivel local, de la disponibilidad de recursos y de las circunstancias de cada caso. La colaboración es más fácil en municipios grandes con centros que atienden a un gran volumen de población donde el PMI, CCAS y ASE, a pesar de su diferente relación con los servicios médicos, el municipio y el departamento, pueden prestar sus servicios en el mismo edificio, que en los municipios rurales, en los que los CCAS sólo abren durante un tiempo limitado a la semana, con las consiguientes demoras en la preparación de expedientes para ser remitidos a la institución adecuada ${ }^{17}$.

\subsubsection{Protección Jurídica del Menor: Servicios del Ministerio de Justicia}

Desde 1945, se reconoce que la Justicia aplicable a los adultos no se puede adaptar a los menores. La Ordenanza del 2 de febrero de 1945 es el texto fundador de la justicia juvenil. Los niños y los adolescentes de menos de 18 años tienen que tener su propia justicia.

La protección jurídica de los niños corresponde al Ministerio de Justicia, tal como recoge el artículo 375 del Código Civil, "los jueces están 
facultados para intervenir en la vida de los jóvenes a fin de prevenir conductas delictivas". Las medidas adoptadas son decisión del Juez, pero la ejecución corresponde a los Departamentos.

En la ley se plantea asegurar la protección de los menores cuando las situaciones familiares ponen en peligro al menor (niños maltratados, incesto, prostitución, etc.), cuando hay dificultades en el medio familiar (conflictos familiares, fugas, escasa presencia de los padres) y fallan las medidas preventivas. Por otro lado también tiene la función de sancionar los actos de delincuencia de los menores (robo, vandalismo, droga, etc.).

De acuerdo con esto, los jóvenes de los que se hace cargo la Justicia de los menores son: los jóvenes en peligro, los jóvenes delincuentes y los jóvenes mayores (18-21 años).

En síntesis las dos misiones fundamentales son: proteger a los jóvenes en peligro, que se considera lo esencial de su actividad, y juzgar a los menores delincuentes.

Los Servicios de Acción Social Comunitaria, el Servicio de Ayuda Social a la Infancia y el Servicio de Protección Maternal e Infantil del Departamento, así como las entidades sin ánimo de lucro actúan en colaboración y con el consentimiento de los propios padres. En caso de que este sistema falle se deben derivar los casos al Juez de Menores para que tome una decisión.

Los casos pueden llegar al Juez remitidos por cualquier profesional o autoridad de los distintos servicios. "Es derecho de todo ciudadano, adulto o menor, requerir la intervención del juez si son conscientes de que un menor está en peligro" o si "las circunstancias de su educación se están viendo seriamente comprometidas". "La Ley de 15 de junio de 1971 obliga a cualquiera no ligado a un código de secreto profesional a notificar a las autoridades cualquier caso de maltrato o negligencia a un menor por debajo de los 15 años que conozcan". "La Ley también releva de cualquier penalización a toda persona obligada por un código de confidencialidad si la rompe informando a las autoridades. La única excepción al derecho general de audiencia con el juez es que la policía sólo puede remitir temas al juez a través del fiscal público. Este es el camino a través del cual los delincuentes llegan al juez, pero también en casos de emergencia por abuso o negligencia, ya que el fiscal ofrece un servicio de 24 horas y recibe derivaciones solicitando protección judicial que ocurren fuera de los horarios de trabajo. En todo caso, los menores, tanto si están en casa como si están bajo la protección pública, pueden solicitar del juez ayuda por ellos mismos o a través de otros, de tal manera que el juez actúa como un defensor de menores" 18 . 
De acuerdo con la circunstancia por la que llega el menor al Juez de menores puede ser necesario un procedimiento civil o penal. En síntesis, corresponde el civil cuando el menor es el perjudicado y no hay ningún tipo de falta por parte de éste, y el procedimiento penal cuando el menor ha cometido alguna falta, delito o crimen. En cualquiera de los casos siempre se trata de potenciar las medidas educativas.

En los casos en que es el menor el perjudicado por abandono, negligencia, malos tratos, etc. puede tomar distintas opciones:

1. Sin ruptura con el medio familiar: se potencia la asistencia educativa, y una solución de conciliación y de acompañamiento para evitar el efecto traumático de una ruptura con el medio familiar, tal como recoge el Código Civil en su artículo 375.2, por lo que puede establecer distintos tipos de medidas socio-educativas. Por una parte puede "designar a una persona cualificada, a un servicio de observación, de educación o reeducación en medio abierto y para dar ayuda y consejo a la familia con el fin de superar las dificultades materiales o morales que ella encuentra. Esta persona o estos Servicios tienen que responsabilizarse del seguimiento del desarrollo del menor y dar un informe periódicamente al Juez". En este caso el menor se mantiene en el hogar familiar para seguir con sus actividades en el medio habitual.

Por otra parte, el Juez puede tomar la decisión de retirarlo del medio familiar, y en este caso puede "confiarlo al padre o madre que no tuviera la guardia del menor, a otro miembro de la familia o a un tercero digno de confianza, a un servicio o a un establecimiento sanitario o educativo, ordinario o especializado, o bien al servicio Departamental de Ayuda Social a la Infancia" ( $\operatorname{art}^{\circ} 375.3$ del Código Civil). En cualquier caso, de modo provisional, el Juez puede ordenar que el menor sea remitido a un centro de acogida o de observación, a un centro de alojamiento familiar especializado, temporalmente o a más largo plazo.

2. Cuando el menor ha cometido alguna falta, delito o crimen, tiene que presentarse ante la Justicia penal de los menores.

En esta situación, dependiendo de la gravedad del delito y de la edad del menor, éste puede tener que comparecer ante distintos tribunales, Tribunal para menores (Juez de Menores y 2 asesores, en el caso de los menores de 16 años que han cometido algún delito), Audiencia de Menores (3 Magistrados, presididos por el Juez de Menores y un jurado de 9 miembros, para los mayores de 16 años que han cometido crímenes).

is Ely, P.; Saunders, R. (1993): Ob. cit. págs 130-131. 
En la justicia penal de los menores se aplican unos principios que lo diferencian de la justicia aplicada a los adultos ${ }^{19}$.

- Las jurisdicciones para menores pronuncian prioritariamente medidas de protección, de asistencia, de vigilancia y de educación (la medida educativa debe primar sobre la sanción penal).

- Los menores de 13 años no pueden ser sancionados penalmente; sólo se pueden pronunciar medidas educativas.

- Los menores de más de 13 años se benefician de un régimen de responsabilidad atenuado y de disminución de la pena.

- Los menores se benefician de reglas de procedimiento particulares adaptadas a su edad (libertad vigilada, detención provisional).

Este planteamiento se basa en que las infracciones penales se pueden considerar un síntoma de inadaptación ${ }^{20}$. No obstante, en los casos graves de delincuencia de los mayores de 16 años, se pueden dictar medidas más contundentes y de mayor control, incluso verdaderas sanciones penales.

De acuerdo con estas bases también en estos casos se priorizan las medidas educativas y el Juez puede adoptar las mismas que en los procedimientos anteriores. Pero, de acuerdo con las circunstancias, puede remitirlos a un establecimiento de educación o de formación profesional o al ASE. Algunos menores delincuentes precisan centros de una mayor especialización.

La Protección Judicial del Menor dispone de sus propios profesionales especializados así como de estructuras específicas y de personal para desarrollar su función con los menores: hay servicios de investigación que ayudan a la decisión del juez y que llevan a cabo medidas provisionales de corta duración, de 3 a 6 meses; el Servicio de Educación Vigilada que asesora y supervisa las situaciones familiares siguiendo las indicaciones del Juez, y que tienen a jóvenes bajo su cuidado; Servicios educativos en medio abierto y establecimientos de tipo penitenciario como casas de arresto, centros de detención, centros de semilibertad.

Además de estos servicios el Juez puede asesorarse de los organismos y profesionales que considere convenientes y remitir a los menores a los servicios Departamentales de Ayuda Social a la Infancia o a los servicios sociales polivalentes.

20 Borgetto, M.; Lafore, R. (1996): Ob. cit. pág. I6I. 
El Juez, en su obligación de salvaguardar los derechos del menor, tiene el deber de intervenir en cualquier organismo público o privado si dichos derechos son lesionados. En cualquier caso el juez puede revisar sus decisiones de acuerdo con la evolución del menor y la situación de su entorno.

Las instituciones, públicas o privadas, que acogen a menores por decisión judicial, son inspeccionadas y autorizadas por el Ministerio de Justicia. En estas instituciones pueden estar tanto menores por decisión judicial como por decisión del Servicio de Ayuda Social a la Infancia. Los recursos que se aplican a los menores son independientes de la vía por la que han llegado a la protección pública.

El juez puede también tomar decisiones acerca del uso de las prestaciones familiares otorgadas en función de los hijos, que se pueden otorgar al tutor del menor.

\subsection{Servicios para menores con discapacidad}

La ley de 1975 considera que los menores con discapacidad deben acceder a las mismas instituciones y prestaciones que el resto de los menores, pero existen una serie de prestaciones específicas: prestaciones para la obligación de educación y subsidio de educación especial hacia su familia ${ }^{21}$.

Tal como establece el artículo 4 de la Ley de 1975 y el Código de la Acción Social y de la Familia, recientemente aprobado, los menores con discapacidad están sometidos a la obligación de la educación y deben ser escolarizados en el medio ordinario, siempre que sus condiciones se lo permitan, con el objetivo de favorecer su integración, desarrollar su personalidad, ayudar a aceptar sus diferencias, favorecer su autonomía y facilitar el acceso al mundo del trabajo y de la participación social. En el medio ordinario se ofrecen medidas de acompañamiento para la mejor integración en el medio escolar, con apoyo de equipos especializados o clases de integración escolar especializada $u$ otras similares. La integración en la enseñanza ordinaria requiere que el menor pueda desarrollar un mínimo de comunicación con su entorno. Si esto no fuera posible se puede escolarizar en medio especializado. Para esto existen diversos tipos de centro, dependiendo de la discapacidad $^{22}$ :

- Centros de acción médico-social precoz, (CAMSP) con la finalidad de lograr la educación del menor y proporcionar entrena-

2 Borgetto, M.; Lafore, R. (1996): Ob. cit. pág. 231.

22 Ely, P; Saunders, R. (1993): Ob. cit. pág. 137. Y Borgetto, M.; Lafore, R. (1996): Ob. cit. pág. 233 . 
miento a las familias para una mejor atención.

- Institutos de Educación Sensorial, dirigidos a los menores con discapacidad sensorial.

- Institutos de Educación Motriz, para los menores con discapacidad motora.

- Instituto Médico-Pedagógicos (IMP) para los menores con dificultades de aprendizaje, con edades comprendidas entre 3 y 16 años.

- Centros Médico-Psico-Pedagógicos,(CMPP) para los menores con dificultades de comportamiento.

- Institutos Medico Educativos (IME), para los afectados de discapacidad mental.

- Institutos Médico profesionales (IMPRO), dirigidos a los que tienen entre 16 y 20 años para prepararlos profesionalmente.

La valoración de las discapacidades se hace por la COTOREP (Comisión Técnica de Orientación y Clasificación Profesional), pero corresponde a la Comisión Departamental de Educación Especializada (CDES) el papel fundamental en cuanto a la orientación sobre los menores con discapacidad, la designación del tipo de centro o servicio que precisa, y las ayudas económicas necesarias para que el afectado reciba la atención adecuada; se encarga, así mismo, del seguimiento de la integración del menor. Solamente se encarga de los afectados por discapacidad física, sensorial y mental.

Existe una prestación económica (Allocation d'éducation spéciale, AES) para que las familias puedan hacer frente a los costes extras de la educación de un menor afectado de discapacidad, mayor de 6 años; es aportada por la Caja Nacional del Seguro Familiar de la Seguridad Social. Para los casos más graves que precisan de una tercera persona para su cuidado, de acuerdo con la valoración de la CDES, existe un complemento, que puede ser distinto según los cuidados que precise:

- menores que precisan cuidados diarios discontinuos,

- niños que necesitan cuidados diarios continuos,

- niños que requieren de cuidados continuos altamente especializados.

Los Servicios para discapacitados pueden ser ofrecidos por Educación, por el Servicio de Salud, o conjuntamente, dependiendo de las circunstancias y de la atención a desarrollar, pero la responsabilidad financiera puede ser de distintos organismos. Aquellos que no están asegurados pueden percibir la prestación económica por el Servicio de Ayuda Social a la Infancia. 
Actualmente hay una preocupación por la atención a los polidiscapacitados, tratando de dar una respuesta a todas las necesidades que tiene el menor, tanto afectivas, pedagógicas, relacionales, como terapeúticas y por una mayor implicación de los padres en la educación especializada.

\section{OTRAS ACCIONES Y PRESTACIONES PARA EL MENOR O LA FAMILIA}

Además de los servicios que se han visto a lo largo de este texto, existen otras actuaciones facultativas desarrolladas por los Municipios, Departamentos y por las distintas entidades no lucrativas, que responden a las distintas circunstancias sociales y económicas así como al grado de iniciativa y capacidad desarrollada. En ellas se observa una gran preocupación por abordar los temas de los menores y jóvenes en situación de riesgo y desarrollar actuaciones dirigida al tiempo libre y el ocio, como medio de lograr la integración social y prevenir la delincuencia. Se trata de potenciar a los propios interesados para que actúen con sus propios proyectos y se impliquen directamente en su ejecución. Es especialmente importante para los grupos de jóvenes con mayor riesgo de marginación, así como para jóvenes de grupos minoritarios de otros países.

Las prestaciones económicas a las familias con menores pueden ser de distinta índole. Unas de carácter universal, y otras por insuficiencia de recursos de la familia, que son una ayuda suplementaria: prestaciones de ayuda social y prestaciones familiares.

La Seguridad Social a través de la Caja Nacional del Seguro Familiar (CNAF) y también por la Mutualidad Agraria, aporta el ingreso mínimo familiar para las familias con hijos menores de tres años, a las familias que tengan al menos tres hijos por encima de los tres años, y para aquellos que tengan a su cuidado, al menos, a tres niños. Ayuda a los padres que interrumpen su trabajo por el nacimiento, adopción o por el cuidado de un tercer hijo o más. Hay prestaciones económicas para menores huérfanos, familias monoparentales y familias con menores con discapacidad (citada anteriormente). Otro tipo de subvenciones a familias jóvenes para afrontar los costes de los intereses bancarios y por vivienda para las familias que tienen menores o personas mayores a su cuidado que vivan con ellas. 


\section{BIBLIOGRAFÍA}

ARNAULT, A.M.; BOUQUET, B. (1991): "Regard socio-historique sur la polyvalence de secteur", Vie Sociale, n' 9-10.

BORGETTO, M.; LAFORE, R. (1996): Droit de l'aide et de l'action sociales. París, Montchrestein.

CENTRE POUR LA RECHERCHE ET L'INNOVATION DANS L'ENSEIGNEMENT: (1996). Integrer les services pour les enfants à risque. Danemark, France, Pays-Bas, Royanne-Uni (Angleterre et pays de Galles) et Suède. OCDE.

CODE DE L'ACTION SOCIALE ET DE LA FAMILE. Journal Officiel de la République Française. 23 décembre 2000.

COLTON, M.J.; HELLINCKX, W. (1995): La atención a la infancia en la Unión Europea. Guía por países sobre acogimiento familiar y atención residencial. Madrid, Ministerio de Asuntos Sociales.

CONSEIL TECNIQUE DES CLUBS ET ÉQUIPES DE PRÉVENTION SPÉCIALISÉE. (1996): La violence des jeunes en milieu urbain. París. Direction de l'Action Sociales.

FAUQUEMBERG, A. (1999): "Temporalités des trajectoires rellationnelles des parents d'enfants placés". Vie Sociale, n 5, págs. 35-42.

LAHEURTE, P. (1998): "Maternités socialement précoces: un foyer de jeunes filles à I'épreuve de ses objectifs". Vie Sociale, nº 6, págs. 71-86.

MAUGER, G.: Les jeunes en France. Etat des recherches. París. La documentation Française. Ministère de Ia Jeunesse et des Sports.

MUNDAY, B. (1993): European Social Services. European Institute of Social Services. University of Kent. Canterbury. 



\title{
CAMBIOS RECIENTES EN LOS SERVICIOS SOCIALES PARA MENORES EN INGLATERRA
}

\author{
M. ${ }^{a}$ ASUNCIÓN MARTÍNEZ ROMÁN* \\ Departamento de Trabajo Social y Servicios Sociales. Universidad de Alicante.
}

\section{INTRODUCCIÓN}

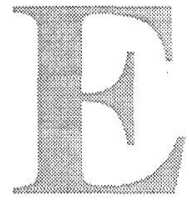

1 modelo de «Estado de bienestar» británico se establece a partir de 1940, cuando el Estado asume la responsabilidad pública en la atención de las necesidades sociales. Se crea el Sistema Nacional de Salud, se universaliza la educación, se diseña el sistema de Seguridad Social, las organizaciones caritativas dejan de ser las principales proveedoras de servicios sociales personales y se asume también la intervención pública en materia de alojamiento ${ }^{1}$. Tras la Segunda Guerra Mundial este modelo se desarrolla y consolida, coincidiendo con una época de crecimiento económico, como resultado de una política de consenso de los principales partidos políticos.

En cuanto a los Servicios Sociales, hay que destacar que han venido siendo uno de los pilares del modelo de Estado de Bienestar en el Reino Unido, habiendo experimentado un desarrollo creciente con sucesivas reformas en su concepción, organización y gestión. Las propuestas del Informe Seebohm ${ }^{2}$ inspiraron la Ley de Servicios Sociales de 1971 por la que se reorientaron los servicios sociales llevándose a cabo su descentralización al gobierno local. El nuevo modelo abandonó la excesiva especializacion anterior promoviendo una atención social más generalista, tendencia que se reorientará de nuevo en los 80 recuperando la apuesta por la especialización en los servicios para la atención de menores y de personas con enfermedades mentales.

El país se encuentra administrativamente dividido en ciscunscripciones a cargo de Autoridades Locales que se constituyen en «conda-

* Agradezco a mi colega Carlos Fernández (Trabajador Social, Doncaster, UK) la valiosa ayuda prestada con la revisión de este trabajo y sus muy oportunas sugerencias, tal como viene haciendo (con paciencia y cariño) desde 1993.

Hills, J. (1990): The State of Welfare. Oxford, Clarendon Press.

2 Home Office (1968): Report of the Committee on Local Authority and Allied Personal Social Services. (Cm 3703). Londres, HMSO. 
dos» (County Council) o en «distritos metropolitanos» (London Boroughs y Metropolitan Districts, que incluyen las grandes ciudades y las áreas que las circundan). Los County Council, London Boroughs y Metropolitan Districts tienen las mismas competencias para proporcionar servicios a través de sus Departamentos de Servicios Sociales.

Estos Departamentos de Servicios Sociales de la Administración local dependen del Ministerio de Salud (Department of Health), desde el que se diseña la política y planificación de los Servicios sociales asegurando la integración de la planificación entre los servicios de salud y los servicios sociales. Además, se financia el gasto social global de la administración local y cada autoridad local puede decidir la distribución de esa financiación; se establecen criterios de actuación de los servicios sociales; y se realiza la inspección y evaluación de los servicios (Social Service Inspectorate).

$\mathrm{El} \ll$ Home Office» es el Ministerio con competencias relacionadas con la ley de la que depende la atención a menores con problemas de delincuecia y que trabaja en estrecha coordinación con los Departamentos de Servicios Sociales locales. También ha cofinanciado con la Unión Europea la creación de servicios sociales comunitarios en grandes ciudades como, por ejemplo, servicios de guardería para menores, centros de día para mayores, unidades residenciales para menores, o servicios para personas con discapacidades. Otro Ministerio que trabaja en coordinación con los Departamentos de servicios sociales locales es el Ministerio de Educación y Empleo.

Pero es en el nivel local en donde se encuentra la mayor responsabilidad en materia de Servicios Sociales, siendo los Departamentos de Servicios Sociales de cada County los encargados de prestar servicios tanto de tipo preventivo, dirigidos a toda la población, como servicios para atender a colectivos específicos:

- Cuidado de personas mayores en la comunidad y residencias.

- Cuidado de personas con discapacidad física.

- Orientación y consejo a homeless.

- Servicios de cuidado de menores (protección de menores, residencias, guarderías, acogimiento familiar, algunos servicios de adopción, trabajo preventivo con maltrato de menores, etc.).

- Trabajo social con personas con enfermedades mentales y sus familias, incluyendo servicios de centros de día, talleres y alojamiento.

- Cuidados de día para niños menores de 5 años, incluyendo guarderías y supervisión de guarderías privadas. 
- Ayuda y comida a domicilio.

- Cuidado de madres solas, incluyendo residencia.

- Trabajadores Sociales para personas ingresadas en hospitales.

- Trabajo con abuso de sustancias (droga y alcohol).

Organizativamente, los Departamentos de Servicios Sociales locales se basan en diferentes modelos, por ejemplo, un Director como responsable de la administración de todos los servicios, auxiliado por Asistentes de dirección. Se establece una división por Distritos y, dentro de cada uno de ellos, se establece una subdivisión de los equipos según se trabaje con menores o con adultos, lo que implica una especialización. Deben coordinarse estrechamente con otros profesionales, como visitadores de salud, enfermeras comunitarias/de distrito, trabajadores sociales sanitarios, médicos, profesores, trabajadores sociales psiquiátricos, trabajadores de comunidad, líderes juveniles y voluntariado social de la zona.

Entre las actividades que se realizan en los Departamentos cabe citar las siguientes:

- Diagnóstico y evaluación de necesidades. Tras la evaluación de necesidades se puede ofrecer la prestación de un servicio bien de la propia Autoridad Local o bien "comprando" el servicio a una entidad privada sea no-lucrativa o mercantil.

- Trabajo de campo: atención a menores y familias, mayores, personas con discapacidades, transporte, ayuda a domicilio, servicios de comidas, guardería, familias sin techo, servicios de adopción.

- Actividades de formación: formación inicial para nuevos incorporados, formación continua, formación profesional especializada, formación para la docencia de alumnos en prácticas, formación para dirección de residencias, formación post-graduada senior para puestos de responsabilidad y dirección-gestión.

- Trabajo social hospitalario, para ayudar a las personas ingresadas y a sus familias a convivir con la enfermedad

- Actividades de elaboración de informes y cumplimentación de formularios de diversa índole exigidos por la normativa vigente, por ejemplo, toda la elaboración de Informes para el Juzgado que establece la Ley de Menores.

En cuanto a la financiación, el gobierno central establece un patrón de gasto tipo (Standard Spending Assessments) por el que se estima el gasto que precisa realizar una Autoridad Local para proporcionar un nivel básico de servicios, teniendo en cuenta las diferentes característi- 
cas demográficas, sociales, económicas, meteorológicas y geográficas del territorio ${ }^{3}$.

\section{LOS SERVICIOS SOCIALES EN INGLATERRA DURANTE LOS $80 / 90$}

Durante la crisis económica de mediados de los 70 se empieza a cuestionar el aumento del gasto social de los servicios sociales públicos y a lo largo de los años 80 el gobierno conservador de Mrs. Thatcher llevó a cabo importantes cambios en el modelo de servicios sociales, tanto en el modo de distribución como en los principios subyacentes ${ }^{4}$, promoviendo un cambio de valores que incluía la aceptación de la existencia de la desigualdad social como un hecho inevitable y asignando un papel relevante al mercado. Las políticas de los 80 se basaron en la idea de un Estado mínimo que cedía el protagonismo a la iniciativa privada, potenciando la centralización con una reorientación de las competencias de las autoridades locales, en detrimento de su autonomía (reducción de independencia financiera y limitación de su rol y funciones) $)^{5}$ en áreas relacionadas con el bienestar como las de salud, educación, vivienda y servicios sociales ${ }^{6}$.

La resistencia a romper el anterior modelo de servicios sociales públicos por parte de los laboristas dio lugar a diferencias territoriales en la oferta de servicios sociales, ya que algunas Autoridades Locales se resistieron a aplicar las nuevas políticas basadas en la drástica reducción del gasto público, reducción de los subsidios, el incremento de las prestaciones sujetas a la demostración de necesidad y la privatización de los servicios. El desarrollo de la intervención del sector mercantil se generalizó con la aplicación en 1991 del plan de cuidados en la comuni$\mathrm{dad}^{7}$ que disminuye el papel del Estado y promueve una mayor intervención de la ayuda informal y de la iniciativa privada, tanto no-lucrativa como mercantil.

3 Carr-Hill, R.; Rice, N.; Smith, P. (1999): "The Determinants of Expenditure on Children's Personal Social Services". British Journal of Social Work, 29, 679-706.

+ Johnson, N. (1991): Reestructuring the Welfare State. Hemel Hempstead, Harvester Wheatsheaf.

5 Young, H. (1989): One of Us. Londres, Macmillan, págs. 124-125.

6 La «Education Reform Act» de 1988, transfiere importantes competencias desde el gobierno local hacía el gobierno central. La «Local Government Act» de 1988, tuvo especial relevancia en este vaciado de poder de los gobiernos locales a favor de una mayor centralización.

7 Department of Health (1989): Caring for People (Cm 849), Londres, HMSO. 
Diversos autores coinciden en señalar que las políticas de los 80-90 ha incrementado la pobreza y la desigualdad y que muchas personas, además de carecer de medios económicos, han tenido negado el acceso a la mayoría de las actividades y servicios. La consecuencia ha sido una falta de oportunidades para ellos y también para sus hijos y, en definitiva, una menor calidad de vida que el resto de la población ${ }^{8}$, pagando un alto costo personal: malnutrición, preocupación cada día por conseguir ingresos y situación permanente de endeudamiento?. En estas familias pobres los niños son los miembros más vulnerables con una alta mortalidad, bajo peso al nacer, más posibilidad de discapacidades, caries dental, bajo crecimiento y malnutrición ${ }^{10}$.

En el origen de esta situación de empobrecimiento se encuentran distintos factores como el aumento del desempleo, los cambios en el empleo (trabajo temporal, ocasional, autoempleo...), que reducen los ingresos, cambios de las pautas familiares (aumento de la monoparentalidad), inadecuada respuesta del sistema de protección social (diseñado para una situación de pleno empleo), etc. ${ }^{11}$ Según Craig, la tendencia general en la composición de la pobreza en UK, como en muchos países de la Comunidad Europea, ha sido pasar de una concentración en las personas mayores hacía la extensión de la pobreza a una serie de diferentes categorías o grupos de personas como: personas desempleadas (especialmente de larga duración), familias con niños, padres/madres solos, personas con escasos ingresos y personas con discapacidad ${ }^{12}$.

\subsection{Infantilización de la pobreza}

Veamos más detenidamente cómo las consecuencias del aumento de las situaciones de pobreza y exclusión social han afectado en gran medida a los menores, especialmente, a aquellos que formaban parte de hogares con bajos ingresos o de hogares monoparentales. Estos menores han estado viviendo en una situación de permanente desventaja que ha mermado sus posibilidades de desarrollo.

Los estudios muestran que ha habido un notable incremento del número de padres/madres solos con hijos menores (en la mayoría de los

s National Children's Home (1991): Children in danger 1991: Family nutrition survey, Londres, $\mathrm{NCH}$.

9 Bradshaw, J. y Millar, J. (1991): Lone-parent families in the UK. Londres, HMSO; Payne, S. (1991): Women, Health and Poverty. Haverster Wheatsheaf.

to Bradshaw, J. (1990): Child Poverty and deprivation in the UK. Londres, National Children's Bureau.

" Oppenheim, C. (1993): Poverty: The Facts. Londres, CPAG, págs. 2-3.

12 Craig, G. (1992): «Anti-Poverty Action and research in the U.K.», Social Policy \& Administration, vol. $26, \mathrm{n}^{\mathrm{o}}$ 2. 131 . 
casos es la mujer la cabeza de familia, que no disponen de medios suficientes para atender las necesidades del hogar, generando stress y falta de oportunidades para los padres/madres y sus hijos ${ }^{13}$. En 1993, los hogares monoparentales tenían la mitad de los ingresos que las parejas; los más pobres de los hogares monoparentales estaban formados por mujeres solteras, seguidos de los formados por mujeres separadas. Según Haskey, la edad media de las madres solas con hijos a cargo era de menos de 25 años para las solteras y de 43 años para las divorciadas $^{14}$.

Uno de los problemas de estas madres ha sido (y continúa siendo) la falta de servicios para cuidar a los niños menores de cinco años, lo que resulta un grave obstáculo al trabajo de las madres, con el agravante de que sobre un $40 \%$ de estas madres no han tenido nunca un empleo ${ }^{15}$. Este hecho, junto con la alta probabilidad que tienen de no encontral más que trabajos inseguros y mal pagados, explica que manifiesten preferir quedarse en casa, cuidando a sus hijos ${ }^{16}$. Millar dibuja el siguiente perfil de las familias monoparentales en 1989: mujer joven (menos de 25 años), con hijos menores a su cargo, que se aloja en una vivienda social de alquiler, con malas condiciones de habitabilidad, carece de empleo y es beneficiaria de una prestación económica pública ${ }^{17}$. Con relación a la vivienda, se ha denunciado que las familias monoparentales han venido teniendo baja prioridad en los baremos de adjudicación de viviendas sociales municipales, por lo que han tenido que conformarse con los peores alojamientos, incluso obtener simplemente la modalidad «bed \& breakfast»y, al tener mayoritariamente muy bajas rentas, no han podido optar a otras modalidades mejores de alojamiento público ${ }^{18}$. Se constata, también, una alta probabilidad de enfermedades y discapacidades en estos padres/madres y sus hijos ${ }^{19} \mathrm{y}$, especialmente, en aquellos alojados en la modalidad de «bed \& breakfast».

Los datos son elocuentes, tal y como lo muestra la tabla con el nú-

13 Algunos estudios señalan que el stress generado por graves carencias económicas aumenta la probabilidad de que los padres maltraten a sus hijos. Ver, por ejemplo, las consecuencias en el caso de las madres solteras, Gorlic, C. (1988): Economic stress, social support and female single parents. Canadian Social Work Review, vol.5, págs. 194-205.

if Haskey, J. (1991): Estimated numbers and demographic characteristics of one parent families in Great Britain. Population Trends, $\mathrm{n}^{\circ}$ 65, págs. 35-47.

15 Marsh, A. y McKay, S. (1993), op. cit., pág. 60.

16 Jowcll, R. et al. (1993): Bristish Social Attitudes: the 9th. Report. Aldershot, Dartmouth.

17 Millar, J. (1989), op. cit., pág. 68.

18 Sexty, C. (1990): Women Losing Out: Access to Housing in Britain Today. Londres, Shelter, págs. 33-35.

19 Hardey, M. y Crow, G. (Eds.) (1991): Lone Parenthood: Coping with constraints and making opportunities. Hemel Hempstead, Harvester Wheatsheaf. 
Tabla 1: Niños en familias en o por debajo del ingreso mínimo. Reino Unido, 1979 , 1989 y 1992

\begin{tabular}{|l|l|r|r|r|}
\cline { 2 - 5 } \multicolumn{2}{c|}{ Con sus padres } & $\mathbf{1 9 7 9}$ & 1989 & 1992 \\
\hline \multirow{2}{*}{ Familia monoparental } & Total & 840 & 1,350 & 1,850 \\
\cline { 2 - 5 } & \% de la categoría & 7 & 13 & 18 \\
\cline { 2 - 5 } & Total & 660 & 1,410 & 1,840 \\
\hline
\end{tabular}

Fuente: CPAC, Poverty: The facts. Eds. 1993 y 1996. Elaboracion propia.

mero y porcentaje de niños viviendo en familias que se encuentran en el nivel del ingreso mínimo o por debajo de él. Como puede verse, los niños que estaban en tal situación eran, en 1979, un $7 \%$ de los niños que vivían con sus padres y un $47 \%$ de los que vivían en familia monoparental. En cambio, en 1992, el porcentaje ha pasado, respectivamente, a un $18 \%$ y a un $78 \%$, es decir, que el $78 \%$ de los niños que vivían en esa fecha en una familia monoparental lo hacían en una familia de renta inferior o igual al ingreso mínimo, o sea, consideradas como pobres.

Esta «infantilización» de la pobreza queda insistentemente reflejada en todos los trabajos consultados, donde se muestra fundada preocupación por las consecuencias a corto y largo plazo de este problema. La tabla hace ver cómo el porcentaje de niños viviendo en familias con la mitad de la renta media (definición habitual en la Unión Europea) es superior al de la población total. Los datos de 1992/1993, sugieren que un cuarto de la población vive en la pobreza (definida como se ha dicho) de la que los niños constituyen un tercio.

Los propios Departamentos de Servicios Sociales locales han señalado como indicadores de ausencia de bienestar infantil las situaciones de familias «sin techo», alojamiento en «bed \& breakfast», en viviendas infraestandard y carencia de gas, electricidad y/o agua; considerando entre los factores de riesgo el pertenecer a una familia de bajos ingresos, monoparental, o de padres desempleados junto a otros factores como ser hijo de refugiados, pertenecer a una minoría étnica o lingüística, vivir en determinadas áreas, etc. ${ }^{20}$

Tabla 2: Porcentaje de niños y de población viviendo con la mitad de la renta media (descontados gastos de vivienda). Reino Unido, 1979 a 1992/93.

\begin{tabular}{|l|r|r|r|r|c|}
\cline { 2 - 6 } \multicolumn{1}{c|}{} & $\mathbf{1 9 7 9}$ & $\mathbf{1 9 8 1}$ & $\mathbf{1 9 8 7}$ & $\mathbf{1 9 8 8 8 9}$ & 199293 \\
\hline Niños & 10 & 16 & 24 & 25 & 33 \\
\hline Población & 9 & 11 & 19 & 22 & 25 \\
\hline
\end{tabular}

Fuente: CPAC, Poverty. The facts. Eds. 1993 y 1996. Elaboracion propia. 
Y unos años después, al finalizar el siglo, la situación no ha mejorado. El más reciente estudio publicado sobre la pobreza y la exclusión social en Gran Bretaña ${ }^{21}$ destaca que, a finales de 1999, un $26 \%$ de la población vivía en situación de pobreza, medida en términos de bajos ingresos y falta de satisfacción en varias de sus necesidades. Se estima que dos millones de menores tienen necesidades no cubiertas siendo peor la situación de los menores que viven en hogares con las siguientes características familiares: estar ambos padres desempleados; tener un solo progenitor; tener miembros de la familia sufriendo enfermedades crónicas; pertenencia a una minoría étnica; habitar una vivienda social; depender económicamente de una prestación de desempleo o una prestación asistencial.

En definitiva, siguen existiendo situaciones de pobreza y exclusión social que afectan en mayor medida a los grupos sociales más vulnerables y, entre ellos, a los menores. Ello se debe, por una parte, a un aumento del desempleo que ha evolucionado a una larga duración o a la precarización del empleo y, por otra parte, a un recorte de los gastos sociales que ha limitado las ayudas públicas para proteger a los más débiles. Tanto el desempleo como el recorte del gasto social público han sido factores comunes en la Unión Europea, sin embargo, en el caso de Gran Bretaña la disminución de la protección social pública ha sido mayor debido a las políticas de los gobiernos conservadores basadas en un Estado mínimo, arguyendo que las prestaciones públicas generan dependencia. Esta orientación política incidió muy directamente en los Departamentos de Servicios Sociales de las Autoridades Locales.

\subsection{Consecuencias en los Servicios Sociales y en la atención so- cial a los menores}

En este contexto de Estado mínimo, los Departamentos de Servicios Sociales locales tuvieron que adoptar nuevas líneas de actuación pasando de prestar directamente los servicios a evaluar e identificar las necesidades para proponer nuevas formas de atención, en la línea del Welfare Mix. Las nuevas modalidades de prestación de los servicios se pueden realizar por una variedad de agencias (con una mayor participación del sector voluntario), entre las que los Departamentos de Servi-

Giller, H. (1993): Children in need: Definition, Managment and Monitoring. A report for the Department of Health. Londres, Social Information Systems-Department of Health; Algate, J. et al. (1994): Implementing Section 17 of the Children Act. The first 18 months. Leiccster, Leicester University.

21 Gordon, D. et al. (2000): Poverty and social exclusion in Britain. York, Joseph Rowntree Foundation. 
cios Sociales locales han pasado a ser uno más, con una fuerte privatización de los servicios sociales públicos. Las consecuencias han sido importantes, por ejemplo, introduciendo la competencia entre los servicios de atención comunitaria para cuya prestación se han constituido consorcios de agencias de cuidados, en las que participan el Servicio Nacional de Salud, el gobierno local y el sector voluntario. Además, a muchos usuarios se les exige contribuir económicamente en el costo de los servicios, por lo que muchas personas no pueden utilizarlos, obligando a algunas a recurrir a cuidados residenciales ${ }^{22}$.

Se fueron reduciendo los recursos públicos, dirigiendo su atención a «los que más lo necesitaban» (con diferentes interpretaciones de «necesidad»), exigiendo una importante participación en los cuidados a las familias y comunidades y atendiendo prioritariamente a la población que carece de apoyo familiar, lo que supone que se han dejado de atender muchos problemas. Los Trabajadores sociales continuaron teniendo un papel muy relevante, pero con un nuevo rol que les asignaba funciones de gerentes y organizadores de los servicios más que realizar trabajo social.

En el caso de la atención social a los menores, la aplicación de la Ley del Menor de 1989 ha supuesto una serie de mejoras en los servicios sociales para menores, sin embargo, también se han puesto de manifiesto una serie de temas no resueltos y a los que la actual reforma trata de encontrar solución, por ejemplo:

- Heterogeneidad territorial de la oferta.

Ha habido una oferta heterogénea en cuanto a cantidad y calidad de servicios como consecuencia de la autonomía de las autoridades locales ${ }^{23}$, lo que ocasiona desigualdades en la atención de los menores.

- Protección en detrimento de la promoción del bienestar.

Se ha seguido dando prioridad a la «protección» de los menores entendida ésta en un sentido muy restrictivo, como actuaciones ante un riesgo considerable de maltrato o abuso. Generalmente, no se han dedicado esfuerzos a intervenir de modo preventivo para evitar el maltrato o el abuso, por ejemplo, actuando ante problemas que pueden tener consecuencias tan graves para bienestar del menor como el hecho de vivir en hogares pobres o con problemas escolares, cuando está demostrada la interrelación

22 House of Commons Health Committee (1993): Sixth Report of the Health Committee. Community Care: The Way Forward. Vol. 1. Londres, HMSO.

23 Department of Health. Social Services Inspectorate (1990): Child Care Policy: Putting it in wrinting. A Review of English Local Authorities' Child Care Policy Statements. Londres, HMSO. 
entre pobreza, privación y necesidad de intervención para proteger al menor ${ }^{24}$.

- Deficiente seguimiento de los menores.

Se han detectado actuaciones de los Departamentos de Servicios Sociales en las que no se realiza un adecuado seguimiento que permita evaluar periódicamente el bienestar del menor. En consecuencia, muchos problemas de los menores no se cono$\operatorname{cen}^{25} \mathrm{e}$, incluso, se han dado casos de abuso y maltrato de menores mientras éstos estaban bajo el cuidado de las Autoridades Locales.

- Insuficiente oferta de servicios de apoyo a las familias y cuidadores de personas dependientes.

La oferta de servicios para menores se ha considerado insuficiente para prevenir dificultades de los menores en su desarrollo con quejas de falta de financiación por parte de las Autoridades Locales. Esta escasez de recursos económicos es la excusa para actuar muy selectivamente, lo que se ha calificado como una atención residual contraria al espíritu de la Ley ${ }^{26}$. Por ejemplo, las madres solas con hijos a cargo no han contado con apoyos públicos suficientes lo que les ha venido ocasionando una situación de inseguridad y de permanente sacrificio, resultándoles casi imposible lograr compaginar trabajo y cuidado de los hijos, tal como se les exige ${ }^{27}$.

- Insuficiente apoyo a quienes prestan servicios a personas con discapacidades.

Los Departamentos de Servicios Sociales tienen obligación de realizar una evaluación de las necesidades de toda persona que es cuidada en la comunidad, incluyendo a quien realiza los cuidados. Sin embargo, parece que esto se ha cumplido en Salud Mental pero en otro casos sólo se ha cumplido por la demanda expresa de la persona con discapacidad.

- Problemas organizativos de los Servicios.

Hay quejas de falta de coordinación, falta de planificación y falta nonths. Leicester, Leicester University.

25 Social Services Inspectorate. Social Services Facing the Future, the $1997 / 98$ anmual report of the Chief Inspector.

26 Tunstill, J. (1995): «Children in need: Is targeting the Answer?», en Targeting those most in need: Winners and losers, Londres, Policy Studies Institute.

27 Van Drenth, A.; Knijn, T.; Lewis, J. (1999): "Sources of Income for Lone Mother Families: Policy Changes in Britain and The Netherlands and the Experiences of Divorced Women". Journal of Social Policy, 28 (4), 619-641 
de cualificación de muchas de las personas que prestan atención a los menores. En el primer caso, parece que se habla indistintamente de coordinación, colaboración y cooperación entre agencias, utilizándose erróneamente como sinónimos y, en realidad, limitándose a una mera cooperación ${ }^{28}$. Se habla mucho de trabajar conjuntamente pero, en la práctica, no se llega a realizar. Otras deficiencias señaladas son la tendencia a actuar con los menores con poco rigor, al detectarse falta de planificación y sistematización en las actuaciones, así como la necesidad de una formación especializada multidisciplinar que incluya conocimientos, valores y destrezas y de apoyo/soporte a los profesionales ${ }^{29}$. La efectividad de un buen trabajo con los menores exige la elaboración de políticas y procedimientos de actuación, además de facilitar los recursos necesarios y el apoyo a los profesionales ${ }^{30}$.

- Conflicto entre los roles asignados a los Trabajadores Sociales. Por una parte, están obligados por la ley a trabajar conjuntamente con los padres y, al mismo tiempo, defender los intereses del menor, por lo que tienen que jugar un rol de agentes de control social. El propio sistema limita la realización de un trabajo social que promueva la mayor participación de los padres y la atención a menores se ha dirigido fundamentalmente a clasificar el riesgo de los menores, registrándolos, antes que a atender las necesida$\operatorname{des}^{31}$.

- Falta de participación de familias y menores.

Se reconoce que es imprescindible considerar el rol central que juegan las familias y los propios menores ${ }^{32}$ y dar carácter prioritario a los servicios de apoyo a las familias, tanto para ayudarles en su tarea como para ofrecer a los padres la capacitación nece-

Department of Health (1991): The Children Act 1989. Guidance and Regulations: Volume 2. Family Support, Day Care and Educational Provision for Young Children. Londres, HMSO; Birchall, E.; Hallett, C. (1995): Working Together in Child Protection. Londres, HMSO. Thoburn, J.; Lewis, A. y Shemmings, D. (1995): Paternalism or Partnership? Families' Involvement in the Child Protection Process. Londres, HMSO. Horwath, J.; Calder, M. (1998): "Working Together to Protect Children on the Child Protection Register: Myth o Reality". British Joumal of Social Work, 28, 879-895.

30 Fisher, T. (1995): Child Protection: What Knowledge Do Social Workers Use? York, The University of York, Social Work Research and Development Unit.

31 Bell, M. (1999): "Working in Partnership in Child Protection: The Conflicts". British Journal of Social Work, 29, 437-455.

32 Documentos oficiales que ofrecen orientaciones para este partenariado con las familias: Department of Health and Social Security (1995): The Challenge of Patemship. Para conocer "buenas prácticas"de participación de la familia en la conferencia inicial ver: Department of Health and Social Security (1995): Child Protection: Messages from Research. Londres, HMSO. 
saria para que puedan prestar una mejor atención a sus hijos.

- Inadecuación de las alternativas familiares asignadas a los menores.

Se ha elaborado un Libro Blanco sobre la Adopción ${ }^{34}$ que analiza la situación de los menores a cargo de los Councils en Inglaterra. El estudio destaca que, a finales de marzo de 1998, había unos 58.000 menores a cargo de los Councils ingleses, estimándose que un $40 \%$ de estos menores vuelven a su familia de origen en menos de 8 semanas y el $60 \%$ restante tiene dificultades en encontrar estabilidad familiar. De este segundo grupo de menores con dificultades, se estima que un $18 \%$ experimenta tres o. más cambios de familia en un año; el $70 \%$ deja de estar al cuidado de los Councils a los 16 años sin ninguna cualificación; el $25 \%$ entre 14-16 años no acude regularmente a un centro escolar y muchos han sido excluidos y no disponen de una plaza escolar; entre el $14 \%$ y $25 \%$ de las jóvenes están embarazadas o tienen un niño mientras en la población general sólo el $3 \%$ de las jóvenes de 20 años tienen un niño; tienen 60 veces más posibilidades de ser homeless y de ser delincuentes el (39\% de los presos menores de 21 años). También se destaca que ha habido una gran heterogeneidad entre los Councils en el uso de la adopción, además de falta de consistencia en la Ley de Adopción (Adoption Act 1976) y falta de concordancia con la Ley del Menor; la insuficiente especialización de los trabajadores sociales y la falta de apoyo a los padres adoptantes.

\subsection{La reforma de Mr. Blair}

Desde 1997 el nuevo gobierno laborista de Mr. Blair está llevando a cabo importantes cambios en los Servicios Sociales, como parte de una estrategia más amplia de reorientación de la política socioeconómica según el nuevo modelo denominado «Tercera vía». Con relación a los servicios sociales, se ha elaborado un Libro Blanco y diversos documentos de evaluación que analizan la situación actual y marcan las nuevas orientaciones que han guiado las reformas en curso ${ }^{35}$.

La nueva política se basa en el mantenimiento del Estado de Bienestar, pero modificando la filosofía original y considerando que la ma-

34 Department of Health (2000): Adoption-a new approach, A White Paper. Londres, The Stationery Office.

35 Department of Health. Social Services. Achievement and Challenge. Londrcs, The Stationery Office; HM Treasury y Cabinet Office (1998): Modern public services for Britain: investing in reform. Londres, The Stationery Office. 
yoría de las personas pueden atender sus necesidades por sí mismas, o con ayuda de su familia, amigos y vecinos, por lo que la principal responsabilidad de la atención social recae en cada individuo y en las redes sociales de ayuda mutua. El nuevo rol de los servicios públicos es apoyar y proporcionar atención a quienes carecen de redes sociales, es decir, a las personas muy dependientes y vulnerables que están aisladas socialmente, pero siempre con el objetivo de promover la independencia de las personas mediante mejores servicios de prevención y rehabilitación, incentivando la salida del sistema asistencial.

Para ello se considera necesaria una reorientación de la formación de los Trabajadores sociales y de los propios Departamentos de Servicios Sociales, así como de las personas que trabajan para el Tercer sector, en el que se ha constatado que hay muchos trabajadores que carecen de una adecuada cualificación. En este sentido, está prevista la sustitución del "Central Council for Education and Training in Social Work" (CCETSW) por el "General Social Care Council" (GSCC), que asumiría las competencias de regulación de la formación de los Trabajadores Sociales en Inglaterra y Gales, además de establecer los estándares para los restantes profesionales de los servicios sociales y mantener un Registro que incluya a los profesionales que, demostrada su adecuada formación, queden autorizados a ejercer ${ }^{36}$.

Se ha comenzado una reorganización de los servicios sociales ${ }^{37}$, como parte de una estrategia a largo plazo, en la que se mantiene la tendencia a apoyar la intervención de la iniciativa privada en la provisión de servicios sociales, asegurando que se pondrán los medios para garantizar la eficacia y eficiencia de los servicios prestados, así como la participación directa de los usuarios de los servicios, tanto en la determinación de sus necesidades como en la manera de satisfacerlas.

Más específicamente, en el caso de la atención social a los menores, este gobierno ha asumido los problemas que hemos señalado anteriormente junto a otros detectados en diferentes informes de evaluación realizados tras las elecciones de 1997. Los responsables de los Departamentos de Educación y Empleo, Seguridad Social y Mujeres presentaron en mayo de 1998 el documento "Meeting the Childcare Challenge" 38 en el que se identifican los problemas y se establecen las nuevas estrategias de acción. Los principales problemas señalados son tres:

36 "Care Standards Act 2000".

37 Department of Health (1998): Modernising Social Services. Pronoting independence, improving protection, raising standards. Londres, The Stationery Office.

38 Department for Education and Employment, Ministers for Women (1998): Meeting the Childcare Challenge. Londres, The Stationary Office. 
a) falta de regulación de los estándares de atención a los menores, por lo que la calidad de los cuidados es muy variable;

b) alto coste de los servicios, por lo que no están al alcance de muchos padres;

c) insuficiencia de plazas de atención a menores en algunas zonas y falta de información sobre la oferta existente.

La nueva estrategia pretende asegurar una atención de calidad y accesible (Working Families Tax Credit) a los menores de edades comprendidas entre los 0 y los 16 años, en cada comunidad, con el fin de promover el bienestar del menor ofreciendo igualdad de oportunidades para los padres, especialmente a las mujeres, y apoyo para conciliar la vida laboral y familiar. Para conseguirlo, deben trabajar conjuntamente (en partenariado) el gobierno central, las Autoridades locales, las entidades privadas y voluntarias que prestan servicios a los menores, empresarios, instituciones de enseñanza superior, escuelas, autoridades de salud, centros para alumnos con necesidades educativas especiales y padres.

Se destaca que los Servicios Sociales para menores no pueden considerarse separadamente del conjunto de servicios que las Autoridades locales y otras entidades ofrecen a los menores, por lo que se tiende a una atención más global, por ejemplo, integrando las actuaciones de Salud y Servicios Sociales (tal como ya se ha comenzado a hacer en el ámbito de la Salud Mental) ${ }^{39}$. Se promete mayor apoyo a la familia; reducir la exclusión social y la conducta anti-social de menores; y proporcionar a cada menor la oportunidad de tener una vida saludable, feliz y con éxito, con especial a los menores más vulnerables.

Para subsanar los problemas identificados, se han establecido tres prioridades nacionales para los nuevos servicios sociales de atención a los menores:

1. Asegurar que los menores están protegidos de maltrato físico y emocional, abuso sexual o negligencia.

2. Mejorar la calidad de la atención a los menores en protección de la forma más parecida a como lo harían unos padres responsables.

3. Aumentar las oportunidades de vida de los menores en protección y de otros menores ("en necesidad") que necesiten apoyo

Esto ha supuesto muchas críticas por considerar que más allá de la unificación de recursos financieros supone un cambio de filosofía que se califica de retroceso al pasado en cuanto puede derivar en una "medicalización" de la atención a menores (tratamientos terapéuticos). 
de los servicios sociales, en particular, mejorando su salud y educación y apoyo cuando dejen de estar en situación de protección.

Como ejemplos para lograr estos objetivos se pueden citar planes de actuación como "Sure Start" (proporcionar oportunidades a menores de áreas sociales en desventaja a través de servicios de salud, educación, servicios sociales y organizaciones voluntarias) y "Early Years Development and Childcare Plans" (Plan integral de educación y atención social para menores y sus familias).

Y se están realizando numerosos cambios legislativos entre los que cabe destacar los siguientes:

- Reforma del sistema de protección social (prestaciones económicas).

La "Welfare Reform and Pensions Act 1999" reforma el sistema de pensiones y subsidios aplicando el nuevo principio de "trabajo para los que pueden y seguridad para los que no pueden" (Welfare to Work). Además, la "Child Support, Pensions And Social Security Act 2000" reforma el sistema de prestaciones por menores a cargo iniciado en 1991 (Child Support Act 1991 y Child Support Act 1995), modificando el procedimiento establecido para los cálculos de las cuantías de las prestaciones, teniendo en cuenta determinados costes extras por el mantenimiento del menor. Por ejemplo, se regulan las responsabilidades de los padres en la obligación de mantenerlos (incluyendo la presunción de paternidad); la relación entre el sistema de prestaciones por menor a cargo y las ordenes judiciales de alimentos; y la introducción de tarifas por los servicios de apoyo a menores en determinados supuestos.

- Reformas en el ámbito de la Administración Local.

La "Local Government Act 2000" asigna un nuevo rol a las Autoridades locales al encomendarles el desarrollo de estrategias comunitarias (en partenariado) con la finalidad de mejorar la calidad de vida de las comunidades locales, mediante la promoción del bienestar económico, social y ambiental de cada territorio. Se establece una nueva financiación para servicios asistenciales para las personas más vulnerables y se autoriza a cobrar por los servicios de cuidado de menores que no estén bajo la custodia de las Autoridades Locales y cuyos padres sean beneficiarios de "Working Families'Tax Credit" y "Disabled Person's Tax Credit". 
- Establecimiento de unos estándares básicos obligatorios.

La "Care Standards Act 2000" establece la reforma del sistema de servicios de cuidados proporcionados por entidades privadas y voluntarias en Inglaterra y Gales. Se crea una Comisión Nacional que establecerá los estándares mínimos de calidad exigibles (National Care Standards Commission) en Inglaterra y se regula una amplia gama de servicios incluyendo desde la atención residencial hasta la ayuda a domicilio, el acogimiento familiar y la adopción (care homes, nursing homes, children's homes, domiciliary care agencies, fostering agencies, voluntary adoption agencies). Estos mismos estándares serán de obligado cumplimiento para los servicios públicos locales.

- Ampliación de la edad de protección a los menores y asignación de nuevas responsabilidades a las Autoridades Locales.

La "Children (Leaving Care) Act 2000" asigna a las Autoridades Locales mayores responsabilidades en el cuidado de los menores y jóvenes a su cargo que van a dejar de estar bajo protección, para lo que deben brindarles mayores oportunidades y prepararles para que puedan llevar a cabo una vida independiente. Como parte de estas nuevas responsabilidades deben ocuparse de que los jóvenes más vulnerables tengan la educación y formación ocupacional que les capacite para emplearse, incluyendo educación superior (con alojamiento y manutención). Los menores pueden abandonar el hogar a los 16 años pero, si es necesario, se amplía la edad de atención hasta los 21 años, para facilitar la transición desde el sistema de cuidados a la vida independiente.

- Prestaciones de apoyo a las personas que cuidan a personas dependientes.

La "Carers and Disabled Children Act 2000" encomienda a las Autoridades Locales la prestación de servicios de apoyo (prestación directa o pago por servicios) a las personas de 16 años o más que cuidan a personas con enfermedades de larga duración o con discapacidades (uno de cada seis hogares tiene una persona cuidadora). La ley establece y regula el derecho de las personas cuidadoras a recibir ayuda física, asesoramiento, formación y cortos descansos. Se establece que los servicios de apoyo deben ser flexibles para adecuarse a las diferentes situaciones concretas, teniendo en cuenta las preferencias de las personas interesadas (cuidadores y cuidados) y que se puede compensar económicamente o establecer un precio por los servicios. La ley también regula el derecho de las personas que tienen a su cargo 
a un menor con discapacidad a recibir por parte de las autoridades locales servicios de apoyo en su calidad de cuidadores.

\section{SERVICIOS SOCIALES PARA LOS MENORES Y SUS FAMI- LIAS}

La atención pública a los menores es una obligación que atañe a varios Departamentos Ministeriales. El Departamento de Seguridad Social es el responsable de una serie de prestaciones económicas para los padres que tienen la finalidad de compensarles los gastos ocasionados por los menores a su cargo. Las reformas recientes en la línea de que trabaje todo el que pueda vinculan las prestaciones a la aceptación de un trabajo, incluyendo a las madres solas con menores a cargo, tal como se ha comentado, quedando regulado en la "Child Support, Pensions and Social Security Act 2000"40. El Departamento de Salud, además de los servicios sociales en sentido estricto, proporciona servicios de protección materno-infantil a través de los Departamentos de Servicios Sociales locales; y el Departamento de Educación y Empleo proporcionan servicios de pre-escolar y extra-escolar, además de oportunidades de formación ocupacional y empleo.

En cuanto a los servicios de cuidado directo a los menores se pueden agrupar en tres grandes grupos ${ }^{41}$ :"Nursery education" (pre-escolar que se rige por la normativa del sistema educativo, Ley de Educación), "Childcare" (cuidados diurnos para hijos de padres trabajadores), "Welfare care" (para menores en riesgo o necesitados de protección). Las tres modalidades de actuación puede ofrecerse en un mismo lugar por autoridades locales, organizaciones voluntarias o entidades privadas y están siendo revisadas en el contexto de la reforma comentada.

a) La mayoría de los niños de 4 años cursan preescolar escolarizados en centros de educación primaria y se está escolarizando a los niños de 3 años $^{42}$. Además del aspecto cuantitativo de la escolari-

40 Un ejemplo de la reforma en este ámbito es la "Working Families'Tax Credit". Puede encontrarsc información detallada sobre la protección social de la Seguridad Social en www.dss.gov.uk

4) Penn, H. (2000): "Policy and Practice in Childcare and Nursery Education". Journal of Social Policy, 29 (1), 37-54.

42 Siguiendo la experiencia de otros países europeos en los que los menores de tres/cuatro años reciben atención integral (cuidado y educación) en centros del sistema educativo ordinario. European Commission (1996): A review of services for young children in the European Union 1990-1995. Bruselas, European Commission Childcare Network, European Commission DG $\mathrm{V}$. 
zación, se está trabajando en el tema de la calidad de los servicios ofrecidos ${ }^{43}$.

b) El Informe "Meeting the Childcare Challenge" destaca la necesidad de proporcionar más plazas para padres trabajadores, como apoyo a la política de "Welfare to Work" que ofrece subsidios para pago de hasta el $70 \%$ de los servicios de cuidado de los menores a los padres trabajadores con bajos ingresos. Un 90\% de los servicios de pre-escolar y cuidados de día se prestan por la iniciativa privada mercantil. La nueva ley "Care Standards Act 2000" transfiere la responsabilidad de estos servicios de cuidado diurno de menores, hasta ahora a cargo de las Autoridades locales de Educación, al Servicio de Inspección Escolar ( $\mathrm{Her}$ Majesty's Chief Inspector of Schools for England -HMCIS).

c) Welfare care. Entre otras medidas de lucha contra la exclusión social, se ha puesto en marcha un programa específico de intervención temprana dirigido a menores de tres años pertenecientes a familias con problemas. Se trata de trabajar con los padres para promover el desarrollo físico, intelectual y social de los menores y prevenir el fracaso escolar. También se ofrecen servicios de recreo, salud, orientación y apoyo a los padres, así como otros necesarios para satisfacer sus necesidades.

\subsection{La Ley de Menores de 1989 (Children Act 1989)}

Esta ley, que continúa en vigor, introdujo importantes cambios en la política de protección de menores, reorganizando el reparto de las responsabilidades entre Administración, familias y menores y asegurando atención a todo niño «en situación de necesidad». La ley establece la obligación de los Departamentos de Servicios Sociales locales de elaborar planes trienales de su oferta de servicios de cuidado de los menores (Children's Services Plans) ${ }^{44}$.

Entre los motivos que se adujeron para el cambio de legislación se señalaba que la anterior Ley de Menores ponía el énfasis en los derechos y obligaciones de los padres y, en la práctica, no garantizaba los

European Commission (1997): Quality Targets in Services for Young European Children. Bruselas, European Commission Childcare Network, European Commission DG V.

Este concepto «en necesidad» se ha relacionado tradicionalmente con situaciones de pobreza y privación material (niños «pobres») y se ha abusado de su separación del entorno familiar. La nueva ley reconsidera esta medida, restringiéndola al máximo y reconociendo también las necesidades de los padres. Sin embargo, los Trabajadores Sociales se quejan de que, en la práctica, se sigue sin trabajar para prevenir el abuso, respondiendo sólo a situaciones de crisis y a los requerimientos del procedimiento legal ante el abuso o maltrato de un menor. 
derechos del menor, considerándose que los Departamentos de Servicios Sociales locales actuaban sólo ante situaciones de abuso de los menores y no en su prevención. Ante una posible situación de maltrato de un menor la solución más común consistía en alejarle de su familia, adoptando los trabajadores sociales un rol de control social al cumplir su función de defender al menor sin tener en cuenta a la familia. La experiencia demostró que las actuaciones con los menores separados de sus familias no garantizaban su bienestar ya que, por una parte, muchos de ellos habían sido objeto de maltrato y abuso en sus nuevos alojamientos $\mathrm{y}$, por otra, gran número de estos menores al cumplir la mayoría de edad no estaban en condiciones de poder vivir de forma independiente. Todo ello puso de manifiesto la carencia o inadecuada atención que se prestaba a los menores, por parte de los Departamentos de Servicios Sociales, tras separarles de su familia, originándose un debate nacional sobre la política de atención a los menores ${ }^{45}$.

En consecuencia, la Ley de Menores de 1989 trata de encontrar el equilibrio entre los derechos de los padres y los derechos de los hijos, siendo el objetivo general el de salvaguardar y promover «el mejor interés del menor» hasta que cumpla los 18 años, asignando a las autoridades locales la responsabilidad de promover el Bienestar del menor, contando con el punto de vista de éste y designándole un tutor o representante cuando sea necesario. Como novedades cabe destacar el concepto de «responsabilidad parental» y la aplicación del principio de presunción de «no-intervención» en la vida familiar si no es necesario, además del reconocimiento de la necesidad de un «partenariado», es decir, de establecer una cooperación estrecha familia-profesionales de los Servicios Sociales trabajando desde una relación de igualdad ${ }^{46}$. Se reconoce así que los padres son responsables del cuidado de sus hijos y que los poderes públicos no deben intervenir en la vida de una familia, salvo que sea estrictamente necesario. En el caso de que se deba intervenir, no se puede hacer al margen de la familia, por el contrario, el punto de partida es que la familia suele ser la mejor opción para el menor, por lo que hay que trabajar con la familia para solucionar los

45 "Sccond Report of the House of Commons Social Service Select Committee" (198384); "White Paper on The Law on Child Care and Family Services" (1987), El estudio con mayor repercusión social fue el Informe sobre el caso Cleveland (1988) que denunciaba la desconsideración hacia los menores, a los que se trataba como a meros objetos o como problemas sociales. «Report of Inquiry into Child Abuse in Cleveland» (Cm 412). Londres, HMSO.

46 Department of Health (1991): The Children Act 1989. Guidance and Regulations. Volume 3. Family Placements. Londres, HMSO. 
posibles obstáculos en el desarrollo del menor, incluso si se separa de ella al menor. ${ }^{47}$

Por «responsabilidad parental» se entiende todos los derechos, deberes, poder, responsabilidades y autoridad que por Ley tienen el padre de un menor en relación con el menor y sus bienes y sólo el juez puede determinar si los padres pierden esta responsabilidad parental. La madre nunca pierde la responsablidad parental, aunque una Orden de Cuidado hace que la comparta con la Autoridad Local. El padre casado legalmente con la madre del menor adquiere automáticamente la responsabilidad parental y, si no hay unión legal, la madre puede solicitarla para él. Los padres pueden perder su responsabilidad parental cuando un juez decida que el menor se encuentra en «situación de necesidad» ${ }^{48}$.

Según la ley, un menor puede encontrarse «en necesidad» en los siguientes supuestos:

a) Si de manera indudable no puede alcanzar un estado de bienestar aceptable sin que se le proporcionen cuidados por la Autoridad Local.

b) Si su salud o su desarrollo puede ser «significativamente» perjudicados si no se le proporcionan cuidados.

c) Si es valorado como discapacitado de acuerdo con la Ley de Menores 1989.

Otro concepto clave es el de «daño significante». La ley considera que hay tal cuando el daño sufrido por el menor, en relación con su salud y desarrollo, es mayor del que razonablemente se puede esperar con relación a un menor similar y, en caso de abuso físico, las circunstancias del daño pueden ser tan significativas como los daños en sí mismos. Las categorías del maltrato son: negligencia, maltrato físico, abuso sexual y maltrato emocional o psicológico.

Se considera crucial la cooperación de los distintos Departamentos de la Autoridad Local (Salud, Vivienda, Educación y Servicios Sociales) para proporcionar un servicio integrado así como con las Agencias, estando todos ellos obligados a apoyar a los responsables del cuidado de los menores (sean sus padres, parientes o familias sustitutas) con información, preparación, y los necesarios servicios de día ${ }^{49}$.

47 En la práctica, hay fuertes presiones para separar al menor de su familia. Una corriente de Trabajadores Sociales lo considera una forma de abuso profesional.

48 Los jueces suelen dictar una Orden de Cuidados sólo en caso de abuso y raramente en caso de maltrato psicológico por la dificultad de acreditarlo suficientemente.

49 Department of Health (1991): The Care of Children. Principles and Practice in Regulations and Guidance. Londres, HMSO.(4a edic.), pág. 12-14. 989). Sin embargo, 
Las obligaciones específicas de los Departamentos de Servicios Sociales implican desde la provisión de servicios de prevención y atención al menor, incluyendo un alojamiento alternativo a su familia, hasta el inicio de procedimientos de protección del menor cuando los servicios no pueden garantizar el bienestar del menor, tal como se describe a continuación.

\subsection{El procedimiento de protección de los menores}

La ley establece que los Trabajadores sociales deben investigar los casos de maltrato de menores y realizar una investigación permanente de los menores en situación de riesgo inscritos en un Registro al efecto. Las situaciones de maltrato de los menores se conocen en los Departamentos de Servicios Sociales, fundamentalmente, a través de los centros escolares y también por denuncias de ciudadanos, policía, profesionales de la salud e, incluso, por miembros de la familia del menor. La investigación con relación al maltrato de un menor debe realizarse conjuntamente por los Departamentos de Servicios Sociales y la policía, que cuenta con profesionales especialmente entrenados para ello. Además, deben colaborar en la investigación otros Departamentos de la Administración Local como Educación, Vivienda y Salud.

Los Trabajadores sociales de los Departamentos de Servicios Sociales tienen la obligación legal de investigar para determinar las necesidades del menor y poder actuar en las siguientes circunstancias:

- Cuando hay sospecha fundada de que un menor que vive o se encuentra en su área está sufriendo o parece sufrir daño significante.

- Cuando hay bajo una Orden de Protección de Emergencia (con intervención del Juzgado) o una Orden de Protección Policial (sin intervención del Juzgado).

- Cuando un Juzgado de Familia solicita que investiguen las circunstancias del menor.

- Cuando el Departamento de Educación les notifica que un menor tiene problemas.

Esta investigación tiene como finalidad evaluar el bienestar del menor, valorando la conveniencia de que se inicien los procedimientos para que quede bajo la protección y cuidado de los Departamentos de Servicios Sociales locales. Cuando esto último ocurre, se comparte la «res-

en la práctica, difícilmente se cumple. Por ejemplo, cuando los Trabajadores Socialcs consideran que es importante otra vivienda para el bienestar del menor y, así lo solicitan, no suelen encontrar respuesta. 
ponsabilidad parental» con los padres biológicos y puede durar hasta que el menor cumple los 18 años, estableciendo el juez el régimen de contactos y visitas entre el menor y su familia. Los contactos y encuentros entre un menor y otra persona incluyen: visitas, estancias, salidas y comunicación por carta, teléfono y similares. La Autoridad local debe permitir al menor (bajo su cuidado) contactos razonables con un determinado número de personas, incluidos sus padres, determinando el juez su naturaleza y frecuencia, que siempre se basará en el beneficio del menor y no en el de los adultos.

La ley obliga a que en cada Distrito haya un "Registro de Protección del Menor" que ha sufrido maltrato o que se considera en riesgo (Child Protection Register) en el que se centraliza la información existente sobre protección de menores, quedando obligados los profesionales que trabajan con los menores a elaborar documentación e información sobre las situaciones de maltrato infantil. Este Registro es estrictamente confidencial y debe estar siempre accesible para ser consultado. $\mathrm{El}$ Informe del menor debe contener la siguiente información: identificación del menor y la familia, así como otros detalles de otros niños en el hogar; la naturaleza del maltrato; el trabajador de referencia y el «core group $»^{50}$; el trabajador social general; el visitador de salud; el nombre de la escuela; personas de referencia; investigaciones, planes de tratamiento, seguimiento y revisiones periódicas.

Para tomar las decisiones, hay unas Comisiones de evaluación de casos (Child Protection Case Conferences) a cuyas reuniones se invita a los padres a participar y en los que los diferentes profesionales implicados en un caso intercambian información, coordinan sus acciones en referencia a un menor y su familia y deciden conjuntamente inscribir o no al menor en el Registro, valorando si hay daño significante para que sea necesario un plan de protección del menor. Periódicamente se revisa y valora la permanencia de los menores en el Registro. La decisión sobre el alejamiento del menor de su familia compete al juez.

También en cada área hay un «Comité de Protección del Menor» (Area Child Protection Committee -ACPC-), formado por un grupo interdisciplinar de profesionales que representan a cada entidad implicada en la protección del menor: Educación, Salud, Servicios Sociales. Su función es elaborar, controlar y evaluar las políticas y la práctica del

Cuando un menor queda incluido en el Registro de Protección del Menor, se nombra un Trabajador Social de referencia que se encarga de coordinar el trabajo con la familia y visitarla regularmente. También se nombra un "Core Group" o pequeño grupo de profesionales que elaboran juntamente con la familia un Plan de Protección del Menor (Child Protection Plan) y deciden quién hará qué y cuándo, reuniéndose periódicamente para llevar a cabo un seguimiento del Plan. 
trabajo en el campo de los menores en su área, coordinando las actuaciones de todos los profesionales que intervengan.

En algunos lugares se sigue el modelo de «Family Group Conference» en el que los miembros de la familia tienen la responsabilidad de decidir cómo proteger mejor al menor, participando el menor y muchos miembros de la familia extensa así como otros miembros de la comunidad que van a poder ser de ayuda para el menor en el futuro. Los profesionales de los servicios sociales están presentes para orientar y ayudar a tomar decisiones, pero las decisiones las toma la fami$\mathrm{lia}^{51}$.

También existe la posibilidad de que los menores en riesgo puedan pasar al cuidado de la Autoridad Local sin medidas judiciales, siempre que así lo acuerden los padres. Se nombra un «Guardian-ad-litem»o trabajador social independiente para asegurar que se vela por los intereses del menor.

En cuanto a la duración de la protección, la Autoridad Local tiene la obligación de cuidar del menor durante el tiempo que dure la Orden de Cuidados, hasta que el menor cumpla los 18 años o hasta que esta Orden se recurra para ser revocada, o se otorgue una Orden de Residencia a favor de un familiar del menor que se ofrece a cuidar de él para evitar un acogimiento en familia extraña o un ingreso institucional y el Juez le otorga la responsabilidad parental. El sistema de protección puede continuar cuando los menores cumplen los 18 años si no son capaces de mantenerse de forma independiente, en estos casos, las Autoridades locales siguen teniendo obligación de orientación y cuidados por parte de la Autoridad local hasta los 21 años, mediante ayudas para alojamiento, salud, ingresos, trabajo y formación.

2.3. Servicios para Menores que se ofrecen desde los Departamentos de Servicios Sociales locales.

Las obligaciones que la ley asigna a los Departamentos de Servicios Sociales de las Autoridades Locales son las siguientes:

a) Supervisar al menor atendido en guarderías privadas, play-groups y childminders.

b) Prevenir la necesidad de tomar bajo tutela al menor o que llegue a un Tribunal Juvenil.

c) Tomar bajo tutela a los menores cuyos padres demuestren su incapacidad de cuidarlos. 
d) Actuar a través de los Tribunales para velar por los intereses del menor y del joven cuando sean necesarias acciones legales.

e) Velar por los intereses de los menores bajo tutela y proporcionarles alojamiento y manutención.

f) Supervisar al menor que va a ser adoptado y acordar el lugar para la adopción teniendo en cuenta el mejor interés del menor.

g) Supervisar al menor que está viviendo en Acogimiento familiar.

Como parte de estas obligaciones, las Autoridades Locales deben proporcionar apoyo a las familias ofreciendo diferentes servicios, bien directamente o bien a través de entidades privadas (tanto mercantiles como sin ánimo de lucro), por ejemplo, orientación y atención psicológica; actividades ocupacionales, sociales, culturales o recreacionales; ayuda a domicilio, incluyendo lavandería; atención a itinerantes; atención a menores con discapacidades; vacaciones para menores y familias. Cuando el menor no pueda convivir con su propia familia se buscará la mejor alternativa, siempre contando con sus deseos y estableciendo un acuerdo con su familia. Las alternativas son una familia de acogida, alojamiento residencial o adopción.

Cada Autoridad local puede establecer su oferta de servicios para cumplir con estas obligaciones. A continuación, de modo muy sintético, se comentan algunas de las características de la atención a menores mediante Acogimiento familiar, Adopción y Centros de familia, así como un breve comentario sobre las líneas básicas de atención a menores con discapacidades, a menores de familias "sin techo", prevención de drogodependencias y atención a menores con problemas legales.

\section{- Acogimiento Familiar.}

Los Departamentos de Servicios Sociales deciden qué menores deben pasar a la situación de acogimiento, pero la prestación del servicio se puede encomendar a entidades privadas que son las responsables de seleccionar y formar a las familias acogedoras así como del seguimiento correspondiente. Los Trabajadores Sociales de los Departamentos de Servicios Sociales deben supervisar el acogimiento y velar por el bienestar del menor, intentando que retorne a su propia familia, siendo la reunificación familiar, y en el más corto tiempo posible, la primera meta de los acogimientos familiares. La ley obliga a tener en cuenta las diferencias debidas a raza, cultura y lengua de los menores. El acogimiento puede considerarse una "actividad profesional" y estar remunerado por los Departamentos de Servicios Sociales exigiendo una cualificación y experiencia en el cuidado de menores y que una figura parental tenga disponibilidad para ocuparse a tiempo completo del cuidado del 
menor. Otras Autoridades Locales, por ejemplo, Doncaster, han preferido optar por familias acogedoras voluntarias de la propia comunidad a las que proporcionan formación para que cuiden adecuadamente al menor y una compensación por los gastos de manutención del menor.

\section{- Adopción}

Hay equipos con Trabajadores sociales especializados en Adopción y se están introduciendo cambios importantes para mejorar los procedimientos hasta ahora habituales siguiendo las orientaciones del citado Libro Blanco sobre Adopción. El gobierno se propone incrementar el número de adopciones modificando la legislación y colocando las necesidades y los derechos del menor en el centro del proceso. Los cambios se dirigen a establecer nuevos procedimientos en la captación, formación y apoyo a los padres adoptantes; mejoras en los servicios de adopción de los servicios sociales locales ${ }^{52}$; mejoras en el sistema judicial relativo a la adopción e, incluso, cambios legislativos en la línea de la Ley del Menor de 1989.

Entre estos cambios legislativos se propone una nueva modalidad de convivencia alternativa a la familia de origen para los casos en los que un menor no puede retornar a su familia pero tampoco la adopción resulta una opción adecuada, por ejemplo, en el caso de algunas minorías culturales o religiosas. Esta nueva figura se denominaría "special guardianship" y proporcionaría a la persona que se hiciera cargo del menor la responsabilidad de su cuidado, convivencia estable, seguridad legal, vínculos legales entre el menor y su familia de origen y acceso a todo tipo de servicios de apoyo a la familia, incluyendo apoyo económico.

En cuanto a la Adopción internacional, la "Adoption (Intercountry Aspects) Act 1999". regula la adopción internacional adaptando la Ley de Adopción ("Adoption Act 1976" para Inglaterra y Gales y "Adoption Act 1978" para Escocia), facultando a las Autoridades locales (Departamentos de Servicios Sociales locales) y a las Agencias privadas autorizadas por el Secretario de Estado.

52 Incluyendo mayor formación especializada para los trabajadores sociales que trabajan con menores. El Department of Health y el Central Council for Education and Trainig in Social Work han creado un nueva titulación de post-grado "Post-Qualifying Award in Child Care", instando a los Departamentos de Servicios Sociales locales para que faciliten a sus trabajadores sociales su obtención. 


\section{- Centros de Familia}

Se atiende a los menores, a sus familias o cuidadores proporcionándoles también actividades ocupacionales, sociales, culturales o recreacionales y orientación/atención psicológica, además de servir de centros de atención diurna de los menores. El Centro de Familia es un Centro de día, con la peculiaridad de que se ofrece ayuda intensiva a una parte o a toda la familia, cuando ésta tiene graves problemas. Los menores acuden en régimen de media pensión y se proporciona formación a los padres para que aprendan a prestar los cuidados adecuados a sus hijos en las actividades de la vida cotidiana, de este modo se promueve la permanencia de los menores en su propio hogar. Los padres pueden ser legalmente obligados a acudir para recibir educación familiar y capacitación para poder satisfacer las necesidades físicas, emocionales y sociales de sus hijos. Es un recurso que puede tener también un carácter preventivo, reduciendo las probabilidades de problemas familiares graves. Se trabaja en coordinación con los Trabajadores Sociales de los Departamentos de Servicios Sociales y de otras entidades sociales de la zona. Estos Centros pueden ofrecer una variada gama de prestaciones trabajando simultáneamente con unos 20 niños de los Registros de Protección de Menores. Se suele incluir la oferta de un club con horario extraescolar, ludoteca, etc. Hay especialistas de apoyo que pueden acudir regularmente al Centro, como logopedas, enfermeras, oficiales de probation, abogados de familia, etc. También se puede utilizar el Centro para grupos de adolescentes u otras necesidades de la comunidad, como lugar de reunión y actividades de las entidades públicas y sociales de la comunidad.

\section{- Atención a menores con discapacidades.}

Como ya se ha comentado, la Children Act de 1989 define a los menores con discapacidades entre las categorías de «menores en necesidad» y establece que los Departamentos de Servicios Sociales locales deben ofrecer servicios a estos menores para reducir los efectos de su discapacidad y darles la oportunidad de vivir una vida tan normal como sea posible (prevención). Se considera que estos menores tienen las mismas necesidades que cualquier otro menor y, además, una serie de necesidades especiales en función de su discapacidad. Por lo tanto, tienen derecho tanto a beneficiarse de los servicios para menores como a recibir ayuda específica complementaria para minimizar las consecuencias de la discapacidad, mejorar su calidad de vida y promover su independencia.

Suele haber Trabajadores Sociales especializados (Children with 
Disabilities Teams) que trabajan en cooperación con otras entidades, con los menores y con sus familias para asegurar una atención integral al menor, realizando, entre otras, las siguientes actuaciones: identificar e incluir en el Registro de menores en riesgo a los menores con discapacidad; evaluar sus necesidades y las de su familia; garantizar y promover el bienestar del menor de acuerdo con los padres y el propio menor; trabajar en cooperación con otras entidades; tener en cuenta los mismos principios generales que la ley señala para los menores en protección y los mismos servicios (integración).

Los padres de menores con discapacidades tienen derecho a nuevos servicios de apoyo en su calidad de cuidadores, en aplicación de la "Carers and Disabled Children Act 2000", tal como ya se ha mencionado.

- Atención a menores de familias "sin techo"

Hay Trabajadores Sociales que trabajan con "Homeless Families". Se les suele ofrecer alojamiento en la modalidad de «Bed \& Breakfast $»$ (alojamiento y desayuno) o un Albergue (Hostel). A estos menores se les proporcionan servicios socioeducativos, como «School Holiday Play Schemes», con programas que proporcionan oportunidades de juego supervisado para menores de 2 a 5 años. A los padres se les estimula a participar activamente en la mayoría de los programas. Hay programas coparticipados por los Departamentos de Salud, Servicios Sociales y Educación, que se llevan a cabo en la Escuela y también se trabaja en coordinación con el sector voluntario.

- Prevención de drogodependencias, dirigida a menores entre 11 y 18 años de edad.

Son Programas interdepartamentales en los que trabajan de modo integrado profesionales de la Policía, servicios de trabajo con jóvenes ("Youth and Commnunity y Youth Offending Teams"), servicios de tratamiento de drogodependencias, servicios de salud y servicios de la prisión. Se realizan intervenciones en las escuelas y en la comunidad, ofreciendo información y apoyo a los jóvenes/sus padres y luchando contra el absentismo escolar como medida de prevención de la exclusión social.

- Los Departamentos de Servicios Sociales también se ocupan del Registro, asesoramiento, formación y supervisión de una serie de servicios para menores de 8 años como, por ejemplo:

- «Chilminders»: Son cuidadoras de niños que cuidan en su propio 
domicilio a uno o varios menores a su cargo.

- «Playgroups»: Actividades socioeducativas para niños de edad pre-escolar (0-5).

Hay childminders y playgroups especializados en la atención a menores «en necesidad», con riesgo de maltrato o en situaciones de ruptura familiar.

- «Creches»: son guarderías en las que se cuida a los menores entre 0-5 años, con atención diferenciada de 0-6 meses y de 6 meses a 5 años.

- «Out of School Clubs» y «School holiday play scheme» (2-5 años) en los que se realizan actividades socioeducativas durante tiempo libre y vacaciones.

- "Adventure play grounds", donde el niño juega con otros niños bajo la supervisión de adultos.

- «Nursery School»: guarderías privadas (0-5).

Estos servicios pueden ser públicos o privados (de iniciativa social o lucrativos). Si son privados, los servicios sociales locales tienen la obligación de inspeccionarlos para asegurase que cumplen los estándares establecidos en la legislación. También deben mantener un Registro de estos servicios y childminders. El Departamento de Empleo cofinancia algunos de estos servicios (tres años) para dar más oportunidades a las madres a aceptar un empleo.

\section{- Atención a menores y jóvenes delincuentes.}

Los "Youth Offender Teams" son equipos pluridisciplinares especializados en el trabajo con jóvenes delincuentes que tienen como finalidad coordinar las actuaciones concernientes a cada joven. Ha habido recientes modificaciones con la aprobación de dos normas legales, la "Crime and Disorder Act 1998" y la "Youth Justice and Criminal Evidence Act 1999", que establecen la reforma del sistema de justicia juvenil en Inglaterra y Gales, tratando de aplicar las conclusiones del Libro Blanco "No More Excuses" (CM 3809 Noviembre 1997), en el que se proponían mejoras en los tribunales juveniles de justicia y en la prevención de la delincuencia de menores y jóvenes.

La filosofía es la de tratar al joven delincuente no como a un criminal sino como a un joven que necesita ayuda social, aplicando una especial consideración cuando un menor de 18 años delinque por primera vez con la finalidad de prevenir su reincidencia. El "Youth Offender Panel" es el encargado de establecer un programa de conducta consensuado con el joven, que debe incluir un elemento de reparación 
del daño causado a todas las personas afectadas, si ellos lo consienten. El programa debe incluir diversas actividades, dependiendo de las circunstancias, por ejemplo: sesiones de mediación; trabajo no remunerado a favor de Ia comunidad; asistencia a un centro escolar; participación en actividades específicas como formación ocupacional o tratamiento de adicciones, etc. En cuanto al procedimiento a seguir, cabe destacar las siguientes actuaciones: evaluación de las necesidades del joven; programas de apoyo para los jóvenes en libertad provisional; acogida en establecimientos o en acogimiento familiar especializado o en medio cerrado; realización de los informes establecidos por los Tribunales, incluyendo la propuesta de la pena; orientación y ayuda a los jóvenes durante y después de la condena.

En conclusión, los Servicios Sociales de atención a menores en Inglaterra están inmersos en una situación de cambio dentro de un contexto de cambio más amplio, que afecta tanto al propio sistema general de Servicios Sociales como a otras áreas directamente relacionadas con el bienestar de las personas. En realidad, se está redefiniendo el propio modelo de Estado de Bienestar, por lo que los cambios han de valorarse desde una perspectiva de globalidad, tanto en su vertiente filosófica como en el ámbito de la práctica ya que, como se ha podido ver, estos cambios también tienen repercusiones en la formación de los profesionales de la atención social, incluyendo a los Trabajadores Sociales. Estamos asistiendo a un proceso que acaba de comenzar, por lo que habrá que seguir de cerca su desarrollo, no sólo por "curiosidad" científica sino, también, porque, como miembros de la Unión Europea, no nos puede resultar indiferente. 



\title{
POBREZA INFANTIL EN VEINTICINCO PAÍSES INDUSTRIALIZADOS. DATOS Y EVIDENCIAS DESDE EL LUXEMBOURG INCOME STUDY
}

\author{
MIGUEL A. MATEO PÉREZ \\ Departamento de Sociología II, Psicología, Comunicación y Didáctica. \\ Universidad de Alicante.
}

\section{INTRODUCCIÓN}

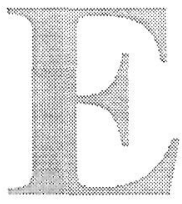

l día doce de julio de 2000 se presentó en Ginebra el Informe El progreso de las Naciones 2000, realizado por UNICEF. Al margen de las cifras sobre pobreza infantil en el conjunto total del planeta, se señalaba (y fue también lo que trascendió a los medios) que uno de cada seis niños que residen en los países de la Organización para la Cooperación y el Desarrollo Económico-OCDE- viven en condiciones de pobreza relativa ${ }^{1}$. No se puede olvidar que son países muy ricos los que integran esta Organización, incluida España.

Las condiciones de salud, la educación formal, las oportunidades vitales de estos niños y niñas están sujetas a situaciones de empobrecimiento. Pero son procesos de exclusión, mucho más profundos y complicados con causas y efectos estructurales, los que subyacen a estas manifestaciones empíricas (Moisio, 2000). El dato es mucho más frío y visible. Los procesos están más ligados a las experiencias personales.

En este trabajo se va a optar por el dato. Las justificaciones pueden ser más o menos plausibles pero lo que no es éticamente correcto es asegurar que la perspectiva con la cual se trabaja es la única. El uso de fuentes numéricas que cuantifican la realidad social es especialmente útil cuando hablamos de pobreza (Hagenaars, de Vos y Zaidi, 1994). La explicación es sencilla: las políticas sociales se articulan gracias a las evidencias empíricas numéricas. Esto, en principio, no es algo perverso aunque al final pueda acabar siéndolo. El problema está en que las estadísticas de pobreza sobre las que trabajamos tienen serias limita-

1 UNICEF define la pobreza relativa como aquella que sufre toda persona (en este caso, todo niño/a, que vive en un hogar cuyos ingresos están por debajo de la mitad de la media nacional). Esta medida de privación relativa basada en el ingreso se tendrá oportunidad de discutirla más adelante. 
ciones, empezando por la definición operativa de pobreza, la unidad de análisis fundamental (el hogar) y de la opacidad casi natural de la población de la cual se quiere obtener información. Cuando la población a estudiar es la infancia, los niños y las niñas, todo lo anterior se complica mucho más.

Entonces, ¿por qué se opta por una perspectiva tan miope? Pues porque la(s) alternativa(s) lo son bastante más aún. No se dispone de una base cualitativa lo suficientemente amplia como para elaborar relatos, historias o trayectorias de vida (si lo que se pretende es una comparación internacional) y la construcción de modelos teóricos, cuestión necesaria por otra parte, requiere un conocimiento sobre la realidad a estudiar mucho más profundo del que realmente se tiene.

Dentro de las opciones menos malas y reconociendo sus limitaciones, es importante, para articular políticas sociales de lucha contra la pobreza infantil en los países industrializados, conocer cuántos niños y niñas viven en situación de pobreza relativa, qué elementos condicionan esta situación y qué dinámicas de empobrecimiento pueden ser las predominantes. Para ello, necesitamos evidencias empíricas con las que trabajar. Evidencias que se buscan para los países llamados "industrializados" (que coinciden en su mayoría con los países de la OCDE -BM, 1999-) y utilizando la base de datos del Luxembourg Income Study como elemento principal para el cálculo de las tasas de pobreza.

La exposición se estructura de la manera siguiente: en primer lugar se hace referencia a los elementos metodológicos de la investigación (investigaciones previas, fuentes de datos, países y ámbito temporal, variables y su construcción y las técnicas de análisis y modelos de regresión, básicamente). En segundo lugar, se exponen los principales resultados descriptivos (tasas de pobreza infantil en los países citados, posibles agrupaciones de países en conglomerados diferenciados) y los más explicativos (modelos de regresión). En el apartado siguiente se realiza la discusión de los resultados para acabar con las conclusiones de la investigación. Se adjuntan dos anexos con las tablas de correlaciones, los elementos técnicos de los análisis de conglomerados y de cada modelo de regresión realizado.

\section{METODOLOGÍA, TÉCNICAS DE ANÁLISIS Y DATOS}

\subsection{Investigaciones previas}

Las investigaciones sobre infancia y pobreza se han centrado desde muy pronto en las relaciones entre familia y pobreza (Hauser, Brown, 
Prosser, 1997). Más concretamente los estudios siguen analizando las relaciones entre el tipo de familia y la pobreza infantil. Dicho de otra manera, la composición del hogar es un elemento determinante a la hora de enfocar los estudios sobre pobreza infantil (Solera,1998; Heydemann, 2000). También se hace referencia en este artículo a esta perspectiva, aunque no de forma exhaustiva.

Estudios precedentes en los que se basa este trabajo son los desarrollados en el propio Luxembourg Income Study y por autores vinculados de alguna manera a este centro. Sirven de base general a este estudio los anteriores de Förster, 1993; Atkinson, Rainwater y Smeeding, 1995; Danzinger, Smeeding y Rainwater, 1995; Gauthier, 1996 y Forssén, 1998. Las características comunes en estos estudios anteriormente citados son: la utilización del análisis comparado tomando como referente países industrializados, la vinculación entre la pobreza general y la pobreza infantil, la utilización de datos la mayoría de ellos procedentes del LIS para la medición de la pobreza infantil y el análisis paramétrico de estos datos.

También para España hay investigaciones sobre pobreza infantil. Quizá la característica más importante sea la ausencia de una sistematización de estos estudios para la población infantil, ya que de los que disponemos son más bien trabajos generales de los que se deriva un apartado dedicado a la infancia. Los trabajos de Ruiz-Castillo,1987; Bosch, Escribano y Sánchez , 1989; Ruiz-Castillo y Del Río, 1997; RuizHuerta y Martínez, 1994; INE, 1996; Mercader-Prats, 1998 y Duclos y Mercader-Prats, 1999, son ejemplos de lo anterior. Son los estudios de Merdader-Prats los que más se acercan a la perspectiva comparada que interesa para este trabajo.

Para este artículo se aplica la metodología y la base empírica de los trabajos de Bruce Bradbury y Markus Jäntti (1999), recalculándose en la mayoría de los casos los datos de los autores citados. Los elementos metodológicos novedosos se refieren a la comparación entre modelos de regresión, cuestiones que no aparecen en los estudios previos citados.

\subsection{Fuentes de datos}

Para calcular las tasas de pobreza se utilizan datos procedentes de la base de datos del Luxembourg Income Study (LIS), parte del CEPS (Center for the Study of Population, Poverty and Public Policy) e iniciativa del gobierno luxemburgués, que aglutina las encuestas de presupuestos familiares de una veintena de países europeos además de países como Israel, Estados Unidos, Canadá y otros del Este asiático y 
del Este de Europa (Smeeding, Schmaus, Allegreza, 1985; Tombeur,1997). Estas encuestas tienen una amplitud temporal desde finales de los 70 hasta los 90. Los países y ámbito temporal objeto de este estudio se presentan en la tabla 1.

Tabla 1. Países y ámbito temporal. Base de datos LIS.

\begin{tabular}{|llll|}
\hline País $\boldsymbol{y}$ año & Id. LIS & País y año & Id. LIS \\
\hline Rusia, 1995 & RU95 & Francia, 1989 & FR89 \\
Estados Unidos, 1994 & EEUU94 & Holanda, 1991 & HO91 \\
Reino Unido,1995 & UK95 & Suiza, 1980 & SZ80 \\
Italia,1995 & IT95 & Taiwan, 1995 & TA95 \\
Australia, 1994 & AU94 & Luxemburgo, 1994 & LX94 \\
Canadá, 1994 & C94 & Bélgica, 1992 & BE92 \\
Irlanda, 1987 & IR87 & Dinamarca, 1992 & DI92 \\
Israel, 1992 & IS92 & Austria, 1987 & AS87 \\
Polonia, 1992 & PO92 & Noruega,1995 & NO95 \\
España, 1990 & ES90 & Suecia, 1992 & SU92 \\
Alemania, 1994 & AL94 & Finlandia, 1991 & FI91 \\
Hungría, 1994 & HU94 & Eslovaquia, 1992 & ESL92 \\
República Checa, 1992 & RCH92 & & \\
\hline
\end{tabular}

Fuente: elaboración propia a partir de la base de datos del LIS.

El acceso a la base de datos del LIS se realiza mediante correo electrónico. Se trabaja con el sistema de datos remotos, disponiendo de los datos elaborados y evitando así el trabajo directo con las matrices de datos contenidas en el servidor del LIS ${ }^{2}$. Otras variables importantes en este artículo tienen como fuentes el Informe Mundial sobre el estado de la Infancia de UNICEF (2000) y datos del Banco Mundial (1999).

\subsection{Variables}

La pobreza infantil se puede calcular de varias formas. Para este trabajo se ha optado por utilizar de forma descriptiva las tres más comunes: la tasa de pobreza infantil tomando como referente la población total (TPI), la tasa de pobreza infantil corregida por la población infantil (TPI2) y la tasa de pobreza infantil tomando como referencia la línea de pobreza de los Estados Unidos en 1995 (TPIUSA). Se entiende

2 Para más información, bases de datos, procedimientos para darse de alta en este servicio, manuales del usuario, etc., se puede consultar la página web del Luxembourg Income Study: http://www.lis.ceps.lu/access.htm 
como niño o niña o población infantil a todos aquellos miembros del hogar entre 0 y 17 años.

Para las dos primeras la tasa de pobreza infantil ajustada o no por la población infantil se calcula de la misma forma: la pobreza se ha medido como el $50 \%$ de la mediana del ingreso neto disponible por hogar (DPI), ajustando esta medida por una escala de equivalencia diferente a la propuesta por la $\mathrm{OCDE}\left(1 ; 0^{\prime} 5 ; 0^{\prime} 7\right)$. Siguiendo a Bradbury y Jäntti (1999), se utiliza la escala de equivalencia siguiente:

$$
\text { E.E }=\left[\left(X_{1}+X_{2}\right) 0^{\prime} 7\right]^{0.85}
$$

Donde:

$\mathrm{X}_{1}=\mathrm{N}^{\circ}$ de adultos en el hogar

$\mathrm{X}_{2}=\mathrm{N}^{\circ}$ de niños/as en el hogar

Esta escala de equivalencia, sus propiedades y pertinencia para el estudio de la pobreza infantil se detalla en Jenkins y Cowell (1994).

Otras variables que se han utilizado para la caracterización de la pobreza infantil en los países industrializados seleccionados son: 1) indicadores demográficos y de desarrollo ${ }^{3}$ ligados a esta perspectiva (millones de niños menores de 18 años y el porcentaje que sobre el total de la población suponen; tasa de mortalidad infantil a los cinco años por cada mil nacidos y la tasa de fertilidad adolescente); 2) indicadores que hacen referencia a cuestiones económicas monetarias $^{4}$. En este sentido se utiliza en Producto Interior Bruto per cápita (PIBpc) en dólares USA de 1995, las variaciones anuales de dicho PIBpc desde 1990 hasta 1997 para observar el componente dinámico y la evolución de las tasas de inflación desde 1990 hasta 1997; 3) tasas de pobreza infantil según la composición del hogar ${ }^{5}$. Se hace referencia a las tasas de pobreza infantil según hogares encabezados por una mujer sola, por madre y padre y otras formas de composición numérica del hogar; y 4) los gastos del gobierno central ${ }^{6}$ (en porcentaje sobre el total de gastos) en las partidas de Salud, Educación y Defensa (militar).

\subsection{Técnicas de análisis}

Primeramente se realiza un análisis descriptivo de los datos para cada uno de los veinticinco países contenidos en este trabajo. También 
se señalan las relaciones intuitivas entre variables que preceden al análisis explicativo basado en modelos multivariables.

Se realizan dos tipos de análisis multivariable. En el primer caso, se efectúa un análisis de conglomerados (jerárquico -método de Ward, distancia euclídea al cuadrado- y un análisis k-medias para confirmar la técnica previa). Este tipo de análisis permite agrupar los países con los que se trabaja en diferentes grupos utilizando como criterios de clasificación más de una variable cuantitativa.

En segundo lugar, se realiza un análisis de regresión lineal múltiple para establecer qué variables explican las tasas de pobreza infantil ajustada por la población infantil (TPI2). También se realiza el mismo tipo de análisis para las tasas de pobreza infantil según la composición del hogar. Es especialmente interesante la comparación entre los modelos extraídos. El modelo de regresión lineal múltiple asume los supuestos paramétricos necesarios para realizar dicho análisis. El método de introducción de variables en el modelo es el de "pasos sucesivos", utilizando un nivel de confianza del 95,5\%. El criterio para la inclusión de variables es de 0,05 y de salida de las mismas del modelo de 0,1 . El análisis se ha realizado con el software estadístico SPSS v.9 para Windows.

\section{RESULTADOS. LA(S) POBREZA(S) DE LOS NIÑOS/AS}

\subsection{Tres medidas de pobreza.}

El país con mayor tasa de pobreza infantil es Rusia, independientemente de la fórmula que se prefiera para medirla. Los cambios más importantes en las posiciones de los países se producen cuando se toma el criterio de la línea oficial de pobreza de los Estados Unidos en 1995, muy correlacionada con el PIB per cápita $(-0,865 \mathrm{p}<0,001)$.

Así, los cinco países con menor PIBpc son los mismos que están en los cinco primeros puestos de pobreza infantil tomando la línea de los EEUU. También es esta última medida de pobreza infantil la que menos correlaciona con el resto de tasas de pobreza infantil que hacen referencia a la composición del hogar.

Al margen de estas tres formas de medir la pobreza infantil, es muy importante estudiar la distribución de ésta en función de la estructura del hogar. Las tasas de pobreza infantil para el conjunto de los veinticinco países propuestos, ajustadas por el número de niños/as en 1996, muestran que en los hogares monoparentales encabezados por una mujer, 
Tabla 2. Tasas de pobreza infantil para 1996. Tres maneras de medirla.

\begin{tabular}{|c|c|c|c|c|c|c|}
\hline & TPI1* & $\begin{array}{c}\text { Ranking } \\
\text { TP11 }\end{array}$ & TPI2** & $\begin{array}{c}\text { Ranking } \\
\text { TPL2 }\end{array}$ & TPIUSA $* * *$ & $\begin{array}{l}\text { Ranking } \\
\text { TPIUSA }\end{array}$ \\
\hline Rusia & 26,6 & $I$ & 25,4 & 1 & 98 & $I$ \\
\hline Estados Unidos & 26,3 & 2 & 18,6 & 2 & 18,5 & 12 \\
\hline Reino Unido & 21,38 & 3 & 11 & 5 & 28,6 & JO \\
\hline Italia & 21,2 & 4 & 15,7 & 3 & 38,1 & 9 \\
\hline Australia & 17,1 & 5 & 11 & 6 & 20,7 & 11 \\
\hline Canadá & 16 & 6 & 11,2 & 4 & 9 & 16 \\
\hline Irlanda & 14,8 & 7 & 6,5 & 13 & 54,4 & 6 \\
\hline Israel & 14,7 & 8 & 10,3 & 8 & 45,3 & 8 \\
\hline Polonia & 14,2 & 9 & 10,9 & 7 & 90,9 & 3 \\
\hline España & 13,1 & 10 & 9,7 & 10 & 47,3 & 7 \\
\hline Alemania & 11,6 & 11 & 7,1 & 11 & 12,4 & 14 \\
\hline Hungría & 11,5 & 12 & 10,1 & 9 & 90,6 & 4 \\
\hline Francia & 9,8 & 13 & 6,8 & 12 & 17,3 & 13 \\
\hline Holanda & 8,4 & 14 & 5,8 & 14 & 10 & 15 \\
\hline Suiza & 6,3 & 15 & 3,9 & 18 & 1,6 & 24 \\
\hline Taiwan & 6,3 & 16 & 4,1 & 17 & 4,3 & 20 \\
\hline Luxemburgo & 6,3 & 17 & 1,9 & 23 & 1,1 & 25 \\
\hline Bélgica & 6,1 & 18 & 4,2 & 16 & 7,9 & 17 \\
\hline Dinamarca & 5,9 & 19 & 5,1 & 15 & 4,6 & 19 \\
\hline Austria & 5,6 & 20 & 3,3 & 20 & 5,4 & 18 \\
\hline Noruega & 4,5 & 21 & 3,5 & 19 & 2,8 & 22 \\
\hline Suecia & 3,7 & 22 & 3,2 & 21 & 3,7 & 21 \\
\hline Finlandia & 3,4 & 23 & 2,5 & 22 & 2,6 & 23 \\
\hline Eslovaquia & 2,2 & 24 & 1,5 & 25 & 95,2 & 2 \\
\hline República Checa & 1,8 & 25 & 1,6 & 24 & 85,1 & 5 \\
\hline
\end{tabular}

Fuente: elaboración propia a partir de datos del LIS.

* Se calcula para cada individuo en la población su ingreso equivalente en el hogar. La línea de pobreza se define como el $50 \%$ de la mediana del ingreso neto disponible sobre el total de la población.

** La línea de pobreza infantil TPI2 se construye en función de los ingresos de los hogares con niños. En este caso se corrige la medida anterior al tomarse la mediana del ingreso equivalente por hogar ajustándolo por el número de niños por hogar.

*** Es la línea oficial de pobreza de los EE.UU. Equivale a 15.299 \$US95 para una pareja con dos hijos. El resto de países se han convertido al dólares americanos a través del poder de paridad de compra ofrecido por la OCDE.

éstas son casi el doble que en el resto de los supuestos (hogares con dos padres y otras formas).

Otra cuestión interesante son las tendencias en cuanto a pobreza infantil en los países citados. Aunque no se disponen datos comparati- 
Tabla 3. Pobreza infantil por tipo de familia.

\begin{tabular}{|lccc|}
\hline & $\begin{array}{c}\text { Hogares } \\
\text { monoparentales } \\
\text { encabezados }\end{array}$ & $\begin{array}{c}\text { Hogares } \\
\text { compuestos } \\
\text { por padre }\end{array}$ & $\begin{array}{c}\text { Hogarescon } \\
\text { otras formas } \\
\text { familiares }\end{array}$ \\
\hline Estados Unijer & ymadre & \\
Canadá & 59,6 & 16,7 & 29,1 \\
Alemania & 45,3 & 12,3 & 13,4 \\
Reino Unido & 43,3 & 8,5 & 7,3 \\
Australia & 40,3 & 17,5 & 13,9 \\
Austria & 38,3 & 14,7 & 16,6 \\
Rusia & 33,2 & 2,9 & 2 \\
Luxemburgo & 31 & 26 & 26,5 \\
Irlanda & 30,1 & 4,4 & 6,8 \\
Holanda & 29,8 & 16,7 & 7,1 \\
Israel & 29,6 & 6,8 & 4,2 \\
Francia & 26,6 & 14 & 14,8 \\
España & 25,4 & 7,7 & 12,6 \\
Suiza & 25,2 & 12,4 & 13,5 \\
Italia & 21,2 & 4,8 & 12,5 \\
Taiwan & 20,2 & 20,9 & 22,3 \\
Hungría & 15,2 & 5,1 & 7,5 \\
Bélgica & 12 & 10,9 & 12,9 \\
Dinamarca & 11,8 & 6,1 & 3 \\
Noruega & 10,5 & 5,5 & 2,8 \\
República Checa & 8,9 & 1,3 & 1,4 \\
Eslovaquia & 7,6 & 2,1 & 1,4 \\
Finlandia & 6,2 & 3 & 4,1 \\
Polonia & 4,9 & 13,7 & 17,5 \\
Suecia & 4,5 & 3,6 & 2,6 \\
\hline Total ajustado a & & & \\
la población infantil & & \\
(1996) & 37,9 & 15,5 & 19,8 \\
\hline
\end{tabular}

Fuente: elaboración propia a partir de datos del LIS.

vos en el tiempo para todos los países es interesante señalar que prácticamente el $75 \%$ de los países considerados o mantienen sus niveles de pobreza infantil o los incrementan entre la década de los setenta y finales de los noventa, independientemente de la medida de pobreza infantil que se utilice. Una vez más, la medida más indulgente con la pobreza infantil para los países de alto PIBpc es la TPIUSA. 
Tabla 4. Tendencias en la pobreza infantil. Comparación de las tres medidas.

\begin{tabular}{|lccc|}
\hline & TPII & TPI2 & TPIUSA* \\
\hline Rusia (92-95) & 2,7 & 2,2 & n.d \\
Italia (86-95) & 0,9 & 0,7 & 0,8 \\
Hungría (91-94) & 1 & 0,5 & 0 \\
Polonia (86-92) & 0,3 & 0,3 & n.d \\
Reino Unido (79-95) & 0,8 & 0,3 & 0,3 \\
Holanda (83-91) & 0,4 & 0,2 & $-2,6$ \\
Alemania (73-94) & 0,2 & 0,1 & 0,4 \\
Australia (81-94) & 0,1 & 0,1 & $-0,3$ \\
Bélgica (85-92) & 0,2 & 0,1 & $-0,4$ \\
Israel (79-92) & $-0,1$ & 0,1 & $n . d$ \\
USA (74-94) & 0,3 & 0,1 & 0 \\
Francia (79-89) & 0 & 0 & 0 \\
Luxemburgo (85-94) & 0 & 0 & $-0,1$ \\
Noruega (79-95) & 0 & 0 & $-1,1$ \\
Suecia (75-92) & 0 & 0 & $-0,6$ \\
Canadá (71-94) & $-0,1$ & $-0,1$ & $-0,4$ \\
Dinamarca (87-92) & 0 & $-0,1$ & 0 \\
Finlandia (87-91) & $-0,2$ & $-0,1$ & $-0,7$ \\
España (80-90) & $-0,1$ & $-0,2$ & $-1,3$ \\
Taiwan (86-95) & $-0,4$ & $-0,4$ & $-4,2$ \\
\hline
\end{tabular}

Fuente: elaboración propia partiendo de datos de LIS y de Bradbury y Jäntti, 1999.

* los países con hiper-inflación no se han incluido.

Los datos anteriores confirman ${ }^{7}$, una vez más, que aunque se produzcan avances significativos en la reducción de la pobreza, los niños/ as que viven en los hogares más pobres tienen dificultades para dejar de ser pobres, o para superar esa situación en el futuro.

\subsection{Un ejercicio clasificatorio}

La situación social, demográfica, económica y política de Rusia difiere sustancialmente de la de Taiwan o de la de Estados Unidos. Estas diferencias son relativamente importantes cuando se habla de pobreza infantil ya que la población menor es especialmente sensible a los contextos en los cuales se inserta. Dentro de las aparentes diferencias entre los países que se han seleccionado, hay elementos comunes muy interesantes que hacen que se puedan agrupar en dos o tres bloques,

7 Para un análisis comparado entre las tendencias de pobreza en el marco de la OCDE tomando como elementos de análisis la pobreza general, la infantil y la de las personas mayores, se puede ver el trabajo de Smeeding, 1995. 
Figura 1. Tendencias pobreza infantil (TPIUSA)

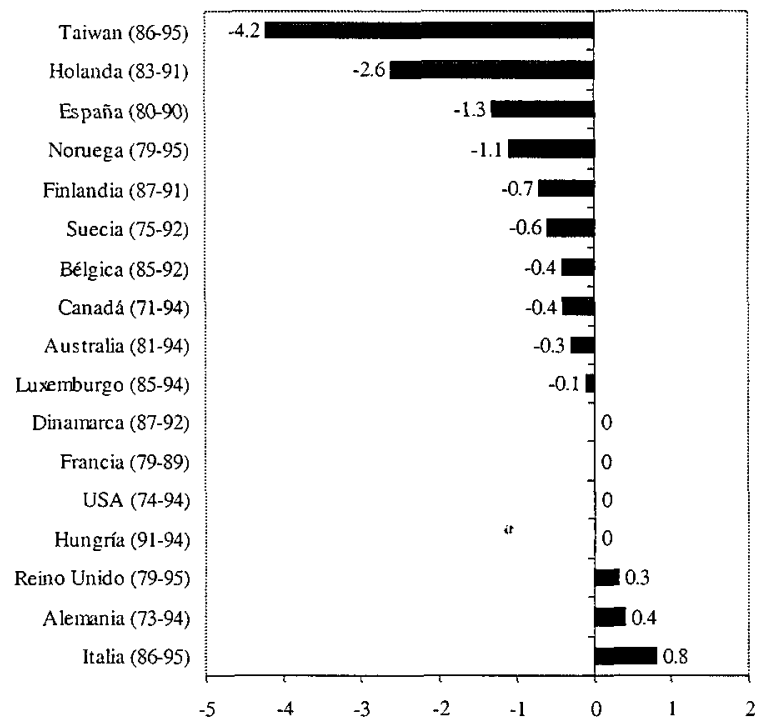

Figura 2. Tendencias pobreza infantil (TPI1/2)

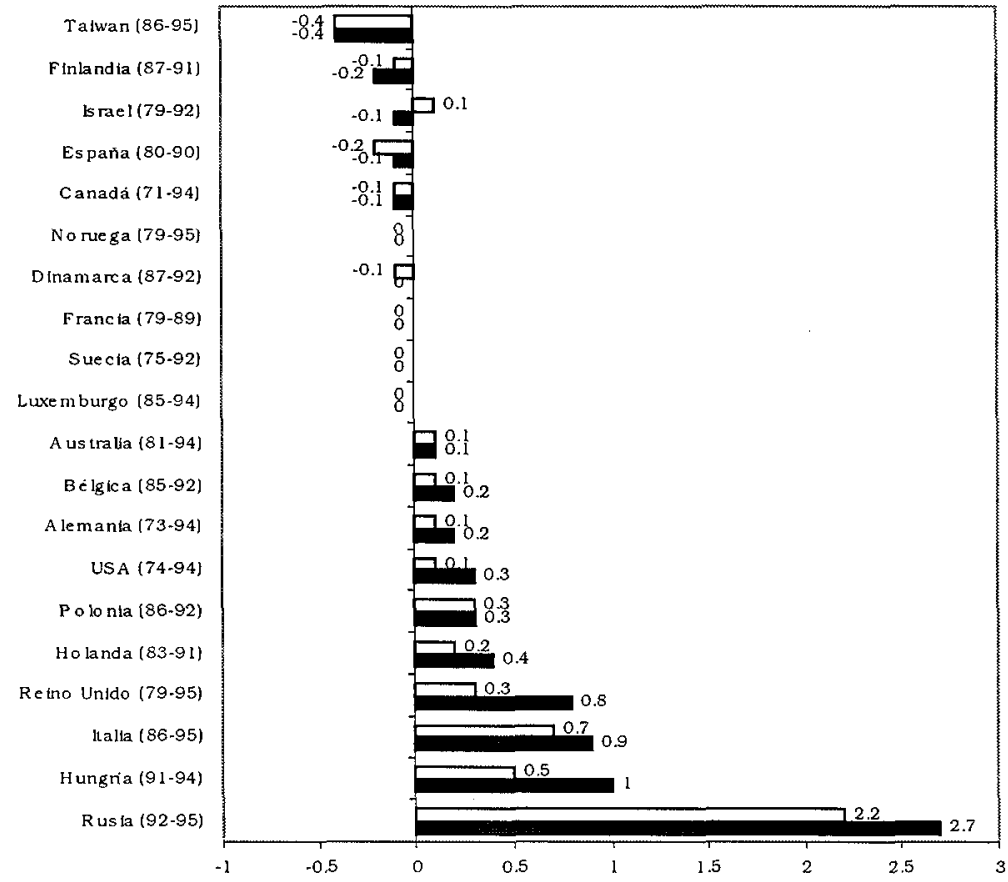

M ediana sobre el to tal $\square$ M edlana so bre los niños 
dependiendo de los criterios de clasificación y de las variables que se utilicen.

La clasificación más sencilla es la que sólo utiliza una variable, por ejemplo, la tasa de pobreza infantil ajustada por la población de niños/ as. Las clasificaciones con más dos variables requieren un tratamiento estadístico especial. Con las variables que se detallan en el Anexo II se establecen tres grupos o conglomerados de países diferentes entre sí. En principio se realiza la agrupación siguiendo un criterio estadístico más laxo al utilizar el análisis de conglomerados jerárquico y establecer el número de grupos y la pertenencia de cada país a cada uno de ellos usando un criterio gráfico, el dendograma.

Figura 3. Análisis de conglomerađos jerárquico. Dendograma*

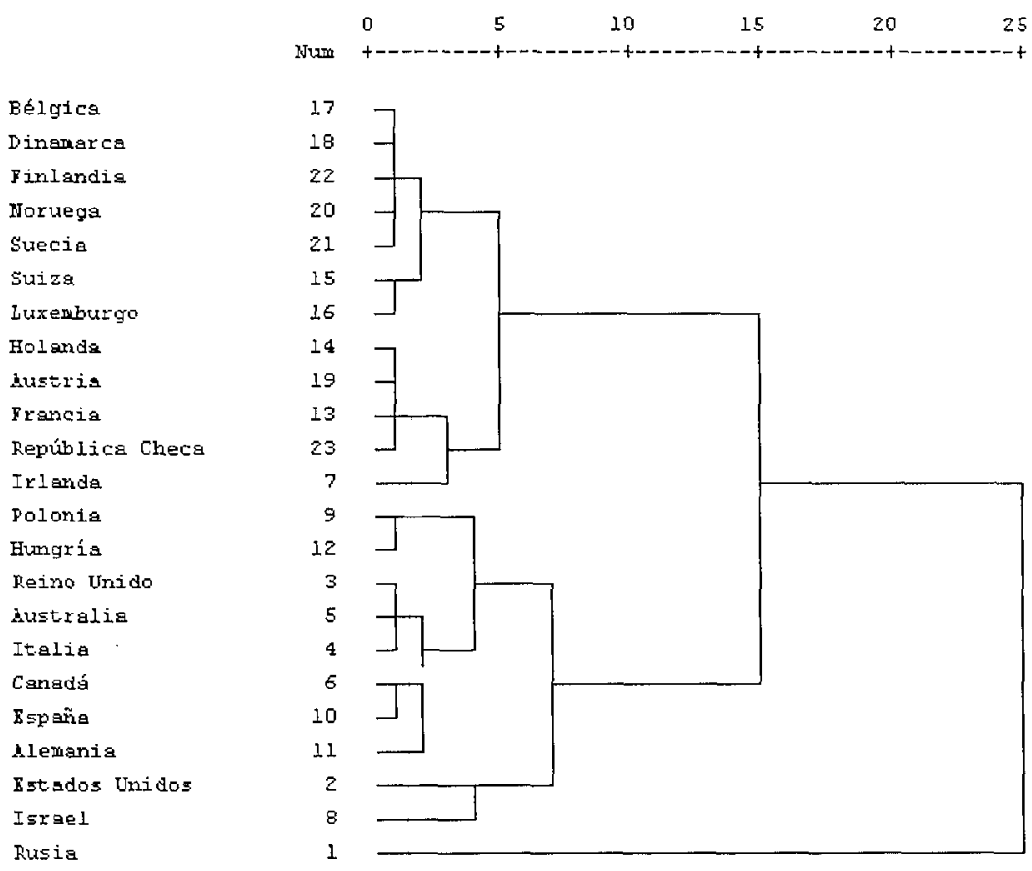

* Quedan excluidas del análisis Holanda y Eslovaquia por falta de datos en algunas de las variables.

Son tres los grupos que se forman. El valor numérico que aparece bajo el indicador "num" señala el orden o posición que sobre la TPI1 tiene cada país. Así, el primer conglomerado lo forman países que entre otras características, tienen bajas tasas de pobreza infantil, mientras que el segundo tendría como elemento básico las tasas de pobreza infantil elevadas. Un tercer conglomerado lo forma Rusia que por sus 
peculiares características no se une en ningún momento con cualquier otro país. De forma intuitiva se puede pensar que hay diferencias importantes entre Polonia y Canadá, ambos en el mismo conglomerado según este análisis. También es curiosa la inclusión de Irlanda y la República Checa en el mismo grupo.

Una forma de intentar corroborar los anteriores resultados consiste en recalcular mediante el análisis de conglomerados k-medias los grupos de pertenencia, forzando el número de conglomerados a tres. Los resultados se muestran en la tabla 5 .

Tabla 5. Pertenencia a nuevos conglomerados y nombres de los grupos.*

\begin{tabular}{|lll|}
\hline $\begin{array}{l}\text { Países industrializados } \\
\text { occidentales (UE, EE.UU) }\end{array}$ & $\begin{array}{l}\text { Países de la } \\
\text { Europa del Este }\end{array}$ & $\begin{array}{l}\text { Caso extremo } \\
\text { incasificable }\end{array}$ \\
\hline Estados Unidos & Polonia & Rusia \\
Reino Unido & Hungría & \\
Italia & República Checa & \\
Australia & Irlanda (**) & \\
Canadá & \\
Israel & \\
España & \\
Alemania & \\
Francia & \\
Holanda & \\
Suiza & \\
Luxemburgo & \\
Bélgica & \\
Dinamarca & \\
Austria & \\
Noruega & \\
Suecia & \\
Finlandia & \\
\hline
\end{tabular}

* Quedan excluidas del análisis Holanda y Eslovaquia por falta de datos en algunas de las variables.

** En términos geopolíticos Irlanda no pertenece a los países de la Europa del Este, sin embargo queda clasificada en este grupo.

Fuente: elaboración propia a partir de datos del LIS. 


\subsection{Modelos de regresión. ¿Qué variables explican la pobreza infantil?}

Se proponen cuatro modelos de regresión lineal múltiple para explicar qué variables están relacionadas con diferentes situaciones de pobreza infantil. Como se verá posteriormente, se acabará trabajando con dos modelos únicamente.

Las variables dependientes, las que se pretenden explicar, en estos modelos son: TPI2 (tasa de pobreza infantil ajustada a esta población), la tasa de pobreza infantil en hogares monoparentales encabezados por una mujer, la tasa de pobreza infantil cuando en el hogar hay una pareja de adultos y la tasa de pobreza infantil cuando en el hogar se dan otras formas diferentes a las anteriores.

Las variables independientes, las que se consideran explicativas, son en todos los casos: la tasa de mortalidad infantil, la tasa de fertilidad en adolescentes, el PIBpc, las variaciones anuales del PIB, la tasa anual de inflación, y los gastos del gobierno central (en porcentaje sobre el total de gastos) en las partidas de Salud, Educación y Defensa (militar). Según los criterios establecidos por los modelos de regresión lineal múltiple, los resultados son los siguientes:

1) para la tasa de pobreza infantil general (TPI2), las variables que mejor explican su comportamiento son $\left(R^{2}=0,725 ; p<0,001\right)$ : con relación positiva (incrementos en una variable implican incrementos en la otra) la tasa de mortalidad infantil ( $\mathrm{p}=0,001)$ y el gasto del gobierno central en defensa $(\mathrm{p}=0,011)$; con relación negativa o inversa, el porcentaje del gasto del gobierno central destinado a educación ( $\mathrm{p}=0,022)$. En otras palabras, la pobreza infantil está relacionada con otro indicador de desarrollo que es la tasa de mortalidad infantil, pero además está condicionada por dos variables que no son económicas en el sentido de producción, si no de distribución: los gastos del Estado central en educación (reduce de manera importante la tasa de pobreza infantil) y los gastos en defensa (militares) que incrementan las tasas de pobreza infantil.

2) La tasa de pobreza infantil en hogares monoparentales encabezados por una mujer varía en función de los siguientes indicadores, todos en relación directa con la variable dependiente, $\left(R^{2}=0^{\prime} 638 ; p<0^{\prime} 001\right)$ : la tasa de fertilidad adolescente $\left(p=0^{\prime} 002\right)$, el PIBpc $\left(\mathrm{p}=0^{\prime} 002\right)$ y el porcentaje de gasto del Estado central en salud $\left(\mathrm{p}=0^{\prime} 008\right)$.

Los resultados anteriores podrían inducir una interpretación errónea. Si bien es claro que teóricamente la tasa de fertilidad ado- 
lescente está ligada a los hogares con pobreza infantil, no está tan claro que el gasto del gobierno en salud tenga una relación positiva con las tasas de pobreza, ni mucho menos que un incremento en el PIBpc revierta incrementando a su vez la pobreza infantil. Lo que sucede en este caso es que desde una perspectiva de género, la pobreza, infantil o no, se explica en otros términos, con otras variables, o mejor dicho, con variables similares pero con signo diferente a la norma general.

3) La tasa de pobreza infantil cuando en el hogar hay dos adultos es explicada casi en su totalidad, aún con un ajuste global del modelo algo bajo $\left(\mathrm{R}^{2}=0,388 ; \mathrm{p}=0,002\right)$, por la tasa de mortalidad infantil $(\mathrm{p}=0,002)$.

4) Por último, señalar que la tasa de pobreza infantil cuando el tipo de familia es cualquier otro a los señalados anteriormente, es explicada $\left(\mathrm{R}^{2}=0,417 ; \mathrm{p}=0,001\right)$ por una única variable, la tasa de fertilidad adolescente $(\mathrm{p}=0,001)$.

Dada la composición de los modelos propuestos, se ha optado por destacar el primero y el segundo como aquéllos que mayor poder explicativo tienen a la hora de realizar un análisis comparado. Mientras que el primero muestra la estructura de la pobreza infantil en términos generales, el segundo incorpora las variables que explicarían la pobreza infantil desde la perspectiva de género.

El resultado general de los modelos de regresión y su expresión gráfica se presenta en la Figura 4.

\section{DISCUSIÓN DE LOS RESULTADOS. LO PÚBLICO Y LA PERSPECTIVA DE GÉNERO.}

La pobreza infantil no es una cuestión que se pueda resumir mediante el estudio de rentas en el hogar. Diferentes trabajos muestran que la relación entre el ingreso familiar y el desarrollo cognitivo y social de los/as niños/as no es tan lineal como se podría pensar (Blau, 1999:262). El papel de las políticas sociales más generales (que incluyen los programas de transferencias y de impuestos), la educación y la salud pública y la formación de capital humano infantil son elementos que no conviene descuidar y que son difícilmente medibles.

Si las políticas sociales (o en el caso de este trabajo, las partidas de gasto público del gobierno central) son cuestiones centrales para entender los procesos de empobrecimiento infantil, la perspectiva de género ofrece un marco analítico complementario. Como demuestran los modelos de regresión, hay diferencias significativas en las variables que 
Figura 4. Modelos de regresión lineal múltiple.

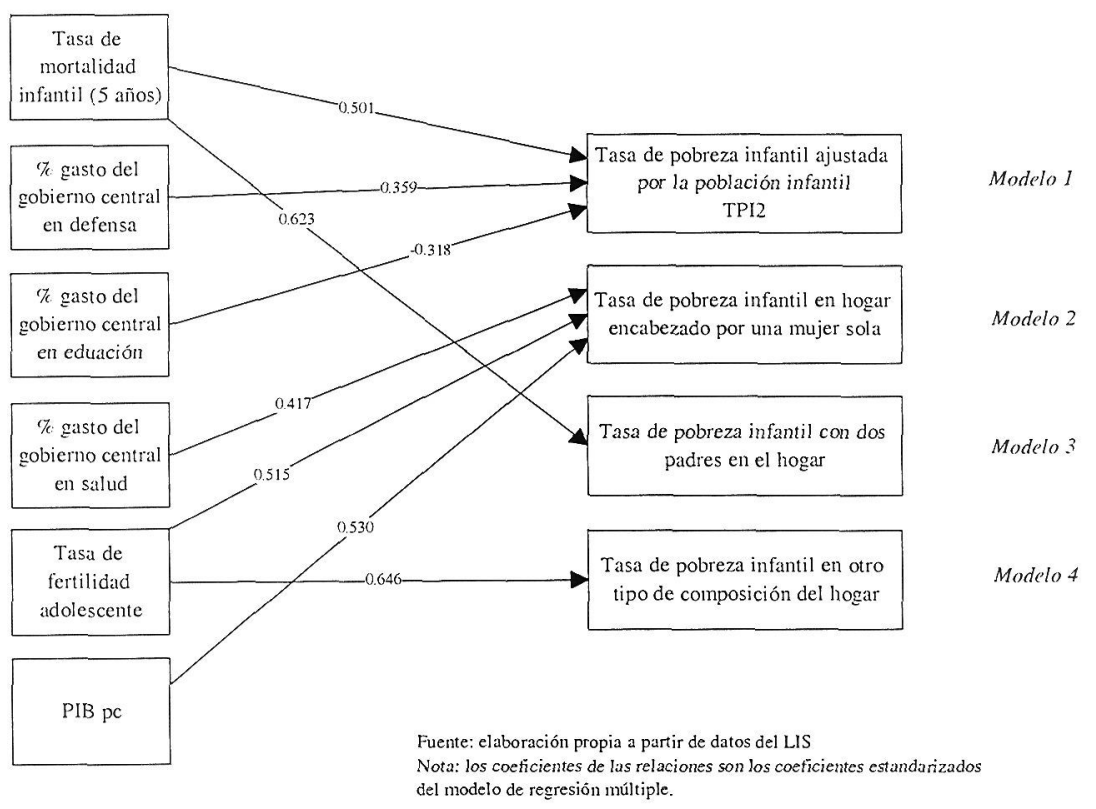

explican la pobreza infantil en hogares monoparentales encabezados por mujer y el resto. El incremento de rentas general (PIBpc) no implica una mejora en la situación de empobrecimiento de los niños/as que viven en hogares encabezados por una mujer sola. Quizá lo más llamativo sea que las políticas encaminadas a la mejora de la salud tengan un efecto contrario al esperado en las familias monoparentales encabezadas por mujeres. Esto no se ha considerado como un error en los cálculos sino como una evidencia más de lo alejados que están los supuestos mecanismos de redistribución estatales de entender y atajar el problema de la pobreza infantil.

La ayuda infantil que reciben por parte del Estado los niños/as tiene diferentes implicaciones dependiendo del país que se trate. Un ejemplo de esto lo observamos si se compara la ayuda infantil según el tipo de familia y el grupo de ingreso al que pertenezca para tres países: Italia (1995), Suecia (1992) y Reino Unido (1995). Se toma la elaboración realizada por Cristina Solera (1998). 
Tabla 6. Ayuda infantil según el tipo de familia y el grupo de ingreso al que pertenecen. Italia, Reino Unido y Suecia.

\begin{tabular}{|c|c|c|c|c|c|c|}
\hline & \multicolumn{2}{|c|}{ Italia, 1995} & \multicolumn{2}{|c|}{ RènoUnido, 1995} & \multicolumn{2}{|c|}{ Suecia, 1992} \\
\hline & Dos adultos & Unadulto & Dos adultos & Un adulto & Dos adulos & Un adulto \\
\hline \multicolumn{7}{|l|}{ Familias pobres* } \\
\hline$\%$ de receptores & 2,4 & 21,1 & 1,7 & 15,8 & 5,1 & 79,3 \\
\hline como \% de su Renta neta disponible & 81,0 & 83,0 & 15,3 & 27,9 & 16,6 & 21,2 \\
\hline como \% de la mediana del país & 13,9 & 26,7 & 4,7 & 8,6 & 5,3 & 11,0 \\
\hline \multicolumn{7}{|l|}{ Familias casi pobres* } \\
\hline$\%$ de receptores & - & 58,9 & 2,8 & 28,6 & 7,4 & 88,2 \\
\hline como \% de su Renta neta disponible & - & 83,0 & 7,9 & 29,7 & 10,2 & 17,8 \\
\hline como $\%$ de la mediana del país & - & 40,4 & 3,8 & 14,5 & 5,6 & 9,5 \\
\hline \multicolumn{7}{|l|}{ Familias medias* } \\
\hline To de receptores & 0,4 & 16,6 & 3,1 & 29,4 & 9,3 & 86,5 \\
\hline conno \% de su Renta neta disponible & 10,6 & 29,7 & 8,3 & 21,5 & 6,2 & 11,9 \\
\hline como $\%$ de la mediana del país & 7,8 & 24,4 & 6,8 & 16,8 & 6,0 & 9,4 \\
\hline \multicolumn{7}{|l|}{ Todas las Familias } \\
\hline$\%$ de receptores & 0,7 & 22,0 & 2,9 & 21,7 & 9,0 & 85,4 \\
\hline como \% de su Renta neta disponible & 36,3 & 58,3 & 8,3 & 25,8 & 6,2 & 13,0 \\
\hline como $\%$ de la mediana del país & 13,9 & 26,8 & 6,9 & 13,4 & 6,0 & 9,5 \\
\hline
\end{tabular}

* familias pobres son las que tienen una renta neta disponible menor que el $50 \%$ de la mediana; familias casi pobres son las que tienen una renta neta disponible cntre el [50\%$62,5 \%]$ de la mediana; familias medias son las que tienen una renta neta disponible entre el [62,5\%-150\%] de la mediana.

Fuente: tomado de Solera,1998 y elaboración propia.

En la tabla anterior se describen dos formas diferentes de entender la ayuda del Estado a los hogares con hijos. Mientras que en Suecia un $85,4 \%$ de los hogares monoparentales recibía ayudas a los niños independientemente del grupo de ingreso al que perteneciese, en Italia y Reino Unido apenas se supera el 20\%. Quizá un caso extremo en la comparación sea el porcentaje que suponen las ayudas estatales sobre el total de las rentas netas disponibles de cada hogar en los hogares más pobres. En Italia este porcentaje es del 83\% (para hogares monoparentales), en el Reino Unido se reduce prácticamente al $28 \%$ y en Suecia se estima en un $21,2 \%$. Esto significa que las ayudas a los niños en Italia prácticamente componen el total de la renta neta disponible de los hogares pobres monoparentales, mientras que en Suecia el monto total de las ayudas a los niños es un quinto de la renta de los hogares en esa situación. Estos datos señalan que mientras que la ayuda a los niños en Suecia es, efectivamente, un apoyo a los niños, en Italia se convierte en el sustento del hogar. En Suecia y Reino Unido las 
transferencias sociales destinadas a la familia siguen cauces diferentes a Italia.

Hay que señalar, en otro orden de cosas, que la perspectiva de género ha estado ausente durante mucho tiempo en los análisis de los procesos de empobrecimiento. Aunque sus bases teóricas están desarrolladas suficientemente, queda por realizar toda la parte metodológica y técnica, operativización, recogida de datos y medición, análisis y diseños de políticas en función de estos nuevos datos.

Se ha utilizado la variable sexo para realizar análisis parciales de encuestas y datos estadísticos pensando que la división hombre/mujer era suficiente para entender la dimensión de género. La llamada "feminización de la pobreza" (Marcoux, 1998; López, 1989; Pressman, 1988) ha resumido en una tabla de dos columnas, dígitos obtenidos con instrumentos pensados para recoger otra información. Estadísticas que han sido realizadas bajo conceptos masculinos de empobrecimiento, y que, a través de artificios estadísticos, han dado lugar a submuestras en grupos de diferente sexo.

La información que aportan estos estudios, que es mucha y útil en términos de acopio de información (Buvinic, 1998), tendría que ser matizada por otros elementos de partida, en los que se mostrara la relación entre los procesos de empobrecimiento o de desarrollo y el género (Jackson, 1996 y 1998; Kabeer, 1996; Razavi, 1997) y, en particular, la vinculación entre bienestar de la mujer y bienestar colectivo (Andersen y Larsen, 1998). En esta última línea, es indudable que mejoras en la situación de la mujer reducirían los niveles de pobreza infantil de una forma más eficaz.

La búsqueda de indicadores sintéticos en los que aparezca información desde la perspectiva de género ex novo ha llevado al PNUD a diseñar los índices de potenciación de la mujer en 1995 y más tarde el índice de potenciación de género (en 1997 y siguientes). El último es el más conocido y reproducido a otras escalas (Villota, 1997) y aunque incluye elementos nuevos que lo acercan al enfoque de género y desarrollo, excluye algunos aspectos claves que tienen que ver con la distribución de las rentas en el interior de la familia (Daviest y Joshi, 1998; Fritzell, 1999) -que es desigual, todo sea dicho- o con las diferencias de género en las trasferencias sociales.

\section{CONCLUSIONES}

En un periodo de diez años la Unión Europea ha visto incrementar sus tasas de pobreza infantil entre dos y tres puntos. En la década de 
los ochenta la media en las tasas de pobreza infantil de los países que formaban entonces la $\mathrm{UE}^{8}$, era del $10,5 \%$, mientras que para esos mismos países en la década de los noventa la media de tasas ascendía al $13,5 \%$.

Ya en la década de los noventa y con la integración de los países de la Europa del Este y de Rusia (antigua URSS) en las economías de mercado, es posible estudiar las situaciones de empobrecimiento infantil en términos comparados. La base de datos del Luxembourg Income Study ofrece esa posibilidad, incluyendo diferentes elementos y formas de medir la pobreza infantil de gran aplicabilidad. Que se opte por una forma u otra de medición es, muchas veces, una elección ideológica.

En este trabajo se han presentado los datos sobre pobreza infantil para veinticinco países industrializados, quedando demostrada la existencia de tres grupos claramente diferenciados entre estos países. Los países de la Europa del Este y Rusia forman parte del grupo con hogares más pobres (si se toma el criterio la línea de pobreza de los Estados Unidos para 1995), mientras que el resto tendría las pautas de los países industrializados capitalistas. Este ejercicio clasificatorio, meramente descriptivo, hace que reflexionemos sobre las unidades de análisis (Estados) y cómo se miden (o no se miden) determinados aspectos de la realidad social.

Pero quizá lo más importante de este trabajo sea la lectura en clave de género y políticas sociales de apoyo a la infancia que se desprende de las variables que están relacionadas con la pobreza infantil tomando el conjunto de los hogares y la pobreza infantil tomando como referencia los hogares monoparentales encabezados por una mujer. Ni el mercado por sí mismo, ejemplificado en el producto interior bruto per cápita, ni el Estado del Bienestar (tan revisado, tan en voluble, tan inexistente en muchos países que se han estudiado) consiguen reducir la pobreza infantil cuando en los hogares viven niños/as con sus madres.

Es el momento para pensar que la pobreza infantil y los procesos de exclusión de las niñas y de los niños son el anticipo de cómo serán de pobres nuestras sociedades industrializadas.

s Los cálculos se han realizado con datos del LIS y reclaborados por parte de Bradbury y Jäntti, 1999. Los países incluidos son: Bélgica, Dinamarca, Finlandia, Alemania, Italia, Holanda, Luxemburgo, Suecia y Reino Unido. Para la década de los 90 se incluyen en los cálculos España y Francia. La tasa de pobreza infantil se corresponde con la TPI2. La escala de equivalencia aplicada es

$\mathrm{E} . \mathrm{E}=[\text { Adultos }+(0.5 * \text { niños/as })]^{0.85}$ 


\section{BIBLIOGRAFÍA}

ANDERSEN, J.; LARSEN, J. (1998): «Gender, poverty and empowerment» Critical Social Policy, 18, 2, p. 241-258.

ATKINSON, A.B.; RAINWATER, L.; SMEEDING, T. (1995): «Income distribution in OECD countries», Social Policy Studies, $n^{\circ} 8$, París, OECD.

BLAU, D.M. (1999): «The effect of income on child development», The review of Economics and Statistics, vol. 81, $\mathrm{n}^{\circ} 2, \mathrm{p} .261-276$.

BM (1999): World Development Report 1999/2000, Oxford University Press, New York.

BOSCH, A.; ESCRIBANO, S.; SÁNCHEZ, I. (1989): Evolución de la desigualdad y la pobreza en España, INE, Madrid.

BRADBURY, B.; JÄNTTI, M. (1999): «Child-poverty across the Industrialized World: evidence from the Luxembourg Income Study», Mimeo, Documentación del congreso Child Well-Being, Luxembourg, 1999.

BUVINIC, M. (1998): «Women in poverty: a new underclass», Population and development review, 24, 1, p. 131-139.

DANZINGER, S.; SMEEDING, T.; RAINWATER, L. (1995): «The Western Welfare State in the 1990's: Towards a new model of antipoverty policy for families with children», Luxembourg Income Study Working Paper, $\mathrm{n}^{\circ} 128$.

DAVIEST, H.; JOSHI, H. (1998): "Gender and income inequality in the UK 19681990: the feminization of earnings or of poverty", en Journal of Royal Statistical Society. Series A, vol. 161, n 1, pp. 33-61.

DUCLOS, J.; MERCADER-PRATS, M. (1999): «Household needs and poverty: with application to Spain and the UK», The review of Income and Wealth, marzo.

FÖRSTER, M.F. (1993): «Comparing poverty in 13 OECD countries. Traditional and synthetic approaches», Luxembourg Income Study Working Paper, $\mathrm{n}^{\circ}$ 100.

FORSSÉN, K. (1998): «Child poverty and family policy in OECD countries», Luxembourg Income Study Working Paper, $n^{\circ} 178$.

FRITZELL, J. (1998): «Incorporating gender inequality into income distribution research», International Journal of Social Welfare, 8, p. 56-66.

GAUTHIER, A.H. (1996): A comparative analysis of family policies in Industrialized Countries, Clarendon Press, Oxford.

HAGENAARS, A.; DE VOS, K.; ZAIDI, M.A. (1994): Poverty statistics in the late 1980's: research based on microdata. Luxemburgo, Oficina de publicaciones oficiales de la Unión Europea.

HAUSER, R.; BROWN, B.; PROSSER, W.R (1997): Indicators of Childrens's Well-Being, Russell Sage Fundation, New York.

HEYMANN, J. (2000): «What happens during and after school: conditions faced by working parents living in poverty and their school-aged children», 
Journal of Children and Poverty, Vol. 6, $\mathrm{n}^{\circ} 1, \mathrm{p} .5-20$.

I.N.E. (1996): Encuesta de Presupuestos Familiares. Desigualdad y pobreza en España, Instituto Nacional de Estadística, Madrid.

JACKSON, C. (1996): "Rescuing Gender from the Poverty Trap", World Development, vol. 24, n³, pp. 489-504.

JACKSON, C. (1998): "Women and poverty or Gender and Well-being", Journal of International Affairs, 52,1, pp. 67-81.

JENKINS, S., COWELL, F. (1994): «Parametric equivalence scales and scale relativities», Economic Journal, n²104, p. 891-900.

KABEER, N. (1996): «Agency, well-being and inequality. Reflections on the gender dimensions of poverty», IDS Bulletin, vol. $27, \mathrm{n}^{\circ} 1$.

LÓPEZ LARREA, M. (1989): «La feminización de la pobreza», Cuadernos de Acción Social, 14, p. 51-55.

MARCOUX, A. (1998): «The feminization of poverty: claims, facts and data needs», Population and development review, vol 24, $\mathrm{n}^{\circ} \mathrm{1}, \mathrm{p} .131-139$.

MERCADER-PRATS, M. (1998): «Identifying low standars of living: evidence from Spain», Research on Economic Inequality, n'8, p. 155-176.

MOISIO, P. (2000): The risk of social exclusion in the EU, IRISS-C/I Working Paper $n^{\circ} 9$.

PRESSMAN, S. (1988): «The feminization of poverty: causes and remedies», Challenge, 31, 2, p. 57-61.

RAZAVI, S. (1997): "Fitting Gender into Development Institutions", en World Development, vol. 25, n⿳0, pp. 1111-1125.

RUIZ-CASTILLO, J. (1987): La medición de la pobreza y la desigualdad en España, 1980-1981, Madrid, Banco de España.

RUIZ-CASTILLO, J.; DEL RÍO, C. (1997): TIPs for poverty analysis. The case of Spain, 1980-81 to 1990-91, Universidad Carlos III de Madrid (Working Papers).

RUIZ-HUERTA, J.; MARTÍNEZ, R. (1994): «La pobreza en España: ¿Qué nos muestran las EPF?» en Documentación Social, nº 96, p.15-110.

SMEEDING, T.; SCHMAUS, G.; ALLEGREZA, S. (1985): An introduction to $L I S$, Luxembourg Income Study Working Paper, $\mathrm{n}^{\circ} 1$.

SMEEDING, T. (1997): "Financial Poverty in Developed Countries: The Evidence from the Luxembourg Income Study", Human Development Papers, Human Development Report Office, The United Nations Development Programme, New York.

SOLERA, C. (1998): "Income transfers and Support for Mother's Employment: The Link to Family Poverty Risks: A Comparison Between Italy, Sweden and the UK". Luxembourg Income Study Working Paper, $\mathrm{n}^{\circ} 192$.

TOMBEUR, C. (1998): «LIS/LES information guide», Luxembourg Income Study Working Papers, $n^{\circ} 17$.

UNICEF (2000): The state of the World's Children 2000, Unicef, New York. 


\section{ANEXO 1. TABLAS. CORRELACIONES DE PEARSON}

Tasas de pobreza infantil con diferentes ajustes y tipos de familia

\begin{tabular}{|c|c|c|c|c|c|c|c|}
\hline & & $\begin{array}{l}\text { Tasa de pobreza } \\
\text { infentil SO\% del } \\
\text { total (mediana) }\end{array}$ & $\begin{array}{c}\text { Tasa de pohreza } \\
\text { intüntil so\% de } \\
\text { los nin̄os } \\
\text { (mediana) }\end{array}$ & $\begin{array}{c}\text { Tasa de } \\
\text { pobreza } \\
\text { infontil Linea } \\
\text { de pobreza de } \\
\text { USA }\end{array}$ & $\begin{array}{c}\text { Tasa de } \\
\text { pobreza infanti } \\
\text { Madre sola }\end{array}$ & $\begin{array}{c}\text { Tasa de pobreza } \\
\text { infantil Dos } \\
\text { padres }\end{array}$ & $\begin{array}{l}\text { Tasa de pobrezat } \\
\text { infantil Otras } \\
\text { ramilias }\end{array}$ \\
\hline $\begin{array}{l}\text { Tasa de pobreza intintit } \\
\text { so\% del total (mediana) }\end{array}$ & $\begin{array}{l}\text { Cortelucion de Peursor } \\
\text { Sig. (bilateral) } \\
\mathrm{N}\end{array}$ & & & & & & \\
\hline $\begin{array}{l}\text { Tusa de potrcza infantil } \\
50 \% \text { de los ninos (mediana) }\end{array}$ & $\begin{array}{l}\text { Conelación de l'earsor. } \\
\text { Sig. (bilaterd) } \\
\mathrm{N}\end{array}$ & $\begin{array}{l}.943^{* *} \\
.000 \\
25\end{array}$ & & & & & \\
\hline $\begin{array}{l}\text { Tusa de pobreza infintil } \\
\text { Linea de pobreza de USA }\end{array}$ & $\begin{array}{l}\text { Correlación de learsor. } \\
\text { Sig (bjuteral) } \\
\mathrm{N}\end{array}$ & $\begin{array}{r}.253 \\
.222 \\
25\end{array}$ & $\begin{array}{r}.364 \\
.074 \\
25\end{array}$ & & & & \\
\hline $\begin{array}{l}\text { Tasa de pobrezn intandi } \\
\text { Madre sola }\end{array}$ & $\begin{array}{l}\text { Correlación de Pearsor. } \\
\text { Sig. (bilaterul) } \\
\text { N }\end{array}$ & $\begin{array}{l}.666^{* 2} \\
.000 \\
25\end{array}$ & $\begin{array}{l}.504^{*} \\
.010 \\
25\end{array}$ & $\begin{array}{r}., 227 \\
.276 \\
25\end{array}$ & & & \\
\hline $\begin{array}{l}\text { Tasa de pobreztu inlantil } \\
\text { Dos padres }\end{array}$ & $\begin{array}{l}\text { Correlación de Pearsor } \\
\text { Sig. (tifateral) } \\
\mathrm{N}\end{array}$ & $\begin{array}{l}958^{* \prime} \\
000 \\
25\end{array}$ & $\begin{array}{l}.924^{* 1} \\
.000 \\
25\end{array}$ & $\begin{array}{r}.376 \\
.064 \\
25\end{array}$ & $\begin{array}{c}.490^{*} \\
.013 \\
25\end{array}$ & & \\
\hline $\begin{array}{l}\text { Tasa de pobreza inf antil } \\
\text { Otras familias }\end{array}$ & $\begin{array}{l}\text { Cortelación de Pearsor. } \\
\text { Sig (bilatern) } \\
N\end{array}$ & $\begin{array}{l}.912^{* *} \\
.000 \\
25\end{array}$ & $\begin{array}{l}.920^{* 1} \\
.000 \\
35 \\
\end{array}$ & $\begin{array}{r}.275 \\
.184 \\
.25 \\
\end{array}$ & $\begin{array}{l}.519 * * \\
.008 \\
25\end{array}$ & $\begin{array}{l}.855^{* 1} \\
.000 \\
25 \\
\end{array}$ & \\
\hline
\end{tabular}

Variables económicas y de gasto social de los gobiernos centrales

\begin{tabular}{|c|c|c|c|c|c|c|c|}
\hline & & $\begin{array}{l}\text { PiB real pe (\$ } \\
\text { USA. 1995) }\end{array}$ & $\begin{array}{l}\text { Variaciones del } \\
\text { PIB Pc anuales } \\
\text { (\%) 1990-1997 }\end{array}$ & $\begin{array}{l}\text { Tass anual de } \\
\text { inflación \% } \\
\text { (1990-1997) } \\
\end{array}$ & $\begin{array}{c}\text { \% del gasto del } \\
\text { gobiemo centrol } \\
\text { en Salud }\end{array}$ & $\begin{array}{c}\text { 7e del gasto del } \\
\text { gobierno central } \\
\text { en educación }\end{array}$ & $\begin{array}{l}\text { \% del gasto del } \\
\text { gobiemo centual } \\
\text { en defensia } \\
\text { (militur) }\end{array}$ \\
\hline PlB real jx (S USA. 1W95) & $\begin{array}{l}\text { Correlikión de Pearson } \\
\text { Sig (bilateral) } \\
\mathrm{N}\end{array}$ & & & & & & \\
\hline $\begin{array}{l}\text { Variaciones del PIB pC } \\
\text { anuiles (\%) I990-1997 }\end{array}$ & $\begin{array}{l}\text { Conrelición de Pearson } \\
\text { Sig. (bilateral) } \\
\mathrm{N}\end{array}$ & $\begin{array}{r}.240 \\
.260 \\
24 \\
\end{array}$ & & & & & \\
\hline $\begin{array}{l}\text { Tasia antal de intlación rs } \\
\text { (1990-1997) }\end{array}$ & $\begin{array}{l}\text { Correlación de Pearson } \\
\text { Sig̨. (bilateral) } \\
\text { N }\end{array}$ & $\begin{array}{c}-.492^{*} \\
.015 \\
24\end{array}$ & $\begin{array}{c}.787^{\circ 0} \\
.000 \\
24\end{array}$ & & & & \\
\hline $\begin{array}{l}\text { F del gakto del gobiemo } \\
\text { central en S:alud }\end{array}$ & $\begin{array}{l}\text { Conclición de Pearxon } \\
\text { Sig. (bilateral) } \\
\text { N }\end{array}$ & $\begin{array}{r}-.050 \\
.820 \\
23\end{array}$ & $\begin{array}{r}.314 \\
.145 \\
23\end{array}$ & $\begin{array}{r}-.274 \\
.282 \\
23\end{array}$ & & & \\
\hline $\begin{array}{l}\text { Fe del gasto del gobietrio } \\
\text { ontral en educacion }\end{array}$ & $\begin{array}{l}\text { Cortelitción de Pearson } \\
\text { Sig. (bilateral) } \\
\text { N }\end{array}$ & $\begin{array}{r}.140 \\
525 \\
23\end{array}$ & $\begin{array}{r}412 \\
.051 \\
23\end{array}$ & $\begin{array}{r}. .310 \\
.150 \\
23\end{array}$ & $\begin{array}{r}.046 \\
.833 \\
23\end{array}$ & & \\
\hline $\begin{array}{l}\text { "zel dequsto del gobiefno } \\
\text { centual en defensa (militur) }\end{array}$ & $\begin{array}{l}\text { Cortelición de Pearson } \\
\text { Sig. (bilateral) } \\
\text { N }\end{array}$ & $\begin{array}{r}-.021 \\
.926 \\
.23 \\
\end{array}$ & $\begin{array}{r}. .170 \\
.438 \\
23 \\
\end{array}$ & $\begin{array}{r}.303 \\
.160 \\
.23 \\
\end{array}$ & $\begin{array}{r}316 \\
.141 \\
23 \\
\end{array}$ & $\begin{array}{r}.110 \\
.619 \\
23 \\
\end{array}$ & \\
\hline
\end{tabular}

Variables demográficas incluidas en los análisis

\begin{tabular}{|c|c|c|c|c|c|}
\hline & & $\begin{array}{l}\text { Nümero de } \\
\text { riños menors } \\
\text { de } 18 \text { años } \\
\text { (millones) }\end{array}$ & $\begin{array}{l}\text { nifios como } \% \\
\text { de la población }\end{array}$ & $\begin{array}{c}\text { Tasa de } \\
\text { moralidad } \\
\text { intantil (-S } \\
\text { años) por cada } \\
1000 \text { nacidos }\end{array}$ & $\begin{array}{c}\text { Tasa de } \\
\text { terrilidad } \\
\text { adolescente } \\
\text { (nacidos por } \\
\text { cade 1000) }\end{array}$ \\
\hline $\begin{array}{l}\text { Número de nifios mencrs de } \\
\text { is anios (millones }\end{array}$ & $\begin{array}{l}\text { Comelación de Pearsc } \\
\text { Sig. (biluteral) } \\
\mathrm{N}\end{array}$ & & & & \\
\hline niños como क de la poblaci & $\begin{array}{l}\text { Corelación de Pearsc } \\
\text { Sig. (bilateral) } \\
\mathrm{N}\end{array}$ & $\begin{array}{r}.101 \\
.630 \\
25 \\
\end{array}$ & & & \\
\hline $\begin{array}{l}\text { Tasia de mortalidad infantil } \\
\text { ( }-5 \text { años) por cada } 9000 \\
\text { nacidos }\end{array}$ & $\begin{array}{l}\text { Correlación de Pearsc } \\
\text { Sig. (bilateral) } \\
\mathrm{N}\end{array}$ & $\begin{array}{r}.380 \\
.067 \\
24\end{array}$ & $\begin{array}{r}.321 \\
.126 \\
24\end{array}$ & & \\
\hline $\begin{array}{l}\text { Tasa de lemilidad adolescer } \\
\text { (nacidos por cada 1000) }\end{array}$ & $\begin{array}{l}\text { Correlación de Pearsc } \\
\text { Sig. (bilateral) } \\
\mathrm{N}\end{array}$ & $\begin{array}{r}.730^{* *} \\
.000 \\
25 \\
\end{array}$ & $\begin{array}{r}.380 \\
.061 \\
.25 \\
\end{array}$ & $\begin{array}{r}.636^{*} \\
.001 \\
24 \\
\end{array}$ & \\
\hline
\end{tabular}

**. $\mathrm{P}<0.01$ (bilateral). 


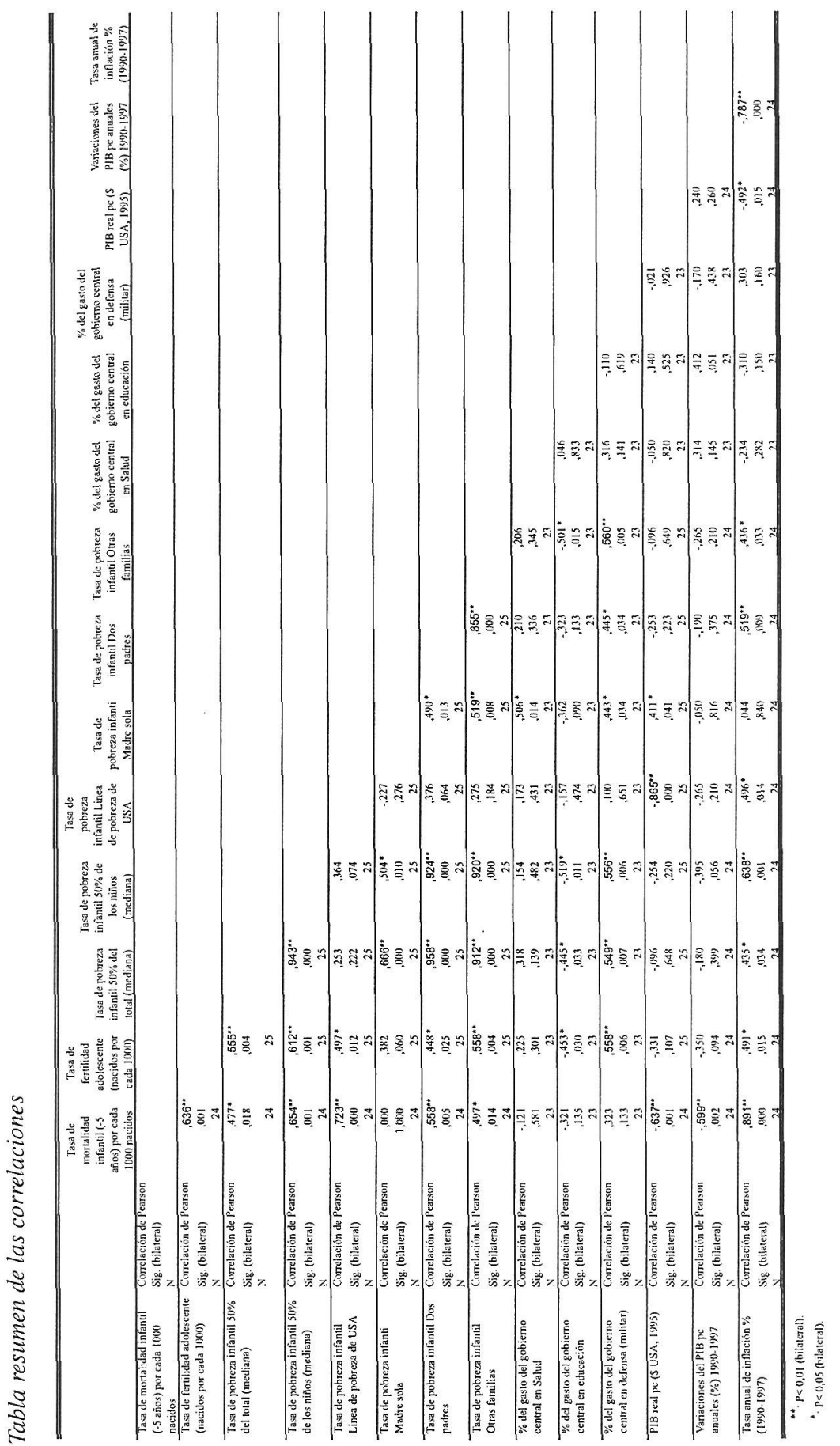




\section{ANEXO 2. ELEMENTOS TÉCNICOS DEL ANÁLISIS DE CON- GLOMERADOS}

\section{1) Análisis de conglomerados jerárquicos (Hierarchical cluster analysis)}

\section{Variables utilizadas}

tasa de mortalidad infantil (5 años)

TPI2

Tasa pobreza infantil en los hogares encabezados por una mujer Tasa de pobreza infantil con otra composición del hogar

$\%$ gasto del gobierno central destinado a educación

Variación anual PIB pc

\section{TPI 1}

TPIUSA

Tasa de pobreza infantil en hogares con los dos padres

\% gasto del gobierno central destinado a salud

$\%$ gasto del gobierno central destinado a defensa (gasto militar)

Variación anual de la tasa de inflación

\section{Consideraciones del modelo}

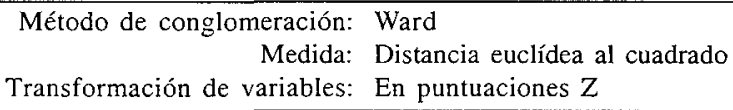

Medida: Distancia euclídea al cuadrado

Transformación de variables: En puntuaciones $Z$

\section{2) Análisis de conglomerados K-Medias}

\section{Variables utilizadas}

tasa de mortalidad infantil (5 años) TPI2

Tasa pobreza infantil en los hogares encabezados por una mujer Tasa de pobreza infantil con otra composición del hogar

$\%$ gasto del gobierno central destinado a educación

Variación anual PIB pc

\section{TPII}

TPIUSA

Tasa de pobreza infantil en hogares con los dos padres

$\%$ gasto del gobierno central destinado a salud

$\%$ gasto del gobierno central destinado a defensa (gasto militar)

Variación anual de la tasa de inflación

\section{Consideraciones del modelo}

Método: Iteración (máx. 10) y clasificación 
Tabla ANOVA del análisis de conglomerados $k$-medias

\begin{tabular}{|c|c|c|c|c|c|c|}
\hline & \multicolumn{2}{|c|}{ Conglomerado } & \multicolumn{2}{|c|}{ Error } & \multirow[b]{2}{*}{$\mathrm{F}$} & \multirow[b]{2}{*}{ Sig. } \\
\hline & $\begin{array}{c}\text { Media } \\
\text { cuadrática }\end{array}$ & $\mathrm{gl}$ & $\begin{array}{c}\text { Media } \\
\text { cuadrática }\end{array}$ & gl & & \\
\hline $\begin{array}{l}\text { Tasa de mortalidad infantil } \\
\text { ( }-5 \text { años) por cada } 1000 \\
\text { nacidos }\end{array}$ & 179.879 & 2 & 3.256 & 20 & 55.253 & .000 \\
\hline $\begin{array}{l}\text { Tasa de pobreza infantil } 50 \% \\
\text { del total (mediana) }\end{array}$ & 115.912 & 2 & 45.900 & 20 & 2.525 & .105 \\
\hline $\begin{array}{l}\text { Tasa de pobreza infanti } 50 \% \\
\text { de los niños (mediana) }\end{array}$ & 154.172 & 2 & 21.844 & 20 & 7.058 & .005 \\
\hline $\begin{array}{l}\text { Tasa de pobreza infantil } \\
\text { Linea de pobreza de USA }\end{array}$ & 9284.191 & 2 & 238.059 & 20 & 39.000 & .000 \\
\hline $\begin{array}{l}\text { Tasa de pobreza infanti } \\
\text { Madre sola }\end{array}$ & 291.358 & 2 & 209.385 & 20 & 1.391 & .272 \\
\hline $\begin{array}{l}\text { Tasa de pobreza infantil Dos } \\
\text { padres }\end{array}$ & 134.616 & 2 & 34.294 & 20 & 3.925 & .036 \\
\hline $\begin{array}{l}\text { Tasa de pobreza infantil } \\
\text { Otras familias }\end{array}$ & 127.380 & 2 & 55.823 & 20 & 2.282 & .128 \\
\hline $\begin{array}{l}\text { \% del gasto del gobierno } \\
\text { central en Salud }\end{array}$ & 45.109 & 2 & 39.785 & 20 & 1.134 & .342 \\
\hline $\begin{array}{l}\text { \% del gasto del gobiemo } \\
\text { central en educación }\end{array}$ & 14.847 & 2 & 13.781 & 20 & 1.077 & .359 \\
\hline $\begin{array}{l}\% \text { del gasto del gobierno } \\
\text { central en defensa (militar) }\end{array}$ & 31.173 & 2 & 15.731 & 20 & 1.982 & .164 \\
\hline $\begin{array}{l}\text { Variaciones del PIB pc } \\
\text { anuales }(\%) \quad 1990-1997\end{array}$ & 44.669 & 2 & $2.18 \mathrm{I}$ & 20 & 20.482 & .000 \\
\hline $\begin{array}{l}\text { Tasa anual de inflación \% } \\
\text { (1990-1997) }\end{array}$ & 41487.397 & 2 & 25.547 & 20 & 1623.949 & .000 \\
\hline
\end{tabular}

Las pruebas $F$ sólo se deben utilizar con una finalidad descriptiva puesto que los conglomerados han sido elegidos para maximizar las diferencias entre los casos en diferentes conglomerados. Los niveles críticos no son corregidos, por lo que pueden interpretarse como pruebas de la hipótesis de que los centros de los conglomerados son iguales. 


\section{ANEXO 2. ELEMENTOS TÉCNICOS Y PRINICPALES RESUL- TADOS DEL ANÁLISIS DE REGRESIÓN LINEAL MÚLTIPLE}

\section{Modelo de regresión I. V.D. TPI2}

Variables y coeficientes incluidos en el modelo

\begin{tabular}{|c|c|c|c|c|c|c|c|c|c|c|c|}
\hline \multirow[b]{2}{*}{ Matklo } & & \multicolumn{2}{|c|}{$\begin{array}{l}\text { Coxfienes vo } \\
\text { ctunderizados }\end{array}$} & \multirow{2}{*}{$\begin{array}{c}\begin{array}{c}\text { Coefciente } \\
5 \\
\text { exsundxuiza } \\
\text { dos }\end{array} \\
\text { Beta } \\
\end{array}$} & \multirow[b]{2}{*}{1} & \multirow[b]{2}{*}{ Sig } & \multicolumn{2}{|c|}{ 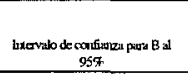 } & \multicolumn{3}{|c|}{ Concinciones } \\
\hline & & B & Enoróp. & & & & Listâte infecia & Línite spporior & Orten reero & Parcial & Sompuriall \\
\hline \multirow[t]{2}{*}{1} & (Constatic) & .902 & 1,70 & & 509 & .616 & $-2,780$ & 4.583 & & & \\
\hline & 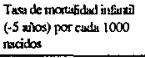 & .952 & .201 & .719 & 4.742 & , & .535 & 1.370 & .719 & .719 & .719 \\
\hline \multirow[t]{3}{*}{2} & (Canscanke) & -.979 & 1.746 & & .561 & .581 & -4.620 & 2,662 & & & \\
\hline & 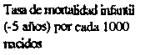 & .798 & 489 &, 602 & 4.214 & .000 & 403 & 1.199 & .719 & .686 & .570 \\
\hline & 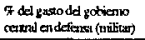 & .508 & .201 & 361 & 2.528 & .020 & .089 & .927 & 556 & 492 & .342 \\
\hline \multirow[t]{4}{*}{3} & (Comanute) & 3,640 & 2,412 & & 3.509 & .148 & $\cdot 1,408$ & 8.689 & & & \\
\hline & 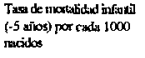 & .663 & דונ. & .501 & 3.750 & .001 & .293 & 1,023 & .719 & .652 & A51 \\
\hline & 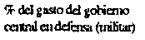 & 505 & .179 & 359 & 2,825 & .011 & .131 & .880 & .566 & 544 & 340 \\
\hline & 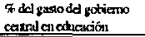 & -.497 & .199 & -318 & -2.503 & .022 & .913 & .081 & .519 & -.498 & .301 \\
\hline
\end{tabular}

Tabla ANOVA

\begin{tabular}{|c|c|c|c|c|c|c|}
\hline Modelo & & $\begin{array}{l}\text { Surnz de } \\
\text { cuadrados }\end{array}$ & $\mathrm{gl}$ & $\begin{array}{c}\text { Medja } \\
\text { cuadrática }\end{array}$ & $\mathrm{F}$ & Sig. \\
\hline \multirow[t]{3}{*}{$\bar{T}$} & Regrestión & 385.322 & 1 & 385.322 & 22.433 & $.0000^{2}$ \\
\hline & Residual & 359.906 & 21 & 17.138 & & \\
\hline & Totsl & 745.229 & 23 & & & \\
\hline \multirow[t]{3}{*}{2} & Regresion & 472,473 & 2 & 236.237 & 17.322 & $.000^{\mathrm{b}}$ \\
\hline & Residual & 272.755 & 20 & 13.638 & & \\
\hline & Total & 745.229 & 22 & & & \\
\hline \multirow[t]{3}{*}{3} & Regresión & 540.116 & 3 & 180.039 & 16.677 & $.000^{6}$ \\
\hline & Residusl & 205.113 & 19 & 10.795 & & \\
\hline & Tocal & 745.229 & 22 & & & \\
\hline \multicolumn{7}{|c|}{$\begin{array}{l}\text { a. Variubles predictoras; (Constante). Tasa de mortslidad inf(antil (-5 â̂ns) por cada } 1000 \\
\text { nacidos }\end{array}$} \\
\hline \multicolumn{7}{|c|}{ 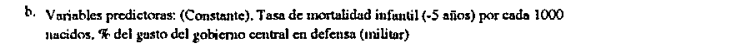 } \\
\hline \multicolumn{7}{|c|}{ 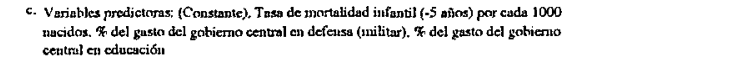 } \\
\hline
\end{tabular}

Resumen del modelo

\begin{tabular}{|c|c|c|c|c|c|c|c|c|c|c|}
\hline \multirow[b]{2}{*}{ Modelo } & \multirow[b]{2}{*}{$\mathbf{R}$} & \multirow[b]{2}{*}{$R$ cuadrado } & \multirow[b]{2}{*}{$\begin{array}{l}\text { R cuadrado } \\
\text { corregida }\end{array}$} & \multirow[b]{2}{*}{$\begin{array}{l}\text { Error típ. de } \\
\text { la estimación }\end{array}$} & \multicolumn{5}{|c|}{ Cambiar los estadísticos } & \multirow[b]{2}{*}{ Durbin-Wutson } \\
\hline & & & & & $\begin{array}{l}\text { Cambio en } \\
\text { R cuadrado }\end{array}$ & Cambio en $\mathrm{F}$ & gll & $\mathrm{gl} 2$ & $\begin{array}{c}\text { Sig. del } \\
\text { cambio en F }\end{array}$ & \\
\hline 1 & $.719^{4}$ & .517 & .494 & 4.1399 & .517 & 22.483 & 1 & 21 & .000 & \\
\hline 2 & $.796^{\mathrm{b}}$ & .634 & .597 & 3.6929 & .117 & 6.390 & 1 & 20 & .020 & \\
\hline 3 & $.851^{\circ}$ & .725 & .681 & 3.2856 & .091 & 6.266 & 1 & 19 & .022 & 1.228 \\
\hline
\end{tabular}

a. Variables predictoras: (Constante). Tasa de mortalidad infantil ( -5 años) por cada 1000 nacidos

b. Variables predictoras: (Constante). Tasa de mortalidad infantil ( -5 años) por cada 1000 nacidos, \% del gasto del gobierno central en defens

c. Variables predictoras: (Constante). Tasa de mortalidad infantil ( -5 años) por cada 1000 nacidos. \% del gasto del gobierno central en defens del gobierno central en educación 
Modelo de regresión II. V.D. Tasa de pobreza infantil en hogar monoparental encabezado por mujer

Variables y coeficientes incluidos en el modelo

\begin{tabular}{|c|c|c|c|c|c|c|c|c|c|c|c|}
\hline \multirow[b]{2}{*}{ Modelo } & & \multicolumn{2}{|c|}{$\begin{array}{l}\text { Coeflicientes is } \\
\text { cotuanderizandos }\end{array}$} & \multirow{2}{*}{$\frac{\begin{array}{c}\text { Coeficietues } \\
\text { estambrizizados }\end{array}}{\text { Beth }}$} & \multirow[b]{2}{*}{ I } & \multirow[b]{2}{*}{ Sig. } & \multicolumn{2}{|c|}{ 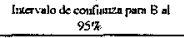 } & \multicolumn{3}{|c|}{ Corteluciotes } \\
\hline & & B & Error tip. & & & & Lemie iffrexior & Lirnie suption & Ordencers & Parrial & Selzipuncial \\
\hline \multirow[t]{2}{*}{1} & (Colstrinte) & 13.991 & 4,853 & & 2,861 & (KX) & 3.790 & 23,972 & & & \\
\hline & $\begin{array}{l}\text { F ded passo det gobicna } \\
\text { cectrol en Salud }\end{array}$ & 1.175 & 4.37 & sos & 2.690 & 0.4 & .266 & 2,083 & .506 & $.5 \%$ & .506 \\
\hline \multirow[t]{3}{*}{2} & (Conzanine) & .1 .568 & 8.367 & & .991 & .850 & -18.597 & 15,476 & & & \\
\hline & 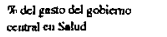 & t.720 & $4(x)$ & .526 & 3.048 & .000 & .385 & 2.055 & .506 & 563 & .52 .5 \\
\hline & P1B teal pe (S UISA. 1995) & $8.162 \mathrm{E}-\mathrm{CW}$ & 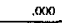 & .388 & 2.353 & .036 & .600 & $(x) ?$ & .362 & .150 & .388 \\
\hline \multirow[t]{4}{*}{3} & (Coutunte) & $-14,932$ & 7.587 & & $.1,968$ & .064 & -30.812 & .949 & & & \\
\hline & 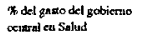 & .267 & .329 & .417 & 2.942 & .008 & .279 & 1,655 & .506 & .559 & $.4 \times 6$ \\
\hline & PIB ral pc (SUSA, 1995) & 1.15SE-03 & .000 & .530 & 3.682 & .002 & . 1000 & .0022 & .362 & GHS & .509 \\
\hline & 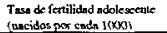 & .587 & .1608 & .515 & 3.454 & $\infty 12$ & .234 & 939 & .456 & 624 & .483 \\
\hline
\end{tabular}

Tabla ANOVA

\begin{tabular}{|c|c|c|c|c|c|c|}
\hline Modelo & & $\begin{array}{c}\text { Suma de } \\
\text { cuadrados }\end{array}$ & $g !$ & $\begin{array}{c}\text { Media } \\
\text { cuadrática }\end{array}$ & $\mathrm{F}$ & Sig. \\
\hline \multirow[t]{3}{*}{1} & Regresión & 1222,429 & I & 1222,429 & 7,235 &, $014^{\mathrm{a}}$ \\
\hline & Residual & 3547,989 & 21 & 168,952 & & \\
\hline & Total & 4770,418 & 22 & & & \\
\hline \multirow[t]{3}{*}{2} & Regresión & 1940,564 & 2 & 970,282 & 6,857 &, $005^{b}$ \\
\hline & Residual & $2829 ; 854$ & 20 & 141,493 & & \\
\hline & Total & 4770,418 & 22 & & & \\
\hline \multirow[t]{3}{*}{3} & Regresión & 3043,728 & 3 & 1014,576 & 11,164 &, $000^{\circ}$ \\
\hline & Residual & 1726,690 & 19 & 90,878 & & \\
\hline & Total & 4770.418 & 22 & & & \\
\hline
\end{tabular}

a. Variables predictoras: (Constante), $\%$ del gasto del gobiemo central en Salud

b. Variables predictoras: (Constante), $\not t$ del gasto del gobiemo central en Salud, PIB real pc ( $\$$ USA, 1995)

c. Variables predictoras: (Constante), $\%$ del gasto del gobierno central en Salud, PIB real pc $(\$$ USA, 1995), Tasa de fertilidad adolescente (nacidos por cada 1000)

\section{Resumen del modelo}

\begin{tabular}{|c|c|c|c|c|c|c|c|c|c|c|}
\hline \multirow[b]{2}{*}{ Modelo } & \multirow[b]{2}{*}{$\mathrm{R}$} & \multirow[b]{2}{*}{ R cuadrado } & \multirow[b]{2}{*}{$\begin{array}{l}\mathrm{R} \text { cuildiado } \\
\text { conegitil }\end{array}$} & \multirow[b]{2}{*}{$\begin{array}{l}\text { Error tip de } \\
\text { la estunación }\end{array}$} & \multicolumn{5}{|c|}{ Cambiar los estadisticos } & \multirow[b]{2}{*}{ Durbin-Watsom } \\
\hline & & & & & $\begin{array}{l}\text { Cambio en } \\
\text { R cuadrado. }\end{array}$ & Cambio en $F$ & gll & $\mathrm{d} / 2$ & $\begin{array}{c}\text { Sig. del } \\
\text { cunbio en F }\end{array}$ & \\
\hline 1 & $.506^{2}$ & .256 & .221 & 12.9981 & .256 & 7.235 & 1 & 21 & .014 & \\
\hline 2 & $.638^{\mathrm{b}}$ & .407 & .347 & $11.895 !$ & .151 & 5.075 & 1 & 20 & .036 & \\
\hline 3 & $.799^{\circ}$ & 638 & .581 & 9.5330 & .231 & 12.139 & 1 & 19 & .002 & 1.411 \\
\hline
\end{tabular}




\section{TRRIBUNA \\ LIBRE}





\title{
ON THE SOCIAL COSTS OF MODERNIZATION: Social Disintregation, Atomie/Anomie and Social Development
}

\author{
JOHAN GALTUNG \\ Senior Advisor, UNRISD, in preparation for the WORLD SUMMIT FOR SOCIAL \\ DEVELOPMENT, Copenhagen, March 11-12 1995. \\ Professor of Peace Studies; Universitaet Witten/Herdecke, University of Hawai'i, \\ European Peace University, Universidad de Alicante, TRANSCEND Member, \\ International Scientific Board, Swiss Academy for Development.
}

Geneva, January 1995

Honolulu, February 1995

SUMMARY

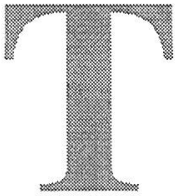

he modernization project launched by the West two centuries ago, was based on three pillars: State-logic, $\mathrm{Ca}$ pital-logic and Ratio-logic; formulated in part by Montesquieu (France), Smith (Britain) and Kant (Germany). The logic of the State implied centralization of coercive power, tempered by democracy. The logic of Capital implied market forces for economic power, tempered by anti-monopoly clauses. The logic of Ratio implied secularization for normative power. The result was spectacular, with bureaucracies, corporations and universities being major carriers of the triple logic, with ring-effects all over.

All of this was colored by Western deep culture, with its focus on dominion over nature; a sharp body-spirit division mirrored in a social division between merchants catering to the body, clergy catering to the spirit and aristocracy protecting both but also having ultimate power (whence grew Capital, Ratio and the State); social atomism (individualism) with hierarchic organization of people; epistemological atomism and hierarchic organization of ideas (deductive systems); a very dichotomous world image; and a religion/ideology seen as singularist (the only Truth) and universalist (valid for the whole world). Abroad "modernization" became Westernization, and with the recent predominance of Economic Man became identified with economic growth as the key program for the whole world the last decades. 
Much naivete is needed to believe that this can happen without enormous social costs, whether in the form of the slow but thorough modernization of the West or the more superficial, but quicker Westernization of the rest. The costs are there.

The focus of the paper is on two basic types of costs: destructuration, or atomie, weakening of direct interaction, deculturation, or anomie, weakening of compelling norms.

The result is "monadization" (Leibniz) of society into mutually isolated monads steered by egocentric cost-benefits.

This is seen as a process "from nomadism to monadism", from dense relatively horizontal structures with norms of compassion for the ingroup, gradually weakened as vertical structures with norms of submission grow stronger and more world-encompassing until the latter also weakens through automation/information. The result is an enormous increase in violence at all levels of social organization, the atomie/anomie syndrome being found in relations to nature, inside the human self, at the micro-level of the family, the meso-level of society and the macrolevel of the world society, for instance in inter-nation relations.

A number of factors are explored for their contribution to this situation, such as economism, secularization, human rights, literacy, health, Roman Law, etc. But no single factor is held responsible for such comprehensive changes. Epistemological atomism would probably itself be a major contributing factor.

If it is in the weakening of structures and cultures that the source of so much violence and social disintegration today can be found, then it is in social development, meaning (re)structuration and (re)culturation that remedies have to be found. Some examples of rehumanization are given. The Japanese social construction is seen in this perspective as still holding out against Westernization. Many, many more are needed. The situation is serious, and rapidly wiping out advances elsewhere.

\section{THREE THESES ON SOCIAL DISINTEGRATION}

To go straight to the issue, the first thesis is simply: many human societies (perhaps most) are in a state of advanced social disintegration at the close of the 20th century, at the threshold of the Third millennium $\mathrm{AD}$. This does not mean the situation is irreparable. But it does mean that remedies have to be found and enacted quickly, partly to halt disintegration (negative social development), and partly to build more solid societies, not only integrated but less susceptible to social 
disintegration (positive social development). Such societies should also be capable of providing "human security", here interpreted as satisfying basic human needs (positive human development), or at least of reversing processes of human needs degradation (negative human development). In the same vein, they should be capable of enhancing the eco-systems, building diversity and symbiosis (positive nature development), or at least of halting processes of eco-system degradation (negative nature development). To this should be added a world dimension: if the world is a society of societies that society should also be integrated (positive world development) or processes toward disintegration should be reversed (negative world development).

Four spaces of development (Nature, Human, Society, World), and for each one a more modest negative task and a very ambitious positive task. A tall bill! In addition, these lofty goals may not even be compatible: a disintegrating society may also be more flexible, capable of meeting new challenges; and an integrated society may also be too rigid to take on, creatively, new tasks. But that all remains to be explored.

Dramatic, somewhat apocalyptic statements like the thesis above are frequently heard nowadays. They can be brushed away as more cases of drama supply to meet a perennial drama demand. Another, less reassuring interpretation, would be that there might be much truth to them. At this introductory phase of the story to be told in these pages one point should be made: a thesis about social disintegration is not in and by itself a statement about eco-crisis (depletion, pollution, overpopulation or any combination of the three), about misery, unemployment, low or negative economic growth, or violence and war. The statement is about society as something sui generis, of its own kind, as sociologists have always insisted. "Social disintegration" in addition as another problem, closely related, perhaps even more significant in its consequences than all the other global problems alluded to as nature, human and world development. And being different the problem will hardly yield to remedies designed for the old problems. New approaches are called for.

So, let us identify social disintegration as a global problem, among other global problems, distributed on the spaces of the human condition used above, adding the "space" of time, so far used mainly for ecology, and culture:

SPACE:

NATURE:

HUMAN:

SOCIETY:

WORLD:

TIME:

CULTURE:

\section{GLOBAL PROBLEM:}

ecological degradation, population

poverty/misery, repression, spiritual alienation economic underdevelopment; social disintegration massive violence, war (inter-state/inter-nation) non-sustainability inadequacy 
The four global problems italicized above have already received general attention to the point of being the basic foci of the many endeavors by the United Nations under the headings: "environment" (for nature), "human rights", "development" (for society) and "peace" (for the world), with a time dimension added recently; "sustainability". Although nobody is in favor of non-sustainable solutions to the problems of environment, human rights, development and peace this is a useful reminder of the importance of solutions being reproducible, if possible even self-reproducible (as opposed to stop-gap measures or measures that consume more problem-solving resources than they produce).

The other three problems on the list above have not entered the general discourse, yet. There are reasons for that. The specialists on "spiritual alienation" would be religionists and psychologists, on social disintegration social scientists in general and sociologists in particular, and on the possible inadequacy of mainstream (meaning Western) culture, religionists again, cultural anthropologists, philosophers. In other words, new expertise, so far mainly limited to UNESCO meetings. They do not carry the same weight as the natural sciences, economics, and security studies assumed adequate for the problems discussed.

The three additional problems are also found in the core of the dominant social formation, in and of the West, questioning individual internalization, social institutionalization, and the culture. Lives lived without meaning, societies disintegrating, cultures without answers, are serious problems sui generis; not only side-effects or side-causes of the problems of eco-breakdown, misery and war. Moreover, they are strongly related.

For the second thesis we need a simple definition formula: social = structural + cultural. By "structure" we simply refer to "patterned interaction", the macro, gross, general picture of "who relates to whom, how, when and where". This is social traffic as seen from the top of Empire State Building, not by watching drivers from the corners of Fifth Avenue and 42nd street in NYC. The key word is pattern, not the individual variations. There are no individual name tags. Human beings appear as "driver", "cop", "pedestrian". The structure changes over time. The term is inseparable from the term "process"; there may be stability, secular trends up or down, cycles (with any period, like the 24 hours and 365 days cycles in the example above).

By "culture" we mean the what and why of interaction; and the what not/why not important in explaining missing interaction; the structure not there, the absent link of interaction. Whereas interaction is between actors (and patterned interaction is the mega-version of the single interact); culture is within actors. But it may be shared: patterned culture is 
the mega-version of the individual why and why not; the mutual rights and obligations of interaction, the expectations, on binding normative culture.

The second thesis can now be formulated: at the roots of social disintegration is a twin process of destructuration and deculturation, heading for structurelessness and culturelessness. Following Durkheim we shall refer to culturelessness as anomie; and then introduce a neologism for structurelessness, atomie. Of course we have not come that far. Society is not yet a heap of mutually isolated social atoms, individuals; and there is still much binding normative culture around. But we may be on the way.

To where, to what? To a society of Leibniz' monads, fully selfsufficient? Obviously not, for human individuals can hardly survive in total isolation. But we can easily imagine inter-action reduced to a thin minimum, like some e-mail contact; making society a set of isolates more than a structure relating positions filled with individuals. In other words, the actor would be the isolated individual as such, not the individual as, for instance, pater familias, as "head" of the family, as CEO ("Chief Executive Officer") or SEO ("State Executive Officer", the head of state/government). And the normative culture informing these individuals about what to do would be centered on that which serves the individual. No interacts, only acts.

In short: at the end of the road winding through history and into the future we see a social formation ("society" may no longer be the term) basically atomized into individuals, thinly and weakly related, each acting out of egocentric cost-benefit. We are close to this state of atomie, but there is still some interaction left. We are also close to anomie, where the only binding normative culture left would be individualized costbenefit analysis. Anarchy would be another term, bellum omnium contra omnes, homo homini lupus. The social fabric (le tissu, el tejido), the social body, lo social, falls apart.

The third thesis might read something like this: we are at a stage in human history where the problem is not only whether interaction structures between individuals, groups and countries are right or wrong, but whether there is any structure at all; and not only whether the culture defining right or wrong is right or wrong, but whether there is any normative culture at all.

On the road we would expect a number of social phenomena.

First, we would expect the focus of interaction to shift from "mutual rights and obligations", a reciprocal mix of egoistic and altruistic 
orientation, to an egoistic orientation of "what is in it for me". For organization members the shift is from reciprocity to "what can the organization do for me". Like predators they descend upon macroorganizations like State and Capital, preying on them for individual benefit, then withdrawing with the booty. Meso-organizations, like NGOs including parties, trade unions, churches, are used as stepping stones. Micro-organizations like families and friends are not spared. Spouses will demand services like sex and security, and in addition "freedom" (particularly husbands). The offspring sees the family as a launching platform in life and offer little or nothing in return after, and even before, take-off.

Second, we would expect increasing corruption at all levels of social organization. By "corruption" we mean a way of using organizations for egoistic purposes, influencing decisions by injecting resources (money, sex) into the process; corruptor or corruptee acting out of egoistic costbenefit analyses.

Third, with social nets, organizations, decreasing in significance and the social knots, the individuals, on the increase, we would expect increasing mobility out of nets, relations and organizations; indicating that they have been used. After exit there may be entry into new ones, or into individual monads. People will vacate bonds between spouses, parents and children, siblings, friends, neighbors and colleagues, frequently and easily. New relations may become increasingly thin, shallow.

Fourth, we would expect increasing violence at all levels of social organization. There would be no absolute, binding norms standing in the way, no homo res sacra hominibus. Other human beings inside the organizations will be seen as substitutable, the relationship being so thin anyhow, hence as expendable. Outside the organizations they will be seen as resources. The utility supposedly accruing from violent acts will be weighed against the disutility of punishment, and the probability of detection/punishment. As violence becomes pandemic the latter probability will tend to zero given the asymmetry between the ease of committing a crime and the difficulty of detecting it.

Fifth, we would expect increasing mental disorder, assuming that human beings are not made for high levels of atomie/anomie but for interactive human togetherness, guided by mutual rights and obligations, in thin and thick human relations, definitely including the latter. Conduct indicative of mental disorders, such as drug consumption, alcoholism, sexoholic and workaholic behavior, perverse physical and verbal violence, are also efforts to find identity in tighter and thicker human interaction, and in the deeper recesses of the Self. They are outer and inner journeys. 
When such efforts fail suicide is a possible way out; not only out of despair, but also as the ultimate act of egoism.

Summarizing, this is a fairly bleak, some would say far too dark image of human society today. But the problem right now is to understand these processes in order to arrive at some idea of where we are right now; ou en sommes-nous. For that we need some kind of macrohistorical perspective, with all the shortcomings of abstracting and generalizing from a super-complex reality.

\section{A MACRO-HISTORICAL PERSPECTIVE: STRUCTURAL TRANSFORMATIONS}

Imagine we now divide human history in four phases, calling them "primitive", "traditional", "modern" and, then, "post-modern". In other words, "modernity" is not seen as the end of history, and certainly not as global market economy cum democratic polity; a social formation seen here as highly unstable. A fourth phase is added, the phase that comes after modernity, like the "middle ages" come between antiquity and modernity, and "metaphysics" comes above or after physics. The post-modern phase. The term is frequently used; the following is an effort to give that term a richer connotation.

"Primitive" will be identified with mobile hunter-gatherers and nomadic pastoralists; "traditional" with sedentary, local agriculture and the emergence of classes and castes that do not have to engage in manual work for a living; "modern" with the large-scale organizations of State, Capital and Media, building state, regional and world bureaucracies, markets and meanings; and post-modern with the destructuration and deculturation alluded to above. The post-modern society is seen as essentially chaotic and anarchic for reasons to be given in some more detail below. In other words, it is not seen as a global version of modernity but as its antithesis, or as one of several antitheses.

The story to be told here, reduced to a brutally simplistic formula, is the story of humanity on its way from nomadism to monadism. For that social story to be told we shall proceed on the two parallel tracks above; one structural and one cultural. To do this some concepts are indispensable.

Above some references have been made to thick versus thin interactive relations. Let us now shift to primary and secondary relations, defining primary (in the Weber-Toennies-Sorokin-Parsons tradition) as "diffuse" ("thick") and particularistic, meaning relating to that 
particular Other, not to anyone of the same kind (in other words, the relation is non-substitutable). The definition of "secondary" would be based on the opposite pair: "specific" ("thin") and universalistic, meaning treating everybody of the same kind, satisfying the same (low) number of characteristics, the same way. The classical examples of primary relations would be to close relatives; the more remote (cousins four+ removed, for instance) being treated the same; and friends. And enemies. But it would also include colleagues and neighbors, work places and voluntary organizations. In short, kinship and friendship, vicinity (also community) and affinity, workship (also school) and worship. High interaction frequencies will rub off; over time small-and-thin relations will be thicker and less standardized. For all six cases some collective Self is defined, offering identity and some security in return for some altruism.

Let us then introduce another variable, so often missing in social analysis: size, the sheer number of people involved. Let us divide organizations into "small" and "big", the dividing line being roughly the upper limit to the number of people a human being can identify, and relate to, positively and negatively. The order of magnitude would be 102-103. Since primary relations are based on identification, we arrive at the simple conclusion that big-and-thick is impossible. Secondary relations will tend to be big (and vice versa); only when small can they be primary.

Thus, human interaction structures come in two basic modes: thinand-big, and thick-and-small. Let us call them Alpha, the pyramid, and Beta, the wheel. In modern societies Alpha is organized by the three pillars of society, State, Capital and Civil Society, in the form of huge bureaucracies (including armies and universities), corporations, and people organizations. But inside Alpha small, informal Beta structures of people with primary relations, such as colleagues who become friends, or enemies, would be nesting; growing in cafeterias, over repeated encounters in lifts, some evolving into super-Beta relations known as love. Seen from Alpha they all introduce personal and subjective elements in the impersonal, objective atmosphere of a perfectly constructed Alpha, with everybody substitutable, even if this means alienated. Alpha people are right: those who spy on Alpha centers for state and corporate secrets often use Beta networks, including love relations, to get access, like the classical secretary making extra photocopies for a friend.

Let us then introduce a third variable, vertical versus horizontal, here seen as relational, not only relative, as exploitative, grossly asymmetric in terms of net benefits. Why do people enter such vertical, exploitative relations? Because they may have no choice, forced by coercion or 
tradition. The alternative to exploitation may be starvation (Marx on capitalism). The result is vast action spaces for people on top, straitjackets at the bottom; material enrichment on top, impoverishment lower down. Challenges on top, routines at the bottom. In horizontal relations this is better distributed; gross asymmetries lead to break-ups in thin relations.

Alpha tends to be vertical. Layer can be added to layer, in principle covering all of humankind through processes of globalization in one big pyramid or hierarchy with a single apex. This projection of the State would be known as World Government, and the corresponding projection of Capital as the World Market. The present G7 has aspects of both. But so far alphaization is clearly more pronounced at the regional than at the world level; the European Union as seen in the Maastricht Treaty being one example (the Soviet Union was another, but State and Capital were more clearly merged into one pyramid than in the EU or the U.S.).

Beta can be both vertical and horizontal (Gamma). A tribe run by chiefs and shamans, villages run by Big Men and land-owning families, families run by a pater familias, marital relations under conditions of patriarchy (and the infrequently found matriarchies), or the small farm/ firm with very tight and very authoritarian relations under the "boss" are thick and small and also vertical. And they can be horizontal like in kinship and friendship/enmity groups, among neighbors and colleagues; with other human beings in general, in worship and workship.

Horizontal Alpha structures can also be imagined (Delta). At present electronic communication, like Internet, may serve as an example, as long as the information superhighway has a topography without centers and peripheries. Transportation superhighways tend to be rooted in big urban centers reaching into the peripheries. However, peripheries could be connected, leveling the center-periphery gradients. In the same vein, the information super-highway will probably develop even steep gradients (like toll gates); and we are back to traditional Alpha.

As pointed out repeatedly, societies, or social formations more generally, as we know them, are mixes of Alpha and Beta. The question is how strongly either one is articulated. So let us answer that question in terms of "strong" and "weak" for both, giving four combinations (Alpha/Beta is not a dichotomy):

Figure 1: Human social (trans)formations: Structural macrohistory

\begin{tabular}{|lcc|}
\hline Alpha strong & II. Traditional society & III. Modern society \\
Alpha weak & I. Primitive Society & IV. Postmodern society \\
& Beta strong & Beta weak \\
\hline
\end{tabular}


The story, as reported here, follows the double line, and starts in the bottom left corner. A humanity divided into small mobile groups, clans, lineages, small enough to be "in-groups", with primary relations dominating, essentially kinship. A tight net of mutual rights and obligations spun inside the group, possibly with negative or no relations at all toward the out-groups they would encounter on their wanderings. They, precisely they, would probably be conceived of as categories of people, not even with the differentiae specificae given to them by Alpha logic in terms of their social positions and their qualifications for being allocated to such positions. The in-group would be too small to develop layers of verticality beyond gender/generation and for that reason be well integrated socially and humanly. The weak point would be not only the thin or empty relation to other groups, but also that integration may be too tight, "suffocating".

With sedentary ways of producing for a livelihood and a higher level of agricultural productivity--one family working on the land producing enough surplus for 1.1, even 1.25 families-- the material basis was laid for the classical caste-systems:

Figure 2. Non-manual castes: Four systems.

\begin{tabular}{|lllll|}
\hline & Europe & India & China & Japan \\
\hline First & clergy & $\begin{array}{l}\text { brahmin } \\
\text { clergy }\end{array}$ & $\begin{array}{l}\text { shi'h } \\
\text { bureaucrats, intellectuals }\end{array}$ \\
\hline Second & aristocracy & $\begin{array}{l}\text { kshatriya } \\
\text { warriors }\end{array}$ & nung & \multicolumn{2}{c|}{ farmers } \\
\hline Third & merchants & vaishya & kung & ko \\
& merchants & \multicolumn{2}{c|}{ artisans } \\
\hline Fourth & workers & $\begin{array}{l}\text { shudra } \\
\text { workers }\end{array}$ & \multicolumn{2}{c|}{ shang merchants } \\
\hline Fifth & outcasts & $\begin{array}{l}\text { outcasts } \\
\text { women } \\
\text { women }\end{array}$ & $\begin{array}{l}\text { outcasts } \\
\text { women }\end{array}$ & outcasts \\
& children & children & children & children \\
\hline
\end{tabular}

The history of traditional society becomes to a large extent the history of the relative power of the upper layers in what has to be an Alpha structure, unless the unit (eg., the village) is small. One possibility is the ranking order indicated above; with the European and Indian systems being quite similar, and the Chinese and Japanese also quite similar (thus, formulas like "Indo-European" and "Sino-Japanese" apply not only to languages). Another possibility, as pointed out by Sarkar, is a circulation of castes, in the order kshatriya-brahmin-vaishya-shudra (the kshatriya enter to create order after the people have had their say, but they are culturally so primitive that the brahmins enter to restore culture, 
but they are economically so amateurish that the vaishya have to put the economy in order, but they are soexploitative that the shudra people make revolts, and so on).

At this point solid vertical distinctions between people and elites have emerged. Alpha structures, mainly local, are being articulated. Modernity brings that process further in Alpha strictu sensu: country-wide, hierarchical, with a well-defined specificity in social relations stipulated in written contracts, and a universalism opening the positions in the structure for citizens satisfying well-defined, explicit qualifiers. Diffuse, particularistic relations have to be weeded out from the Alpha garden, ultimately to look like the orderly French gardens that emerged at about the same time (not baroque!). For Beta relations, please use time after working hours, and weekends.

As Alpha becomes more dominant, Beta not only becomes recessive, but starts disintegrating. One reason is simple: individual time budgets. Alpha requires full attention, because the jobs provided by Alpha are full time jobs, and because the occupants of Alpha positions are not supposed to think Beta thoughts. Some Beta structures have to go, starting with such old work structures as extended families and traditional villages. Cities are to Alpha what villages are to Beta: liberating people from the stranglehold of very tight human relations in a village, then suspending them in the thin air of urban anonymity.

Cities provide more space for Beta structures than villages for modern Alpha structures. However, these Beta structures are decreasingly related to work and increasingly to leisure, leading to the well-known pattern in many modernized countries today: villages gradually being converted from sites of agricultural production to sites of weekend leisure, and to some primary and tertiary production, plantation and tourism, for far-away buyers.

We now have to introduce a thesis, or rather an hypothesis, important for the following: A Beta structure is natural to the point of being indispensable for human beings. Only Beta type relations cater to the whole person and give the person a sense of belongingness. This should not be confused with identity or sense of meaning of life; that can be enjoyed also in an Alpha structure, even in a non-structure (Formation IV). To belong is to have a home, somebody to relate to, somebody who knows more of the story than any bureaucracy can do. The argument is not in favor joint or nuclear families, different sex or same sex unions, with or without children. The argument favors some Beta unit, thick-and-small, with more total relations. 
Objection: if Beta is the natural structural environment, how is it possible for Alpha to expand at the expense of Beta?

Answer: because Alpha has much to offer in the short run. For those on top Alpha offers the material fruits of verticality; power, challenges. For those lower down the gains may turn into losses, but the costs of being marginalized may be still higher. The Alpha lure, you are in it!, even as a peon in the post office in a village in East Bihar, or second speed EU member, is there. For Alpha holds out a reward for good behavior unknown to Beta: upward mobility, if not for you, maybe for your offspring. In Beta there is always room for improving the relation, to become a better friend, a better neighbor. But if an attraction of Beta is precisely its horizontality, then there is no way up. Nor is there any way down. There is a way out: if you do not behave. The problems, and the attractions, in Alpha are vertical. In Beta they are horizontal: belongingness versus loneliness.

One formula often used for modern society is Alpha for production, Beta for reproduction. From Alpha the work output may be considerable. In Beta human beings are repaired, maintained, sustained.

Formation I would show high levels of stability, keeping humans intact, leaving few traces on nature as the work output is negligible and the consumption of natural resources likewise.

Formation II leaves more traces. There will be monuments to the glory of the upper castes: temples (mosques, churches) for the clergy, forts for the warriors, market places, banks etc. for the merchants; poverty for the people; all wrapped together in cities. But even if human beings are exploited and repressed, they still belong somewhere, sustained, repaired. Reproduced.

In formation III, however, production starts outstripping reproduction. The output is phenomenal. Alphas of all kinds get deeper roots and expand geographically and socially, covering ever larger territories, not only countries governed by states, but empires governed by mega-states. The production of goods/bads and (dis)services outstrips what anyone might have imagined. But Betas are disintegrating, and not only the extended family and the traditional villages. The nuclear family splits not only between husband and wife, but also between parents and children, and among siblings. Neighborhoods break down when people move geographically too frequently to sustain relations based on vicinity. Invariably the same will apply to friendship and to affinity: neither can survive the high levels of social mobility, sideward, upward, downward of modern society. Worship under the same God may still remain. About God, however, see next section. 
The transition from primitive to traditional was made possible by the agricultural revolution, growing plants and breeding cattle in a relatively sedentary, basically Beta way. The transition from traditional to modern was made possible by the industrial revolution providing the goods, the scientific revolution providing the knowledge, and the transportationcommunication revolution extending Alpha reach.

But how about the transition from modern to post-modern? As we are talking about destructuration anything removing human beings from direct interaction would count. A key word is tele. Direct interaction is multisensorial; no telecommunication so far goes beyond the auditive and visual. Interaction is till there, but it is trimmed down, stripped, more naked. As anyone talking over the telephone without watching the facial expression and the body language will know information gets lost in the process. And as anyone comparing telefax to telephone knows, the tone of voice may say more than the words. So the term "information revolution" will not be used, not for the obvious reason that what is conveyed is often disinformation, but because of the high level of deinformation when so much quality is lost. Information retrieved from an encyclopedia or CD-ROM is not the same as information conveyed by a loving parent or concerned teacher (but the two obviously do not exclude each other).

Symbolic interaction via words or other symbols, whether arriving on ordinary or information highway substitutes for direct human interaction. The term is symbolic revolution, from proclamation of edicts via modern media to automation-robotization. Alpha is there. But human relations are not.

An image: Los Angeles, 1992. Certain parts of the once magnificent city are wastelands. There are streets and buildings, even shops, even if waste is piling up all over, the buildings are derelict and the shops are barricaded. More importantly, they are all disconnected from each other, there is not even a concept of neighborhood. Nobody knows who is next door, nor dothey care. People come, goods and services are peddled, they disappear. At night everything is locked up, dark, desolate.

And that is when the marauding gangs take over. They are the new nomads; the city-scape is their resource. Unable to survive in nature they know how to survive as hunter-gatherers in the urban wastelands; hunting cars, gathering their contents. They are the products of formation IV, crystallized as a new formation I, preying on the wasteland, fighting rival tribes, including a police tribe hunting and gathering gangs, LAPD. Strong Beta structures re-emerging. Ready for a second cycle?

There is a logic to this. Alpha has not disappeared, but has become 
very lean and mean, devoid of human content (thus, in Figure 1 we are talking about "weak", not "zero" Alpha). There is work output, although some quality may get lost in this dehumanization process. Much more disturbing is the question often raised by the ultimate stage of dehumanization: not only is the interaction symbolic rather than direct, but the receiver, and sometimes also the sender, is even a non-human, a robot. And robots do not crave for Beta groups, they are custom-tailored for a high Alpha life expectancy. So the disturbing question is obvious: if robots do so much better, for what purpose do we have human beings at all?

The first answer is obvious: even if robots are better at production, humans are better at consumption; in fact, the whole purpose of the exercise is to liberate human beings from dirty and dangerous, humiliating and boring work, leaving all of that to robots so that human beings can concentrate on creative and non-programmable tasks and enjoy the fruits, as consumers.

The second answer would be more reflective, taking into account that robots also have to be reproduced, sustained, with energy and spare parts inputs, perhaps also reprogramming. The total cost-benefits, even done in the most naked economistic way, may turn out to be less obvious with the destructuration bill in.

The third answer may point out that not so much is lost anyhow. With the symbolic revolution not only production can be carried out in loneliness; the same applies to consumption. There is a neat isomorphism between assembly line production, in series and bureaucratic production in parallel, on the one hand, and a magazine circulating in an office (in series), and a family consuming TV programs next to each other (in parallel) on the other. All four cases are based on action (like turning nuts in assembly lines or zapping TV at home), not on interaction.

The sum total is not only Alpha but perverted Alpha. If now the thesis of a human need for Beta as something natural is correct, we would expect Beta to be sprouting. But what kind of Beta? Alpha supplies all goods and services, leaving few opportunities for green production on the side. If Alpha is dehumanized anyhow, then why not treat it as such? To whom do you feel more attachment, to your fellow corruptor/ corruptee, perpetrator/victim, or to an abstract, symbolic structure? 
Let us summarize some of the points made:

Figure 3. Formation structural dynamics: Some basic factors.

\begin{tabular}{|l|c|c|c|c|}
\hline & Primitive & Traditional & Modern & Post-modern \\
\hline Alpha & weak & strong & strong & weak \\
\hline Beta & strong & strong & weak & weak \\
\hline Growth & low & high & high & low \\
\hline Exploitation & low & high & high & low \\
\hline Alienation & low & low & high & high \\
\hline
\end{tabular}

Why do human beings engage in such exercises? Because the grass is greener on the other side. We seem to be fascinated with what is missing, and take what we have for granted; assuming it will remain there forever and not be eroded by the relentless search for the new. Till we end with a very bad deal, indeed.

Of course Primitive Man becomes fascinated with the growth, and with the glory, produced by traditional society. So, as Ibn Khaldun points out, the desert tribes knock down the gates and storm the city, sharing in the power and the glory, ultimately running it down for lack of asabiyah, solidarity (a premonition of the theory underlying the present paper). And in the same vein Traditional Man becomes fascinated with the tremendous growth and power, with the national, regional and global reach achieved by Modern society. He no longer knocks down any gates, but he joins as a humble immigrant, at the margin of the host country Alpha structures, contributing to destructuration both places. He came from reproduction without production and enters production without reproduction. He participates in building The Wealth of Nations, at the expense of The Moral Sentiments; the point-counterpoint in Adam Smith's brilliant reflections.

\section{A MACRO-HISTORICAL PERSPECTIVE: CULTURAL TRANSFORMATIONS}

Let us now try the same story from a cultural point of view, focussing on binding normative culture, and particularly on the source of normative culture, religion and such secular successors as national-ism, state-ism, capital-ism, science-ism. Religion contrasts the sacred and the secular; the awe-inspiring, that which cannot be touched, and the ordinary, the profane. In many religions there is also a third category: the evil, to be feared, to be avoided, and if possible, destroyed. Obviously, people are not born with, but into a religion. There may be a basis in the physiology 
of the brain (and elsewhere). But details are learnt.

But what would correspond to Alpha and Beta? There is the theological distinction between the sacred as immanent, inside human beings and nature, and as transcendent, in a God residing outside the planet, above. That god may be a Mother god (like in Japan) or a Father god, but in the Occident (as defined by the abrahamitic religions, JudaismChristianity-Islam) this takes the form of Father-Sky, the Father in the Sky. The opposite would be Mother-Earth; the Earth that gives birth to our livelihood, the Earth that nourishes us, and ultimately receives us upon death.

Immanent religion is more horizontal, transcendent religion more vertical. But rather than dividing religions in immanent and transcendent it might be more fruitful to talk about immanent and transcendent aspects of religions. In the three occidental religions the transcendent aspect is dominant; in addition there is Evil, presided over by Satan. Prayer and submission to God are the adequate approaches. In immanent religions meditation in Self and compassion with Other may play similar roles.

However, immanent religion has a dark side, tending to be particularist rather than universalist. The sacred nature of Other may apply to the in-group only, not to the out-group. The message of transcendent religions like Christianity and Islam (but not Judaism and Shinto) would be that you are all in it, all protected from above. The condition is that you submit and pray.

Figure 4. Human social (trans)formations: Cultural macrohistory.

\begin{tabular}{|lcc|}
\hline Transcendent strong submission & II. Traditional society & III. Modern socicty \\
Transcendent weak & I.Primitive society & IV. Postmodern society \\
& Immanent strong compassion & Immanent weak \\
\hline
\end{tabular}

The story, then, would run approximately as follows.

Primitive society would be protected by strong ingroup norms, being tight and cooperative. Outgroups may prove friendly but also may not; so any notion of the sacred would not a priori extend to Other. They would have to prove themselves, not by submitting to the same FatherSky, but by relating cooperatively. They become human by being accepted parts of the social network, not by any abstract human-ness (that is probably Occidental).

Traditional society might also need some transcendent deities particularly protective of the upper layers of society and more accessible by them than by common people. Religious relations have to mirror social relations. But the social unit is still small. Transcendence and immanence can be combined. 
Modern society is almost inconceivable without transcendent religion; sacred or secular; a deus in the rex gratia dei. There has to be an authority beyond the apex of the Alpha pyramid as there is so much power to legitimize. Father-Sky supplies the authority, not Mother-Earth, she is to close to everybody. And just as imperialism established the first global super-Alphas, imperial rule and trade companies, missionarism established the homologue supremacy of universal, transcendent religion. This holds for Islamic as well as for Christian imperialism.

Immanent religion was considered pagan and particularistic, standing in the way of a universal god in need of (more than willing) missionaries and colonizers to bring the message. Imperialism and transcendent religion came hand-in-hand, one as the condition for the other. Indigenous Beta and immanent religion could then be eliminated together, as pagan, archaic.

Objection: how about the Enlightenment, and secularism in general; does this picture not paint the Occident too religious?

Answer: Islamic colonialism/missionarism started right after the inception of Islam $(+622)$ and had the foundation of the Sultanate of Delhi in +1192 as one crowning achievement. From there it went eastward, stopping so far at the southern end of the Philippines. Christian imperialism (if we disregard the Roman Empire which was not Christian in its expansionist period) started for real in the 1490s, westward (Columbus) and eastward (Vasco da Gama). The pattern was set under religious auspices.Enlightenment came to Christianity much later; to Islam (perhaps) not yet. Needed was a universal, overarching God/ Allah whose commands would be binding on all believing imperial subjects.

Enlightenment and secularization (in the West) set in somewhere on the transition from Formation II to Formation III. The functions fulfilled by universalist/singularist religions with Chosen Peoples still had to be fulfilled, and universally valid science claiming to represent the only possible truth with the scientists of various kinds as the Chosen People met the bill. Alpha construction could now be made in the name of the three modernizations carried by state logic, capital logic and scientific logic; as substitutes for religion (with Ratio, rationality, as the overriding theme). The project is still on, now under the heading of "development assistance".

But what happened to the Church as the Alpha prototype? The role as representative on earth of the omni-present, omniscient and omnipotent causa sua God, went to the three pillars of power in modern society: State, Capital and the Media; the carriers of state logic, capital logic and reality representation of modern society. Underlying that a new 
ethos took shape, nationalism, providing large parts of the world with national statism, national capitalism and national media, with the disequilibria this leads to when the territories covered by state jurisdiction, capital penetration and national settlements do not coincide.

Of course, to some extent posited against State and Capital is Civil Society, with a contract (rule of law/democracy/human rights) with the State and, and no contract, only a market place with Capital and Media. And new priesthoods emerged as carriers of the new faiths: jurists for the State, for Capital the economists, for Media the journalists, for Civil Society political ideologists and for the Nations the nationalists.

In short, the structure of the transcendent God, chosen by Him as the Chosen People and chosen by people as object of worship remained intact. The places of worship were different, the content of the prayers varied, but the submissiveness stayed. For top positions in Alpha new faiths were needed, such as allegiance to the new priesthoods, meaning concretely faith in the human Ratio and such products as jurisprudence and mainstreameconomics. In addition comes faith in the (virtual) reality images produced by the Media, and in nationalism. Modern society has been laboring under such formulas for some centuries by now.

Thus, human beings were almost deprived of immanent religion through the missionary activities of the religions of the imperial powers. But with that project still on the second project of the West, secularism started undermining transcendent religion, leaving human beings deprived of Father-Sky, with no Mother-Earth as alternative, and only small groups (Quakers, Buddhists) still insisting on the sacred nature of life, particularly human life. And this is exactly Formation IV, for secularism, in the shape of humanist ethics, has not been capable of producing binding norms for human behavior. Why shall you not commit adultery, kill, steal and lie when other humans are mere objects and there is no accountability to higher forces as there is no transcendent God anyhow?

The final result is the total anomie of Formation IV, with human beings left with the only normative guidance that always survives: egocentric cost-benefit analysis. The point is not normlessness, the point is that they are not binding; that is the meaning of culturelessness. The process has gone quite far.

\section{ATOMIE AND ANOMIE IN DOMESTIC SOCIETY: SOME IMPLICATIONS}

In Figures 1 and 4 two processes have been indicated, through four social formations. How far concrete societies, groups or individuals have 
come along these trajectories can only be decided through empirical studies. But one interesting point emerges: the more modernized society, the further advanced along this trajectory, since by "modernization" we mean precisely the triumph of Alpha over Beta as dominant social formation, and the triumph of Ratio over the Sacred as dominant moral guidance. What was not taken into consideration was that human beings may need both Beta for their personal sustenance, and the sacred for life to have a meaning and their action to be guided. Alpha alone, and Ratio alone, have provided us with material abundance and impressive control and coordination structures (in need of the counterforces generated by Civil Society, though, with the Media oscillating in their loyalties to State, Capital and Civil Society). But deep sustenance and guidance they cannot offer.

Then two things went wrong, both basically unintended. Together they catapult us into Formation IV, atomie cum anomie.

First, Alpha became more and more naked, stripped of human content as Ratio provided Alpha with its many gadgets. Take only one example: automated telephone systems, not only bypassing the switchboard lady through direct dialing, but then landing the call with "if you want, push 1", some canned music, and finally a recorded response. Whether done do save labor expenses (and time), to standardize responses, or to save the recipient from any further argument, the net result is destructuration as there is no (or very little) direct human interaction involved.

Second, the hope must have been that Ratio, seen by the great Western philosophers as essentially universal, would provide a basis for a binding ethic. The problem is not that Ratio may be less universal and more a product of the general code of the many human cultures, but that Ratio does not generate sufficient ethical commitment.

At this point the synergy between the two trajectories heading for atomie and for anomie set is. Alpha, in the shape of a modern educational system, is very good at schooling people in the products of Ratio, at the level of primary, secondary and tertiary education. The two not only fit each other by being standardized up to the country and regional levels, or the levels of the nation and the super-nation (an example of the latter would be the European Union); they are designed for each other.

But binding norms seem to become rooted in human beings through Beta, through G. H. Mead's significant Others, maybe particularly the mother. If now Betas crumble all over the place, down to the nuclear family, even to the mother-child bond, leaving more and more of the raising of children not even to the school where the single class still may have some Beta character, but to the media, parking the children in 
front of the TV/Video, then it would be a miracle if binding and positive norms should become internalized. Adding to this the well-known content of the media the general picture becomes even worse.

At least for the "advanced countries" one reasonable hypothesis would be that there is a certain synchrony between the processes of destructuration and deculturation. For other countries there may be important asynchronies to explore.

King Midas surrounded by gold, his dream, but that is also all he has? Not quite that far, yet. But we would expect a general sense of pessimism to ensure from this. And that is exactly the general finding that emerged from a major comparative 10-nation study Images of the World in the Year 2000: the more economically advanced the country, the more pessimistic in general terms the inhabitants. A premonition?

Of course, with Betas crumbling all around them they may easily become very lonely. Add to this the alienation at all levels of Alpha due to the strong rules of substitutability, and the exploitation lower down, and the lack of any other moral guidance than individual cost-benefit analysis, how would we expect people to react?

Basically the way indicated by the five theses in the introduction. But they already presuppose a weakening of Alpha, not only the alienation and exploitation/repression of Formations II and III. Under the conditions of modern society as such (not yet post-modern) people might react to Alpha as such. And if we assume those on top basically to be content, wanting to hang on, then the reaction will mainly come from people lower down.

Two formulas: revolt and apathy, boiling and freezing. Whochooses what, both or neither is an interesting problem of social psychology. From a more sociological point of view these are mass phenomena and solid indicators of malfunctioning, in no way saying that revolts may not be justified. However, if there is something humankind should have learnt during the twentieth century then it would be this: a revolution substituting one Alpha for the other, changing priesthood, may not change much.

But political violence, today referred to as "terrorism", may be a problem of structures/cultures partly of the past. Today the problem may be no structure/culture at all, and violence, hurting and harming, erupting all over as a consequence of social disorganization. Here is a typology with eight types of violence:

- Violence against Nature (ecological crimes)

- Violence against Self (alcohol/drugs/tobacco, stress, suicide)

- Violence against Family (child abuse, physical/verbal violence) 
- Violence against Individuals (robbery, assault, rape, homicide)

- Violence against Organizations (corruption)

- Violence against Groups (inter-class, inter-nation violence)

- Violence against Societies (inter-state violence)

- Violence against other Worlds (inter-planetary)

Types 3, 4 and 5 are today referred to as crimes, and types 6 and 7 as wars (for a peace researcher they are all violence). The arenas differ from one type to the other: all over Nature (like in the rain forests), at home, on the streets, in the offices, within a country (internal wars), within the world (external wars), between worlds (so far only as science fiction). But the net result is the same: life is being caused to suffer, to be hurt and harmed and traumatized, even to cease.

All over the world the same: people in shock after reading, listening to, viewing, the media. The world seems to be coming apart. Each nation wanting its state. Weapons of all kinds available everywhere. Big blocs taking shape at the world level: Rich countries against Poor as much as or more than ever; the Rich in North America, Western Europe and East Asia pitted against each other; new military alliances; culture and particularly religion coming up against secularized elites only capable of uttering the standard curse "fundamentalism". Homo homini lupus, bellum omnium contra omnes; everybody for himself; apparently out of control, unrestrained. Disintegration.

One common reflection today is that violence has become more domestic, less global, world-wide. In terms of the above typology that mans more violence of types 1-6 (but type 1 is also global!) and less of type 7. Maybe too early to judge; the data indicate constancy rather than decline in the level of inter-country violence. There is a perception of decreased threat of a nuclearEast-West holocaust in Europe; possibly due to an over-estimation of that danger during the Cold War and an under-estimation of that danger within the Catholic-Protestant/LatinGermanic vs. Orthodox/Slav vs. Muslim/Turkish triangle taking shape in Europe. At any rate, with that danger removed the world system to many (in the Northern part of the world) looks rather peaceful. But not domestic society, with nations pitted against each other all over and types 1-5 apparently on the increase in most societies.

The hope of people working for peace has for a long time been to have the world system catch up with the best social systems in controlling violence, for instance by establishing a binding rule-of-law system. The problem, as usually pointed out, is that such rules are not easily internalized in an anarchic system with everybody (meaning the states) out for themselves and nobody really can function as a Significant Other, 
a nursing mother. And they are not easily institutionalized either. There are mutual rights and obligations. But if A's right becomes B's obligation and there is no reciprocity the mechanisms for handling the conflict (the World Court, the Security Council) are imperfect to say the least. Neither rewards, nor punishment (positive and negative sanctions) are impressive. What then happens is often hierarchic intervention by big powers.

People may develop all kinds of Beta, not to mention Alpha structures across borders, but the inter-state structures are thin (this is where anarchy enters) and vertical (this is where hierarchy enters). Is the structure also big? With 184 members of the United Nations and 184 ambassadors the structure is not larger than what many individuals can handle, fitting nicely into their lists of addresses and telephone numbers. Being thin and vertical it could easily become Alpha by adding more members (such as NGOs, or direct relations to the many nations of the world). But it could not easily become Beta. In that case it would rather be Gamma, with the permanent Security Council members in loco parentis of that extended family. Feudal and paternalistic, in other words, and even so the webs of interaction will have to be spun much more densely.

The basic point here, however, is that far from the world system catching up with the better cases of the social systems, it is the other way round: the social systems are "catching down"with the world system. Read this way Formation IV, replete with atomie and anomie, is a rather adequate image of world society: vertical, with symbolic, abstract relations rather than direct interaction, short on binding norms and altruistic orientation and long on egoistic cost-benefit orientation. There are some Beta structures, like among the Nordic, the European Union and the ASEAN countries, at the world system level, like in social systems. But the Formation IV structure is very evident. And the consequence is obvious: instead of peaceful conflict solution efforts violence is used, respecting neither common values, nor any inner voice of conscience, nor the threat of punishment.

\section{FROM NOMADISM TO MONADISM: SOME FORCES MOTRICES}

The following is not a theory to account for this rather gigantic change in the human condition. Rather than a macro-history it is simply a catalogue of twelve factors often mentioned in this connection, an annotated list so to speak, even alphabetized to make its atheoretical character even more obvious (if not necessarily acceptable to the reader). 


\section{Capitalism}

The reason why capitalism tends to become not only Alpha but Super-Alpha in its basic structure, even if much is happening within, is the verticality of power that follows when high quality production factors (nature, labor, capital, technology and management) are monetized, marketed, and mobile. As they have to be put together for production, they tend to flow together or at least to be controlled together, from a Center.

The Center uses high quality factors for high quality products, in exchange for lower quality factors and products from the Periphery. Capital is supposed to beget more capital, either directly in the finance economy (speculation), or indirectly when invested in production factors used to produce goods and services in the real economy (production). Much begets more which does not mean that little begets less; the cake may expand, but then often at the expense of the external proletariat, nature, and/or future generations. New about capitalism was not that the economy had a peaked structure. What was new was the mobility, not only into the Center by investing some initial capital, much hard work, saving, greed and inconsideration, but also out of the Center through bankruptcy or lack of dynamism. The result was an anti-feudal revolution. For the continuation, see Socialism.

\section{Democracy}

Of course elections are one way of ensuring not only rule by the consent of the ruled, but also nonviolent transition from one set of rulers to the next, if they respect the secret ballot. The problem is the Alpha nature of that type of democracy; a relation between a Center of contending Rulers, and a Periphery of the Ruled, turning the pyramid upside-down once every four years (or so). This Alpha shape of modern democracy, Democracy II, differs from with the Beta shape of a more primordial Democracy I: a group (a small company, a small community or a neighborhood, a family or a group of friends, the elders in a tribe) dialoguing over issues till consensus is obtained. The relation is horizontal, everybody can address everyody's concern, the outcome is unknown in advance, there is neither winner, nor loser; in good dialogues only winners.

\section{Differentiation}

Another term is "division of labor", in a long social philosophy tradition (Adam Smith, Herbert Spencer, Emile Durkheim, Ferdinand Toennies, Max Weber) seen as a basic condition for social progress and economic 
growth in particular. The total human activity called Work is not only subdivided into tasks and subtasks, but new tasks are continuously created. As in production of goods and services so also in the production of knowledge: undifferentiated Philosophy is subdivided intodisciplines and sub-disciplines that in addition are hyphenated into cross-disciplines. The structure of the sets of Tasks and disciplines is highly complex, but the general idea is differentiation, and with it fragmentation, atomization of the individuals having these tasks and disciplines as their job. As book, Limits to Differentiation, is crying to be written.

\section{Economic Growth}

The process is almost inconceivable without a culture accommodating not only hard work and saving, but also greed and inconsideration. Systems may differ as to whether the pressure is put on the internal or external proletariats; on nature, self or the future. But something has to be moved, or transformed, or both (see Capitalism), and in the process organic relations of people to others or raw materials to surrounding nature, will be cut or at least transformed. The open wounds in quarries and mines have their counterparts in the open wounds in souls detached from each other through excessive mobility and transformation. Inconsideration means insensitivity to wounds in Self, Other and Nature. Beta structures break down, partly dehumanized Alpha structures are poor substitutes.

\section{Economism}

The term is interpreted here as a state of mind, not to be confused with the economy (the cycles linking Nature, Production and Consumption) or economics (the science about these cycles, today essentially a description and theory of one particular economic system, capitalism, hence a science that more properly should be called "capitalistics"). Economics, or the culture of homo economicus, can be conceived of as a syndrome:

- a focus on material/somatic satisfaction by goods and services;

- a focus on the human individual as the unit to be satisfied;

- a focus on cost-benefit analysis to guide individual choices.

The syndrome not only detaches individuals from each other by making the single individual the supreme decision-maker (egocentrism), but also detaches satisfiers (goods/services) from each other as objects to possessed and consumed one by one. Costs and benefits are then used to establish preferences.

There are severe problems with this syndrome, mind-set: 
- in practice only a limited number of satisfiers can be used, by definition excluding the externalities of economic action;

- absolute values (with infinite positive or negative utilities) will be excluded or relativized since they will overrule others;

- individual preferences are not easily reconciled collectively.

These are the costs, considerable, of the breakdown of the holism of the actors in collectivities, the holism of the object-world, and of absolute values: destructuration and deculturation. This is also built into the technique used: product-sum maximization, which becomes very unwieldy for collectivities of not harmonized actors and high numbers of satisfiers and useless for absolutes. When used, the result is even more atomization, destructuration and the deculturation implicit in rejecting absolute values. Thus, economism becomes the ultimate consequence of Roman Law.

\section{Gender}

Just to pick up one factor, how the genders seem to differ in their preference for alpha (male) and beta (female) and no (male) structures, assuming that women prefer to relate and network, neither to be isolated in loneliness, nor to be isokated at the top of a hierarchy. Thus, a major force behind the drive toward alphaization, and then toward monadism, from Formation I to II, II to III and on to IV, would be patriarchy: the lading structure is the structure of the leading class. And that should also apply to culture: male preference for deductive thinking and sumbission to first principle is compatible with a transcendent God; less compatible with immanence. But that also opens for a major therapy: parity instead of patriarchy, provided women have not become clones of men in the process.

\section{Globalization}

If this terms stands for global mobility of production factors and products, with more standardization of structures and cultures, then the consequence is to speed up the transition into Formations III/IV. Larger domains for structures and cultural meanings imply thinner scopes, and more reliance on least common denominators, with structural and cultural specifics receding into the background. Given the variety of idioms around the world Super-super-Alphas with truly global reach will be symbolic, based on mathematics, computer language, etc., or based on body language (sport as a universal idiom), and/or on concrete objects, goods, like people with no common idiom pointing and touching. "Here are no Greeks, no Jews; no women no men: we are all one in CocaCola" is reality, not a bad joke or blasphemy. 
And the same goes for structures: no cohesive Alpha has so far emerged covering 6 billion human beings except one: global television. There are two layers: one sender, billions of receivers. No horizontal interaction, they relate via the apex.

Will this structure endure? Probably not. Sooner or later it will go the way of all Alpha: small Beta groups take shape, like guerrillas they will relate, unite and revolt. The condition is their ability, underestimated by Marx, to overcome structural, cultural and geographical divides. But the global market prophets may have underestimated that in its wake will follow globalized workers trade unions and consumers movements. Proletarians (and consumers) all over the world, unite!" may have a reincarnation. Consumer sovereignty, if exercised on a truly global basis, may become a mjor force at the same time as nation-state democracies crumble under the weight of global forces beyond their control.

Actually, globalization may also run into another problem of an equally or more serious nature. Competition has kept capitalism innovative; not only the micro-competition from other firms in the same branch (BMW versus Mercedes), nor the meso-competition from another country (Germany versus the UK), but the macro-competition from other civilization with other capitalisms (Buddhist-Confucian versus JudeoChristian). Globalization will keep the micro and meso challenges but may strive to iron out the macro differences through homogenization into a global business culture. This means a severe reduction of the Toynbee factor of challenge followed by the creative response that presumably keeps minorities in power. And Alpha is, by the very definition built into its pyramidal shape, run by a small minority (relative to the other layers) in need of constant renewal of personnel and ideas. Globalization means mono-culture, less diversity, less symbiosis, less resilience.

\section{Health}

The concern for health fits into the general picture of secularization on two important ways: as focus on the body rather than on the state of the mind and the spirit, and the translation of eternal life/salvation as high life expectancy. Of course modern man enjoys lower morbidity and mortality. But there are no gains without some price to be paid, and the price is in the cultural rather than structural sector. Could it be that the healthy body is less able to share the suffering of others at the same time as health, one's own and that of others, is taken for granted, being no source of shared joy either? That health leads neither to a culture of compassion, nor a culture of submission follows its wake, but a culture of egocentrism? 


\section{Human Rights}

In principle human rights protect exposed individuals, emphasizing the privacy of the individual human body, of the individual human soul/ $\mathrm{mind} / \mathrm{spirit}$, and the equality of all categories of humans relative to the law. Human rights soften relations between the Center (the state) and a Periphery of individualized citizens, which is good; but also emphasize reliance on a protective, soft Center rather than human reliance on each other. An ethics of Alpha submission rather than Beta compassion, designed to soften (not weaken) the strong Alphas of Formation II and III, in ways paving the way to Formation IV.

\section{Industrialization}

No doubt this was a major factor in the transition from Formation II to III, and lead to well known problems of vertical division of labor (exploitation) within the company between employers and employees, within the country between raw material and industrial goods producing district and between countries also according to the degrees of processing. The organization at all three levels was Alpha, with a plethora of Beta groups flourishing at all levels, from boys' clubs of employers to workers' collectivities (not the same as Alpha type trade unions) controlling the level of commitment to the firm. So industrialization has been accompanied by anti-Alpha revolts of all kinds, from sabotage, go-slow, company strikes via general strikes to anti-colonial and antineocolonial movements. The struggle is still on. But the focus here is more on robotized, automated, symbolic interaction pattern with industrialization, if that is still the word. From that destructured and decultured perspective Labor and Third World struggles look almost utopian; people still relate to each other; they are not yet postmodern.

\section{Literacy}

Literacy can only be understood in terms of it alternatives: oralacy on one hand, and picturacy on the other. Oralacy has as a necessary condition memory, stored in the brain. Does it not stand to reason that what has to be memorized often is more easily remembered, recalled, related to others in Beta type relations (rather than the Alpha type relation of readers to authors), and for that reason may be more compelling? The decalogue can be retrieved from books and computers. But does that have the same binding quality as moral commands committed to the individual memory? If not, is literacy, however precious, not also paving the way from Formation II into nos. III and IV? 
Picturacy (TV, video) in principle mirrors reality and in practice constitutes a virtual reality, an as if (als ob, comme si) reality. The choice has been made for the viewer, as subjectively as any choice. Synchronic perception complements the diachrony of oralacy and literacy, but is also more easily confused with reality "out there". This, then, adds to the detachment by dehumanized structures and relativized cultures.

\section{Migration}

Whatever the reason, migration as massive mobility across borders, which often also means across cultures, will speed up transitions to Formation IV considerably, even to the new Formation I of the Los Angeles metaphor. Thus, a person, with or without friends and family, detached from the structures of the country of origin, arrives in the host country, presumably with his/her culture more or less intact. There has to be some attachment to a new Alpha structure, relating to the new State (permits, etc.), the new Capital (job, etc.), and may b also some footholds in the new Civil Society.

However, the cultural idiom being new relations will be thin indeed. The host culture is not easily internalized. A likely result is a tightly spun Beta group of immigrants suspected of being predators rather than prey (or, often, both). Los Angeles. This should not be confused with colonialist transfers of total societies, with the host population marginalized or exterminated.

\section{Poverty}

Of course poverty is important as a problem of all formations, when instead of looking at structures and cultures we focus on basic human needs and their satisfaction. But from a structural point of view poverty must not lead to atomie, it could also lead to tightly woven Beta groups fighting poverty together. And it does not have to lead to anomie, it could also lead to the famous culture of poverty of the favela, etc., which may sustain rather than negate poverty, but also make it more bearable. The worst poverty would be needs-deprivation combined with atomie and anomie, in other words the poverty of Formation IV. And this may very well be the condition under which Los Angeles is no longer a metaphor, but a world reality.

Another, updated perspective on poverty might bring in the jobless growth characteristic of the present world economy. The distinction between employed and unemployed is too sharp, however. More typical is perhaps not only underemployment but underpayment in the sense that the concept of the breadwinner able to feed a whole family, one 
job-one family, is disappearing. In principle this should force a number of people, in a family or other kiship units, or in a neighborhood, a commune, to join their incomes so that all can live from it, thereby fostering beta restructuration and solidarity.

\section{Roman Law}

It was all pre-programmed in Roman Law if the following reading of that law or basic philosophy is accepted. In what we generally assume to be true about primitive societies holism figures as a basic figure of thought, both for Humans and for Nature, although in practice this applies mainly to the near-Humans, meaning the in-group, and the near-Nature, meaning this side of the horizon, which for a nomadic people is considerable. This is very far from a basic figure of thought in Roman Law, dominio, individual ownership. The ownership or use concept of primitive peoples is a coupling of two holisms: we as a group use, with care, what we find in Nature. To go or jump from that figure of thought to the Roman holisms must yield to atomism. Humans must be subdivided into persons capable of ownership, an example being the pater familias, another the emperor; and Nature subdivided into entities capable of being owned, as land, plots and minerals, plants, animals, slaves/women/ children. Obviously, for this a census, the sciences of geometry, geology, botany and zoology gradually had to take shape. But once the subdivision was done on both sides of the Humans-Nature divide, with the holisms broken, the totality could be sewn together again, the Roman (to become the Western) way: through a one-one mapping of juridical persons on objects, the dominio. What belonged toeverybody would then belong to nobody; res communis, res nullius. For the non-Western world ownership was acquired by the "first, come, first see, first own" principle: through "discoveries". There were transition formulas: the Emperor is the only juridical person, like the pater familias for the family, assuming dominio of everything- in the West scorned as "Oriental despotism".

\section{Socialism}

We know it in its stalinist and post-stalinist configuration as superAlpha, with, say, 400 people planning for 400 million in Eastern Europe and the Soviet Union (about the same structure as regional television). Means of production were collectivized, but not at the level of communes as commune-ism but at the level of the state, as state-ism (etatism). Revolts were inevitable, not only because of the brutality and repression of (post-)stalinist countries. Planning made people passive, expropriating from them not only the right to plan their own production, but even to plan their own consumption and economy of their own household, 
restricting the range of what was available. Then people demanded their right to be subjects of their own economic fate. For the continuation, see Capitalism.

\section{Urbanization}

The city is a giant Alpha administratively and often also economically, but also better suited as a host of countless, rich, diverse, shifting and symbiotic Betas than any other human habitat, if for no other reason simply because it combines size and proximity into propinquity. It has other problems, such as slum-formation, and the alienation of those who are marginalized. The young, the old and women are often excluded from the rich Beta variety of bars and clubs. Moreover, modern cities are better designed for cars than for people, eliminating many good meeting places such as parks, open land, old buildings. Like industrialization, urbanization played a key role on the way from Formation II to Formation III. But these are the problems of yesteryear even if very dramatic in many places. The problem now and in the future is that the solutions to these problems should not carry the stamp of Formation IV.

\section{TWO THESES ON SOCIAL DEVELOPMENT}

No surprises for the reader in these two theses on social development, as the antedote to social disintegration:

The first thesis reads: Create strong Alpha and strong Beta structures; to promote structuration and reverse destructuration

The second thesis reads: Promote immanent and transcendent religion; to promote culturation and to reverse deculturation

If enacted this would place us in Formation II which is referred to as "traditional society", referring to that cycle of human history. But the definitions of these formations transcend the concreteness of the travel from nomadism to monadism. We also have a future, and the hunch derived from these deliberations is that we need both Alpha (because "some big is necessary") and Beta (because "small is beautiful"). But this in no way means moving backward in history (which would be impossible anyhow), but to try to create a new cycle. A not very promising beginning has already been indicated, not only the tribal warfare in the wastelands of Los Angeles, but also the warfare in Ulster, ex-Yugoslavia, ex-Soviet Union and Turkey in Europe; Rwanda, Somalia, Liberia and Sierra Leone in Africa; Guatemala and Mexico in Latin America; 
Burma, Indonesia and Cambodia in Asia, to give some examples. Strong on Beta, weak on Alpha, and very violent.

One still positive example of Formation II comes to the mind: Japan. Betas in the form of cohorts are incorporated into the Alphas of bureaucracies and corporations by way of lifelong employment (so that people stay together inside the organization) and seniority promotion (so that people stay at the same level for some time, being promoted together at least to startwith).

But at the same time Japan also benefits from the co- existence, in one society, of both transcendent (State Shinto), immanent (Folk Shinto, Buddhism) and secularism (Confucianism). In principle a Japanese not only lives both in Alpha and in Beta, but may also pay allegiance to all three systems of faith at the same time (and in addition to that Christianity and Rationalism). Thus, we would expect a certain resilience in Japan, being both structurally and culturally intact, playing on both structures and both cultures. This might look like redundance, but the key to resilience is exactly that, redundance to be on the safe side. Hence, we would expect relatively low disintegration rates of the usual kind, adding divorce to the typology of violence.

Japan is today exposed to a tremendous pressure both from the outside, particularly from the U.S., and from the inside, maybe particularly from bureaucrats, businessmen and scholars who have been to the U.S. and found the society liberating. As mentioned above, Beta and immanent religion can be confining; Alpha and transcendent religion both open up grand vistas. But the conclusion from these deliberations would be to be very careful: the costs of that type of modernization are enormous and the remedies not very clear as moving backward, recreating past structures and cultures, may be impossible. To pressure Japan into policies that will have moves toward Formation IV as a likely consequence should be classified as some kind of social crime, structurocide cum culturocide.

Which does not mean that Japan and Japan-similar countries are perfect. With more emphasis on social growth and costs and less on economic growth and costs good policies should emerge.

In general the first thesis would have two sub-theses: to recreate Beta, and to rehumanize Alpha. One way of doing this is found all over in Western countries: create Beta inside Alphas of any kind, bureaucratic, corporate, academic. Individualism being so basic to Western cosmology the Japanese way of tying people to the same organization for life will almost have a taste of imprisonment, and parallel promotion would disregard differences in individual potential and merit. But Beta 
integration does not have to be cohort- (i.e., social generation) based; it could also be work-related. The problem with experiments in teamwork and team-teaching would be the scarcity of compelling indicators of the value of social integration when there are little, no or even negative economic gains. At present the significance of social integration must come as a credo.

Thus, in any trend to abolish assembly-lines in favor of teams assembling the product together there is a clear potential for Beta growth and some Alpha decline. The same applies to modern office landscapes with a high level of mutual visibility, easily organized round tasks, grouping together those who should work together. The contrast would be the one person-one office structure, an architectural recipe for fragmentation, with the lunch, the coffee-break and the water-cooler as the only alternatives. And they are not so likely to be well suited for productionoriented Betas, with the exception of the "business lunch". But what, then, happens to reproduction-oriented Betas?

At the universities this would point to the colloquium as a fine Beta structure, for professors, for students, and for both. In the U.S. these structures are remarkably infrequent.

In banking this might point to the interesting lead by the Grameen Bank introduced in Bangla Desh. Really poor people do not have equity for bank loans, if they did the loan might not have been needed. Instead ten persons guarantee one tenth each, and together they constitute a Beta group around the debtor.

This reminds us of the famous Zehnergruppen in ex-DDR, groups of ten people working together, introduced in economic organizations to increase production and productivity. As such they may have failed, as Beta groups they seem to be much missed. Of course, Western capitalist society have much to offer in terms of voluntary organizations (although they often acquire Alpha character, becoming big and formalized). But they are usually not directly work related.

Another interesting Beta innovation is, of course, what in German is called the WG, the Wohngemeinschaft, the "commune" of like-minded people living and to some extent consuming together, sharing all the work of the household. An extended family except for the kinship factor. Of course this was a longing for Beta in a society where even nuclear families collapse. It should not be judged by the ability or wish of the members to stay together as long as "real" family members; the socio-logic is different. It may also be a major way of internalizing conviviality norms.

Rehumanization of Alpha: simply ban all automated responses, let 
people have a chance to put their questions to a human being and get human answers, however fallible, back. The social costs of not doing so will by far outweigh the economic costs of employing more people in the services. Moreover, such positions do not have to be full time jobs. What is needed is humanity.

Then, some points on culture, in the narrow sense used here of binding ethical rules. In the choice between an ethics of compassion and an ethics of submission, between a religion of meditation and one of prayer the answer might be to choose both, with an important proviso to be spelt out shortly. There is much to build on; rich religious experience to draw upon. There is also room for secular approaches, perhaps not the Enlightenment cult of Ratio so much as the general wisdom of "reciprocal rights and obligations", found all over the world, with at least some ethical inspiration to be derived from its moral basis, the lex talionis, both in its negative and positive formulations.

But there is another distinction that may be more important than the sacred-secular and immanent-transcendent; hard vs. soft. The word religion comes from religare, relink, reconnect with that out there, the holy, the sacred. Union of some kind is the goal of all religions, with Others past-present-future in this life by immersing oneself fully in the net of compassion with all life, with God and others in the afterlife by submitting to His commands. In mysticism this experience probably becomes like a light so strong that everything else loses its contours.

Imagine now a circle around this epicenter of religious experience, divided into sectors for each religion. The notion of religion as linking, connecting, unifying is still there. Religion is not used to draw lines between the adherents of this or that religion, nor between the righteous and the sinners. A religion is more seen like a language, an idiom in which religious experience is expressed. This is the soft circle, perhaps more found in religions of compassion than of submission.

Outside this circle comes the circle for hard religion. The names of the sectors for the religions are the same, but the message changes character. The focus is on what divides rather than ln what unifies. Other religions are denounced as pagan, or even worse, as heresy. The sinners are in for very harsh treatment; even hell, the torture chamber of hard religion, is invoked for their afterlife. The righteous from the right religion are seen as Chosen Persons in the eyes of God, and some nations are often seen as closer to God than others, including the sinners and the non-believers. Naturally, hard religions of that type can be well suited as state religions, mirroring in religious terms the struggle among states in world politics.

So, an elaboration of the second thesis for social development would 
be to promote the softer aspects of the religions, and try to demote the harder (harsher) aspects. Thus, the most important struggle in the religioscape, the religious landscape of the world, is not the traditional struggle among religions as to which one is most suited to carry humanity forward, but he inner struggle between the unifying and the divisive forces. "Soft religionists of the world unite, you have only your harder brother and sisters to lose"? Not quite, because that would draw a too hard line between soft and hard. The important point is that the struggle is within rather than between, and that each religion has this struggle on its agenda. Moreover, the harder aspects (Inquisition, witch-burning) have no doubt contributed to giving religion a bad name. Quakers and Sufis, Buddhists and Baha' is offer much softer approaches. But none of them would be entirely free from the harder aspects.

For humanists this would imply a softening of the line they sometimes draw between themselves and the religionists, following the tradition of 18th century Europe. In short, there is a message to everybody in the word that is No. I in the vocabulary of the present Dalai Lama: compassion.

Do these two theses add up to the standard conservative message of family and Christianity? No, but that message is not rejected either. Her "family" is taken in a much broader sense, Beta. Moreover, attention is paid to how to soften, humanize, the other major structural type, Alpha. And instead of Christianity we are of course speaking about all religions, scared and secular (civil), but then limiting it again to the softer aspects. But conservatives have probably diagnosed the present situation better than many liberals/marxists/greens, by focussing on one structural and one cultural component. People on the left tend to be almost obsessively focused on some kind of Alpha, its proper design, function and structure; its distribution of rights and duties, power and privilege, at the expense of Beta (except for the greens) and culture, ethos. But however that may be, the present paper tries to give something to both, perhaps with the strong admonition to the left of taking culture, ethos, religion more seriously, getting out of the habit of seeing them as "superstructure" or "opium".

Nothing of this will emerge automatically, and in crises people may also turn to the harder aspects of the religions with divisive messages and Alpha organization. But just as we postulate a normal human Beta drive for the small an tight, why not also dare postulate a corresponding religious inclination?

And that brings us to the end of this narrative, with the short excursion into a very uncertain future. With structural and cultural ties being dissolved, we are in the, some would say absurd, situation that the most 
modern and economic/technically developed have become the socially speaking least perhaps least developed, or de-developed. Obviously, we are then not talking about the relative presence of social services (per 1,000 inhabitants, etc.) but of something held to be much more basic: structuration and culturation. Social services may be a part of the problem rather than of the solution to the extent they are operated through increasingly dehumanized Alpha structures. With atomie/anomie being the basic social price paid for modernization because people have taken for granted that society is solid and can be drawn upon for any purpose, the more and most developed have suddenly become the less and least developed.

Does that mean that the economically/technically least developed are the socially most developed? Not necessarily. Some very poor Third World countries have been ravaged by unspeakable violence between classes, nations and clans, with the rest of the world often siding with one against the other(s). Some of this violence may be attributable to atomie/anomie, and there are signs that it has reached the micro level of social organization, with family members butchering each other; i.e., total violence.

However, much is intact, in Southern and Eastern Europe more than in North-Western Europe; in Central and South America more than in North America. One day the present First world may ask the present Third world for advise about social development. If that happens, the world would have taken a major step forward. 



\section{LA INFANCIA EN UN MUNDO DESBOCADO}

\section{JORGE HURTADO}

Departamento de Sociología II, Psicología, Comunicación y Didáctica. Universidad de Alicante.

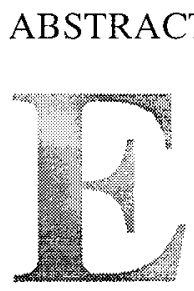

1 artículo repasa las investigaciones recientes sobre el estado de la infancia, a escala global y en los países desarrollados, como indicadores relevantes para medir el progreso y para hacer un balance de la civilización capitalista. A la luz de los datos ofrecidos por instituciones oficiales y de gobierno mundial el arqueo no es alentador. Desde el punto de vista de la situación de la infancia -un indicador privilegiado en la medida en que es previa a cualquier mérito o logro personal- la civilización capitalista es tan bárbara como cualquier otra civilización o sistema social anterior, si no más considerando su superioridad técnica y productiva.

\section{UN MUNDO DESBOCADO}

Nuestra época, dice Giddens en un reciente libro, surgió bajo el impacto de la ciencia, la tecnología y el pensamiento racional, forjado por la Ilustración, «por los libros de pensadores que luchaban contra la influencia de la religión y el dogma, que querían reemplazar por un enfoque más razonado de la vida práctica» (Giddens, 2000: 13). Liberados de los hábitos y prejuicios del pasado, y armados con la posibilidad de una comprensión racional de nosotros mismos y del mundo, el entendimiento de la historia debería haber hecho más fácil su manejo; y el ulterior desarrollo de la ciencia y la tecnología haber facilitado una vida más segura y predecible, un mundo más estable y ordenado. Paradójicamente, sin embargo, en lugar de estar cada vez más bajo nuestro control, el mundo parece fuera de él, un mundo desbocado, y «algunas de las tendencias que se suponía harían la vida más segura y predecible para nosotros, incluido el progreso de la ciencia y la tecnología, tienen a menudo el efecto contrario» (Ibíd.: 14), como es el caso de los impactos medioambientales o de las imponderables modificaciones genéticas. Más aún, la incertidumbre y el riesgo -una categoría que no 
existe en las sociedades tradicionales, poco orientadas al futuro- no sólo son hoy superiores a los de tiempos anteriores sino que afectan a todo el mundo y, lo que es más significativo, provienen de peligros creados por nosotros mismos, son riesgos no externos sino manufacturados (Giddens, 2000: 39; Beck, 1998a).

¿Cómo ha podido prevalecer esta evolución al mismo tiempo fatal e inesperada? Tiene que ver, desde luego, con la expansión de esa civilización, de esa cultura codificada por la Ilustración que consagró el triunfo intelectual de la ciencia racional y experimental, es decir, de la búsqueda de la verdad como algo separado de la indagación sobre lo bueno y lo bello (Wallerstein, 1997). Esa civilización, además, como es sabido, se expandió en tres grandes oleadas entre 1450 y 1900 hasta abarcar todo el mundo, un proceso de larga duración que hoy se denomina globalización, el mantra, la invocación ritual que, al decir de Castañeda, domina nuestra época (Castañeda, 2000).

El término civilización, sin embargo, como recuerda Wallerstein en su balance de la «civilización capitalista» (Wallerstein, ibíd.: 19-40), tiene al menos dos significados. En plural, una civilización designa un conjunto de costumbres, una visión del mundo, una estructura y una cultura (tanto popular, material como de elite) que conforma un todo histórico y que coexiste con otras civilizaciones. Su uso en plural hace referencia, así, a una noción de civilización como particularidad en contraste con otras estructuras y culturas.

En singular, en cambio, como proceso civilizatorio opuesto a la barbarie, el término es ciertamente hijo de la Ilustración. Reflejaba, como bien señala Giddens, el triunfo intelectual de la ciencia racional y experimental, y es concomitante a la idea de un progreso continuo en la condición humana y social, no importa cómo se conceptúe exactamente. Para algunos, en efecto, civilización es sinónimo de modernidad, de éxito económico basado en los avances técnicos y en las mejoras constantes de productividad, que avalan la creencia histórica en el desarrollo y en la posibilidad del progreso. Buena parte de las teorías convencionales sobre el desarrollo sostienen esa fe modernizadora y, frecuentemente, transitiva (Tortosa, 2000). Es decir, la subyacente interpretación whig de la historia a la que se refiere perplejamente Giddens, según la cual el presente es el mejor de los tiempos y el pasado debía desembocar inevitablemente en el presente, ha servido no sólo para analizar y describir, sino también para prescribir: «El progreso no sólo se asumió y analizó, también se impuso» (Wallerstein, 2000: 106), convirtiéndose así en motor de todas las ciencias sociales aplicadas cuya pretensión era, según la vieja fórmula comteana, «savoir pour prévoir et prévoir pour pouvoir». 
Para otros, sin embargo, el desarrollo económico tout court no basta para definir esa civilización en singular, cuya exclusiva occidental se ve hoy amenazada por el desarrollo de los «blancos honorarios» asiáticos. Se requiere, además, el triunfo del individualismo y de los valores fríos frente a las instancias colectivas, recíprocas o redistributivas, la extensión de los derechos como derechos humanos individuales, o la mejora de los comportamientos sociales, la circunscripción de la violencia legítima. Es decir, del conjunto de valores que la civilización occidental ha sancionado como legítimos y que conforman las base del universalismo, al mismo tiempo una visión del mundo y una epistemología (Wallerstein, 1988).

Por supuesto, desde sus orígenes, el universalismo y la idea de progreso fue objeto de feroces críticas teóricas y prácticas. Entre las segundas, el nacionalismo y lo que hoy conocemos como reacciones/regresiones identitarias, cuya cíclica combustión parece guardar relación con los ciclos económicos y con las luchas por la hegemonía (Tortosa, ibíd.), pero también con los momentos de expansión impetuosa del universalismo/globalismo y, en los últimos tiempos, con el derrumbe de las ideologías que nacieron con la Ilustración (Castells, 1998a). En la teoría, por otra parte, las críticas a la idea de progreso y a la posibilidad de generalizaciones universalistas pareció patrimonio de los conservadores/reaccionarios hasta el último tercio del siglo XX, que no dudaron en tildar las intervenciones deliberadas y premeditadas para reconstruir el orden social como una nueva fe, la fe de los verdaderos creyentes, negados para entender que el dominio de la acción humana está gobernado por dos grandes principios, perversidad y futilidad, cuya ignorancia, además, genera riesgo (Hirschman, 1991). Desde 1968, sin embargo, el escepticismo sobre el progreso y las virtudes del universalismo ha ganado también adeptos en la izquierda, receptivos a la idea de que el progreso y la reforma hayan conducido a parte alguna, recelosos sobre las buenas intenciones que han empedrado el terreno de este infierno, empeorando el mundo para la mayoría en vez de mejorarlo (Wallerstein 1988, 1997).

Eric Hobsbawm ha sostenido que el mundo actual es, tal vez, el primero en el que, haciendo bueno el despectivo deseo de María Antonieta, la gente común puede alimentarse con brioches en vez de con pan (Hobsbawm, 2000: 144). Ésta es, sin duda, una descripción bastante ajustada de lo que sucede en las sociedades civilizadas, avanzadas, las que viven de hecho en el mismo tiempo o en tiempos similares. No es evidente, sin embargo, que todas las sociedades actuales sean verdaderamente contemporáneas, ni que las sociedades más avanzadas señalen la senda que, a su debido destiempo, todas habrán de recorrer, a pesar de la pesada retórica sobre la globalización. 
Lo más característico de la globalización, escribe Giddens, no es la muy evidente interdependencia económica, ni siquiera los grandes sistemas, como el orden financiero mundial, sino la transformación del tiempo y del espacio en nuestras vidas (Giddens, 1999). De un lado, acontecimientos lejanos, económicos o no, nos afectan más directamente e inmediatamente que nunca. Por el contrario, decisiones individuales, como hábitos dietéticos o decisiones de consumo o de no consumo, tienen consecuencias sobre productores muy alejados de nosotros. Más aún, «la globalización no tiene que ver sólo con lo que hay 'ahí fuera', remoto y alejado del individuo. Es también un fenómeno de 'aquí dentro', que influye en los aspectos íntimos y personales de nuestras vidas» (Giddens, 2000: 24-25).

Así formulado, en efecto, ¿quién lo negaría? Pero, ¿la posibilidad de evitar sus efectos indeseados, de influir incluso en las decisiones individuales, creando si fuera necesario nuevos escenarios de lucha, es de verdad para todos la misma? ¿Estamos todos dotados de similares recursos, de capacidad de negociación, de posibilidades de elección entre la indudable ampliación de opciones vitales que la modernidad ha acarreado?

No es evidente. Las tradiciones, visiones y valores culturales que han sido denominados «modernismo» implican formas de experiencia caracterizadas por la anomia y por una unidad paradójica, una unidad en la desunión (Anderson, 1998: 51-90). Las transformaciones objetivas, acaecidas en los últimos cinco siglos en los pueblos occidentales, habrían permitido, en efecto, distinguir lo nuevo o lo moderno de lo antiguo o lo tradicional, agrupando las distintas sociedades en un continuo progresivo. Pero, a su vez, las transformaciones subjetivas y personales que se producen bajo su impacto habrían provocado necesariamente una tensión dramática en los individuos, en quienes convivirían inseparablemente la sensación de ensanchamiento y de alborozo liberador y una profunda desorientación e inseguridad, desesperación y frustración. Como bellamente escribe Berman, la modernidad es así también un modo de experiencia vital que comparten los hombres y mujeres de todo el mundo, y que se caracteriza por prometer «aventuras, poder, alegría, crecimiento, transformación de nosotros y del mundo y que, al mismo tiempo, amenaza con destruir todo lo que tenemos, todo lo que sabemos, todo lo que somos» (Berman, 1988: 1).

Las oportunidades de destrucción o de alegría no son, de todos modos, equiparables para todos. De un lado, ciertamente, tenemos élites globalizadas, una cosmocracia que ha abolido las restricciones de espacio y que no tiene tiempo, habitantes de un eterno presente, de un tiempo intemporal (Castells, 1997) y, de otro, pobres localizados adheri- 
dos al espacio y superabundantes en tiempo vacío, cuya capacidad de elección se encierra entre el fuego del hambre y la pira de la patera. Más aún, entre ambos extremos parece haberse roto cualquier tipo de vínculo, incluido el de las viejas dependencias de la explotación, de modo que las desigualdades se despliegan ahora en el ningún lugar de la sociedad mundial (Sartori, 1998: 117-121), y la libertad de acción y de elección de los unos se dobla en el implacable destino de los otros.

Debemos especificar, entonces, en qué universalismo creemos o, mejor aún, confrontar la retórica del universalismo abstracto con la férrea realidad de las oportunidades desiguales. No se me ocurre mejor modo que empezar por la infancia, por una infancia anterior a cualquier mérito contraído, pura distribución aleatoria en el espacio físico y social, previa al ejercicio de la responsabilidad individual. Amartya Sen ha señalado que todos los enfoques contemporáneos referentes a la ética de las condiciones sociales son igualitarios respecto a algún valor o actividad central que las distintas teorías consideran especialmente importantes -e importa subrayar, quizás contra la opinión del autor, el término contemporáneo porque en sistemas sociales anteriores bastaba con la igualdad ante Dios como paliativo de la desigualdad mundana-. Dicha igualdad puede, así, referirse a las libertades y a la distribución de bienes elementales (Dworkin), de ingresos y riquezas (los socialismos materialistas), de utilidades (las distintas variantes benthamianas), de libertades (Nozick), de trato legal o político (Buchanan), o de capacidades (Sen), entendidas como la libertad de la que debiera gozar una persona para buscar su bienestar (Sen, 1995).

Otros autores, como Galtung o Tortosa (1992), pueden ser considerados universalistas al vincular el desarrollo con la cobertura de unas «necesidades básicas»-seguridad, libertad, bienestar e identidadque, éstas, sí, resultan ser verdaderamente universales, es decir, aplicables a cualquier política o situación en cualquier tiempo y en cualquier lugar, aunque los «satisfactores» pueden, ciertamente, variar, y aunque deben contemplarse en su totalidad compleja, sin privilegiar a una en detrimento de las otras, eslabonadas en una cadena indisoluble que no sacrifique ninguna en el altar de las demás, como habitualmente ha sucedido.

Ahora bien, en este elemental sentido, ¿cómo ha evolucionado, digamos en los últimos 40 años, la cobertura de dichas necesidades? ¿Qué pasos se han adelantado en favor de una efectiva igualdad de derechos, de títulos de acceso tanto a los bienes y servicios esenciales para un digno mantenimiento de la vida como a la plena ciudadanía? Respondamos, primero, brevemente a estas preguntas, antes de referimos a los impactos de dicha evolución sobre la infancia. 


\section{EL SISTEMA GLOBAL. DESIGUALDAD Y POLARIZACIÓN}

Los Informes sobre el Desarrollo Humano, pese a las no despreciables críticas de que son objeto (Navarro, 1999), permiten medir de modo sintético la magnitud de las desigualdades y su evolución en el tiempo. ¿Qué nos dicen, a grandes rasgos, dichos Informes? Indican, para empezar, que la relación entre el $20 \%$ de la población más rica y el $20 \%$ más pobre, que era de 30 a 1 en 1960, creció hasta una proporción de 61 a 1 en 1991 y de 82 a 1 en 1995. Mas aún, los mismos Informes hacen notar que las tres personas más ricas del mundo tiene activos que superan el PIB combinado de los 48 países más pobres o menos adelantados y sus 600 millones de habitantes, o que los 225 habitantes más adinerados -los que ocupan los primeros puestos en la clasificación de revistas como Forbes o Fortune- tienen una riqueza combinada igual al ingreso anual del $47 \%$ más pobre de la población, unos 2.500 millones de habitantes (PNUD 1998: 30). El coste de lograr y mantener acceso universal a la enseñanza básica para todos, atención básica de salud para todos, atención a la salud reproductiva de todas las mujeres, alimentación suficiente, y agua limpia y saneamiento para todos, ascendería así a unos 44 mil millones de dólares por año, una cifra equivalente al $4 \%$ de la riqueza combinada de esas mismas 225 personas más ricas del mundo, y casi 20 veces inferior a los gastos anuales en defensa (más de 800.000 dólares anuales).

Sucede, en cambio, que, según el Informe del 99, de los 4.400 millones de personas que viven en los países en desarrollo, tres quintas partes viven en comunidades que carecen de infraestructuras higiénicas básicas, un tercio carece de agua potable para beber, un cuarto no puede acceder a una vivienda adecuada, un quinto está infraalimentado, $y$ otro tercio tiene una esperanza de vida inferior a los 40 años (PNUD 1999: 28). Mientras, los gastos militares en el mundo son más de cien veces superiores al coste de una enseñanza básica para todos; la atención obstétrica y ginecológica para todas las mujeres costaría tanto como se gasta en perfumes en Europa y los Estados Unidos y casi tanto como el consumo de helados en Europa; en fin, el gasto en cigarrillos y alcohol en Europa, o de drogas en el mundo, multiplica casi por dos, por cuatro o por ocho, respectivamente, el coste conjunto de enseñanza básica, agua y saneamiento y salud reproductiva de las mujeres para todo el mundo (PNUD, 1998: 37).

En otros términos, la segunda mitad de este siglo terrible que agoni$\mathrm{za}$-justamente, por cierto, el periodo en el que las políticas de «desarrollo» para los países periféricos adquieren carta de naturaleza oficialha conocido una explosión de desigualdad creciente y vertiginosa, de modo que a las puertas del siglo XXI más de 3.000 millones de personas 
(más de la mitad de la población mundial) viven en la pobreza, con menos de dos dólares al día, y 1.200 millones (una quinta parte de la población mundial, de los que la mitad, 600 millones, son niños ) con menos de un dólar diario (Banco Mundial, 2000).

Pobreza, sin embargo, no es sinónimo de desigualdad, al menos desde una óptica analítica. La desigualdad mide la distancia entre los miembros de una sociedad dada, mientras que la pobreza se refiere a la insatisfacción de las necesidades básicas de una parte de la sociedad de forma involuntaria y permanente, cronificada (Tortosa, 1993: 87 ; 2000). Es decir, teóricamente, es posible el crecimiento de la desigualdad sin un ascenso simultáneo de la pobreza así definida, y no simplemente como una mera diferencia de renta; una «renta baja» respecto a las comunes en una sociedad dada, una «diferencia de ingresos», no equivale a una renta inadecuada para la cobertura de las necesidades básicas (Sen, 1995: 119-133). La pobreza, además, es multidimensional y dinámica. No se refiere sólo a la falta de lo necesario para el bienestar material (ingresos, bienes primarios, recursos) en un momento dado, sino a la denegación de las oportunidades y opciones más básicas del desarrollo humano: una vida larga y decente, dignidad, autoestima, el respeto de los otros y de las cosas que la gente valora en la vida, la participación en la comunidad, poder aparecer en público sin avergonzarse y otros logros sociales más complejos (Towsend, 1993; VV.AA., 1995; PNUD, 1998). Si el ingreso no es la suma total de la vida humana, su carencia no puede ser, por tanto, la suma total de la privación humana, y el acento debe desplazarse hacia el «fracaso de las capacidades básicas para alcanzar determinados niveles mínimamente aceptables» (Sen, op. cit.: 126), es decir, de las posibilidades reales de convertir los ingresos y los recursos en capacidades para funcionar. En otros términos, los recursos son importantes para la libertad, pero no son lo mismo que la libertad, y los ingresos son cruciales para evitar la pobreza, pero su insuficiencia debe referirse al fracaso para generar capacidades mínimamente aceptables más que a los logros, no independientes de características sociales y/o personales.

En los hechos, sin embargo, la «pobreza capitalista» (Tortosa, 1993) con frecuencia es la expresión de la desigualdad. Es decir, con no excesivas excepciones, los países que suelen contener más pobreza son aquellos que se distinguen por mayores desigualdades de renta, y los países con menor pobreza son aquellos con menor desigualdad, como consecuencia de estados más activos en la redistribución de la renta, en políticas activas de empleo o en la procura de educación, atención sanitaria, vivienda y otras formas de salario indirecto. La existencia de paquetes de bienes básicos y universales, como los nombrados, además, 
normalmente correlaciona positivamente con los contenidos del «buen desarrollo», del desarrollo conforme a las necesidades básicas satisfechas, tanto como su ausencia suele coincidir con los signos del «maldesarrollo» según las necesidades básicas insatisfechas (Tortosa, 2000).

¿Cuáles son, no obstante, los efectos de la extensión de la pobreza y de las disparidades reseñadas sobre la infancia?

\section{LAS PROBABILIDADES DE UN RECIÉN NACIDO}

Se ha calculado que en el año 1999 nació el/la niño/a que elevará a 6.000 millones el total de la población mundial. Carol Bellamy, Directora ejecutiva de UNICEF, ha comentado en un sucinto artículo las probabilidades que enfrenta (UNICEF, 1999a). Para empezar, dicho recién nacido tiene menos de una posibilidad entre 10 de nacer en un hogar relativamente próspero, como el de la mayoría de las familias de los países industrializados o el de la minoría rica de un país en desarrollo. Tiene, en cambio, 3 posibilidades entre 10 de nacer en situación de pobreza extrema, y 4 entre 10 probabilidades de formar parte de una pobreza sólo ligeramente más llevadera. De hecho, «la mitad de los pobres del mundo son niños, y el número de criaturas que nacen actualmente en condiciones de pobreza es mayor que en cualquier época previa. Se trata de un aumento sin precedentes históricos en la cifra total de personas en la pobreza» (Bellamy, op. cit: 1).

¿En qué repercute sobre la infancia este inquietante aumento de la pobreza? Desde luego, la probabilidad de morir antes de los cinco años es muy superior en países menos desarrollados -que acogen al $85 \%$ de la población mundial-que en los países avanzados. Si sobreviven a esa edad, sin embargo, es improbable que su estado de salud sea aceptablemente bueno. No sólo escasearán los recursos energéticos, sometidos a una intensa sobreexplotación que acentuará su pobreza futura, sino que se verán expuestos a trastornos causados por la contaminación del agua, el saneamiento deficiente y la degradación del medio ambiente, factores que dañarán gravemente su estado ya valetudinario. También es probable, tanto más si viven en áreas rurales o en los enormes cinturones de miseria de las ciudades del Tercer Mundo, que la desnutrición afecte su desarrollo físico y mental, con pesos y tallas inferiores a la media, y dificultades dramáticas para desarrollar su potencial. Casi 12 millones de niños menores de cinco años mueren todos los años innecesariamente, de enfermedades fácilmente prevenibles (vacunas, atención obstétrica), y más de la mitad de los niños de esa edad en Asia Meridional nacen con un peso inferior al normal, mientras 
que casi la mitad de los lactantes africanos no han sido inmunizados contra las enfermedades mortales más comunes (UNICEF, 1999a: 9$15)$.

Si viven, además, en el África subsahariana, en la India o Camboya, la posibilidad de quedar tempranamente huérfanos a causa del SIDA se incrementará enormemente, así como la posibilidad de morir ellos mismos a causa de esta pandemia (UNICEF, 1999a: 17-25). En África, por ejemplo, el sida ha matado ya a 11 millones de personas, de las que el 25\% (2,75 millones) eran niños. Un $64 \%$ de los que nazcan en Botsuana en el 2000 morirán de sida antes de cumplir los 5 años, y el número de huérfanos por la misma causa se triplicará por tres en el mismo periodo. $\mathrm{Si}$, de todos modos, sobreviven, su esperanza de vida será sustancialmente inferior a la de los países más avanzados, en una proporción que bien puede ser del doble de años vividos (por ejemplo, entre Japón y Suecia, de un lado, y Malawi y Uganda, en el otro).

La desnutrición, así, incrementa la exposición a las enfermedades, y las enfermedades acentúan la desnutrición, alimentándose recíprocamente en una espiral descendente, configurando una «violación de los derechos humanos tan aborrecible como la tortura, además de constituir una desventaja devastadora para el desarrollo económico de los países» (Bellamy, op. cit.: 3). El desarrollo económico se ve, además, lastrado cuando «cerca de 1.000 millones de personas van a entrar en el siglo XXI sin los conocimientos necesarios para leer un libro o firmar con su nombre, y mucho menos para manejar una computadora o comprender un simple formulario» (UNICEF, 1999b: 7; INTERMON 1999; Mayor Zaragoza, 2000).

En efecto, 855 millones de adultos son analfabetos funcionales -de éstos, 2 de cada 3 mujeres-, y 130 millones de niños crecen sin poder recibir una educación básica, mientras que otros muchos millones de niños languidecen en situaciones donde la enseñanza no alcanza los mínimos requisitos. Las niñas, por otra parte, son las más.afectadas por esta situación, representando 3 de cada 5 niños del mundo en desarrollo que no reciben educación primaria ( 73 de los 130 millones de niños sin escolarizar). Y es que nacer niña, por cierto, sólo incrementará las ya enormes desventajas, tanto peor si, además, se forma parte de un grupo étnico minoritario o de poblaciones indígenas mayoritarias, pero radicalmente excluidas. Las niñas reciben así un trato más negligente y peor alimentación; se verán discriminadas en mayor proporción del acceso al estudio, o interrumpirán antes su escolarización por ahorro de costes o para ocuparse de tareas domésticas en el hogar; sufrirán diversos grados de violencia y abuso, incluyendo la mutilación genital (que es infligida a dos millones de niñas por año), o la prostitución infan- 
til forzosa, que afecta a muchos millones en todo el mundo (Congreso Mundial 1996; UNICEF, 2000); resultarán embarazadas en la adolescencia (como la mitad de las mujeres en África o la tercera parte en América Latina), y se convertirán en madres antes de madurar como mujeres. Si no perecen en el alumbramiento -tienen el doble de posibilidades de perecer en el parto que una mujer adulta-, los hijos de esas niñas pesarán normalmente menos de $2,5 \mathrm{~kg}$., por deficiencias nutricionales de la madre, y su insuficiente desarrollo físico prefigurará una mayor exposición a la enfermedad, dificultades intelectuales y un desempeño escolar deficiente, que lastrará sus oportunidades vitales.

Sin embargo, los beneficios de la educación, al menos de la básica, para el progreso de las naciones, y singularmente de la educación de las niñas, no necesita ser resaltada (Núñez y Tortella, 1993). La educación de las madres reduce la mortalidad de lactantes y niños, y la de las mismas madres en el parto. Los hijos de madres más educadas tienden a estar mejor nutridos, a padecer menos enfermedades, y tienen más probabilidades de recibir educación y alfabetización. Cuantos más años de educación haya recibido una mujer, tanto más tardio será su matrimonio y menor el número de hijos que probablemente tendrá. La educación de las mujeres tiene, en fin, profundos efectos no sólo personales (sobre los propios hijos, o sobre ellas mismas, al incrementar sus oportunidades y opciones, y permitir la evitación de situaciones de opresión y abuso), sino sociales, al incrementar su receptividad e influencia en iniciativas de desarrollo en las que desempeñan un papel tan central como frecuentemente ignorado (Declaración de Beijing y Plataforma para la acción, 1996: 73-89 y 245-261; UNICEF, 1999b: 51-62).

Los niños, además, trabajan y mueren como soldados o víctimas en guerras en las que resultan ser, con mujeres y ancianos, los más perjudicados (OIT, 1996; UNICEF, 1999b; Sedky-Lavandero, 1999). Según la Organización Internacional del Trabajo, en efecto, 250 millones de niños entre los 5 y los 14 años trabajaban en 1996 por un salario en los países en desarrollo, de los cuales 120 millones lo hacían a tiempo completo. Dicho cálculo descuenta, no obstante, un incremento del trabajo infantil que la OIT juzga significativo pero que no cuantifica, en Europa Oriental y en las economías asiáticas en transición hacia el mercado. Existe, además, abundante evidencia empírica sobre un crecimiento explosivo del trabajo infantil en los mismos países desarrollados, relacionado con el deterioro de las condiciones de vida y de trabajo de los trabajadores más descualificados, con el incremento de la inmigración ilegal, y con el auge de la pequeña economía criminal. La esclavitud misma, el trabajo cautivo, no ha muerto, y afecta sobre todo a niños que son ofrecidos como garantía por deudas contraídas por los padres, sobre todo en Asia (India, Thailandia, Filipinas). 
En cuanto al impacto de la guerra sobre los niños, en 1996, y sólo durante la última década considerada, UNICEF calculaba que, en los conflictos no estructurados posteriores a la Guerra Fría -conflictos que tienen que ver con guerras civiles internas y la desintegración de numerosos Estados- resultaron muertos dos millones de niños, entre cuatro y cinco millones quedaron inválidos, más de un millón quedaron huérfanos o separados de sus padres, 12 millones perdieron su hogar y más de 10 millones sufrieron traumas sicológicos difícilmente reversibles. En el mundo de la posguerra fría, según OXFAM, el $90 \%$ de las víctimas de la guerra son civiles, el 75\% de los refugiados y desplazados son mujeres y niños, y de las víctimas de la guerra el 50\% son niños (OXFAM, 1998: 8), mientras que en la Primera Guerra Mundial sólo el 5\% de las víctimas fueron civiles, cifra que se elevó ya al $48 \%$ en la Segunda Gran Guerra. Trescientos cincuenta mil niños son, por otra parte, usados en conflictos armados de diverso tipo como soldados baratos, obedientes, fácilmente adoctrinables, fanatizados hasta su propia muerte, mientras que un tropel de niñas prestan servicios domésticos, sexuales o incluso militares, sometidos/as a una brutalidad incesante (Sedky-Lavandero, 1999).

Hasta aquí, sin embargo, me he referido sólo a lo más probable. En la otra cara de la luna, sin embargo, donde las oportunidades materiales abundan, y el horizonte de capacidades se amplía inimaginablemente, los menores parecen sujetos a nuevas de formas de vulnerabilidad, impensables en el que iba a ser el «siglo de los niños», según la célebre fórmula de la educadora feminista sueca Ellen Key. Esa acrecentada vulnerabilidad, aun sin parangón con las situaciones predominantes en los países periféricos, presentan, sin embargo, cierta similitudes con procesos que se desarrollan en el conjunto del planeta. Déjenme explorarlas brevemente, antes de intentar poner de relieve los procesos subyacentes a esta fatal evolución.

\section{MENORES EN EL PARAÍSO. UNA EVOLUCIÓN INESPE- RADA.}

Como ha señalado Therborn, «las dos fuentes fundamentales determinantes en el establecimiento del concepto de minoría de edad han sido las legislaciones relativas a la educación obligatoria y las que regulan las condiciones de trabajo» (Therborn, 1993: 87). La concepción moderna del menor está, además, íntimamente relacionada con el desarrollo del Estado moderno y del mercado, con la lenta emergencia de un individualismo igualitario, que se tradujo, en el ámbito de las relaciones familiares, en el concepto de «familia centrada en el menor», y en 
la lenta consecución, primero por parte de las mujeres, desde la segunda mitad del XIX, de la igualdad de derechos frente a la desigualdad de obligaciones que soportaban como esposas, hijas y por su condición de mujeres en sí. El proceso de emancipación de los menores del poder absoluto de los padres fue, sin embargo, más lento y tardío, inspirado curiosamente en la protección contra el trato cruel que se dispensaba a los animales, y se construyó en alianza conflictiva con la liberación progresiva de la mujer del poder patriarcal. Es decir, los dos procesos (emancipación de las mujeres y reconocimiento de los derechos de los niños), como señala Therborn, «han estado estrechamente ligados pero no son ciertamente idénticos y han competido e incluso entrado en conflicto entre sí» (Therborn, ibíd: 96). Ambos, sin embargo, han resultado decisivos en el resquebrajamiento de esa estructura, tan antigua como la historia, y probablemente tan antigua como la sociedad misma, que es el patriarcado.

¿Qué es el patriarcado? El patriarcado es una estructura básica de las sociedades contemporáneas, y probablemente de todas las sociedades conocidas. El patriarcado, en efecto, se caracteriza por el predominio, arraigado en las instituciones, de los hombres sobre las mujeres y los hijos en la estructura familiar. Por supuesto, el patriarcado permea y modela la organización de la sociedad en su conjunto (economía, política y cultura), incluyendo las relaciones interpersonales, pero su piedra miliar son las pautas de relación que se establecen en el interior de los grupos domésticos y que han mostrado una increíble resistencia al cambio a lo largo de la historia.

Hace 151 años, en el Manifiesto, sin embargo, Marx y Engels ya observaron que, bajo las reglas del capitalismo, los miembros de las sociedades avanzadas se veían sometidos a una incesante conmoción, a una inquietud perpetua, a un constante movimiento. Así, según la fórmula ya clásica: «Todo lo sólido se desvanece en el aire; todo lo sagrado es profanado, y los hombres, al fin, se ven forzados a considerar serenamente sus condiciones de existencia y sus relaciones recíprocas».

Pues bien, no con serenidad sino con mucho dolor, de forma traumática, eso es precisamente lo que ha sucedido. El velo de emocionante sentimentalismo que encubría las relaciones familiares se ha rasgado, pero en su lugar no se han desarrollado nuevos acuerdos, nuevos lazos, nuevas relaciones más recíprocas y democráticas, con menos envoltorio místico si se quiere, pero también menos sujetas al frío cálculo, al cruel pago al contado, para seguir utilizando la terminología de Marx.

Los datos de la crisis de la familia patriarcal son bien conocidos, 
aunque, tal vez, escribiendo en España -uno de los pocos países (relativamente) avanzados, junto con Japón, en el que el familiarismo permanece de momento sólido-no esté de más recordar algunos indicadores elementales (Burguière, 1988). Primero, en vez del compromiso a largo plazo, estamos asistiendo, desde los años 60/70 hasta la actualidad, a un constante incremento de la tasa de divorcios que, salvo en la Europa meridional, oscila entre un tercio y más de la mitad de los matrimonios celebrados. Segundo, se retrasa la edad del matrimonio, y crecen sustancialmente la cohabitación antes del matrimonio, las uniones libres, el porcentaje de hogares con un solo miembro, y la proporción de hogares con un solo progenitor (normalmente mujer) con hijos dependientes. Tercero, en consecuencia, la proporción de niños nacidos fuera del matrimonio se incrementa sustancialmente. En general, concluye Castells tras revisar los indicadores estadísticos disponibles tanto de países desarrollados como no desarrollados, «la familia patriarcal está en proceso de convertirse en una forma minoritaria del modo de vida de la gente. En los Estados Unidos, sólo en torno a un cuarto de los hogares totales en los años 90 cumple con el tipo ideal de una pareja con hijos. Si añadimos la calificación 'con los hijos biológicos de la pareja' la proporción desciende notablemente» (Castells, 1998a: 180). En el mismo país, por otra parte, la proporción de hogares tradicionales, con «varón proveedor» y esposa ama de casa a tiempo completo, no supera el $7 \%$ del total de los hogares.

Importa, además, resaltar que estas tendencias no son privativas de los países industrializados, sino que afectan también a buena parte de los países periféricos - la triste excepción a esta triste regla son los países en los que política y culturalmente predomina alguna forma de integrismo religioso-, de un modo que sugiere que las mismas presiones tecnológicas, económicas, sociales y culturales subyacen en lugares muy diversos a la crisis de la familia patriarcal, aunque modificadas por historias y culturas idiosincrásicas (Giddens, 2000: 65-79).

Ahora bien, ¿de qué forma afectan estas tendencias a la vida de los niños? En Estados Unidos, por ejemplo, la proporción de hijos que en 1991 vivían con sus dos padres biológicos era sólo del 50,8\%. De hecho, uno de cada cuatro hogares norteamericanos cuenta con un solo progenitor, pero de ellos un $90 \%$ está regido en exclusiva por la madre, un proceso tan intenso en las últimas décadas que se ha podido hablar de una «fatherless America» (una América sin padres), en referencia al libro de David Blankenhorn que desencadenó una intensa polémica a mediados de los 90 .

Un rasgo sistémico, en efecto, de las crecientes crisis matrimoniales -o de las separaciones, más numerosas aún, en las uniones de hecho- 
es la dificultad cada vez mayor para compatibilizar matrimonio, trabajo y vida, dificultad que se convierte en carga insoportable en el caso de la mujeres, ante la renuencia del varón a asumir su parte alícuota de responsabilidad en el trabajo doméstico y en la crianza de los hijos. En el caso de los Estados Unidos, por ejemplo, la fuerte orientación al mercado laboral tanto de hombres como de mujeres determina que «la media de conversación entre padres e hijos sea de 7 minutos en los días laborables y 20 en cada uno de los días del fin de semana» (Verdú, 1996: 119).

Por otra parte, el porcentaje de niñas que quedan embarazadas en EE.UU. en torno a los 15 años es actualmente tan alta o más que en los países del Tercer Mundo (por la incidencia de los embarazos adolescentes en los guetos), y la reiteración de admoniciones represivas ha embotado su receptividad y permitido el rebrote del consumo de drogas (blandas y duras, legales e ilegales), de los cíclicos episodios de violencia colectiva sobre el fondo de una inseguridad estructural -más de 150.000 niños acuden diariamente a clase con armas de fuego en EE.UU.-, y un auge sin precedentes de la depresión, la ansiedad y el aislamiento entre los niños (Ibíd: 117-127).

Es decir, para resumir, junto a la disposición de una riqueza de recursos inimaginable, los niños de las clases medias en los países avanzados no es improbable que vivan en condiciones de «aislamiento social e inseguridad emocional como consecuencia de las tasas de divorcio, el exceso de trabajo que atenta contra la vida familiar y la disminución del contacto humano, y que los jóvenes sufran un creciente estado de alienación, que sean considerados más como consumidores que como niños» (Bellamy, op. cit.: 1). En cuanto a los hijos de los pobres y del creciente ejército de los excluidos -el «Tercer Mundo en casa» de los países avanzados-, su situación, desde el punto de vista de su capacidad para llevar una vida digna, para alcanzar los funcionamientos sociales normales, no es tan diferente, pese a los mayores recursos materiales, de la de los pobres del Tercer Mundo. En las sociedades avanzadas, una privación relativa en el ámbito de los ingresos o en la cesta de bienes disponible-por ejemplo, no tener televisión, coche o teléfono, objetos de lujo en sociedades menos desarrolladas- puede producir, en la terminología de Sen, una privación total en el ámbito de las capacidades. El dolor y la destrucción, el deshonor social, el analfabetismo funcional y su más severa consecuencia -la dificultad casi insalvable en la obtención de un trabajo medianamente digno-, el hostigamiento y el encarcelamiento, son su más probable horizonte, como atestigua la experiencia de los guetos en EE. UU. o en las ciudades de la Europa avanzada, una especie de sorda guerra civil interna que resucita el espectro de las clases peligrosas, de las dos ciudades de Dickens y 
Disraeli, la una amurallada, la otra errabunda y anómica.

Con un número creciente, además, de niños en la pobreza -el 22\% de los niños estadounidenses viven en la pobreza, y uno de cada tres niños es pobre en el Reino Unido, según un reciente estudio de la London School of Economics, dirigido por Paul Gregg (Gómez, 1999)- el desmoronamiento de las familias rompe la última, aunque contradictoria, estructura protectora de la infancia, en un momento en el que el Estado se desresponsabiliza de la procura de abrigo y el reformismo social y sus agentes sufren una profunda crisis o se baten en retirada. La crisis del patriarcado, en efecto, escribe Castells, «destruye la familia nuclear tradicional sin reemplazarla, haciendo que las mujeres y los niños paguen por ello (...) De acuerdo con los análisis documentados de Rodgers y Lerman, existe una estrecha relación entre el cambio de la estructura familiar y el aumento de mujeres y niños pobres en EE.UU. Quien desafía al patriarcado lo hace a su propio riesgo y al de sus hijos» (Castells, 1998b: 186).

Más aún, la crisis de la familia, en su doble papel de normalizadora y objeto de transgresión, alienta la institucionalización del deseo, su expansión perversa y descodificada. El sorprendente auge de la pedofilia, la pornografía o la prostitución infantiles se nutre así, probablemente, desde el lado de la oferta, de la extensión de la pobreza y la crisis de la familia y, desde la demanda, de la posibilidad de expresión de una violencia sin fin y sin objeto, de una transgresión pura y enfermiza facilitada por la mercantilización de todas las cosas («todo lo sagrado es profanado»: es decir, todo vale si es rentable, cualquier forma de conducta se hace moralmente permisible en el momento en que se hace económicamente posible y adquiere «valor»), y por la existencia de redes criminales globales y el anonimato permitido por la conexión electrónica o el turismo masivo (Castells, 1998a: 268; 1998b: 181-184).

Estamos, pues, bien lejos de esa «democracia de las emociones en la vida diaria» que propugna Giddens (Giddens, 2000: 76), aunque sin duda éste es un objetivo deseable. Primero, porque la igualdad sexual es sólo un benigno desiderátum y porque «la mitad del cielo» se ve, casi en su mayoría, privada de los derechos de ciudadanía y sometida a las más diversas formas de vejación y violencia de género, que se añaden a las violencias que recaen sobre casi todos. De hecho, según UNICEF, casi la mitad de las mujeres del mundo tiene a su enemigo en casa, ya que entre el 20 y el $50 \%$ de las mujeres y niñas son objeto de violencia física por parte de un miembro varón de su propia familia. Además, entre el 40 y el $60 \%$ de los abusos sexuales dentro del seno familiar son cometidos contra niñas menores de 15 años, que padecen una violencia doméstica perpetrada por varones que están o que han estado en posi- 
ción de confianza, intimidad o poder. Segundo, porque la violencia contra las mujeres afecta, a través de múltiples vías, a sus hijos y a sus posibilidades de supervivencia-los hijos de mujeres víctimas de la violencia doméstica tienen seis veces más posibilidades de morir antes de los cinco años- (UNICEF, 2000).

La violencia de género, el ciclo de abusos que se manifiesta en diferentes formas y etapas de la vida de las mujeres se dobla así en deliberada crueldad contra la infancia, una crueldad que incluye en su catálogo de horrores la desnutrición, el incesto, la mutilación genital -dos millones anuales que se suman a los 130 millones de mujeres ya mutiladas-, la prostitución obligada, el matrimonio forzado, las represalias por impago de la «dote» o por «disputas domésticas»-que incluyen las quemas con fuego o con ácido en la India o Pakistán-, la violación y el «asesinato por honor».

\section{UNA CREACIÓN DIFÍCIL DE AMAR. LA DESTRUCCIÓN DE LA INFANCIA}

Creo que fue Camus quien escribió que le costaba amar una creación en las que los niños eran torturados. Los tiempos de Camus no fueron, como casi ningún tiempo, buenos para los niños -Truffaut, por ejemplo, estrenó Los cuatrocientos golpes el mismo año en que Camus moría, y desde entonces muchos cineastas han filmado la lenta agonía de los niños en los países ricos y en los periféricos-. En el momento de su muerte, 1960, Camus trabajaba en una novela inacabada, El primer hombre, que sin embargo es uno de los textos más intensos y bellos de la segunda mitad de este siglo terrible, y una reivindicación, a un tiempo, de la infancia como la verdadera patria de los seres humanos (SaintExupéry), y de la dignidad de una pobreza escarnecida. Me gustan esos textos en los que la pobreza nos es presentada no sólo como un estado sumamente doloroso y frágil, sino como una escuela corajuda, como la fragua de un orgullo inextinguible, como la trabajosa construcción de un decoro asediado, que requiere de la movilización de muchos recursos, incluyendo la alegría, el extraño furor de vivir aun en la penuria. Fue también Camus, al fin y al cabo, quien escribió en El Verano: «Sí, existe la belleza y existen los humillados. Sean cuales sean las dificultades de la empresa, querría no ser jamás infiel ni a la una ni a los otros».

No lo fue. $\mathrm{Al}$ menos, además, los años 60 representaron el segundo gran periodo de esfuerzo legal en este siglo -el primero comienza a mediados del primer decenio y termina en los años 30- por apuntalar los derechos de los niños, esfuerzo que culminará con la celebración de la Convención de las Naciones Unidas sobre Derechos de los Niños de 


\section{9 y de la Conferencia Mundial sobre Menores de 1990.}

Los nombres de importantes acuerdos y las fechas, sin embargo, no deben inducirnos a engaño. En realidad, como he señalado anteriormente, citando a Carol Bellamy, las dos últimas décadas se caracterizan por un dramático retroceso de las conquistas sociales y de los derechos de los niños obtenidos con mucho sufrimiento en décadas anteriores. Porqué y cómo se ha producido la demolición de esa ciudadela de derechos, trabajosamente erigida, es un asunto que rebasa la pretensión de este artículo, y que además debiera ser objeto de una reflexión colectiva. José María Tortosa ha escrito recientemente que la situación del mundo en este fin de siglo/fin de milenio replantea, a escala global, los dilemas que las sociedades avanzadas enfrentaron en las postrimerías del pasado siglo (Tortosa, 2000). Estoy de acuerdo con él, y con todos los que claman en el próximo siglo por un mundo mejor frente a un «mundo feliz», por la necesidad de nuevos y explícitos contratos frente a la ya no tan utópica proyección huxleyana (Mayor Zaragoza y Bindé, 1999). Déjenme, sin embargo, para finalizar nombrar siquiera los que, para mí, son los obstáculos, no sé si remontables.

Primero, tenemos la poderosa industria de la muerte, de la matanza más o menos organizada, que, como hemos visto, consume recursos anuales ( 866.000 millones de dólares) que multiplican por más de 20 veces los recursos necesarios para que la vida pudiera empezar a considerarse una vida digna para todos, los requisitos mínimos de una existencia humana -educación básica, alimentación mínima adecuada, agua potable, infraestucturas sanitarias elementales, atención a la salud reproductiva de las mujeres-, cuyo coste se evalúa en unos 44.000 millones de dólares anuales. El sistema de la guerra, además, recluta niños para la muerte, bien como soldados, bien como víctimas, en una proporción inédita en periodos históricos anteriores, ofreciendo banderas o un espurio sentido de pertenencia a cambio de la propia vida.

Segundo, tras ese inmenso despilfarro está un sistema que ha creado no sólo una desigualdad creciente y escandalosa en la distribución de la renta o en el consumo de recursos (el $82 \%$ de las rentas mundiales y el $86 \%$ de los recursos renovables y no renovables son consumidos por el $20 \%$ opulento de la humanidad, que acapara además el $93 \%$ de los accesos a Internet), sino que ha generado pobreza y exclusión en todo el mundo y que amenaza la sostenibilidad de la vida humana sobre el planeta Tierra (PNUD, 1999). Es, además, ya un secreto a voces que la promesa de un desarrollo para todos, a semejanza del de los países avanzados, se enfrenta a límites no económicos, sino biológicos, físicos y químicos, que determinan que harían falta tres planetas como el nuestro para que todos pudieran mantener el consumo que hoy pre- 
valece en Norteamérica. Cualquier promesa de «desarrollo» que no parta de esta sencilla premisa, que no contemple una disminución significativa y/o una muy superior eficiencia en el consumo de recursos por parte del Norte desarrollado, no sólo es ilusoria, un señuelo o una racionalización interesada, sino también una invitación a compartir la responsabilidad de un desastre seguro.

Por añadidura, los rasgos básicos del sistema, sus fines y motivaciones esenciales, se han visto extraordinariamente reforzados en las últimas décadas por la desregulación radical de las economías, y el debilitamiento, drástico en los países menos desarrollados, de la acción correctora y protectora del Estado, a hombros de una globalización -«sociedad mundial sin gobierno mundial», en expresión de Ulrich Beck (Beck, 1998b) - facilitada por un uso enemigo para la mayoría de las potencialidades, en sí mismas positivas, contenidas en las nuevas técnicas.

La expresión, por otra parte, más dramática en las últimas décadas de las nuevas reglas de la economía mundial ha sido la «crisis de la deuda», que lastra aún dramáticamente las oportunidades de desarrollo de muchos países terceros y de cientos de millones de personas. No es éste el momento adecuado para recordar las razones de esta crisis, una instructiva historia que involucra como agentes del drama a un sistema financiero internacional irresponsable pero garantizado, a unas élites periféricas depredadoras de sus propias sociedades, y a instituciones de gobierno de la economía mundial (FMI, Banco Mundial, G7, OMC) que, éstas sí, han resultado ser activos propagadores del «riesgo moral» y activistas de la explosión del desorden a escala mundial (Estefanía, 2000; Strange, 2000).

Sin embargo, «la deuda tiene cara de niño» (Rampahal, en UNICEF, 1999a: 27-33). La mayor parte del peso de la deuda «recae sobre las mentes y los cuerpos de los niños» (ibíd), hipotecando sus vidas y trabajos a bancos y gobiernos de los países ricos por préstamos que financiaron proyectos que nunca les beneficiaron. Los países del África subsahariana, por ejemplo, gastan más en el servicio de su deuda que en la salud y educación de sus 306 millones niños. En los países en desarrollo, el promedio per cápita de la deuda es de 417 dólares -tal vez importe subrayar, a efectos comparativos, que en 1993 el PIB per cápita de los 48 países menos adelantados era inferior a 750 dólares anuales frente a los 23.000 de los países de ingreso alto, según el Banco Mundial-, pero en países como Nicaragua cada lactante viene al mundo con una deuda de 1.213 dólares, y en el Congo de 1.872 dólares. Los países al sur del Sahara gastan en el servicio de la deuda entre una cuarta y una tercera parte de sus presupuestos nacionales, y un $40 \%$ en los 
países más endeudados, lo que se traduce en desatención a políticas de sanidad y educación básicas, en la muerte de millones de niños y en la atrofia irreversible de las mentes y los cuerpos de otros más numerosos.

A cambio de la inmensa transferencia de recursos desde el Sur hacia el Norte que constituye el pago de la deuda -sólo entre 1983 y 1990 los países deudores pagaron un billón de dólares-, el monto de la deuda, que era de 800.000 millones de dólares en 1983, no ha cesado de incrementarse, a causa del pago de los atrasos y de nuevos créditos para cubrir lo impagado, ascendiendo a cerca de dos billones de dólares en 1997. En injusta reciprocidad, por el contrario, la ayuda oficial al desarrollo que, según las recomendaciones de Naciones Unidas, debía tender hacia la exigua meta del $0,7 \%$ del PNB de los países industrializados, ha descendido desde el 0,33 de 1992 hasta el 0,21 actual, regresando una cuarta parte de la ayuda bilateral que reciben los países pobres en concepto de pago de la deuda (Ramphal, op. cit.: 28).

Tercero, los procesos económicos descritos -y sus correlatos, la extensión de la pobreza y de la exclusión social, así en los centros como en las periferias-alientan la implosión de sociedades y economías enteras, la desintegración de las sociedades tradicionales, el debilitamiento radical de las instituciones protectoras estatales o de la sociedad civil (sindicatos, asociaciones cívicas, cooperativas, Iglesias), y el derrumbe de las familias como último dique de defensa de los niños.

Nada de esto es nuevo. En los países avanzados asistimos a parecidas «catástrofes culturales», asociadas a la «gran transformación» del siglo XIX, a la expansión de un mercado autorregulado, el sueño utópico y periódicamente renovado de las retóricas y de las políticas de la intransigencia reaccionaria (Polanyi, 1989; Hirchman, 1991). Hoy como ayer, por tanto, afrontamos el mismo desafío, pero a una escala inédita, a escala global. Es decir, con las dificultades adicionales de que no hay un Tercer Mundo para el Tercer Mundo que financie su bienestar relativo, como sucedió en Europa desde la segunda mitad del XIX con la tercera gran expansión colonial, y de los límites que el medio ambiente impone a la expansión indefinida de la producción y del consumo y sus secuelas (el agotamiento, la contaminación, los residuos, el cambio climático, etc.). Nos encontramos, pues, en una encrucijada, en una bifurcación probable, para utilizar la terminología de Prigogine, de un sistema sumamente inestable y que fluctúa lejos del equilibrio (Prigogine, 1997a y b). Para contener los signos, cada vez más evidentes, de un caos que ya está entre nosotros, es necesario, desde luego, organizar la resistencia, nada fácil, de los más damnificados, y probablemente, como antaño, contar con el consenso mínimo de las élites ilustradas sobre el 
hecho de que sus actividades y, sobre todo, las reglas y valores que las vehiculan son dañinas para ellos mismos, que amenazan la continuidad de la vida, la de los niños que son su futuro y la de su soporte físico, químico y biológico.

Cuarto, para que se inviertan las tendencias descritas, la pulsión de muerte destructiva que parece dominar al sistema, sin corrección alguna en las últimas décadas, se imponen no sólo frenos explícitos y eficaces (por ejemplo, el control de los movimientos de capitales a corto plazo, capaces de devastar economías enteras, haciéndolas retroceder en pocos días lo costosamente avanzado en muchos años; o la reconstrucción de los Estados, los únicos centros de poder efectivamente democratizables, más activos en la procura de bienestar para sus ciudadanos; o la recomposición de la capacidad de mediación de la política, deslegitimada por una extensa corrupción y por su sujección a las leyes de una economía al margen de todo control social, moral o político; o la reactivación de una sociedad civil que, contra lo que afirma la ortodoxia liberal, resulta ser menos densa y rica cuando el Estado y la política, la esfera pública, se deslegitima y debilita, como muestra la experiencia del Bloque del Este ), sino un cambio cultural.

El requisito mínimo de ese cambio, su elemental precondición, es desde luego la expansión de la educación para todos y a lo largo de la vida, el desarrollo de una educación planificada como derecho (UNICEF, 1999b), y en tanto que proyecto de ciudadanía e instrumento de democratización. Sin dicho proyecto, sin duda, las bases culturales del actual apartheid social resultarán reforzadas por un apartheid escolar que distribuye a los elegidos y a los condenados según una lógica más social y política que meritocrática (Mayor Zaragoza, 2000).

El cambio cultural, sin embargo, no puede referirse sólo al universo educativo. Las mujeres y las niñas se ven sometidas a diversas formas de discriminación -más o menos sutiles, más o menos brutales-, con consecuencias terribles para ellas mismas, los niños y las mismas estructuras familiares. No habrá, por tanto, recomposición social duradera sin un reparto más justo de todas las formas de trabajo, incluyendo el trabajo doméstico y la atención a los hijos, y sin políticas activas que favorezcan su plena incorporación en condiciones de igualdad a la vida económica, social y política, y a los proyectos de desarrollo. Singularmente, una familia democratizada, apoyada por políticas sociales amplias que proporcionen apoyo material y sicológico, y que vele por la autonomía y la integridad de los menores, parece ser la única alternativa viable a la disolución de las estructuras familiares en el descompromiso personal o en contratos y acuerdos puntuales (Castells, 1998a: 259262). Sin embargo, la resistencia que los varones oponemos a la 
renegociación de los roles sexuales constituye un severo límite a esa recomposición de la familia, cuyo coste es la carga brutal que soportan las mujeres -muchas en condiciones personales y económicas terribles, en lucha desigual por la supervivencia y por su propia autonomía-, y el desamparo de los niños, el incremento brutal de los abandonos, el trato negligente o los malos tratos, con consecuencias duraderas en su psique y en la configuración de sus identidades futuras, supuesto el círculo maligno por el que las víctimas de hoy tienden a convertirse en los verdugos de mañana.

La crisis de la familia, sin embargo, no es exclusivamente un asunto de hombres y mujeres. Un rasgo central de la presente crisis es, en efecto, que el debilitamiento de los vínculos familiares se verifica en el contexto del retroceso de la acción correctora del Estado y de condiciones de vida y de trabajo que dificultan gravemente el desempeño congruente y simultáneo de los distintos roles sociales (Navarro, 1997). $\mathrm{La}$ intensificación del esfuerzo laboral de ambos progenitores en condiciones de una creciente individualización y vulnerabilidad de la relación laboral, el descenso de las rentas de buena parte de la fuerza de trabajo, la crisis de otras instituciones clásicas de integración social -la escuela fundamentalmente, los grupos de iguales-, y la elevación de las barreras de entrada en el mercado de trabajo, someten a una tensión dramática la vida familiar, sobrecargándola de demandas difícilmente compatibles. El individualismo como tendencia cultural disuade, además, la subordinación de los propios deseos y necesidades a los de la familia cuando, en los hechos, las necesidades de ésta son definidas no a través de la negociación de los distintos roles sino según las reglas de un poder patriarcal, con exención de obligaciones por parte del varón.

Un nuevo contrato cultural implica, pues, preservar las potencialidades positivas del individualismo - la libertad de acción y de juicio, la potenciación de las propias capacidades, el «empowerment», la consideración de los deseos y necesidades individuales-, precaviéndose de sus efectos disolventes -la lucha de todos contra todos, el cainismo darwinista, la disolución de la cooperación en la racionalidad de la conducta egoísta, la subordinación al propio interés de los intereses colectivos, la lógica del «gorrón» y del «individualismo posesivo», los pequeños egoísmos privados, la cultura narcisista-.

\section{CONCLUSIÓN}

Isaiah Berlin sostuvo, frente a los que él llamaba ingenieros sociales o del alma, que los sistemas de valores carecen de coherencia interna, y que el conflicto de valores -libertad frente a igualdad; equidad frente 
a eficiencia; justicia frente a clemencia; tolerancia frente a orden; justicia social versus libertad individual; seguridad frente a libertad-es intrínseco a la vida humana y, aunque mitigable, trágicamente ineliminable en los hechos, en las cosas, si bien no en los conceptos, las palabras, que todo lo soportan. También mantuvo que, como escribió Kant, «con madera tan torcida como de la que está hecho el hombre no se puede construir nada completamente recto», y que, puesto que la razón humana es irremediablemente imperfecta y los valores incompatibles, las elecciones vitales, personales o sociales, aun las tomadas a la luz de la razón, son un acto de voluntad, de instinto, de emoción, una jugada decidida en la oscuridad, según su propia y bella fórmula (Berlin, 1992), si bien Perry Anderson ha discutido convincentemente la apropiación que Berlin hace de las Ideas de Kant (Anderson, 1998: 330-332).

Es posible, por supuesto, sostener lo contrario: aspirar a la utopía de una armonía sin mácula o, más razonablemente, a la utopística, a un mundo en el que la igualdad política, el crecimiento económico, la organización eficiente y la justicia social sean compatibles entre sí y con la libertad individual y universal, donde el universalismo deje de estar en conflicto con el particularismo, o la solidaridad con el individualismo, o las lealtades públicas con las privadas (Wallerstein, 1999); pretender, en fin, un mundo que aboliera estos «falsos dilemas» y en el que la verdad, la virtud, la belleza y la felicidad coincidieran y no existieran más conflictos entre valores, más dilemas morales, más incompatibilidad entre lo correcto y lo correcto, ni más tragedia.

Sabemos, de hecho, que esa fue la aspiración, el impulso originario de la Ilustración que animó La paz perpetua (Kant), o el Esbozo de un cuadro histórico de los progresos del espíritu humano (Condorcet). Pero sabemos también que ese sueño se ha convertido frecuentemente en pesadilla, que alentó el racismo imperialista, y que «esa universalización abstracta practicada por el imperialismo ha sido una forma de asesinato disfrazado» (Laroui, citado en Wallerstein, 1997: 23). Tal vez, por tanto, la esperanza de un futuro mejor, el sapere aude, tiene también un poder mortal, tal vez más mortal aún que las tradiciones, los atavismos y las creencias ultramundanas contra las que originariamente se insurgió, como ilustra la experiencia de este siglo terrible o de nuestro actual mundo desbocado. $\mathrm{O}$ tal vez cualquier idea, incluida la más noble, es deformable hasta el fanatismo por el error irreformable que somos.

No hay así ningún motivo para el optimismo, ninguna esperanza de reconciliación, pero tampoco ninguno para la inacción o el quietismo. La civilización capitalista es tan bárbara, tan poco civilizada, si no menos, que las anteriores, como atestiguan los terribles datos sobre el 
estado de la infancia que apenas hemos enunciado. Incluso los beneficios de la educación, en los que he hecho tanto hincapié a lo largo de este texto, son profundamente discutibles y, desde Iuego, no ha hecho disminuir sino tal vez incrementar algunos de los peores rasgos del sistema, a través de una superior capacidad de «racionalización»-en el doble sentido weberiano y freudiano- de la infamia. Así que tenemos trabajo, y el trabajo que tenemos supera en mucho nuestras fuerzas, tal vez nuestra misma voluntad poco heroica. Podemos empezar en casa, con nosotros mismos o con la familia - «el entendimiento humano se ve forzado a elegir entre la perfección de la vida o la perfección del trabajo», escribió Yeats-, o en el ámbito laboral, en el barrio o en la ciudad, en lo que se denomina lo «local» o en la esfera del Estado, o intentar modificar el universo - «¿me atreveré? ¿Me atreveré a perturbar al universo», se preguntaba Prufrock, el enamorado eliotiano-.

No importa, pero debiéramos saber, pese a que tan a menudo lo ignoramos, que si trabajamos con los niños, por los niños, estamos trabajando por la vida, por el futuro de la vida, del mismo modo que, como escribió Francisco Umbral, «por el mal de los niños descubrimos que la vida no es noble ni buena ni sagrada. Descubrimos lo que la vida tiene de alimaña ciega, de cebarse en sí misma». Bien, no sé si la vida, pero sí esta vida, la que tenemos, la que debiéramos modificar, si puede ser, un poco concertados.

\section{BIBLIOGRAFÍA}

ANDERSON, P. (1998): Campos de batalla, Barcelona, Anagrama.

BANCO MUNDIAL (2000): En el umbral del siglo XXI. Informe sobre el desarrollo mundial 1999-2000.

BECK, U. (1998a), La sociedad del riesgo: hacia una nueva modernidad, Barcelona, Paidós.

BECK, U. (1998b): ¿Qué es la globalización?, Barcelona, Paidós.

BERLIN, I. (1992): El fuste torcido de la humanidad, Barcelona, Península.

BERMAN, M. (1988): Todo lo sólido se desvanece en el aire, Madrid, Siglo XXI.

BURGUIÈRE, A. et al. (1988): Historia de la familia, Vol. 2, Alianza, Madrid.

CASTAÑEDA, C. (2000): «Globalización», El País, miércoles I de marzo, pp. 17 18.

CASTELLS, M. (1997): La era de la información. La sociedad red, Madrid, Alianza. 
CASTELLS, M. (1998a): La era de la información. El poder de la identidad, Madrid, Alianza.

CASTELLS, M. (1998b): La era de la información. Fin de milenio, Madrid, Alianza.

ESTEFANÍA, J. (2000): Aquí no puede ocurrir, Madrid Taurus.

GIDDENS, A. (1999): La tercera vía, Madrid, Taurus.

GIDDENS, A. (2000): Un mundo desbocado. Los efectos de la globalización en nuestras vidas, Madrid, Taurus.

GÓMEZ, L. (1999): «Cuatro millones de niños malviven bajo condiciones de pobreza en el Reino Unido», EI País, miércoles 21 de julio, p. 24.

HIRSCHMAN, A. O. (1991): Retóricas de la intransigencia, México, F.C.E.

HOBSBAWM, E. (2000): Entrevista sobre el siglo XXI, Barcelona, Crítica.

MAYOR ZARAGOZA, F. (2000): «La educación para todos, el gran reto del siglo XXI», El País, lunes 24 de abril de 2000, pp. 15-16.

MAYORZARAGOZA, F; BINDÉ, J. (1999): «Siglo XXI: ¿un mundo mejor o un mundo feliz?», El País, viernes 22 de octubre de 1999, pp. 15-16.

NAVARRO, V. (1997): Neoliberalismo y Estado del Bienestar, Barcelona, Ariel.

NAVARRO, V. (1999): «Calidad de vida y desigualdad social», El País, viernes 3 de septiembre, pp. 13-14.

NÚÑEZ, C. E. Y TORTELLA, G. (eds) (1993): La maldición divina. Ignorancia y atraso económico en una perspectiva histórica, Madrid, Alianza.

OIT (1996): Child labour: targetig the intolerance, Ginebra.

PNUD (1998): Informe sobre desarrollo humano 1998.

PNUD (1999): Informe sobre desarrollo humano 1999.

POLANYI, K. (1989): La gran transformación, Madrid, Ediciones La Piqueta. PRIGOGINE, I. (1997a): Las leyes del caos, Barcelona, Crítica.

PRIGOGINE, I. (1997b): El fin de las certidumbres, Madrid, Taurus.

SARTORI, G. (1998): Homo videns, Madrid, Taurus.

SEDKY-LAVANDERO, J. (1999): Ni un solo niño en la guerra. Infancia y conflictos armados, Barcelona, Icaria.

SEN, A. (1995): Nuevo examen de la desigualdad, Madrid, Alianza.

STRANGE, S. (2000): Dinero loco. El descontrol del sistema financiero global, Barcelona, Paidós.

THERBORN, G. (1993): «Los derechos de los niños desde la constitución del concepto moderno de menor: un estudio comparado de los países occidentales», en Moreno L.(comp.), Intercambio social y desarrollo del bienestar, Madrid, CIS.

TORTOSA, J.M. (1992): Sociología del sistema mundial, Madrid, Tecnos. 
TORTOSA, J.M. (1993): La pobreza capitalista, Madrid, Tecnos.

TORTOSA, J.M. (2000): El juego global: pobreza, desarrollo, prospectiva, Barcelona, Icaria.

TOWSEND, P. (1993): The international analysis of poverty, Londres, Harvester Wheatsheaf.

UNICEF (1999a): El progreso de las naciones.

UNICEF (1999b): Estado mundial de la infancia. Educación.

UNICEF (2000): Violencia doméstica. Una epidemia global.

VV. AA. (1996): Declaración de Beijing y plataforma para la acción, Madrid, Ministerio de Asuntos Sociales, Instituto de la Mujer.

VV. AA. (1998): Beyond the threshold. The measurement and analiysis of social exclusion, G. Room (ed.), Bristol, Policy Press.

VERDÚ, V. (1996): El planeta americano, Barcelona, Anagrama.

WALLERSTEIN, I. (1988): El capitalismo histórico, Madrid, Siglo XXI.

WALLERSTEIN, I. (1997): El futuro de la civilización capitalista, Barcelona, Icaria.

WALLERSTEIN, I. (1999): Utopística, México, Siglo XXI.

WALLERSTEIN, I. (2000): «El eurocentrismo y sus avatares: los dilemas de las ciencias sociales», New Left Review 0, pp. 97-113. 



\title{
ENFOQUE COMUNITARIO, MODERNIDAD Y POSTMODERNIDAD. EL TRABAJO SOCIAL CON LA COMUNIDAD EN TIEMPOS DE LA GLOBALIZACIÓN
}

\section{CLARISA RAMOS FEIJÓO}

Profesora Asociada del Departamento de Trabajo Social y Servicios Sociales. EUTS Universidad de Alicante.

\author{
«La realidad inteligente, sí señor. \\ Todos soltamos un hilo, como gusanos de seda. \\ Roemos y nos disputamos las hojas de morera \\ pero ese hilo, si se entrecruza con otros, si se entrelaza, \\ puede hacer un hermoso tapiz, una tela inolvidable» \\ Manuel Rivas, O lapis do carpinteiro
}

\section{RESUMEN}

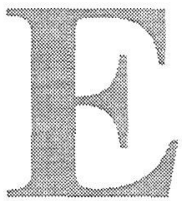

l enfoque comunitario requiere por su propia definición la existencia de la comunidad. Nos planteamos entonces, como cuestionamiento metodológico, la aparente contradicción que existe entre, por una parte, la comunidad tradicional y, por otra, el objetivo del Trabajo Social Comunitario. Aquella es una figura premoderna y el Trabajo Social conlleva, por su filosofía y método, una orientación hacia la modernización de las conductas y las relaciones.

El presente artículo analiza, desde la lectura de los clásicos de la Sociología, las diferencias epistemológicas que confrontan los conceptos de comunidad y sociedad, dando paso a un análisis del Trabajo Social en el contexto de la globalización y la complejidad de la realidad social. Busca, asimismo, recuperar las experiencias de enfoque comunitario, desarrolladas en España y también en otros contextos, para promover el análisis que conduzca a la construcción de nuevas formas de intervención comunitarias.

En tal sentido, la propuesta es conciliar las figuras de comunidad, referente del Trabajo Social Comunitario y la de sociedad referente para este análisis del Trabajo Social.

Palabras clave: Trabajo Social con la comunidad, comunidad, sociedad, modernidad, postmodernidad, globalización. 


\section{INTRODUCCIÓN}

Partimos de considerar que el enfoque comunitario tiene, como cualquier otro enfoque del Trabajo Social, el objetivo de mejorar las condiciones de vida de los usuarios y seguidamente afirmamos que existe la tendencia a identificar mejora con desarrollo, es decir, indicadores de modernidad. Sin embargo, el enfoque comunitario necesita, por definición, de la comunidad, pero veremos que en la historia de la Sociología, la comunidad ha sido definida como una estructura basada en los afectos y el conocimiento directo (premoderna), mientras que la sociedad, con sus características de organización, es la que confiere rasgos de modernidad, lo que en principio parecería conducir a una contradicción metodológica.

Pero si aterrizamos en el planteamiento, deberíamos asumir que nos encontramos en este momento con la coexistencia de múltiples relaciones de integración social. Casi podríamos decir que un sesgo de la postmodernidad tiene que ver con esa multiplicidad de formas de convivencia y de solidaridad social, que relacionamos con lo que Edgar Morin ha definido como complejidad.

¿Cómo se concilia esta realidad desde nuestra ética profesional a la hora de intervenir? Analizaremos algunos ejemplos de casos en que la realidad demuestra un choque de intereses entre la población y los que llevan iniciativas de desarrollo.

¿Cómo se concilia el binomio conceptual "comunidad-sociedad" en la intervención desde el Trabajo Social?

Cuando hablamos de las nuevas formas de intervención: ¿cuál es la fuente conceptual de la que se nutren las nuevas formas de intervención? ¿En qué medida han influido las políticas de la Unión Europea en el Trabajo Social Comunitario?

En el marco de la globalización y las nuevas tecnologías nos hacemos eco de la necesidad de un nuevo discurso para una sociedad cada vez más compleja: jestamos ante una nueva reconceptualización del Trabajo Social? ¿Se materializará esta vez en nuevas formas de intervención?

La nuevas formas de intervención leídas desde el Pensamiento Complejo abren grandes posibilidades al Trabajo Social Comunitario. Es posible intervenir desde expectativas comunitarias en una sociedad postmoderna, pero para hacerlo es preciso ser conscientes y conocedores de los fundamentos de nuestra intervención. Y para poder saber desde dónde y hacia dónde vamos en el campo del Trabajo Social con la comunidad es, a nuestro criterio, necesario asumir que las nuevas 
formas de intervención sólo se entienden desde el análisis de la historia del Trabajo Social Comunitario que se realizaba hace ya 30 años, y la perspectiva histórica que en ello radica.

\section{SOCIEDAD, COMUNIDAD ¿UNA PAREJA DESAVENIDA?}

Las diferentes acepciones de comunidad y sociedad por las que se establecen sus diferencias conceptuales forman parte de la historia misma de las Ciencias Sociales. En muchos casos sus propias definiciones han generado incomodidades conceptuales, dado que no encajaban con los argumentos utilizados en la intervención comunitaria. Desde su propia esencia, el hombre es un ser social que a lo largo de la historia ha buscado la solución a sus problemas y necesidades asociándose.

La lectura de los clásicos nos muestra la larga trayectoria del binomio que viene siendo definido por contraposición a la vez que reconocido como continuidad y simultaneidad. En La Ciudad de Dios, San Agustín distinguía entre comunidad y sociedad como los dos tipos principales de sociabilidad existentes.

Spencer también hace referencia a estas dos posibilidades al describir los rasgos de la sociedad militar y la sociedad industrial. Durkheim establece la división entre solidaridad mecánica, en la que se distinguen la semejanza de afectos y creencias, y la solidaridad orgánica visible en las sociedades con gran división del trabajo. Weber toma directamente de Durkheim esta dicotomía y habla de tradición y de racionalidad.

Charles Cooley define dos tipos de grupos, los primarios, a los que da el nombre de comunidades, y los secundarios, en los que involucra lo que conocemos bajo el concepto de sociedad.

Por su parte, la Sociología marxista conceptualiza la comunidad como una unión de individuos que viven en un mismo territorio ligado por intereses, actividades y objetivos comunes, siempre vinculados a relaciones materiales que se concretan en el proceso de trabajo y reciben mediación del mismo.

El clásico que con mayor detenimiento ha desarrollado estos temas ha sido el alemán Tönnies, que ha determinado visiblemente todo el debate intelectual sobre la dicotomía entre sociedad y comunidad. Tönnies distingue entre la Gemeinschaft (relación social real y orgánica o comunidad), como lo identificado con las relaciones familiares, los afectos, y la Gesellschaft (relación social imaginaria y mecánica o asociación) como lo vinculado a las relaciones secundarias y forma- 
les. La Cultura de la Comunidad en sustitución de la Civilización de la Asociación dirá este autor alemán. En 1931, Tönnies definiría Gemeinschaft como «todas las clases y asociaciones en las cuales predomina la voluntad natural» y Gessellschaft a «las formadas o condicionadas fundamentalmente por la voluntad racional» (Sorokin P. 178). Talcott Parsons situó lo que llamó la «clave de la Gessellschaft» en «la búsqueda racional del propio interés individual» (Parsons: 837).

Pitirim A. Sorokin habla de las relaciones de tipo familístico y las de tipo mixto o contractual. Sorokin reconoce la teoría de Tönnies como una de las más fecundas, sin embargo, encuentra que en ella reside la fuente de grandes defectos lógicos, como, entre otros, el sostener un proceso evolutivo desde la Gemeinschaft hacia la Gessellschaft, ya que es verificable que ambas han coexistido.

Por su parte, Max Scheller distinguió cuatro formas que serían subdivisiones de las definidas por Tönnies, en una línea de investigación semejante se situó Lavrov. R.M. MacIver definió a la comunidad como claramente opuesta a la asociación. El signo distintivo de la comunidad radica, según este autor, en que la vida de cada individuo puede ser vivida totalmente dentro de la comunidad, a la que vincula siempre con un área territorial.

Gurvitch sostiene que mientras la sociedad tiene una presencia estructural objetivada, la comunidad responde a la realidad psicosocial (Badi; B. 1990: 95-115).

Por su parte, el filósofo español, José Luis Aranguren, describe a la comunidad y a la sociedad como tipos ideales que no existen en estado puro, sino que más bien diríamos nosotros «coexisten», sin embargo, Aranguren continuaba diciendo que el problema consiste en que las frías relaciones impuestas por la sociedad nos llevan a echar en falta los vínculos del afecto.

El propio Salvador Giner hace también la salvedad de que comunidad y asociación son dos tipos ideales, dos variedades de grupos humanos que «rara vez se encuentran concretamente en estado puro» (1985:87). En su análisis, Giner describe la existencia de dos tipos de formaciones sociales:

1) las basadas en vínculos afectivos donde cada integrante ve al otro como un fin en sí mismo, y existe un conocimiento directo y profundo del otro (comunidades),

2) las basadas en fines utilitarios donde los demás integrantes son percibidos como medios para lograr un fin. El conocimiento es de tipo superficial (grupos secundarios, asociaciones, sociedades). 
El criterio de diferenciación señalado por Giner entre los conceptos de sociedad y comunidad es un criterio de grado, dependiendo de la prevalencia del factor afectivo en las relaciones.

Así podríamos trazar un mapa conceptual en el que siempre se ha distinguido a la comunidad como el aspecto gregario vinculado a los afectos y las relaciones interpersonales y a la sociedad como aquello que se relaciona con aspectos de racionalidad y modernidad.

Podríamos entonces afirmar que existe una necesidad en las sociedades modernas de retornar a lo comunitario en su sentido más primario, como respuesta a las frustraciones que genera una sociedad moderna donde no se llegan a satisfacer las necesidades básicas y que aun cuando éstas se satisfacen se crean otras nuevas necesidades vinculadas incluso a aspectos inmateriales (comunicación, afecto, compañía).

En este sentido, hemos considerado conveniente el entender estos conceptos desde una estructura de matriz, donde quede reflejada la complejidad de la realidad social. Esto requiere intervenciones que, si bien de manera indudable deban tender a una modernización, o progreso, entendidos como forma de satisfacción de necesidades de las personas, no dejen de lado los aspectos más vinculados a las relaciones interpersonales del ámbito comunitario. Consideramos ilustrativa la imagen que define a la comunidad como un entramado, ya que refleja claramente la fusión y diversidad de variables que intervienen y que determinan la realidad social.

Casi podría decirse que queremos comunidad y sociedad a la vez. Otra cosa es que realmente se logre y, mucho más aún, otra cosa es que las estrategias realmente propicien lo que las ciencias sociales han definido, de manera más o menos ambigua, como comunitario.

Comunidad es, por tanto, un concepto que se encuentra sujeto a diversas revisiones. En nuestro entorno, profesional, temporal y geográfico encontramos opiniones como las del profesor Josep Canals, que mantiene sus reservas hacia el «uso acrítico del concepto de comunidad» (Canals, J. 1997:35). Entre otros, se basa en argumentos como el del trabajo clásico de Hillery (1955) donde, tras analizar 94 definiciones de comunidad, alcanzó la conclusión de que «aparte del concepto de que la gente vive en comunidad, no existe un acuerdo total referente a la naturaleza de la comunidad».

Se contraponen también, en el análisis de lo que entendemos por sociedad y comunidad, las tradiciones sociológicas del aristotelismo comunitario o cooperativo y el individualismo iusnaturalista que han dado lugar a numerosas teorías contrapuestas ${ }^{\prime}$. Pero también se destacan intentos de aunar ambas tendencias. Desde quienes, adhiriendo a una 
dinámica de la teoría antropológica evolucionista, consideran que la modernidad arrasará con la comunidad, pasando por quienes abogan por un cambio social cíclico, hasta quienes ven la necesidad de definir un modelo compensatorio en el que coexistan ambas realidades.

\section{RECONOCIÉNDONOS DESDE LOS ORÍGENES}

Entre los antecedentes del Trabajo Social Comunitario en el ámbito internacional reconocemos las acciones de Organización Comunitaria emprendidas por Robert Owen dentro del movimiento comunitario laico representado por la New York Society for Propagating Communities. Para algunos, desde un modelo utópico, aunque sin olvidar que, situado en un marco reformista, Owen pretendió contraponer un sistema cooperativista al modelo de las ciudades industriales del capitalismo. Sus premisas eran que la «comunidad pura» encontraría las formas para influir sobre el ambiente que moldeaba el carácter del hombre. Lo fundamental era la dignidad humana y la independencia de las personas alcanzada a través de la ciencia, la razón y la educación. Concibió un plan de comunidades rurales autogestionadas con sistemas educativos y culturales. El owenismo representó un movimiento de gran popularidad en Estados Unidos entre los años 1821 y 1828.

Posteriormente, Mary Richmond, en The Interrelation of Social Movements (1910), destacó la importancia del trabajo comunitario, viendo la trascendencia de los movimientos sociales y su capacidad para colaborar en la formulación del diagnóstico de las ciudades donde se trabajaba. La primera conceptualizadora del Método de Trabajo Social aboga claramente por la importancia del entorno social.

Roger Baldwin es quien aparentemente, por primera vez, hasta donde las investigaciones existentes señalan, utiliza en un documento oficial la denominación de Organización de la comunidad, destacando la trascendencia de la planificación del trabajo comunitario, durante la Primera Guerra mundial y su postguerra

Digamos que éstos son, junto con el movimiento de los establecimientos de los Barnett, algunos de los orígenes primigenios del Trabajo Social con la comunidad, pero nos interesa destacar los que podemos encontrar en nuestro país. Así, consideramos que existen interesantes ejemplos del enfoque comunitario que fueron llevados a cabo en el te-

1 Desde el Trabajo Social no se puede obviar el hecho de que las Políticas Sociales de determinados posicionamientos políticos y filosóficos, y, en este sentido, el individualismo y el colectivismo nos brindan claros ejemplos de ello, por eso nos parece importante invitar a la reflexión sobre estos temas. 
rritorio español durante la década de los 60 y 70 .

Es indudable que la incorporación de España al seno de la, ahora, Unión Europea, ha conllevado la adquisición de nuevas filosofías de trabajo en el campo de lo social. Nos parece, sin embargo, que resulta necesario recurrir a las propias fuentes empíricas, y a realizar comparaciones sobre lo hecho hasta el momento y las nuevas propuestas de intervención. Parece importante asumir que el conocimiento en materia social es acumulativo y que las verdaderas conceptualizaciones no consisten en cambiar el nombre a lo que se venía haciendo. En tal sentido, entendemos que recuperar para el análisis de la intervención comunitaria ejemplos como el Plan Social Baza, desarrollado por Cáritas en los años 60 , así como tantas otras experiencias similares de esa época, nos permitirá abordar con mejores herramientas de estudio los desafíos que nos imponen los nuevos tiempos en el ámbito de la intervención comunitaria.

Las experiencias como tales son irrepetibles, porque, como bien sabemos responden a un determinado contexto histórico, a un marco temporoespacial específico. Sin embargo, analizar lo realizado nos permite ver cómo, al claro objetivo de modernización que en aquel contexto se buscaba, se pudo incorporar la permanencia y desarrollo del espíritu comunitario. Esta característica pareciera desprenderse, para nuestro análisis, de la realización de un Trabajo Social no burocratizado y atento al proceso que implica la intervención social en el ámbito comunitario.

Son estas observaciones las que nos interesa retomar a la hora de entender cómo es posible conciliar dos aspectos que desde la formulación teórica se presentan como aparentemente contradictorios y que, sin embargo, las experiencias habidas, nos demuestran que son de posible y deseable convivencia.

\section{EL CONTEXTO FINISECULAR DEL TRABAJO SOCIAL COMUNITARIO. TIEMPO DE BALANCES}

La llegada de un nuevo milenio ha dado pie para el debate reflexivo (aunque no siempre) sobre los problemas sociales y las formas de intervención en la realidad social. El Trabajo Social no podía permanecer ajeno a esta circunstancia y ello ha quedado evidenciado en los títulos de numerosos artículos y convocatorias a Congresos, Jornadas y Seminarios.

En este escenario de fin de siglo resulta evidente, desde la perspectiva del Trabajo Social, que, a pesar de los avances y progresos en 
diversos ámbitos vinculados al desarrollo (económico, científico, teçnológico y social), persisten y se recrean nuevas formas de pobreza y situaciones de desigualdad.

En este sentido, podemos decir que en las cuestiones sociales todo tiempo pasado no ha sido necesariamente peor o mejor, sino que cada momento requiere un análisis desapasionado en la lógica y apasionado en la búsqueda de las mejores alternativas.

La globalización (o mundialización) con su consiguiente característica de multidimensionalidad, no pasa inadvertida en cualquier análisis sobre cuestiones de nuestros días. Anthony Giddens afirma «puede que globalización no sea una palabra particularmente atractiva o elegante. Pero absolutamente nadie que quiera entender nuestras perspectivas en este fin de siglo puede ignorarla» (Giddens, A 2000: 19-20). Así, basta con que recorramos las publicaciones de los últimos cinco años para observar cómo el discurso se ha visto plagado de referencias a lo que MacLuhan definió como la «aldea global». A partir de asumir la realidad de su omnipresencia interesa realizar un «intento de análisis» de lo que implican el discurso sobre la globalización y sus repercusiones en los temas inherentes al Trabajo Social, y particularmente al Trabajo Social con la Comunidad.

En primer lugar, consideramos que el discurso de avances tecnológicos y la entrada en la sociedad de la información son realidades tangibles (de manera real y no virtual) sólo para una pequeña parte de la población mundial. Al decir tangibles nos referimos a que sólo una parte de la población mundial se beneficia en forma directa de ellas, sintiendo más sus ventajas que las nuevas desigualdades que se generan en quienes no pueden acceder a ellas. Al mismo tiempo, es cuantitativamente mayoritaria la permanencia -y en muchos casos el incremento- de situaciones de desigualdad. El incremento se acentúa cuando las condiciones de inaccesibilidad a determinados bienes, o a la formación y a la información, dependen del manejo de herramientas como pueden ser, desde el poseer una línea telefónica hasta el saber cómo realizar una gestión a través de Internet sin necesidad de desplazarse $^{2}$. Digamos que lo que hemos dado en llamar el «efecto Mateo» ${ }^{3}$

2 Al respecto resulta de interés consultar la entrevista publicada por RTS Revista de Treball Social, número 146, junio de 1997, pág. 128 a 137 a Joan Majós (ex-ministro español de Industria y consejero responsable del área de las industrias de la información y las telecomunicaciones en la Comisión de la Unión Europea) donde adjudica un importante papel al Trabajo Social en la preparación de las personas para el mundo de las nuevas Tecnologías. "Deberían actuar (los profesionales del Trabajo Social) en la" implementación de politicas de preparación de la población para extraer el máximo beneficio posible de todos esos cambios y para evitar nuevos riesgos. (...) Todos apren- 
adquiere velocidades cibernéticas y éste es un punto que debe mantenernos alerta desde el Trabajo Social. Las metamorfosis que se producen en las relaciones laborales van dejando fuera del mercado a una gran cantidad de personas, lo que equivale a condenarlas a situaciones que oscilan entre la vulnerabilidad y la marginalidad. Las relaciones cotidianas y los vínculos personales también van sufriendo paulatinamente transformaciones debido al avance de los aspectos de la llamada era de la información.

Es indudable que existen también aspectos positivos en los avances acaecidos en este siglo que termina. Los avances tecnológicos han permitido incorporar al mercado laboral a un buen número de personas con discapacidad que no podrían hacerlo de otra manera. Un alto porcentaje de mujeres pareciera verse beneficiado también, al menos en algunos países, por las virtudes del teletrabajo ${ }^{4}$. Sin embargo, lo importante es que la balanza se incline de manera proporcional a la hora del reparto de oportunidades, para evitar la pérdida de las condiciones reales de equidad. Vemos entonces que la prevalencia de factores societarios de modernización y confort puede dar lugar a un resquebrajamiento de estructuras esenciales para el desarrollo de una comunidad. Al referirnos a esenciales no estamos haciendo una valoración, sino simplemente constatamos un hecho de la realidad, dado que hay ciertas condiciones sine qua non para la existencia de la comunidad tal y como ha sido definida por la Sociología.

En segundo lugar, observamos que existe una tendencia a homologar globalización con nueva economía, hecho que ejemplificamos sirviéndonos de una cita hecha por nuestra colega Concepción Fernández Alvarez en las ponencias del II Congreso de Trabajo Social de la Comunidad de Madrid. En esa oportunidad, citó la definición dada en varios documentos del Banco Mundial que conceptualiza globalización como un cambio general que transforma la economía mundial «que se refleja en vinculaciones internacionales cada vez más amplias e intensas del comercio y las finanzas» (Ponencias del II Congreso de Trabajo Social en la Comunidad de Madrid, 2000:100). Es indudable que lo económico involucra muchísimas variables, pero cuando hablamos de «tendencia a definir globalización desde el campo de lo económico»

derán a teclear, pero no a utilizar lo que esas teclas proporcionan, y aqui es donde, los que estáis en el mundo del trabajo social, os encontraréis con personas a quienes la escuela no ha preparado y se les tendrá que enseñar" (pág. 134).

3 En cste concepto me hago deudora de la definición que daba Demetrio Casado en El bienestar social acorralado, Madrid, Promoción Popular Cristiana, 1986.

4 España es el país de la Unión. Europea con el porcentaje más bajo de personas dedicadas al telctrabajo. 
queremos decir que, si bien existen numerosas voces que hablan de otros aspectos, mayoritariamente se describen en este contexto los netamente económicos.

Alain Touraine afirma que "globalización es una palabra puramente ideológica. Supone una relación necesaria entre varias tendencias sumamente importantes, pero no directamente relacionadas. Lo que se llama globalización es en realidad un proceso de diferenciación de varias dimensiones de la vida colectiva" (Touraine, A. 1998:32). En este sentido, adherimos a la definición de globalización que incorpora una multitud de fenómenos que no sólo se relacionan con el mundo de la economía, sino que involucran otra serie de ámbitos en cuyos campos interviene de manera directa el Trabajo Social.

Estos otros ámbitos de la «globalización», traen implícitos cambios en la vida cotidiana, que repercuten de manera inevitable en las relaciones sociales, quizá con mayor fuerza, o al menos mayor impacto, a la hora de hacerse visibles, que otros cambios que pudieron darse en anteriores etapas de la historia. En ellos centramos nuestro análisis porque allí encontraremos los desafíos del Trabajo Social con la comunidad.

Al poner el acento sobre la tendencia a definir el fenómeno de la globalización desde perspectivas económicas, creemos encontrar un ejemplo del proceso de predominio ideológico de los aspectos societarios, es decir, inherentes a las relaciones secundarias donde el objetivo es obtener un determinado fin. En esta línea, queremos someter a debate la contradicción que en principio pareciera existir entre un Trabajo Social inserto en el siglo XXI, en un mundo globalizado y al parecer netamente societario, con la utilización metodológica de los criterios comunitarios. De esta manera sostenemos la tendencia de la globalización (modernidad+postmodernidad) como refuerzo de los aspectos societarios, en tanto que lo comunitario permanece en un ámbito previo a lo moderno.

Sin embargo, en este caos ordenado, es un hecho que ambas instancias coexisten con mayor o menor éxito. Pareciera además que su coexistencia es necesaria para las personas, y por tanto buscada. De lo que trataremos es de cómo definir qué papel le compete al Trabajo Social con la Comunidad en este contexto.

Con oportunidad de la entrega del premio Príncipe de Asturias de Humanidades a Umberto Eco, circuló en los medios de comunicación una frase suya que dice «en Francia se teme la mundialización que impondrá el inglés. A lo mejor ocurre lo contrario, el modelo del 
milenio será San Pablo, que nació en Persia en una familia judía, que hablaba griego, leía la Torá en hebreo y vivió en Jerusalén donde hablaba arameo. Cuando se le pedia el pasaporte era romano. Es un ejemplo interesante de mundialización».

El fin de una etapa siempre impone un balance. Entre quedarnos con el debe y el haber nos parece más interesante la posibilidad de una tercera opción ${ }^{5}$ de transformación de unos en otros, que serán novedosos y distintos a sus orígenes. En este marco de las sociedades complejas, cabe preguntarnos entonces por el papel que desempeña el Trabajo Social con la comunidad y sus posibles nuevas formas de intervención en el contexto del siglo XXI.

La respuesta a este interrogante constituye un imperativo ético en tanto que, si nos planteamos la responsabilidad de avanzar en la consolidación de la profesión, es preciso identificar las claves con que se mueve la realidad social. La correcta concepción de la relación entre el enfoque comunitario y la modernidad (y la postmodernidad) podrá facilitar el diseño de nuevas formas de intervención «sustentables» ${ }^{6}$.

¿Será posible conciliar los avances de la técnica, el progreso y el desarrollo económico con el desarrollo humano y social? ¿Existirá un ámbito que haga factible el respeto de las necesidades humanas y del medio ambiente? ¿Quedará un papel para la intervención a través del Trabajo Social Comunitario en una sociedad que enarbola como bandera el individualismo?

\section{COMUNIDAD Y SOCIEDAD EN TIEMPOS DE LA GLOBALIZACIÓN}

El marco de la globalización parece siempre visualizado desde un análisis propio del pensamiento binario, casi podríamos decir filosóficamente maniqueo, porque discurre pendularmente entre lo bueno y lo malo según quién lo describa. Para nuestro análisis existe una tercera opción posible. Es la que vincula ambos aspectos para dar lugar a una nueva situación. Desde nuestro criterio, esta tercera opción se ejemplifica en las palabras de la profesora Natividad de la Red quien señala que las actuales transformaciones provocadas por los «procesos de fragmen-

5 Recordamos que J. Galtung siempre plantea la necesidad de evitar las polarizaciones buscando una tercera posibilidad en las situaciones de conflicto, así lo sugiere desde el propio título de una de sus obras: Hay alternativas.

- Utilizamos el término como una adaptación a lo que nos interesa considerar en el Trabajo Social Comunitario, de modo que las formas de intervención no "destruyan" los recursos que las redes sociales primarias brindan. 
tación social, provocan que los sectores impactados por los procesos de exclusión tiendan a organizarse en el contexto local a través de experiencias comunitarias compartidas». (De la Red, N. $\mathrm{V}^{\mathrm{o}}$ Congreso Estatal de Intervención Social.) Es evidente entonces que de situaciones que apriorísticamente son susceptibles de ser definidas como negativas, pueden surgir también alternativas novedosas desde el ámbito de la comunidad.

Todas estas transformaciones que se inician con la Ilustración y la modernidad, y que continúan en la postmodernidad actual, parecieran tener un saldo negativo para las relaciones sociales de tipo comunitario. Sin embargo, es igualmente visible la creciente «pre-ocupación»-que en muchos casos se transforma en «ocupación»- por los diversos problemas sociales y sus posibles formas de resolución. En este sentido son de analizar, por su interés y repercusión sociológica, los movimientos sociales que reivindican una vuelta a los «valores comunitarios». Así, nos encontramos con las revueltas habidas en la Cumbre de Seattle, los planteamientos del filósofo Zearzan, los movimientos ecologistas que fundamentan la necesidad de un desarrollo sustentable, las proclamas de José Bové en Francia enfrentándose a los aspectos considerados como más negativos de la globalización... Todos estos hechos demuestran que existe por parte del hombre y la mujer modernos una necesidad interna de conciliar los muchos beneficios societarios de la modernidad con otros aspectos a los cuales no se ha podido dar respuesta y que repercuten en las relaciones interpersonales.

La caída de los grandes arquetipos en términos de organización social ha traído como fruto una sensación de incertidumbre en cuanto a las formas de alcanzar el bienestar de las personas. La información transmitida de forma masiva e indiscriminada, y respondiendo en todos los casos a intereses no manifiestos, produce en muchos casos más confusión que elementos de análisis.

Citando nuevamente a Touraine "En el mundo entero, y ese es mi concepto de la globalización, los individuos están tratando de buscar una solución al mismo problema: cómo combinar esta participación del mundo que llamamos de racionalidad instrumental, con la defensa de la cultura, de la personalidad. Esto es nuevo y no existe la bipolaridad de antes (...). Todos los grupos sociales -y desde categorías sociales, étnicas, religiosas, sexuales-están tratando de buscar una respuesta particular a un problema de tipo general que es la combinación, no de racionalidad e irracionalidad, sino de racionalidad instrumental, de técnica y mercados, con identidad cultural" (Touraine, A.1998: 32). El texto nos parece absolutamente ilustrativo de la realidad del Trabajo Social de enfo- 
que comunitario. La necesidad de conciliar dos realidades que, si bien en apariencia son contradictorias o, al menos, conceptualmente son definidas como contradictorias, requieren ahora de una necesaria convivencia cooperativa. No podemos hacer determinadas cosas si carecemos del apoyo de la comunidad, pero al parecer lo que queremos hacer es un objeto societario. Es decir, hemos pasado de hablar de realidades contrapuestas a hablar de realidades concéntricas que a la vez requieren un intercambio entre sí para lograr sus respectivos objetivos. Esto tiene también su correlato en el Trabajo Social y de ahí la importancia en plantearse desde la ética las formas de intervención.

Los discursos marcan las tendencias, pero el Trabajo Social ha de concebirse desde una responsabilidad profesional, planteándonos por qué intervenimos en un determinado momento y de una manera dada y analizando si existe coherencia entre nuestro discurso y nuestra actuación.

\section{EL TRABAJO SOCIAL COMUNITARIO DEL SIGLO XXI}

En este contexto que hemos descrito se enmarca la realidad del Trabajo Social comunitario del siglo que se inicia. Un contexto en el que todos asumimos el discurso de los grandes cambios y de las grandes velocidades, de las nuevas tecnologías, pero, a la vez, reclamamos la necesidad de determinadas estructuras que concilien nuestro "bienser" (Rodríguez Villasante, T. 1998:55) con nuestro "bien-estar" (comunidad-sociedad).

Nos interesa «aterrizar» los conceptos y apreciaciones teóricas que hemos analizado en la realidad de la intervención del Trabajo Social.

Existen diversas formas de intervención que, si bien todas pueden situarse bajo el paraguas de «enfoque comunitario», unas parecen favorecer las relaciones comunitarias y otras mucho más las societarias. Ante un primer análisis, podemos decir que se detecta una mayor proporción de intentos conciliadores -al menos en el discurso- entre la sociedad y la comunidad, que excluyentes, es decir, plantearse la comunidad como impuesta a la sociedad o viceversa. Pero no parecería riguroso para el análisis obviar que, en muchos casos, si bien hablamos de Trabajo Social Comunitario, las acciones encaradas desembocan por fuerza en criterios societarios. Ejemplos de esta circunstancia podemos encontrarlos en proyectos de desarrollo donde se capacita a una población para desempeñar ocupaciones que encontrarán salida fuera de su ámbito territorial. En el campo de la cooperación al desarrollo, también pueden encontrarse ejemplos de traspolación de experiencias en que la 
idea del "desarrollo comunitario" albergó un espíritu modernista. Llevar civilización a los pueblos del tercer mundo para lograr un mayor grado de bienestar. El problema fue que en muchos casos no se respetaron las redes naturales, los vínculos comunitarios y se aplicó exclusivamente el "espíritu societario y modernizador". En el camino perdimos el "bien-ser", y, lo peor del caso, es que no llegamos tampoco al "bienestar".

Es indudable que la utilización del enfoque de intervención comunitaria con fines político-partidarios (sin que estos fueran claramente explicitados) ha estado presente en no pocas oportunidades. Este hecho encuentra una mayor posibilidad de desarrollo en los momentos en que no existe una libertad política y, por tanto, la acción social es una de las posibles vertientes por las que se desenvuelven las inquietudes y reclamaciones políticas. En definitiva, el origen del desarrollo comunitario y la organización de la comunidad han respondido a circunstancias políticas. Es decir, que puede darse el caso en que el objetivo primigenio de la «comunidad» quede subsumido o disfrazado detrás de otros objetivos.

El discurso profesional de los años 70 no se concebía sin el trabajo social comunitario con claras connotaciones ideológicas. Esto respondía a una realidad histórica, y a una situación política. El trabajador social de la época era considerado un agente de cambio, que, como bien describe el profesor Barbero, «toleraba malamente el reformismo propio de la profesión», por lo que, decimos nosotros, renegaba de su propio origen.

Por aquel entonces lo comunitario era sinónimo de agitación, movilización, organización (Marco Marchioni). En América Latina también se vivió este proceso con la Reconceptualización ${ }^{7}$ en cuyos textos abrevó buena parte de la generación de Trabajadores Sociales españoles que abogaban por el Trabajo Social Comunitario.

Lo importante es que de todas estas experiencias podemos ir sacando aprendizajes enriquecedores que nos sirven para no repetir -o al menos intentarlo- los mismos errores.

7 El problema de la utilización de conceptos políticos insertados en el discurso profesional demostró en muchos casos una escasa validez metodológica a la hora de ser traducido a hechos concretos, en el campo, claro está, del Trabajo Social. Con esto consideramos que, muy lejos de deslegitimar la incorporación de valores propios del pensamiento político, lo que queremos es evitar la confusión que arrastramos hasta en la conceptualización de lo que es el Trabajo Social. Muchos de los teóricos de la reconceptualización reconocen que, sin dejar de afirmar los efectos movilizadores y revitalizadores que ésta ha tenido, su validación en la práctica terminó resultando escasa. 
Ahora bien, lo comunitario dejó de estar presente en el discurso del Trabajo Social español pasada la década de los 70. ¿Por qué?

Es importante tener en cuenta que convergieron varios factores. Por una parte, nos parece necesario señalar que la situación de desarrollo económico en que fue ingresando España, fruto, por una parte, de las divisas que ingresaban los emigrantes (que a la vez contribuían al descenso del desempleo), por otra, el crecimiento económico con una fuerte demanda de mano de obra en la industria y servicios, y también indudablemente por los ingresos habidos con el turismo. En definitiva, no interesaba la intervención comunitaria para solucionar problemas que se canalizaban desde la perspectiva individual. En muchos pueblos españoles se vivió la paradoja de que aquéllos que habían sido promotores de cooperativas y verdaderos líderes y artífices del desarrollo comunitario se retiraron de su acción comunal para refugiarse en empleos en las grandes urbes que en nada se equiparaban a la trascendencia de su labor en sus lugares de origen ${ }^{8}$. Porque la modernización del conjunto de la sociedad necesitó ocultar lo comunitario y, en términos de prácticas profesionales, nos atrevemos a decir que «lo arrasó». Una sociedad de claras características rurales, con el lastre de una larga dictadura que le había dejado fuera del contexto internacional y que, por ello mismo, le había asignado una serie de tópicos, necesitaba forzosamente hacerse de una nueva imagen, obviamente lo más moderna que fuera posible. El «600» fue el símbolo para España, de una modernidad que traía aparejada la burocratización y la complejización de las relaciones sociales. Era el progreso que permitía una mayor movilidad social, que auguraba tiempos distintos.

Antes hemos hablado de la complejidad de la realidad social y por ello, del mismo modo que el trabajo comunitario desapareció del discurso durante los años 80, aparecieron los Servicios Sociales y la red pública de Servicios Sociales. En tal sentido, el profesor Octavio Vázquez Aguado afirmaba recientemente «existe una íntima relación entre la disciplina y la sociedad en que se desarrolla» (Vázquez Aguado 2000).

El nuevo paradigma trae aparejado una mayor conceptualización desde el punto de vista teórico, lo que lleva a una mayor tecnificación de la intervención. Sin embargo, en muchos casos, el resultado termina

\& Para esta afirmación me sirvo de las anécdotas que al comentar este artículo me hiciera Demetrio Casado sobre lo ocurrido en el pueblo de San Pedro de Gaíllos (Segovia), donde destacados dirigentes de los procesos de desarrollo comunitario se trasladaban a Madrid para trabajar como asalariados en labores que se encontraban muy por debajo de la trascendencia y el status social de las tareas que desarrollaban en su pueblo. 
siendo una creciente burocratización ${ }^{9}$. Esto se corresponde con aquello que el propio Max Weber definió como un fenómeno propio de la modernidad, y el Trabajo Social, que, por definición conceptual, se encuentra directamente vinculado con el contexto histórico, político, económico y axiológico en que se desarrolla, también se vio influido en su discurso por este proceso de modernización.

Interesa también recordar lo que el profesor Barbero describe como las dos lógicas en el discurso del Trabajo Social:

1) la lógica de los servicios, que responde a la estrategia de la autoafirmación y a la del desarrollo de la red de Servicios Sociales, $y$

2) la lógica de los proyectos (actual), que responde a la estrategia de la vertebración. El Trabajo Social asume un papel de mediador, concertador, partner, gestor, ingeniero social.

Cabe, de todos modos, incorporar a este planteamiento el criterio de hasta qué punto estas lógicas son asumidas desde la profesión y son dirigidas y consolidadas con total conciencia, o pasan por ser admitidas desde la práctica cotidiana como una realidad inapelable. Coincidimos plenamente en que, cuando menos, es necesario analizar de qué manera los discursos se van consolidando y cómo desde el discurso se afirman determinadas formas de intervención. No en vano, cuando el Trabajo Social Comunitario ha sido una de las formas pioneras de intervención del Trabajo Social, actualmente pareciera haber cedido su protagonismo a la Psicología Comunitaria, a punto tal que los insumos teóricos utilizados para el estudio del Trabajo Social con la comunidad en muchos casos se nutren mayoritariamente allí, olvidando por completo el propio acervo de la profesión.

En este sentido, nos permitimos incorporar otra variable de análisis al enfoque de las dos lógicas propuesto por el profesor J.M. Barbero, y es el de la influencia que las políticas y formas de intervención de la Unión Europea han tenido en el Trabajo Social.

La lógica de los proyectos responde a una realidad político-económica que se ha instalado en la intervención social. La influencia que los proyectos financiados por la Unión Europea ha establecido sobre el Trabajo Social español es motivo de muchos debates. Existen muchos aspectos de gran importancia, como la construcción de redes europeas, la transferencia de tecnologías y la consolidación de un espacio y len-

9 En su artículo La Burocratización de los Servicios Sociales (UCM, 1993), la profesora Encarna Guillén Sadaba da un certero panorama de lo que implicó este proceso de burocratización para la actitud del estrato profesional del Trabajo Social. 
guaje común en los aspectos sociales ${ }^{10}$. Pero resulta, a nuestro criterio, necesario reconocer que lo hecho anteriormente en el campo de la intervención comunitaria tuvo un valor intrínseco merecedor de ser rescatado y revalorizado. No se trata de una adhesión melancólica, sino de la incorporación de un dato de análisis de la realidad que permita trabajar en el presente del Trabajo Social con la comunidad desde una mejor perspectiva.

La incorporación de pleno derecho en la Unión Europea trae aparejada la aparición de un nuevo lenguaje. Estamos ante lo que ha dado en llamarse el discurso del proyecto, territorialidad, partenariado, multidimensionalidad. Se redimensionan totalmente las formas de intervención. En palabras de Castells estamos ante una nueva cuestión social: la quiebra del estado de bienestar.

Esto implica la toma de conciencia sobre un nuevo concepto que emerge y se reproduce rápidamente el de "vulnerabilidad social", la toma de conciencia por parte de amplias capas de la población de la posibilidad de pasar a incorporar las filas de la que ha dado en llamarse "Nueva Pobreza", modifica rápidamente el contexto en el que se mueve el Trabajo Social.

En este análisis, resulta preceptivo destacar que esta definición corresponde a aquellos países occidentales donde la cultura salarial y la sociedad del bienestar han constituido una realidad palpable, porque en muchos países, de los que, por ejemplo, podríamos citar los llamados "emergentes", este proceso es vivido de manera inversa.

Cuando analizamos las variaciones en el discurso del Trabajo Social podemos ver dónde se sitúa la intervención comunitaria. Hemos de considerar en qué contexto hablamos de la intervención comunitaria. No podemos olvidarnos que los inicios del Desarrollo Comunitario tuvieron una neta carga política.

Insistimos en la importancia de sistematizar los ejemplos de intervención comunitaria que se han dado en nuestro país, como las experiencias de Baza y las habidas en Bésos y tantas otras dentro de nuestro país que supieron aglutinar los aspectos de modernidad y comunidad. También nos parece importante citar un ejemplo de las experienicas que se dan más allá de nuestras fronteras, aun en aquellas culturas que en principio parecieran totalmente diversas a la nuestra. Un modelo de

10 Al respecto del lenguaje, nos parece de sumo interés el análisis realizado por Demetrio Casado sobre el impacto de los Programas Europeos de Lucha contra la Pobreza en la bibliografía española. "Aproximación al impacto de los progranas antipobreza CE/UE en la bibliografía española" en Revista de Políticas Sociales en Europa $N^{\circ} 4$, septiembre de 1998 , p. 139 a 149. 
enfoque de desarrollo comunitario como el propuesto por el economista Yunus con la creación del Grameen Bank en Bangladesh nos demuestra que la integración social a través de los aspectos económicos (tan en boga en la intervención social de nuestros días) requiere de un concienzudo conocimiento de las estructuras sociales en las que se interviene.

Muhamad Yunus inicia su labor en 1976 en la aldea de Jobra. Toma conciencia de que a las personas sin tierra les resulta prácticamente imposible obtener préstamos en bancos comerciales porque no podían presentar avales. Decide entonces avalar personalmente los préstamos de los más pobres y consigue coeficientes de amortización superiores al $99 \%$. En 1983 el proyecto se convirtió en un banco de pleno derecho. El gobierno de Bangladesh aportó el $60 \%$ del capital amortizado inicial. En 1991 el banco había ampliado sus servicios a más de 23.000 aldeas a través de sus casi 900 sucursales. Aproximadamente un millón de hogares había recibido créditos. El promedio de préstamos es de 60 dólares y el tipo de interés (16\%) no contiene ningún tipo de subsidio. Los préstamos, que se destinan fundamentalmente a la compra de materias primas y equipamientos, han generado mucho empleo, especialmente entre las mujeres rurales.

Los prestatarios también han de añadir una taka (moneda nacional) por semana a su cuenta de ahorros. En 1991 este fondo de ahorros obligatorio había acumulado 962 millones de takas: el 62\% de los préstamos pendientes (información del PNUD, 1993). Curiosamente, contamos con información que dice que el modelo no ha podido ser exportado con igual éxito a otras regiones (estudio de J.J. Thomas, 1995 PREALC; y de Hulme, 1993 para Asia -Malasia y Malawi-).

Consideramos que el proyecto del Grameen Bank es un proyecto claramente societario, donde no existen aspectos censurables, pero donde el enfoque de desarrollo comunitario está directamente vinculado a un factor de acceso a la modernidad y a las posibilidades de expansión a través del trabajo de las personas. Nada nos cuenta de la realidad de esas comunidades en cuanto a las posibilidades de una mayor solidaridad entre las personas o de tejido social.

No hemos de olvidar que el enfoque de los microemprendimientos o microempresas tiene un gran arraigo en los enfoques del desarrollo y es también un concepto muy desarollado como estrategia de desarrollo local, por ello nos ha parecido importante citar este ejemplo.

Podemos decir entonces que:

- El proyecto es altamente positivo como elemento de redistribución de riqueza. 
- Es una estrategia claramente democratizadora porque permite el acceso al crédito a personas que habitualmente carecen de él por su condición socioeconónomica.

- No tiene un enfoque en que lo comunitario como tal sea la prioridad, sin embargo, existe un respeto por pautas de relación propias de la comunidad en que se implantan.

- El enfoque se basa en lo societario, sin embargo, concilia lo comunitario en una realidad en la que esta alianza se supone particularmente difícil.

\section{A MODO DE EPÍLOGO}

En todo caso, de estas primeras reflexiones en voz alta se desprende la imposibilidad de lograr un equilibrio social (comunidad) sin un progreso económico (sociedad-modernidad), pero lo que a la vez también ha quedado demostrado para nuestro análisis es que el enfoque exclusivamente modernista no alcanza a cubrir la totalidad de la realidad.

A la vez, inexplicablemente para los postulados economicistas, los grandes avances económicos no han llegado por igual a todos los sectores de la población, los beneficios del crecimiento continuo y las nuevas tecnologías se han quedado en manos de un porcentaje reducido de la población, e irremediablemente oímos una vez más el eco del «efecto Mateo».

Básicamente, el enfoque del desarrollo conlleva hoy en día la irrenunciable premisa de que no basta el crecimiento económico y la modernización tecnológica para enfrentar la pobreza. El Trabajo Social con enfoque comunitario debe destacar la necesidad de incluir mejoras en la distribución de los ingresos y, para ello, es también importante tener en cuenta los aspectos que hacen a las relaciones sociales primarias de las personas, así como el respeto de sus costumbres.

En este sentido, nos parece importante concluir que no pareciera correcto intentar conciliar sin más aspectos que en sí son definidos como contradictorios, tal como hemos visto que son comunidad y sociedad.

Antes bien, resulta necesario ver las formas alternativas de coexistencia de éstos que permitan intervenir creativamente desde el enfoque comunitario en Trabajo Social en una realidad social cada vez más compleja. 


\section{BIBLIOGRAFÍA}

BARBERO, J.M (1999): “20 años en los Discursos de Trabajo Social”, (19781998), pág. 9-41. Revista de Trabajo Social Servicios Sociales y Política Social $N^{\circ} 47$. Madrid.

BADI, B. (1990): “Community, Individualism, and Culture" en Individualism, Theories and Methods, Birnaum y Leca (edits.), Oxford, Clarendon Press.

CASADO, D. (1970): Plan Social Baza, Ediciones Euramérica, Madrid.

CANALS, J. (1997) "Buscando al Trabajo Comunitario entre community y communitas: apuntes sobre unos conceptos importados" páginas 85 a 90 en Revista de Trabajo Social Servicios Sociales y Política Social N ${ }^{\circ} 40$.

DE LA RED, N. (1999): Mesa Redonda: Servicios Sociales Comunitarios redefinición de un modelo en transición. Perspectiva Rural, en CD.ROM V ${ }^{\circ}$ Congreso Estatal de Intervención Social "Calidad y responsabilidad compartida: retos del bienestar en el cambio de siglo", organizado por el Colegio Oficial de Psicólogos de Madrid y la Coordinadora Estatal de Intervención Social. Madrid, noviembre de 1999.

GIDDENS, A. (2000): Un mundo desbocado. Los efectos de la globalización en nuestras vidas, Editorial Taurus, Madrid.

GINER, S. (1985): Sociología. Editorial Nexos. Madrid.

GALLINO, L.: Diccionario de Sociología, pág 196. Siglo XXI Editores.

Ponencias y Comunicaciones Libres del II Congreso de Trabajo Social en la Comunidad de Madrid "Mirando hacia afuera". Editado por el Colegio Oficial de Diplomados en Trabajo Social y Asistentes Sociales de Madrid, noviembre de 1999.

RODRÍGUEZ VILLASANTE, T. (1998): Cuatro Redes para mejor-vivir, Editorial Lumen-Humanitas, Buenos Aires.

SOROKIN, P. (1986): Sociedad, Cultura y Personalidad. Su estructura y su dinámica. Sistema de Sociología General. Editorial Aguilar.

TOURAINE, A. (1998): revista El SEMANAL, 4 de octubre de 1998, entrevista de Mariano Aguirre, pág. 30 a 35. Madrid.

VÁZQUEZ AGUADO, O.: «Relaciones entre Trabajo Social y Sociedad» en Cuadernos de Trabajo Social 1999, 12:93-106, editado por la EUTS de la Universidad Complutense de Madrid. 


\section{LOS FACTORES TERAPÉUTICOS: ¿QUÉ ES LO QUE PRODUCE CAMBIOS EN LOS GRUPOS?}

\section{JOSÉ FRANCISCO CAMPOS VIDAL}

TEU del Área de Trabajo Social y Servicios Sociales, Vicedecano de Trabajo Social de la Facultad de Filosofía y Letras. Universidad de las Islas Baleares.

\section{LOS FACTORES TERAPÉUTICOS: ¿QUÉ ES LO QUE PRO- DUCE CAMBIOS EN LOS GRUPOS?}

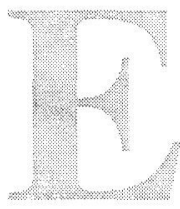

Entendemos al Trabajo Social de Grupo como aquella rama del Trabajo Social que se caracteriza por el uso del grupo como medio y contexto para la modificación de las circunstancias personales generadoras de malestar o circunstancias que impiden a los componentes del grupo desarrollar sus capacidades, afectos, relaciones o responsabilidades sociales. Así mismo, el Trabajo Social de grupo se caracteriza por el uso del grupo como medio e instrumento para la modificación del entorno y contexto social, operando en el marco de colectivos o territorio singulares y diferenciados.

Así pues, reconocemos e identificamos tres dimensiones en las aguas territoriales del Trabajo Social de Grupo:

a) una dimensión individual en la cual el Trabajo Social de Grupo se centra en la singular problemática de cada uno de los sujetos que componen el grupo. Se trata de los grupos centrados sobre sí mismos, creados ad hoc por el propio Trabajo Social, con objetivos de cambio individual y que han dado origen al modelo terapéutico de Vinter (1969) o al modelo socioterapéutico/socioeducativo a los cuales hace referencia Rossell (1997).

b) Una dimensión grupal, en la cual el objeto de atención es el grupo en sí mismo, el grupo como un sistema social en situación de dificultad. Puede tratarse del grupo de autoayuda o el grupo de acción social, en ambos casos, grupos preexistentes en un territorio y en un colectivo concreto. Esta dimensión estimuló la creación del modelo recíproco de Schwartz (1971).

c) Y, por último, una dimensión comunitaria en la cual el grupo existe, opera y persigue objetivos para cambiar, modificar o mejorar 
situaciones que afectan a otros grupos, a otros colectivos o a territorios singulares, y que ha sido el impulsor del modelo de objetivos sociales o el modelo de asesoramiento comunitario de Egan (1981).

Entendemos que esta triple vertiente está asumida en la definición, ya clásica, que hace Konopka' acerca de lo que es el Trabajo Social de Grupo: "un método de Trabajo Social que ayuda a los individuos, por medio de experiencias intencionadas en grupo, a mejorar su funcionamiento social y a enfrentarse de una manera más efectiva con sus problemas personales, de grupo o de comunidad".

Desde la perspectiva de los grupos centrados sobre el cliente, nos interesa interrogarnos sobre las siguientes cuestiones: ¿cómo ayuda el Trabajo Social de Grupo a sus clientes? ¿Cómo se mejora el funcionamiento social? ¿De qué manera es posible que los individuos se enfrenten con más eficacia a sus problemas? Expresándolo de otra forma, $i$ se dan condiciones necesarias fundamentales que posibilitan el desarrollo de procesos de cambio? En el caso de que así sea, ¿cuáles son esas condiciones, bajo qué parámetros se expresan y cuál es su naturaleza?

Generalmente, la bibliografía de referencia, ${ }^{2}$ en lengua castellana e italiana en relación al Trabajo Social de Grupo, ha prestado escasa atención al desarrollo de los fenómenos intra-grupales relacionados con el cambio. En general, los trabajos que se encuentran a nuestra disposición abundan en consideraciones teórico-metodológicas ligadas a la teoría de grupo, generalmente bajo el epígrafe general de "Dinámica de Grupo" (Shaw, 1980): estructura, redes de comunicación, roles, liderazgo, conflicto grupal y ciclo evolutivo del grupo.

El conjunto de las investigaciones desarrolladas en este sentido, asentadas en los laboratorios de grupo bajo el formato general de "T-Group" o grupos de encuentro y crecimiento, nada nos dicen de la dinámica del cambio en la medida de que el cambio no ha sido su objeto concreto de investigación. Desde la perspectiva del Trabajo Social, es evidente que se hace necesario el conocimiento del sujeto objeto de observación -en nuestro caso, el grupo-, aunque, en este caso, el sujeto observado pre-

Konopka, G. (1969): Trabajo Social de Grupo. Euramérica, Madrid.

2 Prestamos atención especial a los trabajos de Contreras (1980), Vinter (1967), Kisnerman (1973), Konopka (1969, 1973), Kisnerman y Mustieles (1997), Williamson (1961, 1969) o Di Carlo, et. alt. (1962, 1997), Brown (1988), Tschorne (1990, 1993), Baten (1969), Domenech (1998) y Ruiz (1996), en lengua castellana, y a los trabajos de Zini y Modini (1999), Bocolan, Carbonaro y Bennici (1990) y Heap (1986), en lengua italiana. 
senta una particularidad que incrementa su nivel de complejidad: es un sujeto que quiere cambiar o que necesita cambiar.

Desde una perspectiva profesional, el grupo de Trabajo Social tiene y adquiere un sentido en la medida que, como tal, se orienta hacia un cambio: identifica problemas o situaciones problemáticas ${ }^{3}$, determina su voluntad de cambio, formula objetivos de cambio, determina tareas encaminadas a alcanzar el cambio y evalúa los cambios resultantes. A nuestro juicio, los grupos de Trabajo Social son algo más que un laboratorio de dinámica grupal, independientemente de que los fenómenos intra-grupales aparezcan y se desarrollen en toda su extensión. Así pues, desde nuestro punto de vista, se hace dramáticamente necesario determinar cuáles son los fenómenos que favorecen el cambio o, si se prefiere, las condiciones necesarias que deben desplegarse para que el cambio sea posible.

Queremos en este momento hacer algunas consideraciones con el objeto de clarificar la intención de este trabajo. Cuando hablamos de condiciones necesarias o fenómenos que favorecen el cambio, no estamos haciendo referencia a técnicas orientadas al cambio. A nuestro entender, una técnica, siendo un procedimiento concreto que ha demostrado su efectividad para conseguir un fin concreto, podrá impulsar o inhibir el desarrollo de los fenómenos grupales de cambio. A nuestro juicio, existen factores de cambio o, si se prefiere, "factores terapéuticos" que, siendo condición necesaria, aunque no suficiente, están potencialmente presentes en todo proceso de cambio en el marco del Trabajo Social de Grupo. Así pues, afirmamos que la técnica en sí misma no cambia nada, no "cura" nada, sino que más bien cataliza cambios que afectan a mecanismos cognitivos, emocionales, relacionales o conductuales, permitiendo a los sujetos experimentar experiencias internas y relacionales que permitirán cambios relacionales e internos. $\mathrm{Si}$

Es evidente que cualquier situación-problema, sea cual sea su origen y naturaleza, impacta en mayor o menor medida sobre los subsistemas constitutivos del sujeto (CASIC: conductual, afectivo, somático, interpersonal y cognoscitivo) y sobre la red social en el cual éste se desarrolla. Entendemos por necesidad a aquella situación problema caracterizada por la precariedad de los medios de subsistencia y supervivencia del sujeto o sistema implicado; entendemos por dificultad a aquella situación problema en la cual es posible una solución satisfactoria pero que, en la cual, el sujeto o el sistema implicado no dispone o no está en condiciones de activar sus recursos y capacidades personales, sistémicos o medioambientales; entendemos por problema a aquella situación que no tendrá solución y que, manteniéndose indefinidamente en el tiempo, va a generar numerosas necesidades, dificultades o conflictos; entendemos por conflicto a aquella situación problema en la cual sujetos y sistemas se encuentran enfrentados y que, toda solución significa, en primera instancia, la resolución de un dilema por alguna de las partes. 
desconocemos qué es lo que favorece el cambio, nunca podremos determinar con precisión la idoneidad de la estructura, el contexto y el proceso grupal, y tampoco la congruencia de la aplicación técnica con los objetivos personales y grupales.

Por otra parte, cabe considerar que los fenómenos relacionales que acontecen en el grupo y que favorecen o inhiben el cambio poseen una naturaleza propia e independiente del marco teórico de observación desde el cual el Trabajador Social ${ }^{4}$ lea, interprete y opere con el grupo. Ello significa que el profesional, independientemente de su marco referencial teórico (psicodinámico, cognitivista, enfoque conductual clásico, psicodramático, rogersiano, transaccional, realista o racional-emotivo, como ejemplo de los marcos fundamentales), no puede ignorar la existencia de una pluralidad de factores terapéuticos y que, algunos de ellos, pueden no ser consistentemente considerados en el desarrollo del modelo terapéutico $0^{5}$ Y, si nos lo permiten, queremos señalar un último elemento que incrementa el nivel de complejidad. Los factores terapéuticos que, a continuación señalaremos, están íntimamente condicionados por dos elementos: la vida evolutiva del grupo y el contexto de intervención en el cual el grupo opera. Desde el punto de vista de la vida evolutiva del grupo, los factores terapéuticos presentan una lógica secuencial particular ligada a los distintos estadios del mismo: la cohesión grupal no actúa como factor de cambio en los primeros estadios y sí en los intermedios y finales, mientras que la universalidad o el mantenimiento de la esperanza son factores precoces ya en los primeros estadios de formación del grupo. El contexto de intervención (asistencial, in-formativo, asesoramiento, clínico, control y evaluación) favorecerá especialmente el desarrollo de aquellos factores terapéuticos más acordes con la naturaleza del propio contexto: relacionales, emocionales, conductuales o cognitivos. Así, por ejemplo, un contexto clínico enfatizará factores terapéuticos de naturaleza emocional, cognitiva y relacional, mientras que un contexto in-formativo muy probablemente destacará factores terapéuticos de naturaleza conductual, cognitiva e interaccional.

Bien, veamos de qué hablamos cuando hacemos referencia a los "factores terapéuticos". El abanico de factores terapéuticos está recogido de forma fragmentada en los trabajos de Weiner-Davis (1989), Watzlawick, Weakland y Fisch (1982), de Shazer (1999), Selekman (1996) y Neuburger (1997), Madanes (1997) y, con especial atención en relación al trabajo de grupo, en las obras de Yalom y Vinogradov

Entiéndase Trabajador y Trabajadora Social, indistintamente.

Por ejemplo, un enfoque conductual ortodoxo no considerará la expresión de emociones o el mantenimiento y el fomento de la esperanza, como elementos a considerar y fomentar. 
(1996), Yalom (2000), Corey (1996), Bloch y Crouch(1985) y Stockton y Hulse (1980), Gutiérrez et. al. (1997), Aznar et. al. (1995), y Tevan (1998), entre otros. A nuestro modesto juicio, los trabajos de Yalom y Vinogradov, Bloch y Crouch, Stockton y Hulse, y, en cierta medida, Corey sintetizan y resumen con claridad la naturaleza de los factores terapéuticos.

Intentado responder a la pregunta ¿qué sucede en el seno de un grupo que hace que los clientes cambien?, nos centraremos en los fenómenos relacionales y psíquicos que se desencadenan en los grupos, desde una perspectiva individual y colectiva. Evidentemente, el desarrollo de actividades grupales facilitará o inhibirá tales fenómenos; sin embargo, en esta ocasión, no trataremos la idoneidad o no de las tareas que se desarrollan en el grupo, sino más bien en los factores que permiten producir el cambio individual y grupal.

\section{LOS FACTORES TERAPÉUTICOS}

\subsection{Infundir y mantener la esperanza}

El infundir y mantener la esperanza es crucial en todo Trabajo Social de grupo. Yalom (1996:25 y ss.; 2000:26) señala que la esperanza no sólo se requiere para mantener al cliente en el grupo, para que puedan tener efecto otros factores terapéuticos, sino en que la fe en un modo de tratamiento puede por sí misma ser efectiva terapéuticamente. De un modo subyacente, plantea el problema de la predeterminación o la capacidad de decisión y la responsabilidad de las personas. Una perspectiva que mantenga la génesis predeterminada de la naturaleza humana difícilmente se apoyará sobre la base de la esperanza. Una perspectiva que se sostenga sobre la tesis de que las personas tienen capacidad de decisión sobre su futuro, de que las personas son responsables de sus actos y que, por tanto, tienen la capacidad de cambiar, influirá enormemente sobre la idea de la esperanza, dicho de otro modo, sobre la firme creencia de que el cambio es posible ${ }^{6}$.

Las investigaciones ${ }^{7}$ de los terapeutas encuadrados en el modelo centrado en la solución, de orientación sistémica, han demostrado que una elevada expectativa de ayuda antes del proceso de tratamiento se correlaciona significativamente con un resultado positivo del mismo.

" Madanes, C. (1997): "Una terapia de acción social", en Violencia Masculina. Granica, Buenos Aires, pp. 17-27.

7 Kim Berg. I.; Miller, S. (1996): Trabajando con el problema del alcohol. Gedisa, Barcelona. 
Hay que considerar también la masiva documentación sobre la eficacia de la creencia en el cambio a partir de la construcción de narraciones alternativas elaboradas conjuntamente entre los clientes y los profesionales ${ }^{8}$.

Es evidente que el mantenimiento y el estímulo de la esperanza, el desarrollo de la idea de que el cambio es posible, es un factor terapéutico inicial que en sí mismo es extremadamente frágil en los comienzos de la relación intra-grupal. Por ello, los Trabajadores Sociales deberemos mantener y transmitir mensajes claros y reiterados que sustenten la esperanza y la idea de que es posible hacer algo, de que es posible cambiar. Se trata de introducir o reforzar en el sistema de creencias de los miembros del grupo tanto la idea de cambio con la creencia de que el cambio es posible a través del trabajo de grupo y, consecuentemente, de la relación interpersonal en el marco del mismo. Este mensaje y la creencia que lo sostiene debe plantearse tanto en los estadios de preparación pre-grupal como en los distintos momentos de la negociación del contrato a los cuales hace referencia Brown (1988:58 y ss.).

Por otra parte, cabe señalar que los grupos de Trabajo Social, especialmente los grupos socioterapéuticos y socioeducativos a los cuales hace referencia Rossell ${ }^{9}$, posibilitan el re-agrupamiento de personas que, compartiendo situaciones de dificultad equivalentes en relación a sus características, se sitúan en momentos distintos, circunstancias particulares distintas, narraciones distintas e intentos de solución-exitosos o excepcionales- también distintos. La constelación de singularidades relacionadas con las situaciones problemáticas y las personas que las experimentan posibilita un caleidoscopio de situaciones que son susceptibles de ejemplificar y demostrar que nada es permanente y que el cambio es posible. Por ejemplo, una pareja de jóvenes padres con un hijo afectado de diabetes, pueden observar y compartir con otra joven pareja en idéntica situación que ya lleva un año de experiencia en el manejo de la situación problema. Esta particularidad es intrínseca al nivel de intervención grupal, dado que la posibilidad de compartir entre iguales -padres jóvenes, por ejemplo- no se da en el nivel individualfamiliar.

Yalom (2000:27) señala que el estímulo y el mantenimiento de la esperanza es una de las variables estructurales de los grupos de autoayuda: narraciones de recaídas y recuperaciones permiten visualizar

3 Neimeyer, R. y Mahoney, M. (1998): Constructivismo en Psicoterapia. Paidós, Barcelona.

9 Rossell, T. (1997): "Trabajo Social de Grupo: grupos socioeducativos y grupos socioterapéuticos", en Cuadernos de Trabajo Social n ${ }^{\circ} 11$, Universidad Complutense de Madrid, Madrid, pp. 103-122. 
a los miembros noveles del grupo de autoayuda que lo que uno está viviendo no es permanente y que el cambio es posible.

Hasta el momento hemos hecho referencia al factor del estímulo y el mantenimiento de la esperanza, fundamentalmente desde la perspectiva de los partícipes del grupo. Sería un error considerar exclusivamente que este factor es atribuible a una de las partes. En términos sistémicos, un grupo de Trabajo Social es definible como un sistema de ayuda y como tal está constituido por el subsistema clientes y el subsistema Trabajador Social.

Los Trabajadores Sociales de grupo no sólo deben tener muy en cuenta este potente mensaje "el cambio es posible", también deben creerlo firmemente, ya que sin esperanza no hay posibilidades de cambio.

Esta cuestión, la creencia de que el cambio es posible, apunta a un elemento crítico del contenido de la relación terapéutica que desarrollan los Trabajadores Sociales de grupo: la congruencia o la discrepancia entre los mensajes digitales (verbales) que el profesional lanza al grupo y que afirman que es posible el cambio, y los mensajes analógicos (no verbales) que acompañan a los primeros. En primer lugar, queremos destacar que si un Trabajador Social no cree firmemente que el cambio es posible, independientemente de que intente transmitir este mensaje a sus clientes o que despliegue todo un arsenal técnico orientado a provocar cambios, analógicamente emitirá un mensaje de "no cambio", congruente con su creencia íntima. Esta contradicción comunicacional, ligada teóricamente a la Teoría del Doble Vínculo, planteada por Bateson y colaboradore ${ }^{10}$, inevitable e inconscientemente será trasmitida a los miembros del grupo. En segundo lugar, e insistiendo en esta tesis, si un Trabajador Social no cree que el cambio es posible, puede llegar a provocar un intercambio comunicacional del tipo "profecía de autocumplimiento": no creo que tú puedas cambiar $\$$ no me empeño en acompañar y facilitar el cambio $\ddagger$ el otro -cliente- no experimenta los cambios "esperados" y no cambia $\$$ yo confirmo que tú no puedes cambiar. La trampa de esta secuencia comunicacionalrelacional se centra en el hecho de que es el propio profesional el que provoca, sin ser consciente de ello, la conducta del cliente, es decir, el que mantiene al cliente en la situación de "no cambio".

10 Bateson, G.; Jackson, D.; Haley, H.; Weakland, J.: "Hacia una teoría de la esquizofrenia", en Behavioral Science, vol.1, número 4, octubre de 1956. Existe una traducción en Iengua castellana en: VV.AA. $(1971,1974)$ Interacción familiar. Ed. Tiempo Contemporáneo. Buenos Aires. 


\subsection{Universalidad}

El Trabajo Social ha reconocido históricamente la singularidad de la vivencia que experimenta el cliente, la particularidad del significado y del impacto que provoca sobre el cliente y su sistema de referencia la situación vivida (Biestek, 1966). Esta singularidad, este significado particular experimentado por el cliente, desde una perspectiva emocional, cognitiva, relacional y conductual, es generalmente hiperdimensionada por el propio cliente. La propia autosingularización siempre tiene una referencia real, independientemente del significado particular para cada uno o de la constelación de fantasías, autopercepciones, pensamientos o impulsos que el sujeto experimenta: lo que le está sucediento, sólo le sucede a él. Siendo esta última afirmación correcta, es falso deducir que la autopercepción de esta singularidad es excepcional y única. Desgraciadamente, la mayoría de clientes que están atravesando situaciones de crisis creen que lo que les está sucediendo "sólo les sucede a ellos" y consecuentemente, "nadie puede hacerse cargo o comprender lo que están viviendo": dolor, ideas y fantasías inaceptables, conductas inapropiadas, autodestructivas o negligentes, etc.

Las investigaciones desarrolladas por Caplan (1994, 1997) y Slaikeu (1988) dejan patente una característica universal que se manifiesta en las personas que atraviesan momentos de crisis: su tendencia al aislamiento social y, consecuentemente, la pérdida significativa de sus redes de apoyo social. Este fenómeno impide a los sujetos experimentar cualquier tipo de aprendizaje interpersonal que proporcione mecanismos o estrategias de corrección de la hiperdimensionada unicidad a la cual hemos hecho referencia anteriormente, por lo que es frecuente que se desencadene un proceso de aislamiento que se retroalimenta a sí mismo: cuanto más solo me siento, más me aíslo + cuanto más me aíslo, más solo me siento.

Las primeras etapas de la experiencia grupal proporcionan una experiencia externa y relacional que posibilita un cambio interno, un cambio en la percepción de sí mismo y una re-colocación de esa hiperdimensionada unicidad. La relación en el marco del grupo, identificando personas en circunstancias similares -mismo malestar, mismo dolor, mismas dificultades y misma voluntad de cambio-, posibilita romper el aislamiento, romper la singularidad, es decir, reconocerse a sí mismo en el otro y reconocer al otro y en el otro un vínculo de unidad.

Este reconocimiento recíproco es generalmente experimentado como un fuerte alivio, es decir, la aceptación de que "no estoy solo, hay más como yo, más que me entienden". Sin duda, se constituye en un significativo corrector de la ansiedad. 
Estas experiencias internas revierten en el sujeto y en el propio grupo en la medida en que naturalizan la situación vivida por cada sujeto, le proporcionan una percepción de mayor normalidad, le permiten frenar los procesos degradadores de la auto-imagen, estimulan la auto-aceptación, la ayuda mutua, refuerzan el vínculo grupal y refuerzan el mensaje de que el cambio es posible.

Yalom (2000:30) señala que la universalidad necesariamente se combina con el resto de factores terapéuticos en la medida que es un facilitador, un catalizador en la aparición y desarrollo de los demás. Nosotros entendemos que la universalidad es el primer factor terapéutico que facilita la cohesión grupal. Sin duda, una cohesión frágil e incipiente en los primeros estadios del grupo, pero que se constituye en el denominador común a partir del cual es posible la aceptación de los otros, la exploración y la exposición de narraciones y experiencias traumáticas, la ayuda mutua y la aceptación de feedbacks correctores.

\subsection{Transmisión de información}

Por transmisión de información entendemos a todos aquellos procesos grupales didácticos que permiten a los miembros del grupo comprender la naturaleza de su situación de dificultad, sus características, su curso evolutivo previsible y los cambios o el impacto que esa situación puede generar sobre el sistema de referencia del sujeto (familia y red relacional primaria). Así mismo, la transmisión de información considera en su seno las instrucciones o el asesoramiento en relación a cómo debe obrar el cliente ante una determinada situación o circunstancia relacionada con su situación problemática. Los contextos de intervención in-formativos utilizan de forma preponderante la transmisión de información, aunque ésta no es exclusiva de dicho contexto.

El impacto de este factor sobre los miembros del grupo no sólo se centra en su componente cognitivo, es decir, el saber más en relación a lo que sucede, a su evolución y a su significado, sino que también permite la alteración de conductas y pensamientos destructivos (como, por ejemplo, la clarificación en relación a temores infundados sobre el desarrollo de enfermedades en pacientes de $\mathrm{VIH}^{11}$ ), preparar a las personas para el afrontamiento de situaciones futuras (como, por ejemplo, la preparación del duelo en grupos de familiares con enfermos terminales) o la comprensión y el manejo de las características de la situación problemática (como, por ejemplo, la revelación sobre la adopción que los padres deberán efectuar a sus hijos) o la comprensión de la 
transitoriedad del dolor que se está experimentado, el cual desembocará en un período posterior de calma (como, por ejemplo, los grupos de padres con hijos con discapacidad visual). ${ }^{12}$

En todos estos elementos, generalmente la educación y la formación están implícitas; de hecho, numerosas experiencias demuestran que los Trabajadores Sociales han hecho de la instrucción formal una herramienta de frecuente utilización, especialmente en contextos informativos. La literatura reciente sobre trabajo de grupo abunda en las descripciones de grupos especializados para clientes que padecen algún desorden específico, o que afrontan alguna crisis vital, como por ejemplo la anorexia ${ }^{13}$, toxicodependencias ${ }^{14}$, diabete ${ }^{15}$, cuidados inten$\operatorname{sivos}^{16}$, adopción y acogimiento ${ }^{17}$ o la inserción social entre otros.

Desde nuestro punto de vista, la transmisión de información es un potente factor terapéutico en la medida en que incide directa y arrolladoramente sobre el "no saber". Desconocer qué sucederá o qué es lo que está sucediendo impide a los sujetos abastecerse de un marco cognitivo-temporal de seguridad establecido sobre la condición de previsibilidad. De hecho, el no saber ha sido siempre la fuente de la búsqueda del conocimiento y la explicación de los fenómenos que nos acontecen y que se desarrollan en nuestro medio ambiente: ha sido la condición para el nacimiento del conocimiento y la explicación del mundo en sus diversas manifestaciones: científicas, religiosas, etc.

El "no saber", la incertidumbre, es una fuente inagotable de desestabilización del equilibrio personal y sistémico, así como una fuente generadora de ansiedad. Frieda Fromm-Reichman subraya el papel de la incertidumbre en la producción de ansiedad ${ }^{18}$. Señala que el darse cuenta de que uno no es el director de escena de su propia obra, que las propias percepciones y la conducta están controladas por fuerzas que ni

12 Cardona, J. (1998): Programa de asesoramiento psicosocial para padres de niños con discapacidad visual. ONCE, Delegación Territorial de Baleares. Palma, Mimeo.

13 Aznar, J. et alt. (1995): "Un año de grupo de autoayuda con familiares de enfermos mentales en Zaragoza". Revista Trabajo Social y Salud $n^{\circ} 20$.

i4 Selekman, M. (1996): "El grupo de padres centrado en la solución", en Abrir caminos para el cambio, Gedisa, Barcelona.

15 Gutiérrez et alt. (1997): "Educación grupal con diabéticos de Motril. Expericncias desde el Trabajo Social sanitario". Revista Trabajo Social y salud n" 26.

16 Tevan, R. (1998): "Grupos de padres de una unidad de cuidados intensivos". Revista Trabajo Social y Salud $n^{\circ} 30$.

17 Triseliotis, J. (1994): El Trabajo de Grupo en la adopción y acogimiento familiar. Ministerio de Asuntos Sociales, Madrid.

18 Fromm-Riechman, F. (1950): Principles of intensive Psychoterapy, citado en Yalom, $\mathrm{I}$. Ob. Cit. pp. 35 . 
entiende ni comprende, es en sí mismo una fuente importante de ansiedad. Significa, en definitiva, el reconocimiento de la pérdida del control sobre la propia vida, independientemente de que el control de la vida de uno sea, evidentemente, relativo. Esto es lo que sucede con los clientes psiquiátricos que se encuentra en período de recuperación de una crisis aguda: su tristeza y los síntomas depresivos que manifiestan están íntimamente relacionados con el miedo y la ansiedad resultante de la incertidumbre respecto a la fuente y el significado de sus síntomas. Este fenómeno fue descrito con maestría en la obra literaria de Malcom Lowry, Bajo el volcán (Tusquets Ed., 1997): “...El horror de una realidad insoportable, esto no debe ser muy distinto, se dijo, del sufrimiento de un demente en aquellos momentos en que, sentado con mansedumbre en los patios del manicomio, la locura deja de ser su refugio...".

Así pues, el "saber" lo que está sucediendo, lo que va a suceder y el cómo sucede permiten al sujeto partícipe del grupo recuperar la percepción del control de los acontecimientos y del autocontrol. Si uno cree o percibe que mantiene un cierto control respecto a lo que sucede, entonces está en mejores condiciones para ejercer la capacidad de decir y, si uno puede decidir, puede orientar esta capacidad de decisión hacia el cambio asertivo, evitando en este caso que los intentos de solución orientados al cambio se conviertan, como expresan los autores de la Escuela de Palo Alto, en un problema, o si se prefiere, en "el problema".

\subsection{Altruismo}

"Una persona muere y se le da oportunidad de visitar el Cielo y el Infiemo. Al entrar en el Infierno, ve un espectáculo muy extraño: hay comida por doquier y, sin embargo, los residentes parecen famélicos. Dirige sus pasos adonde está el Diablo, y le pregunta: ¿Por qué se mueren todos de hambre, habiendo tanta comida por todas partes?

El Diablo responde: La gente no tiene codos. No podemos comer.

La persona visita luego el Cielo y se encuentra con una situación similar: abunda la comida y la gente carece de codos. Pero existe una notable diferencia: está bien alimentada. El visitante pregunta a un Angel: ¿Por qué en el Infierno la gente no tiene codos y se muere de hambre, pero aquí, en el Cielo, aunque la situación es la misma, la gente se ve robusta y bien alimentada?. 
El Angel lo mira directamente a los ojos y contesta: Nos damos de comer unos a otros.

\section{Charles Fishman, 1994 \\ Terapia estructural Intensiva \\ Tratamiento de familias en su contexto social.}

Amorrortu, pp. 279-280

Con anterioridad, hemos hecho referencia al grupo de Trabajo Social como un sistema de ayuda constituido por dos subsistemas claramente diferenciados: el subsistema clientes y el subsistema Trabajador Social. La participación de ambos en el sistema de ayuda adquiere un sentido y una intencionalidad que deberá clarificarse lo más prontamente posible a través de la definición del contexto de intervención. Sin embargo, a priori, los roles que desarrollan ambos subsistemas en relación a sus individualidades vienen definidos por dos perfiles definidos en el metacontexto que permite o facilita el encuentro (nos referimos al servicio o la constelación de servicios implicados, así como a la red relación de referencia de cada uno de los subsistemas implicados). En primer lugar, el rol del cliente es un rol auto-asumido, caracterizado por "la persona que necesita de algo" - sea material o inmaterial-. Este rol auto-asumido (y, en parte, atribuido) se sustenta en la creencia que se apoya en la falta de capacidad, es decir, se trata de personas "que no pueden dar", en todo caso, sólo pueden recibir.

El contra-rol, en este caso, atribuido al Trabajador Social (y, en parte, asumido) está caracterizado por el de la "persona que posee algo" -sea material o inmaterial-, cuya creencia está sustentada sobre la idea de competencia. Se trata, en definitiva, de la o las "personas que dan".

Como ya hemos expuesto anteriormente, los clientes en crisis, en tanto que acentúan su tendencia al aislamiento y a empobrecer sus vínculos de apoyo social, no tienen oportunidades de experimentar situaciones relacionales en las cuales ese rol, de "persona que necesita de algo" y "persona que no puede dar nada", sea puesto en cuestión. Se trata de un cliente con tendencia al aislamiento o claramente aislado.

El cliente que participa en un grupo de Trabajo Social es envuelto en un escenario -el escenario grupal- en el cual el aislamiento no es posible. En dicho escenario no puede dejar de comportarse ni, en congruencia, dejar de comunicarse. Se trata por tanto, de un escenario comunicacional en el cual el sujeto deja de estar aislado.

La conducta altruista significa el desarrollo de un proceso, puntual o permanente, meditado o impulsivo, de dar al otro aquello que uno cree 
que el otro necesita en un momento determinado, sin una finalidad estratégica, sin mediar contraprestación, compensación o ganancia. Sin embargo, en el seno de los grupos centrados sobre el cliente, cuando uno da algo (información, apoyo, afecto, ayuda material, feedback, etc.), está a su vez recibiendo también algo.

William Glasser, creador del modelo de la terapia de la realidad, es un psiquiatra entrenado analíticamente que se sintió insatisfecho con la psiquiatría convencional. La terapia de la realidad enseña al cliente cómo satisfacer dos necesidades psicológicas básicas: 1) la necesidad de amar y de ser amado, y 2) la necesidad de sentirse útil o de mantener un nivel satisfactorio de conducta (Glasser, 1965). Más tarde, fundió las dos en una única necesidad básica: la necesidad de identidad (Glasser,1979).

Para Glasser, la identidad del sujeto juega un aspecto crucial. Un individuo debe hallar cierta identidad, aun cuando ésta sea negativa o de fracaso. La satisfacción de las dos necesidades básicas contribuye a una identidad positiva o de éxito. Hay momentos en la vida en los que el mundo y las situaciones cambian, lo que exige que las personas aprendan una y otra vez a satisfacer sus necesidades bajo diferentes condiciones y tensiones. Los individuos deben vincularse a otras personas si quieren afrontar eficazmente sus necesidades. Si esta unión se interrumpe en algún momento de la vida, no tarda en experimentarse la incapacidad de satisfacer las necesidades básicas. Glasser concluía "que todas las personas que tienen alguna clase de problema psiquiátrico grave carecen de una vinculación satisfactoria con otra persona, lo que las incapacita para satisfacer sus necesidades".

Su modelo destaca los comportamientos sociales como un elemento muy importante para la buena salud mental. Glasser (1979:31-32) cree que "debemos sentirnos vinculados a otras personas, como mínimo a una, pero con la esperanza de llegar a relacionarnos con muchas más. En todos los momentos de nuestra vida debemos tener al menos una persona que se preocupe de nosotros y a la que, por nuestra parte, prestemos toda nuestra atención. Si no contamos con ella, no podremos satisfacer nuestras necesidades básicas». Para poder lograr este objetivo, los clientes deben sentirse vinculados a otras personas a las que aman y por las que son amados. Deben mantener asimismo un nivel satisfactorio de conducta que les permita sentirse valiosos para sí mismos y para otros. Si no satisfacen estas necesidades básicas - que suelen ir unidas en su frustración o en su satisfacción-, los clientes sentirán aflicción y malestar y, como consecuencia, tratarán de aplicar métodos no realistas para remediar sus males.

Veamos con más detalle estas dos necesidades básicas: "La primera es la necesidad de amar y ser amado. En todas sus formas, que se 
ordenan desde la amistad, el amor maternal, el amor familiar, al amor conyugal, es una necesidad que nos induce a la actividad constante en busca de satisfacción. Desde que nacemos hasta la ancianidad necesitamos amar y ser amados, y durante la existencia entera la salud y la felicidad dependerán de la capacidad de conseguirlo. Amar nosotros solamente, o ser amados sin reciprocidad no es bastante; son precisas ambas condiciones. Cuando no podemos satisfacer la necesidad total de amar, forzosamente sufriremos, reaccionando con varios síntomas, desde el ligero desasosiego, ansiedad y depresión, hasta la completa retirada del mundo que nos rodea" (Glasser, 1979:35).

De la misma importancia -sigue Glasser- es la necesidad de sentirnos útiles y de que los demás juzguen que lo somos. "(...) Que se nos ame o no, para ser dignos debemos mantener un tipo de comportamiento satisfactorio. Para lograrlo tenemos que aprender a corregirnos cuando obramos mal y a estimarnos cuando actuamos bien. Si no evaluamos el propio comportamiento, o luego de haberlo evaluado no hacemos por mejorar la conducta en los puntos en que se encuentra por debajo de las normas que nos hemos fijado, no satisfaremos la necesidad de ser dignos y habremos de sufrir tan agudamente como cuando no amamos o no somos amados. Las costumbres, las normas, los valores o el comportamiento bueno o malo están estrechamente relacionados con la satisfacción de la necesidad de estima de uno mismo"(Glasser, 1979:36).

Así pues, en el marco de la relación grupal, la conducta altruista posibilita la satisfacción de la necesidad de sentirse útil y la vinculación a los demás, o como señalan los teóricos de la comunicación humana ${ }^{19}$, satisfacer la necesidad de confirmación. De hecho, la experiencia relacional altruista rompe la autopercepción de sí mismo como sujeto necesitado, no capacitado para dar algo y de sujeto sin valor. El compartir problemas similares en un grupo posibilita desarrollar un contexto relacional en el cual se dan numerosas experiencias y situaciones que estimulan y posibilitan la ayuda mutua y la conducta altruista. El altruismo es un modelo de conducta venerable en la mayoría de sistemas sociales: la gente necesita sentir que es necesaria y útil. Desde la perspectiva de la práctica del Trabajo Social, es extremadamente difícil que una relación profesional en un nivel individualizado permita al cliente sentirse útil; dicho en otras palabras, la relación diática Trabajador Social/Cliente no es precisamente la más idónea como para que el cliente "ayude" al Trabajador Social20.

19 Watzlawik, P.; Helmick, J.; Jackson, D.(1983): Teoria de la conunicación humana. Herder, pp. 80 y ss.

20. Los obsequios y detalles que numerosos clientes realizan al finalizar una relación profesional, no sólo siguen la lógica de una muestra simbólica de agradecimiento, sino que 
El impacto recíproco de la conducta altruista, en tanto que factor terapéutico de gran potencia, es múltiple. Para el que recibe: apoyo emocional, aceptación, confirmación, información, ayuda en las estrategias de cambio, feedbacks correctores, comprensión. El significado de estos elementos posee un valor añadido en la medida de que son conductas altruistas emitidas por un igual, por una persona real, en el mundo real que está atravesando una situación similar. Para el que da, la conducta altruista se constituye en una experiencia relacional y externa que permite un cambio interno: la conducta altruista desarrolla una configuración de la auto-imagen a través de una auto-percepción que se apoya en la capacidad y que apunta hacia una revalorización significativa de la autoestima.

\subsection{Recapitulación correctiva de isomorfismos}

Es frecuente que los grupos de Trabajo Social se constituyan con clientes que atesoran historias familiares altamente insatisfactorias o que sus problemas, necesidades, dificultades o conflictos sólo adquieran significación diagnóstica a partir de la comprensión de la estructura familiar de origen.

En el marco de la relación interpersonal grupal, y pasados los primeros estadios de la vida evolutiva del mismo, los partícipes del grupo tenderán a mostrarse tal y como son, con sus capacidades y sus dificultades. En algunos grupos, podemos observar una correlación significativa entre la naturaleza del problema y las particulares configuraciones de los grupos familiares de pertenencia (recuérdese que un cliente entra a formar parte de un grupo centrado sobre el cliente a través de una derivación, es decir, tras un trabajo de evaluación diagnóstica). Dicho en otros términos, uno tiene la tendencia a mostrarse tal cual es, y ese "ser" está mediatizado por lo aprendido e incorporado en el marco relacional en el cual uno, entendido en términos relacionales, ha construido su identidad y ha aprendido las pautas de relación y conducta social-cultural.

Si, como ya sabemos, un grupo es en sí mismo un microcosmos social, éste posee reglas de funcionamiento y relación que mantienen analogías con el sistema familiar de referencia de cada uno de los miembros del mismo. Yalom y Vinogradov (1996:30) señalan que existen roles y situaciones semejantes a las que existen y se desarrollan en las familias: figuras parentales de autoridad, iguales, intensas relaciones emocionales, conflictos, disputas, reclamos de confirmación, etc. 
Obviamente, ocurren fenómenos similares en trabajo individual y familiar, pero el grupo proporciona un número enormemente mayor y toda una variedad de posibilidades de recapitulación.

El concepto de isomorfismo es un concepto esencial para los Trabajadores Sociales que trabajan en contextos contemporáneos, es decir, en el aquí y el ahora. Isomorfismo significa, simplemente, similitud de forma. Dos o más estructuras complejas pueden ser trazadas en superposición, de manera que cada parte de una estructura tenga una parte correspondiente de la otra, una parte que desempeñe un papel similar en ésa. El concepto de isomorfismo ayuda al profesional a percibir las similitudes estructurales entre las pautas fundamentales en los diferentes contextos en que opera una persona. Desde esta perspectiva puede observarse que una pauta de conducta en el interior de la familia se reproduce con otros en el seno del grupo. Según Fishman, ${ }^{21}$ el concepto de isomorfismo es especialmente útil y potente en la medida en que, cuanto más disfuncional sea un sistema familiar, tanto más posibilidad habrá de que isomorfos invadan otros contextos. Lo importante en el trabajo del grupo será la recapitulación correctiva, el cambio de las pautas rígidas, impenetrables y congeladas en los sistemas familiares. En este caso, el profesional debe examinar y cuestionar los roles fijos existentes, así como las pautas transaccionales repetitivas entre el sujeto y el grupo, induciendo y alentado nuevos comportamientos.

La tesis del cambio a través de la modificación de las pautas isomormas ya aparece en Erickson, el cual sostenía que los pequeños cambios desencadenaban otros mayores (Gordon y Meyers-Anderson, 1981). Una vez que se estimula a los clientes a valorar los cambios mínimos, es probable que realicen otros cambios: las partes de un sistema familiar están interconectadas de tal manera que un pequeño cambio en una parte del sistema repercute y produce modificaciones en las otras partes.

En un estudio realizado para el National Institute on Drug Abuse, Szapocznik y sus colegas ${ }^{22}$ (Szapocznik, Kurtines, Foote, Pérez-Vidal y Hervis) proporcionaron una base empírica a la idea de que los pequeños cambios pueden conducir a cambios mayores en el sistema familiar.

Los investigadores utilizaron dos grupos de sujetos. Uno de ellos estaba compuesto solamente por los adolescentes drogadictos, y el otro por adolescentes drogadictos y sus familias. Ambos grupos recibieron

21 Fishman, H.C. (1994): Terapia estructural intensiva. Tratamiento de familias en su contexto social. Amorrortu. Buenos Aires, pp. 34-39.

32 Sclekman, A. (1996): Abriendo caminos para el cambio. Gedisa, Barcelona,pp.41-42. 
un tratamiento de terapia estratégica breve de familia. Szapocznik y sus colegas descubrieron que el grupo compuesto por un solo miembro cumplió igualmente bien todos los pasos del tratamiento hasta finalizar los tres años de seguimiento. Dos importantes hallazgos surgieron de este estudio: 1) es posible cambiar el sistema familiar entero a través de uno sólo de sus miembros, y 2) no es necesario incorporar al tratamiento a todos los miembros de la familia para cambiar al cliente.

Este último hallazgo refuta el viejo precepto del enfoque sistémico según el cual todos los familiares que viven bajo el mismo techo deben participar en el tratamiento si se desea producir cambios en el cliente.

\subsection{Socialización}

El aprendizaje social es un factor terapéutico que opera en todos los grupos centrados sobre el cliente, independientemente del tipo de habilidades desplegadas o la naturaleza de los cambios planificados o deseados. La interacción grupal que se sustenta sobre continuas espirales de retroalimentación comunicacional, facilita y posibilita el continuo ensayo y error de nuevas conductas, conductas diferentes, nuevas habilidades y modelos de relación distintos. El despliegue y la exhibición de conductas, ideas, valores y pautas de comportamientos, sean éstas apropiadas o inapropiadas, recibirá a su vez numerosos feedbacks correctores o confirmadores que no son ni neutrales ni inocuos al resto de partícipes del grupo. Ello permite conocer y evaluar el impacto de las propuestas relacionales o de las conductas propias que uno desarrolla. Si uno es incapaz de mantener un contacto visual o de aceptar un cumplido, más pronto o más tarde recibirá información precisa en relación a esta dificultad. Estos "espejos" en los cuales el miembro del grupo se ve reflejado facilitan la oportunidad del cambio, es decir, permiten al sujeto ensayar nuevas o diferentes formas de conducta, relación o cognición, más apropiadas, más satisfactorias o más asertivas.

\subsection{Conducta imitativa}

La inmersión en un grupo proporciona a los clientes la observación de conductas apropiadas e inapropiadas, ideas, sentimientos y emociones que impactan a nivel individual y colectivo, modelos de relación y comunicación diversos de los cuales aprender e incorporar o que sirven de ejemplo para no incorporarlo en la constelación cognitiva y comportamental de uno mismo.

Es evidente, y así lo recoge la mayoría de la literatura profesional, que el Trabajador Social conductor de un grupo de Trabajo Social, se 
constituye en primera instancia en un poderoso modelo al cual observar o imitar. De hecho, Corey (1995:93-16) desarrolla un amplio repertorio de estilos de liderazgo, advirtiendo que la naturaleza del estilo propio del profesional influirá de forma decisiva en la relación interpersonal y, consecuentemente, en la consecución de las metas individuales y grupales. A nuestro juicio, ésta sigue siendo una variable -aunque no la únicadeterminante en el marco de la relación de ayuda grupal. El estilo, la imagen corporal, el clima emocional y la conducta del profesional favorecerán o inhibirán el desarrollo de los factores terapéuticos.

Sin embargo, los clientes en el seno del grupo no mantienen una relación unidireccional respecto al profesional, más bien todo lo contrario: la esencia del grupo es la relación multipolar. Si eso es así, cabe esperar que los miembros del grupo ejerzan su influencia unos sobre otros y que, en consecuencia, tengan la posibilidad de observar, ensayar y aprender o rechazar formas distintas de comprender lo que está sucediendo, de afrontar problemas, de expresar emociones, de entender la vida, de expresarse, de razonar, de relacionarse y de comportarse.

\subsection{Expresión de emociones}

El componente emocional inherente y derivado de toda situación de dificultad no es, a estas alturas del conocimiento, discutido por ninguna escuela de pensamiento, independientemente de que alguna de ellas, como es el caso del conductismo, no lo considere como un objeto de observación (en todo caso lo será la emoción expresada -medible-, pero no la emoción individuada).

La atención prestada por algunos enfoques, en mayor o menor medida, como el Psicodrama, la Gestalt, el Análisis Transaccional o la Terapia Racional Emotiva, han llevado, a nuestro juicio, a numerosos profesionales a interpretar que el objetivo de las intervenciones grupales se centraba principalmente en el desbloqueo de los sentimientos y las emociones ligadas a acontecimientos traumáticos, las cuales impiden a las personas alcanzar cambios satisfactorios. A nuestro juicio ésta es una interpretación errónea.

La expresión de emociones en el marco del grupo es un factor terapéutico que, ligado a la universalidad y la cohesión grupal, genera un significativo alivio, una descarga emocional que es reconfortante, pero que no genera necesariamente cambio alguno. Llorar, enfadarse, emocionarse, entristecerse, siendo un expresión de autenticidad y una revelación de la intimidad emocional, es un factor necesario aunque no suficiente para el cambio. 
Aunque la investigación sobre la valoración del cliente de los factores terapéuticos revela la importancia de la expresión de sentimientos, la investigación también sugiere requisitos importantes. En un estudio con doscientos diez participantes en grupos de encuentro, Yalom ${ }^{23}$ y colaboradores encontraron que la expresión de sentimientos era necesaria para un buen resultado, pero no era suficiente. Los miembros que se referían a la importancia exclusiva de la expresión de sentimientos, de hecho, eran, con mayor probabilidad, los que habían tenido una experiencia negativa en el grupo. Aquellos que habían tenido una experiencia de crecimiento personal normalmente la asociaban con alguna forma de aprendizaje cognitivo. Las conclusiones demostraban que la aireación de los problemas, por uno mismo o de uno mismo, no fue considerada por los clientes como muy útil. La expresión de sentimientos efectiva fue vinculada a otros factores. En primer lugar, era parte de un proceso interpersonal: los miembros del grupo expresaban sus emociones, lo hacían en un contexto social. En segundo lugar, se demostraba que la expresión de sentimientos era factible en la medida de que el grupo estaba cohesionado.

A nuestro juicio la expresión de emociones apunta a tres núcleos básicos. En primer lugar, expresar emociones y afecto es esencial para el mantenimiento de la vida afectiva grupal. Independientemente de los objetivos que un grupo se marque, el desarrollo del mismo está ligado al equilibrio inestable entre dos factores: la tarea, es decir, aquellas actividades que permiten al grupo y a sus miembros alcanzar los objetivos y metas propuestas, y la vida afectiva grupal, es decir, aquellos componentes relacionales y emocionales que permiten al grupo relacionarse y existir como tal y en los cuales la tarea pasa a un segundo plano (aspiraciones personales, reconocimiento, apoyo, control, conflicto, etc.). Sin un clima relacional favorable, es imposible alcanzar las metas grupales $y$, a su vez, las metas grupales no pueden alcanzarse sin un clima emocional favorable.

En segundo lugar, la expresión de emociones permite a los miembros del grupo compartir con los demás el mundo interior. Ser aceptado incondicionalmente posibilita romper el estigma o la etiqueta que cada uno soporta y ser aceptado en tanto que ser humano singular, que sufre, se entristece, se alegra o se irrita.

En tercer lugar, considerar que en numerosas ocasiones el proceso de cambio personal exige y requiere revivir una situación dolorosa $\mathrm{o}$, si nos permiten el atrevimiento, requiere de la inducción a la crisis con tal de romper los equilibrios homeostáticos hiperactivados que imposibili-

23. Yalom, I. (2000): Psicoterapia existencial y Terapia de Grupo. Paidós Barcelona, pp. $42-43$. 
tan el cambio. En ambos casos, la expresión de los sentimientos y emociones no puede ser considerada más que una expresión saludable, una reacción congruente y saludable con la situación vivida.

\subsection{Cohesión}

La cohesión ha sido investigada especialmente desde la perspectiva de la estructura y dinámica grupales. Corey (1995:148), citando a Yalom, señala que las investigaciones en el campo de la clínica grupal demuestran que la cohesión es un fuerte determinante de los resultados terapéuticos del grupo. Si la universalidad es el primer factor cohesivo en los estadios iniciales del grupo, la cohesión, entendida en el sentido más abarcativo del término, implicará el conjunto de fuerzas resultantes que hace posible que el grupo sea atractivo para sus miembros. Dado que no deseamos hacer una descripción de la cohesión como fenómeno estructural del grupo, ${ }^{24}$ vamos sólo a destacarla en tanto que factor terapéutico.

En primer lugar, cabe señalar que la cohesión posibilita la construcción de una meta-individualidad, una identidad colectiva, un "nosotros grupal" que posee una valencia incluyente en relación a sus partícipes y una valencia excluyente en relación a terceros. Desde esta perspectiva, la cohesión estimula y favorece relación de inclusión y filiación, es el soporte del mito grupal y da una imagen imaginaria acerca de lo que el grupo es para sus miembros. Filiación y pertenencia son factores intersubjetivos que estimulan la lealtad grupal (so pena de la exclusión), el compromiso entre los miembros, la complicidad tanto en Ias relaciones como en el desarrollo de tareas y la responsabilidad individual y colectiva en relación al grupo mismo.

En segundo lugar, señalar que los factores mencionados son el acicate para el desarrollo de relaciones de ayuda mutua, colaboración, apoyo, solución de problemas y afrontamiento de conflictos intra-grupales. $\mathrm{Y}$, en tercer lugar, la cohesión actúa como una fuerza unificadora y protectora. Sólo tras su experimentación subjetiva, las personas que forman el grupo están en condiciones de arriesgar y compartir las circunstancias, pensamientos, acciones y conductas dolorosas, vergonzosas o inapropiadas.

Corey (1995:149) señala que la cohesión no es el resultado del azar o de la pura relación interpersonal, sino más bien el compromiso del profesional y los miembros del grupo para dar los pasos necesarios que conducen al sentimiento de unidad grupal. Sin la percepción de este

24 Para tal menester, ver Shaw, M.(1980): Dinámica de Grupo. Herder, Barcelona. 
"nosotros grupal" las personas se retraen, no arriesgan, se defienden de las autoimágenes distorsionadas y se mueven en la superficialidad de sus situaciones problema. Sin cohesión no hay auto-apertura ni seguridad de aceptación incondicional. Como señala Yalom, la cohesión es la condición necesaria para el desarrollo de los demás factores terapéuticos y el desarrollo de un trabajo efectivo.

\subsection{Aprendizaje interpersonal}

Desde la perspectiva del modelo sistémico, el grupo es conceptualizado como un sistema (González, 1995:221-246). El grupo es una organización interdependiente en la que la conducta y la expresión de cada uno influye y es influida por el otro. La interacción en el grupo consiste en un acción de mutua influencia, una interacción que tiene lugar entre los integrantes de un grupo.

Cuando un grupo de personas se encuentra, comienza entre ellas una interacción que se plasma mediante la comunicación, que incluye mensajes verbales y no verbales, en los niveles de contenido y relación, a través de los cuales una persona emite un mensaje que genera una reacción en el destinatario, reacción que se transforma, a su vez, en un mensaje, que influye sobre el primero, y así sucesivamente (o en palabras de Bateson, cada mensaje es, a la vez, estímulo, respuesta y refuerzo).

La confirmación de la autodefinición es, probablemente, el factor que pesa más en el desarrollo y la estabilidad mental, de los que hasta ahora se han detectado en el estudio de la comunicación. Sin este efecto confirmador no se habría desarrollado la comunicación humana más que lo imprescindible para los intercambios de protección y supervivencia, no habría motivos para comunicarse por la comunicación misma. Gran parte de nuestras comunicaciones tienen un propósito confirmador. En este punto coinciden las tesis sistémicas y cognitivas.

Parece que, a parte de mero intercambio de información, el ser humano tiene que comunicarse con los otros a fin de verificar su autopercepción. La evidencia experimental de este supuesto es grande (deprivación sensorial y estabilidad emocional, por ejemplo).

La definición que cada miembro del grupo hace de sí mismo puede tener, por parte del otro, tres respuestas: confirmación, rechazo y desconfirmación, por medio de las cuales, los otros responden al primero cómo le ven, y éste cómo ve al otro y cómo ve que el otro le ve a él, etc., mensajes que a su vez pueden ser confirmados, rechazados o desconfirmados. Estos mensajes se desarrollan en base a lo que R. Laing denominó "Niveles de Percepción Interpersonal" (Laing, 1988:13-32). 
El concepto de "Niveles de Percepción" hace referencia a que mi experiencia la desarrollo no sólo en base a "la visión que yo tengo de mí mismo" (ego), o a "la visión que tengo del otro", sino a "la visión de la visión que el otro tiene de $m i n$ ", es decir, "cómo yo creo que el otro me ve". A este tercer nivel lo llamaremos "metaperspectiva". En realidad, no puedo verme como los otros me ven, pero constantemente supongo que ellos me ven de determinadas maneras, y constantemente actúo a la luz de las actitudes, opiniones, necesidades, etc., reales o supuestas, que el otro tiene respecto a mí. Estas distintas formas de actuar de cara al otro son alteraciones de identidad, y en la medida en que me convierto "en otro para ti", dichas alteraciones de mi identidad son re-interiorizadas por mí para transformarse en multifacéticas metaidentidades ("ese otro que supongo que soy para el otro").

Así pues, la visión que el otro tiene de mí es tan importante, al menos en las relaciones personales estrechas, como la visión que yo tengo de mí mismo. En el mejor de los casos, ambas visiones son más o menos similares.

La conducta del otro hacia mí, para que pase a formar parte de mi experiencia personal, la debo percibir e interpretar de acuerdo con cierto conjunto de criterios personales. El ser humano aprende a estructurar sus percepciones dentro de la familia, como un subsistema que interactúa con la cultura de su contexto, las instituciones conexas y la cultura global.

En el marco del grupo, también se generan procesos de aprendizaje interpersonal que influyen significativamente en la identidad del sujeto y en la satisfacción de sus necesidades psicosociales. Yalom señala que: "Esto no quiere decir que todos los clientes, ni siquiera la mayoría que entran en el trabajo de grupo, busquen explícitamente ayuda en sus relaciones interpersonales. Sin embargo, el desplazamiento de la meta, desde el alivio del sufrimiento al cambio en el funcionamiento interpersonal es un primer paso esencial en el proceso terapéutico dinámico. No se trata exclusivamente de aliviar el síntoma o el malestar, sino de pensar o hacer de una forma diferente, con y en relación a los demás." (Yalom, 2000:54).

Todo ello implica que, en el marco del trabajo grupal, se proporciona el contexto dinámico para que cada miembro del grupo manifieste sus formas de entender el mundo y de relacionarse con él. Así, la relación interpersonal, el desarrollo de actividades, la manifestación de dificultades, la exposición y el riesgo de la intimidad y los intentos de solución de problemas no sólo impactan al sujeto mismo sino también al grupo.

De esta manera, mediatizada por los niveles de percepción inter- 
personal, el sujeto aprende de sí mismo, de los otros y de las relaciones entre y con los otros. Este fenómeno terapéutico se escapa al control del profesional, aunque la habilidad para identificar y plantear el cómo aprovechar terapéuticamente el comportamiento interpersonal, visto en el microcosmos social de un grupo pequeño, es una de las principales tareas de un programa de formación para Trabajadores Sociales de Grupo. ${ }^{25}$ La clave para comprender el significado del aprendizaje interpersonal radica, a nuestro juicio, en el hecho de que es el grupo en su conjunto el que se hace responsable del proceso de solución de problemas (tareas) y del mantenimiento de la vida afectiva del mismo: unos aprenden de otros, unos influyen a otros, y viceversa.

\section{CONCLUSIÓN}

Como habrá podido observarse, los denominados "factores terapéuticos" abarcan los aspectos relacionales, comunicacionales, cognitivos, conductuales y emocionales, de origen e implicación intra e interpersonales, que se despliegan en el desarrollo de un Trabajo Social de Grupo eficaz. Cabría ahora señalar, aunque no lo haremos, en qué momento del ciclo evolutivo grupal dichos factores emergen o son especialmente significativos y qué implicaciones se derivan de la relación entre dichos factores y la estructura del grupo y su dinámica. Así mismo, se hace necesario establecer una correlación entre cada uno de los factores terapéuticos y los procedimientos y técnicas de intervención grupal, determinando la congruencia entre la emergencia del factor terapéutico y la/s técnica/s específica/s. Sin duda, estos dos últimos problemas son objeto de uno o varios trabajos, más extensos y, probablemente, más detallados.

Queremos finalizar enlazando con las preguntas que nos planteábamos al principio. No es posible desarrollar un Trabajo Social de Grupo eficaz exclusivamente a través de la aplicación de técnicas estandarizadas, y tampoco es posible desarrollar un trabajo orientado hacia el cambio con la simple comprensión intelectual de lo que está sucediendo en el seno del grupo. Un Trabajo Social eficaz requiere, entre otros elementos, del conocimiento y la comprensión de los mecanismos terapéuticos, de las técnicas que estimulan estos factores terapéuticos y, especialmente, del hacerse cargo del impacto emocional, conductual, cognitivo e interpersonal que dichos factores terapéuticos provocan en las personas integrantes del grupo y en el grupo como un todo.

25 Permítame que lo diga bien claro: con la aplicación de las lamentables "Directrices Generales Propias conducentes a la obtención del Título de Diplomado en Trabajo Social", mucho me temo que se trata de un objetivo imposible de alcanzar. 


\section{BIBLIOGRAFÍA}

AZNAR, J. et alt. (1995): "Un año de grupo de autoayuda con familiares de enfermos mentales en Zaragoza”. Revista Trabajo Social y Salud n ${ }^{\circ} 20$.

BIESTEK, F. (1966): Las relaciones del casework. Aguilar, Madrid.

BLOCH, S.; CROUCH, E. (1985): Therapeutic Factors in Group Psycotherapy. Oxford University Press, Oxford.

BROWN, A. (1988): Treball de Grup. Pòrtic, Barcelona.

CAPLAN, G.; CAPLAN, R. (1997): Consulta y colaboración en salud mental. Paidós, Barcelona.

CAPLAN, G.(1994): Aspectos preventivos en salud mental. Paidós, Barcelona.

CARDONA, J. (1998): Programa de asesoramiento psicosocial para padres de niños con discapacidad visual. ONCE, Delegación Territorial de Baleares. Palma, Mimeo.

COREY, G. (1996): Teoría y práctica de la Terapia de Grupo. Desclée de Brouwer, Bilbao.

DE SHAZER, S. (1999): En un origen las palabras eran magia. Gedisa, Barcelona.

EGAN,G. (1981): El orientador experto. Wasdword International Iberoamérica, México.

FISHMAN, H.C. (1994): Terapia estructural intensiva. Tratamiento de fanilias en su contexto social. Amorrortu, Buenos Aires.

GLASSER, W. (1979): Reality Therapy: un nuevo camino para la psiquiatría. Narcea, Madrid.

GONZÁLEZ, P.(1995): Orientaciones teóricas fundamentales en psicología de los Grupos. EUB, Barcelona.

GORDON, D.; MEYERS-ANDERSON, M. (1981): Phoenix: Therapeutics Patterns of Milton Erikson. Meta. Cupertino, California.

GUTIÉRREZ et alt. (1997): “Educación grupal con diabéticos de Motril. Experiencias desde el Trabajo Social sanitario". Revista Trabajo Social y Salud $n^{\circ} 26$.

HEAP, K. (1986): La pratica del lavoro sociale con i gruppi. Un aprrocio sistematico. Astrolabio, Roma.

KIM BERG, I.; MILLER, S. (1996): Trabajando con el problema del alcohol. Gedisa, Barcelona.

KONOPKA, G. (1969): Trabajo Social de Grupo. Euramérica, Madrid.

LAING, R.; PHILLIPSON, H.; RUSSELL LEE, A. (1988): Percepción interpersonal. Amorrortu, Buenos Aires.

MADANES, C. (1997): Violencia Masculina. Granica, Buenos Aires. 
NEIMEYER, R.; MAHONEY, M. (1998): Constructivismo en Psicoterapia. Paidós, Barcelona.

NEUBURGER, R. (1997): La familia dolorosa. Herder, Barcelona.

O HANLON, W.; WEINER-DAVIS, M. (1989): En busca de soluciones. Paidós, Barcelona.

ROSSELL, T. (1997): "Trabajo Social de Grupo: grupos socioterapéuticos y grupos socioeducativos", en Cuadernos de Trabajo Social n' 11 , Universidad Complutense de Madrid, Madrid.

SCHWARTZ,W. (1971): " On the Use of Grups in Social Work Practice", en SCHWARTZ, W. yZALBA, S. (1971): The Practice of Group Work. Columbia University Press, pp. 3-24.

SELEKMAN, M. (1996): Abrir caminos para el cambio, Gedisa, Barcelona.

SHAW, M. (1980): Dinámica de Grupo. Herder, Barcelona.

SLAIKEU,K. (1988): Intervención en crisis. Manual Moderno, México.

STOCKTON, R.; HULSE, D. (1980): Devoluping cohesion in small groups: theory and research. Journal for Specialists in Group Work. $N^{\circ} 6$. USA.

TEVAN, R. (1998): "Grupos de padres de una unidad de cuidados intensivos" Revista Trabajo Social y Salud $n^{\circ} 30$.

TRISELIOTIS, J. (1994): El Trabajo de Grupo en la adopción y acogimiento familiar. Ministerio de Asuntos Sociales, Madrid.

WATZLAWICK; WEAKLAND; FISCH(1982): La táctica del cambio. Herder, Barcelona.

VINTER, R.(1969): La práctica del Servicio Social de Grupo. Humanitas, Buenos Aires.

VV.AA. (1999): Los grupos de autoayuda con personas VIH positivas. Memoria de actividades de la Asociación de Lucha AntiSida de Mallorca, 1999. Alas, Palma.

YALOM, I.(2000): Psicoterapia existencial y Terapia de Grupo. Paidós, Barcelona.

YALOM, I.; VINOGRADOV, S. (1996): Guía breve de psicoterapia de grupo. Paidós, Barcelona. 



\title{
VIH/SIDA Y REDUCCIÓN DE DAÑOS ENTRE USUARIOS DE DROGAS INYECTABLES
}

\author{
RAÚL SORIANO
}

Trabajador Social. Médicos del Mundo. Valencia.

MARISA DORADO

Médica. Médicos del Mundo. Valencia.

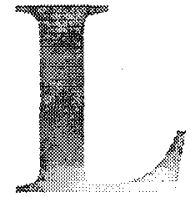

a infección por VIH/SIDA representa un problema de salud pública con una importante repercusión en el contexto de nuestra sociedad actual. El escenario en el que nos encontramos se ha transformado radical y desigualmente durante los últimos años. Mientras en los países más desarrollados los nuevos fármacos han favorecido una tendencia a la cronificación de la infección, en otras latitudes la pandemia queda fuera de todo control. En la área del África subsahariana el avance del virus y de la enfermedad continúa incesante y los medios técnicos invertidos para hacerle frente son desproporcionadamente minúsculos.

En España el patrón de transmisión del virus ha sufrido ciertas variaciones a lo largo del tiempo, pero puede afirmarse que en una gran parte de los casos conocidos, la infección se encuentra relacionada de algún modo con el consumo de drogas por vía parenteral y con las prácticas de estos consumidores, lo que ha promovido la implementación de políticas y recursos encaminados a trabajar la prevención secundaria y terciaria con dicha población.

En el presente texto se recogen algunas orientaciones básicas sobre la infección por VIH/SIDA, y sobre los trastornos adictivos producidos por la dependencia a opiáceos, otras drogas inyectables y su terapéutica. Se explica cómo se relacionan ciertas prácticas de consumo de sustancias con la transmisión del VIH. Y se describe el desarrollo que las políticas de «reducción de daños asociados al consumo» están viviendo en la actualidad, reconociendo sus principales estrategias de intervención desde los Servicios Sociales Especializados.

\section{INTRODUCCIÓN: LA INFECCIÓN POR VIH/SIDA HOY}

El SIDA es una enfermedad que produce una desorganización del sistema inmunológico. Su agente causal es el virus de la inmunode- 
ficiencia Humana (VIH), que pertenece a la familia de los retrovirus y provoca una infección de carácter lento. La persona afectada puede convivir durante un largo periodo de años con la infección sin presentar síntoma alguno. Durante este periodo es cuando se le denomina persona seropositiva, portadora de anticuerpos del VIH, o VIH+. Cuando con el paso del tiempo el virus causa una afectación intensa de las defensas del organismo, éste pierde la capacidad para evitar el desarrollo de infecciones y de ciertos cánceres. Tras el diagnóstico de determinados procesos y afectaciones, la persona llega a la fase de la infección en la que pasa a considerarse enferma de SIDA.

El VIH está presente en varios fluidos del organismo, aunque solo en algunos adquiere la concentración suficiente como para poder transmitirse e infectar, éstos son: la sangre, el semen, los flujos vaginales y la leche materna. Para invadir un organismo el virus necesita acceder al torrente sanguíneo. Las prácticas de riesgo para contraer la infección pueden agruparse en varias categorías. Generalmente nos referimos a éstas como las vías de transmisión, y pueden concretarse en las siguientes: sanguínea, sexual y vertical o materno-infantil.

La transmisión sanguínea se produce básicamente al compartir agujas y objetos punzantes o cortantes que trasladan sangre infectada de una persona a otra. La transmisión sexual tiene lugar cuando fluidos eyaculatorios o vaginales infectados encuentran una puerta de entrada en puntos vulnerables de las mucosas genitales, rectal o bucal. En el caso de la transmisión de madre a hijo, la infección puede darse durante el embarazo, en el momento del parto o en la lactancia.

El patrón de transmisión, o predominio de unas vías sobre otras en la generación de nuevas infecciones, registra variaciones geográficas y cronológicas. Así, en países como España, Italia o Suiza, la vía que genera un mayor número de afectados es la sanguínea, concretada en el uso compartido de material de inyección entre los UDIs (usuarios de drogas inyectables). Mientras, en otras latitudes son más frecuentes los patrones de transmisión sexual y vertical.

Las autoridades sanitarias estiman que el número de personas que conviven con la infección en todo el mundo se encuentra en torno a los 33 millones. La mayor parte de ellas (más del 90\%) viven en el tercer mundo, sobretodo en el África Subsahariana y en el Sur y Sureste de Asia. España es el país europeo con un mayor número de casos. Esto puede relacionarse, entre otros factores, con el importante volumen de usuarios de drogas inyectables que han tenido y tienen prácticas de riesgo, y con la tardanza e insuficiencia en la implementación de acciones preventivas. 
La prevención de infecciones por VIH en la vía sanguínea se centra en el uso de material de inyección nuevo (o en su defecto desinfectado), y en evitar el uso compartido de útiles cortantes o punzantes sin esterilizar. En las prácticas de riesgo de carácter sexual es necesario impedir el intercambio de fluidos sexuales durante las penetraciones anal, vaginal y oral, además de en los contactos bucogenitales, utilizando adecuadamente barreras como los preservativos y los cuadrantes de latex.

Los últimos avances farmacológicos están produciendo grandes cambios en el pronóstico y en la calidad de vida de las personas que conviven con la infección. Las terapias que combinan varios fármacos atacan diferentes momentos del ciclo vital del virus, lo que produce un retraso en la evolución del proceso, aumentando su eficacia y tolerancia cuanto más precoz es su utilización (G.V., 1999).

A pesar de todo, el contraste entre la incidencia geográfica de la infección y el destino final de los recursos que se invierten para hacerle frente, resulta severamente discordante. La aparición de vacunas o medicaciones eficaces puede suponer, en su accesibilidad, un agravio comparativo de proporciones magnicidas. Planificar un acceso racional a los tratamientos es un reto para la comunidad internacional, de una magnitud tan trascendente a nivel humano y demográfico, que las autoridades sanitarias deberían tomar decisiones drásticas para evitar, que las multinacionales y los intereses del mercado, sean quienes juzguen quiénes y cuándo tienen derecho y acceso a una medicación vital (Soriano, 1998).

\section{TRASTORNOS ADICTIVOS POR DEPENDENCIA A OPIÁCEOS}

\subsection{Características del trastorno}

Con el término de «opiáceos» se conoce a las sustancias de la familia del opio, producto obtenido de un tipo de amapola, la adormidera o Papaver somniferum, que crece en diferentes latitudes de forma natural o cultivada. La sustancia se extrae mediante una incisión en las cápsulas inmaduras de la planta, produciéndose un jugo blanco viscoso que se coagula rápidamente y se transforma en una pasta de color parduzco (Sanchís y Martín, 1997). Históricamente, el opio ha sido utilizado en la medicina tradicional por sus propiedades analgésicas, somníferas o antitusivas. Durante los dos últimos siglos se han conseguido identificar numerosos derivados opiáceos (los hay naturales, sintéticos o semisintéticos). Los más populares son la morfina, la heroína, codeína, 
metadona, LAAM y buprenorfina. De algún modo, nuestro organismo también produce unas sustancias opioides endógenas que actúan sobre ciertos receptores del Sistema Nervioso Central (S.N.C.); al parecer se encuentran involucradas en la modulación del estado de ánimo, del dolor, estrés, placer...

La heroína es un derivado químico de la morfina, pero sus efectos son mucho más rápidos y potentes. Su consumo por vía intravenosa produce el llamado «flash»: sensación de placer intenso comparable al orgasmo, pero de diferente cualidad, y que dura escasos segundos. Posteriormente aparece un estado de euforia («rush»), sedación, acompañado de un cálido sonrojo de la piel, boca seca y extremidades pesadas. Durante unas pocas horas se alternan la vigilia con el adormecimiento y se turban las facultades mentales debido a la depresión del Sistema Nervioso Central (Nida, 1999; Castañeda, 1992).

El uso regular de heroína produce tolerancia a la sustancia, lo que lleva al consumidor a tomar una mayor dosis para obtener la misma intensidad o efecto. En el establecimiento de la dependencia intervienen conjuntamente diversos factores de riesgo, que varían de un sujeto a otro. Estos factores pueden tener un carácter personal (como la presencia de patologías psiquiátricas), familiar (como antecedentes de drogodependencia paternos, familias desestructuradas o pareja consumidora), comunitario (domicilio en zonas urbanas marginales, escasez de equipamientos y recursos sociales, presencia del tráfico de sustancias...), etc. El mismo consumo contribuye per se a reforzar la conducta, pues la sustancia actúa reduciendo la ansiedad y generando sensación de calma y evasión. Una vez establecida la adicción física, el organismo puede sufrir el síndrome de abstinencia si se reduce o abandona el uso de la sustancia. El síndrome de abstinencia a opiáceos se caracteriza por una serie de síntomas como lagrimeo, rinorrea, bostezos, temblores o escalofríos y sudoración, completándose con dolores musculares y de huesos, insomnio, ansiedad, diarrea, vómitos...

Al tratarse de una sustancia no controlada y sometida a todo tipo de manipulaciones irregulares, el grado de pureza (que suele ser muy bajo) puede variar según su procedencia. Si el usuario se inyecta la misma cantidad habitualmente, pero en un momento determinado obtiene una dosis de mayor pureza, puede sufrir una sobredosis, e incluso morir bajo la saturación de depresores del S.N.C. Este riesgo es menor en aquellos usuarios que consumen habitualmente por vía fumada/inhalada, lo que en el argot se conoce como «hacerse un chino» o «fumar en plata», ya que por esta vía el aprovechamiento del principio activo es más reducido. En dicho procedimiento de consumo el usuario inhala, a través de un pequeño tubo colocado en la boca, los vapores que desprende la heroína al ser calentada sobre un trozo de papel de aluminio. 
El debut del trastorno por dependencia a opiáceos integra, además de las variables orgánicas, otros componentes de carácter psicológico y social. En la instauración de la adicción psíquica intervienen ciertas respuestas características que retroalimentan la continuidad de la dependencia. El miedo al síndrome de abstinencia y el «craving» o deseo de consumir, operan como verdaderos acicates para movilizar al usuario y satisfacer esta necesidad por encima de otras que se antojarían básicas, como alimentarse o dormir. Como se describe más adelante sobre el perfil de esta población, las relaciones sociales del adicto se redefinen y aglutinan en torno a las drogas y para las drogas.

Actualmente es difícil encontrar un usuario de drogas que consuma una sola sustancia, resulta más habitual el uso simultáneo o combinado de varias de ellas. Este fenómeno se conoce como policonsumo o polidrogodependencia. Entre los dependientes a opiáceos es frecuente el uso, abuso o dependencia de cocaína, alcohol o benzodiacepinas. Cuando el preparado inyectable contiene conjuntamente la mezcla de heroína y cocaína recibe la dominación de «speed-ball». Durante 1997 la dependencia a heroína como droga principal motivó el $84.1 \%$ de las admisiones a tratamiento de todo el Estado (PND, 1999). Sin embargo, el aumento progresivo del consumo de cocaína entre los usuarios de heroína está adquiriendo un protagonismo extraordinario. Entre las personas admitidas a tratamiento por el consumo de heroína como sustancia principal durante 1998, el 74'8\% manifestaban haber consumido también cocaína (PND, 2000). Es necesario mencionar que entre este colectivo el uso de cocaína se produce más frecuentemente por la vía inyectada, por lo que todas las prácticas de riesgo asociadas a dicha vía se hacen extensibles a quienes la utilizan, con independencia de la sustancia o sustancias consumidas.

\subsection{VIH/SIDA y enfermedades asociadas a la via de consumo}

Cualquier consumo de sustancias produce una serie de efectos en el organismo que influyen directamente sobre su salud. En el mercado de las drogas ilegales éstas pasan sucesivamente por intermediarios que añaden substancias no controladas al producto antes de que éste llegue a manos del interesado. Por esta razón las consecuencias de su uso pueden llegar a ser mucho más nocivas y difíciles de prever. La vía de consumo añade un riesgo específico derivado de la manipulación del material de inyección y de las prácticas de autoadministración. Los procesos por los que se consiguen introducir las drogas en el organismo pueden ser muy variados, generalmente se distinguen las siguientes vías de administración: inyectada (también conocida como intravenosa o parenteral), fumada, inhalada (estas dos llamadas también vía pulmonar), 
esnifada (o intranasal), cutánea y oral. Además, diferentes mucosas pueden actuar como vía de acceso para sustancias, como ocurre con las vías rectal, vaginal o sublingual. En nuestro contexto, las vías más habituales para el consumo de heroína son la inyectada y la fumada/ inhalada. Las vías de administración de cocaína presentan más variedad, en el ámbito de los usuarios de drogas inyectables (UDIs) prevalece la vía parenteral y el consumo «en base», para el resto de la población es más común el uso esnifado.

Algunas vías de administración resultan más agresivas y traumáticas que otras. La intravenosa es una de las que presenta más riesgos, tanto por las lesiones e infecciones derivadas de una manipulación inadecuada del material de inyección, como por la transmisión de enfermedades entre individuos que comparten el instrumental durante el ritual de consumo. El riesgo no sólo se encuentra en usar la misma jeringuilla para varios individuos; por ejemplo, preparar la «mezcla» compartiendo un mismo recipiente (cuchara, tapón, bote de bebida...) es también un hábito extendido en esta población. No todos los usuarios de drogas inyectables (UDIs) tienen suficientes conocimientos ni destreza para proceder a inyectarse con un mínimo de garantías. La falta de información y de habilidades puede dar lugar a procesos como los abcesos.

El aprovechamiento del principio activo de una sustancia y el tiempo necesario para percibir sus efectos difiere de unas vías a otras. Es en el caso de la inyectada donde el usuario obtiene un mayor rendimiento de su dosis y donde percibe su actuación más directa y rápidamente. Por este motivo, para alcanzar un determinado nivel de efectos, la cantidad de sustancia necesaria es sensiblemente menor en el caso de utilizar la vía parenteral frente al uso de la vía fumada/inhalada.

Sobre la elección de la vía de consumo operan multitud de circunstancias. Los usos y procesos de autoadministración de las drogas pueden modificarse a lo largo del tiempo, están condicionados por modas locales, variaciones en la accesibilidad física a las sustancias, tipo de sustancia comercializada, variaciones del grado de pureza, disponibilidad de útiles de consumo, creencias... Además entran en colación factores fisiológicos (por ejemplo, tener las venas cangrosadas) y psicológicos individuales (miedo a las agujas). Algunos tipos de heroína son solamente apropiados para el consumo fumado/inhalado. Esta vía es de más reciente incorporación a los usos de la población heroinómana, aunque se estima que se ha popularizado de un modo importante durante los últimos años. Entre las personas heroinómanas admitidas a su primer tratamiento en España durante 1997, el 23'8\% había utilizado la vía parenteral y el 67'2\% la pulmonar, mientras que entre los usuarios que ya habían sido tratados previamente estos porcentajes fueron res- 
pectivamente de un 34'8\% y de un 57'8\% (PND, 1999). Compartir el tubo que se utiliza para «fumar plata» conlleva riesgos para la transmisión de algunas enfermedades.

En cualquier caso, es el uso incorrecto de la vía inyectada lo que comporta mayores daños para esta población, al tratarse de la principal fuente de transmisión del VIH y de la hepatitis vírica. Habiendo ya descrito el primero en un apartado anterior, nos ocupamos ahora de la segunda. El término hepatitis se aplica a aquellos procesos que afectan al hígado produciendo, entre otros síntomas, su inflamación. Existen muchos tipos de hepatitis, pero las más frecuentes son las producidas por unos virus que se identifican con letras (A, B, C, D, E, G). Cuando dichos virus consiguen introducirse en el organismo, se dirigen al hígado penetrando en las células, a las que infectan y en cuyo interior se reproducen. Las hepatitis pueden cursar como un proceso agudo, o bien crónico. Muchas personas padecen una hepatitis asintomática y descubren su infección a través de chequeos rutinarios. La identificación del tipo de hepatitis que sufre un sujeto se realiza mediante una analítica de sangre, que determina cuáles son las partículas víricas que circulan por ella o bien los anticuerpos que el organismo ha generado para combatirlas (Schering-Plough, S.A., 1998).

\subsection{Perfil bio-psico-social de los UDIs}

El perfil bio-psico-social del usuario de drogas resulta determinante para valorar la indicación de una intervención y para decidir su inclusión en un programa determinado. Entre los aspectos objeto de análisis pueden encontrarse: los antecedentes toxicológicos, la trayectoria terapéutica, el historial clínico, el diagnóstico de trastornos asociados, las relaciones con las redes sociales primarias, etc. Además se estiman aspectos complementarios pero tan influyentes como la motivación del usuario por un tipo concreto de terapéutica, la presencia de un embarazo en curso, o las listas de espera para acceder a los dispositivos técni$\cos$.

Si bien por la heterogeneidad de la población no resulta sencillo acreditar datos precisos sobre su perfil medio, pueden anotarse algunos comentarios como referencia. Las estimaciones sobre el sexo de las personas adictas a opiáceos en España reflejan una proporción entre 1/4 y $1 / 5$ de mujeres respecto a hombres, con ligeras variaciones de unas Comunidades Autónomas a otras. La edad media de los usuarios ronda los 33 años, y se aprecia un envejecimiento progresivo de la población. Como característica más uniformemente destacable desde una perspectiva sanitaria puede considerarse la alta presencia de enfermedades asociadas o derivadas de sus prácticas y estilo de vida, como el 


\section{VIH/SIDA, las hepatitis víricas o la tuberculosis.}

Desde la vertiente psicológica, la población adicta a opiáceos presenta una elevada prevalencia de Trastornos de Personalidad. De éstos, los más frecuentes son el Trastorno de Personalidad Antisocial y el Límite, seguidos por el de Evitación y el Paranoide (Gutiérrez, E. et al., 1998; E.T. U.C.A. Cruz Roja Valencia, 1998). La existencia de un tipo concreto de trastorno puede favorecer un deterioro de su situación. Algunos estudios relacionan la personalidad antisocial con mayores probabilidades de contraer la infección por VIH entre usuarios de drogas por vía parenteral (Brooner et al., 1993).

Para interpretar y comprender la naturaleza del fenómeno es necesario incorporar al análisis la perspectiva que aporta el estudio de la Patología Dual. Con este término se hace referencia a la coexistencia simultánea de patología psiquiátrica y trastornos por abuso y dependencia a sustancias en un mismo sujeto. La convivencia de estos trastornos produce una sinergia que repercute sobre el debut y el establecimiento de ambos. El paciente con Patología Dual presenta peor pronóstico al tratarse de dos patologías crónicas y recidivantes (que cursa con periodos de remisión y de agudización). Si además se trata de una persona enferma de SIDA en fases avanzadas puede llegar a padecer, entre otras posibilidades, ciertos tipos de demencia asociada al síndrome, lo que termina por conferir al cuadro unas perspectivas nada alentadoras.

Por lo que se refiere a los aspectos sociales y sus características predominantes en esta población, puede entenderse que su itinerario de marginalización discurre paralelo a la trayectoria de su proceso adictivo. Mayor severidad de la adicción y del deterioro físico y psicológico se corresponden con mayores dificultades para desinhibirse de su rutina de consumo, sobre la que giran la mayor parte de sus interacciones sociales habituales. El reloj biológico de los consumidores de drogas inyectables no está sincronizado con los usos y sistemas de normas que rigen a la población normalizada (Soriano, 2001).

Los primeros encuentros con la sustancia (lo que se conoce como «luna de miel») suelen ser periodos donde el usuario puede tratar de ocultar su consumo, y en los que le es posible mantener vínculos familiares y sociales. Conforme se instaura la dependencia resulta mucho más difícil compatibilizar ambas realidades. Progresivamente una parte de los consumidores deja de transitar por los circuitos normalizados, iniciando una espiral endogámica donde todo interacciona alrededor de la sustancia. Cuando la edad de inicio del consumo es temprana, el truncamiento del proyecto vital llega a ser más considerable. Estudios recientes del Observatorio Español Sobre Drogas aportan datos como que entre los drogodependientes en los que la heroína es la «droga 
principal» de admisión a tratamiento, solamente el 14'1 ha completado estudios de B.U.P. o superiores (PND, 1999).

Por lo general, los usuarios cronificados en el consumo de drogas inyectables presentan un bajo nivel educativo, escasa o nula experiencia laboral reciente y, lógicamente, altas tasas de desocupación. Las relaciones familiares tienden a ser conflictivas o inexistentes. Si hay hijos menores es frecuente la institucionalización o la asunción del cuidado y educación por parte de los abuelos. Una parte de los adictos son transeúntes o viven en casas «ocupadas». La necesidad de obtener importantes recursos económicos para mantener el consumo se traduce habitualmente en el ejercicio de la mendicidad, la prostitución, el tráfico de menudeo de sustancias o la comisión de delitos, entre otras alternativas. El tener causas pendientes con la justicia o haber ingresado en prisión son otra expresión corriente de sus circunstancias personales.

Una parte de esta población debido a su alto deterioro general presenta un mal pronóstico. Hay usuarios severamente deteriorados, de salud precaria y con tantas secuelas de su proceso, que con toda probabilidad nunca llegarán a tener acceso a un trabajo normalizado y a una autonomía económica. Sus posibilidades de integración sociolaboral son bien remotas, escasas aun en el supuesto que evolucionaran favorablemente de su drogodependencia. Si continúan sobreviviendo será necesario prever nuevos conceptos de abordaje superadores de la perspectiva de reducción del daño y que aporten alternativas de convivencia y cuidado sostenibles a medio/largo plazo.

\section{LA REDUCCIÓN DE DAÑOS COMO MARCO DE INTER- VENCIÓN}

\subsection{La infección por VIH/SIDA como impulsora de las políticas} de reducción de daños

La evolución de la oferta terapéutica para el abordaje de las adicciones a la heroína y a la cocaína ha conllevado, desde finales de los años setenta hasta la actualidad, la aparición gradual de diversas alternativas a menudo antagónicas en sus postulados teóricos y metodológicos. Si tuviéramos que trazar un hilo conductor que relacionara cronológica y argumentalmente estas trayectorias terapéuticas, pronto advertiríamos una tendencia creciente por adaptar los objetivos del tratamiento a las posibilidades reales de los pacientes (Soriano, 2001).

Durante las primeras etapas históricas del abordaje terapéutico de 
los trastornos derivados del uso de drogas era frecuente que el fracaso en los tratamientos se achacara a la «falta de motivación» del usuario. El «desmotivado» quedaba así en una posición poco favorable para validar su consideración de sujeto a «tratar». En nuestros días, por el contrario, no se entendería que un profesional dejara de atender a una menor anoréxica o a una persona diagnosticada de «depresión mayor» esgrimiendo como argumento una falta de motivación. Es más, en el caso de los enfermos de anorexia ha prosperado una legislación que promueve incluso el ingreso hospitalario por orden judicial aun en contra de la voluntad del paciente. Se trata así de preservar su salud frente a un deterioro inminente, al estimarse que la enfermedad limita esa capacidad para el autocuidado. Claro que la construcción social sobre la anorexia tiende a victimizar al enfermo, al contrario que ocurre con el drogodependiente, fácilmente satanizado.

Pues bien, en el caso que nos ocupa, la «exigencia» ha sido el marco que ha modulado durante años las relaciones profesional-paciente. Sólo el volumen de fracasos y la entrada en escena de patologías asociadas al consumo de ineludible acomisión, han empujado verdaderamente unos cambios de envergadura en las políticas socio-sanitarias del sector. Desde la aparición del VIH/SIDA, el interés por preservar la vida del sujeto ha impulsado, por ejemplo, la apertura de los criterios de inclusión en los programas de mantenimiento con Metadona. A menudo evitar conductas de riesgo para la infección o reinfección por VIH se antepone a los objetivos orientados a la abstinencia. Desde una perspectiva deontológica, no puede resultar aceptable abandonar a su suerte a aquellos usuarios de drogas cuyo trastorno y/o limitaciones personales le dificultan o impiden operar cambios en sus conductas de riesgo.

La pandemia del VIH/SIDA ha sido, por su dimensión como fenómeno de salud pública, el factor que ha ejercido una mayor influencia sobre la implementación de políticas y estrategias destinadas a aquellos usuarios que no pueden o no quieren abandonar el consumo de drogas. Bajo la premisa de la accesibilidad, se ha reconocido como un derecho una necesidad de atención, la de un público que hasta el momento no encontraba cabida en el circuito asistencial (Soriano, 2001).

\subsection{Reducción de daños - Fundamentos teóricos}

La reducción de daños, también llamada reducción o disminución del riesgo, se trata de una actuación dirigida a aquellos sujetos más deteriorados sanitaria y socialmente, y que básicamente se concreta en aquellas «acciones individuales y colectivas, de carácter social o sanitario, tendentes a disminuir los efectos negativos asociados 


\section{al consumo de drogas".}

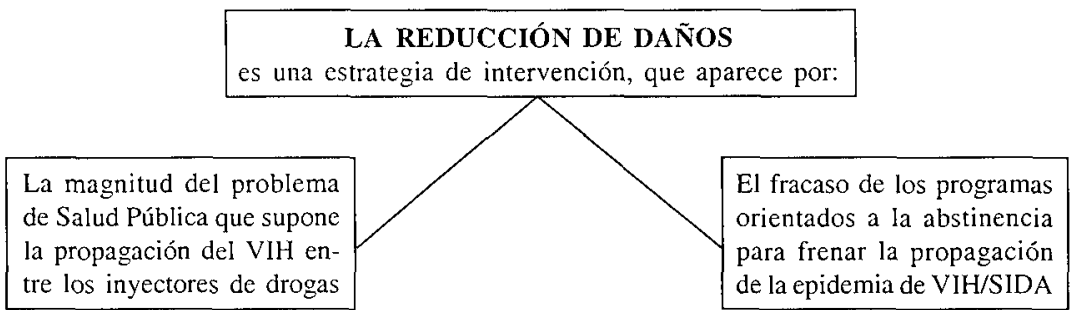

Los objetivos de la reducción de daños se basan en una dinámica jerárquica, que se establece de forma diferente según la meta propuesta. La meta más conocida es la aprobada por el Consejo Consultivo sobre el Abuso de Drogas del gobierno británico (1988-1989), y que se refiere a la implementación de estrategias para reducir la transmisión de la infección por el VIH entre y desde los inyectores de drogas. La escala de sus referencias se apoya en la siguiente secuencia:

No consumir drogas $\rightarrow$ si se consume, no hacerlo por vía intravenosa $\rightarrow$ si se hace por vía intravenosa, utilizar una jeringuilla estéril una sola vez. $\rightarrow$ si se reutiliza la jeringuilla límpiarla con lejía, etc.

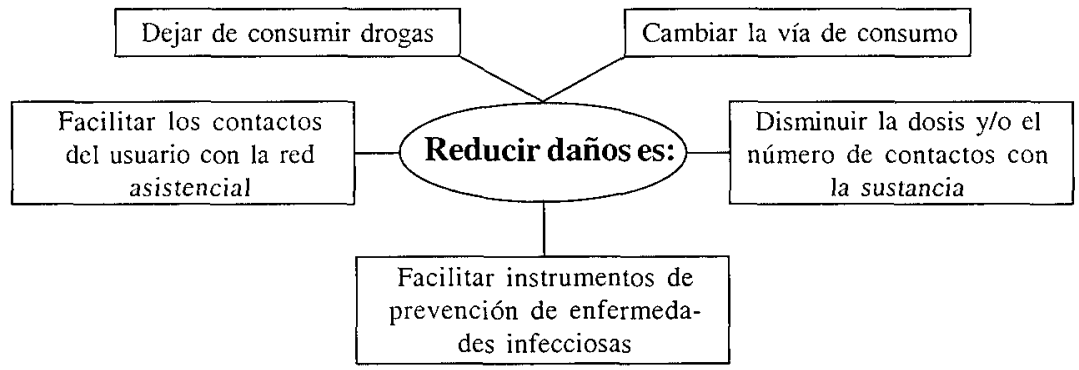

Es importante desarrollar conceptos precisos porque esto permite medir y evaluar la efectividad de las intervenciones de reducción de daños. Así pues se define como:

Riesgo: la probabilidad que tiene la conducta de "consumir drogas" de causar diferentes consecuencias.

Daño y beneficio: son dos términos complementarios, describen si una consecuencia concreta es vista como negativa o positiva.

Las políticas e intervenciones que actúan sobre los daños y beneficios pueden vertebrarse desde diferentes niveles y perspectivas, que se 
traducen en una amplia graduación de objetivos. La conceptualización de la reducción del daño (R.D.) se produce a finales de la década de los 80. Para organizar la planificación de estrategias Newcome realiza en 1989 una propuesta que se traduce en el siguiente cuadro:

\begin{tabular}{|c|c|c|c|}
\hline NIVEL & \multicolumn{3}{|c|}{ TIPO } \\
\hline & Salud & Social & Económico \\
\hline Individuo & & & \\
\hline Comunidad & & & \\
\hline Sociedad & & & \\
\hline
\end{tabular}

Ya a principios de los años 90 Erst Buning, propone el siguiente modificado:

\begin{tabular}{|c|c|c|c|}
\hline \multirow[t]{2}{*}{ NIVEL } & \multicolumn{3}{|c|}{ TIPO } \\
\hline & Salud & Social & Económico \\
\hline Individuo & $\begin{array}{c}\text { SIDA } \\
\text { Tuberculosis } \\
\text { Hepatitis }\end{array}$ & $\begin{array}{c}\text { Relaciones } \\
\text { Encarcelamientos } \\
\text { Marginación }\end{array}$ & $\begin{array}{l}\text { Pérdida de } \\
\text { productividad }\end{array}$ \\
\hline Sociedad & Enfermedades & $\begin{array}{c}\text { Crímenes } \\
\text { Violencia } \\
\text { Inseguridad ciudadana }\end{array}$ & $\begin{array}{l}\text { Aumento de gastos } \\
\text { por: tratamientos, } \\
\text { ingresos cn prisión, } \\
\text { medidas policialcs... }\end{array}$ \\
\hline
\end{tabular}

- La dimensión tipo daño/beneficio para la salud incluye el alcance y el tipo de trastorno, estado físico, lesiones, salud mental etc.

- La dimensión tipo daño/beneficio social incluye el alcance y el tipo de agresión/filiación, orden/desorden público, grupo de conflicto y cohesión e integración /marginación.

- La dimensión tipo daño/beneficio económico se refiere al alcance y clase de variables financieras, incluyendo deudas, delito y economía nacional.

- La dimensión tipo daño/beneficio individual se refiere a las consecuencias para el usuario de drogas.

- La dimensión tipo daño/beneficio sociedad se refiere a los efectos sobre estructuras y organizaciones sociales (por ejemplo, servicios de salud, sistema judicial penal, libertades civiles, cultura, economía).

- La dimensión tipo daño/beneficio comunitario se refiere a las consecuencias para la familia, amigos vecinos y/o compañeros del adicto (no reflejada en el modificado de Erst Buning). 
En definitiva, las respuestas de Salud Publica deben situar sus acciones en relación con las realidades de los individuos y de la comunidad desde actividades sociales, sanitarias y políticas. En estos tres niveles se incluyen y se solapan aspectos tales como los estilos de vida individuales, la oferta de los servicios asistenciales, las normas de grupo, el entorno social y los aspectos políticos y legislativos. Para garantizar la eficacia de las estrategias de reducción de daños asociados al consumo inyectado de drogas, éstas deben basarse en tres premisas básicas:

1. Aceptar que el uso más seguro de drogas es posible ante la evidencia de que no todos los usuarios de drogas vía parenteral están en condiciones de realizar tratamientos orientados a la abstinencia y que muchos de los que consumen no se acercan ni contactan con los servicios socio-sanitarios existentes.

2. Reconocer la existencia de distintos subgrupos de inyectores con diferentes necesidades, a los que hay que ofrecer soluciones múltiples y complementarias. Reconocer al consumidor como un sujeto racional capaz de elegir individualmente, con la debida información, entre distintas opciones para reducir los daños asociados al consumo de drogas, asumiendo que esta elección puede cambiar a lo largo del tiempo.

3. Reconocer la influencia de las situaciones de marginación y estigmatización asociadas al consumo de drogas como fuentes importantes de daños, distintas al consumo en sí mismo. Por ello, desde esta perspectiva, es preciso poner de manifiesto la necesidad de realizar simultáneamente esfuerzos que permitan reconocer y defender los Derechos Humanos de los usuarios de drogas no legalizadas.

\subsection{Las primeras experiencias}

La reducción de daños no es un concepto nuevo, porque los objetivos de estas intervenciones son los propios de la Salud Pública, orientados hacia la prevención y promoción de la salud (por ejemplo, la educación sanitaria para los diabéticos, los programas de infancia sana, los programas de vacunación de hepatitis B, etc.). Sí se puede considerar como estrategia novedosa, en cambio, dentro del área de drogodependencias, donde hasta no hace demasiado tiempo la actividad se orientaba exclusivamente hacia la abstinencia absoluta, y que dejaba fuera del sistema de atención a aquellos usuarios más marginales. En los primeros momentos, la construcción social del fenómeno de las drogodependencias se transcribía en el rechazo y la estigmatización sobre todo lo que rodeaba al consumo y a los consumidores de drogas ilegales. Al 
tratarse de sustancias de uso penalizado, los usuarios de drogas se relacionaban con el resto de la sociedad desde la clandestinidad y la marginalidad, provocando el alejamiento y exclusión de los servicios asistenciales, y en definitiva una mayor vulnerabilidad social y sanitaria.

En este contexto aparece a mediados de los años 80 el SIDA, la gran pandemia del siglo XX. La magnitud del problema de salud pública que supone la propagación del VIH entre los UDIs (España presenta las tasas de incidencia de SIDA más alta de la Unión Europea desde 1990), así como la percepción del fracaso de las políticas de actuación adoptadas anteriormente, constituyeron razones importantes para replantear las aproximaciones al fenómeno y provocar un cambio de ideas y discursos.

Durante los años 80 , Suiza desarrolló diferentes estrategias en el ámbito de la atención en drogodependencias, muchas de ellas canalizadas e impulsadas desde el «trabajo de campo». La creación de los «parques» de Zurich y Berna permitieron poner en evidencia la magnitud del problema, ante lo cual el gobierno Suizo decidió apoyar las iniciativas solicitadas por los profesionales y no cerrar los ojos ante la realidad que se estaba constatando. Los programas de intercambio de jeringuillas, las salas de inyección, la atención socio-sanitaria a las poblaciones más marginales y una amplia oferta de tratamientos de mantenimiento con metadona fueron las principales iniciativas que completaban la oferta de acciones orientadas a la abstinencia. Dentro de esta evolución, se llega a un punto en que se plantea la incorporación de los tratamientos con heroína como una alternativa más. Este programa se puso en marcha en 1993 como ensayo clínico en diferentes ciudades (Berna, Zurich, Basilea y Ginebra). Dichas intervenciones se basaban en la experiencia de Liverpool y Halton, en Inglaterra, donde habían comenzado ya en 1968. En Holanda, desde 1981 se estaba distribuyendo agujas limpias, para prevenir la transmisión de la Hepatitis y en 1984 aparecen los primeros programas de intercambio de jeringuillas.

En España, a pesar de liderar el primer puesto en casos de SIDA de la Unión Europea y el primer puesto mundial de transmisión del virus por vía parenteral, la mayor parte de los programas de reducción de daños aparecen 10 años más tarde (1990) que en algunos de nuestros vecinos europeos, llegan con retraso y de forma poco contundente. Las principales intervenciones en $\mathrm{RD}$ son los Programas de Intercambio de Jeringuillas (PIJ) y los Programas de Mantenimiento con Metadona (PMM). Así, los primeros programas móviles de intercambio de jeringuillas son implementados por MÉDICOS DEL MUNDO, comienzan en Madrid en 1992, y se incorporan Valencia y Sevilla en 1994. 


\section{INTERVENCIONES DE REDUCCIÓN DE DAÑOS}

\subsection{Programas de mantenimiento con Metadona (PMM)}

La Metadona es un derivado sintético del opio que, entre otros usos, se prescribe para tratar trastornos adictivos por dependencia a heroína. Administrada en una dosis estable, por vía oral y a diario, forma una reserva en el organismo que mantiene ocupados los receptores opiáceos y evita el síndrome de abstinencia. Aunque esta sustancia puede utilizarse en procesos de desintoxicación, el uso más extendido se da en programas de mantenimiento, donde la duración es indeterminada, y depende directamente de la evolución del paciente. A diferencia de otros opiáceos, como la heroína y la morfina, cuya vida media en el organismo es de 4 a 6 horas, los efectos de una dosis equivalente de metadona alcanzan una media de 24 a 36 horas. Esta particularidad permite el establecimiento pautado de un programa de «sustitutivos», donde se promueve evitar el consumo incontrolado de una sustancia adulterada e ilegal, reemplazándolo por un fármaco prescrito y regulado por un Equipo Terapéutico profesional, modificando las prácticas de riesgo y el circuito de efectos bio-psico-sociales negativos consecuencia del consumo anterior. Al mismo tiempo se trata de una sustancia farmacológicamente segura, que no genera ninguna disfunción orgánica y que normaliza las funciones alteradas por el consumo.

Tanto la metodología como los objetivos de un PMM pueden ser muy variados, pero generalmente se centran en la transformación de las conductas de dependencia a opiáceos, permitiendo un control sanitario, y mejorando su salud, esperanza y calidad de vida. Se incide sobre las relaciones familiares y sociales del paciente, y procuran la reducción de la actividad delictiva. Con la llegada de la pandemia del VIH/SIDA la orientación de muchos programas añadió a los objetivos de rehabilitación otros dirigidos a disminuir los riesgos asociados al consumo (Llorens y Fernández, 1999). Uno de los grandes pilares de estas intervenciones ha sido la capacidad para retener a los pacientes en tratamiento. Diversos estudios independientes han demostrado continuamente que el estado físico y mental de los pacientes que se mantenían en tratamiento, mejoraba (Kreek, 1983).

Los tratamientos con metadona en la dependencia a opiáceos están ampliamente aceptados e instaurados desde hace décadas en los países de la Unión Europea. En líneas generales España presenta una evolución práctica sobre este tipo de intervenciones comparable con otros Estados de su entorno, con un ritmo de integración más lento que en algunos países (Reino Unido, Holanda, Suiza o Alemania, por ejemplo), pero contemporánea a otros (como Francia, Italia, Bélgica...) 
(Hernández y Giner, 1999). En la actualidad cerca de 60.000 personas se encuentran incluidas en esos programas en el conjunto del Estado. Nunca antes una intervención en drogodependencias había vivido una demanda y un crecimiento tan espectacular.

Ahora bien, este basto crecimiento en la accesibilidad al tratamiento puede llevar a engaños, pues los recursos destinados a materializar el desarrollo práctico de los programas son a todas luces limitados, y en la mayor parte de los casos se pone más el acento en la dispensación del opiáceo que en los apoyos interdisciplinares bio-psico-sociales que constituirían el verdadero tratamiento. Sin dichos apoyos el programa terapéutico se merma tremendamente, al tiempo que impide una intervención y seguimiento adecuado para aquellos pacientes que podrían ser abordados desde un mayor umbral de objetivos terapéuticos. Todo parece indicar que los programas con mayores prestaciones y apoyos psico-sociales están en condiciones de ofrecer los mejores resultados (Brugal y Puigdollers, 1999; Mino et al., 1998; Soriano, 2001; Soriano, 1999). En la práctica y existiendo una fuerte demanda de PMM por parte de los usuarios (lista de espera incluida) se prima la implementación de PMM destinados a drogodependientes de bajo umbral de objetivos terapéuticos, potenciando la vertiente bio-médica en detrimento de la psico-social. En aras de la «dispensación radial» (acercar la toma de MTD a un punto más próximo al lugar de residencia del usuario) se ha potenciado la figura del DUE (Diplomado Universitario en Enfermería). Mientras, Trabajadores Sociales y Educadores no se encuentran presentes en la magnitud en que sería deseable y necesario.

Aún contando con que el aumento del acceso a la dispensación de MTD resulta una conquista irrenunciable y que sin duda supone una válvula de contención de la situación, ello no debería acallar la conciencia de quienes saben que esto no supone ni mucho menos un remedio sostenible. Al fin y al cabo se trata de una población politoxicómana. Los PMM abordan directamente la dependencia a heroína pero si no se interviene en las dependencias y consumos paralelos se deja la puerta abierta a varios efectos perversos e indeseables (George, E. y Woody, M.D., 1999). Por ejemplo, algunos usuarios con una fuerte «dependencia psicológica a la vía de consumo» intravenosa pasan a utilizar la cocaína inyectada, generando una conducta más compulsiva y de peor pronóstico. Abundan también los casos en que el usuario acaba generando un abuso o una dependencia a alcohol o benzodiacepinas que se procura, entre otros motivos, con la intención de sentir el «flash» que la MTD no le da. La ratio de profesionales/pacientes en los actuales programas no es suficiente para abordar integralmente la realidad de policonsumo y polidependencias con la que nos encontramos. En algunos recursos, una parte importante de la población en tratamiento pasa 
meses sin acudir a visitas de seguimiento, algo que tiende a achacarse al perfil de la población. Por la orientación «paliativa» de ciertas intervenciones, la permanencia del sujeto en el programa con asistencia a un número muy limitado de visitas suele asumirse como un mal menor, preferible a perder todo contacto con él.

El proceso de admisión es probablemente la etapa más importante de un programa de mantenimiento con metadona. Para los adictos que acuden por primera vez constituye el inicio de la transición de "consumidor de la calle" a "usuario de un centro asistencial". Adherirse al sistema terapéutico, sus servicios, reglas etc. supone un cambio cualitativo dentro de su proceso. Lo que ocurra en esta fase resultará determinante en su actitud, autoestima, interés y motivación a lo largo del tratamiento, por lo que esta experiencia debería ser positiva para el usuario. Una valoración y diagnóstico personalizado debe considerar como aspectos relevantes las principales necesidades «sentidas» por el recién llegado, facilitando así un establecimiento más favorable de las bases de la intervención clínica.

Los Programas paliativos tienen como «única función frenar el deterioro que provoca el consumo de sustancias, ya sea por la imposibilidad de cambio de los individuos o por la presencia de enfermedades en fase avanzada que hagan inviable ningún cambio». Desde otro ángulo, los Programas orientados al cambio acometen como primera intención la contención del daño, pero prevén una posibilidad de cambio a medio plazo, y tras la estabilización de los individuos no descartan avanzar hacia programas orientados a la abstinencia (PND, 1998). Lógicamente, optimizar la potencialidad de cambio de los pacientes solo es compatible con una política que garantice prestaciones integrales más allá de la dispensación de la sustancia.

Si bien no se dispone de predictores fiables que indiquen al inicio de un programa cómo va a ser la evolución de un usuario, sí que se conoce que una estancia prolongada en «mantenimiento» se relaciona con menor riesgo de recaída y mejor evolución posterior. Si a esto unimos la despreciable toxicidad del fármaco, la consideración de cronicidad para el proceso adictivo padecido por muchos pacientes y su utilidad terapéutica para estabilizar determinados trastornos psiquiátricos, no es de extrañar que cada vez se plantee con menores reservas el mantenimiento a largo plazo o permanente en metadona como una alternativa posible y deseable en determinados casos.

En realidad, la toma diaria del fármaco presenta ciertas facilidades a pesar de que se trata de una sustancia cuyo uso se encuentra escrupulosamente regulado en la legislación vigente. De hecho, un paciente o sus familiares pueden ser autorizados según criterio del equipo tera- 
péutico para retirar cada varios días botes de medicación. Esta práctica conocida como «take home» implica responsabilizarse de custodiar la medicación y permite tomarla en el propio domicilio. En ese contexto, y para los pacientes incluidos en programas de alto umbral de objetivos terapéuticos, el seguimiento farmacológico del tratamiento resulta relativamente cómodo si se compara con el de ciertos enfermos crónicos, siendo menos agresivo que la inyección de insulina en el caso de los diabéticos, o la hemodiálisis utilizada para tratar la disfunción renal. Sin duda, la presentación como fluido para su ingestión oral supone una gran ventaja. Incluso el paciente puede desplazarse a otra ciudad o país (por vacaciones, por motivos laborales, etc.) coordinando anticipadamente con su centro prescriptor la retirada provisional de medicación en otro punto de dispensación.

Sin embargo, todavía hoy existen agujeros negros donde el paciente sólo puede encontrar trabas y dificultades. En la práctica, participar en un P.M.M. suele ser considerado un motivo de exclusión para acceder a una casa de acogida de enfermos de SIDA, un albergue de transeúntes o una residencia materno-infantil para mujeres en situación de riesgo. Desde una óptica más aperturista, la prescripción de MTD a pacientes susceptibles de alcanzar altos objetivos terapéuticos puede ser un apoyo más dentro de otros recursos, como los centros de día o las Unidades de Deshabituación Residencial. La evidencia clínica sugiere que existen sectores entre los actuales usuarios de Comunidades Terapéuticas profesionales y de tratamientos con metadona que pueden requerir de la integración de ambos servicios y beneficiarse de ellos (Llorente y Fernández, 1999). El fármaco tiene muchas posibilidades y su uso no debería postergarse casi exclusivamente a población considerada como «residual» o a los programas de «bajo umbral de objetivos».

\subsection{Programas de intercambio de jeringuillas}

La introducción de los PIJ ha conseguido la estabilización de la prevalencia del VIH y otras infecciones de transmisión sanguínea, como la Hepatitis B y C, entre los UDIs. EI Reino Unido, Holanda y Suiza son los máximos representantes de la puesta en marcha de estrategias y programas para favorecer el acercamiento a los usuarios de drogas inyectables, entre los que se encuentran estas intervenciones. Los PIJ, básicamente, son programas con un objetivo principal, común a otras acciones de reducción de daños: prevenir la infección por VIH y otras enfermedades infecciosas, mediante la dispensación de material estéril para el uso de drogas por vía parenteral. Entre los objetivos específicos que persiguen destacamos: 
- Disminuir las prácticas de inyección de drogas que conllevan riesgos, como el uso compartido de jeringuillas, dar y/o recibir drogas previamente diluidas en una jeringuilla usada, y compartir otros materiales relacionados con la preparación y administración de la dilución de drogas (recipientes para disolver la sustancia, algodones, agua, etc.).

- Disminuir las prácticas sexuales de riesgo.

- Mejorar el acceso de los inyectores de drogas a los recursos sanitarios y sociales generales (como centros de Atención Primaria, servicios sociales generales), y específicos (como consultas hospitalarias para control y tratamiento de infecciones y centros de tratamiento en caso de ser requeridos).

- Aumentar el porcentaje de inyectores que se han realizado el test anti-VIH y pruebas serológicas frente a los virus de la hepatitis (B y C).

- Mantener la vigilancia epidemiológica mediante la recogida sistemática de datos para el estudio de la población que acude a los programas y más específicamente de las conductas de riesgo para la transmisión de VIH.

- Monitorizar las modificaciones de los patrones de consumo de drogas entre la población atendida. Parece que el consumo de cocaína y crack se asocian a un incremento de las prácticas de riesgo para la transmisión de VIH.

- Asegurar a medio y a largo plazo, la asimilación del cambio de hábitos y prácticas de riesgo.

- Contribuir a disminuir el número de jeringuillas usadas abandonadas.

\section{Actividades de los Programas de Intercambio de Jeringuillas}

- Distribución de material de prevención: jeringuillas, agua bidestilada, alcohol, ácido cítrico, papel de plata, preservativos, etc.

- Recogida de jeringuillas usadas en contenedores de residuos especiales (según la normativa para la eliminación de residuos y materiales contaminantes).

- Educación para la salud.

- Instrucción sobre inyección de menos riesgo.

- Instrucción sobre sexo más seguro.

- Derivación a otros recursos asistenciales.

- Elaboración y divulgación de material informativo sobre prevención de riesgos.

Se pueden emplear dos tipos de estrategias:

A. En la que el usuario ha de desplazarse al centro donde se realiza el intercambio, utilizando recursos socio-sanitarios ya existentes 
o un lugar donde se ubica una máquina dispensadora de jeringuillas. Este tipo de intervención requiere una persistente actividad de sensibilización entre los usuarios para motivar que acudan a participar. Algunos PIJ se realizan desde farmacias que colaboran de un modo protocolarizado en la actividad.

B. En la que se utiliza una Unidad Móvil (caravana, furgoneta...) que se desplaza a los lugares de venta/consumo tratando de facilitar al máximo la accesibilidad al programa de intercambio. Normalmente se concretan horarios y lugares estables para organizar la actividad coincidiendo con los usos habituales de esta población.

Ambas estrategias han de ser complementarias, es decir, hay que facilitar el acceso del usuario al material estéril, completando una oferta de atención con puntos fijos de intercambio (centros o locales), unidades móviles (acercamiento) y máquinas intercambiadoras para asegurar así la disponibilidad del material durante las 24 horas del día, todos los días del año. La eficacia de los PIJ está suficientemente consensuada, tanto para disminuir la propagación del VIH (con estimaciones de una reducción de nuevos casos de hasta un $33 \%$ en los usuarios del PIJ que se ha desarrollado en New Haven, Connecticut, EEUU), como por la importante tasa de retorno de jeringuillas suministradas (superior al 70\%).

Cabe recordar, que aunque nos hemos venido refiriendo mayormente a personas con trastorno por dependencia a opiáceos (PTDO), las referencias UDVP (usuarios de drogas vía parenteral) y UDIs (usuarios de drogas inyectables) incluyen a los autoinyectores de cocaína, que presentan análogas prácticas de riesgo asociadas a la vía. De hecho, es común el patrón de consumo que combina el consumo de heroína fumada/inhalada y cocaína inyectada. Este patrón puede estar relacionado, entre otros aspectos, con el tipo y pureza de las sustancias que se encuentran al alcance del usuario.

\subsection{Centros de encuentro y acogida}

En el año 1990, la Comisión mixta Congreso-Senado para el estudio del problema de las Drogas, elaboró una propuesta de medidas, entre las que se encontraba la de "habilitar, en las grandes ciudades, centros abiertos 24 horas para situaciones que requieran una atención inmediata". La Comisión definía estos centros como "Centros de Emergencia Social". Se trata de un recurso de atención y cuidados mínimos, que se apoya en una estructura asistencial diseñada y desarrollada específicamente para población usuaria de drogas inyectables. Este tipo de 
intervención está dirigida a los usuarios de drogas más deteriorados desde el punto de vista socio-sanitario que no acceden a las redes asistenciales normalizadas. En algunos de ellos coinciden varias circunstancias motivo o efecto de marginación, como vivir en la calle, presencia de trastornos mentales, ser inmigrante en situación irregular, ex-reclusos ...

A los centros de acogida se accede directamente, sin derivación previa. En ocasiones se trata de usuarios de otro tipo de recursos, como albergues, comedores sociales, etc. La ubicación de estos centros puede variar en función de las necesidades de cada ciudad, pero suelen preferirse algunas de las siguientes alternativas:

- Zonas céntricas degradadas (como pueden ser algunos barrios antiguos).

- Zonas de especial conflictividad (barrios donde se encuentra población inmigrante en situaciones de grave precariedad, prostitución, áreas portuarias, etc.)

- Espacios abiertos frecuentados por población marginal (solares deshabitados, encrucijadas de carreteras, etc.).

Por regla general se considera que la ubicación ha de ser lo más cercana posible a los escenarios cotidianos del UDI.

Actividades de los centros de encuentro y acogida:

- Servicio de acogida e información: en general se informa de lugares para dormir, comer, recibir atención sanitaria o tratar su adicción, etc.

- Servicio de intercambio de material o PIJ: jeringuillas, preservativos, etc.

- Servicio de estancia y descanso (también se les llama sala de calor y café), donde prima el trato personalizado entre el usuario y el educador, en un clima tranquilo y confortable; algunos centros disponen de salas con camas para dormir unas horas.

- Servicios de higiene: Duchas, cambio de ropa, lavadora, etc.

- Servicio sanitario de urgencia y medicina preventiva: curas, diagnóstico precoz de embarazo, vacunaciones, etc.

- Servicio de educación para la salud: consejo, charlas, talleres, etc.

- Servicio de valoración socio-sanitaria: atención, información, orientación y asesoramiento básico.

- Servicio de coordinación y contacto con otros recursos: gestión de derivación y canalización de atenciones varias.

El talante del equipo profesional en estos centros debe contemplar buenas dosis de flexibilidad, baja exigencia en las normas, respeto y claridad en los límites. 


\subsection{Salas de venopunción higiénica}

Estos dispositivos intentan abrirse camino en nuestro país con una denominación que, como mínimo, se puede catalogar de desafortunada: "Narcosalas". La palabra narcótico viene del griego "narcosis" que quiere decir sueño profundo, sin retorno. Siempre que se utiliza la palabra "narcótico" en el lenguaje actual, está ligada a algo fatal y/o delictivo, ..., brigada de narcóticos, narcotráfico, narcotraficante, etc.

Son salas donde el usuario de drogas inyectables más desestructurado socialmente, que vive y que consume habitualmente en la calle, puede consumir sustancias inyectadas en condiciones sanitarias más dignas. Se les dota de material estéril para el uso parenteral (jeringuilla, agua destilada, alcohol, ácido cítrico, etc.), y están bajo la tutela de médicos, DUEs y trabajadores sociales, etc. Además las instalaciones están equipadas con material de urgencias y reanimación.

Las unidades de venopunción existen en Holanda y Suiza desde hace años. Tienen como objetivo principal acercar a la red asistencial social y sanitaria a los UDIs sin hogar y con numerosos intentos fracasados de integrarse en distintos planes terapéuticos. En España, la primera sala en abrir sus puertas fue la de "La Barranquilla", en Madrid, a principios de 2000 , y su apertura fue objeto de innumerables debates desde distintas esferas de la vida social y política.

Argumentos a favor: Pueden ser el único punto de contacto con la red de recursos socio-sanitarios para un grupo de usuarios de drogas con graves deterioros. Para éstos, la sala de inyección es casi la única posibilidad de consumir en unas condiciones de "menor riesgo".

Argumentos en contra: El usuario aporta la sustancia que se va a inyectar, en la actualidad las drogas "ilegales" son preparadas en laboratorios clandestinos y adquiridas en el mercado negro, por lo tanto no existe ningún control sanitario sobre ellas. El médico o enfermera, en ningún momento saben la cantidad de pureza o la sustancia «de corte» que se está inyectando el usuario, por lo tanto es difícil prevenir las reacciones adversas, situaciones de sobredosis, anafilaxis, etc.

Tal y como ocurre en Holanda, las salas pueden disponer de un servicio de análisis inmediato y voluntario de la composición de las sustancias que aportan los usuarios.

\subsection{Programas de dispensación controlada de heroina}

La utilización de la heroína en programas de mantenimiento para adictos a opiáceos, ha sido objeto de investigaciones de experiencias 
piloto en distintos países de Europa, Inglaterra-Liverpool (1968), Holanda-Amsterdam (1979), Suiza-Ginebra (1994), Bélgica (1995), Australia (1995). Desde los años setenta se propone que la administración de heroína prescrita y controlada por un médico puede producir índices de retención superiores a los obtenidos por los PMM. Si esta idea hubiera tardado menos años en calar se habría contribuido generosamente a controlar la transmisión de enfermedades derivadas de la forma de consumo, entre ellas la infección por VIH/SIDA.

En la Declaración de Helsinki, en la que se formalizan los principios para una buena práctica médica, se contempla el hecho de que cuando no existe un tratamiento adecuado, el paciente recibirá aquél que maximice sus posibilidades de mantener la vida y de mejorar la calidad de ésta. Sabemos, por la experiencia de trabajo en los PMM, que aproximadamente un $30 \%$ de los usuarios de estos programas abandonan el mismo.

El análisis de las experiencias suiza y británica pone en evidencia que el desarrollo de los tratamientos con heroína se ha realizado en armonía con su especificidad social, política, histórica, científica y económica y en el marco de una serie de medidas globales destinadas a ofrecer una respuesta coherente, diversificada y adaptada a un fenómeno complejo y multidisciplinar, como son los trastornos relacionados con el uso de sustancias. La experiencia del estudio australiano confirma la necesidad de abordar progresivamente las etapas, desarrollando la "oferta de heroína" como un elemento más dentro de la gama de respuestas. En el Estado español, sólo dos Comunidades Autónomas (Andalucía y Cataluña) han puesto en marcha iniciativas o comisiones para la valoración del desarrollo de programas de tratamiento con heroína.

\section{CONCLUSIONES}

- La infección por VIH/SIDA representa hoy por hoy el fenómeno que mayores transformaciones ha procurado en el ámbito de abordaje de las conductas adictivas asociadas al consumo de drogas vía parenteral.

- Las políticas de reducción de daños constituyen un vector de intervención en continua expansión y evolución, suponen un avance técnico e ideológico irrenunciable, y gozan progresivamente de mayor consenso y credibilidad científica y social.

- Las políticas de reducción de daños deben contemplar nuevas estrategias más integrales e interdisciplinares, la vertebración del eje 
psico-social requiere un impulso decisivo por parte de Administraciones, instituciones y profesionales.

- El escenario en el que se plantean buena parte de los programas de mantenimiento de metadona en España hoy está más cerca de «reducir los daños a la colectividad» que de procurar una atención personalizada y de suficiente calidad a sus usuarios. No existe infraestructura para optimizar la potencialidad terapéutica de cada paciente en cada momento.

- La población cronificada en el consumo de drogas inyectables que presenta peor pronóstico requiere nuevas respuestas por parte del circuito de recursos. El diseño de nuevas alternativas de convivencia y de espacios para la atención de las necesidades básicas en los procesos terminales debe promover una existencia más digna y más humana.

\section{BIBLIOGRAFÍA}

ARDIZABALAGA, I; SERRANO, M.; (1995): Tratamiento de Mantenimiento con Metadona: "Una intervención multidisciplinaria y comunitaria". III Jornada de Psicología en Navarra. Conferencias y Comunicaciones. Colegio Oficial de Psicólogos de Navarra.

ASTASIO, M.; (1992): Programas de mantenimiento con metadona; En FERNÁNDEZ, A. et al.: Adicción a la heroína. IDEPSA. Madrid.

BALL J.C.; ROSS, A. (1991): The effectiveness of Methadone Maintenance Treatment. Patients, Programs Services, and Outcome. New York, SpringerVerlag.

BROONER, R.K.; GREENFIELD, L.; XCHMIDT, C.W. (1993): Antisocial personality disorders and HIV infection among intravenous drug abusers. Arch. Gen. Psychiatry. 54: 71-80.

CANO, L. y MAYOR, L. (1998): La intervención psicológica en el marco de las Drogodependencias. Informació Psicològica. Col-legi Oficial de Psicòlegs del País Valencià. 1998. n 66. pag. 10-18. Valencia.

CATAÑEDA, M. (1992): Conceptos básicos en adicción a la heroína. En FERNÁNDEZ, A. et al.: Adicción a la heroina. IDEPSA. Madrid.

Decreto 47/1998, de 5 de abril, del Gobierno Valenciano, sobre Registro y Acreditación de Centros y Servicios de Atención y Prevención de las Drogodependencias y otros Trastornos Adictivos en la Comunidad Valenciana (DOGV ñ 3.235 , de 05-05-98).

E.T. U.C.A. CRUZ ROJA VALENCIA (1998): Estudio de una muestra de adictos a opiáceos incluidos en un Programa de Mantenimiento con Metadona: 
perfil psicológico, social y patología orgánica. Libro de Comunicaciones del $V$ Encuentro Nacional sobre Drogodependencias y su Enfoque Comunitario. Dip. de Cádiz, Junta de Andalucía, P.N.D., F.A.D.; Chiclana de la Frontera (Cádiz).

COLEGIO OFICIAL DE PSICÓLOGOS. DELEGACIÓN DE MADRID (1996): Intervención en Drogodependencias: Áreas y Técnicas. Madrid.

DE ANDRÉS, M. (1995): Reducción de riesgos. Jano (monográfico). Drogodependencias diez años después del SIDA. $\mathrm{n}^{\circ} 1.140$.

DEL RÍO, Ma . et al. (1999): Guía de INTERNET sobre alcohol y drogas de abuso. Du Pont Pharma. Valladolid.

DEL RÍO, M. (1994): Programas de Mantenimiento con Heroína. I Conferencia Nacional sobre el SIDA, Madrid, Ministerio de Sanidad y Justicia e Interior. Madrid.

DES JARLAIS, D.J. (1992): The first and second decades of AIDS among injecting drugs users. British Journal of Addiction.

ESTEVE, M.L. et al. (1998): Áreas y técnicas en el proceso de atención psicológica en los Programas de Mantenimiento con Metadona. Intervención Psicosocial, 1.998, vol. 7, n² 2, pags. 217-227. Valencia.

G.V.; (1999): Tú puedes prevenir el SIDA. Dirección General de Salud Pública. Conselleria de Sanitat. Valencia.

GEORGE, E.; WOODY, M.D. (1999): Injected cocaine and other substance use by patiens in methadone maintenance treatment. Libro de Ponencias $V$ Conferencia Nacional sobre SIDA y Drogas. Ministerio de Sanidad y Consumo - Ministerio del Interior. Madrid.

GINER, F. (1999): ¿Tratamientos con heroína?. CREFAT. n 11. Cruz Roja Española. Madrid.

GRUPO SIDA. COP- MADRID (1996): La importancia del Psicólogo en los P.M.M. III Encuentro de Psicología en Drogodependencias. COP - Madrid.

GUTIÉRREZ, E. et al. (1998): Trastornos de personalidad en adictos a opiáceos en tratamiento con agonistas vs antagonistas. ADICCIONES, 98 vol.10, $n^{\circ} 2$.

HERNÁNDEZ, J.J.; GINER, F. (1999): Los programas de mantenimiento con metadona. Una aproximación a sus aspectos jurídicos y clínicos. SEISIDA. vol. 10. n'. 3. pag. 117.

INSÚA, P. et al. (1999): Manual de Educación Sanitaria: recursos para diseñar Talleres de prevención con usuarios de drogas. Programa de Formación para la prevención de los problemas de salud asociados al consumo de drogas. PND - PNS - Universidad del País Vasco.

JOE, G.W.; SIMPSON, D.D.; HUBBAR, R.L. (199 I): Treatment predictors of 
tenure in methadone maintenance. Journal of Substance Abuse, 3: 73-84.

KREEK, M.J. (1983): Health consequences associated with the use of methadone. In: CCOER, J.R.; ALTMAN, F.; BROWN, B.S.; CZECHOWICZ, D., eds.: Research on the Treatment of Narcotic Addiction; State of the Art. National Institute on Drug Abuse Research.

LLORENTE, J.M.; FERNÁNDEZ, C. (1999): La comunidad terapéutica profesional en el abordaje de pacientes en tratamiento de metadona. Trastornos adictivos. Vol. 1 - n $3-4$ pag. 251-258. Madrid.

MAGRANE, M.; VELILLA, A. (1996): La intervención del Trabajador Social en los programas de mantenimiento con metadona para personas drogodependientes. VI Congreso Estatal de Diplomados en Trabajo Social y Asistentes Sociales. Sevilla.

MINO, A. et al. (1998): Análisis de un programa público de metadona de dos años. Libro de Ponencias del V Encuentro Nacional sobre Drogodependencias y su Enfoque Comunitario. Dip. de Cádiz, Junta de Andalucía, P.N.D., F.A.D.; Chiclana de la Frontera (Cádiz).

NEWCOMBE (1989): Working Party on Harm Minimization . Evaluating Drugs and AIDS Prevention Policies. Institute for the Study of Drug Dependence. London.

NIDA; (1999): INFOFAX. Heroína National Institute on Drug Abuse. National Institutes of Health. http://www.nida.nih.gov/

NIEVA, P.; BAULENAS, G.; BORRAS, T. (1995): Centros de Encuentro y Acogida, documento de referencia. IPSS; GRUP IGIA; P.N.D. Barcelona.

O'HARE, P.A.; NEWCOMBE, R. et al. (1995): La reducción de daños relacionados con las drogas. Ed. Grup Igia. Barcelona. (Orig. 1992).

Plan Nacional sobre el S.DA (1996): Guía para la puesta en marcha de programas de intercambio de jeringuillas. Dirección General de Salud Pública. Ministerio de Sanidad y Consumo. Madrid.

P.N.D. (1998): Servicios Sociales y Drogodependencias: Actuar es posible. Delegación del Gobierno para el Plan Nacional sobre Drogas - Ministerio del Interior. Madrid.

P.N.D. (1999): Observatorio Español Sobre Drogas - Informe n" 2. Delegación del Gobierno para el Plan Nacional sobre Drogas - Ministerio del Interior. Madrid.

P.N.D. (2000): Observatorio Español Sobre Drogas. Delegación del Gobierno para el Plan Nacional sobre Drogas - Ministerio del Interior. Madrid.

SANCHÍS, M.; MARTÍN, E. (1997): Alcohol y drogas: depende de todos. Conselleria de Benestar Social. Generalitat Valenciana. Valencia.

SCHERING-PLOUGH, S.A. (1998): Hablemos de La Hepatitis Vírica. ScheringPlough, S.A. BIOTECH. Ediciones ACV. Barcelona. 
SORIANO, R. (2001): Reducción de daños entre usuarios de drogas inyectables: un enfoque social. Valencia (próxima publicación).

SORIANO, R. (1999): Voluntariado como apoyo en un Programa de Mantenimiento con Metadona. R.T.S. Revista de Treball Social. N 155; pag. 87-99. Barcelona.

SORIANO, R. (1998): Intervención Social en VIH/SIDA. Col. Hvmanitas 2.000. Serie Intervención Social. Ed. LUMEN-HVMANITAS. Buenos Aires.

ZUNZUNEGUT PASTOR, M.V.(1998): Estudio comparativo aleatorizado abierto entre heroína intravenosa y metadona oral durante un año en el mantenimiento de pacientes con adicción a opiáceos que han fracasado en tratamientos actualmente disponibles: Programa experimental de prescripción de estupefacientes en Andalucía. (PEPSA). EASP. 



\section{PROS Y CONTRAS DE LA POLÍTICA DE COOPERACIÓN ESPAÑOLA. LA LEY DE COOPERACIÓN INTERNACIONAL PARA EL DESARROLLO A EXAMEN}

\section{ALFREDO HIDALGO LAVIÉ}

Profesor de Servicios Sociales y Política Social. Escuela Universitaria de Trabajo Social de Jerez. Universidad de Cádiz.

\section{INTRODUCCIÓN}

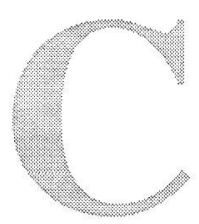

on motivo de la celebración del I Congreso Andaluz de Escuelas de Trabajo Social celebrado en Málaga los días 21 y 22 de mayo de 1998, tuve la ocasión de presentar una comunicación bajo el título «Una valoración sobre la Ley española de Cooperación Internacional para el Desarrollo», en la que expuse en conocimiento de la audiencia los apartados más relevantes de la misma, las posturas políticas sostenidas por los distintos grupos parlamentarios de la cámara del Congreso de los Diputados, así como los contenidos más sobresalientes del proyecto de ley introducido por el gobierno del Partido Popular y los argumentos esgrimidos por la Plataforma 0'7 a este respecto. Esta comunicación, nutrida de comentarios, análisis y valoraciones que incorporé a título propio, finalizaba con una seria advertencia que reproduzco textualmente a continuación: «afirmaba el diputado de Convergència $i$ Uniò, el señor Recorder $i$ Miralles, que no todos los grupos parlamentarios se han tomado con el mismo interés el debate sobre esta ley y no tenía ninguna esperanza de que sus palabras trascendieran más allá de su tribuna. Pues bien, gracias a la admisión de esta comunicación por los organizadores de este Congreso, podemos recordar que la Plataforma 0 '7 ha subrayado que la presión de este grupo parlamentario ha sido no sólo necesaria, sino vital». Detrás de este enunciado se ocultaba un temor no injustificado como ha venido a demostrar el posterior desarrollo legislativo de esta materia. La mayoría absoluta que

Actas del I Congreso Andaluz de Escuelas de Trabajo Social, «El Trabajo Social en los Servicios Sociales y en la Política Social: reto para el tercer milenio», Escuela Universitaria de Trabajo Social de Málaga, 1999. 
detenta el Partido Popular, y como así consta en el Diario de Sesiones del Senado, trastocó substancialmente ciertos contenidos del proyecto de ley aprobado por el Congreso de los Diputados, quebrando, pues, de este modo el elogiable consenso alcanzado entre todas las fuerzas políticas del arco parlamentario y los agentes sociales más involucrados en este ámbito.

Una vez más, el apoyo del grupo parlamentario de Convergència $i$ Unió contribuyó a enderezar las posturas adoptadas en la cámara del Congreso, siendo rechazadas las enmiendas más sobresalientes del Senado y la actual Ley de Cortes 23/1998, de 7 de julio, de Cooperación Internacional para el Desarrollo, publicada en el Boletín Oficial del Estado un día después (núm.162), renaciendo del consenso político, cuya satisfacción no ha dudado en hacer pública, incluso, la Coordinadora de ONGD y la Plataforma 0'7.

Como a continuación tendremos ocasión de comprobar, esta satisfacción es resultado de numerosos esfuerzos realizados desde aquellos emblemáticos días de los meses de septiembre a noviembre de 1994, fecha en la que se organizó la renombrada «Acampada de la Solidaridad» en el Paseo de la Castellana de Madrid, que condujo a la reproducción de este modelo de movilizaciones a lo largo y ancho del Estado, creándose aproximadamente cuarenta acampadas simultáneas; todo un fenómeno social teniendo en cuenta que sólo un reducido grupo de ciudadanos, sin dinero y con escasas infraestructuras organizativas, alcanzaron tanto poder de convocatoria, el cual es, incluso, mencionado indirectamente en el apartado II de la Ley ya en vigor, al enunciar: «el aumento de los fondos dedicados a cooperación, muestra la solidaridad de España y en buena medida propiciado por la creciente sensibilización del conjunto de la sociedad...».

Ciertamente, y como es natural en todo proceso consensual, las reivindicaciones individuales de cada grupo político y de presión no han podido ser enteramente satisfechas, como así consta en el comunicado de prensa de la Plataforma 0'7, pero ya es en sí relevante que una norma con rango de ley tan esperada y solicitada haya alcanzado tan notable capacidad de integración. Es, pues, todo un hito para la historia de la cooperación española en materia de desarrollo la aprobación y entrada en vigor de esta ley. Bastaría recordar, con el ánimo de subrayar y resaltar su relevancia, que hasta el momento presente la cooperación efectuada por nuestro país con los países en vías de desarrollo sólo disponía de reales decretos, relacionados más con la creación de determinados organismos del Ministerio de Asuntos Exteriores que con la naturaleza misma de la cooperación, siendo éstos, por consiguiente, el más alto rango de las normas que regían nuestra ayuda para el desarro- 
llo. Afortunadamente, hoy día puede hablarse ya, y con propiedad, de la existencia de un marco legal que regula las acciones y actividades relacionadas con la cooperación española, debiéndose entender ésta como "el conjunto de recursos y capacidades que España pone a disposición de los países en vías de desarrollo, con el fin de facilitar e impulsar su progreso económico y social, y para contribuir a la erradicación de la pobreza en el mundo en todas sus manifestaciones», impulsando a su vez «...la defensa y protección de los derechos humanos y las libertades fundamentales, las necesidades de bienestar económico y social, la sostenibilidad y regeneración del medio ambiente (y)...la plena consolidación de sus instituciones democráticas y su inserción en la economía internacional» (art.1. de la ley de 1998)².

\section{UNA PANORÁMICA GENERAL DE LA EVOLUCIÓN DE LA COOPERACIÓN ESPAÑOLA PARA EL DESARROLLO.}

Una ligera endoscopia sobre las repercusiones y evolución de las políticas llevadas a cabo en cooperación para el desarrollo en los países de nuestro entorno occidental nos permite sostener, sin lugar a dudas, una primera afirmación concluyente sobre el modelo de nuestro país a este respecto ${ }^{3}$.

Cuando en 1961 se crea en los Estados Unidos la Agencia para el Desarrollo Internacional y en 1962 su equivalente en Suecia (en adelante estos organismos se reproducen por doquier por toda Europa),

2 El elevado número de enmiendas presentadas por los diversos partidos políticos con representación parlamentaria al inicial proyecto gubernamental sobre la ley de cooperación permite afirmar, una vez más y como de este modo así ha sido reconocido por los portavoces de las distintas fuerzas políticas, las mejoras introducidas al proyecto de ley fruto del consenso y de la negociación entre los miembros de la clase política de nuestro país. Prueba de ello, es la modificación de este primer artículo, bajo la rúbrica «Objeto de la ley y ámbito de actuación» al sustituir el siguiente enunciado «...con el propósito fundamental de estimular el desarrollo económico y el bienestar social de sus habitantes, de forma que esos países puedan instrumentar un sistema económico y social estable en un plazo razonable» por el contenido anteriormente recogido casi en su integridad.

3 Las políticas de cooperación para el desarrollo devienen, a mi modo de ver, una variable verosímil para proceder a la elaboración de una nueva tipología sobre los Estados de Bienestar. A este respecto, puede consultarse Alfredo Hidalgo Lavié, "La dimensión internacional del Estado de Bienestar: las politicas de cooperación para el desarrollo», en Servicios Sociales y Política Social, Revista de Trabajo Social, Consejo General de Colegios Oficiales de Diplomados en Trabajo Social, n. ${ }^{\circ}$ 47, Madrid, 1999, pp.111126. 
España es aún un país atrasado social, cultural y políticamente, inmerso en un régimen autoritario, aislado y reticente ante toda influencia exterior. Un legado, tras cuarenta años de régimen franquista, que encuentra un exponente ilustrativo en el hecho de que en 1977 es considerado aún como país receptor de ayuda por la institución del Banco Mundial e incluso en 1981, todavía, figura como país en vías de desarrollo por el Fondo Monetario Internacional. Por consiguiente, económicamente también, nuestro país forma parte del mundo en desarrollo. Este aislamiento junto a la ausencia de infraestructuras necesarias en todos los ámbitos, pero particularmente en el económico (no olvidemos la elevada tasa de desempleo que nos coloca en el ranking de los miembros de la Unión Europea), van a explicar, en gran medida, la naturaleza de nuestras políticas de cooperación y la utilización de las mismas como yacimiento de canalización de excedentes comerciales, creación de empleo $y$, en definitiva, posibilidades de crecimiento económico para nuestras empresas. Las denuncias de los colectivos sociales sobre la utilización desmesurada de los créditos del Fondo de Ayuda para el Desarrollo (FAD), así como las observaciones manifestadas por el Comité de Ayuda al Desarrollo (CAD) y recogidas en el Informe de 1994 de la OCDE, según el cual «España es el país cuyo programa de ayuda presenta el carácter más comercial y se coloca en el segundo puesto de los miembros del CAD por la dureza de las condiciones que aplica» ${ }^{4}$, encuentran su raíz en este aislamiento y lamentable atraso.

No obstante, tímidas realizaciones fueron llevadas a cabo durante esos difíciles años que tal vez, a modo de precedentes, pueden ser consideradas en la breve historia de la política internacional española para el desarrollo. Así, en 1945 se crea, en el seno del Ministerio de Asuntos Exteriores, la Dirección General de Relaciones Culturales con el objetivo de difundir la cultura y lengua españolas en el extranjero, primordialmente América Latina, y fomentar los intercambios culturales, por lo que, para su coordinación, se estableció el Instituto de Cultura Hispánica en 1947 (a partir de 1979, Instituto de Cooperación Iberoamericana). Sin embargo, y ciertamente, mal podemos remitirnos a este instituto como precedente propiamente dicho dado que su único objetivo consistía en conservar unos vínculos espirituales con la comunidad de habla hispana, muy diferentes de las finalidades de las Agencias anteriormente mencionadas y la Resolución adoptada por la Asamblea General de las Naciones Unidas en la misma década.

Más correcto es tomar en consideración como referente, y más ajustado a una auténtica concepción de política de cooperación para el

«Série des examens en matière de coopération pour le développement, Espagne», OCDE, $n^{\circ} 3,1994$, p. 8 . 
desarrollo, el año 1976, fecha de la creación del Fondo de Ayuda para el Desarrollo, ${ }^{5}$ que incorpora a nuestro país al grupo de países donantes (paradójicamente, cuando era receptor de ayuda) con el objeto de otorgar créditos ligados a la adquisición de bienes y servicios españoles.

A partir de esta fecha, la política de cooperación española penetra en una espiral de realizaciones que actualizan las exiguas realizaciones llevadas a cabo en este ámbito de la política exterior y la colocan, grosso modo, al nivel de la realizadas por los Estados de nuestro entorno. De este modo, en 1980 España se adhiere al Convenio de Ayuda Alimentaria, un año después a la Reserva Alimentaria Internacional de Emergencia de la FAO y, finalmente, a mediados de los años ochenta, se establecen las primeras instituciones y organismos españoles consagrados para este fin:

- en 1985, se crea la Secretaría de Estado de Cooperación Internacional y para Iberoamérica (SECIPI) con la función de dirigir, programar, controlar y evaluar las actividades en materia de cooperación adscrita al Ministerio de Asuntos Exteriores. ${ }^{6}$

- en 1986, y con la función de «someter a la aprobación del gobierno, a través del Ministerio de Asuntos Exteriores, dentro del primer semestre de cada año natural, y previamente a la presentación en Consejo de Ministros del anteproyecto de Ley de Presupuestos Generales del Estado, la propuesta del Plan Anual de Cooperación Internacional del ejercicio siguiente, así como de los recursos presupuestados necesarios para su buen fin ${ }^{7}$, se establece la Comisión Interministerial de Cooperación Internacional.

Debe ser subrayado claramente que las críticas de los colectivos sociales y la observaciones emitidas por el CAD sobre los créditos FAD no exigen su eliminación, pues ciertamente otros muchos países utilizan este modelo de crédito para operaciones similares, sino sobre su utilización desmesurada que pone en cuestionamiento la realización de una auténtica política de cooperación. Aunque más adelante haré referencia nuevamente a este punto, recordaré que según este mismo Informe del CAD, el aumento del volumen experimentado en Ayuda Oficial para el Desarrollo en nuestro país se debe fundamentalmente al incremento equivalente en los créditos FAD otorgados, retrocediendo las donaciones bilaterales y las contribuciones a los organismos multilaterales.

- En 1996, se procedió a modificar la estructura orgánica del Ministerio de Asuntos Exteriores. Según el art. 10 del Real Decreto 1881/1996, de 2 de agosto, de estructura orgánica básica del Ministerio de Asuntos Exteriores, corresponde a la SECIPI asistir "al Ministerio de Asuntos Exteriores en la formulación y ejecución de la política de Cooperación para el Desarrollo y de las relaciones económicas, culturales y cientificas, coordinando las actividades que en esas áreas tengan atribuidas otros órganos de la Administración General del Estado...».

7 Art.4.1. del Real Decreto 451/1986, de 21 de febrero, por el que se crea la Comisión Interministerial de Cooperación Internacional. 
- Y, finalmente, en 1988 se crea la Agencia Española de Cooperación Internacional como organismo autónomo de la Administración del Estado, adscrito también al Ministerio de Asuntos Exteriores a través de la SECIPI, con la finalidad de poner en marcha y gestionar los proyectos y programas de ayuda internacional al desarrollo ${ }^{8}$.

No obstante, a pesar de esta aparente concentración de actividades en materia de cooperación para el desarrollo en torno al Ministerio de Asuntos Exteriores, este departamento ministerial no ha monopolizado, ni siquiera con la nueva Ley recién debutada, todas las competencias en este ámbito. Más aún, la inexperiencia española en este campo, como consecuencia del retraso ya resaltado, muestra unas incongruencias difícilmente aceptables, tales como que el Ministerio de Trabajo fue el pionero en cooperación internacional, actividad que posteriormente, en 1965, fue asumida igualmente por otros departamentos, como Sanidad, Obras Públicas, Agricultura, Transportes, Turismo y Comunicaciones. Por ende, ni siquiera hoy día, existe un órgano administrativo que centralice toda la cooperación española (distribuyéndose ésta entre un bien nutrido número de departamentos ministeriales, teniendo que contar además, como poco más adelante señalaré, con la denominada «cooperación descentralizada $»^{9}$ ).

Desde un punto de vista normativo, ya ha sido comentada la ausencia de una ley que hubiese regulado el régimen jurídico de la política española de cooperación internacional. No obstante, se ha hecho mención a los decretos leyes que, como se ha podido comprobar, han dado lugar al establecimiento de organismos indispensables para la planificación, coordinación, evaluación y control de la misma. Por consiguiente, y como veremos en el capítulo siguiente, no ha existido ni una sola norma que determinase los contenidos de la política a seguir. Es muy probable, que esta ausencia, motivada por un incumplimiento político expresado en varias ocasiones, pueda explicar las «anomalías», insuficiencias y marcado alejamiento de las líneas generales de las políticas cuencia de la refundición del Instituto de Cooperación Iberoamericana ya citado y el Instituto Hispano-Arabe de Cultura. Posteriormente, por medio del Real Decreto $1141 /$ 1996, de 2 de mayo se remodela sus órganos de gobierno con el fin de agilizar y hacer más operativo su funcionamiento, tal y como consta en las primeras líneas de esta mencionada norma.

9 El art. 18 de la recién estrenada Ley $23 / 1998$ de 7 de julio determina que «los Ministerios que realicen en materias de cooperación internacional para el desarrollo serán responsables de la ejecuciôn de los programas, proyectos y acciones dentro del ámbito de sus competencias». 
aplicadas por los Estados occidentales. Sin embargo, esta importante ausencia, reclamada incluso por el CAD, no ha impedido la elaboración de recomendaciones por parte de las cámaras que constituyen las Cortes Generales. Así, la Moción sobre Cooperación Internacional de España para el Desarrollo aprobada por el Senado en 1984 ya incluía, entre otras recomendaciones, una indispensable unidad de acción exterior, la necesidad de regirse por una ley, la creación de un órgano planificador y coordinador, el principio inspirador sobre el que tiene que sostener toda política de cooperación (la responsabilidad solidaria en todos los ámbitos) y cierto toque de atención a la orientación comercial de las políticas aplicadas a través de los créditos FAD.

Tres años más tarde, en 1987, el Consejo de Ministros acuerda «las líneas directrices de la política de cooperación al desarrollo» en donde se reafirma el punto de fricción que ha dado lugar a las críticas vertidas sobre la naturaleza de nuestra cooperación al exponer en los Principios Rectores que la cooperación «no debilita el crecimiento económico nacional. Los recursos dedicados... no son restados al crecimiento de nuestra economía. Por el contrario, la Cooperación puede y debe contribuir directamente a ese crecimiento y a la creación de empleo ${ }^{10}$, comprometiéndose, al mismo tiempo, a dedicar el 0'7\% del PIB a la ayuda al desarrollo, anticipando que en 1992 la Ayuda Oficial al Desarrollo de nuestro país alcanzaría la mitad de lo que dedican en concepto de ayuda los países del $\mathrm{CAD}^{11}$.

En 1992, el Informe del Congreso de los Diputados arrojó una estela de esperanza al reconsiderar la polémica suscitada por la utilización de los créditos ligados (FAD), pues en dicho Informe, aunque se reconoce y admite nuevamente «...que estos créditos también constituyen indirectamente ayudas a nuestras exportaciones de bienes y servicios» añade asimismo que «no debe tratarse de incluir dentro de la AOD lo que en realidad responde exclusivamente a la lógica comercial» ${ }^{12}$, recordando, a su vez, el incumplimiento del volumen de la ayuda y esta-

10 Principios Rectores, Acuerdo del Consejo de Ministros de 18 de diciembre de 1987, sobre las Líneas Directrices de la Política de Cooperación al Desarrollo.

"Según datos de la OCDE, en 1992 la media de las inversiones de los países miembros del CAD alcanzó el 0'33\% del PNB. España, con sus 1.518 millones de dólares, logró sólo un $0^{\prime} 27 \%$, sólo por delante de Luxemburgo y Nueva Zelanda con $0^{\prime} 26 \%$ respectivamente, Estados Unidos con 0'26\% y en último lugar Irlanda con $0^{\prime} 16 \%$.

12 Informe del Congreso de los Diputados sobre los objetivos y las líneas generales de la política española de cooperación y ayuda al desarrollo, de 30 de junio de 1992, el cual fue elaborado por la Comisión de Asuntos Exteriores del Congreso de los Diputados y cuyo dictamen fue ratificado por unanimidad ante el pleno de la cámara en su sesión de 26 de noviembre. 
bleciendo para el año 2000 el logro del $017 \%$ y para 1995 el $0^{\prime} 35 \%{ }^{13}$.

Por último, en 1994, el Senado emitió una serie de recomendaciones sumamente importantes, tales como el carácter imprescindible de la participación de los órganos competentes del Ministerio de Asuntos Exteriores en el proceso de selección de proyectos susceptibles de la concesión de un crédito FAD, para identificar y asegurar que se tiene en cuenta los criterios propios de la ayuda al desarrollo, así como la modificación y adecuación «...de la legislación que regula los créditos FAD, para adecuarla al nuevo marco institucional desarrollado en los últimos años, a la normativa del CAD y al Consenso OCDE...» ${ }^{14}$.

Una segunda conclusión, pues, a considerar tras toda esta exposición de acontecimientos nos debe conducir a la siguiente proximidad objetiva.

Por un lado, no todas las recomendaciones emitidas por las Cámaras han sido incumplidas. Ha existido, pues, una voluntad política cierta en modernizar, ¿o habría que decir crear desde cero?, toda una infraestructura administrativa, y junto a ella normativa, en materia de política de cooperación, consolidándose, por ende, un marco institucional inexistente tras la recuperación de las libertades, aunque, obviamente, no con la firmeza ni con la demagogia política utilizada frecuentemente, especialmente a la hora de comprometerse con unos logros que no van a cumplirse, que la sociedad civil hubiese querido ${ }^{15}$.

\section{ANÁLISIS DE LAS ADJUDICACIONES REALIZADAS EN MATERIA DE COOPERACIÓN PARA EL DESARROLLO.}

Otro de los importantes logros realizados en estas dos últimas décadas, a pesar de los lustros de retraso repetidamente esgrimidos ya en párrafos anteriores, reside en el volumen neto de las partidas presu-

13 Esta previsión tampoco fue alcanzada, pues frente al $0227 \%$ de media de los países del CAD, España invirtió sólo 0'24\% de su PNB (0'04\% menos que en 1994).

14 Recomendaciones del Senado contenidas en el Informe de la Política Española de Cooperación para el Desarrollo, de 17 de noviembre de 1994.

is Como veremos a continuación, y en opinión de la OCDE, nuestro país ha vinculado su ayuda a la adquisición y servicios del país donante, por lo que puede afirmarse que se ha estimado mucho más relevante la venta de productos nacionales que las necesidades del país receptor. Es loable, pues, el reconocimiento público del portavoz del grupo socialista, Estrella Pedrola, al admitir que, ya durante la etapa socialista, la política de cooperación se proveía de fondos para ayuda a la exportación, aunque «siendo éstos así en su inmensa mayoría..., se llamaban de ayuda al desarrollo", Diario de Sesiones del Congreso de los Diputados, n. ${ }^{\circ} 153,23$ de abril de 1998, pág. 8172. 
puestarias destinadas a política de cooperaciôn. De los 237 millones de dólares corrientes en 1981 a los 1.305 millones de 1994, casi seis veces más de lo presupuestado a comienzos de este período. Sin embargo, este crecimiento no ha sido sostenido hasta 1986, año a partir del cual las cifras van incrementándose paulatinamente en los años sucesivos, remontando la inestabilidad precedente que llegó a alcanzar la ridícula cantidad de 70 millones en 1983.

$\begin{array}{rr}\text { Año } & \text { AOD } \\ 1981 & 237 \\ 1982 & 233 \\ 1983 & 70 \\ 1984 & 144 \\ 1985 & 169 \\ 1986 & 203 \\ 1987 & 232 \\ 1988 & 248 \\ 1989 & 541 \\ 1990 & 965 \\ 1991 & 1.262 \\ 1992 & 1.518 \\ 1993 & 1.304 \\ 1994 & 1.305\end{array}$

Fuente: OCDE.

Sin embargo, el volumen de la ayuda expresada en porcentaje del Producto Nacional Bruto revela otra lectura bien diferente y, sobre todo, si se tiene como punto de referencia la media de las aportaciones de los países del CAD. Primeramente, las partidas presupuestarias españolas han sido, en general, muy reducidas, por lo que el incremento realizado en los últimos años, que ha permitido acercar nuestro porcentaje del PNB a la media de los miembros del CAD, aunque relevante, no obstante, es deslucido por las pequeñas partidas iniciales. En segundo lugar, nuestro país, en todo este período, no ha alcanzado jamás la media de los países del CAD, produciéndose el mayor distanciamiento a partir de 1983, con un 0'04\% frente al 0'34\%, para remontar posteriormente a partir de 1989, pero cuyo acercamiento a la media de los países de la OCDE es más resultado de la disminución o parálisis de las partidas presupuestarias de _éstos (0’32 y 0’33\% durante los años 1989, 1990, 1991 y 1992) que de un incremento moderado y sucesivo de la ayuda española. 


$\begin{array}{lcc}\text { año } & \text { \% del PNB español } & \text { \% del PNB (total CAD) } \\ 1981 & 0^{\prime} 13 & 0^{\prime} 32 \\ 1982 & 0^{\prime} 13 & 0^{\prime} 36 \\ 1983 & 0^{\prime} 04 & 0^{\prime} 34 \\ 1984 & 0^{\prime} 08 & 0^{\prime} 34 \\ 1985 & 0^{\prime} 10 & 0^{\prime} 33 \\ 1986 & 0^{\prime} 09 & 0^{\prime} 34 \\ 1987 & 0^{\prime} 08 & 0^{\prime} 33 \\ 1988 & 0^{\prime} 07 & 0^{\prime} 34 \\ 1989 & 0^{\prime} 14 & 0^{\prime} 32 \\ 1990 & 0^{\prime} 20 & 0^{\prime} 33 \\ 1991 & 0^{\prime} 24 & 0^{\prime} 33 \\ 1992 & 0^{\prime} 27 & 0^{\prime} 33 \\ 1993 & 0^{\prime} 28 & 0^{\prime} 30 \\ 1994 & 0^{\prime} 28 & 0^{\prime} 30\end{array}$

Fuente: OCDE.

Tan importante como el volumen de la ayuda es la calidad de la misma, manifestada en la distribución de partidas bilaterales/multilaterales como por sectores de aplicación.

Las primeras hacen referencia a los compromisos que adopta nuestro país directamente con los países en vías de desarrollo, mientras que las ayudas multilaterales son aquellas que comprenden cuotas y atribuciones a organismos internacionales, ya financieros (como el Banco Mundial o el FMI), o no (como Naciones Unidas, UNICEF, FAO), y las destinadas directamente al presupuesto comunitario, las cuales experimentan un crecimiento considerable durante los años ochenta, pero descienden a partir de comienzos de la década de los noventa. Nuestro país, a diferencia de otros miembros del CAD, ha dado un especial énfasis a las sumas dirigidas tanto al Fondo Europeo al Desarrollo como para el conjunto del presupuesto de la política de la Unión, mientras que la mayoría de los países del CAD han venido repartiendo más proporcionalmente sus recursos entre todos los organismos internacionales. Obviamente, el peso adquirido por la cooperación de tipo multilateral es producto de los compromisos contraídos por la Administración española en aras de la normalización de nuestra presencia en los foros internacionales. Muchos especialistas en cooperación para el desarrollo han venido enfatizando desde hace ya bastante tiempo la necesidad de que nuestra política en esta área incremente sustancialmente sus cuotas en ayuda multilateral con el objeto de imprimir en ella, subrayan, una cooperación de mayor «calidad», dado que ésta subordina los intereses nacionales (propios de las ayudas bilaterales) a los objetivos establecidos por los organismos internacionales, de mayor contenido general. 


\begin{tabular}{|c|c|c|}
\hline Ã̃o & Bilateral & Multilatera \\
\hline 1981 & $86.5 \%$ & $13.5 \%$ \\
\hline 1982 & $70^{\prime} 4 \%$ & $29.6 \%$ \\
\hline 1983 & $78^{\prime} 8 \%$ & $19^{\prime} 7 \%$ \\
\hline 1984 & $75,7 \%$ & $23.6 \%$ \\
\hline 1985 & $76^{\prime} 3 \%$ & $23.6 \%$ \\
\hline 1986 & $29^{\circ} 0 \%$ & $71 ' 4 \%$ \\
\hline 1987 & $49^{\prime} 1 \%$ & $50^{\prime} 8 \%$ \\
\hline 1988 & $63^{\prime} 7 \%$ & $36.9 \%$ \\
\hline 1989 & $48^{\prime} 9 \%$ & $51 \cdot 2 \%$ \\
\hline 1990 & $65 \% \%$ & $34.4 \%$ \\
\hline 1991 & $60^{\prime} 3 \%$ & $39^{\prime} 7 \%$ \\
\hline 1992 & $72^{\prime} 4 \%$ & $27^{\prime} 6 \%$ \\
\hline 1993 & $71^{\prime} 7 \%$ & $29 \cdot 3 \%$ \\
\hline 1994 & $65^{\prime} 4 \%$ & $34^{\prime} 6 \%$ \\
\hline
\end{tabular}

Fuente: OCDE.

Se observará, en función de los datos proporcionados por la OCDE, que sólo en 1986, 1987 y 1989 las partidas destinadas a la ayuda multilateral superan, particularmente en 1986 con un $71^{\prime} 4 \%$ del total de la AOD, a las realizadas directamente por las autoridades españolas. En lo que respecta a su composición, y como ya ha sido señalado, la Comunidad Europea es la que más fondos recibe con un 62'97\% de media durante este período (teniendo en consideración, lógicamente, la fecha de ingreso de nuestro país en dichas instituciones), seguidas por las del Banco Mundial (13'97\%), Bancos de Desarrollo Regional $\left(10^{\prime} 76 \%\right)$ y Agencias de Naciones Unidas ( 8 '95\%). En millones de dólares corrientes, la evolución ha sido la siguiente:

$\begin{array}{lcrccc} & \text { Com.Eu. } & \text { B.M. } & \text { B.D.R. } & \text { N.U. } & \text { Otras } \\ 1986 & 20 & 52 & 36 & 22 & 15 \\ 1987 & 26 & 34 & 23 & 22 & 12 \\ 1988 & 64 & 9 & 5 & 12 & 2 \\ 1989 & 110 & 107 & 29 & 26 & 4 \\ 1990 & 230 & - & 69 & 28 & 5 \\ 1991 & 318 & 116 & 28 & 28 & 11 \\ 1992 & 343 & 20 & 16 & 35 & 5 \\ 1993 & 281 & 16 & 42 & 22 & 6 \\ 1994 & 334 & 23 & 32 & 37 & 25\end{array}$

Fuente: OCDE.

La ayuda bilateral española ha estado protagonizada por los créditos FAD, los cuales son otorgados por el gobierno español, que libremente elige tanto a los países destinatarios como los programas y criterios para su utilización. Estos tipos de créditos adoptan la forma de ayuda financiera reembolsable, aunque concesional, es decir, ajustada a condiciones financieras más blandas que las que caracterizan las operaciones comerciales ordinarias, pero a su vez ligadas a la adquisición de bienes y servicios españoles, razón por la que los créditos FAD han venido convirtiéndose en un importante instrumento de potenciación de 
la política comercial de nuestro país, no en vano, estos créditos son gestionados directamente por la Dirección General de Política Comercial, adscrita al Ministerio de Comercio y Turismo, y cuyo titular es el Secretario de Estado de dicho Ministerio.

Obviamente, la ayuda bilateral de nuestro país no se agota en esta única vía, pues junto a los créditos $\mathrm{FAD}$, son utilizados otros instrumentos, más acordes con las recomendaciones del CAD, tales como la ayuda alimentaria, la ayuda de emergencia, las subvenciones otorgadas a las ONGD, la asistencia técnica, todas las cuales pueden ser incluidas en un único paquete bajo la rúbrica Ayuda bilateral no reembolsable.

La importancia de estos créditos en el seno de la ayuda bilateral española puede ser constatada de dos modos diferentes.

Por un lado, en función de la importancia de los distintos departamentos ministeriales en relación al reparto de la Ayuda Oficial al Desarrollo. Por ejemplo, en 1995, y según los Planes Anuales de Cooperación Internacional (PACI), el Ministerio de Comercio y Turismo gestionaba nada menos que un $45 \%$ de la ayuda al desarrollo que junto al cercano $30 \%$ gestionado por el Ministerio de Economía y Hacienda constituyen, la suma de ambos, un elevadísimo $75 \%$ del total de la ayuda, cantidades ambas que contrastan nítidamente con el $15 \%$ gestionado por el Ministerio de Asuntos Exteriores.

Por otro, en función de los volúmenes de los porcentajes consagrados a los préstamos FAD frente a las otras ayudas no reembolsables. Como puede observarse en los siguientes datos suministrados por la OCDE, tras un primer estadio de inestabilidad (1981/1987), a partir de 1988 los créditos FAD se convierten, no sólo en el programa pionero, dado que, como hemos acabado de ver, son creados en 1976, sino en el programa estrella de todos los llevados a cabo posteriormente en relación a su volumen, alcanzando su cenit a lo largo de los noventa cuyos porcentajes duplican con creces los dedicados a las ayudas no reembolsables.

Pero la importancia de este tipo de créditos no sólo reside en su volumen, sino también, y probablemente más significativo aún, en las operaciones realizadas con ellos, no sólo en cuanto a su discutida selección de países, no sólo en cuanto a los sectores que promociona, sino, y lo que es peor aún, a la vulneración más incuestionable de toda política de cooperación para el desarrollo: la venta de material militar.

Respecto al primero de los puntos, que constituye de hecho una singularidad más de la política de cooperación realizada, los países beneficiados por estos créditos, durante el período 1977/1995 y según datos del Instituto de Crédito Oficial, han sido: China, México, Marrue- 


\begin{tabular}{|c|c|c|}
\hline Añ 0 & \% no reembolsable & \% préstamos FAD \\
\hline 1981 & $35,1 \%$ & $51 ' 4 \%$ \\
\hline 1982 & $270 \%$ & $43^{\prime} 4 \%$ \\
\hline 1983 & $57^{\prime} 7 \%$ & $21 \%$ \\
\hline 1984 & $39 \cdot 5 \%$ & $36 \cdot 1 \%$ \\
\hline 1985 & $31 \% 3 \%$ & $44.9 \%$ \\
\hline 1986 & $25 \%$ & $3,4 \%$ \\
\hline 1987 & $36.6 \%$ & $12,0 \%$ \\
\hline 1988 & $31^{\prime} 0 \%$ & $32,6 \%$ \\
\hline 1989 & $22,5 \%$ & $26,4 \%$ \\
\hline 1990 & $23,5 \%$ & $42 \times 1 \%$ \\
\hline 1991 & $19 \cdot 2 \%$ & $410 \%$ \\
\hline 1992 & $16 \%$ & $55,9 \%$ \\
\hline 1993 & $14: 5 \%$ & $57 \cdot 2 \%$ \\
\hline 1994 & $19^{\prime} 6 \%$ & $45,8 \%$ \\
\hline
\end{tabular}

Fuente: OCDE.

cos, Argentina, Ecuador y Argelia, que suman el 51'40\% de las concesiones procedentes de los créditos FAD, el resto es repartido entre más de 30 países. La concentración de los créditos en estos seis países responde, según el informe del $\mathrm{CAD}^{16}$, a variables como solvencia económica o viabilidad financiera, aplicadas, paradójicamente, a países con ingresos medio/altos, no viéndose beneficiados los Estados realmente necesitados ${ }^{17}$ de esta modalidad de créditos.

En segundo lugar, y según las Líneas Directrices establecidas en 1987 por el Consejo de Ministros, los sectores prioritarios a favorecer con estos capitales deberían ser: la agricultura, la sanidad, la formación profesional, el reforzamiento de las instituciones, entre otros. Pues bien, en la práctica la distribución ha sido bien distinta. Frente al 17'6\% que los miembros del CAD destinaron a comienzos de los años noventa a infraestructura económica (transporte, comunicaciones, energía, etc.), nuestro país, por medio de los créditos $\mathrm{FAD}$, consagró nada menos que un $48^{\circ} 0 \%$. Las siguientes cifras, tomadas de otros sectores relevantes, destacan, nuevamente, la naturaleza de la instrumentalización económica y comercial de los FAD españoles:

$\begin{array}{lll} & \text { España } & \text { CAD } \\ \text { Servicio educativo } & 4^{\prime} 9 \% & 9^{\prime} 2 \% \\ \text { Agricultura } & 0^{\prime} 9 \% & 7^{\prime} 1 \% \\ \text { Industria, minería... } & 14^{\prime}, 8 \% & 3^{\prime} 3 \% \\ \text { Manufacturas } & 10^{\prime} 7 \% & 1^{\prime} 9 \% \\ \text { Ayuda alimentaria } & 0^{\prime}, 9 \% & 3^{\prime} 2 \% \\ \text { Ayuda de emergencia } & 0^{\prime} 5 \% & 3,3 \% \\ \text { Reorganización deuda } & - & 18^{\prime} 1 \%\end{array}$

Fuente: OCDE.

16 Primer examen elaborado por el CAD sobre la ayuda española y su política de cooperación para el desarrollo, 29 de abril de 1994.

17 Entre los seleccionados, no se encuentra ni uno sólo de los considerados por las Nacio- 
No es de sorprender, pues, que el informe del CAD terminara sugiriendo la necesidad de una modificación de los textos que regulan el FAD, ya que desde su creación éste no ha sido concebido como un instrumento de ayuda, siendo indispensable, por consiguiente, «trazar nítidamente la frontera entre la ayuda y los intereses comerciales». Estimo oportuno recoger en estas páginas la posición de la patronal CEOE, en opinión de la cual hay que «concebir la AOD cubriendo el doble objetivo, tanto de ayuda a los pueblos menos favorecidos como de atender a las necesidades de la sociedad española... En este sentido, se considera que no debe existir una incompatibilidad entre la AOD y la creación de empleo y la proyección exterior de nuestra capacidad económica e industrial a nivel internacional $\gg^{18}$. Es obvio que el problema de nuestra política de cooperación para el desarrollo no versa únicamente sobre una cuestión de volumen, sino también de significado y naturaleza.

Y a propósito de significado y naturaleza, la vulneración más flagrante de la misma, independientemente de que pueda o no existir incompatibilidad entre ambas finalidades (lo que sí existe en materia de cooperación para el desarrollo son prioridades), la encontramos, desgraciadamente, en una operación comercial no ya «meramente» incompatible, sino en las antípodas, inexistente, en toda política que se tercie para el desarrollo: la venta de material militar. La ausencia de información detallada sobre lo que ha venido siendo nuestra política de cooperación (exigida por el Congreso de los Diputados y el Senado en los documentos ya mencionados, criticada por el informe del CAD, reconocida por el Tribunal de Cuentas, y admitida, incluso, en la nueva Ley de $1998^{19}$ ) impide un conocimiento exhaustivo de los destinos de ciertas partidas presupuestarias, pero a pesar de las negaciones sucesivas de los responsables gubernamentales, por vez primera, en el Boletín del Senado núm. 196, pág. 55 de 1994 se reconoce la utilización de 42.893 millones, saltando desde entonces por los aires todas las sospechas existentes, las cuales pueden ser resumidas de la manera siguiente: la utilización de estos créditos para financiar exportaciones ligadas a

nes Unidas como país menos desarrollado (PMA). Lógicamente, las autoridades españolas han venido justificándose argumentando que las ayudas económicas hacia estos países ya se canalizan a través de la ayuda multilateral.

18 La Cooperación al Desarrollo. Informe 1995. Fundación de Cooperación para el Desarrollo en infraestructuras, medio ambiente, equipamientos y servicios. Madrid, 1996. págs. 311 y 312 .

19 «Al mismo tiempo, la Ley de Cooperación no puede eludir los problemas que presenta el marco actual: rigidez excesiva en los procedimientos administrativos, necesidad de una mayor transparencia...». Apartado II, Estado actual de la cooperación, Ley 23/ 1998, de 7 de julio. 
la defensa y al armamento han constituido una práctica habitual.

Un balance desapasionado de la ayuda española al desarrollo no puede prescindir, pues, de unas críticas argumentadas y justificadas que clarifican el prisma por el que se aborda el conocimiento. No puede eludirse que, junto al necesario reconocimiento de los esfuerzos realizados que han aproximado notablemente nuestra ayuda a la cooperación al modelo de los países miembros del CAD, han existido no sólo insuficiencias e instrumentalización comercial, tampoco por ello debe caerse en la ingenuidad de estigmatizar el caso español, sino también vulneración de los principios más elementales que inspiran a cualesquiera de las políticas a aplicar. Y, por supuesto, tampoco debemos escudar nuestros errores en el retraso y en la inexperiencia.

\section{LA LEY DE 1998, UN HITO EN LA HISTORIA DE LA POLÍ- TICA ESPAÑOLA PARA LA COOPERACIÓN AL DESA- RROLLO.}

\subsection{Una ligera endoscopia de los aspectos más relevantes intro- ducidos por la nueva Ley.}

Felizmente, una de las promesas políticas incumplidas ha llegado a buen puerto tras superar ciertos avatares que alarmaron a la oposición parlamentaria y a la Plataforma 0'7 en la cámara del Senado. Tras su devolución al Congreso de los Diputados, la satisfacción del resultado final es un rasgo que, en gran medida, caracteriza este nuevo estadio en el que penetra la cooperación española.

En mi opinión, el enunciado más importante y esperanzador para la evolución futura de nuestra cooperación al desarrollo, tras los argumentos expuestos en páginas precedentes, se recoge en el artículo 1 de la sección $1 .^{\mathrm{a}}$ del capítulo I, según el cual: «para que dichos recursos tengan la consideración de Ayuda Oficial al Desarrollo (AOD), deberán cumplir los requisitos marcados por el Comité de Ayuda al Desarrollo de la OCDE (CAD)» ${ }^{20}$.

Es decir, la ayuda debe regirse por principios éticos, por lo que deben ser las demandas de los beneficiarios, y no los intereses o conveniencias de los donantes, las que deben inspirar la ayuda. Esto no supone, como en principio puede parecer, un «jaque-mate» a los créditos bilaterales reembolsables de la ayuda ligada (créditos FAD), pero sí,

20 Es relevante subrayar que este enunciado no aparecía en el inicial proyecto de ley gubernamental. 
puede y debe ser interpretado, y ahora con peso jurídico, un control más exhaustivo sobre su utilización, tanto sobre el volumen como sobre su destino y significado.

Es importante subrayar igualmente de este mismo artículo la incorporación (también inexistente en el proyecto gubernamental) de objetivos más precisos que deben delimitar toda acción en política de cooperación internacional para el desarrollo, ejecutándose éstos con el fin de:

1. facilitar e impulsar el progreso económico y social de los países en vías de desarrollo,

2. contribuir a la erradicación de la pobreza en el mundo en todas sus manifestaciones,

3. defender y proteger los derechos humanos y las libertades fundamentales, las necesidades de bienestar económico y social y su inserción en la economía internacional,

4. contribuir a la consolidación plena de sus instituciones democráticas y regeneración del medio ambiente.

En segundo lugar, y en relación con los objetivos establecidos, la política española de cooperación para el desarrollo debe inspirarse en los siguientes principios:

1. el reconocimiento del ser humano en su dimensión individual y colectiva,

2. la defensa y promoción de los derechos humanos y la libertades fundamentales, la paz, la democracia y la participación ciudadana, incluyendo además como novedad: «en condiciones de igualdad para mujeres y hombres y, en general, la no discriminación por razón de sexo, raza, cultura o religión, y el respeto a la diversidad».

3. Asimismo ha sido incorporado otro enunciado relevante, indispensable como principio inspirador de este modelo de políticas: «la promoción de un crecimiento duradero y sostenible de los países acompañada de medidas que promuevan una redistribución equitativa de la riqueza para favorecer la mejora de las condiciones de vida y el acceso a los servicios sanitarios, educativos y culturales, así como el bienestar de la poblaciones».

El tercer aspecto relevante a tener en cuenta de esta nueva ley reside en el papel a desempeñar por la denominada cooperación descentralizada, que ciertamente ha venido ya desarrollando en los últimos años, o sea, la llevada por las ONGD, Comunidades Autónomas y Corporaciones Locales.

Quedan recogidos en la Ley tanto el compromiso por parte del Esta- 
do para el fomento de las actividades llevadas a cabo por las ONGD como los requisitos que éstas deben cumplir para acceder a las ayudas y subvenciones, inscripción en el registro y el régimen fiscal que les atañe. Es interesante tener en consideración la supresión del proyecto de ley de la expresión «entidades de reconocido prestigio» a la hora de determinar los criterios que las definen. Como ya señalé en la comunicación presentada en el Congreso de Málaga, para el grupo parlamentario popular, la eliminación de esta expresión dejaría fuera a todas aquellas fundaciones, organizaciones, asociaciones e instituciones que han trabajado por la solidaridad. Pero a mi modo de ver esta expresión supone, por el contrario, no tomar en serio la labor de muchas ONGD de recién constitución que igualmente desempeñan sus labores en este ámbito. Ni qué decir tiene que han sido las organizaciones de naturaleza religiosa las que han venido monopolizando y protagonizando sin interrupción la ayuda a la solidaridad, por lo que la supresión de esta expresión no sólo no excluye, sino que incluye a todas las ONGD, religiosas, aconfesionales y las vinculadas a partidos políticos y sindicatos.

\subsection{Un breve balance de la política de cooperación de los últi- mos años.}

En los últimos años hemos sido testigos de notables cambios producidos tanto en el volumen como en la calidad de nuestra Ayuda Oficial al Desarrollo.

En 1998, el presupuesto destinado para este fin, en miles de millones de pesetas, ha logrado alcanzar un nuevo techo presupuestario, 214.256, de los cuales 131.882 son destinados a la ayuda bilateral y los 82.374 restantes a la ayuda multilateral (61' $55 \%$ y $38^{\prime} 45 \%$ de la AOD respectivamente). Queda por ver si las previsiones finales se cumplen este año y se logra mantener el extraordinario resultado de 1997, superando por primera vez la media ponderada de los países de la OCDE (0'23 frente al 0'22).

$\begin{array}{llc}\text { Año } & \text { España } & \text { Media de países OCDE } \\ 1993 & 0^{\prime} 28 \% & 0^{\prime} 30 \% \\ 1994 & 0^{\prime} 28 \% & 0^{\prime} 30 \% \\ 1995 & 0^{\prime} 24 \% & 0^{\prime} 27 \% \\ 1996 & 0^{\prime} 22 & 0^{\prime} 25 \\ 1997 & 0^{\prime} 23 & 0^{\prime} 22 \\ 1998 & 0^{\prime} 26 \text { (prev.) } & -\end{array}$

Fuente: PACIS Previsiones y Seguimientos y CAD-OCDE. En porcentajes del PNB.

Respecto al tipo de ayuda bilateral, las modificaciones han reconducido substancialmente el modelo de nuestra cooperación, procediéndose en 1995 a una caída notable de las ayudas de tipos re- 
embolsables, pero no en beneficio directo a las ayudas no reembolsables, las cuales han seguido creciendo en cuanto a volumen neto ciertamente, sino más bien de las inversiones adjudicadas a la ayuda multilateral, pasando éstas de 45.999 miles de millones de pesetas en 1996 a 68.714 en 1997 y 82.374 este año $\left(28^{\prime} 73,38^{\prime} 02\right.$ y $38^{\prime} 45 \%$ de la AOD respectivamente).

$\begin{array}{lcccc}\text { A ño } & \text { Reembolsable } & \% & \text { No reembolsable } & \% \\ 1993 & 94.926 & 57^{\prime} 24 & 24.003 & 14^{\prime} 47 \\ 1994 & 80.021 & 45^{\prime}, 56 & 35.169 & 20^{\prime} 02 \\ 1995 & 35.292 & 20^{\prime} 99 & 66.255 & 39^{\prime} 41 \\ 1996 & 41.184 & 25^{\prime}, 72 & 72.924 & 45^{\prime} 55 \\ 1997 & 33.022 & 18^{\prime} 27 & 79.004 & 43^{\prime} 71 \\ 1998 & 40.651 & 18^{\prime}, 97 & 91.231 & 42^{\prime} 58\end{array}$

Fuente: PACIS Previsiones y Seguimientos y CAD-OCDE.

Por distribución geográfica, las áreas beneficiadas por la ayuda española no han sido alteradas considerablemente. Desde los años noventa, América Latina ha sido la principal receptora de nuestra ayuda, con el $37 \%$ de los presupuestos de este año sigue manteniéndose en cabeza, seguida por Africa Subsahariana con el $25 \%$, norte de Africa $10 \%$ y Oriente Próximo un $4 \%$.

Este panorama que ha implicado una nueva distribución de los escasos recursos a disposición de la ayuda al desarrollo junto con la aprobación de la ley para la cooperación internacional española dibujan un horizonte más halagüeño en el desarrollo y evolución futuros de nuestra cooperación. Asimismo, el papel importante que están desempeñando las numerosas ONGD, el aumento de la concienciación y sensibilidad ciudadana han impulsado el incremento de las ayudas y subvenciones que éstas perciben de la Administración Central del Estado ${ }^{21}$. Como es común anhelar en todo Estado de Derecho, sólo nos queda aguardar ahora que la Ley se cumpla.

\section{CONCLUSIONES.}

La política española para la cooperación al desarrollo ha adolecido, ciertamente, de graves insuficiencias y recursos, los cuales, en cierto modo, han ensombrecido los incuestionables esfuerzos realizados a lo largo de estas dos décadas. Como acontece con nuestro Estado de Bienestar, las críticas, aunque reconociendo simultáneamente los logros alcanzados igualmente en esta materia, se centran en el modelo 
ortopédico de nuestro poco desarrollado sistema público de servicios sociales, las exiguas medidas de política social o la insufrible seguridad social, amparadas todas ellas en el abandono de nuestro país durante los grises años del interminable régimen franquista.

La impecable acción política por modernizar nuestro país y europeizar nuestros hábitos, cuya manifestación más sobrecogedora en el campo de la cooperación la encontramos en la proliferación de organizaciones decididas a participar activamente en este ámbito, ha originado un revival del boom asociativo tras la recuperación de las libertades. Afanosamente, acciones como las llevadas a cabo por la Plataforma 0'7 nos han conducido a tomar conciencia de la sensibilización que despierta en nuestra sociedad civil la miseria y las injusticias que padecen ingentes ejércitos de miserables de los denominados Tercer y Cuarto mundo. La generosidad de la sociedad española, expresada en las encuestas publicadas manifestando abiertamente su apoyo y solidaridad hacia los pueblos de la tierra más desfavorecidos, exige el diseño de una política más coherente con los principios inspiradores que configura toda cooperación para el desarrollo. Los contextos económicos, en gran medida, con sus retraimientos poco favorecedores a políticas más expansionistas y ambiciosas, permiten justamente, por su parte, tener siempre en consideración, que en momentos económicos poco propicios a elevadas inversiones públicas, se ha edificado sobre nuestro país un ámbito político prácticamente desconocido por el caduco régimen anterior, así como un insuficiente Estado Social que goza aún de gran apoyo por una amplia mayoría de nuestra ciudadanía. Es interesante destacar como Estado de bienestar y política de cooperación para el desarrollo caminan paralelamente unidos gracias a un sólido pivote sobre el que se sostiene toda la razón de ser de la convivencia en estos modelos de organización política: la ciudadanía social. No en vano, y tampoco es de extrañar, que el welfare escandinavo, convertido en modelo paradigmático por los científicos sociales, lo sea a su vez en política de cooperación para el desarrollo. El arraigado concepto de la ciudadanía en esos lares ha promovido una participación activa en todos los campos y materias, junto con una acción decidida y comprometida por sus respectivas autoridades políticas consolidadas sobre un elemento de cultura política envidiable: el consenso. Noruega, Dinamarca, Suecia están a la cabe$\mathrm{za}$, a pesar de las vicisitudes económicas, de los modelos de gran cohesión social y apoyo político y ciudadano hacia las medidas de cooperación con los países en vías de desarrollo.

La aprobación por las Cortes Generales de una ley de estas características obedece, pues y para concluir, a una deuda pendiente del poder político con todos aquellos, miles de hombres y mujeres, que entregan gratuitamente parte de su tiempo y su ilusión, algunos desgraciada- 
mente incluso sus vidas, al servicio de los más desfavorecidos en aras de la justicia social.

\section{BIBLIOGRAFÍA}

Efforts et Politiques des Membres du Comité d'Aide au Développement, Coopération pour le Développement, OCDE-CAD, Rapport 1997, París, 1998.

Manual de la Ayuda al Desarrollo. Principios del CAD para una ayuda eficaz. Coedición Organización de Cooperación y Desarrollos Económicos, Ediciones Mundi-Prensa, París, 1995.

MARTÍNEZ TABLAS, A. (coord): Visión global de la cooperación para el desarrollo. Centro de Investigación para la paz, Icaria Editorial, Madrid, 1995.

Nuevas perspectivas en la política de cooperación al desarrollo en la Unión Europea, Agencia Española de Cooperación Internacional, Madrid, 1996.

PÉREZ SOBA, I.: La juventud española y la cooperación para el desarrollo. varias entidades colaboradoras, Madrid, 1996.

VV.AA.: La cooperación internacional para el desarrollo: ámbito y configuración. CIDEAL, Madrid, 1994.

VV.AA.: Nuevas tendencias en la cooperación internacional. CIDEAL, Madrid, 1994.

The Reality of Aid, An Independet Review of Poverty Reduction and Development Assistance 1989/1999, Earthscan, London, 1998. 


\section{O C C U M E}





\section{Disposiciones generales}

\section{JEFATURA DEL ESTADO}

LEY ORGÁNICA 5/2000, de 12 de enero, reguladora de la responsabilidad penal de los menores.

\section{JUAN CARLOS I}

REY DE ESPANNA

A todos los que la presente vieren y entendieren Sabed: Que las Cortes Generales han aprobado y Yo vengo en sancionar la siguiente Ley Orgánica.

\section{EXPOSICIÓN DE MOTIVOS}

1. La promulgación de la presente Ley Orgánica reguladora de la responsabilidad penal de los menores era una necesidad impuesta por to establecido en la Ley Orgánica 4/1992, de 5 de junio, sobre reforma de la Ley reguladora de la competencia y el procedimiento de los Juzgados de Menores; en la moción aprobada por el Congreso de los Diputados el 10 de mayo de 1994, y en el artículo 19 de la vigente Ley Orgánica 10/1995, de 23 de noviembre, del Código Penal.

2. La Ley Orgánica 4/1992, promulgada como consecuencia de la sentencia del Tribunal Constitucional 36/1991, de 14 de febrero, que declaró inconstitucional el articulo 15 de la Ley de Tribunales Tutelares de Menores, texto refundido de 11 de junio de 1948 , establece un marco flexible para que los Juzgados de Menores puedan determinar las medidas aplicables a éstos en cuanto infractores penales, sobre la base de valorar especialmente el interés del menor, entendiendo por menores a tales efectos a las personas comprendidas entre los doce y los dieciséis años. Simultáneamente. encomienda al Ministerio Fiscal la iniciativa procesal, y le concede amplias facultades para acordar la terminación del proceso con la intención de evitar, dentro de lo posible, los efectos aflictivos que el mismo pudiera llegar a producir. Asimismo, configura al equipo técnico como instrumento imprescindible para alcanzar el obje tivo que persiguen las medidas y termina estableciendo un procedimiento de naturaleza sancionadora-educativa, al que otorga todas las garantias derivadas de nuestro ordenamiento constitucional, en sintonia con lo establecido en la aludida sentencia del Tribunal Constitucional y lo dispuesto en el articulo 40 de la Convención de los Derechos del Niño de 20 de noviembre de 1989.

Dado que la expresada Ley Orgánica se reconocia a si misma expresamente uel carácter de una reforma urgente, que adelanta parte de una renovada legislación sobre reforma de menores, que será objeto de medidas legislativas posteriores", es evidente la oportunidad de la presente Ley Orgánica, que constituye esa necesaria reforma legislativa, partiendo de los principios básicos que ya guiaron la redacción de aquélla (especialmente, el principio del superior interés del menor), de las garantías de nuestro ordenamiento constitucional, y de las normas de Derecho internacional, con particular atención a la citada Convención de los Derechos del Niño de 20 de noviembre de 1989. y esperando responder de este modo a las expectativas creadas en la sociedad española, por razones en parte coyunturales y en parte permanentes, sobre este tema concreto.

3. Los principios expuestos en la moción aprobada unánimemente por el Congreso de los Diputados el dia 10 de mayo de 1994, sobre medidas para mejorar el marco juridico vigente de protección del menor, se refieren esencialmente al establecimiento de la mayoría de edad penal en los dieciocho años y a la promulgación de uuna ley penal del menor y juvenil que contemple la exigencia de responsabilidad para los jóvenes infractores que no hayan alcanzado la mayoria de edad penal, fundamentada en principios orientados hacia la reeducación de los menores de edad infractores, en base a las circunstancias personales, familiares y sociales. y que tenga especialmente en cuenta las competencias de las Comunidades Autónomas en esta materia.....

4. El artículo 19 del vigente Código Penal, aprobado por la Ley Orgánica 10/1995, de 23 de noviembre, fija efectivamente la mayoria de edad penal en los dieciocho años y exige la regulación expresa de la responsabilidad penal de los menores de dicha edad en una Ley independiente. También para responder a esta exigencia se aprueba la presente Ley Orgánica, si bien lo dispuesto en este punto en el Código Penal debe ser complementado en un doble sentido. En primer lugar, asentando firmemente el principio de que la responsabilidad penal de los menores presenta frente a la de los adultos un carácter primordial de intervención educativa que trasciende a todos los aspectos de su regulación juridica y que determina considerables diferencias entre el sentido y el procedimiento de las sanciones en uno y otro sector, sin perjuicio de las garantias comunes a todo justiciable. En segundo término, la edad límite de die ciocho años establecida por el Código Penal para referirse a la responsabilidad penal de los menores precisa de otro limite minimo a partir del cual comience la posibilidad de exigir esa responsabilidad y que se ha concretado en los catorce años, con base en la convicción de que las infracciones cometidas por los niños menores de esta edad son en general irrelevantes y que, en los escasos supuestos en que aquéllas pueden producir alarma social, son suficientes para darles una respuesta igualmente adecuada los ámbitos familiar y asistencial civil, sin necesidad de la intervención del aparato judicial sancionador del Estado.

5. Asimismo, han sido criterios orientadores de la redacción de la presente Ley Orgánica, como no podía ser de otra manera, los contenidos en la doctrina del Tribunal Constitucional, singularmente en los fundamen- 
tos jurídicos de las sentencias $36 / 1991$, de 14 de febrero, y $60 / 1995$, de 17 de marzo, sobre las garantias $y$ el respeto a los derechos fundamentales que necesariamente han de imperar en el procedimiento seguido ante los Juzgados de Menores, sin perjuicio de las modulaciones que, respecto del procedimiento ordinario, permiten' tener en cuenta la naturaleza y finalidad de aquel tipo de proceso, encaminado a la adopción de unas medidas que, como ya se ha dicho, fundamentalmente no pueden ser represivas, sino preventivo-especiales, orientadas hacia la efectiva reinserción y el superior interés del menor, valorados con criterios que han de buscarse primordialmente $\in n$ el ámbito de las ciencias no juridicas.

II

6. Como consecuencia de los principios, criterios $\gamma$ orientaciones a que se acaba de hacer referencia, puede cecirse que la redacción de la presente Ley Orgánica ha sido conscientemente guiada por los siguientes principios generales: naturaleza formalmente penal pero materialmente sancionadora-educativa del procedimiento $y$ de las medidas aplicables a los infractores menores de edad, reconocimiento expreso de todas las garantías que se derivan del respeto de los derechos constitucionales y de las especiales exigencias del interés del menor diferenciación de diversos tramos a efectos procesales y sancionadores en la categoria de infractores menores de edad, flexibilidad en la adopción y ejecución de las medidas aconsejadas por las circunstancias del caso concreto, competencia de las entidades autonómicas relacionadas con la reforma y protección de menores para la ejecución de las medidas impuestas en la sentencia y control judicial de esta ejecución.

7. La presente Ley Orgánica tiene ciertamente la naturaleza de disposición sancionadora, pues desarrolla la exigencia de una verdadera responsabilidad juridica a los menores infractores, aunque referida especificamente a la comisión de hechos tipificados como delitos o faltas por el Código Penal y las restantes leves penales especiales. Al pretender ser la reacción juridica dirigida al menor infractor una intervención de naturaleza educativa, aunque desde luego de especial intensidad, rechazando expresamente otras finalidades esenciales del Derecho penal de adultos, como la proporcionalidad entre el hecho y la sanción o la intimidación de los destinatarios de la norma, se pretende impedir todo aquello que pudiera tener un efecto contraproducente para el menor, como el ejercicio de la acción por la víctima o por otros particulares.

Y es que en el Derecho penal de menores ha de primar, como elemento determinante del procedimiento y de las medidas que se adopten, el superior interés del menor. Interés que ha de ser valorado con criterios técnicos y no formalistas por equipos de profesionales especializados en el ámbito de las ciencias no juridicas, sin perjuicio desde luego de adecuar la aplicación de las medidas a principios garantistas generales tan indiscutibles como el principio acusatorio, el principio de defensa o el principio de presunción de inocencia.

8. Sin embargo, la Ley tampoco puede olvidar el interés propio del perjudicado o víctima del hecho cometido por el menor, estableciendo un procedimiento singular, rápido y poco formalista para el resarcimiento, en su caso, de daños y perjuicios, dotando de amplias facultades al Juez de Menores para la incorporación a los autos de documentos y testimonios relevantes de la causa principal. En este ámbito de atención a los intereses y necesidades de las víctimas, la Ley introduce el principio en cierto modo revolucionario de la responsabilidad solidaria con el menor responsable de los hechos de sus padres, tutores, acogedores o guarda dores, si bien permitiendo la moderación judicial de la misma y recordando expresamente la aplicabilidad en su caso de la Ley $30 / 1992$, de 26 de noviembre, de Régimen Juridico de las Administraciones Públicas y del Procedimiento Administrativo Común, asi como de la Ley $35 / 1995$, de 11 de diciembre, de ayudas $y$ asistencia a las victimas de delitos violentos y contra la libertad sexual.

Asimismo la Ley regula, para procedimientos por deljtos graves cometidos por mayores de dieciséis años, un régimen de intervención del perjudicado en orden a salvaguardar el interés de la victima en el esclarecimiento de los hechos y su enjuiciamiento por el orden jurisdiccional competente, sin contaminar el procedimiento propiamente educativo $\gamma$ sancionador del menor

Esta Ley arbitra un amplio derecho de participación a las victimas ofreciéndoles la oportunidad de intervenir en las actuaciones procesales proponiendo y practicando prueba, formulando conclusiones e interponiendo recurSos. Sin embargo, esta participación se establece de un modo limitado ya que respecto de los menores no cabe reconocer a los particulares el derecho a constituirse propiamente en parte acusadora con plenitud de derechos y cargas procesales. No existe aqui ni la accion particular de los perjudicados por el hecho criminal, ni la acción popular de los ciudadanos, porcue en estos casos el interés prioritario para la sociedad y para el Estado coincide con el interés del menor.

9. Conforme a las orientaciones declaradas por el Tribunal Constitucional, anteriormente aludidas, se ins taura un sistema de garantías adecuado a la pretensión procesal, aseguranda que la imposición de la sanción se efectuará tras vencer la presunción de inocencia, pero sin obstaculizar los criterios educativos y de valoración del interés del menor que presiden este proceso, haciendo al mismo tiempo un uso flexible del principio de intervención minima, en el sentido de dotar de relevancia a las posibilidades de no apertura del procedimiento o renuncia al mismo, al resarcimiento anticipado o conciliación entre el infractor y la victima, y a los supuestos de suspensión condicional de la medida impuesta o de sustitución de la misma durante su ejecución.

La competencia corresponde a un Juez ordinario, que, can categoria de Magistrado y preferentemente especialista, garantiza la tutela judicial efectiva de los derechos en conflicto. La posición del Ministerio Fiscal es relevante, en su doble condición de institución que constitucionalmente tiene encomendada la función de promover la acción de la Justicia y la defensa de la legalidad. asi como de los derechos de los menores, velando por el interés de éstos. El letrado del menor tiene participación en todas y cada una de las fases del proceso. conociendo en todo momento el contenido del expediente, pudiendo proponer pruebas $\mathrm{e}$ interviniendo en todos los actos que se refieren a la valoración del interés del menor y a la ejecución de la medida, de la que puede solicitar la modificación.

La adopción de medidas cautelares sigue el modelo de solicitud de parte, en audiencia contradictoria, en la que debe valorarse especialmente, una vez más, el superior interés del menor.

En defensa de la unidad de doctrina, el sistema de recursos ordinario se confia a las Salas de Menores de los Tribunales Superiores de Justicia, que habrán de crearse, las cuales, con la inclusión de Magistrados especialistas, aseguran y refuerzan la efectividad de la tutela judicial en relación con las finalidades que se propone la Ley. En el mismo sentido, procede destacar la instauración del recurso de casación para unificación de doctrina, reservado a los casos de mayor gravedad, en paralelismo con el proceso penal de adultos, reforzando la garantia de la unidad de doctrina en el ámbito del 
derecho sancionador de menores a través de la jurisprudencia del Tribunal Supremo.

10. Conforme a los principios señalados, se establece, inequivocamente, el limite de los catorce años de edad para exigir este tipo de responsabilidad sancionadora a los menores de edad penal y se diferencian, en el ámbito de aplicación de la Ley y de la graduación de las consecuencias por los heches cometidos, dos tramos, de catorce a dieciséis y de diecisiete a dieciocho años, por presentar uno y otro grupo diferencias caracteristicas que requieren, desde un punto de vista cientifico y jurídico, un tratamiento diferenciado, constituyendo una agravación específica en el tramo de los mayores de dieciséis años la comisión de delitos que se caracterizan por la violencia, intimidación o peligro para las personas.

La aplicación de la presente Ley a los mayores de dieciocho años y menores de veintiuno, prevista en el articulo 69 del Código Penal vigente, podrá ser acordada por el Juez atendiendo a las circunstancias personales $y$ al grado de madurez del autor, y a la naturaleza y gravedad de los hechos. Estas personas reciben, a los efectos de esta Ley, la denominación genérica de ujóvenes".

Se regulan expresamente, como situaciones que requieren una respuesta especifica, los supuestos en los que el menor presente sintomas de enajenación mental o la concurrencia de otras circunstancias modificativas de su responsabilidad, debiendo promover el Ministerio Fiscal, tanto la adopción de las medidas más adecuadas al interés del menor que se encuentre en tales situaciones, como la constitución de los organismos tutelares previstos por las leves. También se establece que las acciones u omisiones imprudentes no puedan ser sancionadas con medidas de internamiento en régimen cerrado.

11. Con arreglo a las orientaciones expuestas, la Ley establece un amplio catálogo de medidas aplicables. desde la referida perspectiva sancionadora educativa, debiendo primar nuevamente el interés del menor en la flexible adopción judicial de la medida más idónea, dadas las caracteristicas del caso concreto y de la evolución personal del sancionado durante la ejecución de la medida. La concreta finalidad que las ciencias de la conducta exigen que se persiga con cada una de las medidas relacionadas, se detalla con carácter orientador en el apartado lif de esta exposición de motivos.

12. La ejecución de las medidas judicialmente impuestas corresponde a las entidades públicas de protección y reforma de menores de las Comunidades Autónomas, bajo el inexcusable control del Juez de Menores Se mantiene el criterio de que el interés del menor tiene que ser atendido por especialistas en las áreas de la educación y la formación, pertenecientes a esferas de mayor inmediacián que el Estado. El Juez de Menores, a instancia de las partes y oidos los equipos técricos del propio Juzgado y de la entidad pública de la correspondiente Comunidad Autónoma, dispone de amplias facultades para suspender o sustituir por otras las medidas impuestas, naturalmente sin mengua de las garantias procesales que constituyen otro de los objetivos primerdiales de la nueva regulación, o permitir la participación de los padres del menor en la aplicación y consecuencias de aquéllas.

13. Un interés particular revisten en el contexto de la Ley los temas de la reparación del daño causado y la conciliación del delincuente con la victima como situaciones que, en aras del principio de intervención minima, y con el concurso mediador del equipo técnico, pueden dar lugar a la no incoación o sobreseimiento del expediente, o a la finalización del cumplimiento de la medida impuesta, en un claro predominio, una vez más, de los criterios educativos y resocializadores sobre los de una defensa social esencialmente basada en la prevención general y que pudiera resultar contraproducente para el futuro.

La reparación del daño causado y la conciliación con la victima presentan el común denominador de que el ofensor y el perjudicado por la infracción llegan a un acuerdo, cuyo cumplimiento por parte del menor termina con el conflicto jurídico iniciado por su causa. La conciliación tiene por objeto que la victima reciba una satisfacción psicológica a cargo del menor infractor, quien ha de arrepentirse del daño causado y estar dispuesto a disculparse. La medida se aplicará cuando el menor efectivamente se arrepienta y se disculpe, y la persona ofendida lo acepte y otorgue su perdón. En la reparación el acuerdo no se alcanza únicamente mediante la via de la satisfacción psicológica, sino que requiere algo más: el menor ejecuta el compromiso contraido con la victima o perjudicado de reparar el daño causado, bien mediante trabajos en beneficio de la comunidad, bien mediante acciones, adaptadas a las necesidades del sujeto. cuyo beneficiario sea la propia víctima o perjudicado.

\section{III}

14. En la medida de amonestación el Juez, en un acto único que tiene lugar en la sede judicial, manifiesta al menor de modo concreto y claro las razones que hacen socialmente intolerables los hechos cometidos, le expone las consecuencias que para él y para la victima han tenido o podian haber tenido tales hechos, y le formula recomendaciones para el futuro.

15. La medida de prestaciones en beneficio de la comunidad, que, en consonancia con el articulo 25.2 de nuestra Constitución, no podrá imponerse sin consentimiento del menor, consiste en realizar una actividad, durante un número de sesiones previamente fijado, bien sea en beneficio de la colectividad en su conjunto, o de personas que se encuentren en una situación de precariedad por cualquier motivo. Preferentemente, se buscará relacionar la naturaleza de la actividad en que consista esta medida con la de los bienes juridicos afectados por los hechos cometidos por el menor.

Lo caracteristico de esta medida es que el menor ha de comprender, durante su realización, que la colectividad o determinadas personas han sufrido de modo injustificado unas consecuencias negativas derivadas de su conducta. Se pretende que el sujeto comprenda que actuó de modo incorrecto, que merece el reproche formal de la sociedad, y que la prestación de los trabajos que se le exigen es un acto de reparación justo.

16. Las medidas de internamiento responden a una mayor peligrosidad, manifestada en la naturaleza peculiarmente grave de los hechos cometidos, caracterizados en los casos más destacados por la violencia, la intimidación o el peligro para las personas. El objetivo prioritario de la medida es disponer de un ambiente que provea de las condiciones educativas adecuadas para que el menor pueda reorientar aquellas disposiciones o deficiencias que han caracterizado su comportamiento antisocial, cuando para ello sea necesario, al menos de manera temporal, asegurar la estancia del infractor en un régimen fisicamente restrictivo de su libertad. La mayor o menor intensidad de tal restricción da lugar a los diversos tipos de internamiento, a los que se va a aludir a continuación. El internamiento, en todo caso. ha de proporcionar un clima de seguridad personal para todos los implicados, profesionales y menores infractores, lo que hace imprescindible que las condiciones de estancia sean las correctas para el normal desarrollo psicológico de los menores.

El internamiento en régimen cerrado pretende la adquisición por parte del menor de los suficientes recur- 
sos de competencia social para permitir un comportamiento responsable en la comunidad, mediante una gestión de control en un ambiente restrictivo y progresivamente autónomo.

El internamiento en régimen semiabierto implica la existencia de un proyecto educativo en donde desde el principio los objetivos sustanciales se realizan en contacto con personas e instituciones de la comunidad, teniendo el menor su residencia en el centro. sujeto al programa y régimen interno del mismo.

El internamiento en régimen abierto implica que el menor llevará a cabo todas las actividades del proyecto educativo en los servicios normalizados del entorno, residiendo en el centro como domicilio habitual.

El internamiento terapéutico se prevé para aquellos casos en los que los menores, bien por razón de su adicción al alcohol o a otras drogas, bien por disfunciones significativas en su psiquismo, precisan de un contexto estructurado en el que poder realizar una programación terapéutica, no dándose, ni, de una parte, las condiciones idóneas en el menor o en su entorno para el tratamiento ambulatorio, ni, de otra parte, las condiciones de riesgo que exigirian la aplicación a aquél de un internamiento en régimen cerrado.

17. En la asistencia a un centro de dia, el menor es derivado a un centro plenamente integrado en la comunidad, donde se realizan actividades educativas de apoyo a su competencia social. Esta medida sirve el propósito de proporcionar a un menor un ambiente estructurado durante buena parte del dia, en el que se lleven a cabo actividades socio-educativas que puedan compensar las carencias del ambiente familiar de aquél. Lo caracteristico del centro de dia es que en ese lugar es donde toma cuerpo lo esencial del proyecto socio-educativo del menor, si bien éste puede asistir también a otros lugares para hacer uso de otros recursos de ocio o culturales. El sometido a esta medida puede, por lo tanto, continuar residiendo en su hogar, o en el de su familia, o en el establecimiento de acogida.

18. En la medida de libertad vigilada, el menor infractor está sometido, durante el tiempo establecido en la sentencia, a una vigilancia y supervisión a cargo de personal especializado, con el fin de que adquiera las habilidades, capacidades y actitudes necesarias para un correcto desarrollo personal y social. Durante el tiempo que dure la libertad vigilada, el menor también deberá cumplir las obligaciones y prohibiciones que, de acuerdo con esta Ley, el Juez puede imponerle.

19. La realización de tareas socio-educativas consiste en que el menor lleve a cabo actividades especificas de contenido educativo que faciliten su reinserción social. Puede ser una medida de carácter autónomo o formar parte de otra más compleja. Empleada de modo autónomo, pretende satisfacer necesidades concretas del menor percibidas como limitadoras de su desarrollo integra!. Puede suponer la asistencia y participación del menor a un programa ya existente en la comunidad o bien a uno creado wad hoc" por los profesionales encargados de ejecutar la medida. Como ejemplos de tareas socio-educativas, se pueden mencionar las siguientes: asistir a un taller ocupacional, a un aula de educación compensatoria o a un curso de preparación para el empleo: participar en actividades estructuradas de animación sociocultural, asistir a talleres de aprendizaje para la competencia social, etc.

20. El tratamiento ambulatorio es una medida destinada a los menores que disponen de las condiciones adecuadas en su vida para beneficiarse de un programa terapéutico que les ayude a superar procesos adictivos o disfunciones significativas de su psiquismo. Previsto para los menores que presenten una dependencia al alcohol o las drogas, $y$ que en su mejor interés puedan ser tratados de la misma on la comunidad, en su realización pueden combinarse diferentes tipos de asistencia médica y psicológica. Resulta muy apropiado para casos de desequilibrio psicológico o perturbaciones del psiquismo que puedan ser atendidos sin necesidad de internamiento. La diferencia más clara con la tarea socio-educativa es que ésta pretende lograr una capacitación, un logro de aprendizaje, empleando una metodologia, no tanto clinica, sino de orientación psicoeducativa. El tratamiento ambulatorio también puede entenderse como una tarea socio-educativa muy especifica para un problema bien definido.

21. La permanencia de fin de semana es la expresión que define la medida por la que un menor se ve obligado a permanecer en su hogar desde la tarde 0 noche del viernes hasta la noche del domingo, a excepción del tiempo en que realice las tareas socio-educativas asignadas por el Juez. En la práctica, combina elementos del arresto de fin de semana y de la medida de tareas socio-educativas o prestaciones en beneficio de la comunidad. Es adecuada para menores que cometen actos de vandalismo o agresiones leves en los fines de semana.

22. La convivencia con una persona, familia o grupo educativo es una medida que intenta proporcionar al menor un ambiente de socialización positivo, mediante su convivencia, durante un periodo determinado por el Juez, con una persona, $\infty$ una familia distinta a la suya o con un grupo educativo que se ofrezca a cumplir la función de la familia en lo que respecta al desarrollo de pautas socioafectivas prosociales en el menor.

23. La privación del permiso de conducir ciclomotores o vehiculos a motor, o del derecho a obtenerlo. 0 de licencias administrativas para caza o para el uso de cualquier tipo de armas, es una medida accesoria que se podrá imponer en aquellos casos en los que el hecho cometido tenga relación con la actividad que realiza el menor y que ésta necesite autorización administrativa.

24. Por último, procede poner de manifiesto que los principios científicos y los criterios educativos a que han de responder cada una de las medidas, aquí sucintamente expuestos, se habrán de regular más extensamente en el Reglamento que en su día se dicte en desarrollo de la presente Ley Orgánica.

\section{TITULO PRELIMINAR}

\section{Articulo 1. Declaración general.}

1. Esta Ley se aplicará para exigir la responsabilidad de las personas mayores de catorce años y menores de dieciocho por la comisión de hechos tipificados como delitos o faltas en el Código Penal o las leyes penales especiales.

2. También se aplicará lo dispuesto en esta Ley para los menores a las personas mayores de dieciocho años y menores de veintiuno, en los términos establecidos en el artículo 4 de la misma.

3. Las personas a las que se aplique la presente Ley gozarán de todos los derechos reconocidos en la Constitución y en el ordenamiento jurídico, particularmente en la Ley Orgánica $1 / 1996$, de 15 de enero. de Protección Juridica del Menor, asi como en la Convención sobre los Derechos del Niño de 20 de noviembre de 1989 y en todas aquellas normas sobre protección de menores contenidas en los Tratados válidamente celebrados por España.

4. Al efecto de designar a las personas a quienes se aplica esta Ley, en el articulado de la misma se utiliza el término menores para referirse a las que no han cum- 
plido dieciocho años, y el de jóvenes para referirse a las mayores de dicha edad.

Sin perjuicio de lo anterior, cuando esta Ley se refiera genéricamente al menor o a los menores, se entenderá que lo hace a todos los incluidos en su ámbito de aplicación.

\section{TÍTULO 1}

\section{Del ámbito de aplicación de la Ley}

\section{Articulo 2. Competencia de los Jueces de Menores.}

1. Los Jueces de Menores serán competentes para conocer de los hechos cometidos por las personas mencionadas en el articulo 1 de esta Ley, así como para hacer ejecutar sus sentencias, sin perjuicio de las facultades atribuidas por esta Ley a las Comunidades Autónomas respecto a la protección y reforma de menores.

2. Los Jueces de Menores serán asimismo competentes para resolver sobre las responsabilidades civiles derivadas de los hechos cometidos por las personas a las que resulta aplicable la presente Ley.

3. La competencia corresponde al Juez de Menores del lugar donde se haya cometido el hecho delictivo. sin perjuicio de lo establecido en el articulo 20.3 de esta Ley.

\section{Articula 3. Régimen de los menores de catorce años.}

Cuando el autor de los hechos mencionados en los artículos anteriores sea menor de catorce años, no se le exigirá responsabilidad con arreglo a la presente Ley. sino que se le aplicará lo dispuesto en las normas sobre protección de menores previstas en el Código Civil y demás disposiciones vigentes. El Ministerio Fiscal deberá remitir a la entidad pública de protección de menores testimonio de los particulares que considere precisos respecto al menor, a fin de valorar su situación, y dicha entidad habrá de promover las medidas de protección adecuadas a las circunstancias de aquél conforme a lo dispuesto en la Ley Orgánica $1 / 1996$, de 15 de enero.

\section{Artículo 4. Régimen de los mayores de dieciocho años.}

1. De conformidad con lo establecido en el articulo 69 de la Ley Orgánica 10/1995, de 23 de noviembre, del Código Penal, la presente Ley se aplicará a las personas mayores de dieciocho años y menores de veintiuno imputadas en la comisión de hechos delictivos, cuando el Juez de Instrucción competente, oidas el Ministerio Fiscal, el letrado del imputado y el equipo técnico a que se refiere el articulo 27 de esta Ley, asi lo declare expresamente mediante auto.

2. Serán condiciones necesarias para la aplicación de lo dispuesto en el apartado anterior las siguientes:

1. Que el imputado hubiere cometido una falta, o un delito menos grave sin violencia o intimidación en las personas ni grave peligro para la vida o la integridad física de las mismas, tipíficados en el Código Penal o en las leyes penales especiales.

2. Que no haya sido condenado en sentencia firme por hechos delictivos cometidos una vez cumplidos los dieciocho años. A tal efecto no se tendrán en cuenta las anteriores condenas por delitos o faltas imprudentes ni los antecedentes penales que hayan sido cancelados. o que debieran serlo con arreglo a lo dispuesto en el artículo 136 del Código Penal.

3. Que las circunstancias personales del imputado y su grado de madurez aconsejen la aplicación de la presente Ley, especialmente cuando asi lo haya recomendado el equipo técnico en su informe.
3. Contra el auto que resuelva lo indicado en los apartados anteriores, cabrá recurso de apelación en el plazo de tres dias, del que conocerá la Sala de Menores del Tribunal Superior de Justicia correspondiente, sin previo recurso de reforma. La apelación se sustanciará conforme al régimen general establecido en la Ley de Enjuiciamiento Criminal

Del mencionado auto, una vez firme, se dará traslado al Ministerio Fiscal para la tramitación del procedimiento previsto en la presente Ley.

\section{Articulo 5. Bases de la responsabilidad de los menores.}

1. Los menores serán responsables con arreglo a esta Ley cuando havan cometido los hechos a los que se refiere el articulo 1 y no concurra en ellos ninguna de las causas de exención o extinción de la responsabilidad criminal previstas en el vigente Código Penal.

2. No obstante lo anterior, a los menores en quienes concurran las circunstancias previstas en los números $1 .^{\circ}, 2^{\circ}$ y $3 .^{\circ}$ del artícula 20 del vigente Código Penal les serán aplicables, en caso necesario, las medidas terapéuticas a las que se refiere el articulo 7.1, letras d) y e), de la presente Ley.

3. Las edades indicadas en el articulado de esta Ley se han de entender siempre referidas al momento de la comisión de los hechos, sin que el haberse rebasado las mismas antes del comienzo del procedimiento o durante la tramitación del mismo tenga incidencia alguna sobre la competencia atribuida por esta misma Ley a los Jueces y Fiscales de Menores.

\section{Articulo 6. De la intervención del Ministerio Fiscal.}

Corresponde al Ministerio Fiscal la defensa de los derechos que a los menores reconocen las leves, asi como la vigilancia de las actuaciones que deban efectuarse en su interés y la observancia de las garantias del procedimiento, para lo cual dirigirá personalmente la investigación de los hechos y ordenará que la policia judicial practique las actuaciones necesarias para la comprobación de aquéllos y de la participación del menor en los mismos, impulsando el procedimiento.

\section{TÍTULO II \\ De las medidas}

Articulo 7. Enumeración de las medidas susceptibles de ser impuestas a los menores.

1. Las medidas que pueden imponer los Jueces de Menores, ordenadas según la restricción de derechos que suponen, son las siguientes:

a) Internamiento en régimen cerrado. Las personas sometidas a esta medida residirán en el centro y desarrollarán en el mismo las actividades formativas, educativas, laborales y de ocio.

b) Internamiento en régimen semiabierto. Las personas sometidas a esta medida residirán en el centro, pero realizarán fuera del mismo actividades formativas, educativas, laborales y de ocio.

c) Internamiento en régimen abierto. Las personas sometidas a esta medida llevarán a cabo todas las actividades del proyecto educativo en los servicios normalizados del entorno, residiendo en el centro como domicilio habitual, con sujeción al programa y régimen interno del mismo.

d) Internamiento terapéutico. En los centros de esta naturaleza se realizará una atención educativa especializada o tratamiento especifico dirigido a personas que 
padezcan anomalias o alteraciones psíquicas, un estado de dependencia de bebidas alcohólicas, drogas tóxicas o sustancias psicotrópicas, o alteraciones en la percepción que determinen una alteración grave de la conciencia de la realidad. Esta medida podrá aplicarse sola o como complemento de otra medida prevista en este articulo. Cuando el interesado rechace un tratamiento de deshabituación, el Juez habrá de aplicarle otra medida adecuada a sus circunstancias

e) Tratamiento ambulatorio. Las personas sometidas a esta medida habrán de asistir al centro designado con la periodicidad requerida por los facultativos que las atiendan y seguir las pautas fijadas para el adecuado tratamiento de la anomalia o alteración psiquica, adicción al consumo de bebidas alcohólicas, drogas tóxicas o sustancias psicotrópicas, o alteraciones en la percepción que padezcan. Esta medida podrá aplicarse sola o como complemento de otra medida prevista en este articulo. Cuando el interesado rechace un tratamiento de deshabituación, el Juez habrá de aplicarle otra medida ade cuada a sus circunstancias.

f) Asistencia a un centro de dia. Las personas sometidas a esta medida residirán en su domicilio habitual y acudirán a un centro, plenamente integrado en la comunidad, a realizar actividades de apoyo, educativas, formativas, laborales o de ocio.

g) Permanencia de fin de semana. Las personas sometidas a esta medida permanecerán en su domicilio o en un centro hasta un máximo de treinta y seis horas entre la tarde o noche del viernes y la noche del domingo, a excepción del tiempo que deban dedicar a las tareas socio-educativas asignadas por el Juez.

h) Libertad vigilada. En esta medida se ha de hacer un seguimiento de la actividad de la persona sometida a la misma y de su asistencia a la escuela, al centro de formación profesional o al lugar de trabajo, según los casos, procurando ayudar a aquélla a superar los factores que determinaron la infracción cometida. Asimismo, esta medida obliga, en su caso, a seguir las pautas socio-educativas que señale la entidad pública o el profesional encargado de su seguimiento. de acuerdo con el programa de intervención elaborado al efecto $y$ aprobado por el Juez de Menores. La persona sometida a la medida también queda obligada a mantener con dicho profesional las entrevistas establecidas en el programa y a cumplir, en su caso, las reglas de conducta impuestas por el Juez, que podrán ser alguna o algunas de las siguientes:

1. Obligación de asistir con regularidad al centro docente correspondiente, si el interesado está en el periodo de la enseñanza básica obligatoria, y acreditar ante el Juez dicha asistencia regular o justificar en su caso las ausencias, cuantas veces fuere requerido para ello. $2^{a}$ Obligación de someterse a programas de tipo formativo, cultural, educativo, profesional, laboral, de educación sexual, de educación vial u otros similares.

$3^{a}$ Prohibición de acudir a determinados lugares, establecimientos o espectáculos.

4. ${ }^{\mathrm{a}}$ Prohibición de ausentarse del lugar de residencia sin autorización judicial previa.

5. Obligación de residir en un lugar determinado.

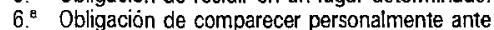
el Juzgado de Menores o profesional que se designe, para informar de las actividades realizadas y justificarlas.

$7^{\circ}$ Cualesquiera otras obligaciones que el Juez, de oficio o a instancia del Ministerio Fiscal, estime convenientes para la reinserción social del sentenciado, siempre que no atenten contra su dignidad como persona.

i) Convivencia con otra persona, familia o grupo educativo. La persona sometida a esta medida debe convivir, durante el periodo de tiempo establecido por el Juez. con otra persona, con una familia distinta a la suya o con un grupo educativo, adecuadamente seleccionados para orientar a aquélla en su proceso de socialización.

j) Prestaciones en beneficio de la comunidad. La persona sometida a esta medida, que no podrá imponerse sin su consentimiento, ha de realizar las actividades no retribuidas que se le indiquen, de interés social o en beneficio de personas en situación de precariedad. Se buscará relacionar la naturaleza de dichas actividades con la naturaleza del bien juridico lesionado por los hechos cometidos por el menor.

k) Realización de tareas socio-educativas. La persona sometida a esta medida ha de realizar, sin internamiento ni libertad vigilada, actividades especificas de contenido educativo encaminadas a facilitarle el desarrolo de su competencia social.

1) Amonestación. Esta medida consiste en la reprensión de la persona llevada a cabo por el Juez de Menores y dirigida a hacerle comprender la gravedad de los hechos cometidos y las consecuencias que los mismos han tenido o podrian haber tenido, instándole a no volver a cometer tales hechos en el futuro.

m) Privación del permiso de conducir ciclomotores o vehículos a motor, o del derecho a obtenerlo, o de las licencias administrativas para caza o para uso de cualquier tipo de armas. Esta medica podrá imponerse como accesoria cuando ol delito o falta se hubiere cometido utilizando un ciclomotor o un vehículo a motor, o un arma, respectivamente.

2. Las medidas de internamiento constarán de dos períodos: el primero se llevará a cabo en el centro correspondiente, conforme a la descripción efectuada en el apartado anterior de este articulo; el segundo se llevará a cabo en régimen de libertad vigilada, en la modalidad elegida por el Juez. La duración total no excederá del tiempo que se expresa en el articulo 9. El equipo técnico deberá informar respecto del contenido de ambos periodos, y el Juez expresará la duración de cada uno en la sentencia.

3. Para la elección de la medida o medidas adecuadas, tanto por el Ministerio Fiscal y el letrado del menor en sus postulaciones como por el Juez en la sentencia, se deberá atender de modo flexible, no sólo a la prueba y valoración juridica de los hechos, sino especialmente a la edad, las circunstancias familiares y sociales, la personalidad y el interés del menor, puestos de manifiesto los dos últimos en los informes de los equipos técnicos y, en su caso, de las entidades públicas de protección y reforma de menores emitidos conforme a lo dispuesto en el articulo 27 de la presente Ley. El Juez deberá motivar la sentencia, expresando con detalle las razones por las que aplica una determinada medida, asi como el plazo de duración de la misma, a los efectos de la valoración del mencionado interés del menor.

\section{Articulo 8. Principio acusatorio.}

El Juez de Menores no podrá imponer una medida que suponga una mayor restricción de derechos ni por un tiempo superior a la medida solicitada por el Ministerio Fiscal

Tampoco podrá exceder la duración de las medidas privativas de libertad contempladas en el articulo 7.1.a). b). c), d) y g), en ningún caso, del tiempo que hubiera durado la pena privativa de libertad que se le hubiere impuesto por el mismo hecho, si el sujeto, de haber sido mayor de edad, hubiera sido declarado responsable, de acuerdo con el Código Penal. 
Artículo 9. Reglas para la aplicación de las medidas.

No obstante lo establecido en el artículo 7.3, la aplicación de las medidas se atendrá a las siguientes reglas:

1. Cuando los hechos cometidos sean calificados de falta, sólo se podrán imponer las medidas de amonestación, permanencia de fin de semana hasta un máximo de cuatro fines de semana, prestaciones en beneficio de la comunidad hasta cincuenta horas, y privación del permiso de conducir o de otras licencias administrativas.

2." La medida de internamiento en régimen cerrado sólo podrá ser aplicable cuando en la descripción y calificación juridica de los hechos se establezca que en su comisión se ha empleado violencia o intimidación en las personas o actuado con grave riesgo para la vida - la integridad física de las mismas.

3. La duración de las medidas no podrá exceder de dos años, computándose en su caso, a estos efectos el tiempo ya cumplido por el menor en medida cautelar. conforme a lo dispuesto en el articulo 28.5 de la presente Ley. La medida de prestaciones en beneficio de la comunidad no podrá superar las cien horas. La medida de permanencia de fin de semana no podrá superar los ocho fines de semana.

4. En el caso de personas que havan cumplido los dieciséis años en el momento de la comisión de los hechos, el plazo de duración de las medidas podrá alcanzar un máximo de cinco años, siempre que el delito haya sido cometido con violencia o intimidación en las personas o con grave riesgo para la vida o la integridad fisica de las mismas y el equipo técnico en su informe aconseje la prolongación de la medida. En estos supuestos, la medida de prestaciones en beneficio de la comunidad podrá alcanzar las doscientas horas, y la de permanencia de fin de semana, dieciséis fines de semana

5. Excepcionalmente, cuando los supuestos previstos en la regla anterior revistieran extrema gravedad apreciada expresamente en la sentencia, el Juez habra de imponer una medida de internamiento de régimen cerrado de uno a cinco años de duración, complementada sucesivamente por otra medida de libertad vigilada con asistencia educativa hasta un máximo de otros cinco años. Sólo podrá hacerse uso de lo dispuesto en los articulos 14 y 51.1 de esta Ley una vez transcurrido el primer año de cumplimiento efectivo de la medida de internamiento.

La medida de libertad vigilada deberá ser ratificada mediante auto motivado, previa audiencia del Ministerio Fiscal, del letrado del menor y del representante de la entidad pública de protección o reforma de menores, al finalizar el internamiento, y se llevará a cabo por las instituciones públicas encargadas del cumplimiento de las penas, conforme a lo establecido en el artículo 105.1 del vigente Código Penal.

A los efectos de este articulo, se entenderán supuestos de extrema gravedad aquellos en los que se apreciare reincidencia $y$, en todo caso, los delitos de terrorismo y los constitutivos de actos de favorecimiento, apoyo o reclamo de la actividad de bandas, organizaciones o grupos terroristas, asi como los de asesinato u homicidio doloso. y la agresión sexual contemplada en los articulos 179 y 180 del Código Penal.

$6^{\text {a }}$ Las acciones $u$ omisiones imprudentes no podrán ser sancionadas con medidas de internamiento en régimen cerrado.

7. Cuando en la postulación del Ministerio Fiscal o en la resolución dictada en el procedimiento se aprecien algunas de las circunstancias a las que se refiere el artículo 5.2 de esta Ley, sólo podrán aplicarse las medidas terapéuticas descritas en el articulo 7.1, letras d) y e) de la misma.

\section{Artículo 10. De la prescripción.}

1. Los hechos delictivos cometidos por los menores prescriben

1. A los cinco años, cuando se trate de un delito grave sancionado en el Código Penal con pena superior a diez años.

2. A los tres años, cuando se trate de cualquier otro delito grave.

3. Al año, cuando se trate de un delito menos grave.

4. A los tres meses, cuando se trate de una falta

2. Las medidas que tengan un plazo superior a los dos años prescribirán a los tres años. Las restantes medidas prescribirán a los dos años, excepto la amonestación. las prestaciones en beneficio de la comunidad y el arresto con tareas de fin de semana, que prescribirán al año.

3. Los hechos delictivos cometidos por mayores de dieciocho años y menores de veintiuno prescribirán con arreglo a las normas contenidas en el Código Penal.

\section{Articulo 11. Concurso de infracciones.}

1. Al menor responsable de una pluralidad de hechos se le impondrá una o varias medidas, teniendo en cuenta los criterios expresados en los articulos 7.3 y 9 de la presente Ley.

2. Sin embargo, cuando una misma conducta sea constitutiva de dos o mas infracciones, o una conducta sea medio necesario para la comisión de otra, se tendrá en cuenta exclusivamente la más grave de ellas para la aplicación de la medida correspondiente.

\section{Articulo 12. Infracción continuada o con pluralidad de victimas.}

En los supuestos de infracción continuada o de una sola infracción con pluralidad de victimas, el Juez impondrá a la persona sentenciada una sola medida, tomando como referencia el más grave de los hechos cometidos, en la máxima extensión de aquélla conforme a las reglas del artículo 9, salvo cuando el interés del menor aconseje la imposición de la medida en una extensión inferior.

\section{Articulo 13. Imposición de varias medidas.}

Cuando a la persona sentenciada se le impusieren varias medidas en el mismo procedimiento y no pudieran ser cumplidas simultáneamente, el Juez, a propuesta del Ministerio Fiscal y del letrado del menor, oídos el representante del equipo técnico y la entidad pública de protección o reforma de menores, podrá sustituir todas o alguna de ellas, o establecer su cumplimiento sucesivo, sin que en este caso el plazo total de cumplimiento pueda superar el doble del tiempo por el que se le impusiere la más grave de ellas.

\section{Articulo 14. Modificación de la medida impuesta.}

1. El Juez de oficio o a instancia del Ministerio Fiscal - del letrado del menor previa audiencia de éstos e informe del equipo técnico y, en su caso, de la entidad pública de protección o reforma de menores, podrá en cualquier momento dejar sin efecto la medida impuesta, reducir su duración o sustituirla por otra, siempre que la modificación redunde en el interés del menor y se exprese suficientemente a éste el reproche merecido por su conducta.

2 . En los casos anteriores, el Juez resolverá por auto motivado, contra el cual se podrán interponer los recursos previstos en la presente Ley. 


\section{Articulo 15. Mayoría de edad del condenado.}

Cuando el menor a quien se le hubiere impuesto una medida de las establecidas en esta Ley alcanzase la mayoria de edad, continuará el cumplimiento de la medida hasta alcanzar los objetivos propuestos en la sentencia en que se le impuso conforme a los criterios expresados en los artículos anteriores.

No obstante lo señalado en el párrafo anterior, cuando las medidas de internamiento sean impuestas a quien haya cumplido veintitrés años de edad 0 , habiendo sido impuestas, no haya finalizado su cumplimiento al alcanzar el joven dicha edad, el Juez de Menores, oído el Ministerio Fiscal, sin perjuicio de lo dispuesto en los articulos 14 y 51 de la presente Ley, ordenará su cumplimiento en centro penitenciario conforme al régimen ordinario previsto en la Ley Orgánica General Penitenciaria.

\section{TITULO III}

\section{De la instrucción del procedimiento}

\section{CAPITULO}

\section{Reglas generales}

\section{Articulo 16. Incoación del expediente.}

1. Corresponde al Ministerio Fiscal la instrucción de los procedimientos por los hechos a los que se refiere el artículo 1 de esta Ley.

2. Quienes tuvieren noticia de algún hecho de los indicados en el apartado anterior, presuntamente cometido por un menor de dieciocho años, deberán ponerlo en conocimiento del Ministerio Fiscal, el cual admitirá o no a trámite la denuncia, según que los hechos sean o no indiciariamente constitutivos de delito; custodiará las piezas, documentos $y$ efectos que le hayan sido remitidos, y practicará, en su caso, las diligencias que estime pertinentes para la comprobación del hecho y de la responsabilidad del menor en su comisión, pudiendo resol ver el archivo de las actuaciones cuando los hechos no constituyan delito o no tengan autor conocido. La resolución recaida sobre la denuncia deberá notificarse a quienes hubieran formulado la misma.

3. Una vez efectuadas las actuaciones indicadas en el apartado anterior, el Ministerio Fiscal dará cuenta de la incoación del expediente al Juez de Menores, quien iniciará las diligencias de trámite correspondientes.

4. El Juez de Menores abrirá al propio tiempo la pieza separada de responsabilidad civil, que se tramitará conforme a lo establecido en las reglas del articulo 64 de esta Ley.

5. Cuando los hechos mencionados en el artículo 1 hubiesen sido cometidos conjuntamente por mayores de edad penal y por personas de las edades indicadas en el mismo articulo 1 y en el 4 de esta Ley, en sus respectivos casos, el Juez de Instrucción competente para el conocimiento de la causa, tan pronto como compruebe la edad de los imputados, adoptará las medidas necesarias para asegurar el éxito de la actividad investigadora respecto de los mayores de edad y ordenará remitir testimonio de los particulares precisos al Ministerio Fiscal, a los efectos prevenidos en el apartado 2 de este articulo.

\section{Articulo 17. Detención de los menores.}

1. Las autoridades y funcionarios que intervengan en la detención de un menor deberán practicarla en la forma que menos perjudique a éste y estarán obligados a informarle, en un lenguaje claro y comprensible y de forma inmediata, de los hechos que se le imputan, de las razones de su detención y de los derechos que le asisten, especialmente los reconocidos en el articulo 520 de la Ley de Enjuiciamiento Criminal, asi como a garantizar el respeto de los mismos. También deberán notificar inmediatamente el hecho de la detención y el lugar de la custodia a los representantes legales del menor y al Ministerio Fiscal. Si el menor detenido fuera extranjero. el hecho de la detención se notificará a las corresponcientes autoridades consulares cuando el menor tuviera su residencia habitual fuera de España o cuando asi lo solicitaran el propio menor o sus representantes legales.

2. Toda declaración del detenido, se llevará a cabo en presencia de su letrado $y$ de aquéllos que ejerzan la patria potestad, tutela o guarda del menor - de hecho o de derecho-, salvo que, en este último caso, las circunstancias aconsejen lo contrario. En defecto de estos últimos la declaración se llevará a cabo en presencia del Ministerio Fiscal, representado por persona distinta del instructor del expediente.

3. Mientras dure la detención, los menores deberán hallarse custodiados en dependencias adecuadas y separadas de las que se utilicen para los mavores de edad y recibirán los cuidados, protección y asistencia social, psicológica, médica y fisica que requieran, habida cuenta de su edad, sexo y características individuales.

4. La detención de un menor por funcionarios de policia no podrá durar más tiempo del estrictamente necesario para la realización de las averiguaciones tendentes al esclarecimiento de los hechos, y, en todo caso, dentro del plazo máximo de veinticuatro horas el menor detenido deberá ser puesto en libertad o a disposición del Ministerio Fiscal. Se aplicará en su caso. lo dispuesto en el articulo 520 bis de la Ley de Enjuiciamiento Criminal, atribuyendo la competencia para las resoluciones judiciales previstas en dicho precepto al Juez de Menores.

5. Cuando el detenido sea puesto a disposición del Ministerio Fiscal, éste habrá de resolver, dentro de las cuarenta y ocho horas a partir de la detención, sobre la puesta en libertad del menor, sobre el desistimiento al que se refiere el articulo siguiente, o sobre la incoación del expediente, poniendo a aquél a disposición del Juez de Menores competente e instando del mismo las oportunas medidas cautelares, con arreglo a lo establecido en el artículo 28.

6. El Juez competente para el procedimiento de hábeas corpus en relación a un menor será el Juez de Instrucción del lugar en el que se encuentre el menor privado de libertad; si no constare, el del lugar donde se produjo la detención, $y$, en defecto de los anteriores, el del lugar donde se hayan tenido las últimas noticias sobre el paradero del menor detenido.

Cuando el procedimiento de hábeas corpus sea instado por el propio menor, la fuerza pública responsable de la detención lo notificará inmediatamente al Ministerio Fiscal, además de dar curso al procedímiento conforme a la ley orgánica reguladora.

Articulo 18. Desistimiento de la incoación del expediente por corrección en el ámbito educativo y familiar.

El Ministerio Fiscal podrá desistir de la incoación del expediente cuando los hechos denunciados constituyan delitos menos graves sin violencia o intimidación en las personas, o faltas, tipificados en el Código Penal o en las leyes penales especiales. En tal caso, el Ministerio Fiscal dará traslado de lo actuado a la entidad pública de protección de menores para la aplicación de lo establecido en el articulo 3 de la presente Ley. Lo dispuesto en este apartado se entenderá sin perjuicio de la tra- 
mitación de la correspondiente pieza de responsabilidad civil.

No obstante, cuando conste que el menor ha cometido con anterioridad otros hechos de la misma naturaleza, el Ministerio Fiscal deberá incoar el expediente y. en su caso, actuar conforme autoriza el articulo 27.4 de la presente Ley.

Articulo 19. Sobreseimiento del expediente por conciliación o reparación entre el menor y la victima.

1. También podrá el Ministerio Fiscal desistir de la continuación del expediente, atendiendo a la gravedad y circunstancias de los hechos y del menor, de modo particular a la falta de violencia o intimidación graves en la comisión de los hechos, y a la circunstancia de que además el menor se haya conciliado con la victima o haya asumido el compromiso de reparar el daño causado a la victima o al perjudicado por el delito. o se haya comprometido a cumplir la actividad educativa propuesta por el equipo técnico en su informe.

El desistimiento en la continuación del expediente sólo será posible cuando el hecho imputado al menor constituya delito menos grave o falta.

2. A efectos de lo dispuesto en el apartado anterior. se entenderă producida la conciliación cuando el menor reconozca el daño causado y se disculpe ante la victima. y ésta acepte sus disculpas, y se entenderá por reparación el compromiso asumido por el menor con la victima o perjudicado de realizar determinadas acciones en beneficio de aquéllos o de la comunidad, seguido de su realización efectiva. Todo ello sin perjuicio de acuerdo al que hayan llegado las partes en relación al ejercicio de la acción por responsabilidad civil derivada del delito o falta, regulada en esta Ley.

3. El correspondiente equipo técnico realizará las funciones de mediación entre el menor y la victima o perjudicado, a los efectos indicados en los apartados anteriores, e informará al Ministerio Fiscal de los compromisos adquiridos y de su grado de cumplimiento.

4. Una vez producida la conciliación o cumplidos los compromisos de reparación asumidos con la victima o perjudicado por el delito o falta cometido, o cuando una u otros no pudieran llevarse a efecto por causas ajenas a la voluntad del menor, el Ministerio Fiscal dará por concluida la instrucción y solicitará del Juez el sobreseimiento y archivo de las actuaciones, con remisión de lo actuado.

5. En el caso de que el menor no cumpliera la reparación o la actividad educativa acordada, el Ministerio Fiscal continuará la tramitación del expediente.

6. En los casos en los que la victima del delito o falta fuere menor de edad o incapaz, el compromiso al que se refiere el presente articulo habrá de ser asumido por el representante legal de la misma, con la aprobación del Juez de Menores.

\section{Articulo 20. Unidad de expediente.}

1. El Ministeric Fiscal incoará un procedimiento por cada hecho delictivo, salvo cuando se trate de hechos delictivos conexos.

2. Todos los procedimientos tramitados a un mismo menor 0 joven se archivarán en el expediente personal que del mismo se haya abierto en la Fiscalia. De igual modo se archivarán las diligencias en el Juzgado de Menores respectivo

3. En los casos en los que los delitos atribuidos al menor expedientado hubieran sido cometidos en diferentes territorios, la determinación del órgano judicial competente para el enjuiciamiento de todos ellos en unidad de expediente, así como de las entidades públicas competentes para la ejecución de las medidas que se apliquen, se hará teniendo en cuenta el lugar del domicilio del menor y, subsidiariamente, los criterios expresados en el articulo 18 de la Ley de Enjuiciamiento Criminal

\section{Articulo 21. Remisión al órgano competente.}

Cuando el conocimiento de los hechos no corresponda a la competencia de los Juzgados de Menores, e Fiscal acordará la remisión de lo actuado al órgano legalmente competente.

\section{Articulo 22. De la incoación del expediente.}

1. Desde el mismo momento de la incoación del expediente, el menor tendrá derecho a:

a) Ser informado por el Juez, el Ministerio Fiscal - agente de policia de los derechos que le asisten.

b) Designar abogado que le defienda, 0 a que le sea designado de oficio y a entrevistarse reservadamente con él, incluso antes de prestar declaración.

c) Intervenir en las diligencias que se practiquen durante la investigación preliminar y en el proceso judicial, y a proponer y solicitar, respectivamente, la práctica de diligencias

d) Ser oido por el Juez o Tribunal antes de adoptar cualquier resolución que le concierna personalmente.

e) La asistencia afectiva y psicológica en cualquier estado y grado del procedimiento, con la presencia de los padres o de otra persona que indique el menor, si el Juez de Menores autoriza su presencia.

f) La asistencia de los servicios del equipo técnico adscrito al Juzgado de Menores.

2. El expediente será notificado al menor desde el momento mismo de su incoación, a salvo lo dispuesto en el articulo 24. A tal fin, el Secretario del Juzgado de Menores, una vez recibido del Ministerio Fiscal el parte de incoación del expediente, requerirá al menor y a sus representantes legales para que designen letrado en el plazo de tres dias, advirtiéndoles que, de no hacerlo. aquél le será nombrado al menor de oficio de entre los integrantes del turno de especialistas del correspondiente Colegio de Abogados.

3. Igualmente, el Ministerio Fiscal notificará a quien aparezca como perjudicado, desde el momento en que así conste en la instrucción del expediente, la posibilidad de ejercer las acciones civiles que le puedan corresponder, personándose ante el Juez de Menores en la pieza de responsabilidad civil que se tramitará por el mismo.

\section{Articulo 23. Actuación instructora del Ministerio Fiscal.}

1. La actuación instructora del Ministerio Fiscal tendrá como objeto, tanto valorar la participación del menor en los hechos para expresarle el reproche que merece su conducta, como proponer las concretas medidas de contenido educativo y sancionador adecuadas a las circunstancias del hecho y de su autor y, sobre todo, al interés del propio menor valorado en la causa.

2. El Ministerio Fiscal deberá dar vista del expediente al letrado del menor, en un plazo no superior a veinticuatro horas, tantas veces como aquél lo solicite.

3. El Ministerio Fiscal no podrá practicar por sí mismo diligencias restrictivas de derechos fundamentales, sino que habrá de solicitar del Juzgado la práctica de las que sean precisas para el buen fin de las investigaciones. El Juez de Menores resolverá sobre esta petición por auto motivado. La práctica de tales diligencias se documentará en pieza separada. 


\section{Articulo 24. Secreto del expediente.}

El Juez de Menores, a solicitud del Ministerio Fiscal del menor o de su familia, y mediante auto motivado, podrá decretar el secreto del expediente, en su totalidad - parcialmente, durante toda la instrucción o durante un periodo limitado de ésta. No obstante, el letrado de menor deberá, en todo caso, conocer en su integridad el expediente al evacuar el trámite de alegaciones. Este incidente se tramitará por el Juzgado en pieza separada.

\section{Artículo 25. Participación del perjudicado e inexisten-} cia de acción particular y popular.

En este procedimiento no cabe en ningún caso el ejercicio de acciones por particulares, salvo lo previsto en el articulo 61. 1 de esta Ley sobre ejercicio de acciones civiles.

No obstante lo anterior, cuando los hechos tipificados como delitos se atribuyan a personas que hayan cumplido los dieciséis años en el momento de la comisión de los hechos, con violencia o intimidación, o con grave riesgo para la vida o integridad fisica de las personas, el perjudicado padrá personarse en el procedimiento, tanto en la fase instructora como en la fase de audiencia, con las siguientes facultades:

Tener vista de lo actuado, siendo notificado de las diligencias que se soliciten y acuerden.

Proponer pruebas que versen sobre el hecho delictivo y las circunstancias de su comisión, salvo en lo referente a la situación psicológica, educativa, familiar y social del menor.

Participar en la práctica de las pruebas, ya sea en fase de instrucción, ya sea en fase de audiencia; a estos efectos el órgano actuante podrá denegar la práctica de la prueba de careo, si ésta fuera solicitada, cuando no resulte fundamental para la averiguación de los hechos o la participación del menor en los mismos.

Contra la denegación por el Fiscal de la personación del perjudicado en fase instructora, éste podrá reiterar su petición ante el Juzgado de Menores en el plazo de cinco días, y contra la denegación de la práctica de una prueba por el Fiscal no se dará recurso alguno, sin perjuicio de la posibilidad de volver a solicitarla en el escrito de alegaciones o en la fase de audiencia.

Asimismo, con carácter previo a la remisión por el Fiscal del escrito de alegaciones con el expediente al Juzgado de Menores, el Ministerio Fiscal concederá al perjudicado que se hubiera personado un plazo de cinco dias para que valore el conjunto de la prueba practicada y, en su caso, proponga aquellas que debieran realizarse en la fase de audiencia.

Cuando proceda la celebración de la audiencia, el Juez invitará al perjudicado personado en la causa a que manifieste lo que tenga por conveniente sobre la práctica de nuevas pruebas, y tras ésta se le oirá en relación a los hechos probados resultantes de las mismas y a la participación del menor, sin que en ningún caso pueda realizar manifestación alguna sobre la procedencia de las medidas propuestas.

Contra los autos y providencias de los Jueces de Menores que afecten al ejercicio de las facultades reconocidas en este articulo, se estará a lo dispuesto en el articulo 41.2.

Contra la sentencia dictada por el Juez de Menores, el perjudicado podrá interponer recurso de apelación de acuerdo con lo establecido en el artículo 41.1, fundamentado en la incompetencia del Juzgado, la inadecuación del procedimiento, el quebrantamiento de las formas esenciales del juicio que haya producido inde- fensión al perjudicado o la falta de apreciación de algún elemento de prueba esencial para la calificación de los hechos, pudiendo, si fuera necesario, solicitar su práctica, igualmente en los términos prevenidos por el articulo 41.1.

\section{Articulo 26. Diligencias propuestas por el letrado de! menor.}

1. El letrado del menor sol icitará del Ministerio Fiscal la práctica de cuantas diligencias considere necesarias El Ministerio Fiscal decidirá sobre su admisión, mediante resolución motivada que notificará al letrado y pondrá en conocimiento del Juez de Menores. Con relación a las diligencias no practicadas, el letrado podrá reproducir su petición, en cualquier momento, ante el Juzgado de Menores.

2. No obstante lo dispuesto en el apartado anterior, cuando el letrado proponga que se lleve a efecto la declaración del menor, el Ministerio Fiscal deberá recibirla en el expediente, salvo que va hubiese concluido la instrucción y el expediente hubiese sido elevado al Juzgado de Menores.

3. Si las diligencias propuestas por el letrado del menor afectaren a derechos fundamentales de éste 0 de otras personas, el Ministerio Fiscal, de estimar pertinente la solicitud, se dirigirá al Juez de Menores conforme a lo dispuesto en el articulo 23.3 de la presente Ley, sin perjuicio de la facultad del letrado de reproducir su solicitud ante el Juez de Menores en las condiciones establecidas en el apartado 1 de este articulo.

\section{Articulo 27. Informe del squipo técnico.}

1. Durante la instrucción del expediente, el Ministerio Fiscal requerirá del equipo técnico, que a estos efectos dependerá funcionalmente de aquél sea cual fuere su dependencia orgánica, la elaboración de un informe o actualización de los anteriormente emitidos, que deberá serle entregado en el plazo máximo de diez dias, prorrogable por un periodo no superior a un mes en casos de gran complejidad, sobre la situación psicológica, educativa y familiar del menor, asi como sobre su entorno social, $y$ en general sobre cualquier otra circunstancia relevante a los efectos de la adopción de alguna de las medidas previstas en la presente Ley.

2. El equipo técnico podrá proponer, asimismo, una intervención socio-educativa sobre el menor, poniendo de manifiesto en tal caso aquellos aspectos del mismo que considere relevantes en orden a dicha intervención.

3. De iqual modo, el equipo técnico informará, si lo considera conveniente y en interés del menor, sobre la posibilidad de que éste efectúe una actividad reparadora o de conciliación con la victima, de acuerdo con to dispuesto en el artículo 19 de esta Ley, con indicación expresa del contenido y la finalidad de la mencionada actividad. En este caso, no será preciso elaborar un informe de las características y contenidos del apartado 1 de este articulo.

4. Asimismo podrá el equipo técnico proponer en su informe la conveniencia de no continuar la tramitación del expediente en interés del menor, por haber sido expresado suficientemente el reproche al mismo a través de los trámites ya practicados, o por considerar inadecuada para el interés del menor cualquier intervención, dado el tiempo transcurrido desde la comisión de los hechos. En estos casos, si se reunieran los requisitos previstos en el articulo 19.1 de esta Ley, el Ministerio Fiscal podrá remitir el expediente al Juez con propuesta de sobreseimiento, remitiendo además, en su caso, testimonio de lo actuado a la entidad pública de protección de menores que corresponda, a los efectos de que actúe en protección del menor. 
5. En todo caso, una vez elaborado el informe del equipo técnico, el Ministerio Fiscal lo remitirá inmediatamente al Juez de Menores y dará copia del mismo al letrado del menor.

6. El informe al que se refiere el presente artículo podrá ser elaborado o complementado por aquellas entidades públicas o privadas que trabajen en el ámbito de la educación de menores y conozcan la situación del menor expedientado.

\section{CAPITULO I}

\section{De las medidas cautelares}

\section{Articulo 28. Reglas generales.}

1. El Ministerio Fiscal, cuando existan indicios raciorales de la comisión de un delito o el riesgo de eludir u obstruir la acción de la justicia por parte del menor, podrá solicitar del Juez de Menores, en cualquier momento, la adopción de medidas cautelares para la custodia y defensa del menor expedientado. Dichas medidas podrán consistir en internamiento en centro, en el régimen adecuado libertad vigilada o convivencia con otra persona, familia a grupo educativo. El Juez, oido el letrado del menor, así como el equipo técnico y la representación de la entidad pública de protección o reforma de menores, que informarán especialmente sobre la naturaleza de la medida cautelar, resclverá sobre lo propuesto tomando en especial consideración el interés del menor. La medida cautelar adoptada podrá mantenerse hasta el momento de la celebración de la audiencia prevista en los articulos 31 y siguientes de esta Ley o durante la sustanciación de los eventuales recursos.

2. Para la adopción de la medida cautelar de internamiento se atenderá a la gravedad de los hechos, su repercusión y la alarma social producida, valorando siempre las circunstancias personales y sociales del menor. El Juez de Menores resolverá sobre la propuesta del Ministerio Fiscal en una comparecencia a la que asistirán también el letrado del menor y el representante del equipo técrico y el de la entidad pública de protección o reforma de menores, los cuales informarán al Juez sobre la conveniencia de la adopción de la medida solicitada, desde la perspectiva del interés del menor $y$ de su situación procesal.

En dicha comparecencia el Ministerio Fiscal y el letrado del menor podrán proponer los medios de prueba que puedan practicarse en el acto o dentro de las veinticuatro horas siguientes

3. El tiempo máximo de duración de la medida cautelar de internamiento será de tres meses, y podrá prorrogarse, a instancia del Ministerio Fiscal y mediante auto motivado, por otros tres meses como máximo

4. Las medidas cautelares se documentarán en el Juzgado de Menores en pieza separada del expediente.

5. El tiempo de cumplimiento de las medidas cautelares se abonará en su integridad para el cumplimiento de las medidas que se puedan imponer en la misma causa 0 , en su defecto, en otras causas que hayan tenido por objeto hechos anteriores a la adopción de aquéllas. El Juez, a propuesta del Ministerio Fiscal y oidos el letrado del menor y el equipo técnico que informó la medida cautelar, ordenará que se tenga por ejecutada la medida impuesta en aquella parte que estime razonablemente compensada por la medida cautelar.

Artículo 29. Medidas cautelares en los casos de exención de la responsabilidad.

Si en ei transcurso de la instrucción que realice el Ministerio Fiscal quedara suficientemente acreditado que el menor se encuentra en situación de enajenación mental o en cualquiera otra de las circunstancias previstas en los apartados $10^{\circ}, 2^{\circ}$ ó $33^{\circ}$ del artículo 20 del Código Penal vigente, se adoptarán las medidas cautelares precisas para la protección y custodia del menor conforme a los preceptos civiles aplicables, instando en su caso las actuaciones para la incapacitación del menor y la constitución de los organismos tutelares conforme a derecho, sin perjuicio todo ello de concluir la instrucción y de efectuar las alegaciones previstas en esta Ley conforme a lo que establecen sus artículos 5.2 y 9 , y de solicitar, por los trámites de la misma, en su caso, alguna medida terapéutica adecuada al interés del menor de entre las previstas en esta Ley.

\section{CAPITULO III}

De la conclusión de la instrucción

\section{Articulo 30. Remisión del expediente al Juez de Menores.}

1. Acabada la instrucción, el Ministerio Fiscal resolverá la conclusión del expediente, notificándosela al letrado del menor, y remitirá al Juzgado de Menores el expediente, junto con las piezas de convicción y demás efectos que pudieran existir, con un escrito de alegaciones en el que constará la descripción de los hechos, la valoración jurídica de los mismos, el grado de participación del menor, una breve reseña de las circunstancias personales y sociales de éste, y la proposición de alguna medida de las previstas en esta Ley con exposición razonada de los fundamentos juridicos y educativos que la aconsejen.

2. En el mismo acto propondrá el Ministerio Fiscal la prueba de que intente valerse para la defensa de su pretensión procesal.

3. Asimismo, podrá proponer el Ministerio Fiscal la participación en el acto de la audiencia de aquellas personas a representantes de instituciones públicas y privadas que puedan aportar al proceso elementos valorativos del interés del menor y de la conveniencia o no de las medidas solicitadas.

4. El Ministerio Fiscal podrá también solicitar de Juez de Menores el sobreseimiento de las actuaciones por alguno de los motivos previstos en la Ley de Enjuiciamiento Criminal, así como la remisión de los particulares necesarios a la entidad pública de protección de menores en su caso.

\section{TÍTULON}

\section{De la fase de audiencia}

\section{Articulo 31. Apertura de la fase de audiencia.}

Recibido el escrito de alegaciones con el expediente, las piezas de convicción, los efectos y demás elementos procesales remitidos por el Ministerio Fiscal, el Juzgado de Menores los incorporará a sus diligencias, y procederá a abrir el trámite de audiencia, para lo cual dará traslado al letrado del menor del escrito de alegaciones del Ministerio Fiscal y del testimonio del expediente, a fin de que en un plazo de cinco dias hábiles formule a su vez escrito de alegaciones comprensivo de los mismos extremos que el escrito del Ministerio Fiscal y proponga la prueba que considere pertinente.

\section{Articulo 32. Sentencia de conformidad.}

Si el escrito de alegaciones del Ministerio Fiscal solicitara la imposición de alguna o algunas de las medidas 
previstas en las letras e) a m) del apartado 1 del articulo 7 , y hubiere conformidad del menor y de su letrado, la cual se expresará en comparecencia ante el Juez de Menores en los términos del articulo 36. éste dictará sentencia sin más trámite imponiendo la medida solicitada.

\section{Articulo 33. Otras decisiones del Juez de Menores.}

En los casos no previstos en el artículo anterior, a la vista de la petición del Ministerio Fiscal y del escrito de alegaciones del letrado del menor, el Juez adoptará alguna de las siguientes decisiones:

a) La celebración de la audiencia.

b) El sobreseimiento, mediante auto motivado, de las actuaciones

c) El archivo por sobreseimiento de las actuaciones con remisión de particulares a la entidad pública de protección de menores correspondiente cuando asi se haya solicitado por el Ministerio Fiscal.

d) La remisión de las actuaciones al Juez competente, cuando el Juez de Menores considere que no le corresponde el conocimiento del asunto.

e) Practicar por si las pruebas propuestas por el letrado del menor y que hubieran sido denegadas por el Fiscal durante la instrucción, conforme a lo dispuesto en el articulo 26.1 de la presente Ley, y que no puedan celebrarse en el transcurso de la audiencia, siempre que considere que son relevantes a los efoctos del proceso. Una vez practicadas, dará traslado de los resultados al Ministerio Fiscal y al letrado del menor, antes de iniciar las sesiones de la audiencia.

Contra las precedentes resoluciones cabrán los recursos previstos en esta Ley.

\section{Articulo 34. Pertinencia de pruebas y señalamiento de la audiencia.}

El Juez de Menores, dentro del plazo de cinco días desde la presentación del escrito de alegaciones del letrado del menor, o una vez transcurrido el plazo para la presentación sin que ésta se hubiere efectuado, acordará, en su caso, lo procedente sobre la pertinencia de las pruebas propuestas, mediante auto de apertura de la audiencia, y señalará el día y hora en que deba comenzar ésta dentro de los diez días siguientes.

\section{Artículo 35. Asistentes y no publicidad de la audiencia.}

1. La audiencia se celebrará con asistencia del Ministerio Fiscal, del perjudicado que, en su caso, se haya personado, del letrado del menor, de un representante del equipo técnico que haya evacuado el informe previsto en el articulo 27 de esta Ley. y del propio menor. el cual podrá estar acompañado de sus representantes legales, salvo que el Juez, oídos los citados Ministerio Fiscal, letrado del menor y representante del equipo técnico, acuerde lo contrario. También podrá asistir el representante de la entidad pública de protección o reforma de menores que haya intervenido en las actuaciones de la instrucción, cuando el Juez asi lo acuerde.

2. El Juez podrá acordar, en interés de la persona imputada a de la victima, que las sesiones no sean públicas y en ningún caso se permitirá que los medios de comunicación social obtengan o difundan imágenes del menor ni datos que permitan su identificación.

\section{Articulo 36. Conformidad del menor.}

1. El Juez de Menores informará al menor expedientado, en un lenguaje comprensible y adaptado a su edad, de las medidas solicitadas por el Ministerio Fiscal en su escrito de alegaciones, asi como de los hechos y de la causa en que se funden.

2. El Juez seguidamente preguntará al menor si se declara autor de los hechos y si está de acuerdo con la medida solicitada por el Ministerio Fiscal. Si mostrase su conformidad con ambos extremos, oido el letrado del menor, el Juez podrá dictar resolución de conformidad. Si el letrado no estuviese de acuerdo con la conformidad prestada por el propio menor, el Juez resolverá sobre la continuación o no de la audiencia, razonando esta decisión en la sentencia.

3. Si el menor estuviere conforme con los hechos pero no con la medida solicitada, se sustanciará el trámite de la audiencia sólo en lo relativo a este último extremo, practicándose la prueba propuesta a fin de determinar la aplicación de dicha medida o su sustitución por otra más adecuada al interés del menor y que haya sido propuesta per alguna de las partes.

\section{Articulo 37. Celebración de la audiencia.}

1. Cuando proceda la celebración de la audiencia, el Juez invitará al Ministerio Fiscal y al letrado del menor a que manifiesten lo que tengan por conveniente sobre la práctica de nuevas pruebas o sobre la vulneración de algún derecho fundamental en la tramitación del procedimiento, 0 , en su caso, les pondrá de manifiesto la posibilidad de aplicar una distinta calificación o una distinta medida de las que hubieran solicitado. Seguidamente, el Juez acordará la continuación de la audiencia o la subsanación del derecho vulnerado, si asi procediere. Si acordara la continuación de la audiencia el Juez resolverá en la sentencia sobre los extremos planteados.

2. Seguidamente se iniciará la práctica de la prueba propuesta y admitida, y la que, previa declaración de su pertinencia, ofrezcan las partes para su práctica en el acto, oyéndose asimismo al equipo técnico sobre las circunstancias del menor. A continuación, el Juez oirá al Ministerio Fiscal $y$ al letrado del menor sobre la valoración de la prueba, su calificación juridica y la procedencia de las medidas propuestas; sobre este último punto, se oirá también al equipo técrico. Por último, el Juez oirá al menor, dejando la causa vista para sentencia.

3. En su caso, en este procedimiento se aplicará lo dispuesto en la legislación relativa a la protección de testigos y peritos en causas penales

4. Si en el transcurso de la audiencia el Juez considerara, de oficio a a solicitud de las partes, que el interés del menor aconseja que éste abandone la sala, podrá acordarlo asi motivadamente, ordenando que continúen las actuaciones hasta que el menor pueda retornar a aquélla.

\section{TÍTULOV}

\section{De la sentencia}

\section{Artículo 38. Plazo para dictar sentencia.}

Finalizada la audiencia, el Juez de Menores dictará sentencia sobre los hechos sometidos a debate en un plazo máximo de cinco días.

\section{Articulo 39. Contenido y registro de la sentencia.}

1. La sentencia contendrá todos los requisitos previstos en la vigente Ley Orgánica del Poder Judicial y en ella, valorando las pruebas practicadas, las razones expuestas por el Ministerio Fiscal y por el letrado del menor y lo manifestado en su caso por éste, tomando 
en consideración las circunstancias y gravedad de los hechos, asi como todos los datos debatidos sobre la personalidad, situación, necesidades y entorno familiar y social del menor y la edad de éste en el momento de dictar la sentencia, resolverá sobre la medida o medidas propuestas, con indicación expresa de su contenido, duración y objetivos a alcanzar con las mismas, y será motivada, consignando expresamente los hechos que se declaren probados y los medios probatorios de los que resulte la convicción judicial. También podrá ser anticipado oralmente el fallo al término de las sesiones de la audiencia sin perjuicio de su documentación con arreglo al articulo 248.3 de la citada Ley Orgánica del Poder Judicial.

2. El Juez, al redactar la sentencia, procurará expresar sus razonamientos en un lenguaje claro y comprensible para la edad del menor.

3. Cada Juzgado de Menores llevará un registro de sentencias en el cual se extenderán y firmarán todas las definitivas.

\section{Articulo 40. Suspensión de la ejecución del fallo.}

1. El Juez de Menores, de oficio o a instancia del Ministerio Fiscal o del letrado del menor, y oidos en todo caso éstos, asi como el representante del equipo técnico y de la entidad pública de protección o reforma de menores, podrá acordar motivadamente la suspensión de la ejecución del fallo contenido en la sentencia cuando la medida impuesta no sea superior a dos años de duración, durante un tiempo determinado y hasta un máximo de dos años. Dicha suspensión se acordará en la propia sentencia, o por auto motivado cuando aquélla sea firme, debiendo expresar, en todo caso, las candiciones de la misma.

2. Las condiciones a las que estará sometida la suspensión de la ejecución del fallo contenido en la sentencia dictada por el Juez de Menores serán las siguientes:

a) No ser condenado en sentencia firme por delito cometido durante el tiempo que dure la suspensión, si ha alcanzado la mayoria de edad, o no serle aplicada medida en sentencia firme en procedimiento regulado por esta Ley curante el tiempo que dure la suspensión.

b) Que el menor asuma el compromiso de mostrar una actitud y disposición de reintegrarse a la sociedad, no incurriendo en nuevas infracciones.

c) Además, el Juez puede establecer la aplicación de un régimen de libertad vigilada durante el plazo de suspensión o la obligación de realizar una actividad socio-educativa recomendada por el equipo técnico o la entidad pública de protección o reforma de menores en el precedente trámite de audiencia, incluso con compromiso de participación de los padres, tutores o guardadores del menor, expresando la naturaleza y el plazo en que aquella actividad deberá llevarse a cabo.

3. Si las condiciones expresadas en el apartado anterior no se cumplieran, el Juez alzará la suspensión y se procederá a ejecutar la sentencia en todos sus extremos. Contra la resclución que asi lo acuerde se podrán interponer los recursos previstos en esta Ley.

\section{TÍTULO V|}

\section{Del régimen de recursos}

\section{Articulo 41. Recursos de apelación y reforma.}

1. Contra la sentencia dictada por el Juez de Menores en el procedimiento regulado en esta Ley cabe recurso de apelación ante la Sala de Menores del correspondiente Tribunal Superior de Justicia, que se interpondrá ante el Juez que dictó aquélla en el plazo de cinco dias a contar desde su notificación, y se resolverá previa celebración de vista pública, salvo que en interés de la persona imputada o de la victima, el Juez acuerde que se celebre a puerta cerrada. A la vista deberán asistir las partes y, si el Tribunal lo considera oportuno, el representante del equipo técnico y el representante de la entidad pública de protección o reforma de menores que hayan intervenido en el caso concreto. El recurrente podrá solicitar de la Sala la práctica de la prueba que, propuesta y admitida en la instancia, no se hubiera celebrado, conforme a las reglas de la Ley de Enjuiciamiento Criminal.

2. Contra los autos y providencias de los Jueces de Menores cabe recurso de reforma ante el propio órgano, que se interpondrá en el plazo de tres dias a partir de la notificación. El auto que resuelva la impugnación de la providencia será susceptible de recurso de apelación.

3. Contra los autos que pongan fin al procedimiento 0 resuelvan el incidente de los articulos $14,28,29$ y 40 de esta Ley, cabe recurso de apelación ante la Sala de Menores del Tribunal Superior de Justicia por los trámites que regula la Ley de Enjuiciamiento Criminal para el procedimiento abreviado.

\section{Artículo 42. Recurso de casación para unificación de doctrina.}

1. Son recurribles en casación, ante la Sala Segunda del Tribunal Supremo, las sentencias dictadas en apolación por las Salas de Menores de los Tribunales Superiores de Justicia cuando se hubiere impuesto una de las medidas a las que se refieren las reglas $4 .^{\circ}$ y $5 .^{\circ}$ del artículo 9 de la presente Ley.

2. El recurso tendrá por objeto la unificación de doctrina con ocasión de sentencias dictadas en apelación por las mencionadas Salas de Menores de los Tribunales Superiores de Justicia que fueran contradictorias entre sí con las de otra u otras Salas de Menores de los reforidos Tribunales Superiores, o con sentencias del Tribunal Supremo, respecto de hechos y valoraciones de las circunstancias del menor que, siendo sustancialmente iguales, hayan dado lugar, sin embargo, a pronunciamientos distintos.

3. El recurso podrá prepararlo el Ministerio Fiscal o el letrado del menor que pretenda la indicada unificación de doctrina dentro de los diez días siguientes a la notificación de la sentencia de la Sala de Menores del Tribunal Superior de Justicia, en escrito dirigido a la misma.

4. El escrito de interposición deberá contener una relación precisa y circunstanciada de la contradicción alegada, con designación de las sentencias aludidas y de los informes en que se funde el interés del menor valorado en la sentencia.

5. Acreditados los requisitos a los que se refiere el apartado anterior, la Sala de Menores del Tribunal Superior de Justicia ante quien se hava interpuesto el recurso requerirá testimonio de las sentencias citadas a los Tribunales que las dictaron, y en un plazo de diez dias remitirá la documentación a la Sala Segunda del Tribunal Supremo, emplazando al recurrente y al Ministerio Fiscal, si no lo fuera, ante dicha Sala.

6. Cuando la parte recurrente hubiese incumplido de modo manifiesto e insubsanable a criterio del Tribunal Supremo los requisitos establecidos para el recurso o cuando la pretensión carezca de contenido casacional. el Magistrado ponente dará cuenta a la Sala de la causa de inadmisión y aquélla acordará oir al recurrente $y$ al Ministerio Fiscal, cuando éste no hubiera interpuesto el recurso, por plazo de tres dias, dictando seguidamente auto contra el que no cabrá recurso alguno. 
7. La Sala Segunda del Tribunal Supremo, constituida en forma ordinaria, convocará a la parte recurrente, y en todo caso al Ministerio Fiscal, a una vista oral, en la que oirá las alegaciones que se efectúen y podrá solicitar informe a la entidad pública de protección o reforma de menores del territorio donde ejerza su jurisdicción el Juzgado que dictó la resolución impugnada, $v$, en su caso, a aquella a la que corresponda la ejecución de la misma, dictando seguidamente la sentencia de casación del modo y con los efectos señalados en la Ley de Enjuiciamiento Criminal.

8. También, y en unificación de doctrina y por los mismos trámites, el Ministerio Fiscal podrá recurrit en casación, los autos definitivos dictados por las Salas de Menores de los Tribunales Superiores de Justicia, al resolver los recursos contra las resoluciones de los Jueces de Instrucción dictadas en aplicación de lo dispuesto en el articulo 4 de la presente Ley Orgánica.

\section{TÍTULO VII}

\section{De la ejecución de las medidas}

\section{CAPITULO}

\section{Disposiciones generales}

\section{Artículo 43. Principio de legalidad.}

1. No podrá ejecutarse ninguna de las medidas establecidas en esta Ley sino en virtud de sentencia firme dictada de acuerdo con el procedimiento regulado en la misma.

2. Tampoco podrán ejecutarse dichas medidas en otra forma que la prescrita en esta Ley y en los reglamentos que la desarrollen.

\section{Articulo 44. Competencia judicial.}

1. La ejecución de las medidas previstas en esta Ley se realizará bajo el control del Juez de Menores que haya dictado la sentencia correspondiente, el cual resolverá por auto motivado, oídos el Ministerio Fiscal, el letrado del menor y la representación de la entidad pública que ejecute aquélla, sobre las incidencias que se puedan producir durante su transcurso.

2. Para ejercer el control de la ejecución, corresponden especialmente al Juez de Menores, de oficio o a instancia del Ministerio Fiscal a del letrado del menor, las funciones siguientes:

a) Adoptar todas las decisiones que sean necesarias para proceder a la ejecución efectiva de las medidas impuestas.

b) Resolver las propuestas de revisión de las medidas a que se refiere el artículo 14 de esta Ley. das.

c) Aprobar los programas de ejecución de las medi-

d) Conocer de la evolución de los menores durante el cumplimiento de las medidas a través de los informes de seguimiento de las mismas.

e) Resolver los recursos que se interpongan contra las resoluciones dictadas para la ejecución de las medidas, conforme establece el articulo 52 de esta Ley.

f) Acordar lo que proceda en relación a las peticiones - quejas que puedan plantear los menores sancionados sobre el régimen, el tratamiento o cualquier otra circunstancia que pueda afectar a sus derechos fundamentales.

g) Realizar regularmente visitas a los centros y entrevistas con los menores.

h) Formular a la entidad pública de protección o reforma de menores correspondiente las propuestas y recomendaciones que considere oportunas en relación con la organización y el régimen de ejecución de las medidas.

i) Adoptar las resoluciones que, en relación con el régimen disciplinario, les atribuye el artículo 60 de esta Ley.

\section{Articulo 45. Competencia administrativa.}

1. La ejecución de las medidas adoptadas por los Jueces de Menores en sus sentencias firmes es competencia de las Comunidades Autónomas y de las Ciudades de Ceuta y Melilla, con arreglo a la disposición final vigésima segunda de la Ley Orgánica 1/1996. de 15 de enero, de Protección Juridica del Menor. Dichas entidades públicas llevarán a cabo de acuerdo con sus respectivas normas de organización, la creación, dirección, organización y gestión de los servicios, instituciones y programas adecuados para garantizar la correcta ejecución de las medidas previstas en esta Ley.

2. La ejecución de las medidas corresponderá a las Comunidades Autónomas y Ciudades de Ceuta y Melilla, donde se ubique el Juzgado de Menores que haya dictado la sentencia, sin perjuicio de lo dispuesto en el apartado 3 del articulo siguiente.

3. Las Comunidades Autónomas y las Ciudades de Ceuta y Melilla podrán establecer los convenios o acuerdos de colaboración necesarios con otras entidades, bien sean públicas, de la Administración del Estado, Local o de otras Comunidades Autónomas, o privadas sin ánimo de lucro, para la ejecución de las medidas de su competencia, bajo su directa supervisión, sin que ello suponga en ningún caso la cesión de la titularidad y responsabilidad derivada de dicha ejecución.

\section{CAPITULO II}

\section{Reglas para la ejecución de las medicas}

Articulo 46. Liquidación de la medida y traslado del menor a un centro.

1. Una vez firme la sentencia y aprobado el programa de ejecución de la medida impuesta, el Secretario del Juzgado que la hubiere dictado practicará la liquidación de dicha medida, indicando las fechas de inicio $y$ de terminación de la misma, con abono en su caso del tiempo cumplido por las medidas cautelares impuestas al interesado, teniendo en cuenta lo dispuesto en el articulo 28.5. Al propio tiempo, abrirá un expediente de ejecución en el que se harán constar las incidencias que se produzcan en el desarrollo de aquélla conforme a to establecido en la presente Ley.

2. De la liquidación mencionada en el apartado anterior y del testimonio de particulares que el Juez considere necesario y que deberá incluir los informes técnicos que obren en la causa, se dará traslado a la entidad pública de protección o reforma de menores competente para el cumplimiento de las medidas acordadas en la sentencia firme. También se notificará al Ministerio Fiscal el inicio de la ejecución, y al letrado del menor si asi lo solicitara del Juez de Menores.

3. Recibidos por la entidad pública el testimonio y la liquidación de la medida indicados en el apartado anterior, aquélla designará de forma inmediata un profesional que se responsabilizará de la ejecución de la medida impuesta y, si ésta fuera de internamiento, designará el centro más adecuado para su ejecución de entre los más cercanos al domicilio del menor en los que existan plazas disponibles para la ejecución por la entidad 
pública competente en cada caso. El traslado a otro centro distinto de los anteriores sólo se podrá fundamentar en el interés del menor de ser alejado de su entorno familiar y social y requerirá en todo caso la aprobación del Juez de Menores que haya dictado la sentencia.

\section{Articulo 47. Ejecución de varias medidas.}

1. Cuando el menor estuviere sometido a varias medidas, el Juez que hubiere dictado la ưltima sentencia firme ordenará el cumplimiento de aquéllas de manera simultánea.

2. Cuando todas 0 algunas de las medidas impuestas no puedan ser cumplidas simultáneamente, se cumplirán sucesivamente, de conformidad con las reglas siguientes, salvo que el Juez disponga un orden distinto atendiendo al interés del menor

1. Las medidas de internamiento se cumplirán antes que las medidas no privativas de libertad, y, en su caso, interrumpirán las que se estuvieren ejecutando que fueran de esta última naturaleza.

2. Cuando concurriere el internamiento terapéutico con otra medida, se impondrá en primer término la medida de internamiento terapéutico. El Juez suspenderá, en su caso, el inicio de la ejecución de las medidas posteriormente impuestas hasta que aquélla finalice o sea alzada, salvo que se haga uso de la facultad establecida en el articulo 14 de la presente Ley.

3. En los supuestos previstos en la regla $5^{\circ}$ del articulo 9 , la medida de libertad vigilada habrá de suceder a la medida de internamiento en régimen cerrado, conforme a la dicción del mencionado precepto.

4. Cuando concurran varias medidas de la misma naturaleza, se cumplirán por orden cronológico de firmeza de las respectivas sentencias.

$5^{\mathrm{B}}$ Cuando el joven cumpla medidas previstas por esta Ley y sea condenado a medidas o penas del Código Penal, el Juez o Tribunal ordenará el cumplimiento simultáneo de las mismas, si ello fuera posible. En caso contraric, la pena de prisión se cumplirá a continuación de la medida de internamiento que se esté ejecutando, salvo que el Juez o Tribunal sentenciador, tratándose de una condena por delitos graves y atendidas las circunstancias del joven, ordene la inmediata ejecución de la pena de prisión impuesta.

3. El Juez, previa audiencia de las partes e informe cel equipo técnico, podrá alterar el orden de cumplimiento previsto en el apartado anterior cuando asi lo hiciere aconsejable el interés del menor.

Artículo 48. Expediente personal de la persona some tida a la ejecución de una medida.

1. La entidad pública abrirá un expediente personal único a cada menor respecto del cual tenga encomendada la ejecución de una medida, en el que se recogerán los informes relativos a aquél, las resoluciones judiciales que le afecten y el resto de la documentación generada durante la ejecución.

2. Dicho expediente tendrá carácter reservado y solamente tendrán acceso al mismo el Defensor del Pueblo o institución análoga de la correspondiente Comunidad Autónoma, los Jueces de Menores competentes, el Ministerio Fiscal y las personas que intervengan en la ejecución y estén autorizadas por la entidad pública de acuerdo con sus normas de organización. El menor. su letrado y, en su caso, su representante legal, también tendrán acceso al expediente.

3. La recogida, cesión y tratamiento automatizado de datos de carácter personal de las personas a las que se aplique la presente Ley, sólo podrá realizarse en fiche- ros informáticos de titularidad pública dependientes de las entidades públicas de protección de menores, Administraciones y Juzgados de Menores competentes - del Ministerio Fiscal, y se regirá por lo dispuesto en la Ley Orgánica 15/1999, de 13 de diciembre. de Protección de Datos de Cáracter Personal, y sus normas de desarrollo.

\section{Artículo 49. Informes sobre la ejecución.}

1. La entidad pública remitirá al Juez de Menores $y$ al Ministerio Fiscal, con la periodicidad que se establezca reglamentariamente en cada caso y siempre que fuese requerida para ello o la misma entidad lo considerase necesario, informes sobre la ejecución de la medida y sus incidencias, y sobre la evolución personal de los menores sometidos a las mismas. Dichos informes se remitirán también al letrado del menor si asi lo solicitare a la entidad pública competente.

2. En los indicados informes la entidad pública podrá solicitar del Ministerio Fiscal, cuando asi lo estime procedente, la revisión judicial de las medidas en el sentido propugnado por el articulo 14.1 de la presente Ley.

\section{Articulo 50. Quebrantamiento de la ejecución.}

1. Cuando el menor quebrantare una medida privativa de libertad, se procederá a su reingreso en el mismo centro del que se hubiera evadido o en otro adecuado a sus condiciones, $o$, en caso de permanencia de fin de semana, en su domicilio, a fin de cumplir de manera ininterrumpida el tiempo pendiente.

2. Si la medida quebrantada no fuere privativa de libertad, el Ministerio Fiscal podrá instar del Juez de Menores la sustitución de aquélla por otra de la misma naturaleza. Excepcionalmente, y a propuesta del Ministerio Fiscal, oídos el letrado y el representante legal del menor, asi como el equipo técnico, el Juez de Menores podrá sustituir la medida por otra de internamiento en centro semiabierto, por el tiempo que reste para su cumplimiento.

3. Asimismo, el Juez de Menores remitirá testimonio de los particulares relativos al quebrantamiento de la medida al Ministerio Fiscal, por si el hecho fuese constitutivo de alguna de las infracciones a que se refiere el articulo 1 de la presente Ley Orgánica y merecedora de reproche sancionador.

\section{Articulo 51. Sustitución de las medidas.}

1. Durante la ejecución de las medidas el Juez de Menores que las haya impuesto podrá de oficio o a instancia del Ministerio Fiscal, del letrado del menor o de la Administración competente, y oidas las partes, as como el equipo técnico y la representación de la entidad pública de protección o reforma de menores, dejar sin efecto aquéllas o sustituirlas por otras que se estimen más adecuadas de entre las previstas en esta Ley, por tiempo iqual o inferior al que reste para su cumplimiento. Todo ello sin perjuicio de lo dispuesto en el apartado 2 del artículo anterior y de acuerdo con el articulo 14 de la presente Ley.

2. La conciliación dei menor con la victima, en cualquier momento en que se produzca el acuerdo entre ambos a que se refiere el articulo 19 de la presente Ley, podrá dejar sin efecto la medida impuesta cuando el Juez, a propuesta del Ministerio Fiscal o del letrado del menor y oidos el equipo técnico y la representación de la entidad pública de protección o reforma de menores, juzgue que dicho acto y el tiempo de duración de la medida ya cumplido expresan suficientemente el 
reproche que merecen los hechos cometidos por el menor.

3. En todos los casos anteriores, el Juez resolverá por auto motivado, contra el cual se podrán interponer los recursos previstos en la presente Ley.

\section{Articulo 52. Presentación de recursos.}

1. Cuando el menor pretenda interponer ante el Juez de Menores recurso contra cualquier resolución adoptada durante la ejecución de las medidas que le hayan sido impuestas, lo presentará de forma escrita ante el Juez o Director del centro de internamiento, quien lo pondrá en conocimiento de aquél dentro del siguiente dia hábil.

Ei menor también podrá presentar un recurso ante el Juez de forma verbal, o manifestar de forma verbal su intención de recurrir al Director del centro, quien dará traslado de esta manifestación al Juez de Menores en el plazo indicado. En este último caso, el Juez de Menores adoptará las medidas que resulten procedentes a fin de oír la alegación del menor.

El letrado del menor también podrá interponer los recursos, en forma escrita, ante las autoridades indicadas en el párrafo primero.

2. El Juez de Menores recabará informe del Ministerio Fiscal y resolverá el recurso en el plazo de dos dias, mediante auto motivado. Contra este auto cabrá recurso de apelación ante la Sala de Menores del correspondiente Tribunal Superior de Justicia, conforme a 10 dispuesto en el articulo 41 de la presente Ley.

\section{Articulo 53. Cumplimiento de la medida.}

1. Una vez cumplida la medida, la entidad püblica remitirá a los destinatarios designados en el artículo 49.1 un informe final, y el Juez de Menores dictará auto acordando lo que proceda respecto al archivo de la causa. Dicho auto será notificado al Ministerio Fiscal y al letrado del menor.

2. El Juez, de oficio o a instancia del Ministerio Fiscal o del letrado del menor, podrá instar de la correspondiente entidad pública de protección o reforma de menores, una vez cumplida la medida impuesta, que se arbitren los mecanismos de protección del menor conforme a las normas del Código Civil, cuando el interés de aquél así lo requiera.

\section{CAPITULO III}

\section{Reglas especiales para la ejecución de las medidas privativas de libertad}

\section{Articulo 54. Centros para la ejecución de las medidas} privativas de libertad.

1. Las medidas privativas de libertad, la detención y las medidas cautelares de internamiento que se impongan de conformidad con esta Ley se ejecutarán en centros especificos para menores infractores, diferentes de los previstos en la legislación penitenciaria para la ejecución de las condenas penales y medidas cautelares privativas de libertad impuestas a los mayores de edad penal.

2. No obstante lo dispuesto en el apartado anterior. las medidas de internamiento también podrán ejecutarse en centros socio-sanitarios cuando la medida impuesta asi lo requiera. En todo caso se requerirá la previa autorización del Juez de Menores.

3. Los centros estarán divididos en módulos adecuados a la edad, madurez, necesidades y habilidades sociales de los menores internados y se regirán por una normativa de funcionamiento interno cuya cumplimiento tendrá como finalidad la consecución de una convivencia ordenada, que permita la ejecución de los diferentes programas de intervención educativa y las funciones de custodia de los menores internados.

\section{Articulo 55. Principio de resocialización.}

1. Toda la actividad de los centros en los que se ejecuten medidas de internamiento estará inspirada por el principio de que el menor internado es sujeto de derecho y continúa formando parte de la sociedad.

2. En consecuencia, la vida en el centro debe tomar como referencia la vida en libertad, reduciendo al máximo los efectos negativos que el internamiento pueda representar para el menor o para su familia, favoreciendo los vinculos sociales, el contacto con los familiares $y$ allegados, y la colaboración y participación de las entidades públicas y privadas en el proceso de integración social, especialmente de las más próximas geográfica y culturalmente.

3. A tal fin se fijarán reglamentariamente los permisos ordinarios y extraordinarios de los que podrá disfrutar el menor internado, a fin de mantener contactos positivos con el exterior y preparar su futura vida en libertad.

\section{Artículo 56. Derechos de los menores internados.}

1. Todos los menores internados tienen derecho a que se respete su propia personalidad, su libertad ideológica y religiosa y los derechos e intereses legítimos no afectados por el contenido de la condena, especialmente los inherentes a la minoría de edad civil cuando sea el caso.

2. En consecuencia, se reconocen a los menores internados los siguientes derechos:

a) Derecho a que la entidad pública de la que depende el centro vele por su vida, su integridad física y su salud, sin que puedan, en ningún caso, ser sometidos a tratos degradantes o a malos tratos de palabra o de obra, ni ser objeto de un rigor arbitrario o innecesario en la aplicación de las normas.

b) Derecho del menor de edad civil a recibir una educación y formación integral en todos los ámbitos y a la protección especifica que por su condición le dispensan las leyes.

c) Derecho a que se preserve su dignidad y su intimidad, a ser designados por su propio nombre y a que su condición de internados sea estrictamente reservada frente a terceros.

d) Derecho al ejercicio de los derechos civiles, politicos, sociales, religiosos, económicos y culturales que les correspondan, salvo cuando sean incompatibles con el objeto de la detención o el cumplimiento de la condena.

e) Derecho a estar en el centro más cercano a su domicilic, de acuerdo a su régimen de internamiento, y a no ser trasladados fuera de su Comunidad Autónoma excepto en los casos y con los requisitos previstos en esta Ley y sus normas de desarrollo.

f) Derecho a la asistencia sanitaria gratuita, a recibir la enseñanza básica obligatoria que corresponda a su edad, cualquiera que sea su situación en el centro, y a recibir una formación educativa o profesional adecuada a sus circunstancias.

g) Derecho de los sentenciados a un programa de tratamiento individualizado y de todos los internados a participar en las actividades del centro.

h) Derecho a comunicarse libremente con sus padres, representantes legales, familiares $u$ otras per- 
sonas, y a disfrutar de salidas y permisos, con arreglo a lo dispuesto en esta Ley y sus normas de desarrollo

i) Derecho a comunicarse reservadamente con sus letrados, con el Juez de Menores competente, con el Ministerio Fiscal y con los servicios de Inspección de centros de internamiento

j) Derecho a una formación laboral adecuada, a un trabajo remunerado, dentro de las disponibilidades de la entidad pública, y a las prestaciones sociales que pudieran corresponderles, cuando alcancen la edad legalmente establecida

k) Derecho a formular peticiones y quejas a la Dirección del centro, a la entidad pública, a las autoridades judiciales, al Ministerio Fiscal, al Defensor del Pueblo o institución análoga de su Comunidad Autónoma y a presentar todos los recursos legales que prevé esta Ley ante el Juez de Menores competente, en defensa de sus derechos e intereses legítimos.

1) Derecho a recibir información personal y actualizada de sus derechos y obligaciones, de su situación personal y judicial, de las normas de funcionamiento interno de los centros que los acojan, asi como de los procedimientos concretos para hacer efectivos tales derechos, en especial para formular peticiones, quejas o recursos.

m) Derecho a que sus representantes legales sean informados sobre su situación y evolución y sobre los derechos que a ellos les corresponden, con los únicos limites previstos en esta Ley

n) Derecho de las menores internadas a tener en su compañia a sus hijos menores de tres años, en las condiciones y con los requisitos que se establezcan reglamentariamente.

\section{Articulo 57. Deberes de los menores internados.}

\section{Los menores internados estarán obligados a:}

a) Permanecer en el centro a disposición de la autoridad judicial competente hasta el momento de su puesta en libertad, sin perjuicio de las salidas y actividades autorizadas que puedan realizar en el exterior.

b) Recibir la enseñanza básica obligatoria que legatmente les corresponda.

c) Respetar y cumplir las normas de funcionamiento interno del centro y las directrices o instrucciones que reciban del personal de aquél en el ejercicio legitimo de sus funciones.

d) Colaborar en la consecución de una actividad ordenada en el interior del centro y mantener una actitud de respeto y consideración hacia todos, dentro y fuera del centro, en espocial hacia las autoridades, los trabajadores del centro y los demás menores internados.

e) Utilizar adecuadamente las instalaciones del centro y los medios materiales que se pongan a su disposición.

f) Observar las normas higiénicas y sanitarias, y sobre vestuario y aseo personal establecidas en el centro.

g) Realizar las prestaciones personales obligatorias previstas en las normas de funcionamiento interno del centro para mantener el buen orden y la limpieza del mismo

h) Participar en las actividades formativas, educativas y laborales establecidas en función de su situación personal a fin de preparar su vida en libertad.

\section{Articulo 58. Información y reclamaciones.}

1. Los menores recibirán, a su ingreso en el centro, información escrita sabre sus derechos y obligaciones, el régimen de internamiento en el que se encuentran, las cuestiones de organización general, las normas de funcionamiento del centro, las normas disciplinarias y los medios para formular peticiones, quejas a recursos. La información se les facilitará en un idioma que entiendan. A los que tengan cualquier género de dificultad para comprender el contenido de esta información se les explicará por otro medio adecuado.

2. Todos los internados podrán formular, verbalmente o por escrito, en sobre abierto o cerrado, peticiones y quejas a la entidad pública sobre cuestiones referentes a su situación do internamiento. Dichas peticiones o que jas también podrán ser presentadas al Director del centro. el cual las atenderá si son de su competencia o las pondrá en conocimiento de la entidad pública o autoridades competentes, en caso contrario.

\section{Artículo 59. Medidas de vigilancia y seguridad.}

1. Las actuaciones de vigilancia y seguridad interior en los centros podrán suponer, en la forma y con la periodicidad que se establezca reglamentariamente, inspecciones de los locales y dependencias, asi como registros de personas, ropas y enseres de los menores internados.

2. De igual modo se podrán utilizar exclusivamente los medios de contención que se establezcan reglamentariamente para evitar actos de violencia o lesiones de los menores, para impedir actos de fuga y daños en las instalaciones del centro o ante la resistencia activa o pasiva a las instrucciones del personal del mismo en el ejercicio legítimo de su cargo.

\section{Articulo 60. Régimen disciplinario.}

1. Los menores internados podrán ser corregidos disciplinariamente en los casos y de acuerdo con el procedimiento que se establezca reglamentariamente, de acuerdo con los principios de la Constitución, de esta Ley y del Título IX de la Ley $30 / 1992$, de 26 de noviembre, de Régimen Jurídico de las Administraciones Públicas y del Procedimiento Administrativo Común, respe tando en todo momento la dignidad de aquéllos y sin que en ningún caso se les pueda privar de sus derechos de alimentación, enseñanza obligatoria y comunicaciones $y$ visitas, previstos en esta Ley y disposiciones que la desarrollen.

2. Las faltas disciplinarias se clasificarán en muy graves, graves y leves, atendiendo a la violencia desarro Ilada por el sujeto, su intencionalidad, la importancia del resultado y el número de personas ofendidas.

3. Las únicas sanciones que se podrán imponer por la comisión de faltas muy graves serán las siguientes:

a) La separación del grupo por un periodo de tres a siete días en casos de evidente agresividad, violencia y alteración grave de la convivencia.

b) La separación del grupo durante tres a cinco fines de semana.

c) La privación de salidas de fin de semana de quince dias a un mes.

d) La privación de salidas de carácter recreativo por un periodo de uno a dos meses

4. Las únicas sanciones que se podrán imponer por la comisión de faltas graves serán las siguientes:

a) Las mismas que en los cuatro supuestas del apartado anterior, con la siguiente duración: dos dias, uno o dos fines de semana, uno a quince dias, y un mes respectivamente

b) La privación de participar en las actividades recreativas del centro durante un periodo de siete a quince días. 
5. Las únicas sanciones que se podrán imponer por la comisión de faltas leves serán las siguientes:

a) La privación de participar en todas a algunas de las actividades recreativas del centro durante un periodo de uno a seis dias.

b) La amonestación.

6. La sanción de separación supondrá que el menor permanecerá en su habitación o en otra de análogas caracteristicas a la suya, durante el horario de actividades del centro, excepto para asistir, en su caso, a la enseñanza obligatoria, recibir visitas y disponer de dos horas de tiempo al dia al aire libre.

7. Las resoluciones sancionadoras podrán ser recurridas, antes del inicio de su cumplimiento, ante el Juez de Menores. A tal fin, el menor sancionado podrá presentar el recurso por escrito o verbalmente ante el Director del establecimiento, quien, en el plazo de veinticuatro horas, remitirá dicho escrito o testimonio de la queja verbal, con sus propias alegaciones, al Juez de Menores y éste, en el término de una audiencia y oído el Ministerio Fiscal dictará auto, confirmando, modificando o anulando la sanción impuesta, sin que contra dicho auto quepa recurso alguno. El auto, una vez notificado al establecimiento, será de ejecución inmediata. En tanto se sustancia el recurso, en el plazo de dos dias, la entidad pública ejecutora de la medida podrá adoptar las decisiones precisas para restablecer el orden alterado, aplicando al sancionado lo dispuesto en el apartado 6 de este articulo

El letrado del menor también podrá interponer los recursos a que se refiere el párrafo anterior.

\section{TITULO VIII}

\section{De la responsabilidad civil}

\section{Articulo 61. Reglas generales.}

1. La acción para exigir la responsabilidad civil en el procedimiento regulado en esta Ley se ejercitará por el Ministerio Fiscal, salvo que el perjudicado renuncie a ella, la ejercite por sí mismo en el plazo de un mes desde que se le notifique la apertura de la pieza separada de responsabilidad civil o se la reserve para ejercitarla ante el orden jurisdiccional civil conforme a los preceptos del Código Civil y de la Ley de Enjuiciamiento Civil.

2. Se tramitará una pieza separada de responsabilidad civil por cada uno de los hechos imputados.

3. Cuando el responsable de los hechos cometidos sea un menor de dieciocho años, responderán solidariamente con él de los daños y perjuicios causados sus padres, tutores, acogedores y guardadores legales o de hecho, por este orden. Cuando éstos no hubieren favorecido la conducta del menor con dolo o negligencia grave, su responsabilidad podrá ser moderada por el Juez según los casos.

4. En su caso, se aplicará también lo dispuesto en el articulo 145 de la Ley $30 / 1992$, de 26 de noviembre, de Régimen Juridico de las Administraciones Públicas y del Procedimiento Administrativo Común, y en la Ley $35 / 1995$ de 11 de diciembre, de ayudas y asistencia a las victimas de delitos violentos y contra la libertad sexual, y sus disposiciones complementarias.

\section{Articulo 62. Extensión de la responsabilidad civil.}

La responsabilidad civil a la que se refiere el articulo anterior se regulará, en cuanto a su extensión, por lo dispuesto en el capitulo I del Título V del Libro I de Código Penal vigente.

\section{Articulo 63. Responsabilidad civil de los aseguradores.}

Los aseguradores que hubiesen asumido el riesgo de las responsabilidades pecuniarias derivadas de los actos de los menores a los que se refiere la presente Ley serán responsables civiles directos hasta el límite de la indemnización legalmente establecida o convencionalmente pactada, sin perjuicio de su derecho de repetición contra quien corresponda.

\section{Articulo 64. Reglas de procedimiento.}

Los trámites para la exigencia de la responsabilidad civil aludida en los artículos anteriores se acomodarán a las siguientes reglas:

1. Tan pronto como el Juez de Menores reciba el parte de la incoación del expeciente por el Ministerio Fiscal, procederá a abrir una pieza separada de responsabilidad civil, notificando a quienes aparezcan como perjudicados su derecho a ser parte en la misma, y estableciendo el plazo limite para el ejercicio de la acción.

$2^{8}$ En la pieza de referencia podrán personarse los periudicados que havan recibido notificación al efecto del Juez de Menores o del Ministerio Fiscal, conforme establece el articulo 22 de la presente Ley. y también espontáneamente quienes se consideren como tales. Asimismo, podrán personarse las compañias aseguradoras que se tengan por partes interesadas, dentro del plazo para el ejercicio de la acción de responsabilidad civil. En el escrito de personación, indicarán las personas que consideren responsables de los hechos cometidos y contra las cuales pretendan reclamar, bastando con la indicación genérica de su identidad.

$3^{a}$ El Juez de Menores notificará al menor y a sus representantes legales, en su caso, su condición de posibles responsables civiles.

4. Una vez personados los presuntos perjudicados y responsables civiles, el Juez de Menores dictaré auto acordando el inicio del procedimiento, en el que se señalarán las partes actoras y demandadas, según lo que se haya solicitado por los actores y se desprenda del expediente, y concederá un plazo de diez días a los demandantes para que presenten un escrito con sus pretensiones y propongan la prueba que consideren necesaria, incluida la confesión en juicio y la de testigos.

5. Transcurrido dicho plazo, el Juez de Menores dará traslado del escrito a los demandados, quienes en un plazo de diez días deberăn contestar a la demanda y proponer a su vez la prueba que consideren necesaria.

$6{ }^{a}$ El Juez, inmediatamente que tenga en su poder los escritos de unos y de otros, convocará a los demandantes y a los demandados a una vista oral en la que aquéllos y éstos, por su orden, expondrán sus pretensiones y sus alegaciones sobre todo aquello que consideren relevante al objeto del proceso. En el mismo acto se admitirán las pruebas pertinentes y se practicarán las pruebas propuestas. No podrá rechazarse la confesión en juicio o la prueba testifical por el hecho de haber sido ya practicadas en el expediente principal

7. ${ }^{\text {a }}$ El Juez, de oficio, mandará unir a los autos aquellos particulares del expediente del procedimiento de menores y de las actas de la audiencia que considere relevantes para su decisión.

$8^{a}$ Una vez celebrada la audiencia en el procedimiento de menores y dictada sentencia o recaida otra resolución definitiva, el Juez dictará sentencia civil absolviendo a los demandados o declarando los responsables 
civiles, con el contenido indicado en el artículo 115 del vigente Código Penal

9. Contra la sentencia indicada en el apartado anterior cabrá recurso de apelación ante la Sala de Menores del Tribunal Superior de Justicia que se sustanciará por los trámites de la apelación regulados en la Ley de Enjuiciamiento Civil que por la cuantia corresponda. Una vez firme la sentencia, podrá ser ejecutada de acuerdo con las normas del Código Penal y de la citada Ley de Enjuiciamiento Civil.

10. La sentencia dictada en este procedimiento no producirá fuerza de cosa juzgada, quedando a salvo el derecho de las partes para promover juicio ordinario sobre la misma cuestión, en el cual se considerarán hechos probados los hechos que el Juez de Menores haya estimado acreditados, asi como la participación del menor

11. En la pieza de responsabilidad civil no se precisa letrado ni procurador, pero, si fuere solicitado, se designará letrado de oficio al presunto responsable. Los representantes legales del menor podrán ser defendidos por el letrado designado al menor en el procedimiento principal, si asi se aceptare por aquél.

\section{Disposición adicional primera. Aplicación en la Juris- dicción Militar.}

Lo dispuesto en el articulo 4 de esta Ley se aplicará a quienes hubieren cometido delitos o faltas de los que deba conocer la Jurisdicción Militar, conforme a lo que se establezca sobre el particular en las leyes penales militares.

Disposición adicional segunda. Aplicación de medidas en casos de riesgo para la salud.

Cuando los Jueces de Menores aplicaren alguna de las medidas terapéuticas a las que se refieren los articulos 5.2.7.1 y 29 de esta Ley, en caso de enfermedaces transmisibles u otros riesgos para la salud de los menores - de quienes con ellos convivan, podrán encomendar a las autoridades o Servicios de Salud correspondientes su control y seguimiento de conformidad con lo dispuesto en la Ley Orgánica $3 / 1986$, de 14 de abril, de medidas especiales en materia de salud pública.

Disposición adicional tercera. Registro de sentencias firmes dictadas en aplicación de to dispuesto en la presente Ley.

En el Ministerio de Justicia se llevará un Registro de sentencias firmes dictadas en aplicación de lo dispuesto en la presente Ley, cuyos datos sólo podrán ser utilizados por los Jueces de Menores y por el Ministerio Fiscal a efectos de lo establecido en los artículos 6.30 y 47 de esta Ley, teniendo en cuenta lo dispuesto en la Ley Orgánica 15/1999, de 13 de diciembre, de Protección de Datos de Carácter Personal, y sus disposiciones complementarias.

\section{Disposición transitoria única. Régimen transitorio}

1. A los hechos cometidos con anterioridad a la entrada en vigor de la presente Ley por los menores sujetos a la Ley Orgánica 4/1992, de 5 de junio, sobre Reforma de la Ley Reguladora de la Competencia y el Procedimiento de los Juzgados de Menores, que se deroga, les será de aplicación la legislación vigente en el momento de su comisión. Quienes estuvieren cumplien- do una medida de las previstas en la citada Ley Orgánica 4/1992 continuarán dicho cumplimiento hasta la extinción de la responsabilidad en las condiciones previstas en dicha Ley.

2. A la entrada en vigor de la presente Ley, cesará inmediatamente el cumplimiento de todas las medidas previstas en la Ley Orgánica 4/1992 que estuvieren cumpliendo personas menores de catorce años, extinguiéndose las correspondientes responsabilidades.

3. A los menores de dieciocho años, juzgados con arreglo a lo dispuesto en el Código Penal de 1973, en las leyes penales especiales derogadas o en la disposición derogatoria del Código Penal vigente, a quienes se hubiere impuesto una pena de dos años de prisión menor o una pena de prisión superior a dos años, que estuvieren pendientes de cumplimiento a la entrada en vigor de la presente Ley, dichas penas les serán sustituidas por alguna de las medidas previstas en esta LeV. a instancia del Ministerio Fiscal, previo informe del equipo técnico o de la correspondiente entidad pública de protección o reforma de menores. A tal efecto, se habrá de dar traslado al Ministerio Fiscal de la ejecutoria y de la liquidación provisional de las penas impuestas a los menores comprendidos en los supuestos previstos en este apartado.

4. Si, en los supuestos a los que se refiere el apartado anterior, la pena impuesta o pendiente de cumplimiento fuera de prisión inferior a dos años o de cualquiera otra naturaleza, se podrá imponer al condenado una medida de libertad vigilada simple por el tiempo que restara de cumplimiento de la condena, si el Juez de Menores, a petición del Ministerio Fiscal y oídos el letrado del menor, su representante legal, la correspondiente entidad pública de protección o reforma de menores y el propio sentenciado, to considerara acorde con la finalidad educativa que persigue la presente Ley. En otro caso, el Juez de Menores podrá tener por cumplida la pena y extinguida la responsabilidad del sentenciado.

5. Las decisiones del Juez de Menores a que se refieren los apartados anteriores se adoptarán en auto recurrible directamente en apelación, en el plazo de cinco días hábiles, ante la Sala de Menores del correspondiente Tribunal Superior de Justicia.

6. En los procedimientos penales en curso a la entrada en vigor de la presente Ley, en los que haya imputadas personas por la comisión de hechos delictivos cuando aún no hayan cumplido los dieciocho años, el Juez o Tribunal competente remitirá las actuaciones practicadas al Ministerio Fiscal para que instruya el procedimiento regulado en la misma

Si el imputado lo fuere por hechos cometidos cuando era mayor de dieciocho años y menor de veintiuno, el Juez instructor acordará lo que proceda, según lo dispuesto en el artículo 4 de esta Ley.

\section{Disposición final primera. Derecho supletorio}

Tendrán el carácter de normas supletorias, para lo no previsto expresamente en esta Ley Orgánica, en el ámbito sustantivo, el Código Penal y las leyes penales especiales, $y$, en el ámbito del procedimienta, la Ley de Enjuiciamiento Criminal, en particular lo dispuesto para los trámites del procedimiento abreviado regulado en el Título lil del Libro IV de la misma.

Disposición final segunda. Modificación de la Ley Orgánica del Poder Judicial y del Estatuto Orgánico del Ministerio Fiscal.

1. El Gobierno, en el plazo de seis meses a partir de la publicación de la presente Ley en el «Boletín Oficial 
del Estadon, elevará al Parlamento un proyecto de Ley Orgánica de reforma de la Ley Orgánica 6/1985, de 1 de julio, del Poder Judicial, para la creación de las Salas de Menores de los Tribunales Superiores de Justicia y para la adecuación de la regulación y competencia de los Juzgados de Menores y de la composición de la Sala Segunda del Tribunal Supremo a lo establecido en la presente Ley.

2. El Gobierno, en el plazo de seis meses a partir de la publicacićn de la presente Ley en el "Boletin Oficial del Estadon, elevará al Parlamento un proyecto de Ley de reforma de la Ley 50/1981, de 30 de diciembre, por la que se regula el Estatuto Orgánico del Ministerio Fiscal, a fin de adecuar la organización del Ministerio Fiscal a lo establecido en la presente Ley.

\section{Disposición final tercera. Reformas en materia de per- sonal.}

1. El Gobierno, a través del Ministerio de Justicia, oido el Consejo General del Poder Judicial, la Fiscalia General del Estado y las Comunidades Autónomas afectadas, en el plazo de seis meses desde la publicación de la presente Ley en el "Boletín Oficial del Estadon adoptará las disposiciones oportunas para adecuar la planta de los Juzgados de Menores y las plantillas de las Carreras Judicial y Fiscal a las necesidades orgánicas que resulten de la aplicación de lo dispuesto en la presente Ley.

2. Las plazas de Jueces de Menores deberán ser servidas necesariamente por Magistrados pertenecientes a la Carrera Judicial. A la entrada en vigor de esta Ley los titulares de un Juzgado de Menores que ostenten la categoría de Juez deberán cesar en dicho cargo, quedando, en su caso, en la situación que prevé el artículo 118.2 y concordantes de la vigente Ley Orgánica del Poder Judicial, procediéndose a cubrir tales plazas por concurso ordinario entre Magistrados.

3. El Gobierno, a través del Ministerio de Justicia, y las Comunidades Autónomas con competencia en la materia, a través de las correspondientes Consejerias, adecuarán las plantillas de funcionarios de la Administración de Justicia a las necesidades que presenten los Juzgados y las Fiscalias de Menores para la aplicación de la presente Ley, y determinarán el número de los equipos técnicos adscritos a los Juzgados y Fiscalias de Menores, su composición y la plantilla de los mismos.

4. Asimismo, el Gobierno, a través del Ministerio del Interior, $y$ sin periuicio de las competencias de las Comunidades Autónomas, adecuará las plantillas de los Grupos de Menores de las Brigadas de Policia Judicial, con objeto de establecer la adscripción a las Secciones de Menores de las Fiscalias de los funcionarios necesarios a los fines propuestos por esta Ley.

5. El Gobierno a través del Ministerio de Justicia, sin perjuicio de las competencias asumidas por las Comunidades Autónomas, y en el plazo de seis meses desde la publicación de la presente Ley en el "Boletín Oficial del Estado", adoptará las disposiciones oportunas para la creación de Cuerpos de Psicólogos y Educadores y Trabajadores Sociales Forenses.

Disposición final cuarta. Especialización de Jueces, Fiscales y abogados.

1. El Consejo General del Poder Judicial y el Ministerio de Justicia, en el ámbito de sus competencias res. pectivas, procederán a la formación de miembros de la Carrera Judicial y Fiscal especialistas en materia de
Menores con arreglo a lo que se establezca reglamentariamente. Dichos especialistas tendrán preferencia para desempeñar los correspondientes cargos en las Salas de Menores de los Tribunales Superiores de Justicia y en los Juzgados y Fiscalias de Menores, conforme a lo que establezcan las leyes y reglamentos.

2. En todas las Fiscalias existirá una Sección de Menores compuesta por miembros de la Carrera Fiscal, especialistas, con las dotaciones de funcionarios administrativos que sean necesarios, según se determine reglamentariamente.

3. El Consejo General de la Abogacia deberá adoptar las disposiciones oportunas para que en los Colegios en los que resulte necesario se impartan cursos homologados para la formación de aquellos letrados que deseen adquirir la especialización en materia de menores a fin de intervenir ante los órganos de esta Jurisdicción.

\section{Disposición final quinta. Cláusula derogatoria.}

1. Se derogan: la Ley Orgánica reguladora de la competencia y el procedimiento de los Juzgados de Menores, texto refundido aprobado por Decreto de 11 de junio de 1948, modificada por la Ley Orgánica 4/1992, de 5 de junio; los preceptos subsistentes del Reglamento para la ejecución de la Ley Orgánica reguladora de la competencia y el procedimiento de los Juzgados de Menores, aprobado por Decreto de 11 de junio de 1948; la disposición transitoria duodécima de la Ley Orgánica 10/1995, de 23 de noviembre, del Código Penal; y los artículos 8.2. 9.3, la regla $1 .{ }^{\circ}$ del artícuto 20 , en lo que se refiere al número $2 .^{\circ}$ del articulo 8 , el segundo párrafo del articulo 22 y el articulo 65 del texto refundido del Código Penal, publicado por el Decreto $3096 / 1973$, de 14 de septiembre, conforme a la Ley $44 / 7971$, de 15 de noviembre.

2. Quedan asimismo derogadas cuantas otras normas, de igual o inferior rango, se opongan a lo establecido en la presente Ley.

Disposición final sexta. Naturaleza de la presente Ley.

Los articulos $16,20,21,23$ a 27,30 a 35,37 a 39 . 41,42 y 61 a 64 , la disposición adicional tercera y la disposición final tercera de la presente Ley Orgánica tienen naturaleza de Ley ordinaria.

Disposición final séptima. Entrada en vigor y desarrollo reglamentario.

1. La presente Ley Orgánica entrará en vigor al an̂o de su publicación en el "Boletin Oficial del Estado». En dicha fecha entrarán también en vigor los articulos 19 y 69 de la Ley Orgánica 10/1995, de 23 de noviembre. del Código Penal.

2. Durante el plazo mencionado en el apartado anterior, las Comunidades Autónomas con competencia respecto a la protección y reforma de menores adaptarán su normativa para la adecuada ejecución de las funciones que les otorga la presente Ley.

Por tanto.

Mando a todos los españoles, particulares y autoridades, que guarden y hagan guardar esta Ley Orgánica.

Madrid, 12 de enero de 2000.

JUAN CARLOS R

El Presidente del Gobierna. JOSÉ MARIA AZNAR LOPEZ 


\section{Disposiciones generales}

\section{JEFATURA DEL ESTADO}

23659 LEY ORGÁNICA 7/2000, de 22 de diciembre, de modificación de la Ley Orgánica 10/1995, de 23 de noviembre, del Código Penal, y de la Ley Orgánica 5/2000, de 12 de enero, reguladora de la Responsabilidad Penal de jos Menores, en relación con los delitos de terrorismo.

\section{JUAN CARLOS 1}

\section{REY DE ESPAÑA}

A todos los que la presente vieren y entendieren. Sabed: Que las Cortes Generales han aprobado y Yo vengo en sancionar la siguiente Ley Orgánica.

$$
\text { I }
$$

La Ley es el instrumento más valioso con el que cuenta el Estado de Derecho para que los derechos y libertades de los ciudadanos proclamados por la Constitución sean reales $y$ efectivos.

Siendo esto especialmente relevante frente al terrorismo, los poderes públicos tienen que afrontar que los comportamientos terroristas evolucionan y buscan evadir la aplicación de las normas aprovechando los resquicios y las complejidades interpretativas de las mismas. Tanto más si se considera que, cuanto más avanza la sociedad ganando espacios de libertad frente al terror. más numerosas y variadas son las actuaciones terroristas que tratan de evitar, atemorizanda directamente a cada ciudadano 0 , en su conjunto, a los habitantes de una población o a los miembros de un colectivo social, politico o profesional, que se desarrolle con normalidad la convivencia democrática y que la propia sociedad se fortalezca e imponga dicha convivencia, erradicando las graves e ilegitimas conductas que la perturban.

Para dar una respuesta efectiva a estas necesidades desde el ordenamiento jurídico, mediante los instrumentos ordinarios que nuestra Constitución admite y demanda, la presente Ley reforma algunas de las disposiciones de la Ley Orgánica 10/1995, de 23 de noviembre, del Código Penal, así como de la Ley 5/2000, de 12 de enero, reguladora de la Responsabilidad Penal de los Menores, por las razones y con los contenidos que más adelante se detallan.

La estructura del presente texto normativo es sencilla, con un primer articulo en el que se contienen todas las modificaciones que afectan al Código Penal y un artículo segundo en el que se detallan los cambios que afectan a la Ley reguladora de la responsabilidad penal de los menores.
11

Los preceptos del Código Penal que se modifican son los articulos 40, 266,346, 351,504, 505, 551, 577 . 578 y 579 . Conviene, sin embargo, referirse a los mismos examinando brevemente las lineas básicas que resumen la presente reforma.

En primer término, cabe mencionar la modificación del artículo 577, que se ocupa del denominado "terrorismo urbanon. En su actual redacción, dicho articulo tipifica las acciones de los que, sin pertenecer a banda armada, comparten sus fines y contribuyen a subvertir el orden constitucional o a alterar gravemente la paz pública. La experiencia demuestra, sin embargo, que estas previsiones no están cumpliendo el objetivo perseguido. Por una parte, porque los sucesos de terrorismo urbano sólo vienen considerados como tales en el caso de que exista riesgo para la vida o la integridad física de las personas. Por otra, porque la actual legislación no facilita que se condene a quienes interviniendo en estas acciones portan, no ya los explosivos o armas que provocan incendios o destrozos, sino solamente los componentes necesarios para provocar la explosión.

Frente a estas complejidades, la nueva redacción del articulo 577. partiendo de que, según se dice ahora expresamente, estas acciones no se limitan a dañar bie nes materiales individuales o colectivos, sino que persiguen atemorizar a toda una población o colectivo para favorecer los fines terroristas, poniendo con ello en entredicho valores constitucionales que, como el respeto a la vida 0 a la dignidad de las personas o la propia libertad, deben ser objeto de la máxima protección, incorpora el delíto de daños al elenco de los enumerados en dicho precepto y resuelve las dudas interpretativas sobre la tenencia de explosivos utilizados para cometer actos de terrorismo.

En lógica consonancia con ello, se modifican los artículos 266, 346 y 351 del propio Código, agravando los delitos de daños causados por incendio, explosión o con riesgo para las personas, cubriendo determinadas lagunas técnicas apreciadas en la redacción actual.

La introducción de un nuevo tipo penal de exaltación del terrorismo en el nuevo articulo 578 del Código Penal se dirige a sancionar a quienes enaltezcan o justifiquen por cualquier medio de expresión pública o difusión los delitos de terrorismo o a quienes participen en su ejecución, o la realización de actos que entrañen descrédito, menosprecio o humillación de las victimas de los delitos terroristas $o$ de sus familiares.

Las acciones que aqui se penalizan, con independencia de lo dispuesto en el artículo 18 del propio Código, constituyen no sólo un refuerzo y apoyo a actuaciones criminales muy graves y a la sostenibilidad y perdurabilidad de las mismas, sino también otra manifestación 
muy notaria de cómo por vias diversas generará el terror colectivo para hacer avanzar los fines terroristas.

No se trata, con toda evidencia, de prohibir el elogio o la defensa de ideas o doctrinas, por más que éstas se alejen o incluso pongan en cuestión el marco constitucional, ni, menos aún, de prohibir la expresión de opiniones subjetivas sobre acontecimientos históricos o de actualidad. Por el contrario, se trata de algo tan sencillo como perseguir la exaltación de los métodos terroristas, radicalmente ilegitimos desde cualquier perspectiva constitucional, o de los autores de estos delitos, asi como las conductas especialmente perversas de quienes calumnian o humillan a las víctimas al tiempo que incrementan el horror de sus familiares. Actos todos ellos que producen perplejidad e indignación en la sociedad y que merecen un claro reproche penal.

La incorporación de este nuevo delito en el articuto 578 origina la reforma de los anteriores articulos 578 y 579, que ahora se refunden en el nuevo articulo 579 . con algunas modificaciones que se examinan a continuación.

IV

También mediante la introducción de nuevos tipos penales se pretende otorgar mayor protección juridica a los miembros de las Corporaciones locales, legitimamente elegidos, y a los Plenos que celebran para el ejercicio de las funciones de la Corporación. A tal fin, se incorpora un nuevo articulo 505 en el Código Penal, que viene a sancionar las perturbaciones graves que se provoquen en las sesiones plenarias de estas Corporaciones, y se modifica el apartado 2 del articulo 551 para definir como atentado a la autoridad el realizado contra los miembros de las mismas, en términos similares a la protección que el Código otorga a los miembros de otras instituciones.

Como consecuencia de la inclusión del nuevo articulo 505, se modifica también el articulo 504, que ahora refunde, en párrafos separados, los anteriores artículos 504 y 505 , sobre injurias 0 amenazas graves a diversas instituciones.

Con el mismo propósito de reforzar las instituciones democráticas y representativas y la dignidad de la función que legitimamente corresponde a quienes resultan elegidos por sus conciudadanos y con la finalidad de adecuar las penas a la naturaleza de los delitos cometidos, se ha considerado necesario limitar la posibilidad de que quien resulte condenado por delitos de terrorismo y que, por tanto, ha atentado gravemente contra la democracia y el propic Estado de Derecho acceda inmediatamente a cargos públicos representativos. Para ello, la pena de inhabilitación absoluta, configurada en el Código Penal hasta esta fecha como pena accesoria en los deljtos de terrorismo, se introduce como pena principal con una duración de seis a veinte años en el apartado segundo del nuevo artículo 579 .

\section{V}

Finalmente, en el articulo segundo de esta Ley, se introduce una modificación en la Ley Orgánica 5/2000. de 12 de enero, de responsabilidad penal de los menores, que se traduce en la incorporación de una nueva disposición adicional -y en la consecuente modificación técnica de algunos preceptos afectados por dicha cisposición-, que tiene por finalidad reforzar la aplicación de los principios inspiradores de la citada Ley a los menores implicados en delitos de terrorismo, así como conciliar tales principios con otros bienes constitucionalmente protegidos a los que ya se ha hecho reiterada alusión en esta exposición y que aqui se ven particularmente afectados por la creciente participación de menores, no sólo en las acciones de terrorismo urbano, sino en el resto de las actividades terroristas.

No se trata, en consecuencia, de excepcionar de la aplicación de la Ley 5/2000 a estos menores, ni tampoco de aplazar o graduar la entrada en vigor de la misma, prevista para el próximo 13 de enero de 2001 . sino de establecer las mínimas especialidades necesarias para que el enjuiciamiento de las conductas de los menores responsables de delitos terroristas se realice en las condiciones más adecuadas a la naturaleza de los supuestos que se enjuician y a la trascendencia de los mismos para el conjunto de la sociedad manteniendo sin excepción todas las especiales garantías procesales que, para los menores, ha establecido la Ley 5/2000, y para que la aplicación de las medidas rehabilitadoras. especialmente valiosas y complejas respecto de conductas que ponen radicalmente en cuestión los valores más elementales de la convivencia, pueda desarrollarse en condiciones ambientales favorables, con apoyos técnicos especializados, y por un tiempo suficiente para hacer eficaz el proceso rehabilitador.

A ello responden la articulación en la Audiencia Nacional de un Juez Central de Menores [apartados a) y b)], la posible prolongación de los plazos de internamiento [apartado c)] y la previsión de la ejecución de las medidas de internamiento que la Audiencia acuerde con el apoyo y control del personal especializado que el Gobierno ponga a disposición y bajo dirección de la propia Audiencia Nacional [apartados c) y d)]. Todo ello, sin mayores modificaciones de las faculiades que la Ley 5/2000 atribuye en estos procedimientos a Jueces y Fiscales, quienes mantienen un amplio margen para discriminar de acuerdo con la diferente gravedad de las conductas el tiempo de duración del internamiento, y para flexibilizar el régimen del menor, mediante modificación, suspensión o sustitución de la medida impuesta, especialmente en lo que se refiere a los menores de dieciséis años.

Del mismo modo que, según acaba de señalarse, se considera conveniente establecer un tratamiento diferenciado entre los menores de dieciséis años y los de edades comprendidas entre los dieciséis y los dieciocho años, se consolida lo que, por otra parte se deduce ya de lo dispuesto en el articulo 4 de la Ley reguladora de la responsabilidad penal de los menores, como es que no procede aplicar dicha norma a los jóvenes mayores de dieciocho años.

Por último, y a consecuencia de las modificaciones de la Ley $5 / 2000$, previstas en esta Ley, relativas al Juzgado Central de Menores, los articulos tercero y cuarto modifican, respectivamente, la Ley Orgánica 6/1985, de 1 de julio, del Poder Judicial, y la Ley 38/1988, de 28 de diciembre, de Demarcación y de Planta Judicial.

\section{Artículo primero. Modificaciones de la Ley Orgánica} 10/1995, de 23 de noviembre, del Código Penal.

Los articulos $40,266,346,351,504,505,551$, 577.578 y 579 de la Ley Orgánica 10/1995, de 23 de noviembre, del Código Penal, se modifican en los siguientes términas:

Primero. Se modifica el articulo 40, quedando redactado en los siguientes términos:

"La pena de inhabilitación absoluta tendrá una duración de seis a veinte años, salvo lo que excepcionalmente dispongan otros preceptos del presente Código; las de inhabilitación especial, de seis meses a veinte años la de suspensión de empleo o cargo público, de seis meses a seis años; la de privación del derecho a conducir vehículos a motor y ciclomotores y la de privación del derecho a la 
tenencia y porte de armas, de tres meses a diez años; la de privación de! derecho a residir o acudir a determinados lugares, de seis meses a cinco años, y la de trabajos en beneficio de la comunidad, de un dia a un año.n

Segundo. Se modifica el artículo 266, quedando redactado en los siguientes términos:

11. Será castigado con la pena de prisión de una a tres años el que cometiere los daños previstos en el artículo 263 mediante incendio, o provocando expiosiones o utilizando cualquier atro medio de similar potencia destructiva, o poniendo en peligro la vida o la integridad de las personas.

2. Será castigado con la pena de prisión de tres a cinco años y multa de doce a veinticuatro meses el que cometiere los daños previstos en el artículo 264, en cualquiera de las circunstancias mencionadas en el apartado anterior.

3. Será castigado con la pena de prisión de cuatro a ocho años el que cometiere los daños previstos en los articulos 265,323 y 560 , en cualquiera de las circunstancias mencionadas en el apartado 1 del presente articulo.

4. En cualquiera de los supuestos previstos en los apartados anteriores, cuando se cometieren los daños concurriendo la provocación de explosiones - la utilización de otros medios de similar potencia destructiva y, además, se pusiera en peligro la vida o integridad de las personas, la pena se impondrá en su mitad superior.

En caso de incendio será de aplicación lo dispuesto en el articulo $351 .$,

Tercero. Se adiciona al artículo 346 el siguiente inciso, al final de su párrafo primero:

"Cuando no concurriere tal peligro, se castigarán como daños previstos en el articulo 266 de este Código."

Cuarto. Se adiciona al articulo 351 un segundo párrafo, del siguiente tenor:

"Cuando no concurra tal peligro para la vida o integridad fisica de las personas, los hechos se castigarán como daños previstos en el articulo 266 de este Código.”

Quinto. Se modifica el articulo 504, quedando redactado en los siguientes términos:

41. Incurrirán en la pena de multa de doce a dieciocho meses los que calumnien, injurien o amenacen gravemente al Gobiemo de la Nación, al Consejo General del Poder Judicial, al Tribunal Constitucional, al Tribunal Supremo, o al Consejo de Gobierno o al Tribunal Superior de Justicia de una Comunidad Autónoma.

El culpable de calumnias o injurias conforme a lo dispuesto en el párrafo anterior quedará exento de pena si se dan las circunstancias previstas, respectivamente, en los articulos 207 y 210 de este Código.

Se impondrá la pena de prisión de tres a cinco años a los que empleen fuerza, violencia o intimidación para impedir a los miembros de dichos Organismos asistir a sus respectivas reuniones.

2. Los que injuriaren o amenazaren gravemente a los Ejércitos. Clases o Cuerpos y Fuerzas de
Seguridad, serán castigados con la pena de multa de doce a dieciocho meses.

El culpable de las injurias previstas en el párrafo anterior quedará exento de pena si se dan las circunstancias descritas en el articulo 210 de este Código."

Sexto. Se modifica el artículo 505, quedando redactado en los siguientes términos:

"Incurrirán en la pena de prisión de seis meses a un año quienes, sin ser miembro de la Corporación local, perturben de forma grave el orden de sus plenos impidiendo el desarrollo del orden del día previsto, la adopción de acuerdos o causen desórdenes que tengan por objeto manifestar el apoyo a bandas armadas, organizaciones o grupos terroristas."

Séptimo. Se modifica el apartado 2 del artículo 551. quedando redactado en los siguientes términos:

42. No obstante lo previsto en el apartado anterior, si la autoridad contra la que se atentare fuera miembro del Gobierno, de los Consejos de Gobierno de las Comunidades Autónomas, del Congreso de los Diputados, del Senado o de las Asambleas Legislativas de las Comunidades Autónomas, de las Corporaciones locales, del Consejo General del Poder Judicial o Magistrado del Tribunal Constitucional, se impondrá la pena de prisión de cuatro a seis años y multa de seis a doce meses.n

Octavo. Se modifica el artículo 577, quedando redactado en los siguientes términcs:

"Los que, sin pertenecer a banda armada, organización o grupo terrorista, y con la finalidad de subvertir el orden constitucional o de alterar gravemente la paz pública, o la de contribuir a estos fines atemorizando a los habitantes de una población o a los miembros de un colectivo social, politico - profesional, cometieren homicidios, lesiones de las tipificadas en los articulos 147 a 150, detenciones ilegales, secuestros, amenazas o coacciones contra las personas, o llevaren a cabo cualesquiera delitos de incendios, estragos, daños de los tipificados en los artículos 263 a 266. 323 ó 560 , - tenencia, fabricación, depósito, tráfico, transporte o suministro de armas, municiones o sustancias o aparatos explosivos, inflamables, incendiarios o asfixiantes, 0 de sus componentes, serán castigados con la pena que corresponda al hecho cometido en su mitad superior."

Noveno. Se modifica el artículo 578, quedando redactado en los siguientes términos:

"El enaltecimiento o la justificación por cualquier medio de expresión pública o difusión de los delitos comprendidos en los artículos 571 a 577 de este Código a de quienes hayan participado en su ejecución, o la realización de actos que entrañen descrédito, menosprecio o humillación de las victimas de los delitos terroristas o de sus familiares se castigará con la pena de prisión de uno a dos años. El Juez también podrá acordar en la sentencia, durante el periodo de tiempo que el mismo señale, alguna o algunas de las prohibiciones previstas en el articulo 57 de este Código."

Décimo. Se modifica el artículo 579, quedando redactado en los siguientes términos:

"1. La provocación, la conspiración y la proposición para cometer los delitos previstos en los 
articulos 571 a 578 se castigarán con la pena inferior en uno o dos grados a la que corresponda, respectivamente, a los hechos previstos en los articulos anteriores.

2. Los responsables de los delitos previstos en esta sección, sin perjuicio de las penas que correspondan con arreglo a los artículos precedentes, serán también castigados con la pena de inhabjlitación absoluta por un tiempo superior entre seis y veinte años al de la duración de la pena de privación de libertad impuesta, en su caso, en la sentencia, atendiendo proporcionalmente a la gravedad del delito, el numero de los cometidos y a las circunstancias que concurran en el delincuente.

3. En los delitos previstos en esta sección, los Jueces y Tribunales, razonándolo en sentencia, podrán imponer la pena inferior en uno o dos grados a la señalada por la Ley para el delito de que se trate, cuando el sujeto haya abandonado voluntariamente sus actividades delictivas y se presente a las autoridades confesando los hechos en que haya participado y además colabore activamente con éstas para impedir la producción del delito o coadyuve eficazmente a la obtención de pruebas decisivas para la identificación o captura de otros responsables o para impedir la actuación o el desarrollo de bandas armadas, organizaciones o grupos terroristas a los que haya pertenecido o con los que haya colaborado."

Artículo segundo. Modificación de la Ley Orgánica $5 / 2000$, de 12 de enero, reguladora de la responsabilidad penal de los menores.

Se modifican los artículos 7 y 9 y se incorpora una disposición adicional en la Ley Orgánica $5 / 2000$ de 12 de enero, reguladora de la responsabilidad penal de los menores, en los siguientes términos:

Primero. Se adiciona una nueva letra n) al apartado 1 del articulo 7. con la siguiente redacción:

un) Inhabilitación absoluta. De conformidad con lo previsto en la disposición adicional cuarta,

la medida de inhabilitación absoluta produce la privación definitiva de todos los honores, empleos y cargos públicos sobre el que recayere, aunque sean electivos; asi como la incapacidad para obtener los mismos a cualesquiera otros honores, cargos o empleos públicos, y la de ser elegido para cargo público, durante el tiempo de la medida.n

Segundo. Los párrafos primero y tercero de la regla 5. ${ }^{g}$ del artículo 9 quedan redactados en los siguientes términos:

$15^{\circ}$ Excepcionalmente, cuando los supuestos previstos en la regla anterior revistieran extrema gravedad, apreciada expresamente en la sentencia, el Juez habrá de imponer una medida de internamiento de régimen cerrado de uno a cinco años de duración, complementada sucesivamente por otra medida de libertad vigilada con asistencia educativa hasta un máximo de otros cinco años. Sólo podrá hacerse uso de lo dispuesto en los artículos 14 y 51.1 de esta Ley una vez transcurrido el primer año de cumplimiento efectivo de la medida de internamiento. Todo ello sin perjuicio de 10 previsto en la disposición adicional cuarta..

«A los efectos de este artículo, se entenderán siempre supuestos de extrema gravedad aquellos en los que se apreciara reincidencian"

Tercero. Se introduce una nueva disposición adicional cuarta en la Ley Orgánica 5/2000, de 12 de enero. reguladora de la Responsabilidad Penal de los Menores, con la siguiente redacción

"Disposición adicional cuarta. Aplicación a los delitos previstos en los articulos $138,139,179$. 180,571 a 580 y aquellos otros sancionados en el Código Penal con pena de prisión igual o superior a quince años.

1. Lo dispuesto en el articulo 4 de la presente Ley Orgánica no será de aplicación a los mayores de dieciocho años imputados en la comisión de los delitos a que se refiere esta disposición adicional.

2. A los imputados en la comisión de los delitos mencionados en el apartado anterior, menores de dieciocho años, se les aplicarán las disposiciones de la presente Ley Orgánica, con las siguientes especialidades:

a) La competencia para conocer de los delitos previstos en los artículos 571 a 580 del Código Penal corresponderá al Juzgado Central de Menores de la Audiencia Nacional, cuyos autos y sentencias podrán ser objeto de recurso de apelación ante la Sala correspondiente de la propia Audiencia. Las sentencias dictadas en apelación por la Audiencia Nacional serán recurribles en casación conforme a lo dispuesto en el artículo 42 de esta Ley Orgánica. El Gobierno promoverá la necesaria adecuación de la estructura de la Audiencia Nacional, conforme a lo previsto en la disposición final segunda, apartado 1, de esta Ley Orgánica.

b) Los procedimientos competencia de la Audiencia Nacional no podrán ser objeto de acumulación con otros procedimientos instruidos en el ámbito de la jurisdicción de menores, sean o no los mismos los sujetos imputados.

c) Cuando alguno de los hechos cometidos sea de los previstos en esta disposición adicional y el responsable del delito fuera mayor de clieciséis años, el Juez impondrá una medida de internamiento en régimen cerrado de uno a ocho años, camplementada, en su caso, por otra medida de libertad vigilada, hasta un máximo de cinco años, con el cumplimiento de los requisitos establecidos en el párrafo segundo de la regla $5 .^{8}$ del artículo 9 de esta Ley Orgánica. En este supuesto sólo podrá hacerse uso de las facultades de modificación suspensión o sustitución de la medida impuesta a las que se refieren los articulos 14,40 y 51.1 de esta Ley Orgánica, cuando haya transcurrido, al menos, la mitad de la duración de la medida de internamiento impuesta.

Si los responsables de estos delitos son menores de dieciséis años, el Juez impondrá una medida de internamiento en régimen cerrado de uno a cuatro años, complementada, en su caso, por otra medida de libertad vigilada, hasta un máximo de tres años, con el cumplimiento de los requisitos establecidos en el párrafo segundo de la regla 5. del articulo 9 de esta Ley Orgánica.

No obstante lo previsto en los dos párrafos anteriores, la medida de internamiento en régimen cerrado podrá alcanzar una duración máxima de diez años para los mayores de dieciséis años y de cinco años para los menores de esa edad, cuando fueren responsables de más de un delito, alguno de los cuales esté calificado como grave y sancionado con pena de prisión igual o superior a quince años de los delitos de terrorismo comprendidos entre los artículos 571 a 580 del Código Penal.

Cuando se trate de los delitos previstos en los artículos 571 a 580 , el Juez, sin perjuicio de otras 
medidas que correspondan con arreglo a esta Ley Orgánica, también impondrá la medida de inhabilitación absoluta por un tiempo superior entre cuatro y quince años al de la duración de la medida de internamiento en régimen cerrado impuesta, atendiendo proporcionalmente a la gravedad del delito, el número de los cometidos y a las circunstancias que concurran en el menor.

d) La ejecución de la detención preventiva, de las medidas cautelares de internamiento o de las medidas impuestas en la sentencia se llevará a cabo en los establecimientos y con el control del personal especializado que el Gobjerno ponga a disposición de la Audiencia Nacional, en su caso, mediante convenio con las Comunidades Autónomas.

e) La ejecución de las medidas impuestas por el Juez Central de Menores o por la Sala correspondiente de la Audiencia Nacional será preferente sobre las impuestas, en su caso, por otros Jueces o Salas de Menores.

f) Los hechos delictivos $\gamma$ las medidas previstas en esta disposición prescribirán con arreglo a las normas contenidas en el Código Penal.

a) La referencia del último inciso del apartado 4 del artículo 17 y cuantas otras se contienen en la presente Ley al Juez de Menores se entenderán hechas al Juez Central de Mencres en lo que afecta a los menores imputados por cualquiera de los delitos a que se refieren los articulos 571 a 580 del Código Penal,»

Cuarto. Se introduce una nueva disposición adicional quinta en la Ley Orgánica $5 / 2000$, de 12 de enero, reguladora de la Responsabilidad Penal de los Menores. con la siguiente redacción:

\section{«Disposición adicional quinta.}

El Gobiemo dentro del plazo de cinco años desde la entrada en vigor de esta Ley Orgánica remitirá al Congreso de los Diputados un informe, en el que se analizarán y evaluarán los efectos y las con secuencias de la aplicación de la disposición adicional cuarta.n

Artículo tercero. Modificación de la Ley Orgánica 6/1985, de 1 de julio, del Poder Judicial.

Se modifican los articulos 65 y 96 de la Ley Orgánica $6 / 1985$ de 1 de julio, del Poder Judicial, en los siguientes términos:

Primero. Se modifica el apartado $5 .^{\circ}$ del articulo 65 , que queda redactado de la siguiente manera:

"De los recursos establecidos en la Ley contra las sentencias y otras resoluciones de los Juzgados Centrales de lo Penal, de los Juzgados Centrales de Instrucción y del Juzgado Central de Menores.n

Segundo. Se introduce un segundo apartado en el articulo 96 , con el contenido que a continuación se recoge, pasando el actual contenido de dicho artículo a constituir un nuevo apartado 1:

«1. En cada provincia, con jurisdicción en toda ella y sede en su capital, habrá uno o más Juzgados de Menores. No obstante, cuando el volumen de trabajo lo aconseje, podrán establecerse Juzgados de Menores cuya jurisdicción se extienda o bien a un partido determinado o agrupación de partidos. o bien a dos o más provincias de la misma Comunidad Autónoma. Tomarán su nombre de la población donde radique su sede.
2. En la villa de Madrid, con jurisdicción en toda España, habrá un Juzgado Central de Menores, que conocerá de las causas que le atribuya la legislación reguladora de la responsabilidad penal de los menores."

Artículo cuarto. Modificación de la Ley 38/1988, de 28 de diciembre, de Demarcación y de Planta Judicial.

Se modifican los artículos 1, 6, 19 y 61 de la Ley $38 / 1988$ de 28 de diciembre, de Demarcación $y$ de Planta Judicial, en los siguientes términos:

Primero. Se modifica el artículo 1, que queda redactado de la siguiente manera:

«El Tribunal Supremo, la Audiencia Nacional, los Juzgados Centrales de Instrucción, los Juzgados Centrales de lo Penal, los Juzgados Centrales de 10 Contencioso-Administrativo y el Juzgado Central de Menores tienen jurisdicción en toda España..

Segundo. Se modifica el articulo 6, que queda redactado de la siguiente manera:

«El Tribunal Supremo, la Audiencia Nacional, los Juzgados Centrales de Instrucción, los Juzgados Centrales de lo Penal, los Juzgados Centrales de lo Contencioso-administrativo y el Juzgado Central de Menores tienen su sede en la Villa de Madrid."

Tercero. Se modifica el articulo 19, que queda redactado de la siguiente manera:

41. La planta del Juzgado Central de Menores y de los Juzgados de Menores es la establecida en el anexo XI de esta Ley.

2. El Juzgado Central de Menores y los Juzgados de Menores deberán ser servidos por Magistrados.

3. La provisión del Juzgado Central de Menores y de los Juzgados de Menores se hace mediante concurso, que se resuelve a favor de quienes acrediten la especialización correspondiente en la Escuela Judicial y tengan mejor puesto en el escalafón y, en su defecto, a favor de los Magistrados con mejor puesto en el escalafón.»

Cuarto Se modifica el artículo 61, que queda redac tado de la siguiente manera:

"1. Los Juzgados de Menores tendrán la competencia establecida en la legisiación reguladora de la responsabilidad penal de los menores.

2. Las Audiencias Provinciales conocerán de los recursos interpuestos contra las resoluciones de los Juzgados de Menores en el ámbito de su respectiva provincia, sin perjuicio de lo dispuesto en la legislación reguladora de la responsabilidad penal de los menores para la Audiencia Nacional.

Quinto. Se modifica parcialmente el anexo $X \mid d e$ la Ley $38 / 1988$, de 28 de diciembre, en el sentido de incorporar al mismo un Juzgado Central de Menores.

\section{Disposición adicional única.}

Todos los preceptos contenidos en la presente Ley tienen carácter orgánico, con excepción de lo dispuesto en el artículo cuarto, que tiene carácter ordinario.

\section{Disposición final única. Entrada en vigor.}

La presente Ley Orgánica entrará en vigor el dia siguiente al de su publicación en el «Boletin Oficial del 
Estadon, con excepción de lo dispuesto en su artículo segundo, que entrará en vigor el día en que lo haga la Ley Orgánica $5 / 2000$, de 12 de enero, reguladora de la Responsabilidad Penal de los Menores.

Por tanto.

Mando a todos los españoles, particulares y autoridades, que guarden y hagan guardar esta Ley Orgánica.

Madrid, 22 de diciembre de 2000.

JUAN CARLOS R.

El Presidente del Gobierno,

JOSÉ MARIA AZNAR LÓPEZ 


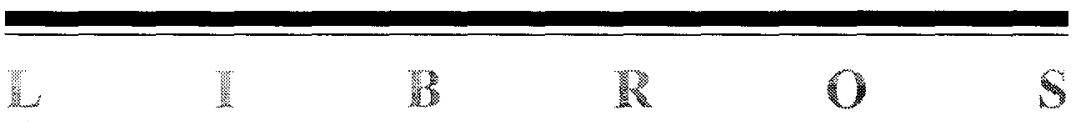



Título: La Violencia Doméstica. Una nueva visión de un viejo problema

Autora: A. Mullender

Traduc.: M. Jiménez

Edita: Paidós, Colección Trabajo Social, 9. Barcelona, 2000

Uno de los más graves problemas sociales con los que actualmente se enfrenta la sociedad contemporánea es el de la violencia doméstica, que en los últimos años ha experimentado un desarrollo espectacular, tal vez porque la crisis social y laboral afecta a la familia o tal vez porque la violencia se denuncia y surge al exterior, o quizá se trate de ambas cuestiones. Sea cual sea la causa, encontramos que la violencia doméstica está cobrando una virulencia inusitada en nuestra sociedad, hasta el punto que puede considerarse un mal endémico.

Ultimamente, raro es el día en que no aparece en los medios de comunicación algún caso grave de violencia doméstica, en muchos casos con resultado de muerte, situación que lleva a la sociedad a la indignación y a la perplejidad, sin embargo, todavía hoy, en muchos casos existe un pacto de silencio entre familiares y el entorno vecinal o de amistades, con el pretexto de que lo que ocurre en el interior del hogar es un asunto privado.

Es frecuente, pues que en la práctica cotidiana del trabajo social nos enfrentemos a estas situaciones, en algunos casos, abiertamente denunciadas por las mujeres, en otros casos, tristemente, la mayoría, ocultadas como parte de los "secretos" de la familia. En cualquier caso, es evidente que se precisa de contribuciones rigurosas que orienten la práctica del tratamiento de estas situaciones.

Y esto es precisamente lo que ofrece este nuevo libro de la colección Trabajo Social de Paidós. No sólo recomienda estrategias a seguir para detectar la problemática, sino que también da orientaciones acer- 
ca de cómo enfocar el tratamiento.

El libro, además, realiza un recorrido sobre los mitos que existen en torno a esta cuestión y que contribuyen a reforzar el problema, apostando por una interpretación de aquél que tiene que ver con las diferencias entre los géneros y el abuso de poder de los hombres sobre las mujeres; abuso que lleva a un control de las relaciones emocionales o a la agresión física o a ambas situaciones a la vez. Además, ofrece una interpretación de la violencia doméstica como un fenómeno universal, presente en todas las épocas y en todas las culturas, enraizado con la propia naturaleza de la sociedad patriarcal.

Pero, además, y esto es lo interesante de esta obra, la autora reflexiona sobre el papel de los y las Trabajadores/as Sociales ante este grave problema y cuestiona muchas de las intervenciones que se han realizado, aceptando las creencias erróneas y perjudiciales para la mujer sobre violencia doméstica y, por tanto, contribuyendo inconscientemente a reforzar la situación.

$\mathrm{Da}$ indicaciones también, para el abordaje del problema desde el punto de vista del Trabajo Social, cuestión que es de agradecer porque hasta ahora los enfoques han sido más bien dirigidos a psicólogos y no tanto a profesionales de los servicios sociales.

Es, por tanto, una obra aconsejable, no sólo para profesionales que trabajen directamente con el tema de la violencia doméstica, sino también para reflexionar sobre la responsabilidad que tenemos los profesionales de ayuda a la hora de hacer una interpretación justa y honesta de los problemas de nuestros clientes y, por tanto, poder ofrecer ayudas adecuadas para contribuir a eliminar un problema que afecta a hombres y mujeres, cual es el de la violencia doméstica.

$M^{a}$ José Escartín Caparros.

Departamento de Trabajo Social y Servicios Sociales Universidad de Alicante. 
Título: Nuevas perspectivas de los Servicios Sociales.

Coord.: José A. Díaz Martínez y M. ${ }^{a}$ José Salvador Pedraza

Edita: Universidad Nacional de Educación a Distancia. Madrid, 2000.

El libro se compone de 8 capítulos escritos por distintos autores, que abordan la necesidad de incorporar determinados planteamientos para seguir avanzando en el desarrollo de los servicios sociales. Los cambios que se producen en la sociedad y su influencia en las necesidades sociales, tanto individuales como colectivas, aconsejan introducir modificaciones en los Servicios Sociales y adaptarse a estos cambios para ser útiles a la sociedad.

En «Los Derechos Sociales en España y en la Unión Europea: marco actual y líneas prospectivas», escrito por Manuel Aznar López, se analizan los derechos sociales desde el punto de vista de la exigibilidad y hasta qué punto se garantiza la prestación de los servicios que los materialicen. Aborda igualmente la situación en la Unión Europea y establece una líneas de por dónde se debería caminar para que realmente los servicios sean accesibles a todos los ciudadanos, especialmente a aquellos que más dificultades tienen para hacerlos efectivos.

Carmen Alemán Bracho y Margarita Pérez Sánchez, en el capítulo sobre «Nuevas estrategias para el avance de los Servicios Sociales. Nueva gestión, análisis y evaluación», analizan, en primer lugar, los logros conseguidos en los Servicios Sociales, para pasar a plantear un nuevo modelo de gestión basándose en tres elementos básicos: servicio, cliente y estrategia organizativa. Finaliza el capítulo con el tema de la evaluación y los aspectos esenciales a valorar.

En «Prospectiva y planificación estratégica de Servicios Sociales», José Antonio Díez Martínez y Ana Buñuel Heras tratan del tema de la planificación estratégica, el proceso y todos los aspectos a tener en cuenta para ello, desarrollando por último el modo de implantación de 
dicha planificación.

En el capítulo sobre «Los proyectos de intervención integral en el ámbito de los Servicios Sociales en cooperación con otras Redes y Sistemas de Bienestar Social», Natividad de la Red Vega y Carmen Conde Rodríguez justifican la necesidad de desarrollar proyectos de actuación integrales como mejor modo de abordar las situaciones de necesidad desde los servicios sociales. Analizan los distintos marcos desde los que se debe establecer y las dimensiones a tener en cuenta en la intervención de carácter integral.

Francisco Javier Jimeno de la Maza, en «Aplicaciones del análisis económico y financiero en los Servicios Sociales y en la planificación» aborda ampliamente sobre cuestiones económicas y financieras en los servicios sociales. En su análisis parte de que no se pueden valorar dichos servicios sólo con criterios económicos, sino que hay que tener en cuenta la función social que cumplen, para lo que se debe incluir criterios basados en la eficiencia social y la equidad. Establece distintos indicadores que se podrían incluir para su valoración.

«Calidad y Servicios Sociales», escrito por $M^{\mathrm{a}}$ José Salvador Pedraza, gira en torno a la calidad en la prestación de servicios sociales, señalando como imprescindible que se incorpore esta cuestión en su gestión, para evitar los efectos que puede tener la no inclusión de la calidad. Presenta los aspectos a considerar para valorarla, entre ellos la satisfacción de los beneficiarios y los posibles indicadores relacionados con la calidad.

José Daniel Rueda Estrada, en «Redes de apoyo y Servicios Sociales» se centra en las redes de apoyo y los servicios sociales, planteando la dinamización de la sociedad en los nuevos movimientos sociales y la formación de distintos tipos de redes sociales que sirven de apoyo a los ciudadanos y la importancia creciente que está teniendo el tercer sector. Dicho sector debe actuar conjuntamente con los servicios públicos, ya que ambos se complementan.

Por último, $\mathrm{M}^{\mathrm{a}}$ Asunción Martínez Román, en el capítulo sobre «Pobreza, exclusión social y cultura de paz», establece la interrelación que hay entre los tres conceptos y la necesidad de abordar los dos primeros para conseguir una mayor justicia social y una cultura de paz, todo ello facilitará que las personas puedan lograr su desarrollo humano. La pobreza y la exclusión social se pueden evitar si hay voluntad política, lo que corresponde tanto a los representantes democráticamente elegidos, como a los propios ciudadanos. Su propuesta es promover no sólo solidaridad, sino una cultura de paz, promoviendo opciones de aprendizaje y ejercicio de las capacidades de participación social vinculadas al 
ámbito político.

Todas las aportaciones y reflexiones que los autores plantean en este libro serán de gran utilidad para los profesionales que actúan en el ámbito de los Servicios Sociales, así como para los estudiantes de Trabajo social, ya que nos ayuda a cuestionarnos aspectos importantes sobre las posibles nuevas orientaciones a desarrollar desde los Servicios Sociales.

Hortensia Redero Bellido

Departamento de Trabajo Social y Servicios Sociales Universidad de Alicante 


\section{Título: Política Social. Una introducción}

\section{Autora: Teresa Montagut}

Edita: Ariel. Barcelona, 2000

Dice Esping-Andersen, en el prólogo que abre este libro, que la opinión pública considera que el Estado del bienestar está condenado, "destinado a ir a parar al cubo de la basura de los experimentos históricos fallidos". Es ésta quizá la única objeción que hacer a toda la obra. Si la opinión pública es la que, aun adelgazada y simplificada, transmite los estudios de opinión, no cabe estar de acuerdo con esta afirmación. Bien al contrario, esa opinión pública conformada parece mucho más fiel y comprometida en la defensa del Estado del bienestar que la mayoría de las opiniones publicadas. Incluso, si consideramos el voto como la forma legítima de expresión de dicha opinión en Europa, la adhesión al Estado de bienestar es mayoritaria.

El Estado del bienestar es objeto de interés público, político y científico, y lo ha sido de forma permanente a lo largo de las tres últimas décadas. No es extraño que así sea. El Estado de bienestar está en la agenda política porque forma parte, seguramente junto a la seguridad, de esos problemas con los que se ganan o se pierden elecciones. Preocupa a los ciudadanos, porque les afecta muy directamente, porque tienen intereses, bien es cierto que selectivos, en su mantenimiento y desarrollo. Forma parte de los intereses de la ciencia, porque una gran parte de la ciencia no es, ni siquiera lo pretende, ajena a los intereses políticos y sociales.

Es posible que tengamos que ir pensando en erradicar la ya vieja fórmula de la crisis del Estado del bienestar, que, enunciada en su inicio por el pensamiento de izquierda, fue acogida gustosamente por aquellos interesados en hacer efectiva su crisis. La crisis, como una profecía autocumplida, parece amenazar el bienestar que tantos ciuda- 
danos defienden cada día. Es posible que, frente a la evolución social, sea mucho más interesante hablar de la necesidad ineludible y creciente del Estado del bienestar, en mayor medida que, en la práctica eludida, de la crisis del bienestar social.

El libro de Teresa Montagut, que ella misma califica de introducción, puede quizá engañar al lector no avisado, pues no se trata de un conjunto de cuestiones preliminares al tratamiento de un problema, sino bien al contrario, de un recorrido muy amplio por todas las cuestiones esenciales que forman parte de los debates sobre el Estado de bienestar. Un recorrido que ella enfrenta con la seguridad de quien conoce esos debates y quiere ponerlos a disposición del lector, como si se tratara de una guía para orientarse con seguridad entre términos, conceptos, teorías y perspectivas casi siempre presentados bajos formas más arduas.

Si algo habría que destacar de este libro, por muchos motivos reseñable, es, en primer lugar, su enfoque. La política social y el Estado del bienestar son enfrentados desde una perspectiva muy amplia: la historia, la Economía, la Sociología y el Trabajo Social permiten un acercamiento realmente interdisciplinar, infrecuente en la práctica por más que los científicos sociales afirmen su necesidad. En segundo lugar, el esfuerzo de la autora por traducir a palabras sencillas lo que ella ha aprendido en jergas mucho más académicas. Éste es, sin ninguna duda, el libro de una profesora que se impone el deber de interesar para enseñar, y trata de que el lenguaje y la erudición no sean barreras que separen a los alumnos del conocimiento, haciendo que el manejo de los conceptos y la erudición se reflejen en la estructura de la obra y en sus contenidos.

El estudiante o el lector poco avezado agradecerán esta introducción de la que, sin duda, aprenderán mucho. Los que frecuenten la literatura especializada admirarán el esfuerzo de concisión, claridad expositiva y ambición de miras del libro. Estos tres requisitos deberían formar parte de un manual de disciplina intelectual para todos aquéllos que, formando parte de la opinión pública, tienen el privilegio de constituir la opinión publicada. 

W 

Seminario de la Federación Internacional de Trabajadores Sociales Asia Pacífico. "Millenium Challenges and Action for Social Work Education and Practice". Singapur, del 31 de julio al 3 de agosto de 2001 .

Secretaría:

Asia Pacific Social Work Conference 2001

Department of Social Work and Psychology

National University of Singapore

10 Kent Ridge Crescent

SINGAPORE 119260

Fax (65) 7781213

E-mail: swksec@nus.edu.sg

Seminario Europeo de la Federación Internacional de Trabajadores Sociales. "Managing Conflicts in Social Work-Dealing with Contradictions". Viena y Bratislava, del 27 al 30 de agosto 2001.

Secretaría:

Austrian Association of Social Workers

Mariahilferstrasse 81/1/14

A-1060 Vienna, AUSTRIA

Tel: (43) 15874656

Fax: (43) 1587465610

e-mail: oebds@ins.at

Website: www.sozialarbeit.at

Inscripción on-line: https://trust.nextra.at/vb1/tak_danube.htm 
Congreso Mundial de la Federación Internacional de Trabajadores Sociales (IFSW) "Building Effective Strategies in Social Work Practice in a New Era". Zimbawe, del 28 de julio al 2 de agosto de 2001.

\section{Secretaría:}

IFSW 2002 Conference Secretariat, Zimbabwe Convention Bureau (Pvt) Ltd.

Mr. Satchmo Witness

PO Box BE 1080. Belvedere, Harare, ZIMBABWE

Tel: (263) 4702811

Fax: (263) 4724242

e-mail: zcb@harare.iafrica.com

Programa de Doctorado. Curso 2000-2001. "Análisis del estado de bienestar: estrategias de intervención social". Departamento de Trabajo Social. Universidad Pública de Navarra.

Dirigido a titulados en Sociología, Filosofía, Psicología, Antropología, Historia, Economía, Ciencias de la Educación y Derecho, este programa tiene como objetivos: a) analizar de forma crítica el sistema social occidental llamado "Estado de Bienestar" y b) proponer estrategias de intervención social desde dicho estado, buscando elementos que ayuden a la cohesión social y eviten situaciones de exclusión, marginación, pobreza...

Se ofrece una formación teórico-práctica, desde una perspectiva interdisciplinar y tiene una duración mínima de tres años.

Información:

Tfno. 94819026

Fax 948169695

e-mail: milagros.lerendegui@unavarra.es 
NUMEROS PUBLICADOS 



\section{NUMERO 1 (1992)}

Jesús Daza Martínez, director.

Presentación

María José Escartín Caparrós. Profesora de Trabajo Social. E.U.T.S. Alicante

Consideraciones preliminares

\section{Estudios sobre la familia}

Isabel Ramírez de Mingo. Titular de Trabajo Social. Universidad Complutense. Madrid.

El Trabajo Social con familias

María Asunción Martínez Román, María Teresa Mira-Perceval Pastor, Hortensia Redero Bellido. E.U.T.S. de Alicante.

Función específica de la Familia en la atención social comunitaria: su valor como recurso para la sociedad

María José Escartín Caparrós. Profesora E.U.T.S. Alicante.

El Sistema familiar y el Trabajo Social

Dr. D. Agustín Bueno Bueno. Profesor del Departamento de Psicología de la Salud. Universidad de Alicante.

Estilos de vida familiar y riesgo social infantil

María Asunción Martínez Román. Profesora de Servicios Sociales. E.U.T.S. Alicante.

Participación de la Familia en el proceso de rehabilitación de los enfermos crónicos: Los Insuficientes Respiratorios Crónicos Graves (I.R.C.G.) y el Bienestar Social.

Josefa Lorenzo García, Manuela Palomar Villena, Esperanza Suárez Soto. Trabajadoras sociales. Profesoras de la E.U.T.S. Alicante.

Mujer y Fanilia. Reflexiones críticas desde nuestra experiencia profesional

Dr. Don Francisco Ortega Beviá. Director Master Terapia Familiar y Profesor Terapia Familiar, Curso Superior Psicosociológico. Da Elisa Pérez de Ayala Morenos Santa María. Profesora de Trabajo Social Familiar. Universidad de Sevilla.

La ilusión de las alternativas: vivir en pareja

Antonio Bellido Alonso, Esther Villegas Castrillo. Profesores del Area de Trabajo Social y Servicios Sociales. E.U.T.S., Alicante.

Influencia de la Familia en el desarrollo de pautas inadecuadas de conducta

Josep-Lluís Orts Molines. Profesor de Valencià a l'E.U.T.S. Universitat d'Alacant.

Idees sobre la familia a la tardor medieval a través de Lo Libre de les dones de Francesc Eiximenis (1327-1490).

M. ${ }^{2}$ Dolores Vargas Llovera. Profesora del Area de Antropología. Universidad de Alicante.

La función familiar en el actual pluralismo religioso: El caso de los Testigos de Jehová

Jesús Daza Martínez. Catedrático de Derecho Romano.

La ley de Divorcio de 1932. Presupuestos ideológicos y significación política 


\section{Tribuna Libre}

Manuel Moix Martínez. Catedrático de Trabajo Social y Serv. Sociales.

Problematismo del Bienestar Social

Esther Villegas Castrillo, Antonio Bellido Alonso. Profesores de Trabajo Social. E.U.T.S. Alicante.

La Teoria Sistémica en Trabajo Social. Criterios de apli-cación y observaciones críticas

Ana M. ${ }^{a}$ Herthogue. Trabajadora Social jubilada de la «Family Welfare Association» de Londres.

Relevancia de algunos conceptos y arquetipos de C. Jung para la labor profesional de los trabajadores sociales

Jorge Garcés Ferrer, M. ${ }^{a}$ José Lahoz Campos, Fco. José Ródenas Riga, Estrella Durá Ferrandis. Profesores de SS.SS. en la Escuela de Trabajo Social. U. de Valencia.

Valores y características de personalidad en estudiantes de Trabajo Social de la Comunidad Valenciana

\section{Actualidad bibliográfica}

María Asunción Martínez Román, María Teresa Mira-Perceval, Hortensia Redero Bellido. E.U.T.S. de Alicante. Jorge Garcés Ferrer. Escola Universitària de Treball Social. Universitat de València.

La familia

IV. Apéndice documental

Decreto 23/1988 de 8 de febrero, del Consell de la Generalitat Valenciana, de medidas de protección de menores en situación de desamparo en la Comunidad Valenciana

Orden de 20 de marzo de 1986, de la Conselleria de Trabajo y Seguridad Social, por la que se establece el recurso de familias Educadoras en la Comunidad Valenciana

Ley 21/1987, de 11 de noviembre, por la que se modifican determinados artículos del Código Civil y de la Ley de Enjuiciamiento Civil en materia de adopción

Decret 23/1988, de 8 de febrer, del Consell de la Generalitat Valenciana, de mesures de protecció de menors en situació de desamparament a la Comunitat Valenciana

Ordre de 20 de març de 1986, de la Conselleria de Treball i Seguretat Social, per la qual s'estableix el recurs de Famílies Educadores de la Comunitat Valenciana

\section{NUMERO 2 (1993)}

Jesús Daza Martínez.

Presentación

\section{Algunas claves del Estado social contemporáneo}

Jorge Hurtado Jordá. Profesor del Departamento de Ciencias Sociales y de la Educación. Universidad de Alicante.

Sociedad, Estado, tal vez mercado

Fermín Aliaga Aliaga. Profesor del Departamento de Economía Aplicada y Política Económica. Universidad de Alicante.

Política econónica y calidad de vida

Ramón Martín Mateo. Catedrático de Derecho Administrativo.

La cultura del ocio 


\section{Cuestiones teórico-prácticas sobre el Trabajo Social}

M. ${ }^{a}$ José Escartín Caparrós. Profesora titular de Trabajo Social de la EUTSA de Alicante

Influencia de las diferencias culturales en la relación de ayuda

Esperanza Suárez Soto, Manuela Palomar Villena. Profesoras titulares de Trabajo Social en la EUTSA de Alicante.

El cliente en Trabajo social. Cuestiones conceptuales y análisis tipológico

Esther Villegas Castrillo. Profesora titular de Trabajo Social en la EUTSA de Alicante.

El Trabajador Social en el trabajo de grupo

Antonio José Bellido Alonso. Profesor titular de Trabajo Social en la EUTSA de Alicante.

La primera entrevista en la relación de ayuda del Trabajo Social Individualizado

Josefa Lorenzo García. Profesora Titular de Trabajo Social en la EUTSA de Alicante.

La intervención profesional con familias multiproblema desde los Servicios Sociales Municipales

Manuela Palomar Villena y Esperanza Suárez Soto. Profesoras Titulares de Trabajo Social en la EUTSA de Alicante.

El modelo sistémico en el Trabajo Social familiar. Claves teóricas e intervención práctica

\section{Problemas y perspectivas de los servicios sociales}

Manuel Moix Martínez. Catedrático de Trabajo Social y Servicios Sociales.

«Universalidad» versus «Selectividad» en los Servicios Sociales. La «discriminación positiva».

María del Carmen Alemán Bracho. Catedrática de Servicios Sociales de la EUTS de la Universidad de Granada.

Una perspectiva de los Servicios Sociales en España

M. ${ }^{a}$ Asunción Martínez Román, M. ${ }^{a}$ Teresa Mira-Perceval Pastor y Hortensia Redero Bellido. Prof. titulares de SS.SS. de la EUTS de Alicante.

¿Viejos o nuevos? Orientaciones actuales de los Servicios Sociales en España

Rafael Barranco Vela. Profesor de Derecho Administrativo de la EUTS de la Universidad de Granada.

El principio de participación en las Leyes de Servicios Sociales

\section{Miscelánea}

Manuel Oliver Narbona y M. ${ }^{a}$ Dolores Vargas Llovera. Profesores del Departamento de Humanidades Contemporáneas. Y M. ${ }^{\mathrm{a}}$ José Escartín Caparrós, Josefa Lorenzo García, Antonio Bellido Alonso, Roberto Mohedano Menéndez, Manuela Palomar Villena, Esperanza Suárez Soto y Esther Villegas Castrillo. Profesores de Ia EUTS de Alicante.

Inmigración y cultura: Reflexiones críticas sobre las diferencias sociales y culturales que produce el hecho migratorio

Carmen Gimeno Escrig, Médica Experta Universitaria en Drogodependencias; $\mathrm{M}^{\mathrm{a}}$ Angeles Amérigo Martínez, Trabajadora Social y Experta Universitaria en Drogodependencias; $M^{a}$ José Martí García, Psicóloga Experta Universitaria en Drogodependencias.

Perfil de los drogodependientes y familias atendidos en el Servicio Municipal de Drogodependencias de la Vila Joiosa 
Francisco Martínez Carrasco y M.a Dolores Vargas Llovera. División de Antropología. EUTS de Alicante.

Cultura y salud mental. Influencia del medio institucional en los enfermos profundos adultos

Agustín Bueno Bueno. Departamento de Psicología de la Salud. Universidad de Alicante

Autoconcepto adolescente y clase social

\section{Actualidad bibliográfica}

M. Asunción Martínez Román, M* Teresa Mira-Perceval Pastor y Hortensia Redero Bellido. Prof. titulares de SS.SS. de la EUTS de Alicante.

Bienestar Social y Política Social

\section{NUMERO 3 (1995)}

M. Teresa Mira-Perceval Pastor. Directora E.U. Trabajo Social. Universidad de Alicante.

Presentación

M. 'José Escartín Caparrós, Esperanza Suárez Soto.

Editorial

\section{Trabajos sobre la mujer}

Jose Manuel Díez Fuentes. Universidad de Alicante.

República y Primer Franquismo: La mujer española entre el esplendor y la miseria, 1930-1950

M. $^{a}$ José Frau Llinares. Departamento Ciencias Sociales y de la Educación. Universidad de Alicante.

La tipificación sexual del trabajo mercantil. El caso valenciano

M.. Dolores Díez García y Sergio Quesada Rettschlag. Catedráticos Matemáticas E.U. Trabajo Social. Departamento de Economía Aplicada. Universidad de Alicante. Silvia M. ${ }^{a}$ Quesada Díez. ICADE. Madrid.

Una empresaria de los 90 . Análisis y valoración de un caso

María José Escartín Caparrós. Profesora titular de Trabajo Social. Universidad de Alicante.

Violencia y Mujer. La intervención de crisis con mujeres maltratadas y sus hijos

Trinidad Pablo Cervera, Ruth Pérez Segovia y M. ${ }^{a}$ Dolores Vargas Llovera. Area de Antropología. Escuela Universitaria de Trabajo Social. Universidad de Alicante.

Mujer, Familia y mundo rural. Dos modelos para un cambio social

Yolanda Domenech López. Profesora ayudante del Area de Trabajo Social y Servicios Sociales. Universidad de Alicante.

La situación de la mujer en Honduras

\section{Tribuna Libre}

Carmen Gimeno Escrig. Médica Servicio Municipal de Alcoholismo y Drogodependencia. Villajoyosa. Angeles Amérigo Martínez. Trabajadora Social, Servicio Municipal de Alcoholismo y Drogodependencia. Villajoyosa.

Programa de intervención en familias. Evaluación con el cuestionario de salud general de Goldberg.

Agustín Bueno Bueno. Profesor titular de Psicología Social de la Escuela Universitaria de Trabajo Social. Universidad de Alicante. $\mathrm{M}^{\mathrm{a}}$ Teresa MiraPerceval Pastor. Profesora titular de Servicios Sociales de la Escuela Uni- 
versitaria de Trabajo Social. Universidad de Alicante.

Reflexiones ante la Ley de la Infancia de la Comunidad Valenciana.

Antonio Gutiérrez Resa. Profesor titular de Servicios Sociales. Universidad de Zaragoza.

Las ONGs y su papel en el futuro de la sociedad

María José Gallego Ayilón. Trabajadora Social. Estrella Gualda Caballero. Socióloga. Octavio Vázquez Aguado. Trabajador Social. Departamento de Filosofía, Sociología y Trabajo Social. Universidad de Huelva.

Las ideas previas de los alumnos de $1^{\circ}$ de Trabajo Social de Huelva respecto a la profesión

Yolanda Domenech López. Profesora ayudante del Area de Trabajo Social y Servicios Sociales. Universidad de Alicante. Juan Carlos Gómez Díaz. Licenciado en Ciencias Económicas y Empresariales. Universidad de Alicante.

Una altennativa al trabajo social institucionalizado: El trabajo social en la empresa privada

\section{Apéndice documental}

Ley $7 / 1994$, de 5 de diciembre, de la Generalitat Valenciana, de la Infancia. DOGV n. ${ }^{\circ} 2$

La Declaración de Pekín. Conclusiones de la IV Conferencia Mundial sobre las Mujeres. Beijing. Septiembre 1995

\section{Libros}

M. ${ }^{a}$ Carmen Santos Aguado. Profesora de la E.U. de Trabajo Social de la Universidad Complutense de Madrid.

Título: "Las enseñanzas de Trabajo Social en España: 1932-1983. Estudio socio-educativo». Autora: M. ${ }^{a}$ Victoria Molina Sánchez

\section{NUMERO 4 (1996)}

Esperanza Suárez Soto. Directora técnica del consejo editorial de la revista "Alternativas. Cuadernos de Trabajo Social».

Presentación

\section{Trabajos sobre migración}

Abel Albet-Mas. Departamento de Geografía. Universidad Autónoma de Barcelona. Maria Dolors Garcia-Ramon. Universidad Autónoma de Barcelona. Joan Nogué-Font. Departamento de Geografía. Universidad de Gerona. Lluis Ruidor-Gorgas. Facultad de Humanidades. Universidad Pompeu Fabra. Barcelona.

Geografia, ordenación del territorio y colonialismo español en Marruecos.

Mikel de Epalza. Catedrático de Estudios Arabes e Islámicos. Universidad de Alicante

Estructuras de acogida de los moriscos emigrantes de España en el Magreb (siglos XIII a XVIII).

Joan Lacomba. Departamento de Trabajo Social y Servicios Sociales. Escuela Universitaria de Trabajo Social. Universidad de Valencia.

Identidad y religión en innigración. A propósito de las estrategias de inserción de los musulmanes senegaleses.

M. ${ }^{a}$ Dolores Vargas Llovera. Area de Antropología. Universidad de Alicante.

Inmigración, etnicidad y pluralismo cultural.

José Cabanes Hernández. Sociólogo. Luz Vera García. Trabajadora social. 
Asociación P.G. Arakerando. Alicante. María Isabel Bertomeu Martínez. Trabajadora social. Asociación P.G. Arakerando. Alicante.

Gitanos: historia de una migración.

D. Ribera, A. Reig, M. Carrillo, J.L. Talavera, A. Caruana, C. Ferrera, A. Majos, R. Climent, C. Clavijo, M. Verdú. Escuela Universitaria de Enfermería. Universidad de Alicante. Hospital General de Alicante. Facultad de Medicina. Universidad de Alicante. Ayto. de Alfaz del Pi (Alicante).

Hábitos y necesidades de cuidados en el colectivo de extranjeros de 80 y más años residentes en la costa mediterránea.

Mercedes González. Octavio Vázquez. Departamento de Filosofía, Sociología y Trabajo Social. Universidad de Huelva.

Trabajo social e inmigrantes. Las intervenciones del trabajo social.

Carmen Santos Aguado. Escuela Universitaria de Trabajo Social. Universidad Complutense de Madrid.

Trabajo social en el campo de actuación de immigración y refugio.

Socorro Escobar Rubio. Trabajadora social. IRCOSAN. Madrid. Nieves Gascón Navarro. Trabajadora social. Mancomunidad Intermunicipal de La Encina. Madrid.

Metodología del trabajo social con innigrantes y refugiados.

Ana M.* Ortiz Duque. Trabajadora social. Ayutamiento de Majadahonda. Madrid.

Fases de la intervención social con innigrantes.

M. Jesús Vega Pascual. Trabajadora social. Alto Comisariado de las Naciones Unidas para los Refugiados (ACNUR). Secretaria de la sección legal.

Fases de la intervención social con refugiados.

\section{Tribuna libre}

Nieves Lillo Herranz. Trabajadora social. Area de bienestar social del Excmo. Ayuntamiento de Elche (Alicante).

El educador gitano, profesional clave para una intervención integral con el pueblo gitano.

Sonia Ródenas Picardat. Trabajadora social. Asociación ciudadana contra el SIDA de la provincia de Alicante.

Grupos de ayuda mutua: una respuesta alternativa en la práctica del trabajo social.

Alfredo Hidalgo Lavié. E.U. Relaciones Laborales - Trabajo Social. Jerez. Universidad de Cádiz.

El marco juridico-administrativo de los Servicios Sociales de la Comunidad Autónoma Andaluza.

Jorge Hurtado Jordá. Departamento de Ciencias Sociales. Universidad de Alicante.

Lecciones de la informalidad.

Idris M. Iwaki. Hector O. Beaton. Ernesto A. López. Departamento de Sociología. Universidad de Oriente-Santiago. Cuba. Javier M. Ferrer. Departamento de Trabajo Social. Universidad de Alicante.

Turismo y cambio social en Santiago de Cuba.

III. Actualidad bibliográfica

Carmen Santos Aguado. M." Jesús Vega Pascual. Socorro Escobar Rubio. Ana M. ${ }^{2}$ Ortiz Duque.

Actualidad bibliográfica sobre inmigración y refugio. 


\section{Libros}

Gonzalo Musitu. Coordinador del Area de Psicología Social. Universidad de Valencia.

Titulo: "Estudio longitudinal de la presencia de la mujer en los medios de comunicación de prensa escita». Cuadernos de Investigación de Psicología Comunitaria. Universidad de Valencia. Nau Llibres. Valencia, 1996. Autor: José Ramón Bueno Abad.

\section{NUMERO 5 (1997)}

Esperanza Suárez Soto. Directora técnica del consejo editorial de la revista «Alternativas. Cuadernos de Trabajo Social».

Presentación

I. Trabajos sobre violencia

M.a Asunción Martínez Román. Departamento de Trabajo Social y Servicios Sociales. Universidad de Alicante.

"Pobreza y exclusión social como formas de violencia estructural". La lucha contra la pobreza y la exclusión social es la lucha por la paz.

Gonzalo Musitu Ochoa. Profesor y director del Area de Psicología Social. Facultad de Psicología. Universidad de Valencia.

Violencia y terrorismo: Un análisis desde la perspectiva ecológica.

E. Bosch-Fiol, M. Gili-Planas y V.A. Ferrer-Pérez. Departamento de Psicología. Universidad de las Islas Baleares.

La violencia donéstica como una forna de expresión deactitudes misóginas.

Dra. M.a Dolores Díez García. Profesora de la E.U. de Trabajo Social. Universidad de Alicante. Dr. Sergio Quesada Rettschlag. Profesor de la E.U. de Trabajo Social. Universidad de Alicante. M. ${ }^{3}$ Dolores Sala Bonmatí. Trabajadora social.

El maltrato a menores en la provincia de Alicante en el periodo 1980-1997.. Agustín Bueno Bueno. Profesor de Psicología Social. Universidad de Alicante.

El maltrato psicológicolemocional como expresión de violencia hacia la infancia.

Javier Domínguez, José R. Brocal, José J. Cases, Virginia Tovar y Agustín Bueno.

Análisis del programa de seguimiento de medidas judiciales de régimen abierto en la ciudad de Alicante durante 1996.

José Conrado Moya Mira. Psicólogo. Jefe de la Sección de Familia, Infancia y Juventud de la Dirección Territorial de Bienestar Social de Alicante Organización de los Servicios de Protección a la Infancia en la Comunidad Valenciana. Análisis normativo y funcional.

M. ${ }^{2}$ José Escartín Caparrós. Profesora Titular de Trabajo Social. Departamento de Trabajo Social y Servicios Sociales. Universidad de Alicante.

Los niños maltratados y sus familias. Algunas indicaciones para la intervención del trabajador social.

\section{Tribuna libre}

Salvador Amigó Borrás. Profesor asociado de la Facultad de Psicología. Universidad de Valencia.

El "problema de la droga" y la prevención del consumo de drogas: mitos y alternativas, con una especial referencia al consumo de cannabis.

M. ${ }^{2}$ José Salvador Pedraza, Eva Domínguez Sánchez, Raquel Carracedo Manzanera. Técnicos de la Consejería de Sanidad y Bienestar Social de la 
Junta de Castilla y León.

Marco operativo de las intervenciones de inserción asociadas a la percepción de rentas mínimas.

Jesús Moragón Nava. Trabajador Social. Centro de Salud de Atención Primaria. INSALUD. Albacete.

La realidad rural: situación en una región. La organización de equipanientos.

Trinidad Banda Gallego. Profesora titular de la Escuela Universitaria de Trabajo Social. Universidad de Huelva.

El debate sobre la provisión pluralista de los Servicios Sociales.

Víctor M. Giménez Bertomeu. Trabajador Social. Coordinador del Centro Social n. ${ }^{\circ} 4$. Servicios Municipales del Ayuntamiento de Alicante.

El trabajador social en la dirección de un Centro de Servicios Sociales.

Enrique di Carlo. Equipo E.I.E.M. Universidad Nacional de Mar del Plata. Argentina.

El paradigma humanista como sustancia del Trabajo Social. El Trabajo Social y el paradigma humanista dialéctico. Alternativa de reorganización teorética y metodología del trabajo social profesional

III. Libros

M. José Escartín Caparrós. Profesora Titular del Departamento de Trabajo Social y Servicios Sociales. Universidad de Alicante.

Título: "Violencia. Memoria amarga». Siglo XXI de España Editores, S.A. Madrid, 1997, 303 páginas. Autor: Javier Urra Portillo. Defensor del Menor en la Comunidad de Madrid.

M.' Asunción Martínez Román. Departamento de Trabajo Social y Servicios Sociales. Universidad de Alicante.

Título: «Los Modelos en Trabajo Social. Intervención con personas y familias». Siglo XXI de España Editores, S.A. Madrid, 1996, 405 páginas. Autora: Mathilde du Ranquet.

M. Victoria Molina Sánchez. Catedrática de Trabajo Social. Universidad Complutense de Madrid.

Título: «Introducción al Trabajo Social 1l. Trabajo Social con individuos y familias». Editorial Aguaclara. Alicante, 1997, 287 páginas. Autoras: Escartín Caparrós, M.J., Palomar Villena, M., Suárez Soto, E.

\section{NÚMERO 6 (1998)}

M. a Asunción Martínez Román y Hortensia Redero Bellido. Directora técnica y Secretaria respectivamente del Consejo Editorial de la Revista «Alternativas. Cuadernos de Trabajo Social».

Presentación.

I. El marco actual de la acción social: ¿Servicios Sociales públicos o privados?

M. ${ }^{2}$ del Carmen Alemán Bracho. Catedrática E.U. de Servicios Sociales. Universidad de Granada. Mercedes García Serrano. Univ. de Granada. Tercer sector: buscando el equilibrio entre solidaridad y eficiencia.

Michael Barratt Brown. Universidad de Sheffield (Reino Unido).

Defending the Welfare State.

Antonio Gutiérrez Resa. Catedrático E.U. de Trabajo Social y Servicios Sociales. Universidad de Zaragoza.

Público-privado. Un modo de intervenir en la sociedad global-local. ....

Manuel Enrique Medina Tornero. Profesor titular de Servicios Sociales. E.U. de Trabajo Social. Universidad de Murcia.

El debate de lo público y lo privado en Servicios Sociales. 


\section{Tribuna libre}

Agustín Bueno Bueno y Conrado Moya Mira. Area de Psicología Social. Universidad de Alicante.

La delincuencia juvenil como síntona: perspectivas de intervención psicosocial.

José Cabanes Hernández. Sociólogo. Servicios Sociales Municipales de Villena (Alicante). Monitor de minorías étnicas.

La escolarización de los niños gitanos ell el País Valenciano.

Yolanda Domenech López. Profesora titular de Trabajo Social de la E.U.T.S. Universidad de Alicante.

Los grupos de autoayuda como estrat. de intervención en el apoyo social.

Alfredo Hidalgo Lavié. Profesor de Servicios Sociales y Política Social. E.U. de Trabajo Social de Jerez de la Frontera. Universidad de Cádiz. Ciencia Política y Servicios Sociales. Del entendimiento al "concubinage».

Silvia Quesada Díez. Universidad Pontificia de Comillas, ICADE.

La acción social en la Unión Europea: evolución histórica.

Elena Roselló Nadal. Profesora ayudante del Depto. de Trabajo Social y Servicios Sociales. Universidad de Alicante.

Reflexiones sobre la intervención del trabajador social en el contexto educativo.

Ana Rosser Limiñana. Psicóloga de la Unidad de Adopción de la Conselleria de Bienestar Social. Alicante.

Marco legislativo del acogimiento familiar.

Octavio Vázquez Aguado. Profesor titular de E.U. Depto de Sociología y Trabajo Social. Universidad de Huelva.

Pensar la epistemología del Trabajo Social.

III. Libros

José María Tortosa. Catedrático de Sociología. Universidad de Alicante. Título: «Trabajo Social Experimental». Tirant lo Blanch. Valencia, 1998. Autora: Rosario Conde Megias.

\section{NÚMERO 7 (1999)}

M. Asunción Martínez Román. Directora técnica del Consejo Editorial de la Revista "Alternativas. Cuadernos de Trabajo Social».

Editorial

I. Integración sociolaboral.

Idoia Martín Aranaga. Profesora de la E.U. de Trabajo Social. Departamento de Sociología, Área de Trabajo Social y Servicios Sociales. Universidad del País Vasco.

Las Politicas de Inserción en la Unión Europea: una comparación Francia - Reino Unido - España.

Joaquín García Roca. Profesor de la E.U. de Trabajo Social. Departamento de Trabajo Social y Servicios Sociales. Universidad de Valencia.

Tercer sector e inserción social.

Carlos Arias. Centro Especial de Empleo Limencop, S.L.

Empresa de inserción. Centro Especial de Empleo Limencop, S.L.

Herminia Torreblanca y M. ${ }^{2}$ Francisca Albert. Trabajadoras Sociales del Departamento de Empleo de la Asociación de Padres y Amigos de Niños y Adolescentes Hipoacúsicos (A.P.A.N.A.H.)

Integración socio-laboral de personas con deficiencia auditiva. 
II. Tribuna libre

Esther Villegas Castrillo. Profesora de la E.U. de Trabajo Social. Departamento de Trabajo Social y Servicios Sociales. Universidad de Alicante. Autoconciencia personal y creatividad femenina. Un proceso abierto. Víctor M. Giménez Bertomeu. Trabajador Social. Coordinador del Centro Social Comunitario "Gastón Castelló". Servicios Sociales Municipales del Ayuntamiento de Alicante.

Polivalencia versus especialización. Aproximación a un modelo saludable de intervención primaria.

José Ramón Bueno Abad. Catedrático E.U. de Psicología Social. José Vicente Pérez Cosín. Profesor Asociado del Departamento de Trabajo Social y Servicios Sociales. E.U. de Trabajo Social. Universitat de València. Acoginiento familiar. Estudio de las interacciones ante las visitas familiares.

III. Documentos

Dictamen del Comité Económico y Social de la Unión Europea sobre la "Aplicación de las directrices para el empleo en 1999».

Ley 39/1999, de 5 de noviembre, para promover la conciliación de la vida familiar y laboral de las personas trabajadoras.

IV. Libros

M. Asunción Martínez Román. Catedrática de Trabajo Social y Servicios Sociales. Universidad de Alicante.

Título: "Hacia una economía plural. Un trabajo, una actividad, una renta para todos». Miraguano-Promocions. Madrid, 1999. Autores: Aznar, G., Caillé, A., Laville, J.L., Robin, J. y Sue, R.

Título: "Trabajar para vivir. Una propuesta innovadora de inserción sociolaborals. Miraguano-Promocions. Madrid, 1999. Autores: Frago, E., Jover, D., López, V.M., Márquez, F. y Mora, G.

Título: "Trabajo Social. Orientaciones y prácticas formativas». Editorial Gules. Valencia, 1999. Autores: Gómez Moya, J., Julve Negro, M. y Pérez Cosín, J.V. Prólogo de Cristina de Robertis.

Título: "Los innigrantes irregulares en España. La vida por un sueño». Universidad de Deusto-Serie Derechos Humanos, vol. 4. Bilbao, 1999. Autores: Ruiz Olabuénaga, J.L., Ruiz Vieytez, E.J. y Vicente Torrado, T.L. Isabel Pla Julián. Departamento de Economía Aplicada. Universidad de Valencia.

Titulo: "Crítica y futuro del Estado del Bienestar. Reflexiones desde la izquierda». Tirant lo Blanch. Valencia, 1999. Coordinadores: Fernández García, T. y Garcés Ferrer, J.

\section{v. Noticias}

"II Curso de Especialista en Dificultad y Conflicto Social: Técnicas de Intervención». Universidad Pontificia de Comillas - Fundación Universidad-Empresa. Madrid. Enero-diciembre 2000.

Federación Internacional de Trabajadores Sociales (IFSW) Conferencias de Trabajo Social 2000-2001: «Promoting equitable societies in the global economy: Social work in the 2Ist century», Montreal (Canadá), del 29 de julio al 2 de agosto del 2000; «Managing conflicts in Social Work. Dealig with contradictions», Viena (Austria) y Bratislava (Eslovaquia), del 7 al 30 de agosto del 2000.

Conclusiones del Congreso Internacional «Una sociedad para todas las edades». Alicante, 5-7 mayo 1999. 


\section{PAUTAS GENERALES PARA LA PRESENTACION DE ARTICULOS}



1. La Revista «Alternativas. Cuadernos de Trabajo Social» está abierta a aportaciones, investigaciones, trabajos teóricos y metodológicos, de carácter profesional o académico, tanto del trabajo social, política social y servicios sociales, como de otras disciplinas y profesiones que desde un punto de vista multi e interdisciplinar enriquecen y complementan la acción profesional.

2. Contenido de los artículos.

El Consejo Editorial solicitará el asesoramiento de expertos independientes quienes, valorando la calidad técnica y científica de los artículos, realizarán la correspondiente selección. Los autores de los artículos publicados recibirán un ejemplar de la Revista.

3. Los artículos publicados quedan en propiedad de la Revista, siendo necesaria la autorización del Consejo Editorial para su reproducción total o parcial.

4. Los artículos que no sean inéditos se publicarán bajo la valoración del Consejo editorial y en función de:

- Que su difusión haya sido en algún medio de difícil acceso a la profesión y disciplina del trabajo social.

- Que haya sido publicado en otro idioma.

- Que se consideren de particular relevancia e interés científico profesional.

5. Normas de presentación

- Los artículos deberán ser remitidos a la Redacción de la Revista «Alternativas. Cuadernos de Trabajo Social». Escuela Universitaria de Trabajo Social. Universidad de Alicante. 03690 San Vicente del Raspeig. Alicante.

- Tres copias escritas y diskette (Microsoft Word y Word Perfect para Windows). Mecanografiados en papel tamaño DIN-A4, a doble espacio (escritura en $12 \mathrm{CPI}$ ), por una sola cara.

- La extensión deberá ajustarse a un mínimo de 10-12 páginas y un máximo de 40.

- De cada uno de los artículos los autores presentarán las claves

* conceptuales y un «abstract» de 12/15 líneas al comienzo del trabajo.

- Todos los artículos deberán ir acompañados en folio aparte de los datos personales del autor/res: nombre y apellidos, D.N.I., dirección, teléfono, profesión, actividad, cargo, teléfono de con- 
tacto, indicando claramente el título del artículo y si ha sido publicado en algún otro medio.

- Las anotaciones a pie de página se numerarán por orden de aparición en el texto y se mecanografiarán en hoja aparte.

- Las referencias bibliográficas se presentarán al final del texto y por orden alfabético de autores, en la forma siguiente:

- Para los libros: Apellidos e inicial del nombre del autor/a/ o autores/as, título de la obra (cursiva), editorial, ciudad, año y número de las páginas a que se hace referencia.

- Para las revistas: Apellidos e inicial del nombre del autor/a o autores/as, título del artículo (entre comillas), nombre de la revista (en cursiva), nombre de la entidad editora, ciudad, año, número de la revista y el de las páginas a que se hace referencia.

- Las tablas y figuras deberán presentarse en hoja aparte numerándose correlativamente e indicando el lugar de colocación en el artículo.

- Los apartados y subapartados se confeccionarán de manera homogénea utilizando la numeración I, II, III; 1.1.,1.2; etc. 
Próxima sección monográfica:

\section{CUANDO CRECE LA ESPERANZA DE VIDA}

Plazo para presentación de artículos: 1 de septiembre de 2001 





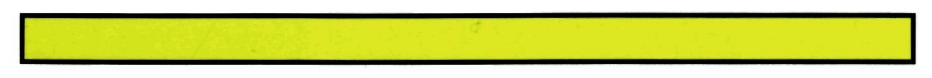

